\author{
UNIVERSIDADE DE SÃO PAULO \\ ESCOLA DE ENGENHARIA DE SÃO CARLOS
}

Programa de Pós-graduação em Ciências da Engenharia Ambiental

Laira Lúcia Damasceno de Oliveira

\title{
Biomarcadores enzimáticos e testes ecotoxicológicos na avaliação da toxicidade de fármacos em invertebrados aquáticos
}

Versão corrigida

São Carlos-SP 
Laira Lúcia Damasceno de Oliveira

\section{Biomarcadores enzimáticos e testes ecotoxicológicos na avaliação da toxicidade de fármacos em invertebrados aquáticos}

Tese apresentada à Escola de Engenharia de São Carlos, Universidade de São Paulo, como parte dos requisitos para obtenção do título de doutor em Ciências da Engenharia Ambiental.

Orientadora: Profa. Dra. Odete Rocha

São Carlos-SP 
AUTORIZO A REPRODUÇÃO TOTAL OU PARCIAL DESTE TRABALHO, POR QUALQUER MEIO CONVENCIONAL OU ELETRÔNICO, PARA' FINS DE ESTUDO E PESQUISA, DESDE QUE CITADA A FONTE.

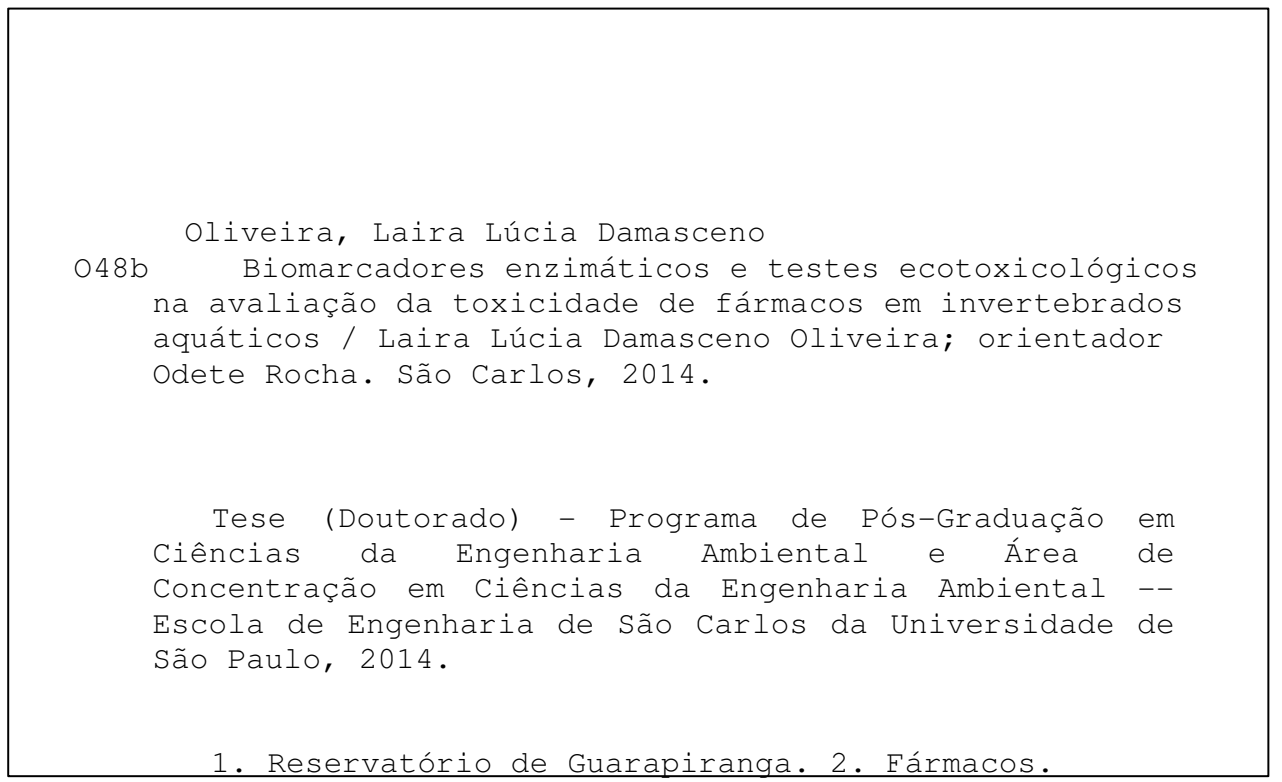

3. Biomarcadores enzimáticos. 4. Toxicidade aguda

e crônica. 5. Biota aquática. I. Título. 


\section{FOLHA DE JULGAMENTO}

Candidata: Licenciada LAIRA LÚCIA DAMASCENO DE OLIVEIRA.

Título da tese: "Biomarcadores enzimáticos e testes ecotoxicológicos na avaliação da toxicidade de fármacos em invertebrados aquáticos".

Data da defesa: $24 / 10 / 2014$

\section{Comissão Julgadora:}

Profa. Titular Odete Rocha (Orientadora)

(Universidade Federal de São Carlos/UFSCar)

Prof. Associado Evaldo Luiz Gaeta Espíndola

(Escola de Engenharia de São Carlos/EESC)

Profa. Dra. Eny Maria Vieira

(Instituto de Química de São Carlos/IQSC-USP)

Dr. Alessandro Minillo

(Universidade Estadual de Mato Grosso do SUI/UEMS)

Prof. Dr. Bruno André Fernandes de Jesus da Silva Nunes (Universidade de Aveiro/Portugal)

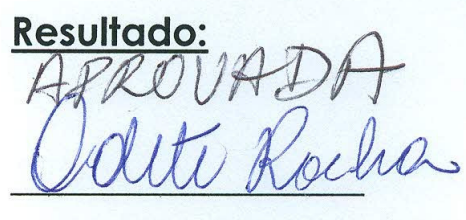

Aprorada.
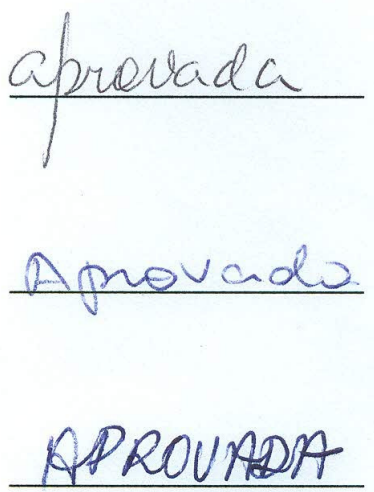

Coordenador do Programa de Pós-Graduação em Ciências da Engenharia Ambiental:

Prof. Dr. Frederico Fabio Mauad

Presidente da Comissão de Pós-Graduação:

Prof. Associado Paulo César Lima Segantine 
Dedico este trabalho:

Á minha eterna e querida mãe avó, Idalina “in memorian” e aos meus pais, Iracilda e Siderlei, em especial a minha mãe, pelos valiosos ensinamentos, pela confiança, amor $e$ incentivo incondicionais que me conferiram em todos os momentos felizes e tristes da minha vida. 


\section{AgRADECIMENTOS}

$\checkmark$ À $\operatorname{Prof}^{\mathrm{a}} \operatorname{Dr}^{\mathrm{a}}$ Odete Rocha, pela orientação, amizade, incentivo, confiança e ensinamentos ao longo desses 6 anos em São Carlos. Durante esses anos você me demostrou, com seu exemplo, como ser uma pesquisadora paciente, compreensiva e competente nesta vida.

$\checkmark$ Aos meus pais Iracilda e Siderlei, que com seus exemplos de vida e apoio, me fizeram seguir sempre em frente na busca dos meus objetivos de vida.

$\checkmark$ À minha eterna mãe avó, Idalina “in memorian”, pelo carinho, valiosas orações e pelos divertidos e inesquecíveis momentos que passamos juntas.

Ao meu querido irmão, Laurence, pela amizade, união e apoio em todos os momentos.

$\checkmark$ A todos os meus familiares, pela eterna confiança, carinho, atenção e apoio.

$\checkmark$ Ao Dr. Alessandro Minillo, pela amizade, apoio, sugestões e pela colaboração desde o inicio da realização deste trabalho.

$\checkmark$ Ao coordenador Ângelo Saggio, do Projeto intitulado "Sistema de Diagnóstico de Prognóstico de Florescimentos Algais para o Reservatório de Guarapiranga com Modelagem 3D da Hidrodinâmica e Qualidade de água" (Processo UFSCar/PROEX: 23112.001431/2009-48), pela amizade, sugestões, auxílio financeiro nas coletas e permissão para a realização deste trabalho na represa do Guarapiranga-São Paulo.

$\checkmark$ Aos técnicos do Departamento de Ecologia e Biologia Evolutiva da Universidade Federal de São Carlos, Airton Santo Soares e Alcídio Culósio pelo auxílio nas coletas de campo e principalmente pela amizade.

Ao Dr. José Valdecir de Lucca, pela amizade, sinceridade, hospitalidade e ajuda nas análises químicas deste trabalho.

Aos Profs. Assocs. Antônio Aparecido Mozeto e Pedro Sérgio Fadini pela parceria e disposição para a realização da identificação e quantificação dos resíduos de fármacos no Laboratório de Biogeoquímica Ambiental, Universidade Federal de São Carlos- São Paulo.

Ao técnico Guilherme Grosseli, às amigas Diana Nara Ribeiro e Bianca Ferreira da Silva pelo auxílio nas análises químicas dos resíduos de fármacos e processamentos dos dados.

$\checkmark$ À Prof ${ }^{\mathrm{a}}$ Dr $^{\mathrm{a}}$ Eny M. Vieira pela amizade, simpatia e sugestões para o presente 
trabalho no exame de qualificação.

$\checkmark$ À Doutora Mariana Duó, pela amizade e ajuda nas análises de Teor de carbono orgânico total (TOC) realizados do Departamento de Hidrobiologia, Universidade Federal de São Carlos-São Paulo.

Ao Doutorando Tiago Silva, pela amizade e ajuda nas análises estatísticas para a construção das curvas de distribuição das sensibilidades das espécies.

$\checkmark$ À SABESP pelo auxílio nas análises químicas que foram de extrema importância para a realização deste trabalho.

$\checkmark$ Ao Prof. Assoc. Fernando José Mendes Gonçalves, pela amizade, atenção, apoio, acolhimento e por proporcionar no Centro de Estudos do Ambiente e do Mar (CESAM) as condições imprescindíveis à realização da componente enzimática deste estudo durante o período do doutorado sanduíche realizado na Universidade de AveiroPortugal.

Ao Dr. Bruno André Fernandes de Jesus da Silva Nunes, pela co-orientação, amizade, paciência, disponibilidade e apoio que demonstrou durante meu doutorado sanduíche e por todos os inesquecíveis ensinamentos sobre os procedimentos laboratoriais dos biomarcadores enzimáticos e interpretação dos resultados, assim como todo o seu auxilio na realização das análises estatísticas.

$\checkmark$ À Prof ${ }^{\mathrm{a}} \operatorname{Dr}^{\mathrm{a}}$ Sara Cristina Antunes, pela co-orientação, simpatia, amizade, atenção e ensinamentos, e, sobretudo por ter sido minha "segunda mãe" durante os 11 meses do meu doutorado sanduíche realizado em Aveiro-Portugal.

Ao Dr. Bruno Castro, pela amizade, confiança e todo apoio desde a minha chegada em Aveiro- Portugal.

$\checkmark$ À secretária do DEBE/UFSCar, Edna, pelo carinho e amizade.

$\checkmark$ A todos os amigos de turma da Escola de Engenharia de São Carlos pelos momentos de descontração, incentivo e amizade.

Aos amigos do Departamento de Ecologia e Biologia Evolutiva (DEBE/UFSCAR): Daniele, Natália, Renata, Lidiane, Fernanda, Denise, Jaqueline, Emanuela, Maiara, Adrislaine, Marcos e Germano pela amizade e descontração em vários momentos deste trabalho.

$\checkmark$ Às queridas amigas do Laboratório de Cultivo e Ecotoxicologia do DEBE/UFSCAR: Maíra, Adrislaine e Raquel pela amizade, respeito, união e por todos os momentos compartilhados durante o trabalho.

Ao Doutor Raphael pelo companheirismo, apoio e colaboração neste trabalho. 
Às companheiras de república Lucimeire, Jussara, Juliana e Manuella pela amizade, palavras de apoio, compreensão e carinho.

$\checkmark$ Ao meu amigo Tony, pela amizade, apoio na fase final da redação da tese, e também pelo auxílio nos esquemas ilustrativos deste trabalho.

$\checkmark$ À querida amiga Mariângela, pelo carinho, amizade, atenção e pelos conselhos durante este trabalho.

Aos inesquecíveis e queridos amigos portugueses do Laboratório de Ecologia de águas doces, Ecotoxicologia e Risco (LEADER- Universidade de Aveiro, Portugal): Ana Catarina, Joana Pereira, Ana Patrícia, Inês Nogueira, Inês Efe, Daniela, Sérgio, Micael, Carlos, Sofia, Mélanie e Ana Ré pela amizade, atenção e descontração em vários momentos durante minha estadia em Portugal.

$\checkmark$ Às técnicas Joana Santos e Tânia Vidal pela amizade, respeito, ajuda e paciência desde a minha chegada ao laboratório de Ecologia de águas doces, Ecotoxicologia e Risco da Universidade de Aveiro, Portugal.

Aos amigos que tive o prazer em conhecer e conviver durante o tempo que permaneci em Portugal.

$\checkmark$ À Escola de Engenharia de São Carlos e ao PPG-SEA, pela oportunidade de realização do curso de doutorado.

Ao CNPQ, pela bolsa de doutorado e todo apoio financeiro que foi imprescindível para concretização desse trabalho.

A todos que de alguma forma contribuíram para a conclusão desta importante etapa da minha vida acadêmica, pessoas que jamais serão esquecidas, os meus mais sinceros agradecimentos.

E, sobretudo, agradeço a Deus por todas as oportunidades conquistadas durante a minha vida. 
"Bom mesmo é ir à luta com determinação abraçar a vida com paixão, perder com classe e vencer com ousadia, porque o mundo pertence a quem se atreve e a vida é "muito" para ser insignificante"

(Augusto Branco) 


\section{RESUMO}

\section{Oliveira, L.L.D. Biomarcadores enzimáticos e testes ecotoxicológicos na avaliação}

da toxicidade de fármacos em invertebrados aquáticos. Tese (Doutorado) - Escola de Engenharia de São Carlos, Universidade de São Paulo, São Carlos, SP, Brasil, 2014.

Dentre os compostos xenobióticos que podem vir a promover efeitos prejudiciais em ecossistemas aquáticos, os fármacos recebem atualmente maior destaque devido à capacidade de persistirem nestes ambientes e também pela escassez de informações de seus efeitos aos diferentes componentes da biota aquática. Dada a presença dessas substâncias, magnitude das concentrações (ng L $\mathrm{L}^{-1}$ a $\mu \mathrm{g} \mathrm{L}^{-1}$ ), e carência de informações sobre seus riscos aos organismos aquáticos nas águas doce no país, o presente estudo estabeleceu como objetivos: i) avaliar a presença dos compostos farmacológicos: diclofenaco de sódio (anti-inflamatório), paracetamol (analgésico) e propranolol ( $\beta$ bloqueador) nas amostras de água em diferentes pontos selecionados no Reservatório de Guarapiranga-SP; ii) estabelecer o grau de toxicidade aguda destes compostos farmacológicos notoriamente encontrados nas amostras naturais sobre diferentes grupos de organismos aquáticos, como: Ceriodaphnia silvestrii, Daphnia magna, Hydra viridissima e Dugesia tigrina; iii) Avaliar a toxicidade crônica dos fármacos estudados, com a inclusão do antipsicótico clorpromazina, aos cladóceros Ceriodaphnia silvestrii e Daphnia magna; iv) Analisar os efeitos sobre biomarcadores de neurotransmissão, como colinesterases solúveis (ChE); e de estresse e dano oxidativo, tais como catalase (CAT), glutationa-S-transferases (GSTs) e glutationa-peroxidase total e selêniodependente (GPx total e Se-GPx) na espécie D. magna. Os resultados mostraram que as concentrações dos fármacos variaram de $6,04 \mathrm{ng} \mathrm{L}^{-1}$ para o diclofenaco sódico (estação Santa Rita) a 531,4 ng L ${ }^{-1}$ para o paracetamol (estação Guavirutuba), durante os períodos analisados. Em relação aos resultados obtidos das exposições agudas observou-se uma variabilidade considerável na toxicidade dos dois compostos farmacêuticos estudados, com valores de $\mathrm{CE}_{50}$ e $\mathrm{CL}_{50}$ variando de 0,55 a $123,3 \mathrm{mg} \mathrm{L}^{-1}$, respectivamente, sendo que a espécie $D$. tigrina foi mais sensível ao fármaco diclofenaco sódico, e ao mesmo tempo apresentou uma maior tolerância ao propranolol. Os dados dos testes de toxicidade crônica mostraram a ocorrência de efeitos adversos na reprodução, mas também efeitos estimulantes para as espécies de Cladocera estudadas. O fármaco propranolol causou um aumento significativo na fecundidade e no parâmetro taxa de crescimento populacional ocorreu um aumento significativo na menor concentração testada para $C$. silvestrii. Para a espécie D. magna, a clorpromazina e o propranolol causaram uma diminuição significativa na fecundidade e na variável taxa de crescimento populacional. A exposição aos fármacos paracetamol e diclofenaco sódico causou uma inibição na atividade de ChE, Se-GPx e GPx total em D. magna, sendo que o propranolol foi responsável por uma redução significativa nas atividades das duas últimas enzimas mencionadas, e também por um ligeiro aumento na atividade de GSTs. 
Além disso, somente a atividade da CAT foi alterada de forma significativa na exposição à clorpromazina. Diante do exposto, conclui-se que os fármacos estudados causaram toxicidade aos organismos aquáticos avaliados neste estudo, e que há necessidade de maiores estudos visando integrar a avaliação de risco de fármacos e a proteção dos organismos não-alvo, da ameaça representada pela presença destes produtos no ambiente.

Palavras-chave: Reservatório de Guarapiranga, fármacos, biomarcadores enzimáticos, toxicidade aguda e crônica, biota aquática. 


\begin{abstract}
Oliveira, L.L.D. Enzymatic biomarkers and ecotoxicological tests to evaluate the toxicity of pharmaceutical drugs to aquatic invertebrates. Thesis (Doctorate/PhD) Escola de Engenharia de São Carlos, Universidade de São Paulo, São Carlos, SP, Brazil, 2014.
\end{abstract}

Among the xenobiotic compounds that may cause deleterious effects on aquatic ecosystems, the drugs currently receive greater prominence due to the ability to persist in these environments and also by the lack of information of their effects on different components of the aquatic biota. Given the presence of these, the magnitude of concentrations (ng $\mathrm{L}^{-1}$ to $\mathrm{mg} \mathrm{L}^{-1}$ ), and lack of information about their risks for aquatic organisms in fresh waters in the country, this study has established the following objectives: i) to evaluate the presence of the pharmacutical compounds: diclofenac sodium (anti-inflammatory), paracetamol (analgesic) and propranolol ( $\beta$-blocker) in water samples at different selected sites in Guarapiranga Reservoir -SP; ii) establish the degree of acute toxicity of these pharmacological compounds notoriously found in natural samples on different groups of aquatic organisms, such as: Ceriodaphnia silvestrii, Daphnia magna, Hydra viridissima and Dugesia tigrina; iii) to assess the chronic toxicity of the drugs studied, with the inclusion of antipsychotic chlorpromazine to cladocerans Ceriodaphnia silvestrii and Daphnia magna; iv) analyze the effects on biomarkers of neurotransmission, such as soluble cholinesterase (ChE); and oxidative stress defense, such as catalase (CAT), glutathione S-transferases (GSTs) and total and selenium-dependent glutathione-peroxidase (total GPx; Se-GPx) in the species $D$. magna. The results showed that the concentrations of the drugs ranged from $6.04 \mathrm{ng} \mathrm{L}^{-1}$ for diclofenac (Santa Rita station) to $531.4 \mathrm{ng} \mathrm{L}^{-1}$ for paracetamol (Guavirutuba station) during the periods analyzed. Regarding the results obtained from acute exposures a considerable variability in toxicity of the two pharmaceutical compounds studied was observed, and the $\mathrm{EC}_{50}$ and $\mathrm{LC}_{50}$ values ranged from 0.55 to $123.3 \mathrm{mg} \mathrm{L}^{-1}$, and the species D. tigrina was more sensitive to the drug diclofenac, and at the same time had a higher tolerance to propranolol. The data from chronic toxicity tests showed the occurrence of adverse effects on reproduction, but also stimulating effects to the species of Cladocera studied. The drug propranolol caused a significant increase in fertility and regarding the rate of population growth parameter there was a significant increase in the lowest concentration tested for $C$. silvestrii. For the species D. magna, chlorpromazine and propranolol caused a significant decrease in fertility and the rate of population increase parameter. Exposure to the drugs paracetamol and diclofenac caused an overall inhibition in the activity of ChE, Se-GPx and total GPx in D. magna, and propranolol was responsible for a significant reduction in the activities of the last two enzymes mentioned, and also for a slight increase in the activity of GSTs. Furthermore, only CAT activity was significantly altered in the exposure to chlorpromazine. Given the 
above, it is concluded that the studied drugs caused toxicity to the aquatic organisms evaluated in this study, which suggests that further studies are necessary to integrate risk assessment of drugs to the protection of non-target organisms of the threat posed by the presence of these products in the environment.

Keywords: Guarapiranga Reservoir, enzymatic biomarkers, pharmaceuticals, acute and chronic toxicity, aquatic biota. 


\section{LISTA DE FIGURAS}

Estruturação da tese

Figura 1. Fluxograma mostrando as diferentes etapas desenvolvidas neste estudo 3

Contextualização e justificativa da pesquisa

Figura 2. Vias de transformação de produtos farmacêuticos 7

Figura 3. Possíveis rotas de exposição e destino de fármacos para o tratamento humano e veterinário no ambiente .11

Capítulo 1- Ocorrência de resíduos de fármacos em amostras de água da Represa Guarapiranga- São Paulo

Figura 1. Mapa do Brasil mostrando a localização do Reservatório de Guarapiranga com os pontos de amostragens

Figura 2. Perfil cromatográfico obtido por LC-MS/MS de padrões dos três fármacos estudados ( $\beta$ - bloqueador, anti-inflamatório e analgésico) 1) Propranolol (2,10 min), 2 (Diclofenaco sódico (1,45 min), 3) Paracetamol (0,78 min). .51

Figura 3. Diagrama de ordenação da Análise de Componentes Principais (PCA) relacionando as variáveis físicas, químicas e biológicas com as concentrações dos fármacos durante o primeiro período amostrado (01/03/2012)

Figura 4. Diagrama de Ordenação da Análise de Componentes Principais (PCA) relacionando as variáveis físicas, químicas e biológicas com as concentrações dos fármacos durante o segundo período amostrado (09/10/2012)..... 62

Capítulo 2- Efeitos ecotoxicológicos agudos e crônicos de três fármacos sobre o cladócero tropical de água doce Ceriodaphnia silvestrii

Figura 1. Porcentagem de organismos imóveis de Ceriodaphnia silvestrii expostas a diferentes concentrações de produtos farmacêuticos (paracetamol, diclofenaco sódico e propranolol), após 48 horas de exposição. 85 
Figura 2. Parâmetros avaliados em relação às respostas da história de vida de Ceriodaphnia silvestrii exposta por 8 dias aos fármacos paracetamol, diclofenaco sódico e propranolol (eixo-x, em $\mathrm{mg} \mathrm{L}^{-1}$ ).

Capítulo 3- Avaliação da toxicidade aguda de fármacos sobre diferentes invertebrados de água doce

Figura 1. Resposta das hidras à toxicidade com base nas alterações morfológicas de acordo com a descrição e pontuação (score) (0 -10) elaborada por Wilby (1998) e adaptada neste estudo para o organismo-teste Hydra viridissima.

Figura 2. Distribuição das sensibilidades das espécies (SSD) de organismos de diferentes grupos taxonômicos, com base nos valores de $\mathrm{CE}_{50}$ e $\mathrm{CL}_{50}\left(\mathrm{mg} \mathrm{L}^{-1}\right)$ para o fármaco diclofenaco sódico

Figura 3. Distribuição das sensibilidades das espécies (SSD) de organismos de diferentes grupos taxonômicos, com base nos valores de $\mathrm{CE}_{50}$ e $\mathrm{CL}_{50}\left(\mathrm{mg} \mathrm{L}^{-1}\right)$ para o fármaco propranolol 125

Capítulo 4- Efeitos ecotoxicológicos agudos e crônicos de quatro compostos farmacológicos sobre a espécie Daphnia magna

Figura 1. Parâmetros avaliados em relação às respostas da história de vida de Daphnia magna exposta por 21 dias aos compostos paracetamol, clorpromazina, diclofenaco sódico e propranolol (eixo $\mathrm{x}$, em $\mathrm{mg} \mathrm{L}^{-1}$ ). 152

Capítulo 5- Avaliação dos efeitos ecotoxicológicos de fármacos em Daphnia magna, utilizando diferentes biomarcadores enzimáticos

Figura 1. Efeitos do acetaminofeno nas atividades da $\mathrm{ChE}$ (A) e das enzimas de stresse oxidativo (GST, CAT, GPx-Se-dependente e GPx-total) (B), em Daphnia magna.....181 Figura 2. Efeitos da clorpromazina nas atividades da $\mathrm{ChE}(\mathrm{A})$ e das enzimas de stresse oxidativo (GST, CAT, GPx-Se-dependente e GPx-total) (B), em Daphnia magna .....182 Figura 3. Efeitos do diclofenaco sódico nas atividades da $\mathrm{ChE}$ (A) e das enzimas de stresse oxidativo (GST, CAT, GPx-Se-dependente e GPx-total) (B), em Daphnia magna. .183 
Figura 4. Efeitos do propranolol nas atividades da $\operatorname{ChE~(A)~e~das~enzimas~de~stresse~}$ oxidativo (GST, CAT, GPx-Se-dependente e GPx-total) (B), em Daphnia

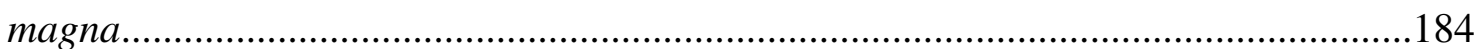




\section{LISTA DE TABELAS}

Contextualização e justificativa da pesquisa

Tabela 1. Características físico-químicas e informações gerais dos compostos farmacológicos estudados .26

Capítulo 1- Ocorrência de resíduos de fármacos em amostras de água da Represa Guarapiranga- São Paulo

Tabela 1. Principais características do Reservatório de Guarapiranga. .45

Tabela 2. Condições monitoradas para a determinação dos compostos farmacêuticos por Cromatografia Líquida acoplada ao Espectrômetro de Massas (LC-MS/MS).........51

Tabela 3. Valores médios obtidos para os parâmetros físicos, químicos e biológicos nas amostras de água das diferentes estações amostradas no reservatório de Guarapiranga, durante os dois períodos estudados. .54

Tabela 4. Concentrações dos compostos detectados nas amostras de água $(n=3)$, valores expressos em ng $\mathrm{L}^{-1}$ .55

Capítulo 2- Efeitos ecotoxicológicos agudos e crônicos de três fármacos sobre o cladócero tropical de água doce Ceriodaphnia silvestrii

Tabela 1. Resumo dos principais endpoints ecotoxicológicos obtidos na literatura para diferentes organismos aquáticos expostos aos fármacos: acetaminofeno, diclofenaco sódico e propranolol. 80

Capítulo 3- Avaliação da toxicidade aguda de fármacos sobre diferentes invertebrados de água doce

Tabela 1. Resumo dos principais endpoints ecotoxicológicos obtidos na literatura para diferentes organismos aquáticos expostos aos fármacos: diclofenaco sódico e propranolol.

Tabela 2. Resumo dos valores de $\mathrm{CE}_{50} / \mathrm{CL}_{50}\left(\mathrm{mg} \mathrm{L}^{-1}\right)$ e seus respectivos intervalos de confiança de $95 \%$ obtidos para as diferentes espécies expostas aos fármacos diclofenaco sódico e propranolol. .123 
Capítulo 4- Efeitos ecotoxicológicos agudos e crônicos de quatro compostos farmacológicos sobre a espécie Daphnia magna

Tabela 1. Valores de Concentração mediana $\left(\mathrm{CE}_{10}\right.$ e $\left.\mathrm{CE}_{50}, \mathrm{mg} \mathrm{L}^{-1}\right)$ dos compostos farmacêuticos: acetaminofeno, clorpromazina, diclofenaco sódico e propranolol em testes agudos e crônicos com Daphnia magna e seus respectivos intervalos de confiança de $95 \%$ (IC95\%)... 


\section{SUMÁRIO}

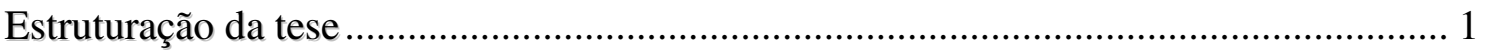

Contextualização e justificativa da pesquisa .................................................................. 4

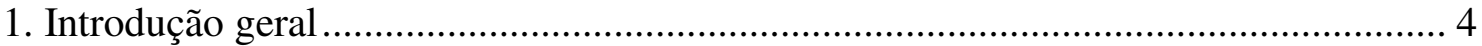

1.1. Compostos farmacêuticos- fonte de contaminação do ambiente ........................... 4

1.2. Destino dos fármacos no meio ambiente …........................................................ 8

1.3. Possíveis efeitos de fármacos no meio ambiente.................................................. 11

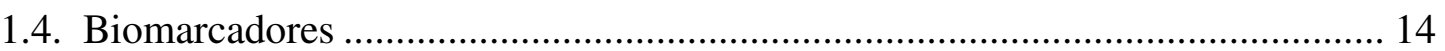

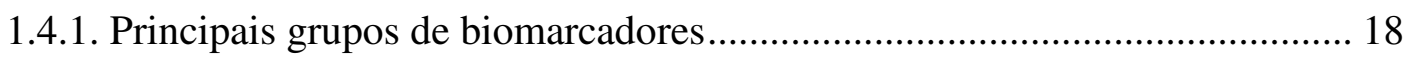

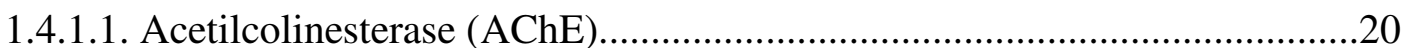

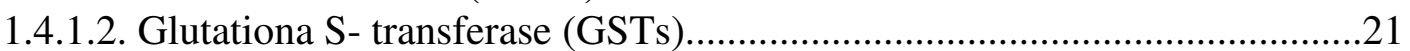

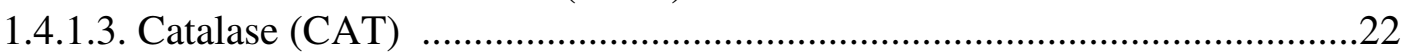

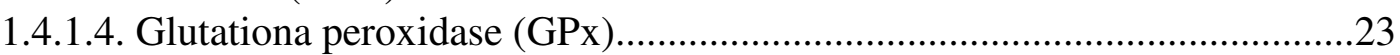

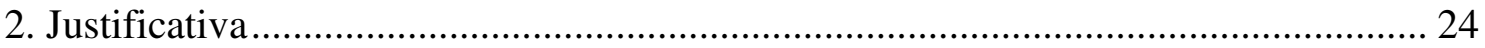

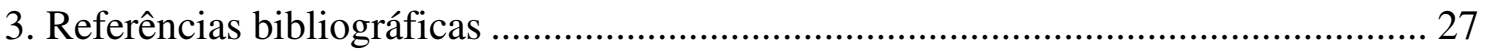

Capítulo 1- Ocorrência de resíduos de fármacos em amostras de água da Represa Guarapiranga- São Paulo

Resumo

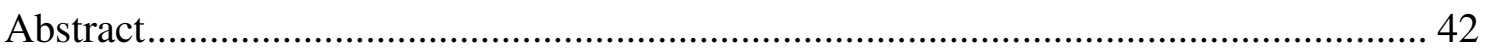

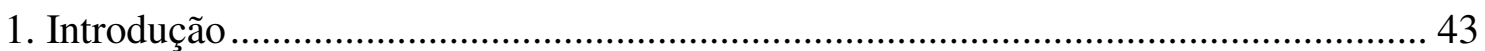

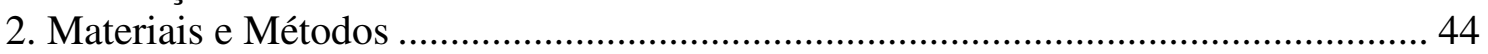

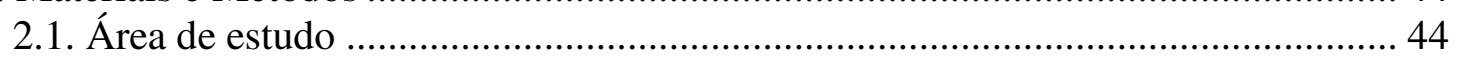

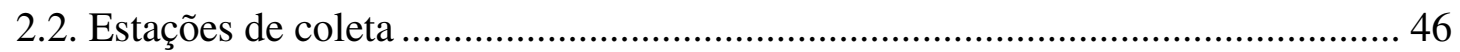

2.2.1. Caracterização dos pontos de amostragem................................................ 47

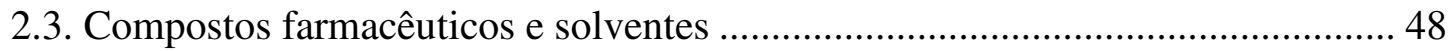

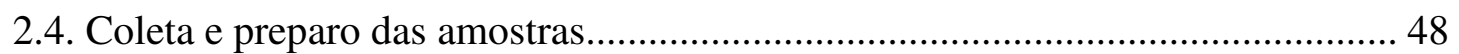

2.5. Extração dos Analitos por SPE (Extração de Fase sólida) ................................. 49

2.6. Determinação por Cromatografia Líquida acoplada ao Espectrômetro de Massas

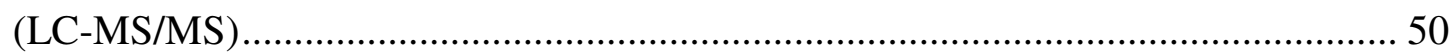

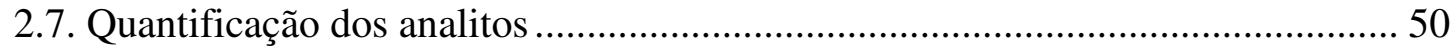

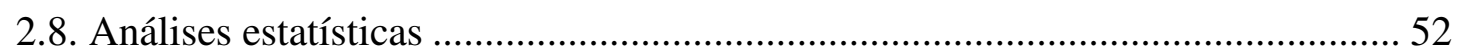

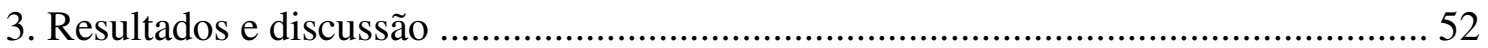

3.1. Parâmetros de qualidade de água ..................................................................... 52

3.2. Presença de fármacos na Represa de Guarapiranga-SP .................................... 55

3.3. Relação entre os parâmetros físico-químicos e biológicos e os fármacos ............ 59

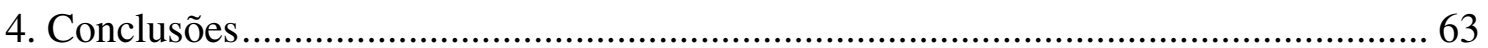

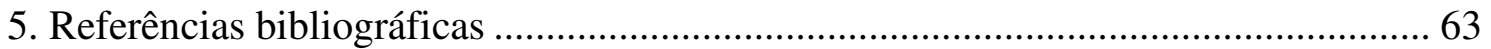


Capítulo 2- Efeitos ecotoxicológicos agudos e crônicos de três fármacos sobre o cladócero tropical de água doce Ceriodaphnia silvestrii

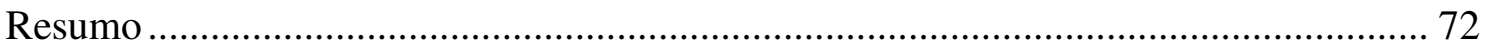

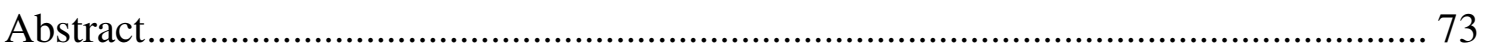

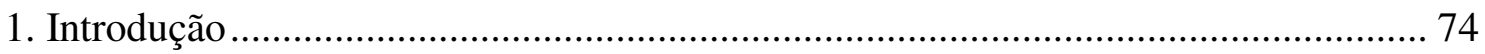

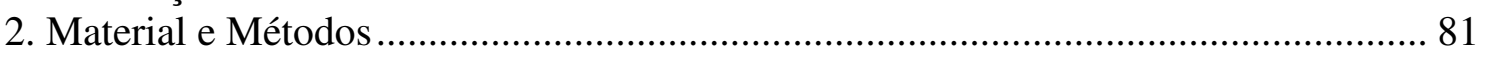

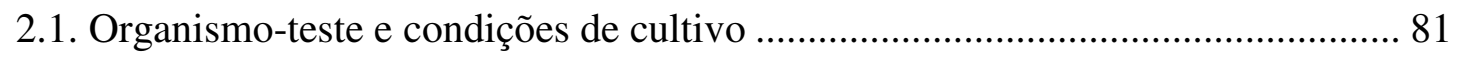

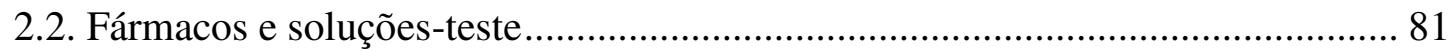

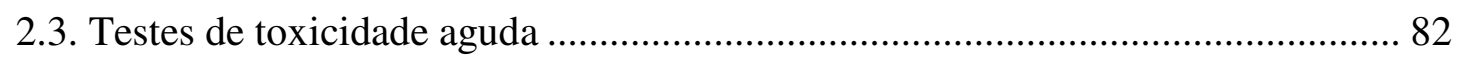

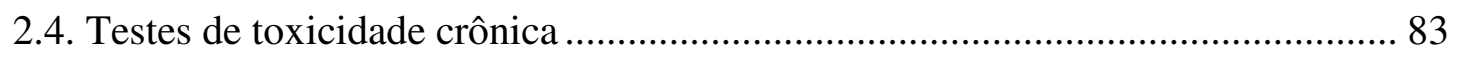

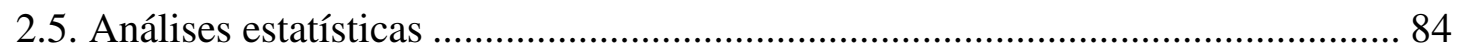

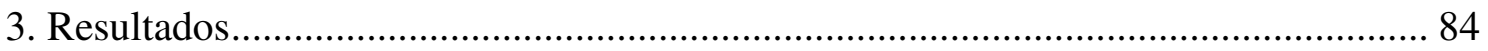

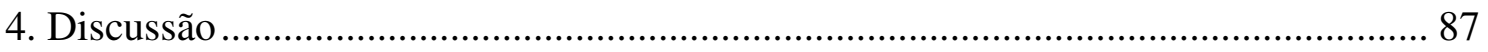

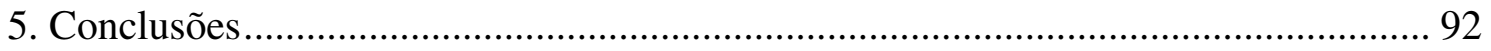

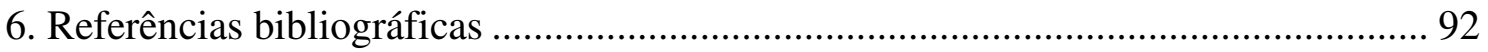

Capítulo 3- Avaliação da toxicidade aguda de fármacos sobre diferentes invertebrados de água doce

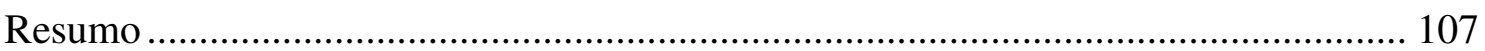

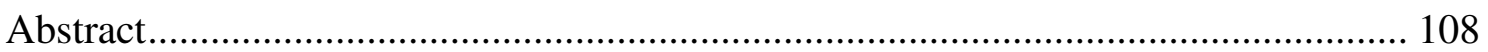

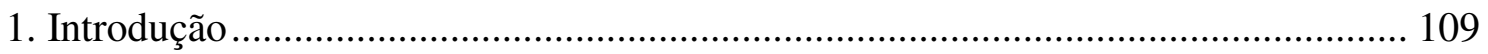

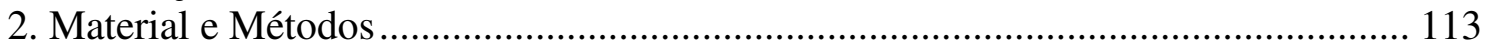

2.1. Cultivo e manutenção dos organismos-teste....................................................... 113

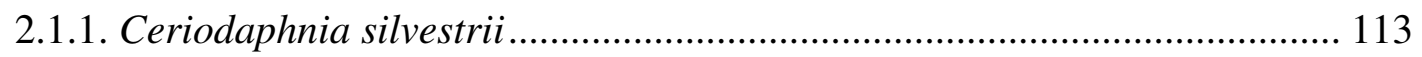

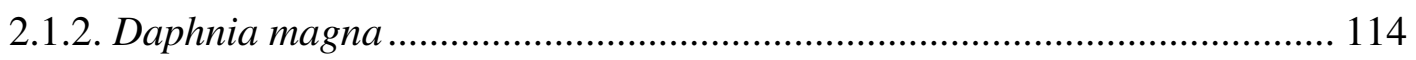

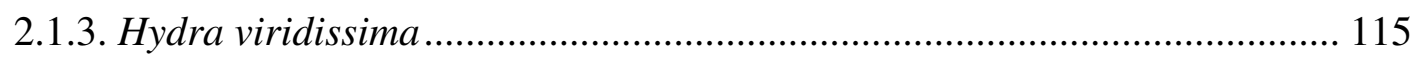

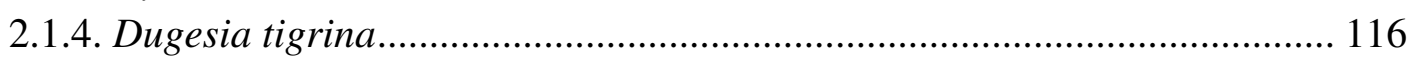

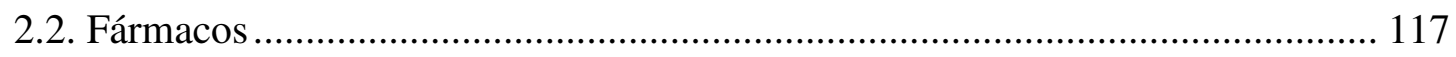

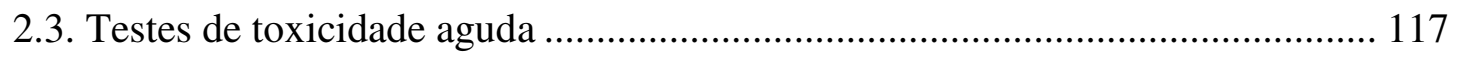

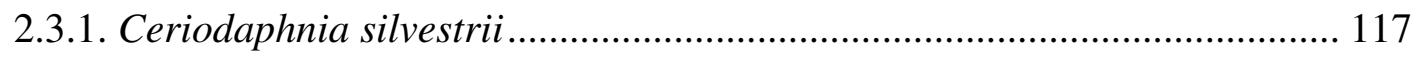

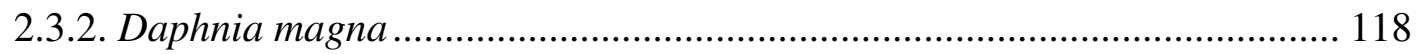

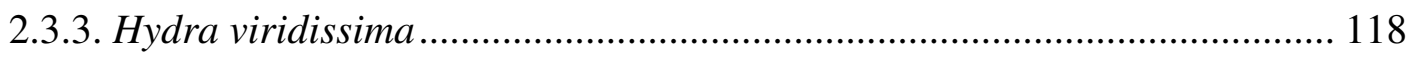

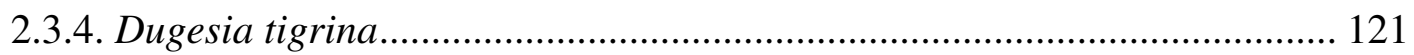

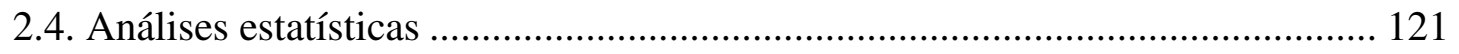

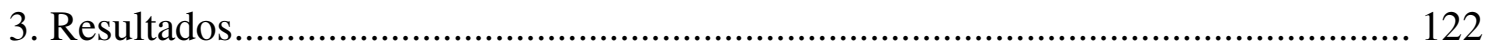

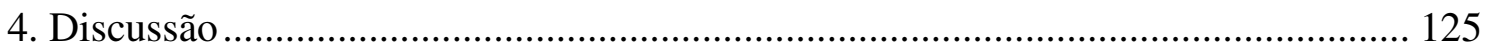

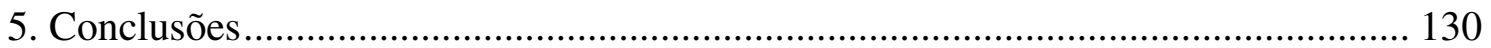

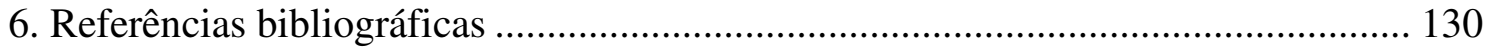

Capítulo 4- Efeitos ecotoxicológicos agudos e crônicos de quatro compostos farmacológicos sobre a espécie Daphnia magna

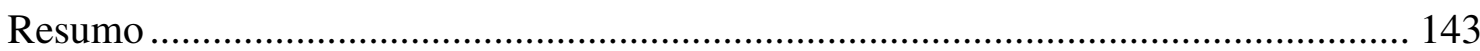

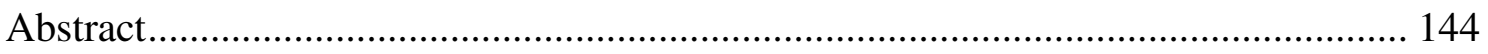

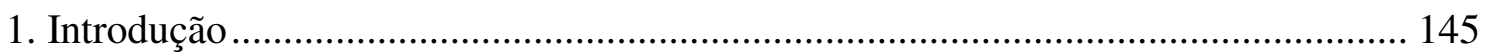

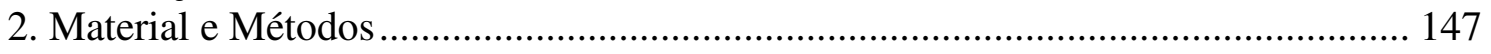




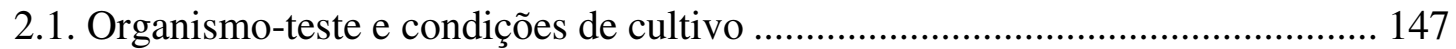

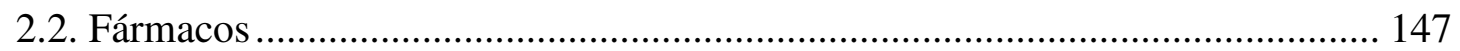

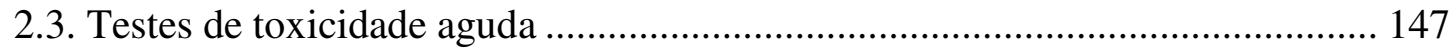

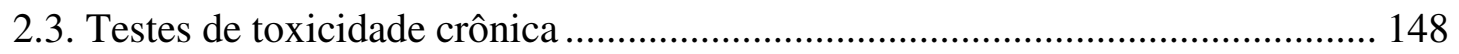

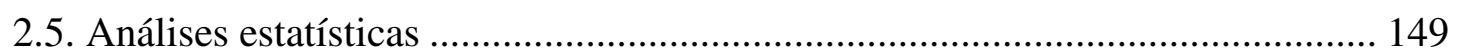

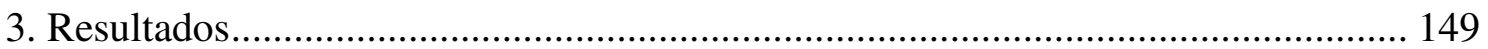

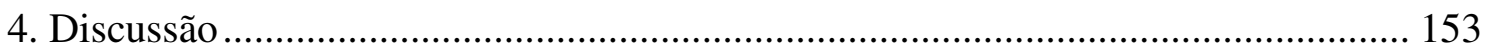

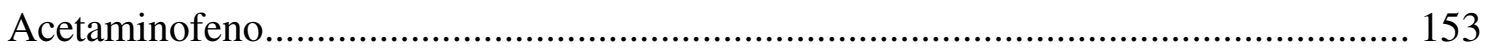

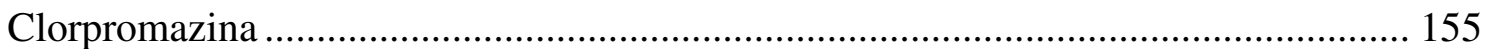

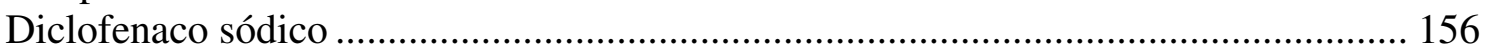

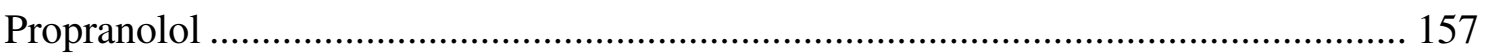

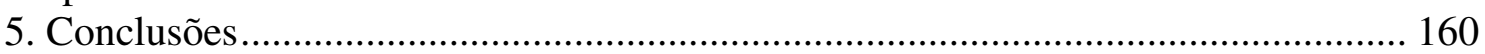

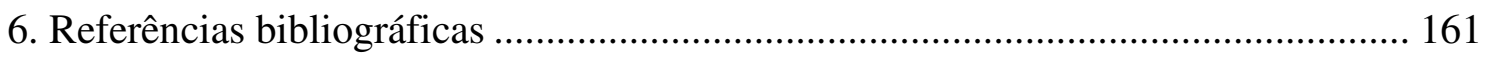

Capítulo 5- Avaliação dos efeitos ecotoxicológicos de fármacos em Daphnia magna, utilizando diferentes biomarcadores enzimáticos

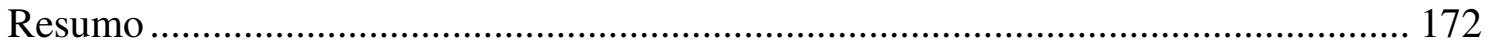

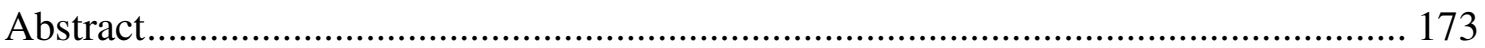

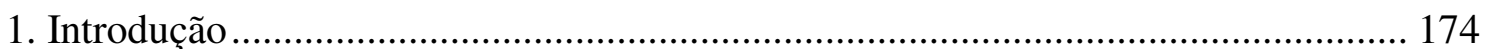

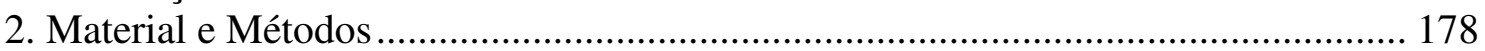

2.1. Organismo-teste e condições de cultivo ...................................................... 178

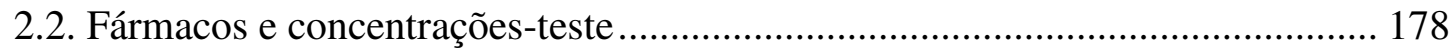

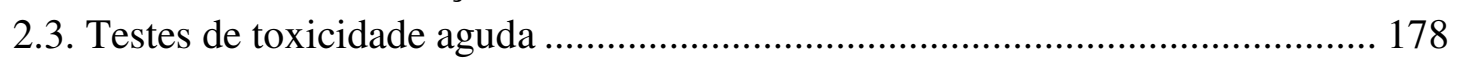

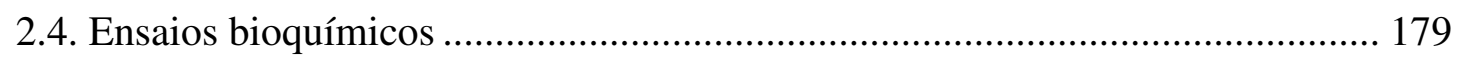

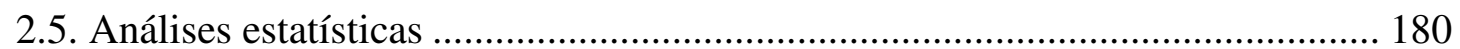

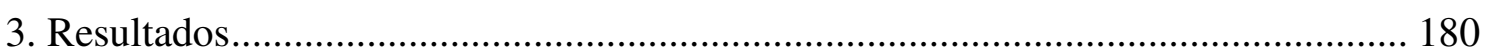

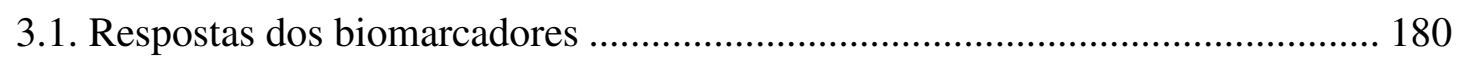

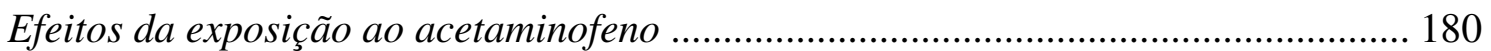

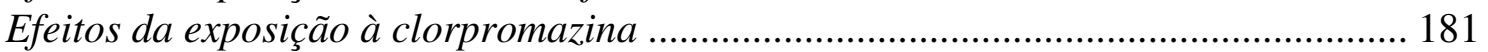

Efeitos da exposição ao diclofenaco sódico .................................................................... 182

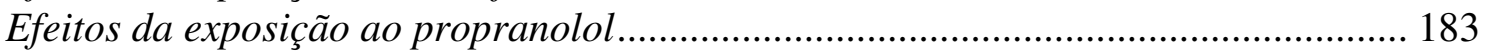

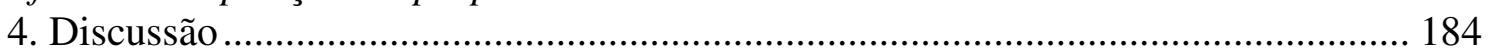

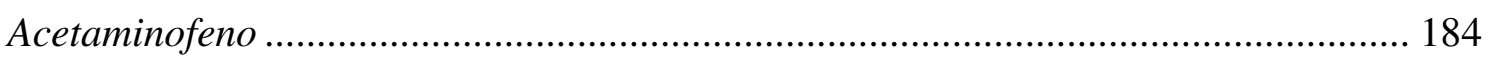

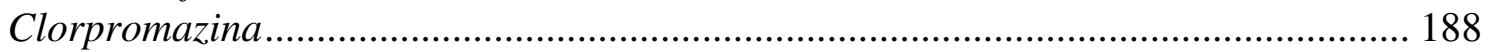

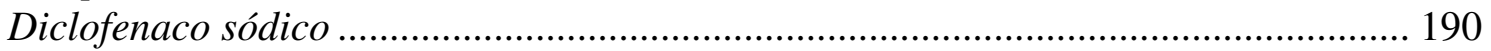

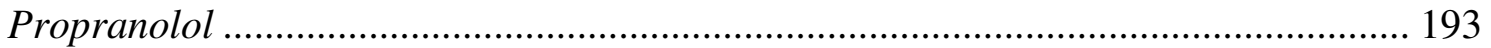

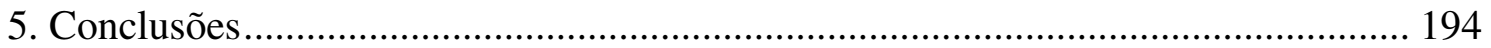

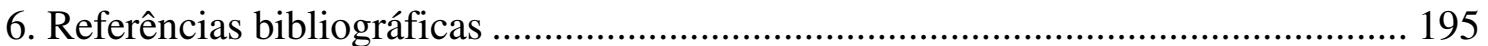

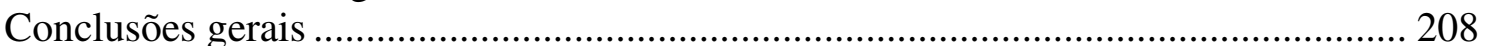

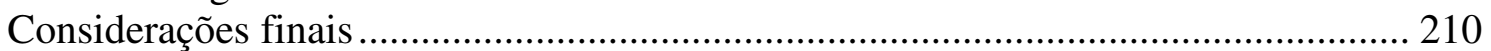

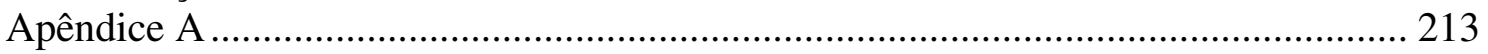

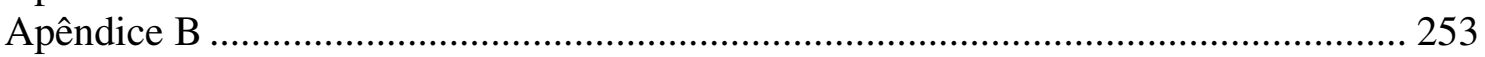

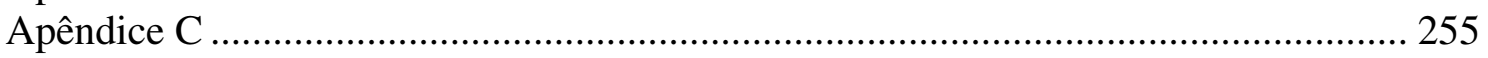



ESTRUTURAÇÃO DA TESE

Esta tese é apresentada na forma de capítulos, os quais foram escritos contemplando os itens Resumo, Introdução, Metodologia, Resultados, Discussão e Referências bibliográficas, já na forma de manuscritos de trabalhos que depois de revisados serão submetidos para publicação em periódicos especializados. Deste modo, além de um capítulo inicial no qual se contextualizou a pesquisa, discorrendo de forma ampla sobre os compostos farmacológicos (definição, rotas de exposição, usos e efeitos ecotoxicolóxicos para os organismos aquáticos) e a importância da utilização de diferentes biomarcadores enzimáticos, foram elaborados cinco capítulos, os quais estão distribuídos em função do período de desenvolvimento das diferentes etapas da pesquisa realizada no Brasil e em Portugal, conforme descrito abaixo. Os capítulos 4 e 5 fazem parte dos estudos realizados durante o período de doutorado sanduíche realizado na Universidade de Aveiro, Portugal.

\section{Capítulo 1 - Ocorrência de resíduos de fármacos em amostras de água da Represa} Guarapiranga- São Paulo - Este capítulo teve o propósito de identificar e quantificar os fármacos: paracetamol (analgésico), diclofenaco de sódio (anti-inflamatório) e propranolol ( $\beta$-bloqueador) presentes em amostras de água de pontos selecionados no Reservatório de Guarapiranga, na cidade de São Paulo, em dois períodos sazonais (seco e chuvoso).

\section{Capítulo 2 - Efeitos ecotoxicológicos agudos e crônicos de três fármacos estudados} sobre o cladócero tropical de água doce Ceriodaphnia silvestrii - Neste capítulo procurou-se descrever os resultados obtidos através dos experimentos laboratoriais de toxicidade aguda e crônica realizados para avaliar diferentes respostas do cladócero Ceriodaphnia silvestrii, quando exposto aos fármacos pertencentes a classes terapêuticas diferentes: paracetamol, diclofenaco de sódio e propranolol. Os parâmetros avaliados foram: imobilidade, sobrevivência e reprodução.

Capítulo 3 - Avaliação da toxicidade aguda de fármacos sobre diferentes invertebrados de água doce - A partir de bioensaios de toxicidade aguda buscou-se 
avaliar a sensibilidade de quatro espécies de organismos-teste: Ceriodaphnia silvestrii (Cladocera), Daphnia magna (Cladocera), Hydra viridissima (Cnidaria) e Dugesia tigrina (Platyhelminthes) aos fármacos: diclofenaco de sódio e propranolol.

\section{Capítulo 4 - Efeitos ecotoxicológicos agudos e crônicos de quatro compostos} farmacológicos sobre a espécie Daphnia magna - Neste capítulo objetivou-se determinar os possíveis efeitos na mobilidade, sobrevivência e reprodução da espécie $D$. magna quando exposta a diferentes concentrações dos fármacos: paracetamol (analgésico), clorpromazina (antipsicótico), diclofenaco de sódio (anti-inflamatório) e propranolol ( $\beta$-bloqueador).

\section{Capítulo 5 - Avaliação dos efeitos ecotoxicológicos de fármacos em Daphnia magna, utilizando diferentes biomarcadores enzimáticos - Considerando-se o envolvimento de todos os compostos estudados nas atividades colinesterásicas e sistema redox celular, visou-se avaliar através de exposições de curta duração a concentrações subletais dos referidos compostos, a quantificação da atividade de enzimas de desintoxicação (glutationa-S-transferases), estresse oxidativo (catalase e glutationa peroxidase) e de neurotoxicidade (colinesterases) em Daphnia magna.}

A fim de propiciar uma melhor compreensão do presente trabalho apresenta-se, na Figura 1, um fluxograma com todas as etapas desenvolvidas no Brasil e em Portugal, as quais contribuíram para atender aos objetivos deste estudo. 
ANÁLISE DA OCORRÊNCIA DE DIFERENTES FÁRMACOS EM ECOSSISTEMAS AQUÁTICOS E AVALIAÇÃO DE SUA TOXICIDADE PARA

INVERTEBRADOS AQUÁTICOS

\section{Atividades em campo}

(1) Análise de resíduos de fármacos em amostras de água da Represa Guarapiranga- SP

\section{Atividades em laboratório}

(2) Testes de toxicidade aguda e crônica com Ceriodaphnia silvestrii exposta a três fármacos

Imobilidade, $\mathrm{n}^{\mathrm{o}}$ total de descendentes e taxa de crescimento populacional (r)
(3) Testes de toxicidade aguda com invertebrados aquáticos expostos a dois fármacos

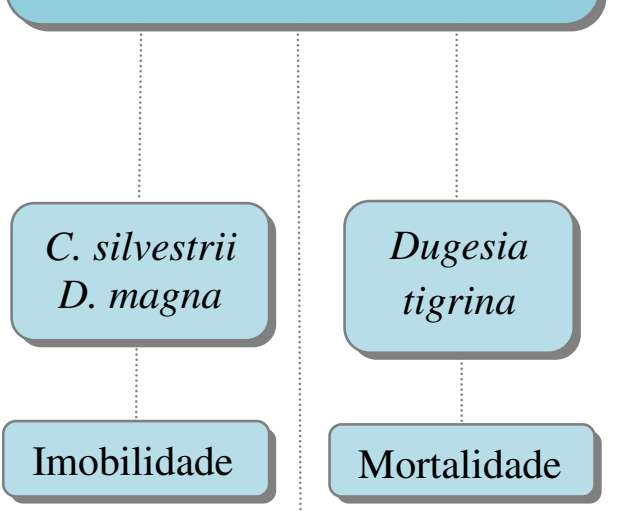

Hydra viridissima
(4) Testes de toxicidade aguda e crônica com Daphnia magna exposta a quatro fármacos
(5) Análise dos efeitos ecotoxicológicos de quatro fármacos em $D$. magna, utilizando diferentes biomarcadores

Modificações morfológicas

Figura 1. Fluxograma mostrando as diferentes etapas desenvolvidas neste estudo.

* (1), (2), (3), (4) e (5) referem-se aos capítulos apresentados na tese. 


\section{CONTEXTUALIZAÇÃO E JUSTIFICATIVA DA PESQUISA}

\section{Introdução geral}

\subsection{Compostos farmacêuticos- fonte de contaminação do ambiente}

A degradação contínua da parte abiótica de rios, lagos e reservatórios tem ocorrido em todo o mundo, bem como a interrupção do estado homeostático da biota aquática que pode ser atribuído ao aumento da taxa de impacto humano sobre o meio ambiente.

Dentre a diversidade de substâncias produzidas pelo homem, os contaminantes emergentes são considerados novas substâncias que, com as mudanças sociais e econômicas das últimas décadas, têm sido detectadas nos corpos d' água em quantidades relevantes, tendo como consequência os riscos ecológicos para o ambiente aquático.

Estes compostos não são rotineiramente monitorados no ambiente, por não serem inseridos nas legislações vigentes que regulamentam a qualidade da água. Além disso, o conhecimento sobre o destino dos mesmos no ambiente e os possíveis efeitos nocivos à biota aquática e à saúde humana nem sempre são bem esclarecidos (ZENKER et al., 2014).

Dentro da classe dos contaminantes emergentes, os fármacos de utilização humana são considerados um dos grupos de substâncias ambientalmente mais relevantes, pelo fato de sua produção e utilização ocorrer em grande volume, por possuírem moléculas extremamente ativas biologicamente e por suas propriedades físico-químicas importantes (lipofílidade, resistência à biotransformação e aos processos de tratamento de água e pseudopersistência no ambiente) (BOTTONI et al., 2010).

Devido à crescente sensibilidade dos instrumentos analíticos, vários estudos realizados durante as últimas décadas (ROBERTS \& THOMAS, 2006; BENOTTI et al., 2009; PETROVIĆ et al., 2014) permitiram encontrar muitos resíduos farmacêuticos no ambiente aquático em baixas concentrações (ng $\mathrm{L}^{-1}$ a $\mu \mathrm{g} \mathrm{L}^{-1}$ ), especialmente em efluentes de águas residuárias, águas superficiais e subterrâneas, águas residuárias não tratadas, na proximidade de estações de tratamento de águas residuárias (ETARs), e mesmo em água potável da rede de distribuição. 
A concentração em que são encontrados geralmente é considerada muito baixa para representar um risco grave para os seres humanos; no entanto, ainda é desconhecido se outros receptores em organismos não-alvo, como os organismos aquáticos, são sensíveis à presença de resíduos farmacêuticos individuais, ou às suas misturas (PETROVIĆ et al., 2014). Segundo Howard e Muir (2011), atualmente já foram encontrados globalmente 275 diferentes compostos farmacêuticos no ambiente, incluindo antibióticos (sulfametoxazol, oxitetraciclina), anticonvulsionantes (carbamazepina), antinflamatórios (ibuprofeno, naproxeno), antidislipidêmicos (bezafibrato, gemfibrozil) (FENT et al., 2006), antipiréticos, citostáticos, e hormônios (GANIYAT, 2008). A ocorrência de fármacos no compartimento aquático está intimamente relacionada ao estilo de vida da sociedade moderna, aos padrões de consumo e ao envelhecimento da população (CORTEZ, 2011).

O consumo mundial de fármacos é bastante significativo; um exemplo disso pode ser visto na União Européia onde aproximadamente 3.000 diferentes substâncias são usadas em medicamentos para consumo humano, como analgésicos e anti-inflamatórios, antibióticos, $\beta$-bloqueadores, reguladores de lipídios, e muitos outros (PETROVIĆ et al., 2014). O Brasil encontra-se entre os maiores consumidores de medicamentos do mundo, de acordo com dados da Associação Brasileira de Redes de Farmácias e Drogarias (Abrafarma), que apontam este país como o sétimo maior mercado mundial, podendo alcançar a quinta posição em 2015 (PEREIRA, 2012). Segundo estes autores, no ano de 2011, o setor de fármacos no Brasil movimentou $\mathrm{R} \$ 43,9$ bilhões em vendas e a previsão é de que, em 2017, esse faturamento seja duplicado.

Os compostos farmacêuticos são administrados topicamente (inalação e aplicação na pele), internamente (administração oral), ou parenteralmente (injeções e infusões) em domicílios, farmácias, hospitais e clínicas. Estes podem ser usados com a finalidade de fornecer elementos carentes ao organismo, como vitaminas, sais minerais e hormônios; prevenção de doenças ou infecções; bloqueio temporário de uma função normal; correção de uma função desregulada; desintoxicação do organismo e agentes auxiliares de diagnóstico (WENZEL et al., 2001).

Depois do uso, as moléculas são absorvidas, distribuídas, e parcialmente metabolizadas no corpo humano, sendo finalmente excretadas para o sistema de tratamento de esgoto como compostos ligeiramente transformados ou mesmo inalterados, principalmente como conjugados com moléculas polares. A excreção pode 
ser realizada pelos pulmões, trato gastrointestinal, rins e também por secreções corporais. Estes conjugados podem ser facilmente clivados durante o tratamento de águas residuárias e os medicamentos originais, então, liberados para o ambiente aquático, principalmente nos efluentes de estações de tratamento de águas residuárias (ETAR) (HORDERN et al., 2008). A excreção dos fármacos e de seus metabólitos finaliza a atividade farmacológica no organismo, pois eles somente deixam de influenciar as propriedades bioquímicas de um individuo quando são eliminados definitivamente pelas vias excretoras (NAMIESNIK et al., 2014).

Após a sua excreção e introdução no meio ambiente, ambos os compostos originais e seus metabólitos podem ocorrer mudanças estruturais por uma variedade de processos bióticos e abióticos. Segundo Gröning et al. (2007) e Trautwein et al. (2008), os fármacos podem ser transformados de forma incompleta por microorganismos, tais como bactérias e fungos, no ambiente, bem como pela luz solar e por outros processos químicos abióticos. Transformações estruturais podem também ser resultado de processos tecnológicos, tais como o tratamento de efluentes por oxidação, hidrólise e fotólise (PÉREZ-ESTRADA et al., 2007; MÉNDEZ-ARRIAGA et al., 2008). As moléculas resultantes com novas propriedades (incluindo farmacológicas e toxicológicas) são denominadas de produtos de transformação (LÄNGIN et al., 2008) (Figura 2). 


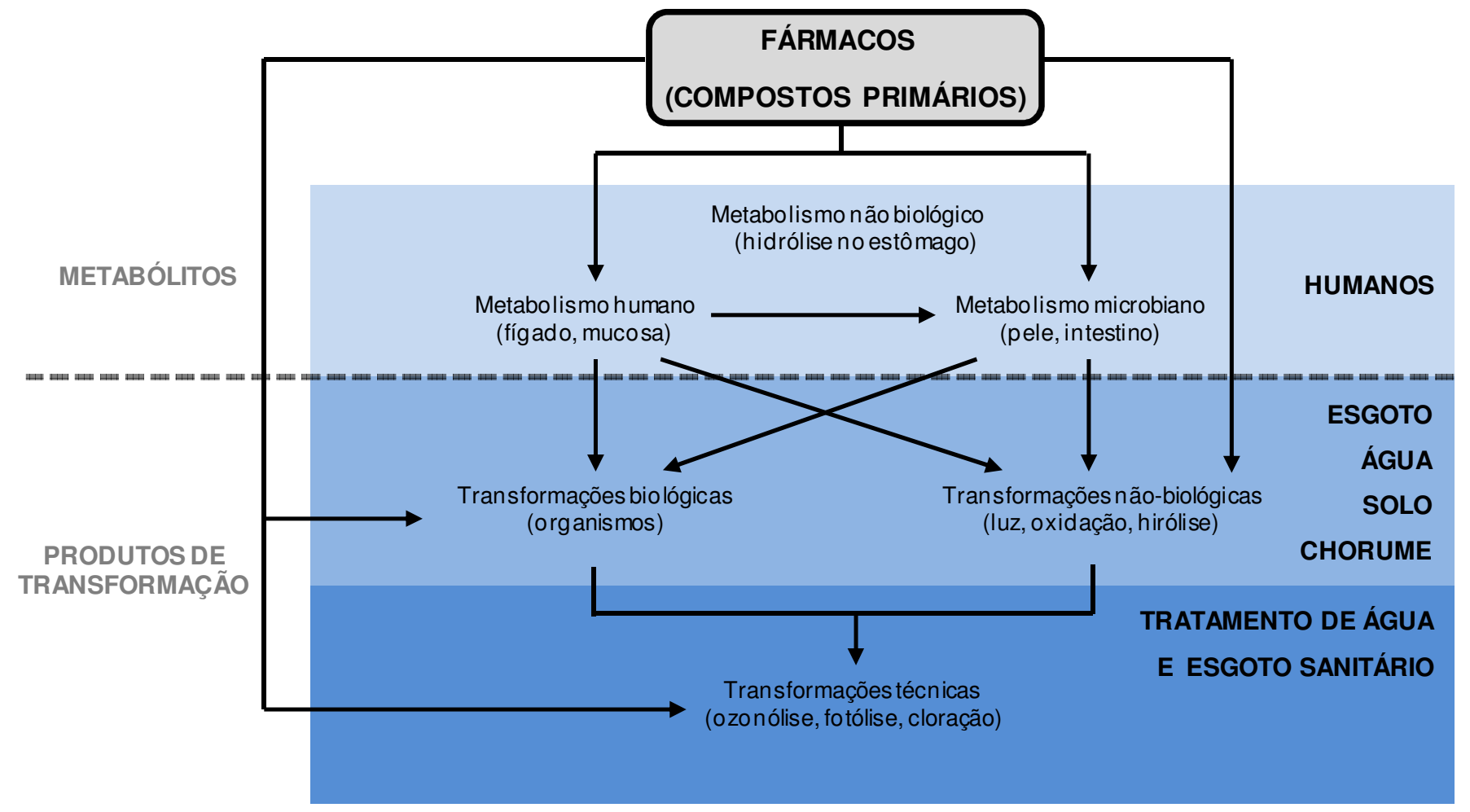

Figura 2. Vias de transformação de produtos farmacêuticos (Adaptado de KÜMMERER, 2004/2008).

De acordo com Lameira (2008) resíduos de fármacos, sejam eles de consumo humano ou animal, quando introduzidos nos ecossistemas aquáticos podem ser total ou parcialmente biodegradados, fotodegradados, ou podem-se acumular no sedimento ou ao longo da teia trófica. A principal rota de entrada de resíduos de fármacos no ambiente é o lançamento de esgotos sanitário, tratados ou não, no ambiente aquático (MELO et al., 2009; LAMEIRA, 2012). No entanto, outras vias de liberação destas substâncias no ambiente devem ser consideradas, como esgotos hospitalares, produção industrial, esgoto sanitário, descarte inadequado de fármacos após a expiração do prazo de validade, disposição em aterros, e excreções animais (como por exemplo, os promotores de crescimento utilizados em aquicultura, ou na aplicação de excrementos de animais tratados com medicamentos em agropecuária como na avicultura, suinocultura e outros) (SANDERSON et. al., 2004; TERNES et al., 2004). Sendo assim, muitos resíduos de fármacos resistem a vários processos de tratamento convencionais de água (métodos biológicos, químicos, físicos) por possuírem ação biocida ou estruturas químicas complexas, não passíveis de biodegradação (KLAVARIOTI et al., 2009).

Esforços devem ser feitos estão para o desenvolvimento de métodos mais eficazes para a remoção de fármacos nas estações de tratamento de esgoto sanitário. Segundo 
Melo et al. (2009), os processos oxidativos avançados (POA) têm sido extensivamente verificados pelo seu potencial alternativo ou complementar aos processos simples de tratamento de efluentes, sendo que os radicais hidroxilas produzidos são altamente reativos e pouco seletivos, podendo atuar na oxidação química de uma vasta gama de substâncias. Outros métodos como tratamentos físico e biológico também tem sido bastante investigados a fim de promover a remoção de resíduos de fármacos.

O descarte e a chegada desses compostos em matrizes ambientais acarretam vários tipos de problemas, pois a grande maioria é persistente no ambiente, assim como seus produtos de degradação e mesmo aqueles com tempos de meia-vida curtos, são passíveis de causarem exposição crônica devido à sua permanência continua no ambiente; além disso, podem apresentar efeitos pronunciados devido ao mecanismo de ação sinérgica (REIS-FILHO et al., 2007).

\subsection{Destino dos fármacos no meio ambiente}

De acordo com Hirsch et al. (1999), os fármacos com maior probabilidade de serem encontrados no ambiente são provenientes de aplicações na medicina humana e veterinária devido à eliminação incompleta durante o tratamento de esgoto, porém pouco se conhece sobre o destino e o comportamento destes compostos no ambiente. As vias de exposição aos fármacos são vastas, sendo que os principais sítios de ocorrência ambiental de fármacos residuais podem ser divididos em cinco grupos principais; são eles: (1) Lençóis freáticos: por infiltração de linhas de esgoto ou efluentes; (2) Rios: por despejo de esgotos doméstico, hospitalar, industrial ou rural quando transportadas do solo com o auxilio das chuvas; (3) Oceanos: por despejo de esgotos ou dos rios contaminados; (4) Sedimentos: pela deposição de espécies ativas insolúveis; (5) $\underline{\text { Solo: }}$ pelo despejo urbano inadequado ou do uso rural (GIL \& MATHIAS, 2005). A Figura 3 apresenta um esquema que sugere possíveis caminhos para os fármacos, quando descartados no meio ambiente. Cerca de $50 \%$ a $90 \%$ de uma dosagem do fármaco é excretada inalteradamente via urinária ou pelas fezes e que por sua vez, acabam atingindo a estação de tratamento de esgoto (BILA \& DEZOTTI, 2003).

Segundo Jorgensen e Halling-Sorensen (2000) há três destinos possíveis nas estações de tratamento de esgoto (ETEs) para qualquer fármaco individual, assim como para todos os outros xenobióticos: 
(I) O fármaco ou os seus metabólitos podem ser mineralizados por microorganismos a dióxido de carbono e água, como por exemplo, o ácido acetilsalicílico (RICHARDSON \& BOWRON, 1985).

(II) O fármaco ou os seus metabólitos podem passar por algum processo metabólico ou serem degradados parcialmente, como as penicilinas.

(III) O fármaco ou os seus metabólitos podem ser persistentes (por exemplo, clofibrato, que é um antilipidêmico) e, ao mesmo tempo, serem muito polares e nãovinculantes para sólidos. Portanto, a substância não será mantida não degradada nas ETARs e assim, poderá atingir facilmente o ambiente aquático podendo causar diferentes efeitos aos organismos aquáticos.

O uso de fármacos veterinários na aquicultura e no trato de criações intensivas de animais (bovinos, suínos e aves) representa a principal via de entrada de antibióticos no ambiente, podendo ocasionar a contaminação de ambientes tanto aquáticos quanto terrestres (BOXALL et al., 2003). Estes compostos podem atingir diretamente o ambiente por meio das excreções dos animais em pastejo ou, então, podem ser indiretamente disseminados ao ambiente pela aplicação de esterco animal no solo (BLACKWELL et al., 2007). O estrume é muitas vezes conservado em sistemas de tanques por um período de tempo antes de ser aplicado em campos de cultivo.

A mobilidade das drogas ou de seus metabólitos no solo permite predizer se a droga poderá atingir as águas subterrâneas, através de lixiviados de aterros sanitários, ou de resíduos de produção (LI \& RANDAK, 2009).

Os fármacos usados como aditivos alimentares em piscicultura são descarregados diretamente no ambiente aquático, sendo que uma grande parte destes medicamentos aplicados não são consumidos pelos peixes (JACOBSEN \& BERGLIND, 1988). Para minimizar esta situação, muitas estações de tratamento locais acabam tratando a água de pisciculturas antes de atingirem os ambientes aquáticos. O lodo digerido, proveniente dessas estações de tratamento, também é utilizado na agricultura, como condicionador de solo. Assim, os medicamentos empregados em pisciculturas também podem ser dispostos em solos agrícolas, tendo o mesmo destino que os promotores de crescimento e substâncias usadas terapeuticamente. Deve-se salientar também que a disposição de resíduos provenientes de indústrias farmacêuticas em aterros sanitários, contaminando as águas do subsolo nas cercanias dos aterros é uma importante fonte de contaminação ambiental, bastante frequente. Sendo assim, muitos resíduos de fármacos resistem a 
vários processos de tratamento convencionais de água (métodos biológicos, químicos, físicos) por possuírem ação biocida ou estruturas químicas complexas, não passíveis de biodegradação (KLAVARIOTI et al., 2009). Além disso, é importante referir que tradicionalmente, nunca se deu muita atenção a esta questão até a década de 90, porque se pensava que grandes diluições dos fármacos fariam com que estes nunca atingissem concentrações suficientes para exercerem efeitos significativos.

Muitos esforços estão sendo realizados para o desenvolvimento de métodos mais eficazes para a remoção de fármacos nas estações de tratamento de esgoto. Segundo Melo et al. (2009), os processos oxidativos avançados (POA) têm sido extensivamente investigados pelo seu potencial alternativo ou complementar aos processos simples de tratamento de efluentes, sendo que os radicais hidroxilas produzidos são altamente reativos e pouco seletivos, podendo atuar na oxidação química de uma vasta gama de substâncias. Outros métodos como tratamentos físicos e biológicos também tem sido bastante investigados a fim de promover a remoção de resíduos de fármacos (AQUINO et al., 2013).

O descarte e a chegada desses compostos em matrizes ambientais acarretam vários tipos de problemas, pois a grande maioria é persistente no ambiente, assim como seus produtos de degradação e mesmo aqueles com tempos de meia-vida curtos, são passíveis de causarem exposição crônica devido à sua introdução continua no ambiente, sendo considerados compostos pseudopersistentes; além disso, podem apresentar efeitos pronunciados devido ao mecanismo de ação sinérgica (REIS-FILHO et al., 2007). 


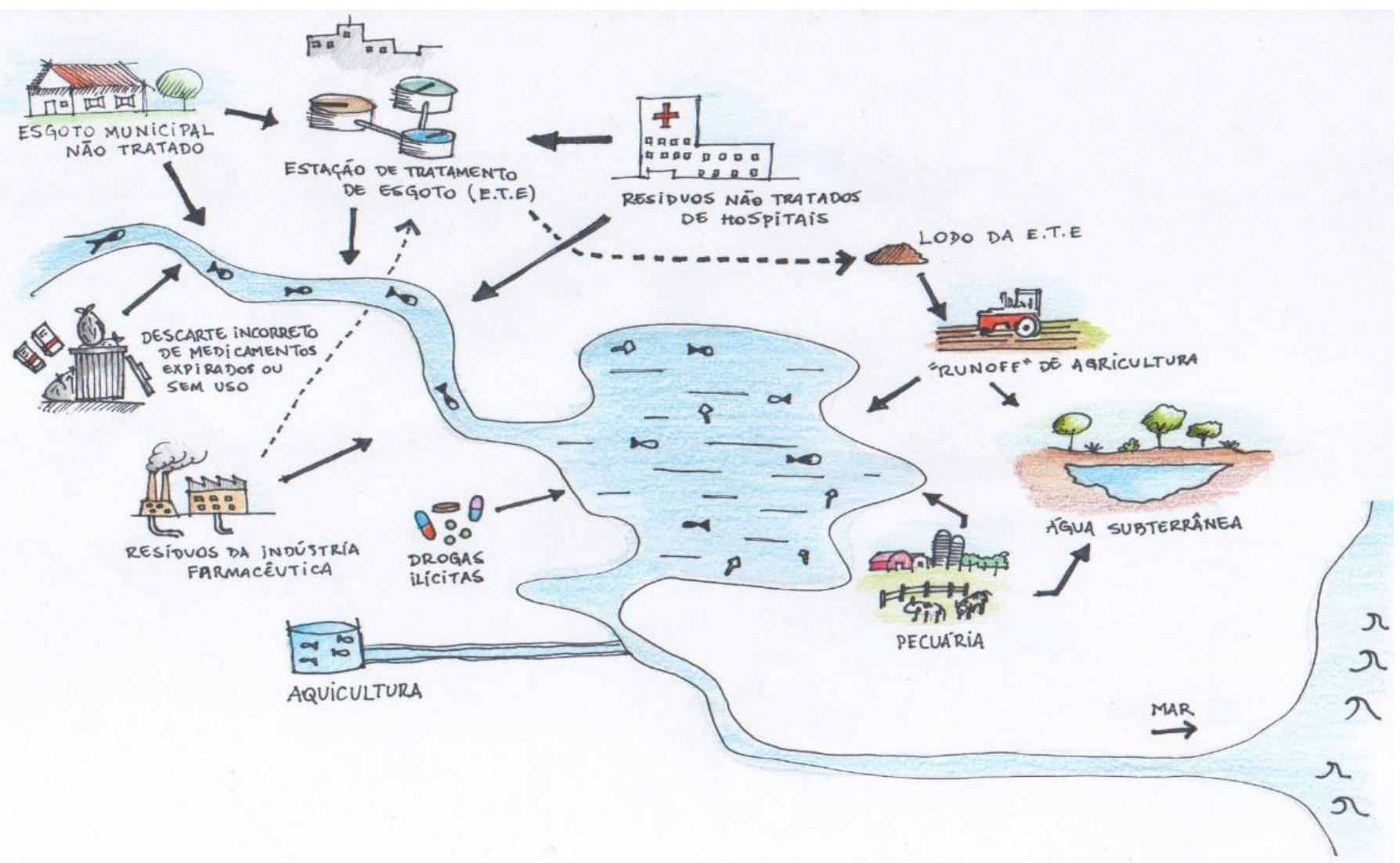

Figura 3. Possíveis rotas de exposição e destino de fármacos para o tratamento humano e veterinário no ambiente (Adaptado de MATOZZO, 2014).

\subsection{Possíveis efeitos de fármacos no meio ambiente}

A comunidade científica tem alertado para a ampla possibilidade de que efeitos inesperados possam surgir a partir da presença de produtos farmacêuticos, não só para a saúde humana, mas também para os organismos aquáticos. Considerando que muitas das vias e dos receptores farmacológicos que são ativados por fármacos são amplamente conservados evolutivamente, é possível que possam exercer efeitos em múltiplos organismos. Estes efeitos podem ocorrer em qualquer nível da hierarquia biológica, tendo consequências deletérias em múltiplas estruturas tais como célula, órgão, organismo, podendo inclusivamente comprometer a população e ecossistema. Adicionalmente, estes efeitos podem ser observados mesmo em baixas concentrações, da ordem de g L $^{-1}$ (JORGENSEN \& HALLING-SORENSEN, 2000).

Diversos estudos relatam a ocorrência, o destino e o comportamento de fármacos no ambiente aquático, assim como a diversidade de organismos que poderão ser afetados e em que grau (SUCHARA, 2007). Avaliações sobre o risco ambiental provocado por fármacos não eram frequentemente requeridos para aprovar a sua 
comercialização com vista ao consumo pelos seres humanos, razão pela qual os dados ecotoxicológicos de resíduos de medicamentos no ambiente aquático ainda são escassos e insuficientes. No entanto, desde meados da década passada, a comercialização de uma nova substância requer obrigatoriamente a apresentação de dados ecotoxicológicos sobre os seus potenciais efeitos e os níveis que se espera que a substância futuramente possa ocorrer no meio receptor (EMA, 2006).

No momento, uma das maiores dificuldades na avaliação do impacto ambiental de fármacos em ambiente aquático é saber se existe um nível suficientemente elevado dessas substâncias para exercer efeitos adversos nos seres vivos. Este aspecto está relacionado com a variedade de metabólitos formados e as possíveis interações toxicológicas entre os resíduos farmacêuticos (por exemplo, sinérgicas, aditivas, antagônicas) em organismos não-alvo no estado selvagem (CLEUVERS, 2003).

É importante reconhecer que para muitas drogas, o efeito específico ou o modo de ação para a biota em geral não é ainda muito bem conhecido e que no ambiente natural estas podem agir de modo diferente. Apesar desta dificuldade, experimentos devem ser orientados e concebidos para cumprir objetivos específicos da indústria farmacêutica, mesmo em vertebrados inferiores e invertebrados, com base na hipótese de semelhança de modos de ação (FENT et al., 2006), pois muitos dos mecanismos farmacológicos e receptores estão amplamente conservados.

A avaliação dos efeitos e alterações sobre os componentes biológicos, por meio do biomonitoramento e testes de toxicidade, representa uma forma mais efetiva para predizer ou observar impactos diversos. Se por um lado, as análises químicas identificam e quantificam alguns dos poluentes presentes, por outro os bioensaios permitem medir a capacidade que os compostos químicos têm de interferir nas vias bioquímicas e mecanismos celulares, causando-lhes efeitos adversos.

A dificuldade de analisar os efeitos de fármacos em nível ambiental prende-se inclusivamente com a tipologia de efeitos ou de testes que se devem procurar. Efeitos de toxicidade aguda em organismos de diferentes níveis tróficos da biota aquática têm sido relatados para um número considerável de fármacos; no entanto, tais dados isolados podem não ser apropriados para avaliar os seus potenciais efeitos ambientais, e, subseqüentemente, serem utilizados em avaliações de risco e periculosidade (FENT et al., 2006). 
Os testes de toxicidade aguda visam estimar a dose ou concentração de um agente tóxico que seria capaz de produzir uma resposta específica mensurável em um organismo-teste ou população, em um período de tempo relativamente curto, geralmente de 24 a 96 horas (GHERARDI-GOLDSTEIN et al., 1990). Normalmente, o efeito medido em estudos de toxicidade aguda com organismos aquáticos é a letalidade ou alguma outra manifestação do organismo que a antecede como, por exemplo, o estado de imobilidade e alterações comportamentais. Geralmente os valores de concentrações efetivas e letais são expressos em relação a $50 \%$ dos organismos $\left(\mathrm{CE}_{50}\right.$ e $\left.\mathrm{CL}_{50}\right)$, porque estas respostas são mais reprodutíveis, sendo estimadas com maior grau de confiabilidade para serem extrapoladas para uma população (ABNT, 2004). No entanto, este tipo de resposta carece de relevância ecológica, pois os níveis isolados de agentes terapêuticos requeridos para causar esse efeito mensurável são muito superiores aos encontrados no ambiente aquático.

A falta atual de conhecimento se prende, em particular, em relação aos efeitos crônicos da maioria dos produtos farmacêuticos, os quais são investigados muito raramente (SCHULTE-OEHLMANN et al., 2004). Os efeitos crônicos são respostas a um estímulo que atua por longo tempo, podendo abranger parte ou todo o ciclo de vida dos organismos, através da exposição a concentrações sub-letais, ou seja, concentrações que permitem a sobrevivência dos organismos, mas que afetam suas funções biológicas, tais como reprodução, desenvolvimento de ovos, crescimento e maturação, dentre outras. Além disso, permitem o cálculo da NOEC - concentração de efeito não observado (do inglês, No Observed Effect Concentration), concentração de agente tóxico considerada segura, e da LOEC - concentração de efeito observado (do inglês, Lowest Observed Effect Concentration) (MAGALHÃES \& FILHO, 2008). Estudos sobre possíveis efeitos crônicos dos fármacos individualmente e/ou em misturas, podem fornecer informações importantes sobre o risco destes compostos no ecossistema aquático (CLEUVERS, 2003; FENT et al., 2006).

A quantificação de parâmetros subindividuais em organismos expostos a agentes tóxicos é atualmente uma modalidade de avaliação de toxicidade que se debruça sobre a influência que os compostos podem exercer sobre vias bioquímicas e enzimáticas específicas. Mais do que os parâmetros individuais clássicos, como a mortalidade, a avaliação de parâmetros subindividuais permite estabelecer relações de causalidade entre a agressão tóxica e o comprometimento de múltiplos mecanismos de regulação 
fisiológica, que podem provocar fenônemos toxicológicos observáveis em nível individual, ou até comprometer o desenvolvimento populacional da espécie analisada (MARTINS, 2013).

Os parâmetros subindividuais podem funcionar como respostas de avaliação precoce, que indiciam alterações sutis na organização e funcionalidade de organismos expostos, muito antes da ocorrência e estabelecimento de danos (WALKER, 2004). Assim, o destaque atribuído a este tipo de determinação tem crescido e se desenvolvido em múltiplas áreas, nomeadamente com a introdução do conceito de biomarcador.

A utilização de biomarcadores têm recebido muita atenção com o surgimento de estudos detalhados que estabelecem que algumas vias metabólicas existem em múltiplos organismos, e que são afetadas de modo semelhante após exposição a um mesmo agente tóxico (ou a agentes da mesma classe toxicológica) (HYNE \& MAHER, 2003; MARTINS, 2013).

Nos estudos com biomarcadores grande destaque tem sido atribuído ao desenvolvimento de ensaios que visam a quantificação da atividade de enzimas que desempenham papel-chave em processos fisiológicos comuns, como a neurotransmissão, a desintoxicação, a respiração ou a resposta anti-oxidante. Efeitos nestes níveis terão muito provavelmente consequências sobre a fisiologia dos organismos expostos, que poderão condicionar, a posteriori, alterações sobre a sobrevivência ou a reprodução, com eventuais consequências populacionais (JEMEC et al., 2009).

\subsection{Biomarcadores}

A entrada cada vez maior de poluentes para os ecossistemas aquáticos tem levado à necessidade de melhor compreensão e avaliação dos efeitos biológicos desses contaminantes sobre a biota aquática. Diversos estudos têm utilizado biomarcadores como ferramentas funcionais para avaliar a toxicidade de uma ampla variedade de compostos sobre as populações naturais (RODRIGUES et al., 2011).

Os biomarcadores podem ser definidos, em termos ecotoxicológicos, como uma alteração numa resposta biológica (desde mudanças moleculares por meio de respostas celulares e fisiológicas, a mudanças comportamentais) que reflete os efeitos tóxicos de substâncias químicas dispersas no ambiente (ISLAS-FLORES et al., 2013). 
Existem biomarcadores moleculares, celulares e em nível de indivíduo. As duas características mais importantes dos biomarcadores são: a) permitem identificar as interações que ocorrem entre os contaminantes e os organismos vivos; b) possibilitam a mensuração de efeitos sub-letais. Daí a importância e o interesse atual de incorporação da análise de biomarcadores em programas de avaliação da contaminação ambiental (JESUS \& CARVALHO, 2008).

Segundo a WHO (Organização Mundial de Saúde) (1993) e a NRC (Comissão dos Marcadores Biológicos do Conselho Nacional de Pesquisa) (1987), os biomarcadores podem ser sub-divididos nas três classes seguintes:

- Biomarcadores de exposição: são alterações biológicas mensuráveis que evidenciam a exposição dos organismos a um poluente. Um exemplo de biomarcadores de exposição são os parâmetros bioquímicos que tem sido avaliados em peixes com relação a suas respostas a substâncias tóxicas. Entre os indicadores mais investigados nesses animais encontram-se as enzimas presentes no tecido hepático, envolvidas na desintoxicação de xenobióticos e seus metabólitos, englobando as enzimas de biotransformação de fase I e fase II e cofatores de enzimas antioxidantes (LECH \& VODICNIK, 1985); aqui se incluem parâmetros como a avaliação da indução do citocromo P-4501A (CYP1A) monoxigenase, sob exposição a hidrocarbonetos poliaromáticos (BUCHELI \& FENT, 1995). Uma das grandes vantagens do uso desses biomarcadores é o baixo custo, que chega a ser de 100 a 200 vezes menor em relação ao de análise química (SCLENK, 1999).

- Biomarcadores de efeito: geralmente, estes não são específicos em relação aos estressores químicos e não fornecem informações sobre a sua natureza, mas são característicos da ocorrência de um estresse que poderá ser reversível após a cessação da atuação do estressor. Caracterizam-se pela indução de mecanismos de defesa celular, que se iniciam sempre como uma resposta adaptativa em nível molecular-bioquímico. Entretanto, se esse mecanismo falha ou se sua capacidade de resposta é ultrapassada, poderão ser desencadeadas alterações fisiológicas ou histológicas, que podem ser irreversíveis, dependendo da capacidade do sistema ou órgão em responder ao estressor. Assim, o organismo pode ter sua capacidade de reprodução ou crescimento afetada. Alguns desses biomarcadores são órgão-específicos como as enzimas, que são lançadas na corrente sanguínea após lesão em tecidos (como várias hepato-amino-ácidos 
transaminases), indicativas de respostas adaptativas a estressores que são as envolvidas com a peroxidação lipídica ou estresse oxidativo (WINZER et al., 2001).

- Biomarcadores de susceptiblidade: podem ser definidos como indicadores de processos que causam variações de respostas ao longo do tempo e entre exposição e efeito (BARRET et al., 1997), determinando condições como: indivíduo sadio, compensação do metabolismo, perturbação das funções, alterações morfológicas e morte. Estas condições aumentam a taxa de transição entre esses dois extremos (exposição e efeito). Os organismos, mesmo sendo da mesma espécie, não respondem igualmente à exposição a xenobióticos. Sexo, jejum, estresse pelo confinamento, tamanho e estádio de desenvolvimento são parâmetros de variação nas respostas a estressores, bem como o polimorfismo genético de uma população. Estes biomarcadores correspondem aos chamados biomarcadores de efeito latente (FOSSI \& LEONZIO, 1993), significando que um organismo pode em determinadas circunstâncias, ter limitada a habilidade de se adaptar ou sobreviver, o que pode ser determinado por mensuração de respostas fisiológicas que, analisadas em conjunto, expressam a diminuição da energia disponível para o crescimento (NASCIMENTO et al., 2006).

Existe similarmente uma outra classificação dos biomarcadores enzimáticos (PEAKALL, 1992) mais abrangente, defendida por alguns autores que consideram a classificação anterior bastante limitada, do ponto de vista fisiológico ou funcional, nominalmente:

a) biomarcadores de enzimas de biotransformação (indução vs. inibição das atividades das enzimas de biotransfomação após exposição a um xenobiótico, tais como a glutationa S-transferase e UDP -glicuroniltransferases);

b) biomarcadores de alteração de proteínas reguladoras (como por exemplo, medição dos níveis de proteínas de estresse, como as metalotioneínas);

c) biomarcadores de disrupção endócrina e reprodutiva (por exemplo, avaliação dos níveis de estrogênio, anomalias no sistema reprodutor e capacidade de reprodução);

d) biomarcadores de genotoxicidade (análise de alterações em nível da estrutura do DNA) e imunotoxicidade como a concentração de imunoglobulinas;

e) biomarcadores histopatológicos (por exemplo, detecção de lesões tecidulares ou necrose);

f) biomarcadores de metabolismo energético (teor de reservas lipídicas); 
g) biomarcadores de neurotoxicidade (como por exemplo, a avaliação da atividade das colinesterases);

h) biomarcadores de estresse oxidativo (por exemplo, avaliação da atividade de enzimas antioxidantes, tais como a catalase, glutationa reductase e glutationa peroxidase);

i) biomarcadores comportamentais (como por exemplo, avaliação de categorias morfofuncionais de acordo com reações morfofisiológicas (distúrbios respiratórios, distúrbios natatórios, distúrbios tegumentares e reprodutivos; dentre outros);

Como os aspectos comuns entre organismos diferentes se acentuam principalmente em nível molecular, muitos biomarcadores moleculares possuem a vantagem de poderem ser aplicados a uma ampla variedade de organismos vivos (LAM \& GRAY, 2003). Sua metodologia é geralmente baseada em um princípio básico para o destino respectivo molécula/enzima e, em seguida, adaptadas de acordo com o organismo utilizado.

Além da classificação apresentada anteriormente, Livingstone et al. (2000) aponta que em Ecotoxicologia é crucial a distinção dos biomarcadores em gerais e específicos. Os biomarcadores gerais respondem aos principais tipos de estresse ambiental e fornecem uma medida quantitativa de performance animal ou condição física, enquanto os específicos respondem a grupos particulares de compostos químicos e, por este motivo, são o diagnóstico das referidas condições de exposição.

Em estudos ecotoxicológicos é recomendada a utilização de uma bateria de biomarcadores, uma vez que apenas a avaliação de uma única resposta biológica pode não refletir de forma ampla e complementar os danos na saúde dos organismos vivos de determinado ambiente impactado (ZORITA et al., 2008). Além disso, o uso concomitante de vários biomarcadores é essencial para minimizar interpretações errôneas nos casos de situações complexas de poluição (PACHECO \& SANTOS, 2002). Nestes estudos é imprescindível que seja feita a escolha mais apropriada da espécie indicadora da qualidade do ambiente em estudo. Assim, e dentro dos biomarcadores, grande destaque tem sido atribuído ao desenvolvimento de ensaios que visam a quantificação da atividade de enzimas que desempenham papel-chave em processos fisiológicos comuns, tais como a neurotransmissão, a desintoxicação, a respiração ou a resposta anti-oxidante. 
Por tudo o que já foi mencionado, a utilização de biomarcadores em estudos de Ecotoxicologia apresenta várias vantagens, pois permitem: (1) observar antecipadamente a existência de contaminação por substâncias tóxicas biologicamente significativas, (2) identificar espécies ou populações em risco de contaminação, (3) analisar a magnitude da contaminação, (4) prever o grau de severidade dos efeitos causados pelos poluentes e (5) estabelecer relações de causalidade entre espécies químicas e efeitos em vias metabólicas específicas que podem justificar respostas biológicas mais complexas, como alterações comportamentais e reprodutivas (BRANDÃO et al., 2011).

\subsubsection{Principais grupos de biomarcadores}

De acordo com a literatura mais recente, existem diversos grupos de biomarcadores, que têm sido objeto de intensa investigação, em particular, em nível de ecossistemas aquáticos (VAN DER OOST et al., 2003). Dentre os biomarcadores mais sensíveis, destacam-se as alterações das enzimas de biotransformação, cuja atividade nos organismos pode ser induzida ou inibida após a exposição a xenobióticos. As reações catalisadas por enzimas de biotransformação de xenobióticos são geralmente divididas em três classes, denominadas de fase I, fase II e fase III. As reações de fase I envolvem a hidrólise, redução e oxidação do composto estranho. Já as reações de biotransformação de fase II incluem a glucuronidação, a sulfatação, a acetilação, a metilação, a conjugação com glutationa (síntese de ácido mercaptúrico), e a conjugação com aminoácidos (como a glicina, taurina e ácido glutâmico) (KLAASSEN, 2001). Os co-factores para estas reações reagem com grupos funcionais que estão presentes nos xenobióticos ou que são introduzidos/expostos durante a fase I da biotransformação. Tanto alterações em nível de atividade das enzimas envolvidas nas reações de fase I como nas de fase II são frequentemente utilizadas como critérios de toxicidade em estudos ecotoxicológicos. Finalmente, as enzimas de fase III (por exemplo, peptidases, hidrolases e biliases) catalisam o catabolismo dos metabólitos conjugados, com o objetivo de formar produtos excretáveis (KLAASSEN, 2001).

Os parâmetros de estresse oxidativo constituem outro grupo importante de biomarcadores, devido ao fato que diversos compostos tóxicos existentes no ambiente ou seus metabólitos podem exercer efeitos tóxicos neste domínio (WINSTON \& DI 
GIULIO, 1991). O estresse oxidativo é produzido por um desequilíbrio entre espécies reativas de oxigênio (ROS) e os sistemas antioxidantes do corpo (BARATA et al., 2005).

Segundo Livingstone (2003), os organismos são capazes de se adaptar ao aumento da produção de espécies reativas de oxigênio (reactive oxygen species, ROS) por um acréscimo também na regulação pelas defesas antioxidantes. O fracasso no sistema de defesa antioxidante para equilibrar o excesso de produção de ROS pode ocasionar danos oxidativos, tais como inativação de enzimas, degradação de proteínas, danos ao DNA e peroxidação lipídica (HALLIWELL \& GUTTERIDGE, 1999). Os sistemas de defesa que tendem a inibir a formação ou a limitar a ação de oxiradicais incluem as enzimas antioxidantes, tal como a superóxido-dismutase (SOD), catalase (CAT), glutationaperoxidase (GPx), glutationa S-transferases (GSTs), e a glutationa-redutase (GRed), cuja dosagem enzimática é utilizada frequentemente em estudos de Ecotoxicologia (GONZÁLEZ-GONZÁLEZ et al., 2014).

Livingstone (2000) descreveu o uso de parâmetros de estresse oxidativo num vasto número de situações e organismos. Nunes et al. (2006 e 2008) avaliaram os efeitos de compostos farmacêuticos amplamente utilizados e de um detergente em nível de biomarcadores de estresse oxidativo para o crustáceo Artemia parthenogenetica e o peixe Gambusia holbrooki, após a exposição aguda a estes compostos. Pandey et al. (2003) e Oakes e Van Der Kraak (2003) utilizaram estes biomarcadores para avaliar os efeitos de misturas complexas nos tecidos dos peixes Wallaga attu e Catostomus commersoni. Ainda, Brandão et al. (2011) utilizou-os para investigar os efeitos dos fármacos carbamazepina, diazepam e fenitoína no peixe de água doce Lepomis gibbosus. Portanto, os resíduos de fármacos que são persistentes no ambiente aquático podem estimular a produção de ROS e resultar em dano oxidativo em diferentes organismos.

De igual modo, a análise de determinados parâmetros neurotóxicos tem assumido um particular interesse neste domínio, sendo as colinesterases as enzimas que assumem maior relevância do ponto de vista das funções neurais (PAYNE et al., 1996). Alguns xenobióticos como os pesticidas das classes dos organofosforados e dos carbamatos, têm sido referidos como inibidores efetivos da enzima referida, cuja dosagem tem sido utilizada em diversos estudos realizados em diferentes níveis de poluição (STURM et al., 2000). As enzimas colinesterases podem ser de dois tipos: (1) acetilcolinesterases 
(AChE), que são altamente específicas para a acetilcolina, e (2) pseudocolinesterases (PChE), que são esterases não específicas.

As alterações ao nível fissiológico e morfológico constituem importantes respostas do ponto de vista químico e celular à presença de poluentes, sendo um indicador de danos irreversíveis (HINTON et al., 1992). Na realidade, os indicadores de crescimento e de reprodução têm a vantagem de possuir um elevado significado biológico e ecológico, embora tenham uma reduzida sensibilidade ao estresse. Com efeito, as alterações histológicas têm lugar mais cedo do que as de natureza reprodutiva e são mais sensíveis do que o crescimento ou os parâmetros reprodutivos e, por outro lado, como parâmetro integrado fornecem uma melhor avaliação do estado de saúde do que um simples parâmetro bioquímico. No entanto, e considerando a importância dos efeitos no nível das populações, o estudo de alterações do desempenho reprodutivo de organismos expostos a fármacos é hoje uma prioridade.

\subsubsection{Acetilcolinesterase (AChE)}

As colinesterases (ChE) pertencem à família de enzimas designadas como esterases, com a capacidade de hidrolisar ésteres carboxílicos. As ChE podem ser distinguidas das outras esterases, uma vez que exibem preferência pela hidrólise de ésteres de colina, em vez de outros ésteres carboxílicos e são inibidas pela fisiostigmina (eserina) em concentrações da ordem de $10^{-5}$ M. A importância global das ChEs para avaliação da ecotoxicidade moderna é elevada, principalmente a acetilcolinesterase (AChE). Esta enzima desempenha uma função central no mecanismo de neurotransmissão, uma vez que promove a clivagem do neurotransmissor acetilcolina após sua liberação nas fendas sinápticas durante a transmissão colinérgica. A acetilcolina (ACh) é possivelmente a substância neurotransmissora mais bem conhecida nas sinapses químicas.

Quando a atividade de AChE é inibida de alguma forma, ocorre o bloqueio na transmissão de impulsos nervosos, paralisando as funções vitais devido à sobreposição dos impulsos nervosos, causados pela permanência dos canais de $\mathrm{Na}^{+}$abertos (STENESH, 1998). Este fato é muitas vezes responsável por efeitos agudos, resultando

freqüentemente em morte dos organismos expostos, como conseqüência da hiperestimulação do sistema nervoso autônomo parassimpático. 
A AChE é sensível à exposição aos pesticidas das classes dos organofosforados e dos carbamatos, sendo a dosagem da sua atividade frequentemente utilizada como biomarcador de efeito para a verificação dos efeitos primários da contaminação ambiental por estes agentes em diversos organismos, e na avaliação da qualidade das águas (VIANA, 2005). Nas últimas décadas tem sido relatada a inibição das colinesterases em várias espécies por outros contaminantes ambientais que não organofosforados e carbamatos (GUILHERMINO et al., 2000), tais como metais, detergentes, e misturas complexas de contaminantes.

Existem vários estudos ecotoxicológicos utilizando a enzima $\mathrm{AChE}$ como um biomarcador. Nunes et al. (2005 e 2006) estudaram os efeitos agudos e crônicos dos fármacos clofibrato e do ácido clofíbrico sobre a atividade de AChE no peixe Gambusia holbrooki e na espécie Artemia parthenogenetica.

Rocha (2011) estudou os efeitos toxicológicos (imobilização, comportamento alimentar, reprodução e crescimento) em Daphnia magna, quando expostos a diferentes concentrações de dois fármacos, a neostigmina e a piridostigmina, que têm como efeito terapêutico uma inibição reversível da atividade da acetilcolinesterase.

Guilhermino et al. (2000) relataram uma inibição significativa da AChE por agentes surfactantes na espécie Daphnia magna. Os autores concluíram que todos os agentes foram capazes de inibir a $\mathrm{AChE}$, tanto em exposições in vitro como in vivo. Um outro estudo realizado por Guiloski et al. (2013) visou avaliar parâmetros cinéticos da enzima AChE em Corydoras paleatus, e o efeito inibitório do carbamato (carbaril) na sua atividade.

Portanto, a metodologia para determinação espectrofotométrica da atividade enzimática de colinesterases é considerada simples, bem fundamentada e de baixo custo, além da grande adaptabilidade a um vasto número de espécies de ecossistemas distintos e de significativa relevância biológica e ecológica, o que torna a inibição das colinesterases um biomarcador extremamente útil em biomonitoramentos e em estudos ecotoxicológicos.

\subsubsection{Glutationa S- tranferases (GSTs)}

Outro grupo de biomarcadores que também é de grande relevância e relacionado com o potencial de desintoxicação em organismos é a atividade das isoenzimas 
glutationa S- transferases (GSTs). As GSTs representam uma família de enzimas amplamente distribuídas que catalisam a conjugação de vários xenobióticos com a glutationa (GSH) reduzida. No seu papel para a desintoxicação, esta é responsável pela conjugação com GSH, que se traduz no aumento da hidrofilia de tóxicos lipofílicos, o que reduz a probabilidade destes compostos de se ligarem a outras macromoléculas, tais como o DNA (SCHELIN et al., 1983). Além disso, esta conjugação é seguida por transferência do glutamato por c-glutamiltranspeptidase, por perda de glicina através de glicinase cisteinil e finalmente por acetilação do grupo cisteína amino. A importância toxicológica do processo de conjugação é muito elevada, uma vez que a remoção de electrófilos reativos permite a proteção de grupos nucleofílicos em macromoléculas, tais como proteínas e ácidos nucleícos. Os conjugados formados nestas reações de desintoxicação são geralmente excretados na bile, por meio de bombas dependentes de ATP. Podem também ser degradados e acetilados para formar ácidos mercaptúricos (conjugados de $\mathrm{N}$-acetilcisteína), os quais são excretados na urina. Segundo HermesLima (2004), a GST pode também apresentar atividade de GPx selênio-independente (exceto sobre $\mathrm{H}_{2} \mathrm{O}_{2}$ ).

As GSTs parecem estar presentes em muitas espécies animais, senão todas. $\mathrm{O}$ fígado é a maior fonte de GSTs em vertebrados. Apesar de algumas isoformas microssomais de GST terem sido descritas, a atividade das GSTs é principalmente localizada no citosol (CNUBBEN et al., 2001).

Esta enzima de biotranformação é aplicada principalmente como biomarcador em estudos com peixes para a avaliação de efeitos de substâncias químicas. Alguns exemplos incluem estudos da avaliação dos efeitos de fármacos amplamente usados (diazepam, clofibrato e ácido clorifibrato) e um detergente (SDS) na espécie de peixe Gambusia holbrooki (NUNES et al., 2008), bem como a avaliação das respostas bioquímicas no músculo de Salmo salar após a exposição ao etinilestradiol e ao tribultilestanho (GRECO et al., 2007), e também a avaliação dos efeitos subcrônicos da dipirona em Rhamdia quelen (PAMPLONA et al., 2011).

\subsubsection{Catalase (CAT)}

A enzima catalase é encontrada nas células animais, principalmente no fígado, rins e eritrócitos. O ferro e a vitamina E são coadjuvantes importantes para a atividade da enzima. A estrutura molecular da catalase apresenta quatro subunidades, cada uma com 
um agrupamento porfirina (FeIII-protoporfirina) e uma molécula de NADPH (HERMES-LIMA, 2004). A catalase apresenta um duplo papel, podendo funcionar como um catalisador na dismutação de moléculas de $\mathrm{H}_{2} \mathrm{O}_{2}$ e realiza a peroxidação quando se comporta apenas como aceptora de elétrons (AHMAD, 1995).

A elevada atividade da catalase geralmente está relacionada com uma alta proliferação de peroxissomos e acredita-se que as espécies reativas de oxigênio não induzam, por si só, altas atividades desta enzima. Assim, a proliferação de peroxissomos aumenta a concentração de espécies reativas de oxigênio. Existem catalases presentes tanto no citoplasma como nas mitocôndrias (LACKNER, 2008). A atividade da catalase parece estar ligada à atividade da glutationa peroxidase (GPx) para combater a exposição ao estresse oxidante.

Alguns estudos ecotoxicológicos mostram a utilização desta enzima como um biomarcador de stress oxidativo, tais como o de Pamplona et al. (2011), que buscou avaliar os potenciais efeitos tóxicos do fármaco dipirona na espécie de peixe Rhamdia quelen, utilizando diferentes biomarcadores (hematológicos, bioquímicos, genéticos e morfológicos). Tonissi (2009) avaliou através de bioensaios os efeitos de exposição independente e em conjunto dos metais cobre, cádmio e zinco sobre o stress oxidativo em Oreochromis niloticus em laboratório. Um outro estudo importante foi o de Barata et al. (2007), o qual realizou ensaios in situ com a espécie de Cladocera Daphnia magna, combinando respostas toxicológicas (sobrevivência e inibição da alimentação) e biomarcadores bioquímicos para avaliar riscos ambientais e identificar pesticidas tóxicos associados principalmente com o cultivo de arroz no Delta do rio Ebro, na Espanha.

\subsubsection{Glutationa peroxidase (GPx)}

A glutationa peroxidase (GPx) é uma enzima citosólica tetramérica, dependente ou não de selênio, sendo a forma dependente de selênio a com maior expressão. Esta enzima antioxidante pertence a uma família de enzimas capazes de remover o peróxido de hidrogênio e outros peróxidos através do acoplamento da redução de água à oxidação da glutationa reduzida (GSH) (COMINETTI et al., 2011). O átomo de selênio está presente no centro reativo da enzima na forma de selenol, num resíduo de aminoácido denominado de selenocisteína, sendo este grupo oxidado na presença de diversos 
peróxidos, levando à formação de um derivado designado de ácido selênico. Uma deficiência de selênio no organismo, um nutriente essencial, acarreta uma diminuição na atividade desta enzima em sua forma reduzida e tem sido associada com alterações no metabolismo celular (COGO et al., 2009).

Além disso, esta age de maneira importante na proteção celular dos organismos quanto às mudanças oxidativas, especialmente na prevenção da peroxidação lipídica por hidroperóxidos lipídicos, sendo este um dos mecanismos de defesa antioxidantes mais relevantes do sistema biológico. A atividade destas enzimas como biomarcador tem sido largamente utilizada na deteç̧ão precoce de respostas oxidativas em plantas e animais para diferentes poluentes (STEGEMAN et al., 1992).

Estudos como o de Gómez- Oliván et al. (2014) mostraram a utilização da GPx, da qual procurou avaliar o estresse oxidativo induzido por misturas binárias dos antiinflamatórios não-esteróides (AINEs): diclofenaco sódico, paracetamol, ibuprofeno e naproxeno com ácido acetilsalicílico, utilizando a espécie Hyalella azteca como um bioindicador. Magni et al. (2014) investigou diferentes efeitos subletais através de um conjunto de biomarcadores induzidos pela substância morfina à espécie de bivalve de água doce Dreissena polymorpha. O estudo realizado por Bartoskova et al. (2014) também avaliou os efeitos das exposições sub-crônicas do antibiótico norfloxacina para o peixe Danio rerio, usando parâmetros de estresse oxidativo como endpoint.

\section{Justificativa}

Nos últimos anos, os compostos farmacêuticos têm recebido atenção especial no mundo todo, por serem considerados contaminantes emergentes responsáveis por um novo tipo de poluição ambiental, apresentando possíveis riscos ecológicos para a biota aquática. Espera-se que o consumo mundial de fármacos aumente no futuro por causa de padrões de vida mais elevados e por um número crescente de pessoas vivendo maior período de tempo e usando mais drogas à medida que envelhecem. Em vista disso, uma crescente e significativa sensibilidade dos instrumentos analíticos a produtos farmacêuticos faz com que estes sejam detectados no meio ambiente em baixas concentrações (ng $\mathrm{L}^{-1}$ a $\mu \mathrm{g} \mathrm{L}^{-1}$ ). Dada a magnitude destas concentrações, presença dessas substâncias e a carência de informações sobre seus possíveis riscos aos organismos aquáticos, estudos sobre a presença de diferentes compostos farmacológicos e a avaliação da toxicidade destes em ecossistemas aquáticos, principalmente no que se 
refere a diferentes níveis tróficos são imprescindíveis. Neste contexto, o presente estudo visou a identificação e quantificação dos fármacos: diclofenaco de sódio (antiinflamatório), propranolol ( $\beta$-bloqueador) e paracetamol (analgésico/antipirético) em amostras de água de pontos selecionados no reservatório de Guarapiranga, na cidade de São Paulo, além de assegurar a caracterização de respostas agudas e crônicas de diferentes invertebrados aquáticos, quando expostos a estes compostos, incluindo também o antipsicótico clorpromazina. $\mathrm{Na}$ Tabela 1 são apresentadas algumas características físicas, químicas e informações importantes sobre os compostos farmacológicos estudados. 
Tabela 1. Características físico-químicas e informações gerais dos compostos farmacológicos estudados (Fonte: SUCHARA, 2007; http://www.3dchem.com/atoz.asp, acessado em 14/08/10, modificada).

Composto Clorpromazina Diclofenaco sódico Paracetamol Proplol
Fórmula
$\mathrm{C}_{17} \mathrm{H}_{19} \mathrm{~N}_{2} \mathrm{CIS}$
$\mathrm{C}_{14} \mathrm{H}_{10} \mathrm{Cl}_{2} \mathrm{NNaO}_{2}$
$\mathrm{C}_{8} \mathrm{H}_{9} \mathrm{NO}_{2}$
$\mathrm{C}_{16} \mathrm{H}_{21} \mathrm{NO}_{2}$

Massa Molecular $\quad 355,33 \mathrm{~g} \mathrm{~mol}^{-1} \quad 318,13 \mathrm{~g} \mathrm{~mol}^{-1} \quad 151,163 \mathrm{~g} \mathrm{~mol}^{-1} \quad 259,34 \mathrm{~g} \mathrm{~mol}^{-1}$

Ponto de fusão $\quad 194-196^{\circ} \mathrm{C} \quad 170-174{ }^{\circ} \mathrm{C} \quad 168-172{ }^{\circ} \mathrm{C} \quad 163-165^{\circ} \mathrm{C}$

$\begin{array}{lllll}\text { Solúvel em água } & \operatorname{sim} & \operatorname{sim} & \operatorname{sim} & \operatorname{sim}\end{array}$

Estrutura Química
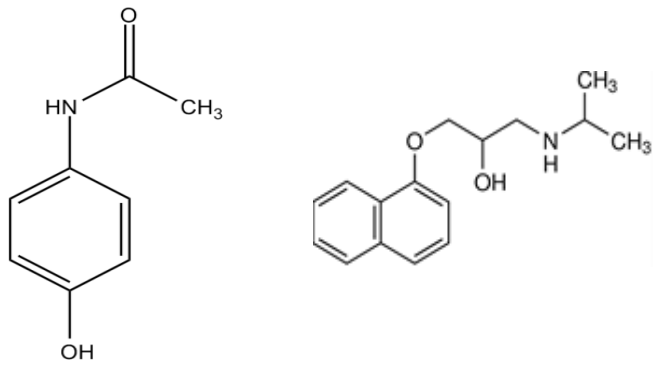

Uso Terapêutico Antipsicótico Anti-inflamatório Analgésico/antipirético $\quad \beta$-Bloqueador

No seguimento das exposições agudas e crônicas, variáveis como imobilidade, sobrevivência, reprodução e taxas de incremento populacional foram também avaliadas. A avaliação dos parâmetros subindividuais, no seguimento de exposições tanto agudas como crônicas a concentrações subletais dos referidos compostos, envolveu a quantificação da atividade de enzimas de desintoxicação (glutationa-S-transferases), estresse e dano oxidativo (catalase e glutationa peroxidase) e de neurotoxicidade (colinesterases) em Daphnia magna. Na seleção dos agentes tóxicos optou-se por 
avaliar a toxicidade destes quatro princípios ativos de fármacos, pertencentes a classes terapêuticas distintas, devido à ênfase atual em poluentes emergentes. Os compostos farmacológicos selecionados são alguns dos mais vendidos no Brasil e no mundo e que surgem com grande frequência nos estudos de monitoramento do ambiente aquático.

\section{Referências bibliográficas}

ABNT- ASSOCIAÇÃO BRASILEIRA DE NORMAS TÉCNICAS. NBR 12713: Ecotoxicologia aquática - Toxicidade aguda - Método de ensaio com Daphnia spp (Cladocera, Crustacea). Rio de Janeiro, 21p. 2004.

AHMAD, S. Oxidative stress from environmental pollutants. Archives of insect biochemistry and Physiology. v. 29, p. 135-157, 1995.

AQUINO, S.F.; BRANDT, E.M.F.; CHERNICHARO, C.A. L. Remoção de fármacos e desreguladores endócrinos em estações de tratamento de esgoto: revisão da literatura. Engenharia Sanitária e Ambiente, v.18, p. 187-204, 2013.

BARATA, C.; VARO, I.; NAVARRO, J.C.; ARUN, S.; PORTE, C. Antioxidant enzyme activities and lipid peroxidation in the freshwater cladoceran Daphnia magna exposed to redox cycling compounds. Comparative Physiology and Biochemistry $\mathbf{C}$, v. 140, p.175-186, 2005.

BARATA, C., BAIRD, D.J., NOGUEIRA, A.J.A., AGRA, A.R., SOARES, A.M.V.M. Life history responses of Daphnia magna Straus to binary mixtures of toxic substances: pharmacological versus ecotoxicological modes of action. Aquatic Toxicology, v.84, p.439-449, 2007.

BARRETT, J.C.; VAINIO, H.; PEAKALL, D.; GOLDSTEIN, B.D. 12TH Meeting of the scientific group on methodologies for the safety evaluation of chemical: susceptibility to environmental hazards. Environmental Health Perspective. v.10, p. 699-737, 1997. 
BARTOSKOVA, M.; DOBSIKOVA, R.; STANCOVA, V.; PANA, O.; ZIVNA, D.; PLHALOVA, L.; BLAHOVA, J.; MARSALEK, P. Norfloxacin- Toxicity for Zebrafish (Danio rerio) focused on oxidative stress parameters. BioMed Research International. 2014. Available at: http://dx.doi.org/10.1155/2014/560235. Acessed on 01 July 2014.

BILA, D.M.; DEZOTTI, M. Fármacos no Meio Ambiente. Química Nova. v.26, p.523$5,2003$.

BENOTTI, M.J.; TRENHOLM, R.A.; VANDERFORD, B.J; HOLADY, J.C; STANFORD, B.D; SNYDER, S.A. Pharmaceuticals and endocrine disrupting compounds in U.S. drinking water. Environmental Science \& Technology. v.43, p.597-603, 2009.

BLACKWELL, P.A.; KAY, P.; BOXALL, A.B.A. The dissipation and transport of veterinary antibiotics in a sandy loam soil. Chemosphere, v.67, p.292-299, 2007.

BOTTONI, P.; CAROLI, S.; BARRA-CARACCIOLO, A. Pharmaceuticals as priority water contaminants. Toxicological \& Environmental Chemistry, v.92, p. 549-565, 2010.

BOXALL, A.B.A.; KOLPIN, D.W.; HALLING-SØRENSEN, B.; TOLLS, J. Are veterinary medicines causing environmental risks? Environmental Science \& Technology. v.37, p.286- 294, 2003.

BRANDÃO, F.P.; PEREIRA, J.L.; GONÇALVES, F.; NUNES, B. The Impact of Paracetamol on Selected Biomarkers of the Mollusc Species Corbicula fluminea. Environmental Toxicology, v.29, p.74-83, 2011.

BUCHELI, T.D.; FENT, K. Induction of cytochrome P450 as biomarker for environmental contamination in aquatic ecosystems. Critical Review in Environmental Science Technology, v.25, p. 201-268, 1995. 
CLEUVERS, M. Aquatic ecotoxicity of pharmaceuticals including the assessment of combination effects. Toxicology Letters, v.142, p.185-194, 2003.

CNUBBEN, N. H. P. The interplay of glutathione-related process in antioxidant defense. Environmental Toxicology and Pharmacology, v.10, p. 141-152, 2001.

COGO, A.J.D.; SIQUEIRA, A.F.; RAMOS, A.C.; CRUZ, Z.M.A.; SILVA, A.G. Utilização de enzimas de estresse oxidativo como biomarcadores de impactos ambientais. Natureza on line, v.7, n. 37-42, 2009.

COMINETTI, C.; BORTOLI, M. C.; ABDALLA, D. S.; COZZOLINO, S. M. Estresse oxidativo, selênio e nutrigenética. Nutrire: Sociedade Brasileira de Alimentação e Nutrição, v. 36, n. 3, p. 131-153, 2011.

CORTEZ, F.S. Avaliação da toxicidade do fármaco triclosan através de ensaios ecotoxicológicos empregando organismos marinhos em água e sedimento marcado (spiked). 2011. Dissertação (Mestrado), Instituto de Pesquisas Energéticas e Nucleares da Universidade de São Paulo, São Paulo, SP, 2011.

EUROPEAN MEDICINES AGENCY (EMA). Guideline on the Environmental Risk Assessment of Medicinal Products for Human Use. European Chemical Agency. Doc ref. EMEA/CHMP/SWP/4447/00, 2006.

FENT, K.; WESTON, A. A.; CAMINADA, D. Ecotoxicology of human pharmaceuticals. Aquatic Toxicology, v.76, p. 122-159, 2006.

FOSSI, C.; LEONZIO, C. Nondestructive biomarkers invertebrates. Boca Raton. Florida, Lewis. 313p, 1993.

GANIYAT, A. M. The toxicological evaluation of sewage effluents and pharmaceuticals with the use of zebrafish as a model organism. 2008. 58p. (Master of Science Programme in Veterinary Medicine for International Students and Faculty of 
veterinary medicine and animal science and Swedish university of agricultural sciences), Uppsala, 2008.

GHERARDI-GOLDSTEIN, E.; BERTOLETTI, E.; ZAGATTO, P. A.; ARAÚJO, R. P. A.; RAMOS, M. L. L. C. Procedimentos para utilização de testes de toxicidade no controle de efluentes líquidos. Companhia de Tecnologia de Saneamento Ambiental (CETESB): São Paulo, 1990.

GIL, E. S.; MATHIAS, R. O. Classificação e riscos associados aos resíduos químicosfarmacêuticos. Revista Eletrônica de Farmácia, v. 2, p.87-93, 2005.

GÓMEZ-OLIVÁN， L.M.; NERI-CRUZ， N.; GALAR-MARTINEZ， M.; ISLAFLORES, H.; GARCIA-MEDINA, S. Binary mixtures of diclofenac with paracetamol, ibuprofen, naproxen, and acetylsalicylic acid and these pharmaceuticals in isolated form induce oxidative stress on Hyalella azteca. Environmental Monitoring and Assessment. 2014. Available at: http://www.doi 10.1007/s10661-014-3925-0. Accessed on 02 May 2014.

GONZÁLEZ-GONZÁLEZ, E.D.; GÓMEZ-OLIVÁN, L.M.; GALAR-MARTINEZ, M.; VIEYRA-REYES, P.; ISLA-FLORES.; GARCIA-MEDINA， S.; JIMÉNEZVARGAS, J.M.; RAZO-ESTRADA， C.; PÉREZ， PASTÉN， R. Metals and nonsteroidal anti-inflammatory pharmaceuticals drugs present in water from Madín reservoir (Mexico) induce oxidative stress in gill, blood, and muscle of common carp (Cyprinus carpio). Archives of Environmental Contamination and Toxicology, v. 67, p.281-295, 2014.

GRECO, L.; CAPRI, E.; RUSTAD, T. Biochemical responses in Salmo salar muscle following exposure to ethynylestradiol and tributyltin, Chemosphere, v.68, p.564-571, 2007.

GRÖNING, J.; HELD, C.; GARTEN, C.; CLAUSSNITZER, U.; KASCHABEK, S.R.; SCHLÖMANN, M. Transformation of diclofenac by the indigenous microflora of river 
sediments and identification of a major intermediate. Chemosphere, v.69, p.509-16, 2007.

GUILHERMINO, L.; LACERDA, M. N.; NOGUEIRA, A. J. A.; SOARES, A. M. V. M. In vitro and in vivo inhibition of Daphnia magna acetylcholinesterase by surfactant agents: possible implications for contamination biomonitoring. Science of the Total Environment. v.247, p.137-141, 2000.

GUILOSKI, I.C.; ROSSI, S.C.; SILVA, C.A.; ASSIS, H.C.S. Insecticides biomarker responses on a freshwater fish Corydoras paleatus (Pisces: Callichthyidae). Journal of Environmental Science and Health B, v.48, p. 272-277, 2013.

HALLIWELL, B.; GUTTERIDGE, J.M.C. 1999. Free Radicals in Biology and Medicine. Oxford University Press, Oxford, UK.

HERMES-LIMA, M. Oxygen in Biology and Biochemistry: role of free radicals. In: Functional metabolism: regulation and adaptation. Ed: Kenneth B. Storey. 594 p, 2004.

HINTON, D.E.; BAUMANN, P.C.; GARDNER, G.C.; HAWKINS, W.E.; HENDRICKS, J.D.; MURCHELANO, R.A.; OKIHIRO, M.S. Histopatologic biomarkers. In: Hugget, R.J., Kimerly, R.A., Mehrle, P.M. e Bergman, H.L. (eds), Biomarkers: Biochemical, Physiological and Histological Markers of Anthropogenic Stress. Lewis Publishers, Chelsea, MI, USA, p. 155-210, 1992.

HIRSCH, R.; TERNES, T.; HABERER, K.; KRATZ, K.-L. Occurrence of antibiotics in the aquatic environment. The Science of the Total Environment, v.225, p.109, 1999.

HORDERN, B.K.; DINSDALE, R.M.; GUWY, A.J. The occurrence of pharmaceuticals, personal care products, endocrine disruptors and illicit drugs in surface water in South Wales, UK. Water Research, v.42, p.3498-3518, 2008. 
HOWARD, P.H.; MUIR, D.C.G. Identifying new persistent and bioaccumulative organics among chemicals in commerce II: pharmaceuticals. Environmental Science \& Technology, v.45, p.6938-6946, 2011.

HYNE, R.V.; MAHER, W.A. Invertebrate biomarkers: links to toxicosis that predict population decline. Ecotoxicology and Environmental Safety, v.54, p.366-74, 2003.

ISLA-FLORES, H.; GÓMEZ- OLIVÁN, L.M.; GALAR- MARTÍNEZ, M.; COLÍNCRUZ, A.; NERI-CRUZ, N.; GARCÍA- MEDINA, S. Diclofenac-induced oxidative stress in brain, liver, gill and blood of common carp (Cyprinus carpio). Ecotoxicology and Environmental Safety, v.92, p.32-38, 2013.

JACOBSEN, P.; BERGLIND, L. Persistence of oxytetracycline in sediments from fish farms. Aquaculture, v.70, p.365-370, 1988.

JEMEC, A.; DROBNE, D.; TIŠLER, T.; SEPCIC', K. Biochemical biomarkers in environmental studies-lessons learnt from enzymes catalase, glutathione $S$-transferase and cholinesterase in two crustacean species. Environmental Science and Pollution Research, v.17, p.571-581, 2009.

JESUS, T. B.; CARVALHO, C.E.V. Utilização de biomarcadores em peixes como ferramenta para a avaliação de contaminação ambiental por mercúrio (Hg). Oecologia brasiliensis, v.12, p. 680-693, 2008.

JORGENSEN, S.E.; HALLING-SORENSEN, B. Drugs in the environment. Chemosphere, v.44, p.691-699, 2000.

KLAASSEN C.D. Casarett; Doull's Toxicology: The Basic Science of Poisons. $6^{\text {th }}$ Edition. McGraw-Hill, p. 133-224, 2001.

KLAVARIOTI, M.; MANTZAVINOS, D.; KASSINOS, D. Removal of residual pharmaceuticals from aqueous systems by advanced oxidation processes. Environmental International. v. 35, p.402-417, 2009. 
KÜMMERER, K. Pharmaceuticals in the Environment: Sources, Fate, Effects and Risks. Berlin/Heidelberg/New York: Springer. $2^{\text {nd }} / 3^{\text {rd }}$ Ed., $2004 / 2008$.

LACKNER, R. "Oxidative stress" in fish by environmental pollutants. BRAUNBECK et. al. (Ed.) Fish Ecotoxicology. Birkhäuser Verlag. p. 203-224, 2008.

LAM, P.K.S.; GRAY, J.S. The use of biomarkers in environmental monitoring programmes. Marine Pollution Bulletin, v.46, p.182-186, 2003.

LAMEIRA, V. Estudo dos efeitos letais e subletais (reprodução e teratogênese) do fármaco Triclosan para Daphnia similis, Ceriodaphnia dubia, Ceriodaphnia silvestrii (CLADOCERA, CRUSTACEA). 2008. 209 p. (Mestrado em Ciências na Área de Tecnologia Nuclear - Materiais). Instituto de Pesquisas Energéticas e Nucleares, Universidade de São Paulo, São Paulo, 2008.

LAMEIRA, V. Estudo dos efeitos ecotoxicológicos dos fármacos dipirona sódica e paracetamol para organismos aquáticos. 2012. 266 p. (Mestrado em Ciências na Área de Tecnologia Nuclear - Materiais). Instituto de Pesquisas Energéticas e Nucleares, Universidade de São Paulo, São Paulo, 2012.

LÄNGIN A.; SCHUSTER, A.; KÜMMERER, K. Chemicals in the environment-the need for a clear nomenclature: parent compounds, metabolites, transformation products and their elimination. Clean- soil, air, water, v. 36, p. 349-350, 2008.

LECH, J.J.; VODICNIK, M.J. Biotransformation. In: Rand, G.M. e Petrocelli, S.R. (eds), Fundamentals of Aquatic Toxicology; Methods and Applications. Hemisphere Publishing Corporation, New York, USA, p. 526-557, 1985.

LI, Z. H.; RANDAK, T. Residual pharmaceutically active compounds (PhAcs) in aquatic environment-status, toxicity and kinetics: a review. Veterinarni Medicina, v.54, p.295-31, 2009. 
LIVINGSTONE, D. R. Contaminant-stimulated Reactive Oxygen Species Production and Oxidative Damage in aquatic Organisms. Marine pollution bulletin. v.42, p.656$666,2000$.

LIVINGSTONE, D.R. Oxidative stress in aquatic organisms in relation to pollution and aquaculture. Revista de Medicina Veterinária, v.154, p.427-430, 2003.

MAGALHÃES, D.P.; FILHO, A.S.F. A ecotoxicologia como ferramenta no biomonitoramento de ecossistemas aquáticos. Oecologia Brasiliensis, v.12, p. 355 $381,2008$.

MAGNI, S.; PAROLINI, M.; BINELLI, A. Sublethal effects induced by morphine to the freshwater biological model Dreissena polymorpha. Environmental Toxicology. 2014. Available at: http://www.doi: 10.1002/tox.22021. http://onlinelibrary.wiley.com/doi/10.1002/tox.22021/abstract?deniedAccessCustomise dMessage $=\&$ userIsAuthenticated=false. Accessed on 05 June 2014.

MARTINS, L.P.S. Efeitos tóxicos subletais de paracetamol em dois níveis de organização biológica: Lemna minor e Daphnia magna. 2013. 67p. Dissertação (Mestrado em Ciências Farmacêuticas), Universidade Fernando Pessoa, Porto, Portugal, 2013.

MATOZZO, V. Effects of pharmaceuticals on immune parameters of aquatic invertebrates. Review. ISJ, v.11, p.163-173, 2014. Available: http://www.isj.unimo.it/articoli/ISJ332.pdf.

MELO, S.A.S.; TROVÓ, A.G.; BAUTITZ, I.R.; NOGUEIRA, R.F.P. Degradação de fármacos residuais por processos oxidativos avançados. Química Nova, v.32, p.188197, 2009. 
MÉNDEZ-ARRIAGA, F.; ESPLUGAS, S.; GIMÉNEZ, J. Photocatalytic degradation of non-steroidal anti-inflammatory drugs with $\mathrm{TiO}_{2}$ and simulated solar irradiation. Water Research, v.42, p.585-94, 2008.

NAMIESNIK， J.; WOLSKA， L.; CZERNYCH， R.; GALEZOWSKA， G.; CIESZYNSKA, M. Classifying the transformation products (TPs) of emerging contaminants (ECs) for prioritizing research into their impact on the environment and human health. In: Transformation Products of Emerging Contaminants in the Environment: Analysis, Processes, Occurrence, Effects and Risks. First Edition. Edited by Dimitra A. Lambropoulou and Leo M. L. Nollet. \# 2014 JohnWiley \& Sons, Ltd. Published 2014 by John Wiley \& Sons, Ltd, 63p.

NASCIMENTO, I.A.; PEREIRA, S.A.; LEITE, M.B. Biomarcadores como instrumentos preventivos de poluição. p. 413-431. In: P.A Zagatto \& E. Bertoletti. (eds.). Ecotoxicologia Aquatica- Principios e Aplicações. São Paulo. 478p, 2006.

NUNES, B.; CARVALHO, F.; GUILHERMINO, L. Acute toxicity of widely used pharmaceuticals in aquatic species: Gambusia holbrooki, Artemia parthenogenetica and Tetraselmis chuii. Ecotoxicology and Environmental Safety. v.61, p.413-419, 2005.

NUNES, B.; CARVALHO, F.; GUILHERMINO, L. Effects of widely used pharmaceuticals and a detergent on oxidative stress biomarkers of the crustacean Artemia parthenogenetica. Chemosphere, v.62, p.581-594, 2006.

NUNES, B.; GAIO, A. R.; CARVALHO, F.; GUILHERMINO L. Behaviour and biomarkers of oxidative stress in Gambusia holbrooki after acute exposure to widely used pharmaceuticals and a detergent. Ecotoxicology and Environmental Safety, v.71, p.341-354, 2008.

OAKES, K. D.; VAN DER KRAAK, G. J. Utility of the TBARS assay in detecting oxidative stress in white sucker (Catostomus commersoni) populations exposed to pulp mill effluent. Aquatic Toxicology.v. 63, p.447-463, 2003. 
PACHECO, M.; SANTOS, M.A. Biotransformation, genotoxic, and histopathological effects of environmental contaminants in European eel (Anguilla anguilla L.). Ecotoxicology and Environmental Safety, v.53, p.331-347, 2002.

PAMPLONA, J. H.; OBA, E. T.; DA SILVA, T. A; RAMOS, L. P.; RAMSDORF W. A.; CESTARI, M. M.; OLIVEIRA RIBEIRO, C. A.; ZAMPRONIO, A. R., E .; SILVA DE ASSIS, H. C. Subchronic effects of dipyrone on the fish species Rhamdia quelen. Ecotoxicology and Environmental Safety, v.74, p.342-349, 2011.

PANDEY, S.; PARVEZ, S.; SAYEED, I.; HAQUE, R.; BIN-HAFEEZ, B.; RAISUDDIN, S. Biomarkers of oxidative stress: a comparative study of river Yamuna fish Wallago attu (B1.\&Schn.), The Science of the Total Environment, v.309, p.105$115,2003$.

PAYNE, J. F.; MATHIEU, A.; MELVIN, W.; FANCEY, L. L. Acetylcholinesterase, an old biomarker with a new future? Field trials in association with two urban rivers and a paper mill in Newfoundland. Marine Pollution Bulletin. v.32, p. 225-231, 1996.

PEAKALL, D.W. Biomarkers: the way forward in environmental assessment. Toxicology Ecotoxicology News, v.1, p.55-60, 1992.

PEREIRA, L.A. Brasil será quinto maior mercado farmacêutico em 2015. Pharmacia Brasileira, n.86, setembro/outubro/novembro, 2012. Disponível em: http://www.cff.org.br/sistemas/geral/revista/pdf/138/pb86web.pdf. Acesso em: 05 jan. 2.13 .

PÉREZ-ESTRADA, L.A.; MALATO, S.; AGÜERA, A.; FERNÁNDEZ-ALBA, R.S. Degradation of dipyrone and itsmain intermediates by solar AOPs. Identification of intermediate products and toxicity assessment. Catalysis Today, v.129, p.207-14, 2007.

PETROVIĆ, M.; ŠKRBIĆ, B.; ŽIVANČEV, J.; FERRANDO-CLIMENT, L.; BARCELOA, D. Determination of 81 pharmaceutical drugs by high performance liquid 
chromatography coupled to mass spectrometry with hybrid triple quadrupole -linear ion trap in different types of water in Serbia. Science of the Total Environment, v. 468469, p.468-469, 2014.

REIS- FILHO, R. W.; BARRETO, J. C.; VIEIRA, E. M.; CASS, Q. B. Fármacos, ETEs e corpos hídricos. Revista Ambiente e Água, v.2, p.54-61, 2007.

RICHARDSON, M.L.; BOWRON, J.M. The fate of pharmaceutical chemicals in the aquatic environment: a review. Journal of Pharmacy and Pharmacology. v.37, p.1$12,1985$.

ROBERTS, P.H.; THOMAS, K.V. The occurrence of selected pharmaceuticals in wastewater effluent and surface waters of the lower Tyne catchment. Science Total Environment, v. 356, p.143-153, 2006.

ROCHA, R. J. A. Toxicidade de drogas anticolinesterásicas terapêuticas em $\boldsymbol{D}$. magna. 2011. 69 p. Dissertação (Mestrado em Biologia Aplicada- Ramo Toxicologia e Ecotoxicologia)- Universidade de Aveiro, Aveiro, Portugal, 2011.

RODRIGUES, S. R.; CALDEIRA, C.; CASTRO, B. B.; GONÇALVES, F.; NUNES, B.; ANTUNES, S. C. Cholinesterase (ChE) inhibition in pumpkinseed (Lepomis gibbosus) as environmental biomarker: $\mathrm{ChE}$ characterization and potential neurotoxic effects of xenobiotics. Pesticide Biochemistry and Physiology, v.99, p.181-188, 2011.

SANDERSON, H.; BRAIN, R.A.; JOHNSON D. J.; WILSON, C. J.; SOLOMON, K.R. Toxicity classification and evaluation of four pharmaceuticals classes: antibiotics, antineoplasics, cardiovascular, and sex hormones. Toxicology. v. 203, p. 27- 40, 2004.

SCHELIN, C.; TUNEK, A.; JERGIL B. Covalent binding of benzo[a]pyrene to rat liver cytosolic proteins and its effect on the binding to microsomal proteins. Biochemical Pharmacology. v.32, p.1501-1506, 1983.

SCHLENK, D. Necessity of defining biomarkers for uses in ecological risk assessments. Marine Pollution Bulletin. v. 39, p. 48-53, 1999. 
SCHULTE-OEHLMANN, U.; OETKEN, M.; BACHMANN, J.; OEHLMANN, J. Effects of ethinylestradiol and methyltestosterone in prosobranch snails. In: Kümmerer K, editor. Pharmaceuticals in the Environment: Sources, Fate, Effects and Risks. $2^{\text {nd }}$. Ed. Berlin, Germany: Springer; 2004. p. 233-47.

STEGEMAN, J.J.; BROUWER, M.; DI GIULIO, R.T.; FORLIN, L.; FOWLWE, B.A.; SANDERS, B.M.; VAN VELD, P.A. Molecular Responses to Environmental Contamination: Enzyme and Protein Systems as Indicators of Chemical Exposure and Effect. In: Huggert, R.J, 1992.

STENESH, J. Biochemistry. In: COSTA, JRMA. Bioindicadores de contaminação em peixes de água doce, por exposição ao Chumbo (II): ensaios laboratoriais e estudos de caso preliminar no Rio Ribeira (SP/PR). 1998.

STURM, A.; WOGRAM, J.; SEGNER, H.; LIESS, M. Different sensitivity to organophosphates of acetylcholinesterase and butyrilcholinesterase from three-spined stickleback (Gasterosteus aculeatus): application in biomonitoring. Enviromnental Toxicology Chemistry, v.19, p. 1607-1615, 2000.

SUCHARA, E.A. Desenvolvimento de metodologias analíticas para determinação de fármacos em fluidos biológicos e amostras por cromatografia líquida e gasosa. 2007. 125 p. Tese (Doutorado em Química). Instituto de Química, Universidade Federal de Santa Catarina, Florianópolis, SC, 2007.

TERNES, T. A.; STUMPF, M.; SCHUPPERT, B.; HABERER, K. VOM WASSER, v.90, p.295, 1998. In: RODRIGUES, J. et al. Solid-phase microextraction with on-fiber derivatization for the analysis of anti-inflammatory drugs in water samples. Journal of Chromatography A, v.1024, n. 1-2, p.1-8, 2004.

TONISSI, F. B. Bioensaios com metais (Cd, Cu e Zn) e as alterações em biomarcadores do estresse oxidativo, em brânquias, fígado e rim de Oreochromis niloticus. 2009.143 p. Tese (Doutorado em Ciências da Engenharia Ambiental)- Escola de Engenharia de São Carlos, Universidade de São Paulo, São Carlos, SP, 2009. 
TRAUTWEIN, C.; METZGER, J.; KÜMMERER, K. Aerobic biodegradability of the calcium channel antagonist verapamil and identification of a microbial dead-end transformation product studied by LC-MS/MS. Chemosphere, v.72, p.442-50, 2008.

VAN DER OOST, R.; BEYER, J.; VERMEULEN, N.P.E. Fish bioaccumulation and biomarkers in environmental risk assessment: A review. Environmental Toxicology and Pharmacology, v.13, p.57-149, 2003.

VIANA, T.A.P. Bioindicadores e mercúrio em tubarões costeiros pescados no estado do Rio de Janeiro, Brasil (Monografia de bacharelado)- Universidade Federal do Rio de Janeiro - UFRJ, Rio de Janeiro, 2005.

WALKER, C.H.; HOPKIN, S. P.; SIBLY, R. M.; PEAKALL, D. B. Biomarkers. In: Francis T (ed) Principles of Ecotoxicology Second Edition edn., p 326, 2004.

WENZEL, A.; SCHAFERS, C. A.; SCHIMITZ, V. V. Research efforts towards the identification of endocrine disrupting chemicals. In: TERNES, T. A. Analytical methods for the determination of pharmaceuticals in aqueous environmental samples. Trends in analytical chemistry, v. 20, p. 419, 2001.

WINSTON, G.W., DI GIULIO, R.T. Prooxidant and antioxidant mechanisms in aquatic organisms. Aquatic toxicology, v.19, p. 137-161, 1991.

WINZER, K.; WINSTON, G.W.; BECKER, W.; VAN NOORDEN, C.J.F; KOCHELER, A. Sex-related responses to oxidative stress in primary cultured hepatocytes of European flounder (Platichthys fl esus L.). Aquatic Toxicology, v.52, p.143-155, 2001.

ZENKER, A.; CICERO, M.R.; PRESTINACI, F.; BOTTONI, P.; CARERE, M. Bioaccumulation and biomagnification potential of pharmaceuticals with a focus to the aquatic environment. Journal of Environmental Management, v.133, p.378- 387, 2014. 
ZORITA, I.; ORTIZ-ZARRAGOITIA, M.; APRAIZ, I.; CANCIO, I.; ORBEA, A.; SOTO, M.; MARIGÓMEZ, I.; CAJARAVILLE, M.P. Assessment of biological effects of environmental pollution along the NW Mediterranean Sea using red mullets as sentinel organisms. Environmental Pollution, v.153, p.157-168, 2008. 
Capítulo 1

\author{
Ocorrência de resíduos de fármacos em amostras de água da Represa \\ Guarapiranga- São Paulo
}

\title{
Resumo
}

Os compostos farmacêuticos são uma classe de contaminantes emergentes que são amplamente e cada vez mais utilizados na medicina humana e veterinária. Devido à sua extensiva produção e elevado consumo dos fármacos pela população, muitos estudos em todo o mundo demonstraram níveis mensuráveis nos ambientes aquáticos, contribuindo para a bioacumulação destes compostos pelos organismos, riscos à sobrevivência e reprodução em componentes da biota e perda da qualidade da água. Produtos farmacêuticos, tais como diclofenaco sódico, paracetamol e propranolol, têm sido frequentemente encontrados em diversos compartimentos ambientais. Considerando o estado de degradação das águas superficiais do Estado de São Paulo, e incluindo a Represa do Guarapiranga, responsável por parte do abastecimento público da região metropolitana de São Paulo, este presente estudo buscou avaliar a ocorrência e a distribuição dos três fármacos mencionados anteriormente, em amostras de água de seis pontos selecionados neste reservatório, em dois períodos climáticos distintos. Para a detecção e quantificação dos fármacos foi utilizada a metodologia de extração de fase sólida (SPE) e determinação por Cromatografia Líquida acoplada ao Espectrômetro de Massas (LC-MS/MS). Foi possível observar que no primeiro período amostrado, apenas o fármaco paracetamol foi encontrado em três dos pontos amostrados (Parelheiros, Guavirutuba e Embu-Mirim), sendo também o composto registrado nos seis pontos amostrados na segunda coleta. As concentrações máximas encontradas foram 531,4 ng $\mathrm{L}^{-1}$ para o paracetamol (estação Guavirutuba), 20,3 $\mathrm{ng} \mathrm{L}^{-1}$ para o diclofenaco sódico e $14,7 \mathrm{ng} \mathrm{L}^{-1}$ para o propranolol em Embu- Mirim durante o segundo período analisado. De um modo geral, os dados obtidos refletem o resultado da contaminação nas estações analisadas, em decorrência das altas cargas de esgoto sanitário e industrial recebidos, ocupação desordenada em seu entorno dentre outros problemas ambientais relacionados às atividades antrópicas.

Palavras-chave: Reservatório de Guarapiranga, paracetamol, diclofenaco sódico, propranolol, ecotoxicidade. 


\begin{abstract}
The pharmaceutical compounds are an emerging class of contaminants that are widely and increasingly used in human and veterinary medicine. Because of its extensive production and high consumption of drugs by the population, many studies worldwide have reported measurable levels in aquatic environments, contributing to the bioaccumulation of these compounds in the organisms, risks to the survival and reproduction of the aquatic biota components of and loss of water quality. Pharmaceuticals, such as diclofenac sodium, paracetamol and propranolol, have been frequently found in various environmental compartments. Considering the state of degradation of surface waters of the State of São Paulo, in particular the Guarapiranga Reservoir, responsible for a major part of the water public supply in the metropolitan region of São Paulo, the present study aimed to evaluate the occurrence and distribution of the three pharmaceutical drugs previously, in water samples obtained for six selected points in this reservoir, in two distinct periods. For the detection and quantification of these drugs the methodologies of solid phase extraction (SPE) and determination by liquid chromatography coupled with mass spectrometry (LC-MS/MS) were used. It was observed that in the first sampling period, only the drug paracetamol was found in three of the sampled points (Parelheiros, Guavirutuba and Embu-Mirim), being also the only compound found in the six sampling points in the second sampling. The maximum concentrations found were $531.4 \mathrm{ng} \mathrm{L}^{-1}$ for paracetamol (Guavirutuba station), $20.3 \mathrm{ng}$ $\mathrm{L}^{-1}$ for diclofenac sodium and $14.7 \mathrm{ng} \mathrm{L}^{-1}$ for propranolol in the Embu-Mirim station, during the second period analyzed. In general, the data obtained reflect the result of any contamination found in the analyzed stations, due to high loads of domestic and industrial sewage received, caused by the disorderly occupation in their surroundings among other environmental problems associated with human activity.
\end{abstract}

Keywords: Guarapiranga Reservoir, paracetamol, sodium diclofenac, propranolol, ecotoxicity. 


\section{Introdução}

A ocorrência e o destino de compostos farmacêuticos e seus metabólitos no ambiente aquático tem sido consideradas questões preocupantes em todo o mundo. A avaliação do risco ambiental e humano dos fármacos, bem como a sua distribuição e acumulação entre os compartimentos ambientais não estão ainda muito elucidados (GINEBREDA et al., 2010; DU et al.; 2014; SCHAIDER et al., 2014). Alguns destes compostos podem acumular-se no lodo de esgoto, solos e sedimentos (SIPMA et al., 2010), outros permanecem de preferência em águas, e para muitos deles, não há informações disponíveis na literatura ainda.

Os compostos farmacológicos geralmente utilizados na medicina humana e veterinária podem entrar no ambiente aquático, como compostos de origem, metabólitos ou conjugados de ambos. Estas substâncias são projetadas para ter um modo de ação específico, e muitas mostram um metabolismo lento e persistência no ambiente. No compartimento aquático, os esgotos sanitários, hospitalares e águas residuais são as fontes mais importantes de produtos farmacêuticos humanos (CHRISTEN et al., 2010).

Devido à incompleta eliminação nas estações de tratamento de esgotos (ETEs) pelos processos de tratamentos convencionais (métodos biológicos, químicos, físicos), os resíduos de fármacos e seus metabólitos têm sido reportados em águas superficiais (FENT et al., 2006). A presença de medicamentos nas estações de esgoto sanitário são geralmente na faixa de $n g \mathrm{~L}^{-1}$ para $\mu \mathrm{g} \mathrm{L}^{-1}$, e de $n g \mathrm{~L}^{-1}$ em rios, lagos e água do mar (HALLING-SORENSEN et al., 1998; DAUGHTON \& TERNES, 1999; KOLPIN et al., 2002). Sendo assim, nos últimos anos, o conhecimento sobre a ocorrência ambiental de resíduos farmacêuticos tem aumentado, devido a novas técnicas analíticas sensíveis e capazes de detectar compostos polares em baixas concentrações (FENT et al., 2006; KOLPIN et al., 2002).

Como resultado de sua extensiva produção, utilização e características farmacocinéticas (como por exemplo, meia vida, excreção urinária e fecal, metabolismo e baixa eficiência de remoção nas estações de tratamento de esgoto), os antiinflamatórios não-esteróides (AINEs ou NSAIDs) tem sido comumente detectados nos ecossistemas aquáticos. Estudos mostram que dentre estes compostos, o diclofenaco sódico, o ibuprofeno e o paracetamol são relatados como as três substâncias mais frequentemente detectadas em várias matrizes ambientais (FENT et al., 2006; 
KASPRZYK-HORDERN et al., 2008; SANTOS et al., 2010). Os AINEs possuem propriedades analgésicas e antipiréticas, sendo utilizados para tratamento de dor, inflamação e rigidez. Outra classe terapêutica amplamente utilizada pela população mundial (tratamento de angina e hipertensão) são os bloqueadores de receptores badrenérgicos ( $\beta$-bloqueadores) (propranolol, metoprolol, atenolol e nadolol), que por sua vez, também são comumente encontrados em rios, córregos e esgotos em nível mundial (ROBERTS \& THOMAS, 2006; OSORIO et al., 2012; THOMAS et al., 2014).

Tais compostos não possuem limites ambientais nacionais e internacionais estabelecidos, sendo que uma das maiores dificuldades na avaliação do impacto ambiental de fármacos no meio ambiente é verificar se existe um nível suficientemente elevado dessas substâncias capaz de exercer efeitos adversos nos seres vivos. Segundo Cleuvers (2003), este aspecto está relacionado com a variedade de metabólitos formados e as possíveis interações toxicológicas entre os resíduos farmacêuticos (por exemplo, sinérgicas, aditivas, antagônicas) em organismos não-alvo no ambiente natural.

Além disso, a presença de compostos farmacológicos no ambiente aquático, especialmente em água potável e em águas superficiais utilizadas para abastecimento público deve ser considerada como questão importante em termos de segurança da saúde humana (GROS et al., 2012). Portanto, é necessária a realização de estudos que visem identificar e monitorar a ocorrência de diferentes fármacos no ecossistema aquático.

Em vista deste contexto, o objetivo do presente estudo foi avaliar a ocorrência e a distribuição dos fármacos: paracetamol (analgésico), diclofenaco sódico (antiinflamatório) e propranolol ( $\beta$-bloqueador) em amostras de água de pontos selecionados no Reservatório de Guarapiranga, na cidade de São Paulo, em dois períodos distintos (chuvoso e seco). Este é um dos primeiros estudos sobre a ocorrência simultânea de compostos farmacêuticos nesta represa, sendo que estas informações se tornam muito importantes na avaliação do risco de exposição da biota aquática a estas substâncias.

\section{Materiais e Métodos}

\section{1. Área de estudo}

O Reservatório de Guarapiranga está localizado na Bacia do Alto Tietê, e faz parte do sistema de abastecimento de água da cidade de São Paulo, localizando-se na região 
sudoeste da área metropolitana. A represa foi inicialmente utilizada para a geração de energia elétrica da Usina de Parnaíba, no rio Tietê e, a partir de 1927, tornou-se fonte de abastecimento para a região metropolitana de São Paulo. Este reservatório constitui o segundo maior da região e contribui com cerca de $20 \%$ da água de abastecimento da região metropolitana de São Paulo, fornecendo 11 mil litros de água por segundo para aproximadamente 3,7 milhões de pessoas de diversos municípios (WHATELY \& CUNHA, 2006), além de ser utilizado também como área de lazer para esportes náuticos, natação e pesca. Suas coordenadas geográficas e principais características são apresentadas na Tabela 1.

Tabela 1. Principais características do Reservatório de Guarapiranga.

\begin{tabular}{lc}
\hline \multicolumn{1}{c}{ Características } & Reservatório de Guarapiranga \\
\hline Coordenadas & $23^{\circ} 40^{\prime} 13,63^{\prime}$ 'S e $46^{\circ} 43^{\prime} 12,12^{\prime \prime} \mathrm{W}$ \\
Ano de construção & $23^{\circ} 46^{\prime} 46,35^{\prime}$ 'S e $46^{\circ} 47^{\prime} 27,966^{\prime \prime} \mathrm{W}$ \\
Uso preponderante & 1906 \\
Altitude & Abastecimento público \\
Perímetro & $740 \mathrm{~m}$ \\
Área da lâmina d' água & $85 \mathrm{~km}$ \\
Área de drenagem & $33 \mathrm{~km}^{2}$ \\
Área inundada & $630 \mathrm{~km}^{2}$ \\
Volume total & $33,9 \mathrm{~km}^{2}$ \\
Profundidade máxima & $194 \times 10^{6} \mathrm{~m}^{3}$ \\
Profundidade média & $13 \mathrm{~m}$ \\
Tempo de retenção da água & 5,7 \\
\hline
\end{tabular}

Modificado de: Cetesb (2009) e Morais et al. (2010)

A bacia do rio Guarapiranga apresenta características heterogêneas, com variada ocupação do solo, áreas verdes tipicamente rurais, bairros densamente habitados, rodovias, indústrias, extração de areia, clubes esportivos e atividades agrícolas (WHATELY \& CUNHA, 2006). Atualmente cerca de 550.000 dos 3,7 milhões de 
pessoas ocupam as regiões imediatamente no entorno do reservatório. Em 2010, apenas a metade destes habitantes da região possuía algum sistema de coleta de esgotos e a maioria do esgoto coletado continua sendo despejado no reservatório (ISA, 2010).

O Reservatório de Guarapiranga é formado pelo represamento do rio Guarapiranga e de seus afluentes: Laura, Santa Rita, Embu-Guaçu, Embu-Mirim, Ribeirão Mirim e outros 17 córregos de menor extensão. Encontra-se inserido na Unidade de Gerenciamento de Recursos Hídricos 06, a qual compreende a parte superior do Rio Tietê, desde as suas cabeceiras até a barragem do reservatório de Pirapora, numa extensão de $133 \mathrm{~km}$, abrangendo 34 cidades (CETESB, 2002).

De modo geral este corpo hídrico tem sido cenário nos últimos anos de uma constante degradação ambiental, representada principalmente pela intensa urbanização, uso e ocupação de seu entorno de forma desordenada e pelo lançamento de efluentes gerados pelos habitantes de cinco municípios e suas indústrias. No início da década de 1980, florações de algas passaram a influenciar o processo de tratamento de água, ocasionando entupimentos dos filtros na captação da água, demora na filtração e problemas para o abastecimento público (WHATELY \& CUNHA, 2006).

A melhoria das condições socioambientais da represa Guarapiranga é urgente, uma vez que a região metropolitana de São Paulo dispõe de poucas fontes de água com qualidade e quantidade adequadas para o abastecimento público. No inicio de 2006, ano do centenário da represa Guarapiranga, foi aprovada uma lei que tem como objetivo proteger e recuperar a região, sendo o marco inicial para reverter o processo de degradação e garantir o uso deste importante reservatório para o abastecimento público (ISA, 2006).

\subsection{Estações de coleta}

Foram selecionados seis pontos de coleta georeferenciados na represa de Guarapiranga, município de São Paulo (Figura 1), de modo que representassem diferentes secções e tipos de interferência humana nesta represa. As coletas das amostras de água da superfície foram realizadas em dois períodos do ano (chuvoso e seco) nos dias 01/03/2012 (período chuvoso) e 09/10/2012 (período seco), para a avaliação da ocorrência e concentração dos compostos farmacológicos em estudo. As medidas de precipitação pluviométrica foram obtidas junto ao Banco de dados 
hidroenergéticos da SABESP (Companhia de Saneamento Básico do Estado de São Paulo), referentes ao período de março a dezembro de 2012.

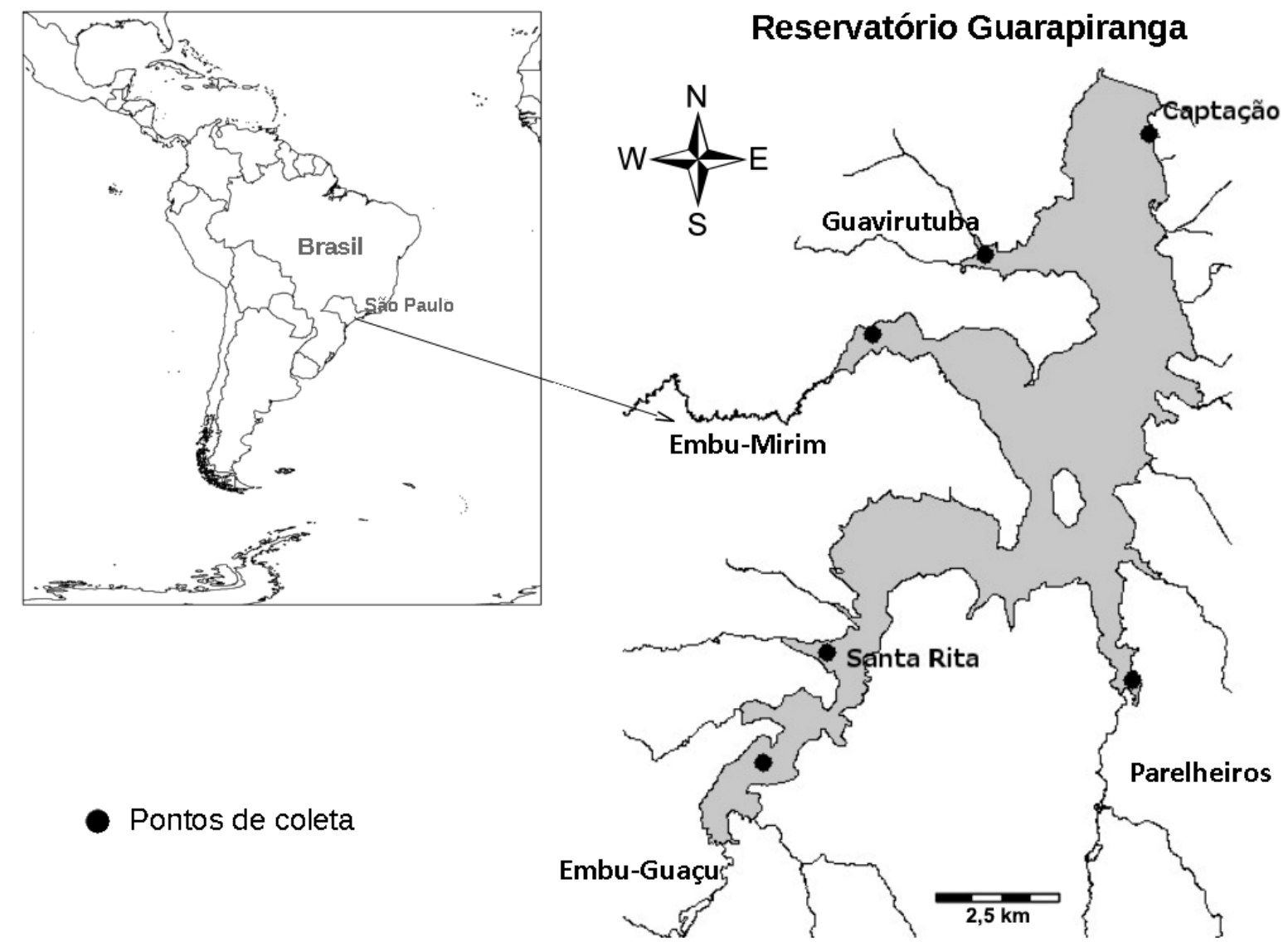

Figura 1. Mapa do Brasil mostrando a localização do Reservatório de Guarapiranga com os pontos de amostragens.

\subsubsection{Caracterização dos pontos de amostragem}

O critério para a seleção dos pontos deveu-se à localização na bacia de drenagem e à proximidade com a captação de água no reservatório de Guarapiranga, SP:

Santa Rita: $\left(23^{\circ} 45^{\prime} 22,71^{\prime \prime} S\right.$ e $\left.46^{\circ} 46^{\prime} 23,13^{\prime \prime} \mathrm{W}\right)$ - localizado próximo à região do afluente Embu-Guaçu e de córregos que drenam bacias urbanas densas;

Parelheiros: $\quad\left(23^{\circ} 75^{\prime} 12,50^{\prime \prime} \mathrm{S}\right.$ e $\left.46^{\circ} 72^{\prime} 76,10^{\prime \prime} \mathrm{W}\right)$ - localizado no braço do reservatório de Guarapiranga que recebe águas da transposição do reservatório Billings; 
Embu-Guacu: $\left(23^{\circ} 73^{\prime} 87,00^{\prime \prime}\right.$ S e 46² $\left.76^{\prime} 22,80^{\prime \prime W}\right)$ - considerado o maior tributário da represa de Guarapiranga com uma grande área de drenagem essencialmente rural;

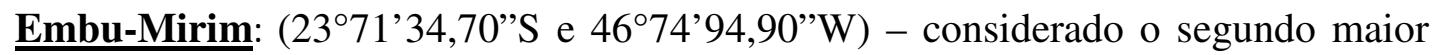
tributário de drenagem. A área de ocupação é mista. É considerado o braço que tem as florações mais intensas de algas;

Guavirutuba: $\quad\left(23^{\circ} 69^{\prime} 71,90^{\prime}\right.$ S e $\left.46^{\circ} 73^{\prime} 67,10^{\prime \prime} \mathrm{W}\right)$ - recebe contribuição de drenagem de área urbana, sendo que seu principal afluente passa por um processo de flotação para redução de carga;

Captacão: $\left(23^{\circ} 67^{\prime} 99,20^{\prime}\right.$ S e 46 72'69,50”W) - área de captação da SABESP (Companhia de Saneamento Básico do Estado de São Paulo);

\subsection{Compostos farmacêuticos e solventes}

Os princípios ativos dos fármacos utilizados no preparo das soluções padrão apresentaram grau de pureza maior que $96 \%$. Os compostos diclofenaco sódico, paracetamol e propranolol foram obtidos do Dr. Ehrenstorfer (Augsburg, Alemanha). Já os compostos deuterados de diclofenaco- $d_{4}$, paracetamol- $d_{3}$ e propranolol- $d_{7}$ foram utilizados como padrões internos, todos obtidos da CDN Isotopes (Quebec, Canadá).

Metanol e acetona grau HPLC foram obtidos da JT Baker (Ecapetec, México), $\mathrm{NH}_{4} \mathrm{OH}$ da Sigma-Aldrich (Scheweiz, Suíça) e $\mathrm{HCl}$ (Marca). Água ultra pura (18,2 $\mathrm{M} \Omega . \mathrm{cm}$ ) foi obtida em um sistema Milli-Q produzido pela Millipore (Merck Millipore, São Paulo, Brasil). Ácido clorídrico $(37 \%, \mathrm{~m} / \mathrm{m}$ ) fornecido pela Merck (Darmstadt, Alemanha) foi utilizado para o ajuste dos valores de pH. Nitrogênio com $99 \%$ de pureza foi utilizado na secagem das amostras e fornecido pela White Martins Gases Industriais LTDA (São Paulo, Brasil).

\subsection{Coleta e preparo das amostras}

Para cada ponto amostrado foram coletados 3L de água (no máximo a $50 \mathrm{~cm}$ de profundidade), armazenados em frascos de vidros âmbar previamente etiquetados e descontaminados. Em seguida estas amostras de água superficial foram colocadas em caixa térmica com gelo, para posterior análise em laboratório. No laboratório, as 
amostras foram filtradas primeiramente em membranas de fibra de vidro $(1,2$ e $0,7 \mu \mathrm{m})$ e posteriormente de celulose $(0,45 \mu \mathrm{m})$, obtidas da marca Waters, a fim de remover partículas suspensas e eliminar a ação de agentes interferentes. Após filtração, as amostras foram armazenadas em garrafas PET de cor âmbar e mantidas a $-20^{\circ} \mathrm{C}$ até posterior extração.

Para caracterizar melhor a represa estudada foram efetuadas algumas medições in situ como a do $\mathrm{pH}$, temperatura $\left({ }^{\circ} \mathrm{C}\right)$, teor de oxigênio dissolvido $\left(\mathrm{mg} \mathrm{L}^{-1}\right) \mathrm{e}$ condutividade elétrica da água $\left(\mu \mathrm{S} \mathrm{cm}^{-1}\right)$ com o uso de um multisensor da marca Horiba, modelo U-10, sendo que as leituras foram realizadas somente na camada superficial de cada ponto amostrado. Para as análises químicas e biológicas da água, foram coletadas alíquotas de $500 \mathrm{~mL}$ de água superficial para verificar a concentração de material em suspensão orgânico $\left(\mathrm{mg} \mathrm{L}^{-1}\right)$, de acordo com a metodologia de gravimetria em filtros GF/C Millipore $(0,25 \mu \mathrm{m})$ segundo Teixeira et al.(1965).

Foram coletados também $100 \mathrm{~mL}$ de água superficial para determinação das concentrações de nitrogênio e fósforo totais e outra alíquota de $50 \mathrm{~mL}$ de água superficial para a análise de carbono orgânico total (do inglês, TOC), respectivamente. Em seguida, as amostras para análise de nutrientes $\left(\mu \mathrm{g} \mathrm{L}^{-1}\right)$ e carbono orgânico total $(\mu \mathrm{g}$ $\mathrm{L}^{-1}$ ), foram armazenadas em frascos de polietileno e mantidas congeladas até a posterior análise em laboratório. As análises de nutrientes foram realizadas de acordo com o método de digestão em microondas e cromatografia iônica (COLINA \& GARDINER, 1999). Já as concentrações de carbono orgânico total (TOC) foram determinadas em fração dissolvida das câmaras por combustão e detecção por infravermelho, através do analisador de carbono (Shimadzu TOC-5000A) (APHA, 2005).

\subsection{Extração dos Analitos por SPE (Extração de Fase sólida)}

Para a extração dos analitos foram utilizados cartuchos Oasis HLB da Waters (200 $\mathrm{mg}, 6 \mathrm{~mL}$ ) em um dispositivo para SPE tipo manifold. Os cartuchos foram inicialmente condicionados com $5 \mathrm{~mL}$ de acetona, $5 \mathrm{~mL}$ de água e $5 \mathrm{~mL}$ de água $\mathrm{pH} 3$, seguidas da adição de $500 \mathrm{~mL}$ de amostra em pH $3(\mathrm{HCl})$, em triplicata. A adição da amostra foi

realizada sob vácuo a um fluxo de $5 \mathrm{~mL} \mathrm{~min}^{-1}$. Posteriormente, os cartuchos foram lavados com $6 \mathrm{~mL}$ de água $\mathrm{pH} 3$ e secos sob vácuo por 30 minutos. A eluição foi realizada utilizando $2 \times 4 \mathrm{~mL}$ de metanol: $\mathrm{NH}_{4} \mathrm{OH}(95: 5$, v/v), sob gravidade. Os 
extratos foram evaporados em um sistema Dry-Block SL (Solab, Brasil) e reconstituídos em $1 \mathrm{~mL}$ de solvente na proporção metanol:água (25:75, v/v) (Figura 1, A a C, em apêndice C).

\subsection{Determinação por Cromatografia Líquida acoplada ao Espectrômetro de Massas (LC-MS/MS)}

Para a determinação dos analitos foi utilizado o equipamento UPLC-MS/MS, modelo TQD, Waters. A separação cromatográfica foi obtida em coluna de fase reversa Acquity UPLC BEH C18 (1,7 $\mu \mathrm{m} ; 2,1$ x $50 \mathrm{~mm}$ ) e pré-coluna, ambas de C18 (Waters). Água Milli-Q contendo $0,05 \%$ de $\mathrm{NH}_{4} \mathrm{OH}$ e metanol foi utilizada como fase móvel, eluentes A e B, respectivamente. O modo de eluição gradiente foi utilizado da seguinte forma: $0-0,5 \min (95 \% \mathrm{~A}-5 \% \mathrm{~B}) ; 0,5-2,0 \min (0 \% \mathrm{~A}-100 \% \mathrm{~B}) ; 2,0-3,0 \mathrm{~min}$ (95\% A - $5 \%$ B). Foi utilizado o fluxo de $0,45 \mathrm{~mL} \mathrm{~min}^{-1}$ e $10 \mu \mathrm{L}$ de volume de injeção. As análises foram realizadas nos modos positivo e negativo, com a voltagem do capilar de $3000 \mathrm{~V}$ e $2000 \mathrm{~V}$, respectivamente. O nitrogênio foi utilizado como gás nebulizador e de dessolvatação com fluxos de $10 \mathrm{~L} \mathrm{~h}^{-1}$ e $700 \mathrm{~L} \mathrm{~h}^{-1}$, respectivamente. A temperatura do bloco da fonte foi de $150^{\circ} \mathrm{C}$ e de $500^{\circ} \mathrm{C}$ para o gás de arraste.

\subsection{Quantificação dos analitos}

A quantificação dos analitos estudados foi realizada de acordo com os critérios estabelecidos na Diretiva Europeia (2002/657/CE). Para cada composto farmacêutico foram monitoradas duas transições no modo de varredura de monitoramento seletivo de reações (MSR). A primeira transição foi utilizada para quantificação e a segunda para confirmação. Na Tabela 2 são apresentadas as condições monitoradas para cada composto analisado. As curvas de calibração foram preparadas em concentrações equivalentes ao extrato final, variando de 0,1 a $200 \mu \mathrm{g} \mathrm{L}^{-1}$ e com uma concentração fixa $50 \mu \mathrm{g} \mathrm{L}^{-1}$ de cada padrão interno. Os gráficos analíticos foram representados pelos valores do coeficiente de correlação (r) e pela equação da curva analítica (Figuras 1 a 3, em apêndice A). Para todos os compostos farmacológicos foram obtidos coeficientes de correlação (r) maiores que 0,99. Estes resultados foram válidos segundo o INMETRO 
(2003) e ANVISA (2002), que estipulam coeficientes de correlação acima de 0,90 e 0,95 como aceitáveis, respectivamente.

O perfil cromatográfico obtido por LC-MS/MS dos padrões dos três fármacos detectados nas amostras de água das estações amostradas é apresentado na Tabela 2 e Figura 2. Como pode ser observado, o composto paracetamol apresentou o menor tempo de retenção (0,78 min), seguido pelo diclofenaco sódico (1,45 min) e propranolol $(2,10 \mathrm{~min})$.

Tabela 2. Condições monitoradas para determinação dos compostos farmacêuticos por Cromatografia Líquida acoplada ao Espectrômetro de Massas (LC-MS/MS).

\begin{tabular}{lccccccc}
\hline Composto & $\begin{array}{c}\mathbf{R}_{\mathbf{t}} \\
(\mathbf{m i n})\end{array}$ & $\mathbf{I S E}$ & $\begin{array}{c}\text { Ion } \\
\text { Precursor }\end{array}$ & VC - EC & MSR1 & VC - EC & MSR2 \\
\hline Diclofenaco & 1,45 & - & 294 & $20-12$ & 250,1 & $20-12$ & 252 \\
Diclofenaco- $d_{4}$ & 1,45 & - & 298 & $20-12$ & 254 & & \\
Paracetamol & 0,78 & - & 150 & $34-18$ & 107,1 & $34-8$ & 150 \\
Paracetamol- $d_{3}$ & 0,76 & - & 153 & $32-18$ & 107 & & \\
Propranolol & 2,10 & + & 260,1 & $34-24$ & 72 & $34-22$ & 116 \\
Propranolol- $d_{7}$ & 2,08 & + & 267,2 & $34-25$ & 72 & & \\
\hline
\end{tabular}

Energia de colisão; MSR= Monitoramento Seletivo de Reações.

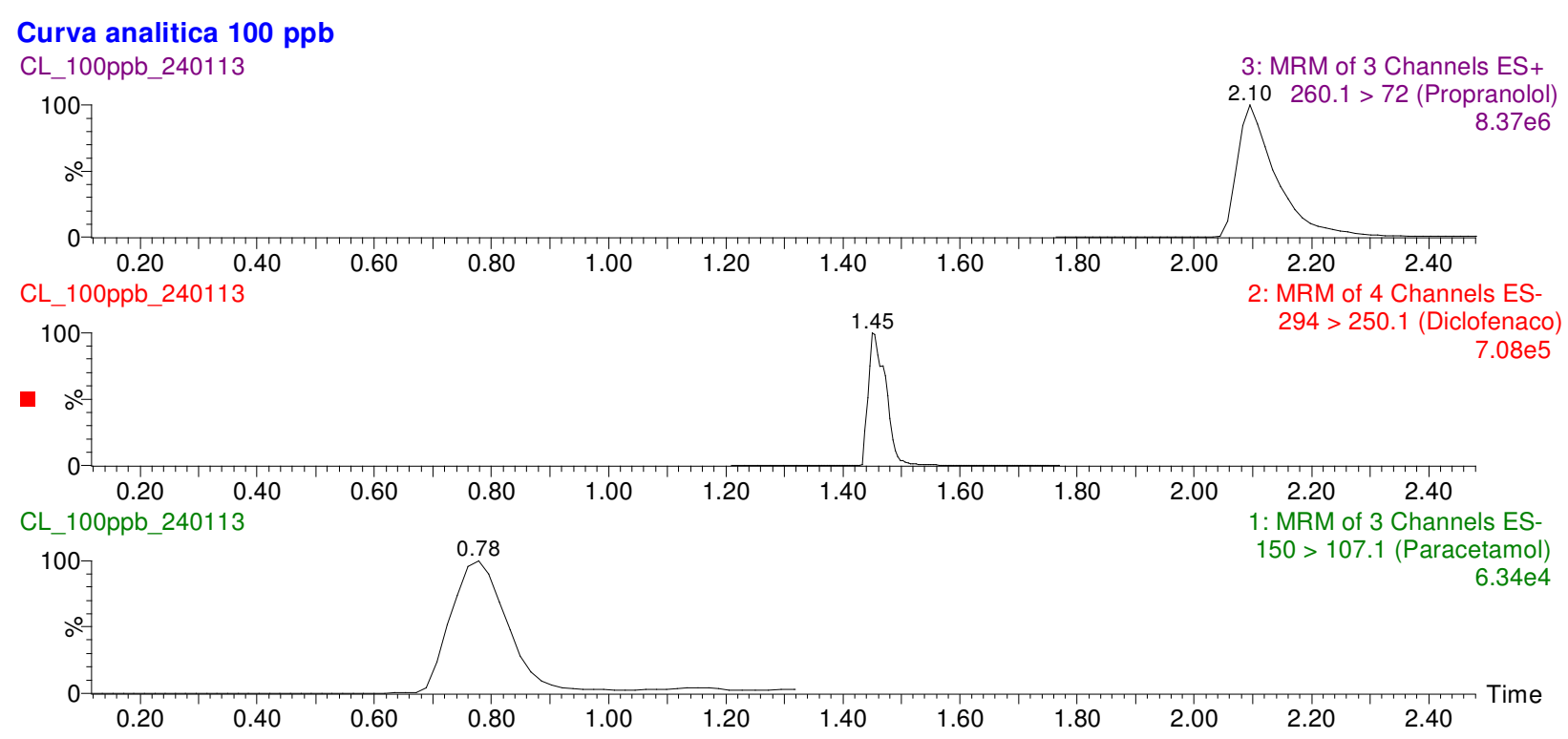

Figura 2. Perfil cromatográfico obtido por LC-MS/MS de padrões dos três fármacos estudados ( $\beta$-bloqueador, anti-inflamatório e analgésico) 1) Propranolol (2,10 min), 2) Diclofenaco sódico (1,45 min), 3) Paracetamol (0,78 min). 
Assim, para cada coleta foram realizados juntamente com a etapa de extração, testes de recuperação utilizando amostras do ponto denominado Captação, servindo como controle em relação às outras amostras. As áreas dos analitos adicionados antes e depois da etapa de extração em fase sólida (SPE) foram comparadas em um nível de fortificação de $100 \mathrm{ng} \mathrm{L}^{-1}$ e as recuperações médias obtidas variaram entre 50 e $92 \%$, respectivamente. Os limites de quantificação (LQ) foram obtidos através da relação sinal/ruído das amostras do ponto referenciado como Captação, sendo fortificadas a 100 ng $\mathrm{L}^{-1}$, e consideradas a uma relação de $3: 1$ e 10:1, respectivamente. Os valores obtidos dos limites de quantificação (LQ) foram de 5,54 $\mathrm{ng} \mathrm{L}^{-1}$ para o diclofenaco sódico; 10,04 $n g \mathrm{~L}^{-1}$ para o paracetamol e $6,26 \mathrm{ng} \mathrm{L}^{-1}$ para o propranolol, respectivamente.

\subsection{Análises estatísticas}

Os resultados obtidos durante este estudo foram armazenados em planilhas eletrônicas dos programas Excel (Windows Vista) e Origin (versão 8.0). Os dados foram submetidos á Análise de Componentes Principais (PCA), disponível no Programa CANOCO 3.12 (TER BRAAK \& ŠMILAUER, 2002), a qual foi utilizada para identificar os principais padrões de variação dentro das variáveis abióticas da água e ordenar as amostras com respeito às concentrações dos fármacos presentes durante os períodos distintos.

\section{Resultados e discussão}

\subsection{Parâmetros de qualidade de água}

A variação dos valores mensais de precipitação pluviométrica registrados no Reservatório de Guarapiranga é apresentada na Figura 1, em apêndice B, durante o período de março a dezembro de 2012.

Os valores médios das variáveis físicas, químicas e biológicas nas seis estações amostradas da represa de Guarapiranga-SP entre os dois períodos analisados são apresentados na Tabela 3. Os valores de $\mathrm{pH}$ variaram dentro da faixa de 6,61 a 8,56 e os de temperatura da água entre $23,00-29,70{ }^{\circ} \mathrm{C}$. Em relação aos valores de condutividade elétrica verificou-se uma tendência ao aumento dos seus valores entre os 
períodos analisados (variação de 23,00 a $191,00 \mu \mathrm{S} \mathrm{cm}^{-1}$ ). As concentrações de oxigênio dissolvido foram de 7,10 a 17,68 $\mathrm{mg} \mathrm{L}^{-1}$. Em relação às concentrações de material em suspensão orgânico (MSO) os valores foram de 0,20 a $9,30 \mathrm{mg} \mathrm{L}^{-1}$, as de teor de carbono orgânico total (TOC) encontraram-se dentro da faixa de 1,49-12,13 $\mu \mathrm{g} \mathrm{L}^{-1}$. Os valores das concentrações de nitrogênio e fósforo total variaram de 368,88-4210,27 $\mu \mathrm{g}$ $\mathrm{L}^{-1}$ a 34,99- 482,59 $\mu \mathrm{g} \mathrm{L}^{-1}$, respectivamente. 
Tabela 3. Valores médios obtidos para os parâmetros físicos, químicos e biológicos nas amostras de água das diferentes estações amostradas no reservatório de Guarapiranga, durante os dois períodos estudados. Temp.= temperatura; Cond.= condutividade elétrica da água; $\mathrm{OD}=$ oxigênio dissolvido; $\mathrm{MSO}=$ material em suspensão orgânico; $\mathrm{TOC}=$ teor de carbono orgânico total; $\mathrm{C} 1=1^{\mathrm{a}}$ coleta $(01 / 03 / 2012)$ e $\mathrm{C} 2=2^{\mathrm{a}}$ coleta $(09 / 10 / 2012)$

\begin{tabular}{|c|c|c|c|c|c|c|c|c|c|c|c|c|c|c|c|c|}
\hline \multirow{2}{*}{$\begin{array}{c}\text { Estações } \\
\text { amostradas }\end{array}$} & \multirow[b]{2}{*}{$\mathrm{C} 1$} & \multicolumn{3}{|c|}{ Temp. } & \multicolumn{2}{|c|}{$\begin{array}{c}\text { Cond. } \\
\left(\mu \mathrm{S} \mathrm{cm}^{-1}\right)\end{array}$} & \multicolumn{2}{|c|}{$\begin{array}{c}\text { OD } \\
\left(\mathrm{mg} \mathrm{L}^{-1}\right)\end{array}$} & \multicolumn{2}{|c|}{$\begin{array}{c}\text { MSO } \\
\left(\mathrm{mg} \mathrm{L}^{-1}\right)\end{array}$} & \multicolumn{2}{|c|}{$\begin{array}{c}\text { TOC } \\
\left(\mu g \mathrm{~L}^{-1}\right)\end{array}$} & \multicolumn{2}{|c|}{$\begin{array}{l}\text { Nitrogênio Total } \\
\qquad\left(\mu \mathrm{g} \mathrm{L}^{-1}\right)\end{array}$} & \multicolumn{2}{|c|}{$\begin{array}{l}\text { Fósforo total } \\
\qquad\left(\mu \mathrm{g} \mathrm{L}^{-1}\right)\end{array}$} \\
\hline & & $\mathrm{C} 2$ & $\mathrm{C} 1$ & $\mathrm{C} 2$ & $\mathrm{C} 1$ & $\mathrm{C} 2$ & $\mathrm{C} 1$ & $\mathrm{C} 2$ & $\mathrm{C} 1$ & $\mathrm{C} 2$ & $\mathrm{C} 1$ & $\mathrm{C} 2$ & $\mathrm{C} 1$ & $\mathrm{C} 2$ & $\mathrm{C} 1$ & $\mathrm{C} 2$ \\
\hline Captação & 8,04 & 6,97 & 27,50 & 23,00 & 82,00 & 119,00 & 8,88 & 7,10 & 4,80 & 0,20 & 9,43 & 12,13 & 1035,53 & 3180,94 & 40,21 & 128,95 \\
\hline Parelheiros & 8,30 & 6,94 & 29,70 & 24,30 & 99,00 & 191,00 & 13,72 & 9,42 & 7,80 & 0,20 & 10,88 & 10,88 & 1167,95 & 4210,27 & 64,03 & 482,59 \\
\hline Guavirutuba & 6,91 & 6,72 & 27,70 & 26,60 & 89,00 & 146,00 & 7,61 & 13,49 & 3,40 & 0,80 & 10,36 & 10,36 & 987,26 & 3697,57 & 80,67 & 106,44 \\
\hline Embu-Mirim & 8,56 & 6,80 & 29,30 & 27,10 & 92,00 & 169,00 & 13,14 & 17,68 & 4,40 & 9,30 & 11,49 & 1,49 & 837,88 & 4096,77 & 66,96 & 52,61 \\
\hline Embu-Guaçu & 7,21 & 6,80 & 29,60 & 24,20 & 23,00 & 40,00 & 8,25 & 7,33 & 2,20 & 0,40 & 7,37 & 7,37 & 475,86 & 1944,18 & 35,65 & 52,61 \\
\hline Santa Rita & 7,71 & 6,61 & 29,70 & 25,80 & 35,00 & 90,00 & 9,22 & 9,27 & 2,10 & 2,60 & 8,59 & 10,01 & 368,88 & 3200,51 & 34,99 & 92,74 \\
\hline
\end{tabular}




\subsection{Presença de fármacos na Represa de Guarapiranga-SP}

$\mathrm{Na}$ Tabela 4 são apresentados os resultados das análises de ocorrência e concentrações dos fármacos diclofenaco sódico, paracetamol e propranolol em termos espaciais nas duas campanhas amostrais.

Tabela 4. Concentrações dos compostos detectados nas amostras de água $(n=3)$, valores expressos em ng $\mathrm{L}^{-1}$.

\begin{tabular}{lcccccc}
\hline Estações & \multicolumn{2}{c}{ Diclofenaco sódico } & \multicolumn{2}{c}{ Paracetamol } & \multicolumn{2}{c}{ Propranolol } \\
\cline { 2 - 7 } amostrais & Coleta 1 & Coleta 2 & Coleta 1 & Coleta 2 & Coleta 1 & Coleta 2 \\
\hline Captação & $<$ LQ & $<$ LQ & $<$ LQ & 60,0 & $<$ LQ & $<$ LQ \\
Parelheiros & $<$ LQ & 36,4 & 21,0 & 12,2 & $<$ LQ & 11,4 \\
Guavirutuba & $<$ LQ & 9,19 & 54,2 & 531,4 & $<$ LQ & 7,79 \\
Embu-Mirim & $<$ LQ & 20,3 & 80,9 & 14,8 & $<$ LQ & 14,7 \\
Embu-Guaçu & $<$ LQ & $<$ LQ & $<$ LQ & 11,4 & $<$ LQ & 11,9 \\
Santa Rita & $<$ LQ & 6,04 & $<$ LQ & 337,1 & $<$ LQ & $<$ LQ \\
\hline
\end{tabular}

$<$ LQ: menor que o limite de quantificação.

É possível observar que no primeiro período amostrado (01/03/2012), apenas o fármaco paracetamol foi observado em três dos pontos amostrados (Parelheiros, Guavirutuba e Embu-Mirim), sendo também o único composto reportado nos seis pontos amostrados na segunda coleta (09/10/2012).

No ponto captação (área de captação da SABESP e próxima a barragem do reservatório), apenas o paracetamol foi observado nas amostras da segunda coleta (09/10/2012), mostrando que este medicamento também pode ocorrer no local menos impactado do reservatório. Este composto farmacológico foi relatado com as maiores concentrações e com maior frequência de ocorrência, com níveis de 11,4 ng L ${ }^{-1}$ (estação Embu-Guaçu) a 531,4 ng L-1 (estação Guavirutuba) no período seco (coleta 2). Similarmente aos menores níveis reportados, Almeida e Weber (2005) reportaram a ocorrência deste fármaco nas concentrações de $0,3-10,3 \mathrm{ng} \mathrm{L}^{-1}$ na represa Billings. A estação Guavirutuba, onde foi reportada a maior concentração deste composto, é conhecida por ser altamente impactada, pois recebe grande contribuição de drenagem de área urbana, o que ajuda a confirmar a entrada desse contaminante no ambiente. Mesmo sendo altas as concentrações de paracetamol obtidas no nosso estudo, ainda assim 
ficaram abaixo das encontradas por Montagner e Jardim (2011) na cidade de Campinas, que chegou ao valor $13,440 \mathrm{ng} \mathrm{L}^{-1}$ na bacia hidrográfica do Atibaia.

O paracetamol é um medicamento amplamente utilizado como analgésico e antipirético, sendo considerado um composto seguro em doses terapêuticas, que pode ser adquirido sem prescrição médica na maioria dos países, e é atualmente um dos medicamentos mais usados em nível mundial (AN et al., 2009). Devido à grande produção e extensivo uso, esta substância é relatada como um dos medicamentos mais frequentemente detectados em amostras de água de superfície, águas residuais e água potável (PAROLINI et al., 2010). Num levantamento de 139 córregos dos Estados Unidos, Kolpin et al. (2002) reportou a ocorrência de acetaminofeno em $24 \%$ das amostras analisadas, a uma concentração média de $0,11 \mu \mathrm{g} \mathrm{L}^{-1}$, com um nível de detecção máxima de até $10 \mu \mathrm{g} \mathrm{L}^{-1}$, o que está de acordo com o valor de PEC (Concentração ambiental previsível) calculada por Kim et al. (2007) para as águas coreanas $\left(16,5 \mu \mathrm{g} \mathrm{L}^{-1}\right)$. Nas águas de superfície de vários países, a concentração média deste composto é de 0,055 $\pm 0,051 \mu \mathrm{g} \mathrm{L}^{-1}$ (BOUND \& VOULVOLIS, 2006; GROS et al., 2006), enquanto nas águas residuais foi encontrada numa concentração média mais elevada, de $48 \pm 75 \mu \mathrm{g} \mathrm{L}^{-1}$ (GROS et al., 2006). Portanto, nossos resultados não estão de acordo com estes estudos apresentados, mostrando que o nível de detecção da presente pesquisa é mais sensível e em ordem de ng $\mathrm{L}^{-1}$. Por sua vez, Wu et al. (2014), não conseguiram encontrar este fármaco em 16 pontos amostrados na região central e inferior do rio Yangtze, na China; porém reportou a concentração de 84,4 ng L ${ }^{-1}$ em um dos quatro lagos analisados nessa região (lago Chao).

Devido à sua ampla presença nos ecossistemas aquáticos, o paracetamol é um dos possíveis compostos perigosos para toda a biocenose aquática (SCHULTEOEHLMANN et al., 2007). Embora estudos tenham sido realizados para avaliar o seu risco ambiental, Henschel et al. (1997) classificaram esta droga como nociva para os organismos aquáticos, com base em alguns bionsaios ecotoxicológicos com diferentes modelos biológicos, incluindo bactérias, algas, cladóceros e peixes.

Os níveis do composto diclofenaco sódico ficaram abaixo do limite de quantificação (LQ) para todos os locais amostrados no primeiro período (estação chuvosa), o que pode indicar uma alta degradabilidade (Tabela 4). Essa degradabilidade é constatada no estudo de Buser, Poiger e Müller (1998), no qual os autores relataram que em lagos naturais da Suiça, 90\% do fármaco diclofenaco detectado na entrada é 
fotodegradado, confirmando que em experimentos em laboratório o tempo de meia-vida com a incidência da luz foi menos de uma hora.

De todas as estações analisadas no período seco, este fármaco foi encontrado em 4 pontos amostrais, o que corresponde a 66,67 \% das amostras (Tabela 4). A estação Parelheiros, que sofre com a influência antrópica, apresentou o maior nível de diclofenaco sódico neste período, a qual foi quantificada na concentração de $36,4 \mathrm{ng} \mathrm{L}^{-1}$, seguida dos pontos Embu-Mirim (20,3 ng L $\left.{ }^{-1}\right)$, Guavirutuba $\left(9,19 \mathrm{ng} \mathrm{L}^{-1}\right)$ e Santa Rita $\left(6,04 \mathrm{ng} \mathrm{L}^{-1}\right)$. Parelheiros é localizado no braço do reservatório de Guarapiranga e recebe águas da transposição da represa Billings, onde este fármaco foi encontrado em maior concentração (8,1-394,5 $\mathrm{ng} \mathrm{L}^{-1}$ ), seguido dos compostos ibuprofeno (10- 78,2 ng $\left.\mathrm{L}^{-1}\right)$ e da cafeína (0,35-28,3 ng L $\left.{ }^{-1}\right)$ (ALMEIDA \& WEBER, 2005). Comparando-se os dados de outros estudos e as condições sanitárias dos dois reservatórios, é perfeitamente previsível a ocorrência de resíduos farmacêuticos, como o diclofenaco sódico, pois diariamente é aportado um grande volume de esgotos provenientes das moradias que estão no seu entorno. Devido às suas altas taxas de produção e consumo pela população mundial, adicionadas à sua solubilidade em água e incompleta remoção do esgoto durante o sistema de tratamento convencional, este composto farmacêutico tem sido considerado um dos 10 compostos mais frequentemente encontrados nos ecossistemas aquáticos (BOYD et al., 2003; SOTELO et al., 2014).

Por mais significativas que pareçam as concentrações encontradas na represa de Guarapiranga, em um estudo realizado na cidade do Rio de Janeiro (STUMPF et al., 1999) foram quantificadas concentrações de até $60 \mathrm{ng} \mathrm{L}^{-1}$ e em Campinas

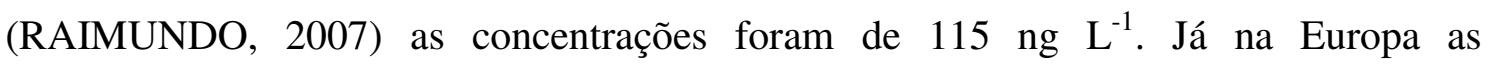
concentrações encontradas são superiores, especialmente na Alemanha, onde a quantificação nos rios chegou até $600 \mathrm{ng} \mathrm{L}^{-1}$ (SACHER et al., 2001; HEBERER, 2002), que deve estar relacionada com o maior consumo desse medicamento. Contrariamente a esses dados, Muñoz et al. (2009) reportaram níveis deste anti-inflamatório de 0,08 a 18,4 $\mathrm{ng} \mathrm{L}^{-1}$ no rio Llobregat (nordeste da Espanha), sendo que este corpo hídrico recebe amplas descargas de águas residuais urbanas e industriais $\left(137,000,000 \mathrm{~m}^{3} / \mathrm{ano}\right)$, onde $92 \%$ vem das estações de tratamento de águas residuais. Além disso, o diclofenaco é considerado como um dos fármacos mais relevantes que podem exercer efeitos tóxicos nos organismos aquáticos pertencentes a níveis tróficos diferentes. 
O propranolol é um $\beta$ - bloqueador não seletivo indicado para o tratamento de hipertensão arterial, arritmias cardíacas e controle de angina (GABET-GIRAUD et al., 2014). Uma vez consumidos, os $\beta$-bloqueadores são excretados em parte inalterados (VIENO et al., 2006). Segundo Osorio et al. (2012), este composto é comumente encontrado em rios e córregos que são contaminados por meio da disposição incorreta de esgoto sanitário e industrial. Este fármaco na maioria dos pontos amostrados no período chuvoso esteve abaixo dos limites de quantificação (Tabela 4). Já no segundo período amostrado, nas estações Captação e Santa Rita, os níveis encontrados para este composto se encontraram abaixo dos limites de quantificação, respectivamente. Este $\beta$ bloqueador foi encontrado em 4 pontos amostrais, com concentrações variando de 7,79 ng L ${ }^{-1}$ (estação Guavirutuba) a 14,7 ng L ${ }^{-1}$ (estação Embu-Mirim) (Tabela 4). Esta última estação mencionada é conhecida pela grande ocupação desordenada em seu entorno, ocorrência de contaminação por esgoto doméstico, e ainda é considerado o braço onde ocorrem as florações mais intensas de cianobactérias, recebendo assim, altas concentrações de algicidas para controlar este grave problema (CETESB, 2002). Alguns destes fatos contribuem para a ocorrência deste composto farmacêutico, comprometendo assim, a qualidade da água neste local.

Na Europa e na América do Norte, os níveis de propranolol presente em rios e

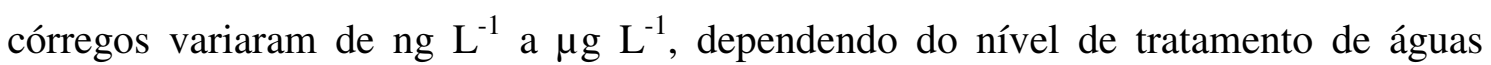
residuais (taxas de eliminação de cerca de 20\%; VIENO et al., 2007) e da quantidade de águas residuais presente. Na Europa, o uso de $\beta$ - bloqueadores é variável entre os países, mas dados publicados sugerem ser na faixa de 0,1 a 3,2 g/ pessoa/ano (ALDER et al., 2010); entretanto, não existem dados disponíveis para o Brasil. Além disso, de acordo com Cleuvers (2005), dados sobre a fotodegradação de propranolol foi avaliado como tendo uma meia-vida de 16,8 dias.

Concentrações de propranolol superiores aos registrados no nosso estudo foram relatados por Ternes (2001) e Ashton et al. (2004) em amostras de águas superficiais da Alemanha e Reino Unido com níveis de concentrações máximas de 590 ng L L $^{-1} 215$ ng $\mathrm{L}^{-1}$, respectivamente. Por sua vez, Vazquez-Roig et al. (2011) descreveram a ocorrência deste fármaco em 33\% das amostras de água coletadas no lago L'Albufera, na Espanha, onde o nível de detecção foi de $8,4 \mathrm{ng} \mathrm{L}^{-1}$ e em algumas amostras não foi encontrado. Esta área estudada sofre efeitos em resposta à industrialização de áreas vizinhas, expansão demográfica, urbanização turística em áreas costeiras e com construções de 
redes de estradas. Outro estudo importante foi realizado por Gabet-Giraud et al. (2014), que observou que os $\beta$ - bloqueadores bisoprolol, metoprolol, propranolol e timolol foram quantificados em frequências intermediárias (44-82\%) em amostras de água de superfície (Rios Ardières, Bourbre e Saône, localizados na França e que são impactados também por diferentes fontes de contaminação: estação de tratamento de águas residuais, indústria e agricultura). Embora haja uma correlação entre as concentrações destes compostos e a relação em que estes estão disponíveis na indústria farmacêutica, nenhuma conclusão direta deve ser delineada como múltiplos fatores que podem ter alguma influência. O composto propranolol foi identificado com frequência de quantificação de $50 \%$ nas amostras analisadas $(n=6)$ e concentração média de $12 \mathrm{ng} \mathrm{L}^{-1}$; resultados estes que se assemelham aos dados obtidos no presente estudo. Esta mesma frequência de quantificação também foi observada no estudo conduzido nos rios Taff (Inglaterra) e Warta (Polônia) com concentrações entre 5 e 6 ng L ${ }^{-1}$ (KASPRZYKHORDEM et al., 2007).

Apenas nos pontos Parelheiros, Guavirutuba e Embu- Mirim todos os compostos farmacológicos foram reportados simultaneamente no último período analisado, fato este que reforça serem estes três pontos estudados os mais impactados, favorecendo assim, ainda, para com a crescente alteração e a baixa qualidade das águas do reservatório de Guarapiranga. No entanto, as consequências de sua presença no ambiente aquático não estão bem documentadas e um fator importante a ser considerado é que o propranolol pode ser absorvido por organismos aquáticos, sofrendo bioacumulação, como mostrado por Claessens et al. (2013). Além disso, estudos ecotoxicológicos mostram que os $\beta$-bloqueadores podem afetar os organismos aquáticos, sendo o propranolol o mais prejudicial dentre estes (FENT et al., 2006; KÜSTER et al., 2009).

\subsection{Relação entre os parâmetros físico-químicos e biológicos e os fármacos}

A análise de componentes principais (PCA) foi realizada para estudar as relações entre as variáveis abióticas e as concentrações dos fármacos nos dois períodos amostrados (Figuras 3 e 4). Como pode ser observada na Figura 3, a análise mostrou fortes relações entre as variáveis no primeiro período amostrado, como evidenciado pela alta explicabilidade alcançada pelos dois primeiros eixos, que juntos explicaram 99,9\% 
do total da variância dos dados, sendo $98,7 \%$ pelo $1^{\circ}$ eixo e $1,2 \%$ pelo $2^{\circ}$ eixo. $\mathrm{O}$ primeiro eixo mostrou correlações positivas entre todas as variáveis abióticas (com exceção da temperatura) e os pontos amostrais de Embu-Mirim, Guavirutuba, Parelheiros e Captação. Um grupo foi formado pelas estações Santa Rita e Embu-Guaçu e a variável temperatura. Foi possível observar, que este parâmetro foi negativamente relacionado com as estações Parelheiros e Captação, sendo que o fármaco paracetamol foi negativamente relacionado com os últimos pontos citados (Santa Rita e Captação).

Além disso, somente este composto farmacológico foi identificado no primeiro período amostrado, revelando que as estações Embu-Mirim e Guavirutuba apresentaram maior influência de substâncias provenientes de esgotos domésticos e industriais, principalmente em função das concentrações de nutrientes, material em suspensão orgânico e do paracetamol, o que comprova fontes de poluição similares para os dois locais, a ação antropogênica da população ao seu entorno, com despejos de esgotos, tratamentos ineficientes ou até mesmo coletas de esgotos inadequadas. Resultados similares foram encontrados no estudo de Kramer (2012), nos rios Iguaçu, Atuba e Belém localizados na Bacia hidrográfica do Alto Iguaçu. Características físico-químicas de cada fármaco também são fatores muito importantes que podem influenciar na explicabilidade destes dados, mas estes são pouco reportados na literatura para este tipo de análise. 


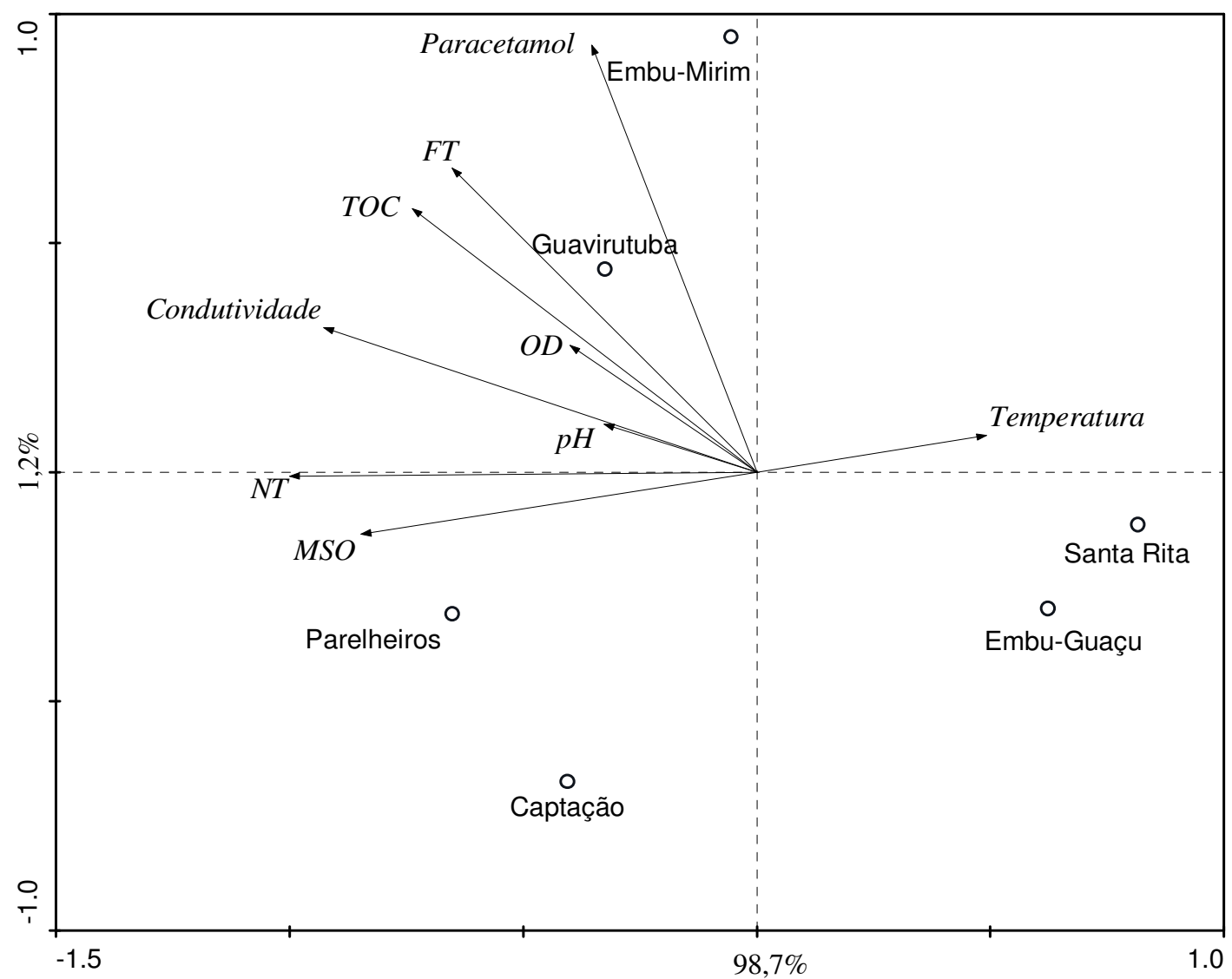

Figura 3. Diagrama de ordenação da Análise de Componentes Principais (PCA) relacionando as variáveis físicas, químicas e biológicas com as concentrações dos fármacos durante o primeiro período amostrado (01/03/2012): TOC = teor de carbono orgânico total; $\mathrm{OD}=$ concentração de oxigênio dissolvido; $\mathrm{MSO}$ = material em suspensão orgânico; NT = nitrogênio total e FT = fósforo total.

A Análise de Componentes principais (PCA) revelou fortes associações entre as variáveis abióticas e os fármacos encontrados nas estações amostradas no segundo período, sendo que os dois primeiros eixos juntos explicaram 97,9\% do total da variância dos dados, sendo $91,1 \%$ pelo $1^{\circ}$ eixo e $6,8 \%$ pelo $2^{\circ}$ eixo (Figura 4). Todas as variáveis abióticas foram fortemente associadas com os pontos amostrais de Guavirutuba, Embu-Mirim e Parelheiros, além da ocorrência dos três fármacos neste grupo. Todos os parâmetros abióticos analisados foram positivamente associados com estas estações mencionadas e também com as concentrações de paracetamol, diclofenaco sódico e propranolol. Estes locais são considerados os mais impactados no reservatório de Guarapiranga, com grande contribuição de efluentes com maior carga de nutrientes e contaminantes ambientais. Por outro lado, os pontos amostrais Santa Rita, 
Captação e Embu-Guaçu foram negativamente relacionados com todas as variáveis abióticas e os fármacos estudados. A estação Santa Rita foi negativamente relacionada com os compostos propranolol e diclofenaco sódico, além das variáveis TOC, MSO, condutividade, FT e pH, respectivamente. Já os pontos Captação e Embu-Guaçu foram negativamente relacionados com o paracetamol e as variáveis temperatura e OD. Portanto, com base nos mesmos componentes, as estações amostradas se separaram de acordo com as suas particularidades, tendo como referência a separação das características das variáveis estudadas.

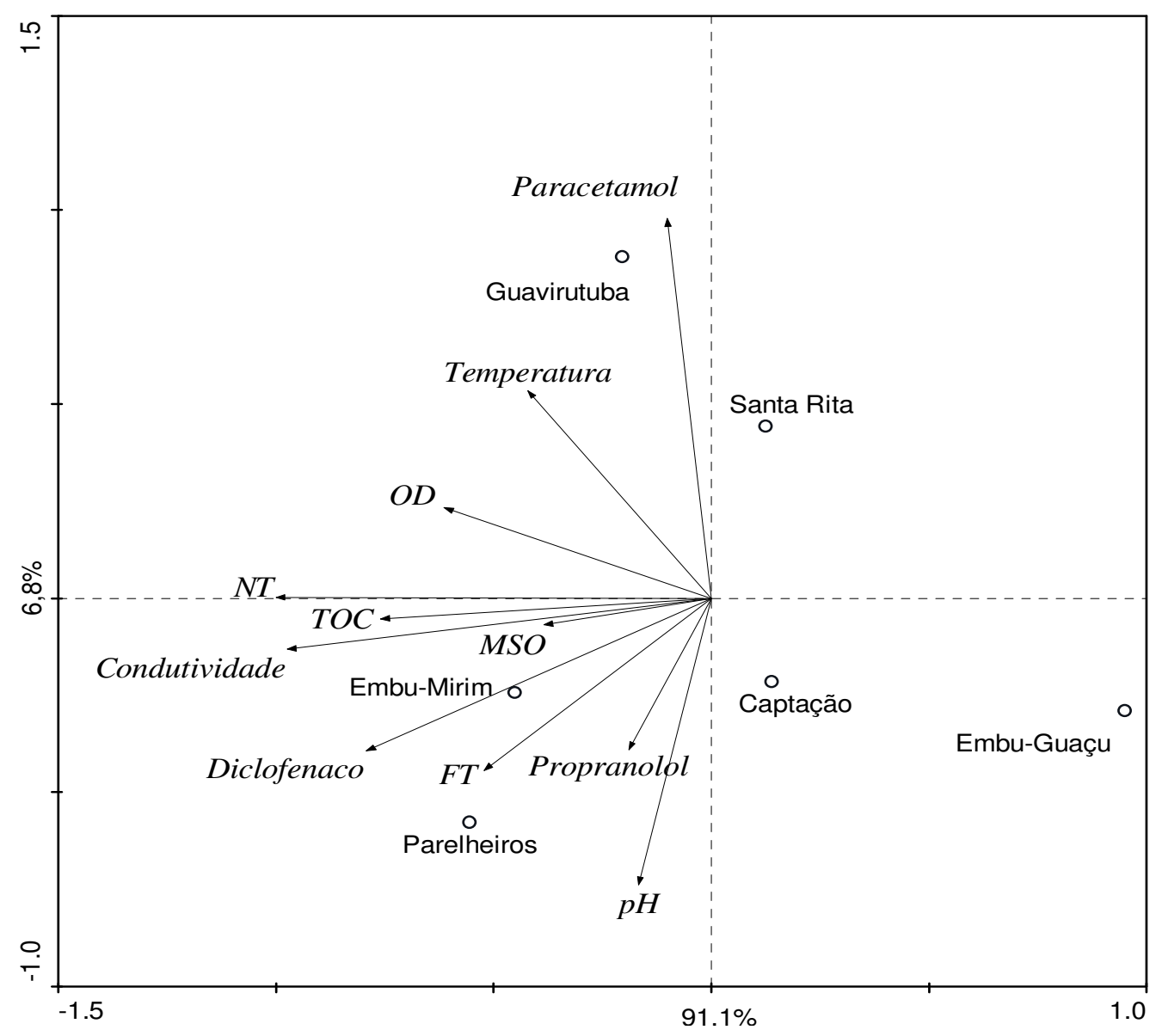

Figura 4. Diagrama de ordenação da Análise de Componentes Principais (PCA) relacionando as variáveis físicas, químicas e biológicas com as concentrações dos fármacos durante o segundo período amostrado (09/10/2012): TOC $=$ teor de carbono orgânico total; OD = concentração de oxigênio dissolvido; MSO = material em suspensão orgânico; NT = nitrogênio total e FT = fósforo total. 


\section{Conclusões}

Foi possível a análise e a quantificação dos três produtos farmacêuticos avaliados neste estudo, tendo como destaque o paracetamol, que foi encontrado em três dos pontos amostrados (Parelheiros, Guavirutuba e Embu-Mirim) no primeiro período estudado e em todos os pontos na segunda coleta, confirmando a persistência e o extensivo uso deste composto pela população. Os fármacos diclofenaco sódico e propranolol estiveram abaixo dos níveis de quantificação na primeira amostragem, sendo que no segundo período este anti-inflamatório apresentou maiores concentrações nas estações estudadas. As concentrações encontradas no presente estudo são baixas, na ordem de $n g \mathrm{~L}^{-1}$, sendo que, possivelmente efeitos crônicos e a biomagnificação desses contaminantes pode ter um grande impacto nos organismos presentes nos ambientes estudados.

De modo geral, é possível concluir que as estações Parelheiros, Guavirutuba e Embu-Mirim destacam-se negativamente com a presença de contaminantes ambientais enquanto que os outros locais não foi encontrado os mesmos níveis de concentrações, mas também apresentam influência desse tipo de degradação. Na Represa de Guarapiranga, a presença de resíduos de fármacos é facilmente explicável, dadas as condições sanitárias do corpo hídrico, uma vez que ela recebe um volume considerável de esgoto sanitário e industrial, decorrentes principalmente da falta de tratamento destes, pela falta da vegetação no entorno do reservatório e pela ocupação ilegal em seu entorno. Os dados obtidos com este estudo de prospecção neste reservatório contribuem para informações sobre o grau de contaminação destes compostos, suas distribuições e localização das fontes problemáticas, uma vez que também representam uma linha de base importante para futuras e mais abrangentes investigações neste local.

\section{Referências bibliográficas}

ALDER, A.C.; C. SCHAFFNER, C; MAJEWSKY, M.; KLASMEIER, J.; FENNER, K. Fate of $\beta$-Blocker human pharmaceuticals in surface water: comparison of measured and simulated concentrations in the Glatt Valley Watershed, Switzerland. Water Research, v.44, p.936-948, 2010. 
ALMEIDA, G.A.; WEBER, R.R. Fármacos na Represa Billings. Revista Saúde e Ambiente, v.6, p.7-13, 2005.

AN, J.; ZHOUA, Q.; SUN, F.; ZHANG, L. Ecotoxicological effects of paracetamol on seed germination and seedling development of wheat (Triticum aestivum L.). Journal of Hazardous Materials, v. 169, p.751-757, 2009.

ANVISA. Resolução - RE no 475, de 19 de março ANVISA 2002.

APHA-AMERICAN PUBLIC HEALTH ASSOCIATION. Standard Methods for the Examination of water and wastewater, 16 ed. APHA, Washington, American Water Works Association, 1995.

ASHTON, D.; HILTON, M.; THOMAS, K. V. Investigating the environmental transport of human pharmaceuticals to streams in the United Kingdom. The Science of the Total Environment, v.333, p.167-184, 2004.

BOUND, J.P.; VOULVOULIS, N. Predicted and measured concentrations for selected pharmaceuticals in UK rivers: implications for risk assessment. Water Research, v. 40, p.2885-2892, 2006.

BOYD, G. R.; REEMTSMA, H.; GRIMM, D. A.; MITRA, S. Pharmaceuticals and personal care products (PPCPs) in surface and treated waters of Louisiana, USA and Ontario, Canada. The Science of the Total Environment, v.311, p.135 -149, 2003.

BUSER, H. R.; POIGER, T.; MULLER, M. D. Occurrence and fate of the pharmaceutical drug diclofenac in surface waters: Rapid photodegradation in a lake. Environmental Science \& Technology, v. 32, p. 3449-3456, 1998.

CALEFFI, S. Estudo da comunidade zooplanctônica da represa de Guarapinga: Aspectos ecológicos e qualidade ambiental. 2000. 163 p. (Doutorado em Saúde Ambiental). Faculdade de Saúde Pública da Universidade de São Paulo, São Paulo, 2000. 
CETESB - COMPANHIA DE TECNOLOGIA DE SANEAMENTO AMBIENTAL. Relatório da qualidade das águas interiores do estado de São Paulo. Relatório da Diretoria de Controle da Poluição do Interior, CETESB, São Paulo, 274 p, 2002.

CETESB - COMPANHIA DE TECNOLOGIA DE SANEAMENTO AMBIENTAL. Relatório de qualidade das águas de interiores do Estado de São Paulo. 2008. São Paulo: CETESB, Secretaria do Meio ambiente, 2009, 528p.

CHRISTEN, V.; HICKMANN, S.; RECHENBERG, B.; FENT, K. Highly active human pharmaceuticals in aquatic systems: A concept for their identification based on their mode of action. Aquatic Toxicology, v. 96, p. 167-181, 2010.

CLAESSENS, M.; VANHAECKE, L.; WILLE, K.; JANSSEN, C.R. Emerging contaminants in Belgian marine waters: Single toxicant and mixture risks of pharmaceuticals. Marine Pollution Bulletin, v.71, p.41-50, 2013.

CLEUVERS, M. Aquatic ecotoxicity of pharmaceuticals including the assessment of combination effects. Toxicology Letters, v.142, p.185-194, 2003.

CLEUVERS M. Initial risk assessment for three $\beta$-blockers found in the aquatic environment. Chemosphere, v.2, p.199-205, 2005.

COLINA, M.; GARDINER, P.H.E. Simultaneous determination of total nitrogen, phosphorus and sulphur by means of microwave digestion and ion chromatography. Journal of Chomatography A, v.847, p.285-290, 1999.

DAUGHTON, C.G.; TERNES, T.A. Pharmaceuticals and personal care products in the environment: agents of subtle change? Environmental Health Perspectives, v.107, p.907-938, 1999.

DU, B.; PRICE, A.E.; SCOTT, W.C.; KRISTOFCO, L.A.; RAMIREZ, A.J.; CHAMBLISS, C.K.; YELDERMAN, J.C.; BROOKS, B.W. Comparison of 
contaminants of emerging concern removal, discharge, and water quality hazards among centralized and on-site wastewater treatment system effluents receiving common wastewater influent. Science of the Total Environment, v.466-467, p.976-84, 2014.

FENT, K.; WESTON, A.A.; CAMINADA, D. Ecotoxicology of human pharmaceuticals. Aquatic Toxicology, v.76, p.122-159, 2006.

GABET-GIRAUD, V.; MIÈGE, C.; COQUERY, M. Impact of wastewater treatment plants on receiving surface waters and a tentative risk evaluation: the case of estrogens and beta blockers. Environmental Science and Pollution Research, v.21, p.1708$1722,2014$.

GINEBREDA, A.; MUÑOZ, I.; DE ALDA M.L.; BRIX, R.; LÓPEZ-DOVAL, J.; BARCELÓ, D. Environmental risk assessment of pharmaceuticals in rivers: relationships between hazard indexes and aquatic macroinvertebrate diversity indexes in the Llobregat River (NE Spain). Environment International, v. 36, p. 153-162, 2010.

GROS, M.; PETROVIC', M.; BARCELÓ, D. Development of a multi-residue analytical methodology based on liquid chromatography-tandem mass spectrometry (LC-MS/MS) for screening and trace level determination of pharmaceuticals in surface and wastewaters. Talanta, v. 70, p.678-690, 2006.

GROS, M.; RODRÍGUEZ-MOZAZA, S.; BARCELÓ, D. Fast and comprehensive multi-residue analysis of a broad range of human and veterinary pharmaceuticals and some of their metabolites in surface and treated waters by ultra-high-performance liquid chromatography coupled to quadrupole-linear ion trap tandem mass spectrometry. Journal of Chromatography A, v.1248, p.104-21, 2012.

HALLING- SORENSEN, B.; NIELSEN, S. N.; LANZKY, P. F.; INGERSLEV, F.; LUTZHOFT, H.C.H.; JORGENSEN, S.E. Occurrence, fate and effects of pharmaceutical substances in the environment-a review, Chemosphere, v 36, p. 357393, 1998. 
HEBERER, T. Tracking persistent pharmaceutical residues from municipal sewage to drinking water. Journal of Hydrology, v. 266, p. 175-189, 2002 b.

HENSCHEL, K.P.; WENZEL, A.; DIEDRICH, M.; FLIEDNER, A. Environmental hazard assessment of pharmaceuticals. Regulatory Toxicology and Pharmacology, v. 25 p.220-225, 1997.

INSTITUTO NACIONAL DE METROLOGIA, NORMALIZAÇÃO E QUALIDADE INDUSTRIAL-(INMETRO). Orientações sobre validação de métodos de ensaios químicos; DOQ-CGCRE-008, março de 2003.

INSTITUTO SÓCIOAMBIENTAL (ISA) Mananciais de São Paulo: Guarapiranga. Disponível em: <http://www.mananciais.org.br/site/mananciais_rmsp/guarapiranga>. Acesso em: 10 jul. 2010.

KASPRZYK-HORDEM, B.; DINSDALE, R.M.; GUWY, A.J. Multi-residue method for the determination of basic/neutral pharmaceuticals and illicit drugs in surface water by solid-phase extraction and ultra performance liquid chromatography-positive electrospray ionization tandem mass spectrometry. Journal of Chromatography A, v.1161, p.132-145, 2007.

KASPRZYK-HORDERN, B.; DINSDALE, R.M.; GUWY, A. J. The occurrence of pharmaceuticals, personal care products, endocrine disruptors and illicit drugs in surface water in South Wales, UK. Water Research, v. 42, p. 3498-3518, 2008.

KIM, Y.; CHOI, K.; JUNG, J.; PARK, S.; KIM, P.G.; PARK, J. Aquatic toxicity of acetaminophen, carbamazepine, cimetidine, diltiazem and six major sulfonamides, and their potential ecological risks in Korea. Environment International, v.33, p. 275-370, 2007. 
KOLPIN, D.W.; FURLONG, E.T.; MEYER, M.T.; THURMAN, E.M.; ZAUGG, S.D.; BARBER, L.B.; BUXTON, H.T. Pharmaceuticals, hormones and other organic wastewater contaminants in US streams, 1999-2000: a national reconnaissance. Environmental Science \& Technology, v.36, p.1202-1211, 2002.

KRAMER, R.D. Bacia Hidrográfica do Alto Iguaçu: Caracterização física e química e determinação de diclofenaco, ibuprofeno e paracetamol. 2012. 121p. (Mestrado em Ciência e Tecnologia Ambiental)- Universidade Tecnológica Federal do Paraná, Curitiba, Paraná.

KÜSTER, A.; ALDER, A.C.; ESCHER, B.I.; DUIS, K.; FENNER, K.; GARRIC, J.; HUTCHINSON, T.H.; LAPEN, D.R.; PÉRY, A.; RÖMBKE, J.; SNAPE, J.; TERNES, T.; TOPP, E.; WEHRHAN, A.; KNACKER, T. Environmental risk assessment of human pharmaceuticals in the European Union: a case study with the beta-blocker atenolol. Integrated Environmental Assessment and Management, v.6, p. 514-523, 2009.

MONTAGNER, C. C.; JARDIM, W. F. Spatial and Seasonal variations of pharmaceuticals and endocrine disruptors in the Atibaia River, Sao Paulo State (Brazil). Journal of the Brazilian Chemical Society, v. 22, p. 1452-1462, 2011.

MUNÕZ, I.; LÓPEZ-DOVAL, J.; RICART, M.; VILLAGRASA, M.; BRIX, R.; GEISZINGER, A.; GINEBREDA, A.; GUASCH, H.; LÓPEZ-ALDA, M.J.; ROMANI, A.M. Bridging levels of pharmaceuticals in river water with biological community structure in the Llobregat River Basin (Northeast Spain), Environmental Toxicology and Chemistry, v.28, p.2706-2714, 2009.

MORAIS, M.A.; CASTRO, W.A.C.; TUNDISI, J.G. Climatologia de frentes frias sobre a Região metropolitana de São Paulo (RMSP), e sua influência na limnologia dos reservatórios de abastecimento de água. Revista Brasileira de Meteorologia, São Paulo, v.25, n.2, 2010. 
OSORIO, V., MARCÉ, R.; PÉREZ, S; GINEBREDA, A.; CORTINA, J.L.; BARCELÓ, D. Occurrence and modeling of pharmaceuticals on a sewage-impacted Mediterranean River and their dynamics under different hydrological conditions. Science of the Total Environment, v. 440, p.3-13, 2012.

PAROLINI, M.; BINELli, A.; COGNI, D.; RIVA, C.; PROVINI, A. An in vitro biomarker approach for the evaluation of the ecotoxicity of non-steroidal antiinflammatory drugs (NSAIDs). Toxicology in Vitro, v. 23, p.935-942, 2010.

RAIMUNDO, C. C. M. Ocorrência de interferentes endócrinos e produtos farmacêuticos nas águas superficiais da bacia do rio Atibaia. 2007. 126p. (Mestrado em Química). Departamento de Química Analítica, Universidade Estadual de Campinas, Campinas, São Paulo.

ROBERTS, P.H.; THOMAS, K.V. The occurrence of selected pharmaceuticals in wastewater effluent and surface waters of the lower Tyne catchment. Science Total Environment, v. 356, p.143-153, 2006.

SACHER, F.; LANGE, F. T.; BRAUCH, H.; BLANKENHORN, I. Pharmaceuticals in groundwaters - Analytical methods and results of a monitoring program in BadenWurttemberg, Germany. Journal of Chromatography A, v. 938, p. 199-210, 2001.

SANTOS, L.H.M.L.M.; ARAUJO, N.A.; FACHINI, A.; PENA, A.; DELERUEMATOS, C.; MONTENEGRO, M.C.B.S.M. Ecotoxicological aspects related to the presence of pharmaceuticals in the aquatic environment. Review. Journal of Hazardous Materials, v.175, p.45-95, 2010.

SCHAIDER, L.A.; RUDEL, R.A.; ACKERMAN, J.M.; DUNAGAN, S.C.; BRODY, J.G. Pharmaceuticals, perfluorosurfactants, and other organic wastewater compounds in public drinking water wells in a shallow sand and gravel aquifer. Science of the Total Environment, v.468-469, p.384-93, 2014. 
SCHULTE-OEHLMANN, U.; OEHLMANN, J.; PÜTTMANN, W. Human pharmakawirkstoffe in der Umwelt: Einträge, Vorkommen und der Versuch einer Bestandsaufnahme. Umweltwiss Schadst Forsch, v. 19, p.68-179, 2007.

SIPMA, J.; OSUNA, B.; COLLADO, N.; MONCLUS, H.; FERRERO, G.; COMAS, J.; RODRIGUEZ-RODA, I. Comparison of removal of pharmaceuticals inMBR and activated sludge systems. Desalination, v.250, p.653-9, 2010.

SOTELO, J.L.; OVEJERO, G.; RODRÍGUEZ, A.; ÁlVAREZ, S.; GALÁN, J.; GARCÍA, J. Competitive adsorption studies of caffeine and diclofenac aqueous solutions by activated carbon. Chemical Engineering Journal, v.240, p.443-453, 2014.

STUMPF, M.; TERNES, T. A.; WILKEN, R.; RODRIGUES, S. V.; BAUMANN, W. Polar drug residues in sewage and natural waters in the state of Rio de Janeiro, Brazil. Science of the Total Environment, v. 225, p. 135-141, 1999.

TEIXEIRA, C.; TUNDISI, J.G.; KUTNER, M.B. Plankton studiesin a magrove. IV: size fraction of phytoplankton. Bulletin of Institute Oceanography, v. 26, p. 39-42, 1965.

TER BRAAK, C.J.F.; ŠMILAUER, P. Canoco reference manual and CanoDraw for Windows user's guide: software for canonical community ordination. Ithaca, NY: Microcomputer Power, 2002.

TERNES, T. A. Analytical methods for the determination of pharmaceuticals in aqueous environmental samples. TrAC Trends in Analytical Chemistry, v.20, p.419434, 2001.

THOMAS, K.V.; SILVA, F.M.A.; LANGFORD, K.H.; SOUZA, A.D.L.; NIZZETO, L.; WAICHMAN, A.V. Screening for selected human pharmaceuticals and cocaine in the urban streams of Manaus, Amazonas, Brazil. Journal of the American water resources association, v.50, p.302-308, 2014. 
VAZQUEZ-ROIG, P.; ANDREU, V.; ONGHENA, M.; BLASCO, C.; PICÓ, Y. Assessment of the occurrence and distribution of pharmaceuticals in a Mediterranean wetland (L'Albufera, Valencia, Spain) by LC-MS/MS. Analitical and Bioanalitical Chemistry, v.400, p.1287-1301, 2011.

VIENO, N.M.; TUHKANEN, T.; KRONBERG, L. Analysis of neutral and basic pharmaceuticals in sewage treatment plants and in recipient rivers using solid phase extraction and liquid chromatography-tandem mass spectrometry detection. Journal of Chromatography A, v. 1134, p.101-111, 2006.

VIENO, N.; TUHKANEN, T.; KRONBERG, L. Elimination of Pharmaceuticals in Sewage Treatment Plants in Finland. Water Research, v. 41, p.1001-1012, 2007.

WHATELY, M.; CUNHA, P.M. Guarapiranga 2005: Como e por que São Paulo está perdendo este manancial: resultados do diagnóstico socioambiental participativo da bacia hidrográfica de Guarapiranga. São Paulo: Instituto Sócio Ambiental. 2006. 51p.

WU, C.; HUANG, X.; WITTER, J.D.; SPONGBERG, A.L.; WANG, D.; LIU, J. Occurence of pharmaceuticals and personal products and associated environmental risk in the central and lower Yangtze river, China. Ecotoxicology and Enviromnental Safety, v.106, p.19-26, 2014. 


\title{
Capítulo 2
}

\author{
Efeitos ecotoxicológicos agudos e crônicos de três fármacos sobre o cladócero \\ tropical de água doce Ceriodaphnia silvestrii
}

\section{Resumo}

Entre os contaminantes emergentes, os compostos farmacêuticos são um dos grupos mais relevantes de substâncias encontradas no ambiente aquático, devido ao seu uso universal, grandes quantidades empregadas, propriedades físico-químicas específicas, e modo de ação em organismos aquáticos, em baixas concentrações. Considerando a magnitude das concentrações, a onipresença dessas substâncias, e poucas informações consideráveis sobre seus potenciais efeitos ecotoxicológicos sobre a biota aquática, o presente estudo teve como objetivo avaliar os efeitos agudos e crônicos dos seguintes fármacos: paracetamol (analgésico), diclofenaco sódico (anti-inflamatório) e propranolol (anti-hipertensivo) na espécie de Cladocera Ceriodaphnia silvestrii. Foram analisados parâmetros de toxicidade aguda como a imobilidade e subsequentes efeitos crônicos na história de vida (número total de descendentes e taxa de crescimento populacional). Os resultados das exposições agudas mostraram uma variabilidade considerável na toxicidade entre os fármacos estudados, sendo que a espécie $C$. silvestrii apresentou-se mais sensível ao composto propranolol $\left(\mathrm{CE}_{50}=3,17 \mathrm{mg} \mathrm{L}^{-1}\right)$. Os dados dos testes de toxicidade crônica mostraram uma redução nas variáveis número total de descendentes e taxa de crescimento populacional para o fármaco paracetamol. Já o composto farmacêutico propranolol causou um aumento significativo na fecundidade para as concentrações de até $0,0313 \mathrm{mg} \mathrm{L}^{-1}$ e para o parâmetro taxa de crescimento populacional ocorreu um aumento significativo na menor concentração testada.

Palavras-chave: toxicidade de fármacos, paracetamol, diclofenaco sódico, propranolol, contaminantes emergentes, cladóceros. 


\begin{abstract}
Among the emerging contaminants, pharmaceuticals are one of the most relevant groups of substances found in aquatic environments, due to their universal use, large quantities employed, specific chemical-physical properties, and mode of action in aquatic organisms at low concentrations. Considering the magnitude of concentrations, the ubiquity of these substances, and the considerable small amount of information about their potential ecotoxicological effects on wildlife, the present study intended to assess the acute and chronic effects of the following pharmaceuticals: the analgesic acetaminophen, the anti-inflammatory diclofenac sodium and the antihypertensive propranolol in the Cladocera species Ceriodaphnia silvestrii. Parameters such as immobility and subsequent life-history (total number of offspring and increase rate of population) were analyzed. Results of acute exposures showed a considerable variability of toxicity among pharmaceuticals, being $C$. silvestrii more sensitive to the compound propranolol $\left(\mathrm{EC}_{50}=3.17 \mathrm{mg} \mathrm{L}^{-1}\right)$. Data of chronic toxicity tests showed a reduction in the variables total number offspring and the population growth rate for the drug paracetamol. The drug propranolol caused a significant increase in fecundity for the concentrations up to $0.0313 \mathrm{mg} \mathrm{L}^{-1}$ and the rate of population increase parameter had a significant increase in the lowest concentration tested.
\end{abstract}

Keywords: pharmaceuticals toxicity, paracetamol, sodium diclofenac, propranolol, emerging contaminants, cladocerans. 


\section{Introdução}

Os compostos farmacologicamente ativos são produzidos em todo o mundo e consumidos em grandes quantidades, favorecendo sua freqüente ocorrência em águas residuais, águas superficiais e subterrâneas em uma faixa de concentrações que variam de $n g L^{-1}$ a $\mu \mathrm{g} \mathrm{L}^{-1}$, e que podem representar riscos para a fauna aquática (DAUGHTON \& TERNES, 1999; KOLPIN et al., 2002; BROOKS et al., 2005; BENOTTI et al., 2009; KWON et al., 2009; BRANDÃO et al., 2013). Os fármacos pertencem a diferentes classes terapêuticas, como analgésicos, antibióticos, anti-inflamatórios, agentes hipolipomiantes, antipiréticos, citostáticos, hormônios e anticonvulsivantes (FENT et al., 2006a).

Existem diferentes rotas pelas quais os fármacos de uso humano e veterinário podem atingir os corpos d'água, como: excreção através de urina/fezes após o uso terapêutico, eliminação direta de drogas domésticas, efluentes de estações de tratamento de esgoto (ETEs), descarte inadequado após a expiração do prazo de validade, disposição em aterros (KUMMERER, 2009), aquicultura, bem como a utilização de águas residuárias para irrigação (XU et al., 2009). A confirmação da presença de resíduos de fármacos no ambiente aquático e seus potenciais impactos ambientais tornou-se uma questão de grande importância, especialmente quando se considera que essas substâncias são biologicamente ativas, e apresentam reduzidas taxas de biodegradação, contribuindo assim para um alto potencial de bioacumulação e persistência no ambiente (CHRISTENSEN, 1998; BRANDÃO et al., 2013).

Os compostos farmacêuticos apresentam algumas características especiais, sendo que a mais importante é o fato de que são designados para exercer específicas atividades biológicas no organismo. Os efeitos específicos ou modo de ação dos fármacos em seres humanos e mamíferos são geralmente bem descritos na literatura (FENT et al., 2006a), enquanto que o conhecimento sobre a interação com a biota aquática, principalmente em invertebrados, ainda é limitado. Isso é considerado problemático e preocupante em relação a estes contaminantes, pois mesmo em concentrações muito baixas podem exercer efeitos potencialmente prejudiciais sobre organismos não-alvo que apresentam vias moleculares ou moléculas-alvo idênticas e /ou similares. Segundo Contardo-Jara et al. (2011), mais estudos são necessários para melhor compreensão dos possíveis efeitos 
deletérios desses compostos, em determinadas espécies-chave que compõem a biota aquática como um todo.

Grande parte dos dados de toxicidade aquática e estudos de avaliação de risco envolvendo produtos farmacêuticos são baseados em trabalhos de curto prazo com organismos pertencentes a diferentes níveis tróficos da biota aquática (PARK \& CHOI 2008; KIM et al., 2009a; LI, 2013). No entanto, esses dados isolados podem não ser apropriados para responder questões sobre efeitos ambientais, e serem utilizados posteriormente em avaliações de risco e programas de monitoramento (FENT et al., 2006a), se não forem complementados com dados crônicos, obtidos após exposições de longo prazo. Embora a exposição crônica a baixas concentrações destes compostos químicos bioativos possam resultar em efeitos de longo prazo (que abrangem parte ou todo ciclo de vida dos organismos), os distúrbios provocados por fármacos podem incluir efeitos deletérios em suas funções biológicas, tais como no crescimento ou na reprodução. Em geral, pouco se sabe sobre efeitos de longo prazo e ações de resíduos farmacêuticos nos ecossistemas aquáticos, particularmente em águas superficiais (LÓPEZ-SERNA et al., 2010). No presente estudo, foi utilizada a espécie tropical de Cladocera Ceriodaphnia silvestrii como organismo-teste para avaliar os efeitos agudos e crônicos de três fármacos pertencentes a diferentes classes farmacoterapêuticas: paracetamol (analgésico, antitérmico), diclofenaco (anti-inflamatório) e propranolol (anti-hipertensivo). Esta espécie apresenta ampla distribuição geográfica na América do Sul, possui ciclo de vida curto, procedimentos de cultivo simples, pertence a um dos grupos de organismos mais sensíveis para uma ampla gama de substâncias tóxicas, além de ocupar uma posição central dentro das cadeias alimentares aquáticas (FONSECA \& ROCHA, 2004).

Compostos farmacêuticos: Ocorrência no meio aquático e relevância em ensaios ecotoxicológicos

De acordo com o Programa Ambiental 2012-2016 que foi formulado pela Secretaria de Meio Ambiente do Conselho do Condado de Estocolmo e Apoteket AB (A Corporação Nacional de Farmácias suecas), os fármacos são classificados tanto em termos de sua capacidade inerente de afetar o meio ambiente (risco ambiental), como em relação ao risco ambiental quando utilizados em sua extensão atual. $\mathrm{O}$ risco 
ambiental é baseado na razão entre a concentração ambiental prevista para a substância (PEC) e a concentração ambiental prevista não prejudicial (PNEC). O risco é classificado como: insignificante $(\mathrm{PEC} / \mathrm{PNEC}<0,1)$; baixo $(\mathrm{PEC} / \mathrm{PNEC}=0,1-1)$; moderado $(\mathrm{PEC} / \mathrm{PNEC}=1-10)$ e alto $(\mathrm{PEC} / \mathrm{PNEC}>10)$. As características das substâncias sobre bioacumulação, persistência e toxicidade são consideradas muito importantes. Os riscos classificados para os medicamentos paracetamol, diclofenaco de sódio e propranolol foram: baixo, insignificante e moderado, respectivamente (DE VOOGT et al., 2009; EMEA 2006).

O acetaminofeno, vulgarmente conhecido como paracetamol (N-acetil-paminofenol), é um analgésico- antipirético frequentemente usado na terapêutica humana em quase todos os países. Seu uso é favorecido pelo acesso simples (que pode ser comprado em lojas de varejo sem prescrição médica), sendo atualmente o medicamento mais consumido no mundo (SOLÉ et al., 2010). Isto leva à sua classificação como um composto de Classe 2 - produtos farmacêuticos prioritários (AN et al., 2009; ANTUNES et al., 2013). O paracetamol é um inibidor da enzima ciclo-oxigenase, e os seus efeitos secundários são geralmente associados com a formação de metabólitos hepatotóxicos (TIMBRELL, 2002). Este fármaco em superdosagem pode causar hepatotoxicidade, que consequentemente induz à insuficiência hepática e à morte (HADI, 2013). A administração do presente composto, em dosagens normais, resulta na sua conjugação com os co-factores (ou seja, com sulfato e ácido glucurônico), resultando na formação de metabólitos conjugados não tóxicos (acetaminofeno glucuronida e sulfato de acetaminofeno) que são excretados (JAESCHKE \& BAJT 2006; KLAASSEN, 2001; PATEL et al., 1992; XU et al., 2008). Estas vias de desintoxicação podem ser responsáveis por mais de $90 \%$ do metabolismo do acetaminofeno pelo fígado. Sob condições normais, cerca de 5\% a 9\% sofre conversão oxidativa por meio dos CYP (CYP1A2, CYP2A6, CYP2E1, CYP3A4) para o metabólito tóxico intermediário imina de N-acetil-p-benzoquinona (NAPQI) (WHITCOMB \& BLOCO, 1994; MANYIKE et al., 2000). O grau de toxicidade hepática se correlaciona com a atividade dos sistemas de catalisação de enzimas, e disponibilidade de GSH para pequenas quantidades de acetaminofeno; O NAPQI por sua vez, é conjugado com a glutationa intracelular para a desintoxicação interior (KLAASSEN, 2001; PATEL et al., 1992; PRESCOTT, 1980; XU et al., 2008). No caso de excessivas doses de acetaminofeno, a acumulação do metabólito altamente reativo 
NAPQI é muito provável, levando a vários efeitos tóxicos, tais como modificações covalentes de grupos tiol em proteínas celulares (XU et al., 2008), disfunção mitocondrial, perda de ATP celular, danos no DNA e RNA e modificação da proteína intracelular, resultando em necrose e morte celular (COHEN \& KHAIRALLAH, 1997; JAESCHKE \& BAJT, 2006). Este composto é de considerável preocupação ambiental, devido à sua presença comum no ambiente aquático, sendo um dos fármacos mais frequentemente detectados em estações de tratamento de águas residuárias, em concentrações que variam de 10 (efluente) para $7.460 \mathrm{ng} \mathrm{L}^{-1}$ (afluente) (BEHERA et al., 2011). Verificou-se também a ocorrência deste fármaco em concentrações de $6 \mu \mathrm{g} \mathrm{L}^{-1}$ em efluentes de ETARs europeias (TERNES, 1998), de $10 \mu \mathrm{g} \mathrm{L}^{-1}$ em águas naturais dos Estados Unidos (KOLPIN et al., 2002) e acima de $65 \mu \mathrm{g} \mathrm{L}^{-1}$ no rio Tyne, Reino Unido (ROBERTS \& TOMAS, 2006). O acetaminofeno, também foi encontrado em amostras de água potável de Taiwan, China, em concentrações de até $7 \mathrm{ng} \mathrm{L}^{-1}$ (CHOI et al., 2008; KLEYWEGT et al., 2011; VALCÁRCEl et al., 2012; YANG et al., 2014). A toxicidade deste composto farmacêutico tem sido extensivamente documentada em diferentes organismos e seres humanos (Tabela 1).

O diclofenaco sódico é um importante fármaco anti-inflamatório não-esteróide (AINEs ou NSAIDs), com propriedades analgésicas e antipiréticas, sendo usado para tratamento de dor, inflamação e rigidez. Este fármaco é produzido em grandes volumes e o consumo mundial anual estimado de diclofenaco sódico como medicamento de uso humano e veterinário é > 1000 toneladas/ano (ZHANG et al., 2008). Como todos os AINEs, o diclofenaco atua por inibição reversível ou irreversível de uma ou ambas isoformas das enzimas ciclo-oxigenase (COX-1 e COX-2), levando à inibição periférica da síntese das prostaglandinas (VANE \& BOTTING, 1998). Por outro lado, a atividade farmacológica do diclofenaco sódico vai além de inibição da COX e inclui mecanismos de ação novos e multimodais (MOA) (GAN, 2010). Devido às suas altas taxas de produção mundial e a sua prescrição ocorrer em grande volume, este fármaco tem sido considerado um dos 10 compostos mais comumente encontrados nos ecossistemas aquáticos, além de ser classificado como de Classe 1 - alta prioridade farmacêutica (SOTELO et al., 2014). Pouco se sabe sobre a degradação microbiana desta droga e as taxas de eliminação do diclofenaco em estações de tratamento de esgoto são normalmente baixas (cerca de 50\%), e tanto a biodegradabilidade como a eliminação por adsorção são ineficazes (revisado por ZHANG et al., 2008; PAL et al., 2010). Este 
composto é frequentemente encontrado em efluentes de ETARs e água de superfície em níveis de até $4,7 \mu \mathrm{g} \mathrm{L}^{-1}$ e $1,2 \mu \mathrm{g} \mathrm{L}^{-1}$, e até mesmo em água subterrânea e água de torneira em concentrações de até $380 \mathrm{ng} \mathrm{L}^{-1}$ e abaixo de $10 \mathrm{ng} \mathrm{L}^{-1}$, respectivamente (AGUINACO et al., 2012; HEBERER, 2002). O diclofenaco sódico é considerado como um dos fármacos mais relevantes que podem exercer efeitos tóxicos nos diferentes organismos aquáticos, tais como bactérias, várias espécies de algas, macrófitas, cladóceros, bivalves de água doce, planárias e vertebrados (Tabela 1).

O propranolol é um bloqueador adrenérgico não seletivo indicado para o tratamento de hipertensão, arritmias cardíacas, cardio-proteção após ataques cardíacos, glaucoma, e perturbações da ansiedade (BARBIERI et al., 2012). $\beta$-bloqueadores atuam através da inibição competitiva dos receptores adrenérgicos. O sistema adrenérgico está envolvido em muitas funções fisiológicas, por exemplo, na regulação cardíaco, nos níveis de oxigênio e na vasodilatação dos vasos sanguíneos, podendo também atuar como broncodilatador em mamíferos (FENT et al., 2006b). Como os organismos aquáticos podem ter receptores adrenérgicos que são distintos daqueles de mamíferos, são esperados diferentes impactos potenciais sobre estes organismos. No entanto, algumas semelhanças são compartilhadas entre mamíferos, peixes e até mesmo invertebrados aquáticos, o que sugere que os efeitos causados por $\beta$-bloqueadores podem ocorrer na biota aquática (OWEN et al., 2007). O propranolol é um medicamento cuja presença ambiental requer atenção, uma vez que, se a relação PEC/PNEC for superior a 1, o limite adotado consensualmente indica potenciais preocupações ambientais (ÅGERSTRAND \& RÜDEN, 2010). Informações sobre as taxas de eliminação para $\beta$ bloqueadores em ETARs variam entre menos de 10\% até 96\% (ANDREOZZI et al., 2003; TERNES, 1998). Como os $\beta$-bloqueadores são amplamente utilizados, este fármaco foi detectado em efluentes de ETARs em concentrações de 30 a $373 \mathrm{ng} \mathrm{L}^{-1}$ (BENDZ et al., 2005; ROBERTS \& THOMAS, 2006; ALDER et al., 2010), e em águas de superfície em níveis de $<10 \mathrm{ng} \mathrm{L}^{-1}$ e abaixo de $37 \mathrm{ng} \mathrm{L}^{-1}$, respectivamente (HILTON \& THOMAS, 2003; KIM et al., 2009b). A presença deste composto farmacêutico também foi reportada em efluentes de hospitais, em concentrações de até 6,5 $\mu \mathrm{g} \mathrm{L}^{-1}$ (GOMEZ et al., 2006; LIN \& TSAI, 2009). Um fator importante a ser considerado é que o propranolol pode ser absorvido por organismos aquáticos, sofrendo bioacumulação, como mostrado por Claessens et al. (2013). Além disso, estudos ecotoxicológicos mostram que os $\beta$-bloqueadores podem afetar a biota aquática, sendo o 
propranolol o mais nocivo dentre estes (FENT et al., 2006a; KÜSTER et al., 2009). Os potenciais efeitos ecológicos adversos do propranolol foram estudados em diferentes organismos aquáticos, tais como os cladóceros Daphnia magna, Daphnia pulex e Ceriodaphnia dubia, algas verdes, crustáceos de água doce e vertebrados (Tabela 1). 
Tabela 1. Resumo dos principais endpoints ecotoxicológicos obtidos na literatura para diferentes organismos aquáticos expostos aos fármacos: acetaminofeno, diclofenaco sódico e propranolol.

\section{ENDPOINTS ECOTOXICOLÓGICOS REFERÊNCIAS}

\section{ACETAMINOFENO}

Pseudokirchneriella subcapitata Vibrio fischeri

Tetrahymena pyriformis

Streptocephalus proboscideus

Photobacterium phosphoreum

Brachionus calyciflorus

Hydra vulgaris

Artemia salina

Daphnia magna

Daphnia magna

Daphnia magna

Daphnia magna

Daphnia longispina

Moina macrocopa

Dugesia japônica

Oryzias latipes

$$
\begin{aligned}
& \mathrm{CE}_{50}(96 \mathrm{~h})=2,300 \mathrm{mg} \mathrm{L}^{-1} \\
& \mathrm{CE}_{50}(15 \mathrm{~min})=567,5 . \mathrm{mg} \mathrm{L}^{-1} \\
& \mathrm{CE}_{50}(48 \mathrm{~h})=112 \mathrm{mg} \mathrm{L}^{-1} \\
& \mathrm{CE}_{50}(24 \mathrm{~h})=29,6 \mathrm{mg} \mathrm{L}^{-1} \\
& \mathrm{CE}_{50}(15 \mathrm{~min})=331 \mathrm{mg} \mathrm{L}^{-1} \\
& \mathrm{CL}_{50}(24 \mathrm{~h})=5306 \mathrm{mg} \mathrm{L}^{-1} \\
& \mathrm{CL}_{50}(24 \mathrm{~h})=>10 \mathrm{mg} \mathrm{L}^{-1} \\
& \mathrm{CL}_{50}(24 \mathrm{~h})=577 \mathrm{mg} \mathrm{L}^{-1} \\
& \mathrm{CE}_{50}(24 \mathrm{~h})=2,04 \mathrm{mg} \mathrm{L}^{-1} \\
& \mathrm{CE}_{50}(48 \mathrm{~h})=30,1 \mathrm{mg} \mathrm{L}^{-1} \\
& \mathrm{CE}_{50}(48 \mathrm{~h})=50 \mathrm{mg} \mathrm{L}^{-1} \\
& \mathrm{CE}_{50}(24 \mathrm{~h})=55,5 \mathrm{mg} \mathrm{L}^{-1} \\
& \mathrm{CE}_{50}(48 \mathrm{~h})=65,9 \mathrm{mg} \mathrm{L}^{-1} \\
& \mathrm{CE}_{50}(48 \mathrm{~h})=56,34 \mathrm{mg} \mathrm{L}^{-1} \\
& \mathrm{CL}_{50}(48 \mathrm{~h})=371,5 \mathrm{mg} \mathrm{L}^{-1} \\
& \mathrm{CL}_{50}(48 \mathrm{~h})=>160 \mathrm{mg} \mathrm{L}^{-1}
\end{aligned}
$$

Yamamoto et al. (2007)

Kim et al. (2007)

Henschel et al. (1997)

Kuhn et al. (1989)

Calleja et al. (1994)

Webb (2001)

Pascoe et al. (2003)

Webb (2001)

Dave \& Herger (2012)

Kim et al. (2007)

Henschel et al. (1997)

Calleja et al. (1994)

Nunes et al. (2014)

Kim et al. (2012)

Li (2013)

Kim et al. (2007)

Quin et al. (2011)

Schmidt et al. (2011)

Cleuvers (2004)

Quin et al. (2011)

DeLorenzo \& Fleming (2008)

Schmidt et al. (2011)

Láng \& Kohidai (2012)

Ferrari et al. (2004)

Quin et al. (2011)

Cleuvers (2004)

Haap et al. (2008)

Lee et al. (2011)

Schmidt et al. (2011)

Li et al. (2013)

Van den Brandhof \& Montforts (2010)
Nałecz-Jawecki et al. (2008)

Ferrari et al. (2004)

Claessens et al. (2013)

Cleuvers (2003)

Cleuvers (2003)

Ferrari et al. (2004)

Kim et al. (2009a)

Liu et al. (2009)

Huggett et al. (2002)

Ferrari et al. (2004)

Huggett et al. (2002)

Cleuvers (2003)

Lilius et al. (1995)

Kim et al. (2009a)

Stanley et al. (2006) 


\section{Material e Métodos}

\subsection{Organismo-teste e condições de cultivo}

O organismo-teste selecionado foi o cladócero Ceriodaphnia silvestrii, uma espécie nativa e endêmica da região Neotropical (COELHO \& ROCHA, 2010). Indivíduos desta espécie foram obtidos a partir de cultivos já estabelecidos no Laboratório de Ecotoxicologia da Universidade Federal de São Carlos, e originalmente isolados do reservatório do Broa, Itirapina-SP.

As culturas de $C$. silvestrii foram constituídas com uma densidade inferior a 70 indivíduos por litro, mantidas em frascos de vidro de $2 \mathrm{~L}$ com água reconstituída como recomendado pela Sociedade Americana de Testes e Materiais (ASTM, 2001). Maiores detalhes sobre os procedimentos da preparação da água reconstituída podem ser encontradas em Freitas e Rocha (2011). Os organismos foram mantidos em temperatura controlada a $25 \pm 1^{\circ} \mathrm{C}$ com fotoperíodo de 12 horas (luz): 12 horas (escuro). A manutenção das culturas foi realizada com renovação do meio três vezes por semana, e também renovação do alimento. $\mathrm{O}$ alimento consistiu de uma mistura de suspensão da microclorofícea Pseudokirchneriella subcapitata, cultivada em meio CHU-12 (MÜLLER, 1972), a uma densidade de $10^{5}$ células de algas $\mathrm{mL}^{-1}$, com adição de uma suspensão de levedura $\left(1 \mathrm{~mL} \mathrm{~L}^{-1}\right)$, preparada com levedura comercial e água destilada $\left(0,25 \mathrm{~g} \mathrm{em} 50 \mathrm{~mL}^{-1}\right)$, tal como recomendado pela USEPA (2002).

Todos os testes foram iniciados com neonatos ( $\leq 24$ horas de idade), nascidos entre a terceira e a quinta ninhadas. A saúde e a sensibilidade das culturas foram avaliadas mensalmente por meio de testes de toxicidade aguda com a substância de referência $\mathrm{NaCl}$ (cloreto de sódio) ( $\mathrm{CE}_{50}(48 \mathrm{~h})$ variando entre 1,14-1,28 $\mathrm{g} \mathrm{L}^{-1}$ ) (Figura 4, em apêndice A).

\subsection{Fármacos e soluções-teste}

Os compostos acetaminofeno, diclofenaco sódico e propanolol com pureza $\geq 99 \%$, foram adquiridos da Sigma-Aldrich Chemical. As soluções-estoque foram preparadas durante a realização dos bioensaios ecotoxicológicos pela diluição de $500 \mathrm{mg} \mathrm{L}^{-1}$ de cada fármaco estudado em água destilada. 


\subsection{Testes de toxicidade aguda}

Os testes de toxicidade aguda com $C$. silvestrii foram realizados de acordo com as diretrizes da Organização para a Cooperação Econômica e Desenvolvimento (OECD, 2004), sob os mesmos regimes de fotoperíodo e temperatura descritos para os procedimentos de cultivo. As concentrações nominais finais testadas foram: 0,00;0,62; 6,$25 ; 12,5 ; 25 ; 50$ e $100 \mathrm{mg} \mathrm{L}^{-1}$ de acetaminofeno; 0,00; 3,12;6,25; 12,5;25; 50 e 100 $\mathrm{mg} \mathrm{L}^{-1}$ para o diclofenaco de sódio; e 0,$00 ; 0,62 ; 1,25 ; 2,5 ; 5$ e $10 \mathrm{mg} \mathrm{L}^{-1}$ para o propranolol.

Estas concentrações foram definidas a partir de bioensaios preliminares com os princípios ativos dos fármacos selecionados, a fim de encontrar uma faixa adequada de concentrações para a realização dos testes definitivos com o organismo-teste.

Para a realização dos testes de toxicidade aguda foram utilizados frascos de vidro de $50 \mathrm{~mL}$, cada um com $10 \mathrm{~mL}$ de solução-teste ou $10 \mathrm{~mL}$ de água reconstituída (controle), com 20 neonatos ( $\leq 24$ horas de idade), divididos em quatro réplicas com cinco organismos cada. Para cada concentração de cada fármaco, quatro repetições e um controle foram testados. Os organismos expostos não foram alimentados no decorrer dos experimentos e foram mantidos por 48 horas sob-regime de escuro, como recomendado pela OECD (2004).

Os parâmetros físicos e químicos dos testes foram medidos no início e no final de cada teste, com a necessidade destes resultados estarem dentro dos níveis aceitáveis do protocolo seguido (OECD, 2004) ( $\mathrm{pH}$ : 7,2-7,6; temperatura de $25^{\circ} \mathrm{C} \pm 1,0^{\circ} \mathrm{C}$; condutividade elétrica cerca de $160 \mu \mathrm{S} \mathrm{cm}^{-1}$; e dureza total variando entre 40 e $48 \mathrm{mg}$ $\mathrm{L}^{-1}$ de $\mathrm{CaCO}_{3}$ ).

Os testes de toxicidade aguda foram conduzidos para cada fármaco, e após o tempo de exposição de 48 horas, os organismos foram observados e contados sob microscópio estereoscópico. Posteriormente foi calculada a concentração efetiva mediana a 50\% dos organismos $\left(\mathrm{CE}_{50}\right)$ através do Software Statistica 11.0. O critério adotado foi a imobilidade dos organismos, conforme definido e recomendado na diretriz OECD (2004). 


\subsection{Testes de toxicidade crônica}

Os testes de toxicidade crônica com $C$. silvestrii foram realizados com base nos procedimentos descritos nas orientações da OECD (OECD, 2008). O objetivo destes bioensaios foi avaliar os efeitos das três substâncias sobre a reprodução da espécie estudada após uma exposição de 8 dias sob condições semi-estáticas de renovação.

Neonatos ( $\leq 24 \mathrm{~h}$ de idade) nascidos entre a terceira e quinta ninhada foram expostos às seguintes concentrações nominais: 0,00 (controle); 0,$0625 ; 0,125 ; 0,25 ; 0,5$; 1 e $2 \mathrm{mg}$ de $\mathrm{L}^{-1}$ de acetaminofeno e diclofenaco de sódio; 0,0156;0,0313; 0,0625; 0,$125 ; 0,25$ e $0,5 \mathrm{mg} \mathrm{L}^{-1}$ de propranolol. Estas concentrações sub-letais foram selecionadas após os resultados obtidos para os ensaios agudos. Dez organismos foram expostos para cada concentração testada (10 réplicas).

Os neonatos foram mantidos em frascos de vidro de $50 \mathrm{~mL}$ contendo $20 \mathrm{~mL}$ de solução-teste, ou seja, $20 \mathrm{~mL}$ de água reconstituída (controle), mantidos sob as mesmas condições descritas para as condições de cultivo. Os testes foram semi-estáticos, sendo as soluções-teste renovadas a cada 48 horas. Os organismos foram alimentados e mantidos como descrito na secção "organismo-teste e condições de cultivo". Parâmetros físicos e químicos ( $\mathrm{pH}$, condutividade elétrica e temperatura) das soluções-teste foram medidos a cada troca, mas apenas para as concentrações menores, intermediárias e altas dos compostos farmacêuticos estudados. Durante oito dias, os organismos foram observados sob microscópio estereoscópico, a fim de verificar diariamente a sobrevivência dos neonatos, sendo os descendentes contados e descartados a cada renovação. Foram registrados parâmetros subsequentes de história de vida: número total de descendentes e número de ninhadas. As estimativas de sobrevivência e fecundidade foram utilizadas para calcular a taxa de crescimento populacional (r), a partir da equação (1) de Euler-Lotka:

$1=\sum 1 x m x e^{-r m x}$

em que $r$ é a taxa de aumento da população $\left(\right.$ dia $\left.^{-1}\right), x$ é a classe de idade em dias $(0, \ldots$ n), $l x$ é a probabilidade de sobrevivência na idade $x$, e $m x$ representa a fecundidade por fêmea em idade $x$. Os erros-padrão de $\mathrm{r}$ foram estimados utilizando-se a técnica de Jack -knife descrita por Meyer et al. (1986), permitindo assim os testes de hipóteses sobre este parâmetro demográfico. 


\subsection{Análises estatísticas}

Os valores de $\mathrm{CE}_{50}$ e limites de confiança de $95 \%$ para o número de organismos imóveis nos testes de toxicidade aguda para cada fármaco correspondente foram determinados por análise de regressão não-linear, ajustando-se uma equação logística aos dados utilizando-se a técnica dos quadrados mínimos. O Software Statistica 11.0 foi utilizado para esta finalidade. Uma análise de variância (ANOVA), seguida pelo teste de Dunnett (se aplicável), foi aplicada a cada endpoint dos testes crônicos para verificar a existência de diferenças estatisticamente significativas entre os diferentes tratamentos e o controle $(\mathrm{p}<0,05)$.

\section{Resultados}

As faixas de valores obtidos para os parâmetros físicos e químicos determinados durante as exposições agudas e crônicas estão dentro ou próximos dos valores recomendados pela $\operatorname{OECD}(2004,2008)$. Os valores de $\mathrm{pH}$ das soluções -teste encontraram-se dentro da faixa de 7,02-8,05, e não variaram mais do que 2,0 unidades. A condutividade elétrica variou de $120,1-186,7 \mu \mathrm{S} \mathrm{cm}^{-1}$, a dureza da água entre 40- 48 $m g \mathrm{~L}^{-1}$ de $\mathrm{CaCO}_{3}$ e a temperatura entre $20,1-27,9^{\circ} \mathrm{C}$. Ao final dos testes, os valores de imobilidade para o controle não foram superiores a $10 \%$, como recomendado pelas diretrizes da OECD (Tabelas 1 a 5, 16 a 20, e 22 a 26, em apêndice A).

A Figura 1 mostra os resultados obtidos nos testes de toxicidade aguda. Foi possível observar uma clara relação dose-resposta, uma vez que conforme as concentrações dos fármacos se tornaram crescentes houve um aumento na \% de organismos imóveis. A partir dos dados obtidos nestes bioensaios de toxicidade aguda foram calculados valores médios de $\mathrm{CE}_{50}(48 \mathrm{~h})$ e seus respectivos intervalos de confiança (IC 95\%). Os dados obtidos para os compostos acetaminofeno, diclofenaco sódico e propranolol mostraram uma toxicidade variável importante, com o seguinte ranking de toxicidade: acetaminofeno $\left(\mathrm{CE}_{50}=40,3 \mathrm{mg} \mathrm{L}^{-1}\right)<$ diclofenaco sódico $\left(\mathrm{CE}_{50}\right.$ $\left.=37,9 \mathrm{mg} \mathrm{L}^{-1}\right)<$ propranolol $\left(\mathrm{CE}_{50}=3,17 \mathrm{mg} \mathrm{L}^{-1}\right)$. Portanto, baseando-se nestes resultados, a espécie $C$. silvestrii foi mais sensível ao fármaco propranolol em comparação com os outros dois compostos farmacêuticos avaliados. 


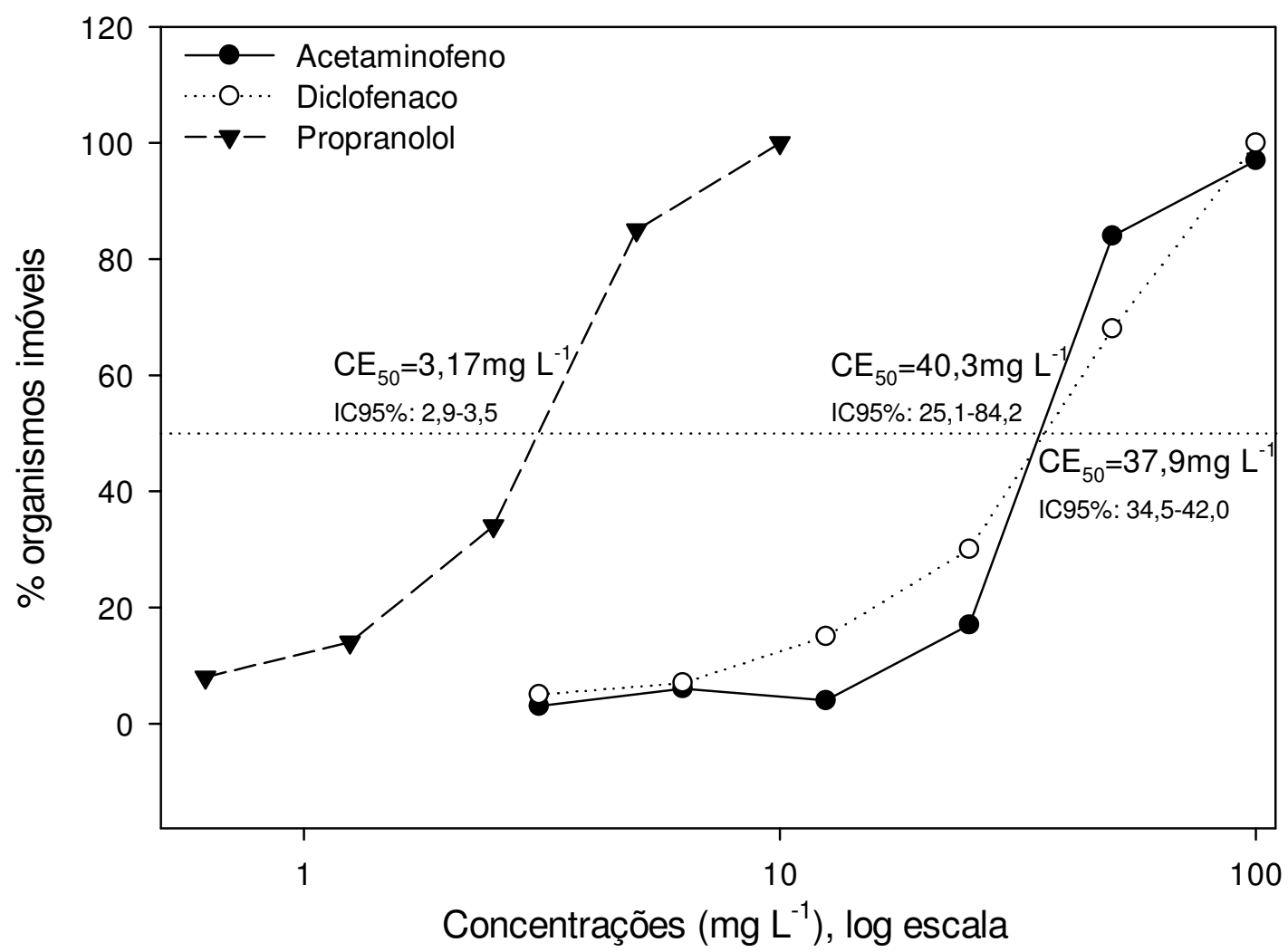

Figura 1. Porcentagem de organismos imóveis de Ceriodaphnia silvestrii expostas a diferentes concentrações de produtos farmacêuticos (paracetamol, diclofenaco sódico e propranolol), após 48 horas de exposição. Os valores apresentados correspondem aos valores médios de imobilidade, com os respectivos valores de Concentração Efetiva Mediana $\left(\mathrm{CE}_{50}, \mathrm{mg} \mathrm{L}^{-1}\right)$ e seus correspondentes intervalos de confiança de 95\% (IC95).

Os dados obtidos para os testes de toxicidade crônica mostraram a ocorrência de efeitos adversos na reprodução, mas também efeitos estimulantes (Figura 2). O fármaco acetaminofeno causou uma redução significativa na produção de neonatos apenas para a concentração mais elevada $\left(2,0 \mathrm{mg} \mathrm{L}^{-1}\right)$ quando comparado com o controle (ANOVA: $\left.\mathrm{MS}=38,285 ; \mathrm{F}_{[6,54]}=4,272 ; \mathrm{p}<0,001\right)$. Foi obtido o valor de $\mathrm{CE}_{50} 0,8989 \mathrm{mg} \mathrm{L}^{-1}$ deste composto sobre a reprodução de $C$. silvestrii. Parâmetros de sobrevivência e fecundidade foram integrados para obtenção da taxa de crescimento populacional (r), que mostrou uma redução significativa na população de $C$. silvestrii, quando exposta à maior concentração testada de paracetamol $\left(2,0 \mathrm{mg} \mathrm{L}^{-1}\right)$. 

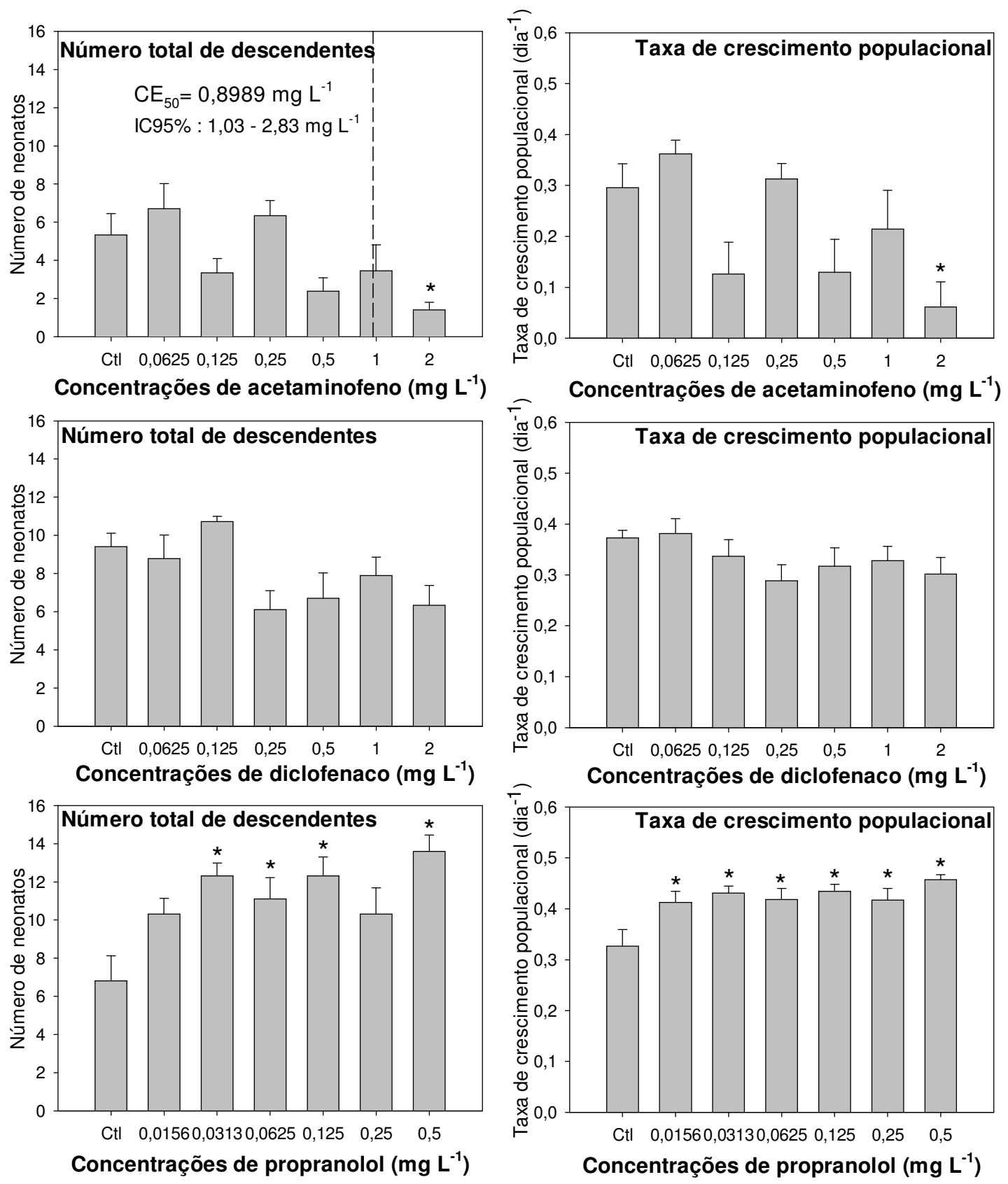

Figura 2. Parâmetros avaliados em relação às respostas da história de vida de Ceriodaphnia silvestrii exposta por 8 dias aos fármacos paracetamol, diclofenaco sódico e propranolol (eixo-x, em $\left.\mathrm{mg} \mathrm{L}^{-1}\right)$. As barras de erro correspondem ao erro padrão e $(*)$ denota a existência de diferenças estatisticamente significativas (teste de Dunnett, $\mathrm{p} \leq 0,05$ ) entre as diferentes concentrações dos fármacos estudados em comparação com o controle.

Diferentemente do que foi observado para o acetaminofeno, o fármaco propranolol causou um aumento significativo na fecundidade de $C$. silvestrii para as concentrações a partir de $0,0313 \mathrm{mg} \mathrm{L}^{-1}$, com exceção da penúltima concentração testada (one way ANOVA: $\left.\mathrm{MS}=47,929 ; \mathrm{F}_{[6,63]}=4,281 ; \mathrm{p}=0,001\right)$. Para o parâmetro taxa de 
crescimento populacional foi observado um aumento significativo a partir da menor concentração testada (one way ANOVA: $\mathrm{MS}=0,0171 ; \mathrm{F}_{[6,63]}=4,027 ; \mathrm{p}=0,002$ ). Nenhuma diferença significativa foi observada para os organismos expostos ao composto diclofenaco sódico, considerando-se os parâmetros número total de descendentes (one way ANOVA: $\mathrm{MS}=25,028 ; \mathrm{F}_{[6,56]}=2,628 ; \mathrm{p}=0,026$ ) e taxa de crescimento populacional, respectivamente (one way ANOVA: $\mathrm{MS}=0,0119 ; \mathrm{F}_{[6,63]}=$ 1,$324 ; p=0,260$, respectivamente).

\section{Discussão}

Os valores de $\mathrm{CE}_{50}$ obtidos para o fármaco propranolol $\left(3,17 \mathrm{mg} \mathrm{L}^{-1}\right)$ estão próximos aos já relatados na literatura para outras espécies de crustáceos, tais como os cladóceros: Ceriodaphnia dubia (0,8 a 1,51 $\left.\mathrm{mg} \mathrm{L}^{-1}\right)$ e Daphnia magna (1,6 a 7,5 mg L $\left.{ }^{-1}\right)$ (HUGGETT et al., 2002; FENT et al., 2006a ), e para a espécie de Rotifera Brachionus calyciflorus $\left(0,45 \mathrm{mg} \mathrm{L}^{-1}\right)$ (LIU et al., 2009). O CE 50 (48h) obtido no nosso estudo também é comparável ao $\mathrm{CE}_{50}(24 \mathrm{~h})$ relatado por Nałęcz-Jawecki et al. (2008) para o anóstraco da espécie Thamnocephalus platyurus.

No entanto, os valores aqui apresentados são ligeiramente maiores do que os valores reportados na literatura, indicando que a espécie $C$. silvestrii pode ser mais resistente à toxicidade do propranolol. Apesar dessas comparações, é possível observar que as condições experimentais podem ter uma contribuição decisiva para a variabilidade dos resultados. Um caso exemplificativo foi mostrado por Cleuvers (2003), com um valor de $\mathrm{CE}_{50}$ para D. magna (de 7,5 $\mathrm{mg} \mathrm{L}^{-1}$ ), significativamente acima dos anteriormente mencionados, ultrapassando o mesmo valor aqui obtido, mas na mesma ordem de grandeza. Se as comparações são feitas com organismos-teste aquáticos filogeneticamente distintos, é possível observar que $C$. silvestrii pode ser mais sensível do que espécies de macrófita (por exemplo, Lemna minor) e de algas unicelulares (por exemplo, Desmodesmus subspicatus) (CLEUVERS, 2003). Alternativamente, espécies como a cianobactéria Synechococcus leopoliensis (FERRARI et al., 2004), as diatomáceas Cyclotella meneghiniana (FERRARI et al., 2004) e Phaeodactylum tricornutum (CLAESSENS et al., 2013), e o protozoário Spirostomum ambiguum (NALECZ-JAWECKI et al., 2008) são mais sensíveis do que C. silvestrii ao propranolol, com valores de $\mathrm{CE}_{50}$ inferiores a $1,77 \mathrm{mg} \mathrm{L}^{-1}$. 
Os valores de $\mathrm{CE}_{50}$ do diclofenaco sódico para $C$. silvestrii mostram que, em termos comparativos, esta espécie pode ser mais sensível do que outros organismos-teste padronizados, incluindo crustáceos (D. magna; QUINN et al., 2011; CLEUVERS, 2004), algas (Pseudokirchneriella subcapitata, QUINN et al., 2011; Desmodesmus subspicatus, CLEUVERS, 2004), e macrófita (Lemna minor, QUINN et al., 2011). No entanto, quando analisam-se os dados da literatura verifica-se que as condições de cultivo (alimentação, temperatura, fotoperíodo e dureza da água) e experimentais, apesar de serem padronizadas podem variar, sendo que a utilização de organismos-teste padronizados sob condições distintas, também podem produzir resultados diferentes. $\mathrm{O}$ estudo realizado por Haap et al. (2008) mostrou que a espécie de Cladocera D. magna pode ser igualmente sensível ao diclofenaco sódico, quando comparada com $C$. silvestrii. $\mathrm{O}$ valor $\mathrm{CE}_{50}$ aqui calculado para o diclofenaco é em ordem de grandeza acima do $\mathrm{CE}_{50}$ para a espécie de peixe Danio rerio (VAN DEN BRANDHOF \& MONTFORTS, 2010). C. silvestrii não é tão sensível quanto outros organismos, tais como a clorofícea fitoplanctônica Dunaliella tertiolecta (DELORENZO \& FLEMING, 2008), a diatomácea Skeletonema costatum, o copepodo Tisbe battagliai (SCHMIDT et al., 2011) e o ciliado Tetrahymena pyriformis (LANG \& KOHIDAI, 2012). A exposição crônica a concentrações ambientais relevantes do diclofenaco sódico deverão ter efeitos mais graves sobre os vertebrados, considerando-se o seu modo de ação (SIMONS et al., 2005), pela inibição reversível ou irreversível de uma ou ambas isoformas das enzimas ciclo-oxigenase (COX-1 e COX-2), levando à inibição periférica da síntese das prostaglandinas (VANE \& BOTTING, 1998), como mostrado por Schwaiger et al. (2004) para a truta arco-íris e por Hoeger et al. (2005) para a truta marrom, causando alterações patológicas nas brânquias, fígado e rins.

A comparação dos resultados de $\mathrm{CE}_{50}$ do fármaco paracetamol para $C$. silvestrii em relação a valores previamente calculados para outras espécies pode resultar em grandes diferenças, conforme valores relatados em diversos estudos. Um exemplo paradigmático envolve o crustáceo D. magna; no qual o estudo realizado por Dave e Herger (2012) resultou em um valor de $\mathrm{CE}_{50}(24 \mathrm{~h})$ de 2,04 $\mathrm{mg} \mathrm{L}^{-1}$, enquanto Kim et al. (2007), Henschel et al. (1997), Calleja et al. (1994), e Kim et al. (2012) observaram valores de $\mathrm{CE}_{50}$ (48h) de $30,1 \mathrm{mg} \mathrm{L}^{-1} ; 50 \mathrm{mg} \mathrm{L}^{-1} ; 55,5 \mathrm{mg} \mathrm{L}^{-1}$; e $53,9 \mathrm{mg} \mathrm{L}^{-1}$, respectivamente.

A espécie $C$. silvestrii foi mais sensível ao acetaminofeno do que os organismosteste: Artemia salina, com $\mathrm{CE}_{50}(24 \mathrm{~h})$ de $577 \mathrm{mg} \mathrm{L}^{-1}$, Moina macrocopa, com $\mathrm{CE}_{50}(24$ 
h) de 56,34 $\mathrm{mg} \mathrm{L}^{-1}$, Brachionus calyciflorus, $\mathrm{CL}_{50}(24 \mathrm{~h})$ de $5,30 \mathrm{~g} \mathrm{~L}^{-1}$, e Photobacterium phosphoreum (teste Microtox, $\mathrm{CE}_{50}(15 \mathrm{~min})$ de $\left.331 \mathrm{mg} \mathrm{L}^{-1}\right)$. Contrariamente a estes resultados, C. silvestrii é menos sensível à exposição ao paracetamol que o crustáceo Streptocephalus proboscideus ( $\mathrm{CE}_{50}(24 \mathrm{~h})$ de 29,6 $\mathrm{mg} \mathrm{L}^{-1}$ ) (WEBB, 2001; KIM et al., 2012; CALLEJA et al., 1994; KUHN et al., 1989). Outros estudos sobre a ecotoxicidade do acetaminofeno são de difícil extrapolação e comparação com os nossos resultados, pois os endpoints avaliados são muito distintos ( $\mathrm{AN}$ et al., 2.009). $\mathrm{O}$ trabalho realizado por An et al. (2009) com a espécie de planta Triticum aestivum permitiu calcular a $\mathrm{CE}_{50}$ para a inibição do alongamento radicular de $668,8 \mathrm{mg} \mathrm{L}^{-1}$ de acetaminofeno que é uma ordem de grandeza acima do nosso resultado. No entanto, e dadas as diferenças entre $C$. silvestrii e T. aestivum, é difícil determinar questões como a sensibilidade comparável para este composto. Os nossos resultados mostram que o cladócero $C$. silvestrii pode ser uma espécie moderadamente sensível para efeitos de acetaminofeno, sendo um potencial candidato para ser utilizado em ensaios de ecotoxicidade para determinar os diferentes efeitos de drogas farmacêuticas.

Outra questão a discutir é a relevância ecológica dos critérios de toxicidade aguda. Considerando-se os níveis de propranolol necessários para causar efeitos agudos em espécies aquáticas, considera-se não provável que esta substância possa comprometer a sobrevivência de $C$. silvestrii, uma vez que os dados obtidos sobre as concentrações de propranolol encontradas nas amostras de água na Represa Guarapiranga-SP (Capítulo 1) chegaram a atingir no máximo $14,7 \mathrm{ng} \mathrm{L} \mathrm{L}^{-1}$. Já no estudo realizado por KasprzykHordem et al.(2007), foi observada concentrações entre 5 e $6 \mathrm{ng} \mathrm{L}^{-1}$ nos rios Taff (Inglaterra) e Warta (Polônia), mostrando que as concentrações ambientais deste fármaco são várias ordens de grandeza inferiores às testadas em laboratório e que podem causar efeitos agudos nos organismos. Consequentemente, a relevância ecológica da toxicidade aguda do propranolol, apesar de sua $\mathrm{CE}_{50}$ ser o mais baixo calculado a partir de todas as drogas testadas, é pequena e não representa quaisquer desafios consideráveis para a fisiologia de $C$. silvestrii. No entanto, não se devem desconsiderar os potenciais efeitos crônicos causados pelo fármaco propranolol. Como mostrado por Claessens et al. (2013), os níveis de exposição ao propranolol em vários portos marítimos belgas pode ser causador de exposições crônicas, provavelmente resultando em efeitos deletérios a longo prazo. Apesar da baixa probabilidade de efeitos agudos causados por diclofenaco sódico, tanto este composto quanto o propranolol não 
estão isentos de problemas ecotoxicológicos, especialmente em áreas altamente impactadas, para exposições crônicas que também podem envolver outros fármacos que atuam por mecanismos semelhantes (FENT et al., 2006). Considerações em parte similares podem ser realizadas considerando-se os dados de toxicidade obtidos para o paracetamol, pois o valor calculado de $\mathrm{CE}_{50}$ está distante dos níveis documentados para o compartimento aquático (TERNES, 1998; KOLPIN et al., 2002; ROBERTS \& TOMAS, 2006). Consequentemente, os dados relativos à toxicidade aguda dessa substância são de baixa relevância ecológica.

O paracetamol foi capaz de provocar efeitos significativos em nível populacional, com reduções dose-dependentes do número total de descendentes e da taxa de crescimento populacional (Figura 2). Os efeitos endócrinos desta substância foram recentemente reconhecidos, mostrando as implicações do uso deste composto farmacêutico e sua exposição (BERGMAN et al., 2013.), que estão relacionados com a sua atividade estrogênica (FENT et al., 2006b; ISIDORI et al., 2009). Espécies de crustáceos são extremamente sensíveis à exposição ao acetaminofeno, uma vez que este fármaco parece estar envolvido em distúrbios endócrinos, por interferência no processo de muda (RODRIGUEZ et al., 2007; FANJUL-MOLES \& GONSEBATT, 2011). A estrutura alquil-fenólica do paracetamol pode ser responsável por este efeito, uma vez que ações deste composto apresentam semelhanças estruturais com outros compostos que são já bem conhecidos por seus efeitos endócrino-disruptores em crustáceos (RODRÍGUEZ et al., 2007), atuando como hormônios anti-ecdise-esteroidais (LEBLANC, 2007). No entanto, o número de estudos sobre os efeitos potenciais como disruptor endócrino do paracetamol em organismos aquáticos, incluindo crustáceos, é ainda limitado, e as conclusões destes estudos são um pouco difíceis de interpretar. O estudo realizado por Kim et al. (2012) mostrou que, para concentrações superiores às utilizadas em nosso estudo, não foram registrados efeitos populacionais para a espécie D. magna. Apesar da baixa possibilidade de impactos negativos ocorrerem nos níveis relatados, os efeitos do acetaminofeno em populações de organismos não-alvo, expostas através do ambiente são uma possibilidade. Assim, é possível concluir que os níveis de risco provocados pelo paracetamol para a biota aquática não são desprezíveis (BOTTONI et al., 2010).

O $\beta$ - bloqueador propranolol, no entanto, causou efeito oposto, aumentando o número total da prole e a taxa de crescimento da população (Figura 2). Estas não são 
consideradas respostas comuns, uma vez que alguns estudos relacionados com a exposição ao propranolol verificaram redução no desempenho reprodutivo de espécies de crustáceos, tais como Daphnia magna (DZIALOWSKI et al., 2006). Esta situação normalmente foi seguida por reduções significativas em outros parâmetros fisiológicos, tais como taxas metabólicas e cardíacas, que resultaram em diminuições significativas na massa corporal seca, refletindo retardo de crescimento. Os autores sugerem que, devido à redução da frequência cardíaca causada pelo bloqueio dos $\beta$-receptores de propranolol, uma consequência direta é a redução no metabolismo. Isso pode levar a um equilíbrio entre o uso da energia disponível para o crescimento, ou, alternativamente, no aumento na reprodução, como foi observado em nosso estudo. A resposta aqui obtida pode ser considerada de natureza paradoxal, reforçando a ideia de que são necessários mais estudos com $C$. silvestrii, para melhor compreender o processo de regulação fisiológica do seu desempenho reprodutivo. Impactos no metabolismo de organismos aquáticos causadas por propranolol também tem sido demonstrado por Ericson et al. (2010). Este estudo evidenciou o efeito do propranolol sobre a redução do metabolismo em mexilhões azuis do Mar Báltico (Mytilus edulis trossulus), refletidos pela redução significativa no crescimento, na abundância e resistência dos segmentos do bisso.

As características metabólicas da espécie Chironomus riparius também foram afetadas pela exposição ao propranolol, como demonstrado por López-Doval et al. (2012); este estudo relatou a redução do crescimento e da biomassa deste organismo. Como verificado por Franzellitti et al. (2011), os efeitos deste composto sobre os organismos aquáticos (ou seja, as espécies de mexilhão Mytilus galloprovincialis) estão relacionados à interferência na rota dependente de cAMP, o que pode explicar a perturbação nas funções metabólicas neuroendócrinas que são vitais para este organismo. No entanto, e considerando a inexistência de estudos que consideram esse mecanismo de toxicidade em crustáceos, somente é possível sugerir a ocorrência de um caminho similar em $C$. silvestrii que explica os dados reprodutivos obtidos. Outros organismos que apresentaram respostas similares foram as espécies Ceriodaphnia dubia e Hyalella azteca (HUGGETT et al., 2002). Este último estudo também relatou uma diminuição não significativa no número de ovos produzidos e nos níveis hormonais de esteróides sexuais do peixe da espécie Oryias latipes; o que sugere que a insuficiência reprodutiva causada pelo propranolol não é restrito apenas para os invertebrados. Entretanto, os autores sugerem que uma resposta bifásica com o propranolol pode 
ocorrer, e a exposição a baixos níveis pode resultar em respostas opostas às registradas para as concentrações mais elevadas, que são mediadas através da alteração dos níveis hormonais. A interferência deste fármaco no sistema reprodutivo de organismos aquáticos, também foi mostrado no estudo de Giltrow et al. (2009). Neste estudo foi observado que o propranolol pode alterar o índice gonadossomático de machos e fêmeas do peixe Pimephales promelas, e que a eclodibilidade dos ovos também foi afetada. Além disso, a relação entre a exposição do propranolol e a diminuição no metabolismo foi novamente demonstrada, uma vez que o peso corporal dos organismos expostos reduziu significativamente.

\section{Conclusões}

Os nossos resultados sugerem que o cladócero Ceriodaphnia silvestrii é uma espécie sensível e adequada para utilização como organismo-teste em ensaios de ecotoxicidade a serem realizados nas regiões tropicais, especialmente para determinação dos efeitos dos compostos farmacêuticos. Contudo, e apesar da ocorrência de impactos importantes causados pelos fármacos estudados na sobrevivência e reprodução de $C$. silvestrii, deve-se enfatizar que os níveis destes compostos necessários para a obtenção destes efeitos são consideravelmente superiores aos documentados no compartimento aquático. Apesar disso, deve-se considerar que com a produção extensiva, o uso intensivo de medicamentos e suas cargas crescentes no meio ambiente podem resultar em potenciais riscos ecológicos a longo prazo para a biota aquática, onde diferentes agentes tóxicos podem interagir entre si.

\section{Referências bibliográficas}

ÅGERSTRAND, M.; RUDÉN, C. Evaluation of the accuracy and consistency of the Swedish Environmental Classification and Information System for pharmaceuticals. Science of the Total Environment, v.408, p. 2327-2339, 2010.

AGUINACO, A.; BELTRÁN, F.J.; GARCÍA-ARAYA, J.F.; OROPESA, A. Photocatalytic ozonation to remove the pharmaceutical diclofenac from water: influence of variables. Chemical Engineering Journal, v.189-190, p.275-282, 2012. 
ALDER, A.C.; SCHAFFNER, C.; MAJEWSKY, M.; KLASMEIER, J.; FENNER, K. Fate of $\beta$-blocker human pharmaceuticals in surface water: comparison of measured and simulated concentrations in the glatt valley watershed, Switzerland. Water Research, v. 44, p. 936-948, 2010.

AN, J.; ZHOUA, Q.; SUN, F.; ZHANG, L. Ecotoxicological effects of paracetamol on seed germination and seedling development of wheat (Triticum aestivum L.). Journal of Hazardous Materials, v. 169, p.751-757, 2009.

ANDREOZZI, R.; RAFFAELE, M.; NICKLAS, P. Pharmaceuticals in STP effluents and their solar photo-degradation in aquatic environment. Chemosphere, v.50, p. 13191330, 2003.

ANTUNES, S.C.; FREITAS, R.; FIGUEIRA. E.; GONÇALVES, F.; NUNES, B. Biochemical effects of acetaminophen in aquatic species: edible clams Venerupis decussata and Venerupis philippinarum. Environmental Science and Pollution Research, v.20, p.6658-6666, 2013.

AMERICAN SOCIETY FOR TESTING AND MATERIALS (ASTM). Standard Guide for Conducting Acute Toxicity Testing on Test Materials with Fishes, Macroinvertebrates, and Amphibians. West Conshohocken, PA: American Society for Testing and Materials, 2001, p729- 796.

BARBIERI, M.; LICHA, T.; NÖDLER, K.; CARRERAA, J.; AYORAA, C.; SANCHEZ-VILAC, X. Fate of $\beta$-blockers in aquifer material under nitrate reducing conditions: Batch experiments. Chemosphere, v.9, p.1272-1277, 2012.

BEHERA, S.K.; KIM, H.W.; OH, J.E.; PARK, H.S. Occurrence and removal of antibiotics, hormones and several other pharmaceuticals in wastewater treatment plants of the largest industrial city of Korea. Science of the Total Environment, v.409, p. 4351-4360, 2011. 
BENDZ, D.; PAXEUS, NA.; GINN, TR.; LOGE, F.J. Occurrence and fate of pharmaceutically active compounds in the environment, a case study: Hoje River in Sweden. Journal of Hazardous Materials, v.122, p.195-204, 2005.

BENOTTI, M.J.; TRENHOLM, R.A.; VANDERFORD, B.J.; HOLADY, J.C.; STANFORD, B.D.; SNYDER, S.A. Pharmaceuticals and endocrine disrupting compounds in U.S. drinking water. Environmental Science \& Technology, v.43, p. 597-603, 2009.

BERGMAN, Å.; HEINDEL, J.J.; KASTEN, T.; KIDD, K.A.; JOBLING, S.; NEIRA, M.; ZOELLER, R.T.; BECHER, G.; BJERREGAARD, P.; BORNMAN, R.; BRANDT, I.; KORTENKAMP, A.; MUIR, D.; DRISSE, M-NB.; OCHIENG, R.; SKAKKEBAEK, N.E.; BYLÉHN, A.S.; IGUCHI, T.; TOPPARI, J.; WOODRUFF, T.J. The Impact of Endocrine Disruption: A Consensus Statement on the State of the Science. Environmental Health Perspectives, v.121, p.104-106, 2013.

BOTTONI, P.; CAROLI, S.; BARRA-CARACCIOLO, A. Pharmaceuticals as priority water contaminants. Toxicological \& Environmental Chemistry, v. 92, p.549-565, 2010.

BRANDÃO, F.P.; RODRIGUES, S.; CASTRO, B.B.; GONÇALVES, F.; ANTUNES, S.C.; NUNES, B. Short-term effects of neuroactive pharmaceutical drugs on a fish species: Biochemical and behavioural effect. Aquatic Toxicology, v.144, p.145218$229,2013$.

BROOKS, B.W.; CHAMBLISS, C.K.; STANLEY, J.K.; RAMIREZ, A.; BANKS, K.E.; JOHNSON, R.D.; LEWIS, R.J. Determination of select antidepressants in fish from an effluent-dominated stream. Environmental Toxicology \& Chemistry, v.24, p. 464-469, 2005.

CALlEJA, M.C.; PERSOONE, G.; GELADI, P. Comparative Acute Toxicity of the First 50 Multicentre Evaluation of In Vitro Cytotoxicity Chemicals to Aquatic Non- 
Vertebrates. Archives of Environmental Contamination and Toxicology, v.26, p. 6978, 1994.

CHOI, K.; KIM, Y.; PARK, J.; PARK, C.K.; KIM, M.; KIM, H.S.; KIM, P. Seasonal variations of several pharmaceutical residues in surface water and sewage treatment plants of Han River, Korea. Science of the Total Environment, v.405, p.120-128, 2008.

CHRISTENSEN, F.M. Pharmaceuticals in the environment - A Human Risk? Regulatory Toxicology \& Pharmacology, v.28, p.212-221, 1998.

CLAESSENS, M.; VANHAECKE, L.; WILlE, K.; JANSSEN, C.R. Emerging contaminants in Belgian marine waters: Single toxicant and mixture risks of pharmaceuticals. Marine Pollution Bulletin, v.71, p.41-50, 2013.

CLEUVERS, M. Aquatic ecotoxicity of pharmaceuticals including assessment of combination effects. Toxicology Letters, v.142, p.185-194, 2003.

CLEUVERS, M. Mixture toxicity of the anti-inflammatory drugs diclofenac, ibuprofen, naproxen, and acetylsalicylic acid. Ecotoxicology \& Environmental Safety, v.59, p.309-315, 2004.

COHEN, S.D.; KHAIRALLAH, E.A. Selective protein arylation and acetaminopheninduced hepatotoxicity. Drug Metabolism Reviews, v. 29, p.59-77, 1997.

COELHO, K.S.; ROCHA, O. Assessment of the potential toxicity of a linear alkylbenzene sulfonate (LAS) to freshwater animal life by means of cladoceran bioassays. Ecotoxicology, v.19, p.812-818, 2010.

CONTARDO-JARA, V.; LORENZ, C.; PFLUGMACHER, S.; NUETZMANN, G.; KLOAS, W.; WIEGAND, C. Exposure to human pharmaceuticals Carbamazepine, Ibuprofen and Bezafibrate causes molecular effects in Dreissena polymorpha. Aquatic Toxicology, v.105, p.428-37, 2011. 
DAUGHTON, C.G.; TERNES, T.A. Pharmaceuticals and personal care products in the environment: agents of subtle change? Environmental Health Perspectives, v.107, p.907-938, 1999.

DAVE, G.; HERGER, G. Determination of detoxification to Daphnia magna of four pharmaceuticals and seven surfactants by activated sludge. Chemosphere, v.88, p.459466, 2012.

DELORENZO, M.E.; FLEMING, J. Individual and Mixture Effects of Selected Pharmaceuticals and Personal Care Products on the Marine Phytoplankton Species Dunaliella tertiolecta. Archives of Environmental Contamination and Toxicology, v.54, p.203-210, 2008.

DE VOOGT, P.; JANEX-HABIBI, M-L.; SACHER, F.; PUIJKER, L.; MONS, M. Development of a common priority list of pharmaceuticals relevant for the water cycle. Water Science \& Technology, v.59, p.39-46, 2009.

DZIALOWSKI, E.M.; TURNER, P.K.; BROOKS, B.W. Physiological and Reproductive Effects of Beta Adrenergic Receptor Antagonists in Daphnia magna. Archives of Environmental Contamination and Toxicology, v. 50, p.503-510, 2006.

EUROPEAN MEDICINES AGENCY (EMEA). Guideline on the Environmental Risk Assessment of medicinal products for human use. 7 Westferry Circus, Canary Wharf, London E14 4HB, UK, 2006.

ERICSON, H.; THORSÉN, G.; KUMBLAD, L. Physiological effects of diclofenac, ibuprofen and propranolol on Baltic Sea blue mussels. Aquatic Toxicology, v.99, p.223-231, 2010.

FANJUL-MOLES, M. L.; GONSEBATT, M E. In: Oxidative stress in aquatic ecosystems. Eds: Doris A, Vazquez-Medina JP, Zenteno-Savin T. Wiley-Blackwell, 2011. 
FENT, K.; WESTON, A.A.; CAMINADA, D. Ecotoxicology of human pharmaceuticals. Aquatic Toxicology, v.76, p.122-159, 2006a.

FENT, K.; ESCHER, C.; CAMINADA, D. Estrogenic activity of pharmaceuticals and pharmaceutical mixtures in a yeast reporter gene system. Reproductive Toxicology, v.22, 175-185, 2006b.

FERRARI, B.; MONS, R.; VOLLAT, B.; FRAYSSE, B.; PAXEUS, N.; LO GIUDICE, R.; POLLIO, A.; GARRIC, J. Environmental risk assessment of six human pharmaceuticals: Are the current environmental risk assessment procedures sufficient for the protection of the aquatic environment? Environmental Toxicology and Chemistry, v.23, p.1344-1354, 2004.

FONSECA, A.L.; ROCHA, O. The life-cycle of Ceriodaphnia silvestrii, Daday, 1902, a neotropical endemic species (Crustacea, Cladocera, Daphnidae). Acta Limnologica Brasiliensis, v. 16, p.319-328, 2004.

FRANZELLITTI, S.; BURATTI, S.; VALBONESI, P.; CAPUZZO, A.; FABBRI, E. The $\beta$-blocker propranolol affects cAMP-dependent signaling and induces the stress response in Mediterranean mussels, Mytilus galloprovincialis. Aquatic Toxicology, v.101, p.299-308, 2011.

FREITAS, E.C.; ROCHA, O. Acute and Chronic toxicity of chromium and cadmium to the tropical cladoceran Pseudosida ramosa and the implications for ecotoxicological studies. Environmental Toxicology, v. 29, p.176-186, 2011.

GAN, T.J. Diclofenac: an update on its mechanism of action and safety profile. Current Medical Research and Opinion, v.26, p.1715-1731, 2010.

GILTROW, E.; ECCLE, P.D.; WINTER, M.J.; MCCORMACK, P.J.; RANDWEAVER, M.; HUTCHINSON, T.H.; SUMPTER, J.P. Chronic effects assessment and plasma concentrations of the $\beta$-blocker propranolol in fathead minnows (Pimephales promelas). Aquatic Toxicology, v.95, p.195-202, 2009. 
GOMEZ, M.J.; PETROVIC, M.; FERNANDEZ-ALBA, A.R.; BARCELO, D. Determination of pharmaceuticals of various therapeutic classes by solid-phase extraction and liquid chromatography-tandem mass spectrometry analysis in hospital effluent wastewaters. Journal of Chromatography A, v.1114, p.224-233, 2006.

HAAP, T.; TRIEBSKORN, R.; KÖHLER, H.R. Acute effects of diclofenac and DMSO to Daphnia magna: Immobilization and hsp70-induction. Chemosphere, v.73, p.353$359,2008$.

HADI, M.; DRAGOVIC, S.; VAN SWELM, R.; HERPERS, B.; VAN DE WATER, B.; FRANS, G.M.; COMMANDEUR, J.N.M.; GROOTHUIS, G.M.M. AMAP, the alleged non toxic isomer of acetaminophen is toxic in rat and human liver. Archives of Toxicology, v. 87:155-165, 2013.

HEBERER, T. Tracking persistent pharmaceutical residues from municipal sewage to drinking water. Journal of Hydrology, v.266, p.175-189, 2002.

HENSCHEL, K.P.; WENZEL, A.; DIEDRICH, M.; FLIEDNER, A. Environmental Hazard Assessment of Pharmaceuticals. Regulatory Toxicology and Pharmacology, v.25, p. 220-225, 1997.

HILTON, M.J.; THOMAS, K.V. Determination of selected human pharmaceutical compounds in effluent and surface water samples by high-performance liquid chromatography-electrospray tandem mass spectrometry. Journal of Chromatography A, v.1015, p.129-141, 2003.

HOEGER, B.; KÖLLNER, B.; DIETRICH, D.R.; HITZFELD, B. Water-borne diclofenac affects kidney and gill integrity and selected immune parameters in brown trout (Salmo trutta f. fario). Aquatic Toxicology, v. 5, p.53-64, 2005.

HUGGETT, D.B.; BROOKS, B.W.; PETERSON, B.; FORAN, C.M.; SCHLENK, D. Toxicity of select beta adrenergic receptor-blocking pharmaceuticals ( $\beta$-Blockers) on 
aquatic organisms. Archives of Environmental Contamination and Toxicology, v. 43, p.229-235, 2002.

ISIDORI, M.; BELLOTTA, M.; CANGIANO, M.; PARRELLA, A. Estrogenic activity of pharmaceuticals in the aquatic environment. Environment International, v.35, p.826-829, 2009.

JAESCHKE, H.; BAJT, M.L. Intracellular signaling mechanisms of acetaminopheninduced liver cell death. Toxicological Sciences, v.89, p.31-41, 2006.

KASPRZYK-HORDEM, B.; DINSDALE, R.M.; GUWY, A.J. Multi-residue method for the determination of basic/neutral pharmaceuticals and illicit drugs in surface water by solid-phase extraction and ultra performance liquid chromatography-positive electrospray ionization tandem mass spectrometry. Journal of Chromatography A, v.1161, p.132-145, 2007.

KIM, Y.; CHOI, K.; JUNG, J.; PARK, S.; KIM, P.G.; PARK, J. Aquatic toxicity of acetaminophen, carbamazepine, cimetidine, diltiazem and six major sulfonamides, and their potential ecological risks in Korea. Environment International, v.33, p. 275-370, 2007.

KIM, J.W.; ISHIBASHI, H.; YAMAUCHI, R.; ICHIKAWA, N.; TAKAO, Y.; HIRANO, M.; KOGA, M.; ARIZONO, K. Acute toxicity of pharmaceutical and personal care products on freshwater crustacean (Thamnocephalus platyurus) and fish (Oryzias latipes). The Journal of Toxicological Sciences, v.34, p.227-232, 2009a.

KIM, J.W.; JANG, H.S.; KIM, J.G.; ISHIBASHI, H.; HIRANO, M.; NASU, K.; ICHIKAWA, N.; TAKAO, Y.; SHINOHARA, R.; ARIZONO, K. Occurrence of pharmaceutical and personal care products (PPCPs) in surface water from Mankyung River, South Korea. Journal of Health Science, v.55, p.249-258, 2009 b.

KIM, P.; PARK, Y.; JI, K.; SEO, J.; LEE, S.; CHOI, K.; KHO, Y.; PARK, J.; CHOI, K. Effect of chronic exposure to acetaminophen and lincomycin on Japanese medaka 
(Oryzias latipes) and freshwater cladocerans Daphnia magna and Moina macrocopa, and potential mechanisms of endocrine disruption. Chemosphere, v.89, p.10-18, 2012.

KLAASSEN, C.D. Casarett and Doull's Toxicology: The Basic Science of Poisons. 6th edition. Mc Graw Hill. 2001.

KLEYWEGT, S.; PILEGGI, V.; YANG, P.; HAO, C.; ZHAO, X.; ROCKS, C.; THACH, S.; CHEUNG, P.; WHITEHEAD, B. Pharmaceuticals, hormones and bisphenol A in untreated source and finished drinking water in Ontario, Canada Occurrence and treatment efficiency. Science of the Total Environment, v.409, p.1481-1488, 2011.

KOLPIN, D.W.; FURLONG, E.T.; MEYER, M.T.; THURMAN, E.M.; ZAUGG, S.D.; BARBER, L.B.; BUXTON, H.T. Pharmaceuticals, hormones and other organic wastewater contaminants in US streams, 1999-2000: a national reconnaissance. Environmental Science \& Technology, v.36, p.1202-1211, 2002.

KÜHN, R.; PATTARD, M.; PERNAK, K.D.; WINTER, A. Results of the harmful effects of selected water pollutants (anilines, phenols, aliphatic compounds) to Daphnia magna. Water Research, v.4, p.495-499, 1989.

KUMMERER, K. The presence of pharmaceuticals in the environment due to human use - present knowledge and future challenges. Journal of Environmental Management, v. 90, p.2354-2366, 2009.

KÜSTER, A.; ALDER, A.C.; ESCHER, B.I.; DUIS, K.; FENNER, K.; GARRIC, J.; HUTCHINSON, T.H.; LAPEN, D.R.; PÉRY, A.; RÖMBKE, J.; SNAPE, J.; TERNES, T.; TOPP, E.; WEHRHAN, A.; KNACKER, T. Environmental risk assessment of human pharmaceuticals in the European Union: a case study with the beta-blocker atenolol. Integrated Environmental Assessment and Management, v.6, p. 514-523, 2009. 
KWON, J.W.; ARMBRUST, K.L.; VIDAL-DORSCH, D.; BAY, S.M. Determination of 17 alpha-ethynylestradiol, carbamazepine, diazepam, simvastatin, an oxybenzone in fish livers. Journal AOAC International, v.92, p.359-369, 2009.

LÁNG, J.; KOHIDAI, L. Effects of the aquatic contaminant human pharmaceuticals and their mixtures on the proliferation and migratory responses of the bioindicator freshwater ciliate Tetrahymena. Chemosphere, v. 89, p.592-601, 2012.

LEE, J.; JI, K.; KHO, Y.L.; KIM, P.; CHOI, K. Chronic exposure to diclofenac on two freshwater cladocerans and Japanese medaka. Ecotoxicology and Environmental Safety, v.74, p.1216-1225, 2011.

LEBLANC, G.A. Crustacean endocrine toxicology: a review. Ecotoxicology, v.16, p.61-81, 2007.

LI, M.H. Acute toxicity of 30 pharmaceutically active compounds to freshwater planarians, Dugesia japonica. Toxicological \& Environmental Chemistry, v.95, p. 1157-1170, 2013.

LILIUS, H.; HASTBACKA, T.; ISOMAA, B. A comparison of the toxicity of 30 reference chemicals to Daphnia magna and Daphnia pulex. Environmental Toxicology and Chemistry, v. 12, p.2085-2088, 1995.

LIN, A. YU-CHEN.; TSAI, YU-TING. Occurrence of pharmaceuticals in Taiwan's surface waters: impact of waste streams from hospitals and pharmaceutical production facilities. Science of Total Environment, v. 407, p.3793-3802, 2009.

LIU, Q-T.; WILLIAMS, T.D.; CUMMING, R.I.; HOLM, G.; HETHERIDGE, M.J.; MURRAY-SMITH, R. Comparative Aquatic Toxicity of Propranolol and its Photodegraded Mixtures: Algae and Rotifer Screening. Environmental Toxicology and Chemistry, v.28, p. 2622-2631, 2009. 
LÓPEZ-DOVAL, J.C.; KUKKONEN, J.V.; RODRIGO, P.; MUÑOZ, I. Effects of indomethacin and propranolol on Chironomus riparius and Physella (Costatella) acuta. Ecotoxicology and Environmental Safety, v.78, p.110-115, 2012.

LÓPEZ-SERNA, R.; PÉREZ, S.; GINEBREDA, A.; PETROVIĆ, M.; BARCELÓ, D. Fully automated determination of 74 pharmaceuticals in environmental and waste waters by online solid phase extraction-liquid chromatography-electrospray-tandem mass spectrometry. Talanta, v.83, p.410-424, 2010.

MANYIKE, P.T.; KHARASCH, E.D.; KALHORN, T.F.; SLATTERY, J.T. Contribution of CYP2E1 and CYP3A to acetaminophen reactive metabolite formation. Clinical Pharmacology \& Therapeutics, v. 67, p.275-282, 2000.

MEYER, J.S.; INGERSOLL, C.G.; MCDONALD, L.L.; BOYCE, M.S. Estimating uncertainty in population growth rates: JackKnife vs. Bootstrap techniques. Ecology, v.67, p.1156-1166, 1986.

MÜLLER, H. Wachstum and phosphatbedarf von Nitzschia actinastroides (Lemn.) v. Goor in statischer und homokontiuierliecher Kultur unter Phosphatlimitierung. Archives fuer Hydrobiologie Supplement, v.38, p.399-484, 1972.

NAŁĘCZ-JAWECKI, G.; WÓJCIK, T.; SAWICKI, J. Evaluation of in vitro biotransformation of propranolol with HPLC, MS/MS, and two bioassays. Environmental Toxicology, v. 23, p.52-58, 2008.

NUNES, B.; ANTUNES, S.C.; SANTOS, J.; MARTINS, L.; CASTRO, B.B. Toxic potential of paracetamol to freshwater organisms: a headache to environmental regulators? Ecotoxicology and Environmental Safety, v. 107, p.178- 1885, 2014.

ORGANISATION FOR ECONOMIC CO-OPERATION AND DEVELOPMENT (OECD). Guideline for Testing of Chemicals. Daphnia sp., Acute immobilization test. OECD 202. Paris, France: Organization for Economic Cooperation and Development, 2004. 
ORGANISATION FOR ECONOMIC CO-OPERATION AND DEVELOPMENT (OECD). Guidelines for Testing of Chemicals. Daphnia magna, Reproduction test. OECD 211. Paris, France: Organization for Economic Cooperation and Development, 2008 .

OWEN, S.F.; GILTROW, E.; HUGGETT, D.B.; HUTCHINSON, T.H.; SAYE, J.; WINTER, M.J.; SUMPTER, J.P. Comparative physiology, pharmacology and toxicology of $\beta$-blockers: Mammals versus fish. Aquatic Toxicology, v. 82, p.145-162, 2007.

PAL, A.; GIN, KY-H.; LIN, A.Y.C.; REINHARD, M. Impacts of emerging organic contaminants on freshwater resources: Review of recent occurrences, sources, fate, and effects. Science of Total Environment, v. 408, p.6062- 6069, 2010.

PARK, S.; CHOI, K. Hazard assessment of commonly used agricultural antibiotics on aquatic ecosystems. Ecotoxicology, v.17, p.526-538, 2008.

PATEL, M.; TANG, B.K.; KALOW, W. Variability of acetaminophen metabolism in Caucasians and Orientals. Pharmacogenetics, v.2, p.38-45, 1992.

PRESCOTT, L.F. Kinetics and Metabolism of Paracetamol and Phenacetin. British Journal of Clinical Pharmacology, v. 10, p.291-298, 1980.

QUINN, B.; SCHMIDT, W.; O'ROURKE, K.; HERNAN, R. Effects of the pharmaceuticals gemfibrozil and diclofenac on biomarker expression in the zebra mussel (Dreissena polymorpha) and their comparison with standardized toxicity tests. Chemosphere, v. 84, p.657-663, 2011.

ROBERTS, P.H.; THOMAS, K.V. The occurrence of selected pharmaceuticals in wastewater effluent and surface waters of the lower Tyne catchment. Science of the Total Environment, v. 356, p.143-153, 2006. 
RODRÍGUEZ, E.M.; MEDESANI, D.A.; FINGERMAN, M. Endocrine disruption in crustaceans due to pollutants: a review. Comparative Biochemistry and Physiology Part A, v. 146, p.661-671, 2007.

SCHMIDT, W.; O'ROURKE, K.; HERNAN, R.; QUINN, B. Effects of the pharmaceuticals gemfibrozil and diclofenac on the marine mussel (Mytilus spp.) and their comparison with standardized toxicity tests. Marine Pollution Bulletin, v. 62, p.1389-1395, 2011.

SCHWAIGER, J.; FERLING, H.; MALLOW, U.; WINTERMAY, H.; NIGELE, R.D. Toxic effects of the non-steroidal anti-inflammatory drug diclofenac. Part I: histopathological alterations and bioaccumulation in rainbow trout. Aquatic Toxicology, v.68, p.141-150, 2004.

SIMONS, D.L.; BOTTING, R.M.; HLA, T. Cyclooxygenase Isozymes: The Biology of Prostaglandin Synthesis and Inhibition. Pharmacological Reviews, v.56, p.387-437, 2005.

SOLÉ, M.; SHAW, J.P.; FRICKERS, P.E.; READMAN, J.W.; HUTCHINSON, T.H. Effects on feeding rate and biomarker responses of marine mussels experimentally exposed to propranolol and acetaminophen. Analytical and Bioanalytical Chemistry, v.396, p.649-656, 2010.

SOTELO, J.L.; OVEJERO, G.; RODRÍGUEZ, A.; ÁlVAREZ, S.; GALÁN, J.; GARCÍA, J. Competitive adsorption studies of caffeine and diclofenac aqueous solutions by activated carbon. Chemical Engineering Journal, v.240, p.443-453, 2014.

STANLEY, J.K.; RAMIREZ, A.J.; MOTTALEB, M.; CHAMBLISS, C.K.; BROOKS, B.W. Enantiospecific toxicity of the $\beta$-blocker propranolol to Daphnia magna and Pimephales promelas. Environmental Toxicology and Chemistry, v. 25, p.17801786, 2006. 
TERNES, T.A. Occurrence of drugs in German sewage treatment plants and rivers. Water Research, v. 32, p.3245-3260, 1998.

TIMBRELL, J. Principles of Biochemical Toxicology Taylor \& Francis, London, 2002.

UNITED STATES ENVIRONMENTAL PROTECTION AGENCY (USEPA). Methods for measuring the acute toxicity of effluents and receiving waters to freshwater and marine organisms. EPA-821-R-02-013. Washington, DC: U.S. Environmental Protection Agency, 2002.

VALCÁRCEL, Y.; GONZÁLEZ ALONSO, S.; RODRÍGUEZ-GIL, J.L.; CASTAÑO, A.; MONTERO, J.C.; CRIADO-ALVAREZ, J.J.; MIRÓN, I.J.; CATALÁ, M. Seasonal variation of pharmaceutically active compounds in surface (Tagus River) and tap water (Central Spain). Environmental Science and Pollution Research, v. 20, p.1396-1412, 2012.

VAN DEN BRANDHOF E.J.; MONTFORTS, M. Fish embryo toxicity of carbamazepine, diclofenac and metoprolol. Ecotoxicology and Environmental Safety, v.73, p.1862-1866, 2010.

VANE, J.R.; BOTTING, R.M. Mechanism of action of anti-inflammatory drugs. International Journal of Tissue Reactions, v. 20, p.3-15, 1998.

VOOGT, P.; JANEX-HABIBI, M.L.; SACHHER, F.; PUIJKER, L.; MONS, M. Development of a common priority list of pharmaceuticals relevant for the water cycle. Water Science \& Technology, v.59, p.39-46, 2009.

WEBB, S.R. A data-based perspective on the environmental risk assessment of human pharmaceuticals. In: Kümmerer K, editor. Pharmaceuticals in the Environment, Springer- Verlag, Berlin, p 175-201, 2001.

WHITCOMB, D.C.; BLOCK, G.D. Association of acetaminophen hepatotoxicity with fasting and ethanol use. Jama, v. 272, p.1845-1850, 1994. 
YAMAMOTO, H.; NAKAMURA, Y.; NAKAMURA, Y.; KITANI, C.; IMARI, T.; SEKIZAWA, J.; TAKAO, Y.; YAMASHITA, N., HIRAI, N.; ODA, S.; TATARAZAKO, N. Initial ecological risk assessment of eight selected human pharmaceuticals in Japan. Environmental Science, v.14, p.177-193, 2007.

YANG, G. C.C.; YEN, C.-H.; WANG C.-L. Monitoring and removal of residual phthalate esters and pharmaceuticals in the drinking water of Kaohsiung City, Taiwan. Journal Hazard Mater. 2014. http://dx.doi.org/10.1016/j.jhazmat.2014.03.005.

XU, J.; WU, L.; CHANG, A.C. Degradation and adsorption of selected pharmaceuticals and personal care products (PPCPs) in agricultural soils. Chemosphere, v.77, p.12991305, 2009.

ZHANG, Z.; HIBBERD, A.; ZHOU, J.L. Analysis of emerging contaminants in sewage effluent and river water: Comparison between spot and passive sampling. Analytica Chimica Acta, v. 607, p.37-44, 2008. 


\title{
Capítulo 3
}

\author{
Avaliação da toxicidade aguda de fármacos sobre diferentes invertebrados de água \\ doce
}

\section{Resumo}

Fármacos de uso humano e veterinário pertencentes a diferentes classes vêm sendo detectados em efluentes de estações de tratamento de esgoto, águas de abastecimento público e em outras matrizes ambientais, tais como solos, sedimentos e águas naturais em concentrações na faixa de $\mu \mathrm{g} \mathrm{L}^{-1}$ e $n g \mathrm{~L}^{-1}$. A concentração crescente de resíduos de fármacos em ecossistemas aquáticos tem despertado grande interesse científico, quer pelo aumento em quantidade e variedade, quer pela toxicidade a que pode acarretar à biota aquática. Por estas razões estudos sobre os possíveis efeitos destes compostos aos organismos aquáticos são importantes para o entendimento dos problemas que podem impor às espécies individuais e para a avaliação dos riscos e danos ocasionados por estes possíveis agentes tóxicos. O presente estudo teve como objetivo avaliar a toxicidade aguda dos fármacos: diclofenaco sódico (anti-inflamatório) e propranolol (anti-hipertensivo), sobre as espécies Ceriodaphnia silvestrii, Daphnia magna (Crustacea, Cladocera), Hydra viridissima (Cnidaria, Hydrozoa) e Dugesia tigrina (Platyhelminthes, Turbellaria), em condições de laboratório. Os resultados obtidos das exposições agudas mostraram uma variabilidade considerável na toxicidade dos compostos farmacêuticos estudados, sendo que os valores de $\mathrm{CE}_{50}$ e $\mathrm{CL}_{50}$ variaram de 0,55 a $123,3 \mathrm{mg} \mathrm{L}^{-1}$. Foi possível observar o seguinte ranking de toxicidade para o diclofenaco sódico e o propranolol entre os organismos-teste: $D$. tigrina $<H$. viridissima $<C$. silvestrii $<D$. magna; e $H$. viridissima $<C$. silvestrii $<D$. magna $<D$. tigrina, respectivamente. Portanto, baseando-se nestes resultados, a espécie $D$. tigrina foi mais sensível ao fármaco diclofenaco sódico, e ao mesmo tempo apresentou uma maior tolerância ao propranolol. Os resultados demonstram os riscos associados à presença destes compostos farmacológicos às duas espécies avaliadas.

Palavras-chave: diclofenaco sódico, propranolol, fármacos, biota aquática, toxicidade aguda. 


\begin{abstract}
Drugs for human and veterinary use belonging to different classes have been detected in effluents from sewage treatment, public water supply stations and other environmental matrices, such as soils, sediments and natural waters at concentrations in the range of $\mathrm{mg} \mathrm{L}^{-1}$ and $\mathrm{ng} \mathrm{L}^{-1}$. The increasing concentration of drug residues in aquatic ecosystems has attracted scientific interest either by the increase in quantity and variety, or given the toxicity that may be imposed to aquatic biota. For these reasons studies on the possible effects of these compounds on aquatic organisms are important for understanding their effects on individual species and to assess the risks and possible damage caused by these toxic agents. The present study aimed to evaluate the acute toxicity of the pharmaceutical drugs: diclofenac sodium (anti-inflammatory) and propranolol (antihypertensive), on species Ceriodaphnia silvestrii, Daphnia magna (Crustacea, Cladocera), Hydra viridissima (Cnidaria, Hydrozoa) and Dugesia tigrina (Platyhelminthes, Turbellaria), under laboratory conditions. The results of the acute exposures showed considerable variability in toxicity of the pharmaceutical compounds investigated, and the $\mathrm{EC}_{50}$ and $\mathrm{CL}_{50}$ values ranged from 0.55 to $123.3 \mathrm{mg} \mathrm{L}^{-1}$. It was possible to observe the following ranking of toxicity diclofenac and propranolol between the test organisms: $D$. tigrina $<H$. viridissima $<C$. silvestrii $<D$. magna; and $H$. viridissima $<C$. silvestrii $<D$. magna $<D$. tigrina, respectively. Therefore, based on these results, the species $D$. tigrina was more sensitive to the drug diclofenac, and at the same time had a higher tolerance to propranolol. The results demonstrate that the presence of these drug compounds impose risks associated to both species evaluated.
\end{abstract}

Keywords: diclofenac sodium, propranolol, pharmaceuticals, aquatic biota, acute toxicity. 


\section{Introdução}

Nas últimas décadas, uma das classes de xenobióticos que se encontra em foco na Toxicologia Ambiental corresponde aos compostos farmacêuticos utilizados na medicina humana e veterinária, agricultura e aquicultura (OGGIER et al., 2010). Muitos dos fármacos de uso humano não são totalmente eliminados pelo organismo (HEBERER, 2002), e são frequentemente excretados apenas ligeiramente transformados ou mesmo inalterados através da urina e das fezes (LI \& RANDAK, 2009; NUNES, 2010).

Diversos estudos têm demonstrado a ocorrência de elevados níveis de contaminação por resíduos farmacêuticos em efluentes (VIENO et al., 2006; GÓMEZ et al., 2007; YUAN et al., 2013) de estações de tratamento de águas residuais (ETARs), águas de superfícies tais como rios, lagos, estuários (BENDZ et al., 2005; ROBERTS \& THOMAS, 2006; VULLIET \& CREN-OLIVÉ, 2011), águas subterrâneas (BARNES et al., 2008), oceanos (FANG et al., 2012) e água potável (BENOTTI et al., 2009).

Os compostos farmacêuticos e seus metabólitos normalmente encontrados em ambientes aquáticos incluem antibióticos, anticonvulsionantes, $\beta$ - bloqueadores, antiinflamatórios, antidislipidémicos, antipiréticos, citostáticos, e hormônios (YANG et al., 2008; GANIYAT, 2008). Estes compostos podem atingir o compartimento aquático a partir de várias fontes, entre as quais: a eliminação direta de medicamentos excedentes em domicílios, excreção de seres vivos após o uso terapêutico, lançamento direto de esgotos domésticos, tratados ou não tratados, efluentes de indústrias farmacêuticas e efluentes rurais (YANG et al., 2008; GANIYAT, 2008; LI \& RANDAK, 2009; LAMEIRA, 2012).

Os fármacos são geralmente detectados no meio ambiente numa ordem que varia de $n g \mathrm{~L}^{-1}$ a $\mu \mathrm{g} \mathrm{L}^{-1}$ (SCHRAP et al., 2003), mas em casos específicos, podem atingir valores mais elevados, em $\mathrm{mg} \mathrm{L}^{-1}$; a tendência geral aponta para um aumento nas concentrações destas substâncias no ambiente (OGGIER et al., 2010). Segundo Gomes (2013), os compostos farmacológicos são delineados de forma a exercerem uma atividade biológica específica, ou seja, são moléculas capazes de superar as barreiras fisiológicas, característica importante que deve ser levada em consideração quando se avalia o seu impacto ecotoxicológico. 
Além disso, outras características importantes estão relacionadas à sua lipofilia, uma condição básica para adquirir considerável absorção através das membranas biológicas (CLEMENTE, 2011), baixa biodegradação e por serem consideradas pseudopersistentes (substâncias cuja degradação é igual à sua taxa de entrada para o ambiente) (NUNES et al., 2014). Um outro aspecto a ser levado em consideração é a possibilidade da existência de uma variedade de metabólitos formados e a ocorrência de possíveis interações toxicológicas como efeitos sinérgicos, antagonismo e adição (CLEUVERS, 2003). A soma de todos estes fatores referidos contribui para a importância global de sua persistência no ambiente e por consequência à ocorrência de efeitos potencialmente nocivos em organismos não-alvo, principalmente nos ecossistemas aquáticos.

Em relação aos efeitos específicos ou ao modo de ação dos compostos farmacêuticos para a biota aquática, estes não são ainda muito bem conhecidos e no ambiente natural podem agir de modo diferente. De acordo com Fent et al. (2006), não obstante esta dificuldade, experimentos devem ser orientados e concebidos para cumprir objetivos específicos da indústria farmacêutica, mesmo em vertebrados inferiores e invertebrados, com base na hipótese de semelhança de modos de ação, pois muitos dos mecanismos farmacológicos e receptores estão amplamente conservados.

Apesar da crescente incidência destes compostos nos corpos d' água e da sua periculosidade à biota aquática, não existem leis que estabeleçam limites de concentração para estas substâncias nos ecossistemas aquáticos, porém algumas leis fazem menção à ecotoxicidade, ou seja, relacionam o controle de emissão com a toxicidade permissível aos organismos aquáticos. Assim, potencializa-se a importância do desenvolvimento de estudos ecotoxicológicos. Segundo Ribo (1997) é importante que o efeito tóxico de um poluente seja avaliado para mais de uma espécie sendo estas, de preferência, pertencentes a diferentes níveis tróficos da cadeia alimentar. Deste modo, há um aumento na representatividade ecológica dos dados obtidos. Neste contexto, o presente estudo buscou avaliar a toxicidade aguda dos fármacos: diclofenaco sódico (anti-inflamatório) e propranolol (anti-hipertensivo) para quatro espécies de organismos-teste: Ceriodaphnia silvestrii (Cladocera), Daphnia magna (Cladocera), Hydra viridissima (Cnidaria) e Dugesia tigrina (Platyhelminthes).

O diclofenaco sódico é uma das drogas mais utilizadas dentre os anti-inflamatórios não-esteróides (AINE) e prescrito para aliviar condições que incluem inflamação, 
osteoartrite e artrite reumatoide, atuando como um inibidor da ciclo-oxigenase, e na síntese de DNA através de múltiplos mecanismos (ELRON-GROSS et al., 2008; CHAE et al., 2015). O consumo mundial de diclofenaco sódico é estimado em 940 toneladas por ano, com uma dose diária definida de $100 \mathrm{mg}$ (RADJENOVIC et al., 2007; ZHANG et al., 2008). Aproximadamente $65 \%$ da dose é excretada na urina, principalmente como metabólitos hidroxilados conjugados com glucuronídeos após a circulação enterohepática (ZHANG et al., 2008). Entretanto, a quantidade real de metabólitos nas fezes ainda não está clara (WANG et al., 2014). Além disso, as taxas de eliminação do diclofenaco em estações de tratamento de esgoto são normalmente baixas (cerca de $50 \%$ ), e tanto a biodegradabilidade como a eliminação por adsorção são consideradas ineficazes (revisado por ZHANG et al., 2008; PAL et al., 2010).

Este composto farmacêutico foi considerado como um dos três medicamentos mais frequentemente detectados em ecossistemas aquáticos (SANTOS et al., 2010). O diclofenaco sódico é classificado como de classe IIA, ou "composto potencialmente perigoso" com efeitos adversos relevantes (BESSE \& GARRIC, 2008); e consequentemente, é incluído na lista de substâncias prioritárias pela União Europeia (EUROPEAN COMMISSION, 2012 a,b). A ocorrência deste composto foi reportada em efluentes de ETARs e águas superficiais de até $4,7 \mu \mathrm{g} \mathrm{L} \mathrm{L}^{-1}$ e $1,2 \mu \mathrm{g} \mathrm{L} \mathrm{L}^{-1}$, respectivamente, e até mesmo em águas subterrâneas e de consumo, em concentrações de até $380 \mathrm{ng} \mathrm{L}^{-1}$ e abaixo de $10 \mathrm{ng} \mathrm{L}^{-1}$ (HEBERER, 2002; AGUINACO et al., 2012). O diclofenaco sódico é considerado como um dos fármacos mais relevantes em termos de ecotoxicidade e persistência no meio ambiente, podendo exercer efeitos tóxicos em diferentes organismos aquáticos, tais como bactérias, várias espécies de algas, macrófitas, cladóceros, bivalves de água doce, planárias e vertebrados (Tabela 1).

O propranolol é um $\beta$-bloqueador adrenérgico não seletivo indicado para o tratamento de doenças cardiovasculares humanas, incluindo angina, arritmias, hipertensão e cardio-proteção após infarto do miocárdio (KÜSTER et al., 2010). Os $\beta$ bloqueadores também são usados na medicina veterinária e ilegalmente como doping em muitos esportes (BARBIERI et al., 2012). O composto é completamente absorvido pelo sistema gastrointestinal e é altamente metabolizado pelo fígado formando metabólitos presentes na urina. O principal metabólito é o 4-hidroxipropanolol, sendo que aproximadamente $4 \%$ da dose é encontrada inalterada nas fezes e o seu tempo de meia vida é de aproximadamente 4 horas (MCEVOY, 2003). Este medicamento requer 
atenção especial, visto que, se a relação PEC/PNEC for superior a 1, o limite adotado consensualmente indica potenciais preocupações ambientais (ÅGERSTRAND \& RÜDEN, 2010).

Pelo seu extensivo uso e metabolismo muitas vezes incompletos (KÜSTER et al., 2009), este fármaco tem sido comumente detectado em efluentes de ETARs em concentrações de 30 a 373 ng L ${ }^{-1}$ (BENDZ et al., 2005; ROBERTS \& THOMAS, 2006; ALDER et al., 2010). Ternes (1998) relatou concentrações de propranolol em rios e

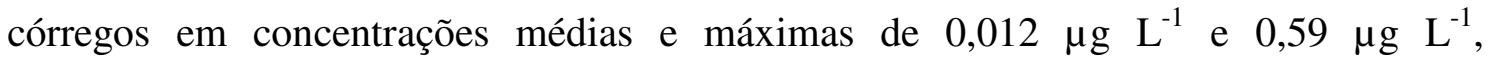
respectivamente.

Dentre os $\beta$-bloqueadores, o propranolol é considerado o mais hidrofóbico e com potencial de bioacumulação (WILDE et al., 2013). Além disso, estudos mostram que este composto pode causar diversos efeitos na biota aquática, tais como na natação, sobrevivência, alterações na reprodução e crescimento, no desenvolvimento embrionário, entre outros. Os potenciais efeitos ecológicos adversos desta substância foram avaliados em diferentes organismos aquáticos, tais como os cladóceros, algas verdes, crustáceos de água doce e vertebrados (Tabela 1). 
Tabela 1. Resumo dos principais endpoints ecotoxicológicos presentes na literatura para diferentes organismos aquáticos expostos aos fármacos: diclofenaco sódico e propranolol.

\begin{tabular}{|c|c|c|}
\hline & ENDPOINTS ECOTOXICOLÓGICOS & REFERÊNCIAS \\
\hline \multicolumn{3}{|l|}{ DICLOFENACO } \\
\hline Pseudokirchneriella subcapitata & $\mathrm{CI}_{50}(72 \mathrm{~h})=16,3 \mathrm{mg} \mathrm{L}^{-1}$ & Ferrari et al. (2004) \\
\hline Vibrio fischeri & $\mathrm{CE}_{50}(15 \mathrm{~min})=27,8 \mathrm{mg} \mathrm{L}^{-1}$ & Schmidt et al. (2011) \\
\hline Desmodesmus subspicatus & $\mathrm{CE}_{50}(72 \mathrm{~h})=71,9 \mathrm{mg} \mathrm{L}^{-1}$ & Cleuvers (2004) \\
\hline Lemna minor & $\mathrm{CI}_{50}(7 \mathrm{~d})=47,6 \mathrm{mg} \mathrm{L}^{-1}$ & Quin et al. (2011) \\
\hline Dunaliella tertiolecta & $\mathrm{CE}_{50}(96 \mathrm{~h})=0,18569 \mathrm{mg} \mathrm{L}^{-1}$ & DeLorenzo \& Fleming (2008) \\
\hline Cyclotella meneghiniana & $\mathrm{CE}_{50}(96 \mathrm{~h})=19,4 \mathrm{mg} \mathrm{L}^{-1}$ & Ferrari et al. (2004) \\
\hline Tetrahymena pyriformis & $\mathrm{CE}_{50}(24 \mathrm{~h})=26,56 \mathrm{mg} \mathrm{L}^{-1}$ & Láng \& Kohidai (2012) \\
\hline Ceriodaphnia dubia & $\mathrm{CE}_{50}(48 \mathrm{~h})=22,7 \mathrm{mg} \mathrm{L}^{-1}$ & Ferrari et al. (2004) \\
\hline Ceriodaphnia silvestrii & $\mathrm{CL}_{50}(48 \mathrm{~h})=25,0 \mathrm{mg} \mathrm{L}^{-1}$ & Machado et al. (2009) \\
\hline Daphnia similis & $\mathrm{CE}_{50}(48 \mathrm{~h})=46,0 \mathrm{mg} \mathrm{L}^{-1}$ & Castro et al. (2014) \\
\hline Daphnia magna & $\mathrm{CE}_{50}(48 \mathrm{~h})=80,10 \mathrm{mg} \mathrm{L}^{-1}$ & Han et al. (2006) \\
\hline Daphnia magna & $\mathrm{CE}_{50}(48 \mathrm{~h})=22,43 \mathrm{mg} \mathrm{L}^{-1}$ & Ferrari et al. (2004) \\
\hline Moina macrocopa & $\mathrm{CE}_{50}(48 \mathrm{~h})=142,67 \mathrm{mg} \mathrm{L}^{-1}$ & Lee et al. (2011) \\
\hline Hydra salmacidis & $\mathrm{CL}_{50}(96 \mathrm{~h})=29,57 \mathrm{mg} \mathrm{L}^{-1}$ & Massaro. (2011) \\
\hline Dugesia japonica & $\mathrm{CL}_{50}(48 \mathrm{~h})=15,8 \mathrm{mg} \mathrm{L}^{-1}$ & Li et al. (2013) \\
\hline Danio rerio & $\mathrm{CE}_{50}(72 \mathrm{~h})=5,3 \mathrm{mg} \mathrm{L}^{-1}$ & Van den Brandhof \& Montforts (2010) \\
\hline \multicolumn{3}{|l|}{ PROPRANOLOL } \\
\hline Vibrio fischeri & $\mathrm{CI}_{50}(30 \mathrm{~min})=61,0 \mathrm{mg} \mathrm{L}^{-1}$ & Ferrari et al. (2004) \\
\hline Spirostomum атbiguит & $\mathrm{CE}_{50}(24 \mathrm{~h})=1,77 \mathrm{mg} \mathrm{L}^{-1}$ & Nałecz-Jawecki et al. (2008) \\
\hline Cyclotella meneghiniana & $\mathrm{CE}_{50}(96 \mathrm{~h})=0,244 \mathrm{mg} \mathrm{L}^{-1}$ & Ferrari et al. (2004) \\
\hline Lemna minor & $\mathrm{CE}_{50}(168 \mathrm{~h})=114 \mathrm{mg} \mathrm{L}^{-1}$ & Cleuvers (2003) \\
\hline Synechococcus leopoliensis & $\mathrm{CE}_{50}(96 \mathrm{~h})=0,668 \mathrm{mg} \mathrm{L}^{-1}$ & Ferrari et al. (2004) \\
\hline Thamnocephalus platyurus & $\mathrm{CL}_{50}(24 \mathrm{~h})=10,31 \mathrm{mg} \mathrm{L}^{-1}$ & Kim et al. (2009a) \\
\hline Brachionus calyciflorus & $\mathrm{CE}_{50}(48 \mathrm{~h})=0,45 \mathrm{mg} \mathrm{L}^{-1}$ & Liu et al. (2009) \\
\hline Ceriodaphnia dubia & $\mathrm{CL}_{50}(48 \mathrm{~h})=1,4 \mathrm{mg} \mathrm{L}^{-1}$ & Fraysse et al. (2005) \\
\hline Ceriodaphnia dubia & $\mathrm{CL}_{50}(48 \mathrm{~h})=1,51 \mathrm{mg} \mathrm{L}^{-1}$ & Ferrari et al. (2004) \\
\hline Daphnia magna & $\mathrm{CL}_{50}(24 \mathrm{~h})=15,87 \mathrm{mg} \mathrm{L}^{-1}$ & Calleja et al. (1994) \\
\hline Daphnia magna & $\mathrm{CE}_{50}(48 \mathrm{~h})=1,60 \mathrm{mg} \mathrm{L}^{-1}$ & Hugget et al. (2002) \\
\hline Streptocephalus proboscideus & $\mathrm{CL}_{50}(48 \mathrm{~h})=1,87 \mathrm{mg} \mathrm{L}^{-1}$ & Calleja et al. (1994) \\
\hline Hyalella azteca & $\mathrm{CL}_{50}(48 \mathrm{~h})=29,8 \mathrm{mg} \mathrm{L}^{-1}$ & Hugget et al. (2002) \\
\hline Oryzias latipes & $\mathrm{CL}_{50}(96 \mathrm{~h})=11,4 \mathrm{mg} \mathrm{L}^{-1}$ & Kim et al. (2009a) \\
\hline Pimephales promelas & $\mathrm{CL}_{50}(48 \mathrm{~h})=1,69 \mathrm{mg} \mathrm{L}^{-1}$ & Stanley et al. (2006) \\
\hline
\end{tabular}

\section{Material e Métodos}

\subsection{Cultivo e manutenção dos organismos-teste}

\subsubsection{Ceriodaphnia silvestrii}

Indivíduos desta espécie foram obtidos a partir de cultivos já estabelecidos no Laboratório de Ecotoxicologia no Departamento de Ecologia e Biologia Evolutiva da Universidade Federal de São Carlos (DEBE/UFSCar), e originalmente isolados do 
reservatório do Broa, Itirapina-SP. As culturas de C. silvestrii foram constituídas com uma densidade inferior a 70 indivíduos por litro mantidas em frascos de vidro de $2 \mathrm{~L}$ com água reconstituída conforme indicado pela Sociedade Americana de Testes e Materiais (ASTM, 2001). Maiores detalhes sobre os procedimentos da preparação da água reconstituída podem ser encontradas em Freitas e Rocha (2011). Os procedimentos de cultivo e manutenção de $C$. silvestrii foram previamente descritos no capítulo 2 deste trabalho.

Todos os bioensaios foram iniciados com neonatos ( $\leq 24$ horas de idade), nascidos entre a terceira e a quinta ninhadas. A saúde e a sensibilidade das culturas foram avaliadas mensalmente por meio de testes de toxicidade aguda com a substância de referência $\mathrm{NaCl}$ (cloreto de sódio) $\left(\mathrm{CE}_{50}(48 \mathrm{~h})\right.$ variando entre 1,14 e 1,28 g L $\left.{ }^{-1}\right)$ (Figura 4, em apêndice A).

\subsubsection{Daphnia magna}

Culturas monoclonais de Daphnia magna (clone A sensu BAIRD et al., 1989) foram mantidas em laboratório por várias gerações em meio ASTM (ASTM, 1980; USEPA, 2002), complementadas com aditivo orgânico (suspensão extraída da alga Ascophyllum nodoso). Os organismos foram mantidos em temperatura de $20 \pm 2{ }^{\circ} \mathrm{C}$ e fotoperíodo de 16 horas (luz): 8 horas (escuro). As culturas foram renovadas regularmente com recém-nascidos a partir da terceira até a quinta ninhada. Os organismos foram alimentados três vezes por semana com suspensão algácea de Pseudokirchneriella subcapitata $\left(3,0 \times 10^{5}\right.$ células $\left.\mathrm{mL}^{-1} \mathrm{dia}^{-1}\right)$, cultivada em meio MBL, sob as mesmas condições de laboratório acima descritas para D. magna (STEIN, 1973). As algas foram recolhidas regularmente, enquanto ainda na fase de crescimento exponencial (5-7 dias de idade) e inoculadas em meio fresco. Todos os experimentos foram iniciados com neonatos $(\leq 24$ de idade), nascidos entre a terceira e quinta ninhadas.

Todos os bioensaios foram iniciados com neonatos ( $\leq 24$ de idade), nascidos entre a terceira e quinta ninhadas. Além disso, mensalmente foram realizados testes de sensibilidade com a substância de referência $\mathrm{K}_{2} \mathrm{Cr}_{2} \mathrm{O}_{7}$ (dicromato de potássio), para que a saúde dos organismos fosse comprovada, conforme recomendado pela OECD (2004), sendo que os valores de $\mathrm{CE}_{50}(48 \mathrm{~h})$ variaram de 0,89 a $1,06 \mathrm{mg} \mathrm{L}^{-1}$ (Figura 5, em apêndice A). Estes testes foram realizados com clones de D. magna mantidas no 
Laboratório de Ecotoxicologia no Departamento de Ecologia e Biologia Evolutiva da Universidade Federal de São Carlos (DEBE/UFSCar).

\subsubsection{Hydra viridissima}

Os indivíduos da espécie Hydra viridissima (Cnidaria) foram coletados em tanques de cultivo da Reserva experimental do Departamento de Ecologia e Biologia evolutiva (DEBE), localizada no campus da Universidade Federal de São Carlos. Os organismos estavam associados às folhas da espécie de macrófita aquática submersa Cabomba aquática e também com as raízes de duas espécies flutuantes: Salvinia sp e Lemna sp. Os espécimes pertencentes às espécies de macrófitas citadas anteriormente foram armazenados em baldes de plástico atóxico com a água do tanque e levadas para o laboratório. No laboratório, as macrófitas foram colocadas em bandejas grandes de plástico atóxico contendo água reconstituída (ASTM, 2001; ABNT, 2004). Em seguida, com a utilização de uma pisseta (também contendo água reconstituída), as macrófitas foram lavadas, dissociando-se assim os organismos. As hidras foram, em seguida, individualmente recolhidas com o auxílio de pipetas Pasteur e transferidas para béqueres de vidro.

As populações de $H$. viridissima cresceram e foram mantidas em béqueres de vidro de $200 \mathrm{~mL}$ contendo água reconstituída conforme indicado pela Sociedade Americana de Testes e Materiais (ASTM, 2001). Os cultivos foram mantidos sob condições controladas a $25 \pm 1{ }^{\circ} \mathrm{C}$ e fotoperíodo de $12 \mathrm{~h}$ (luz): $12 \mathrm{~h}$ (escuro), com densidades abaixo de 100 indivíduos por unidade de cultivo $(200 \mathrm{~mL})$. Como alimento para as hidras foram utilizadas os neonatos de Ceriodaphnia silvestrii, fornecidos três vezes por semana, na densidade de 3 a 4 neonatas por hidra (MASSARO, 2011). A troca de água e a limpeza do cultivo foram realizadas três vezes por semana. Antes de serem utilizados nos testes de toxicidade aguda, os indivíduos permaneceram em aclimatação durante um intervalo de tempo de no mínimo sete dias. A sensibilidade dos organismos foi avaliada mensalmente por meio de testes de toxicidade aguda com a substância de referência dicromato de potássio $\left(\mathrm{K}_{2} \mathrm{Cr}_{2} \mathrm{O}_{7}\right)$, sendo que a $\mathrm{CE}_{50}(96 \mathrm{~h})$ e a $\mathrm{CL}_{50}(96 \mathrm{~h})$ variaram entre 1,58-2,55 $\mathrm{mg} \mathrm{L}^{-1}$ e 4,25-6,27 $\mathrm{mg} \mathrm{L}^{-1}$ ), respectivamente (Figuras $6 \mathrm{e} \mathrm{7,} \mathrm{em}$ apêndice A). 


\subsubsection{Dugesia tigrina}

Os espécimes utilizados no presente estudo pertencem a uma população de Dugesia tigrina (Platyhelminthes, Turbellaria, Tricladida) obtidos a partir de cultivos já estabelecidos em laboratório. As planárias foram coletadas em tanques de cultivo da Reserva experimental do Departamento de Ecologia e Biologia evolutiva (DEBE), localizada no campus da Universidade Federal de São Carlos. Os indivíduos estavam associados com macrófitas ou galhos em decomposição e folhas oriundas das árvores circundantes. Os espécimes de macrófitas foram amostrados, armazenados em baldes de plástico atóxicos com a água local e levados em seguida para o laboratório. Em laboratório, o material foi separado em bandejas de plástico atóxico para a coleta dos organismos com o auxílio de pipetas de Pasteur (de polietileno, com boca larga) para serem transferidos para béqueres. Os cultivos de D. tigrina foram iniciados apenas com adultos ou indivíduos juvenis grandes e mantidos em béqueres de vidro (2 L), contendo água reconstituída (ASTM, 2001; ABNT, 2004). Os organismos foram mantidos em temperatura de $25 \pm 1{ }^{\circ} \mathrm{C}$, com um fotoperíodo de $12 \mathrm{~h}$ (luz): $12 \mathrm{~h}$ (escuro), e densidade populacional inferior ou igual a 40 indivíduos em béqueres de $2 \mathrm{~L}$. Como alimento para cada planária foi fornecida duas vezes por semana cerca de duas larvas da espécie Chironomus sancticaroli (7-8 dias de idade - IV instar). Os procedimentos para cultivo e manutenção de $C$. sancticaroli seguiram os métodos propostos por Fonseca e Rocha (2004). Após 12h as larvas que não foram consumidas pelas planárias foram removidas, os béqueres foram limpos e a água reconstituída foi trocada. Aproximadamente dois a quatro dias após a limpeza, os casulos foram separados e retirados dos béqueres (comumente fixados na parede ou no fundo dos béqueres) com o auxílio de pipetas de Pasteur. Posteriormente, os casulos foram transferidos para béqueres de vidro de 250 $\mathrm{mL}$, contendo água reconstituída e cultivados sem troca de água e limpeza, até a eclosão destes. Após aproximadamente 10 dias, a maior parte das planárias recém-nascidas já não se encontravam no interior dos casulos, sendo que quaisquer resíduos presentes nos recipientes foram removidos e o alimento para os organismos foi fornecido. Com o intuito de facilitar a ingestão das larvas de quironomídeos pelas planárias recémnascidas e evitar que alguns indivíduos ficassem sem se alimentar, como observado quando larvas grandes (IV instar) eram fornecidas com idade de cinco dias (II instar) para as pequenas planárias (uma larva por indivíduo). Na falta de larvas deste tamanho, 
larvas maiores eram colocadas em pequenos recipientes de plástico atóxico sem água e deixadas no freezer por pelo menos 20 minutos, visando a paralisia parcial ou morte das larvas para que assim, as planárias pudessem se alimentar (RAMOS, 2013). Para avaliar a saúde e as condições fisiológicas desta espécie, foram realizados testes de sensibilidade mensalmente com a substância de referência dicromato de potássio $\left(\mathrm{K}_{2} \mathrm{Cr}_{2} \mathrm{O}_{7}\right)$, conforme recomendado pela OECD (2004). Os valores de $\mathrm{CL}_{50}$ (96h) variaram de 2,9 a 4,0 mg L $\mathrm{m}^{-1}$, conforme demonstrado por Ramos (2013), pois os cultivos foram mantidos conjuntamente com o estudo citado. Ilustrações mostrando as condições de cultivo e manutenção de organismos de D. tigrina são apresentados na Figura 2, A a $\mathrm{H}$, em apêndice $\mathrm{C}$.

\subsection{Fármacos}

Os medicamentos: diclofenaco de sódio (CAS: 15307-79-6) e propranolol (CAS: 318-98-9) foram adquiridos da Sigma Aldrich, com pureza $\geq 99 \%$.

\subsection{Testes de toxicidade aguda}

\subsubsection{Ceriodaphnia silvestrii}

Os bioensaios de toxicidade aguda com $C$. silvestrii foram realizados de acordo com as diretrizes da Organização para a Cooperação Econômica e Desenvolvimento (OECD, 2004), sob as mesmas condições de fotoperíodo e temperatura descritos para os procedimentos de cultivo. As concentrações nominais finais testadas foram: 0,00; 3,12; 6,$25 ; 12,5 ; 25 ; 50$ e $100 \mathrm{mg} \mathrm{L}^{-1}$ para o diclofenaco de sódio; e 0,00; 0,62; 1,25; 2,5; 5 e $10 \mathrm{mg} \mathrm{L}^{-1}$ para o propranolol. Os procedimentos para a realização dos testes de toxicidade aguda com $C$. silvestrii foram previamente descritos no capítulo 2 desta tese.

Os parâmetros físicos e químicos dos testes foram medidos no início e no final de cada teste, com a necessidade destes resultados estarem dentro dos níveis aceitáveis do protocolo seguido (OECD, 2004) ( $\mathrm{pH}$ : 7,2-7,6; temperatura de $25^{\circ} \mathrm{C} \pm 1,0^{\circ} \mathrm{C}$; condutividade elétrica cerca de $160 \mu \mathrm{S} \mathrm{cm}^{-1}$; e dureza total variando entre 40 e $48 \mathrm{mg}$ $\mathrm{L}^{-1}$ de $\mathrm{CaCO}_{3}$ ). Os testes de toxicidade aguda foram conduzidos para cada fármaco, e 
após o tempo de exposição de 48 horas, os organismos foram observados e contados sob microscópio estereoscópico.

\subsubsection{Daphnia magna}

Bioensaios de toxicidade aguda foram realizados para avaliar a toxicidade dos fármacos: diclofenaco sódico e propranolol ao cladócero Daphnia magna. Os testes de toxicidade aguda foram realizados de acordo com protocolos-padrão (ASTM, 1997; ISO, 1996; OECD, 2000), sob as mesmas condições de laboratório descritas para a manutenção das culturas.

Os ensaios agudos foram conduzidos em tubos de vidro contendo $10 \mathrm{~mL}$ de solução-teste e $10 \mathrm{~mL}$ de meio de ASTM (controle negativo). Foram utilizados vinte animais $(\leq 24 \mathrm{~h}$ de idade), divididos em quatro grupos de cinco organismos por concentração. Para todos os testes de toxicidade aguda, uma gama de 6 a 7 concentrações foram obtidas por diluição dos diferentes compostos farmacêuticos, com o meio de cultivo. Bioensaios foram realizados para definir diluições apropriadas para obtenção dos valores de $\mathrm{CE}_{50}$ com melhores intervalos de confiança. As concentrações nominais finais utilizadas nos testes agudos foram: 0,$0 ; 52,0 ; 62,4 ; 74,9 ; 89,9 ; 107,8$; 129,4 e 155,3 $\mathrm{mg} \mathrm{L}^{-1}$ para o diclofenaco de sódio e 0,$0 ; 4,0 ; 4,8 ; 5,8 ; 6,9 ; 8,3 ; 10,0$ e $11,9 \mathrm{mg} \mathrm{L}^{-1}$ para o propranolol, respectivamente. Os organismos-teste não foram alimentados durante o experimento, e depois de 48 horas de exposição foram observados e registrados o número total de organismos imóveis/mortos, em cada réplica, por concentração analisada.

\subsubsection{Hydra viridissima}

Os testes de toxicidade foram realizados em placas de cultivo celular $(12 \times 8 \mathrm{~cm})$ com 12 orifícios, cobertas com tampa transparente. As concentrações nominais testadas foram: 0,$0 ; 10 ; 20 ; 30 ; 40 ; 50$ e $60 \mathrm{mg} \mathrm{L}^{-1}$ de diclofenaco sódico e 0,$0 ; 0,5 ; 0,75 ; 1,0$; 1,25 e $1,5 \mathrm{mg} \mathrm{L}^{-1}$ de propranolol. As concentrações foram preparadas a partir de uma solução estoque (500 $\left.\mathrm{mg} \mathrm{L}^{-1}\right)$, utilizando-se água de cultivo como água de diluição (ASTM, 2001). Foram feitas quatro repetições, tanto para o controle (somente água reconstituída), como para cada diluição fármaco, sendo que cada orifício da placa representou uma repetição. Em todos os testes de toxicidade foram utilizados quatro 
indivíduos adultos com aproximadamente 2,5 milímetros de comprimento, mantidos em jejum por $24 \mathrm{~h}$, e sem a presença de brotos conforme sugerido por Massaro (2006). Foi adicionado um volume de $4 \mathrm{~mL}$ a cada orifício, assim como em placas de Petri de $35 \mathrm{x}$ $10 \mathrm{~mm}$ (uma para cada concentração dos fármacos testados), as quais foram utilizadas para a lavagem prévia dos organismos, antes da montagem dos experimentos (TROTTIER et al., 1997). Os bioensaios foram mantidos sob as mesmas condições de temperatura, conforme descritas anteriormente. Os organismos expostos não foram alimentados no decorrer dos experimentos e foram mantidos por $96 \mathrm{~h}$ sob-regime de escuro, como recomendado pela OECD (2004).

Durante este período os organismos foram observados diariamente (a cada 24 horas) sob microscópio óptico para o registro das mudanças morfológicas. Cada organismo foi classificado de acordo com as alterações morfológicas no seu corpo e tentáculos (por exemplo, tentáculos com bulbo, corpo encurtado, fase de tulipa, desintegrado), utilizando microscópio estereoscópico. As modificações graduais na morfologia das hidras foram registradas e pontuadas em uma escala de 10 (tentáculos alongados e corpo normal) a 0 (desintegrado), conforme elaborada por Wilby (1988) e adaptada neste estudo para a espécie H. viridissima (Figura 1). Pontuações variando entre 10 e 6 foram consideradas sub-letais e reversíveis, enquanto na fase de tulipa (ou qualquer pontuação inferior a 5) as alterações foram consideradas irreversíveis e utilizadas como parâmetro para a letalidade (BLAISE \& KUSUI, 1997). De acordo com o número total de indivíduos afetados nos níveis sub-letais e letais, foi possível calcular os valores de $\mathrm{CE}_{50}$ e $\mathrm{CL}_{50}$ a cada 24 horas de exposição, respectivamente. Os parâmetros físicos e químicos das soluções-teste ( $\mathrm{pH}$, condutividade elétrica, temperatura e dureza) foram medidos no início e no final de cada teste, sendo apresentados nas Tabelas 8 a 15 e 29 a 38, em apêndice A. 
Morfologia de Hydra sp- Avaliação de toxicidade para a fase de pólipo

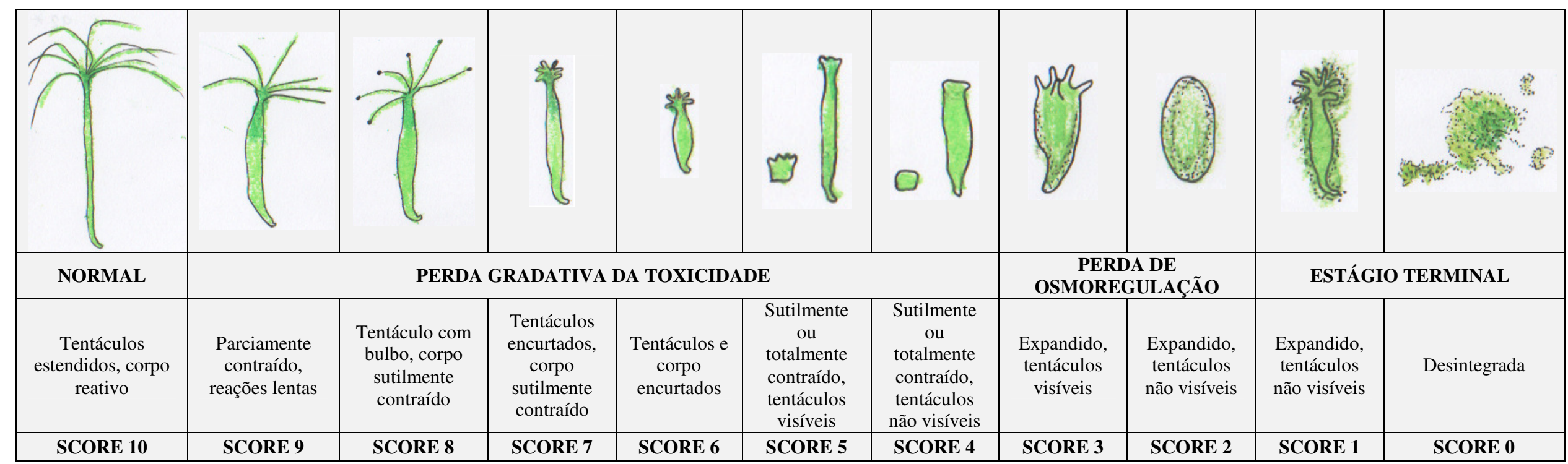

Figura 1. Resposta das hidras à toxicidade com base nas alterações morfológicas de acordo com a descrição e pontuação (score) $(0$ - 10) elaborada por Wilby (1988) e adaptada neste estudo para o organismo-teste Hydra viridissima. 


\subsubsection{Dugesia tigrina}

Os testes de toxicidade aguda definitivos com os fármacos diclofenaco sódico e propranolol foram realizados com as seguintes concentrações nominais: 0,0;1,0;2,0; 4,$0 ; 8,0 ; 16,0$ e $32,0 \mathrm{mg} \mathrm{L}^{-1}$ e 0,$0 ; 0,5 ; 4,5 ; 8,5 ; 12,5 ; 16,5 ; 20,5$ e $24,5 \mathrm{mg} \mathrm{L}^{-1}$. As concentrações foram estabelecidas por meio da realização de testes de toxicidade preliminares. Em todos os testes, organismos com no máximo de sete dias de idade (e 48h sem alimentação) foram utilizados em cada tratamento, com quatro repetições cada. A água utilizada para preparar as diluições e o tratamento controle foi a mesma utilizada como meio nos cultivos, tal como descrito anteriormente. Foram utilizados béqueres de vidro com capacidade de $80 \mathrm{~mL}$, completados com $50 \mathrm{~mL}$ de cada solução-teste. Seis organismos foram adicionados em cada recipiente replicativo. Antecipadamente à preparação dos bioensaios, as planárias foram transferidas para placas de Petri, a fim de serem observadas sob o microscópio estereoscópico, visando averiguar e remover, eventualmente, indivíduos que apresentassem algum tipo de lesão ou dano (possivelmente causado por predação ou ataque dentro dos casulos por outros indivíduos da mesma ninhada ou por deformidade natural). Os organismos foram mantidos sob as mesmas condições de temperatura, como descrito anteriormente para a manutenção das culturas.

Os bioensaios tiveram a duração de 96h, sendo que após diferentes períodos de exposição os organismos vivos remanescentes foram contados nos intervalos de tempo de 24, 48, 72 e 96 horas. Os organismos foram mantidos no escuro e sem alimentação, conforme recomendado pela OECD (2004). A dureza total, a condutividade elétrica, a temperatura e o pH foram avaliados no início e no final de cada ensaio, em todos os tratamentos (Tabelas 7 e 28, em apêndice A).

\subsection{Análises estatísticas}

Os valores de $\mathrm{CE}_{50}$ e $\mathrm{CL}_{50}$ e seus respectivos limites de confiança de $95 \%$ para o número de organismos imóveis, mortos ou que apresentassem algum tipo de modificação morfológica para cada fármaco correspondente foram determinadas por análise de regressão não-linear, ajustando-se uma equação logística aos dados 
utilizando-se a técnica dos quadrados mínimos. O Software Statistica 11.0 foi utilizado para esta finalidade.

As curvas de distribuição das sensibilidades das espécies (SSD) foram construídas com base nos dados de toxicidade aguda a partir deste estudo, e também de dados reportados na literatura. Para isso, foi utilizado o programa ETX 2,0 (VANV LAARDINGEN et al., 2004). Este programa também inclui o teste de AndersonDarling para aderência do ajuste (goodness of fit) de log-normalidade. Valores de HC5 (concentração perigosa para $5 \%$ das espécies analisadas, ou do inglês hazardous concentration) foram calculados usando interpolação gráfica.

\section{Resultados}

As faixas de valores obtidos para os parâmetros físicos e químicos determinados durante as exposições agudas com os fármacos estudados utilizando as espécies: $C$. silvestrii, D. magna, $H$. viridissima e $D$. tigrina se encontraram dentro ou próximos dos valores recomendados pela $\operatorname{OECD}(2004,2008)$. Os valores de $\mathrm{pH}$ das soluções -teste encontraram-se dentro da faixa de 7,01-8,34 e não variaram mais do que 2,0 unidades. A condutividade elétrica variou $120,9-186,7 \mu \mathrm{S} \mathrm{cm}^{-1}$. A dureza da água variou entre 40$48 \mathrm{mg} \mathrm{L}^{-1}$ de $\mathrm{CaCO}_{3}$. A temperatura variou entre $20,4-27,9^{\circ} \mathrm{C}$. Ao final dos testes, os valores de imobilidade e mortalidade para o controle não foram superiores a 10\%, como recomendado pelas diretrizes da OECD (Tabelas 1 a 15, e de 22 a 38, em apêndice A).

Na Tabela 2, estão representados os resultados obtidos nos testes de toxicidade aguda, indicando os valores médios calculados de $\mathrm{CE}_{50}$ (48h) para as espécies de Cladocera, $\mathrm{CE}_{50}$ e $\mathrm{CL}_{50}$ (96h) para a espécie de Cnidaria $H$. viridissima e de $\mathrm{CL}_{50}$ (96h) para a espécie D. tigrina, e os seus respectivos intervalos de confiança (IC 95\%) para os dois compostos farmacêuticos analisados. Os valores de $\mathrm{CE}_{50}(96 \mathrm{~h})$ e $\mathrm{CL}_{50}$ (96h) para a espécie H. viridissima variaram de 24,4 a $36,93 \mathrm{mg} \mathrm{L}^{-1}$ e 39,54 a $52,02 \mathrm{mg} \mathrm{L}^{-1}$ (diclofenaco sódico), e de 0,41 a $0,65 \mathrm{mg} \mathrm{L}^{-1}$ e 0,78 a $1,15 \mathrm{mg} \mathrm{L}^{-1}$ (propranolol), respectivamente. Observou-se uma diminuição na maioria dos valores de $\mathrm{CE}_{50}$ e $\mathrm{CL}_{50}$ ao longo dos experimentos (24 a 96h), indicando um aumento da toxicidade dos fármacos estudados para as espécies $H$. viridissima e $D$. tigrina em função do tempo de exposição (Figuras 8 a 11, em apêndice A). 
De acordo com a Diretiva 93/67/EEC da União Européia (CEC, 1996 apud BLAISE et al., 2006), a toxicidade dos fármacos pode ser classificada baseando-se em seus valores de $\mathrm{CE}_{50}, \mathrm{CL}_{50}$ e/ou $\mathrm{CI}_{50}$ : valores menores que $0,1 \mathrm{mg} \mathrm{L}^{-1}$ (extremamente tóxico aos organismos aquáticos), entre 0,1 e 1,0 $\mathrm{mg} \mathrm{L}^{-1}$ (muito tóxico), entre 1,0 e 10,0 $\mathrm{mg} \mathrm{L}^{-1}$ (tóxico), entre 10,0 e $100,0 \mathrm{mg} \mathrm{L}^{-1}$ (nocivo) e acima de $100,0 \mathrm{mg} \mathrm{L}^{-1}$ (não tóxico). Assim, pode-se observar que o diclofenaco sódico foi considerado não tóxico ao cladócero D. magna $\left(\mathrm{CE}_{50}=123,3 \mathrm{mg} \mathrm{L}^{-1}\right)$, e nocivo às espécies D. tigrina $\left(\mathrm{CL}_{50}=17,9\right.$ $\left.\mathrm{mg} \mathrm{L}^{-1}\right)$, C. silvestrii $\left(\mathrm{CE}_{50}=37,91 \mathrm{mg} \mathrm{L}^{-1}\right)$ e H. viridissima $\left(\mathrm{CE}_{50}=31,81 \mathrm{mg} \mathrm{L}^{-1}\right.$ e $\mathrm{CL}$ $=43,59 \mathrm{mg} \mathrm{L}^{-1}$ ). Já o fármaco propranolol mostrou-se muito tóxico à espécie $H$. viridissima $\left(\mathrm{CE}_{50}=0,55 \mathrm{mg} \mathrm{L}^{-1} \mathrm{e} \mathrm{CL}=0,93 \mathrm{mg} \mathrm{L}^{-1}\right)$, tóxico às espécies de Cladocera $C$. silvestrii $\left(\mathrm{CE}_{50}=3,17 \mathrm{mg} \mathrm{L}^{-1}\right)$ e $D$. magna $\left(\mathrm{CE}_{50}=5,531 \mathrm{mg} \mathrm{L}^{-1}\right)$ e nocivo à espécie $D$. tigrina $\left(\mathrm{CE}_{50}=10,86 \mathrm{mg} \mathrm{L}^{-1}\right)$.

Foi possível observar uma alta variabilidade entre as espécies, com a seguinte ordenação de toxicidade para o diclofenaco sódico e o propranolol (em termos de valores de $\mathrm{CE}_{50}$ e $\mathrm{CL}_{50}$, da mais sensível para a mais tolerante): D. tigrina $<H$. viridissima $<$ C. silvestrii $<D$. magna; e $H$. viridissima $<$ C. silvestrii $<D$. magna $<D$. tigrina, respectivamente. Portanto, a espécie D. tigrina mostrou maior sensibilidade ao composto diclofenaco sódico, e ao mesmo tempo uma maior tolerância ao propranolol.

Tabela 2. Resumo dos valores de $\mathrm{CE}_{50} / \mathrm{CL}_{50}\left(\mathrm{mg} \mathrm{L}^{-1}\right)$ e seus respectivos intervalos de confiança de $95 \%$ obtidos para as diferentes espécies expostas aos fármacos diclofenaco sódico e propranolol.

$\mathrm{CE}_{50} / \mathrm{CL}_{50}\left(\mathrm{mg} \mathrm{L}^{-1}\right)(\mathrm{IC}-95 \%)$

Espécies Diclofenaco sódico

(anti-inflamatório)

\section{Propranolol}

(anti-hipertensivo)
Ceriodaphnia silvestrii (Cladocera)
$37,91 \mathrm{mg} \mathrm{L}^{-1}\left(34,5-42,0 \mathrm{mg} \mathrm{L}^{-1}\right)$
$3,17 \mathrm{mg} \mathrm{L}^{-1}\left(2,90-3,5 \mathrm{mg} \mathrm{L}^{-1}\right)$
Daphnia magna (Cladocera)
$123,3 \mathrm{mg} \mathrm{L}^{-1}\left(117,0-131,0 \mathrm{mg} \mathrm{L}^{-1}\right)$
$5,531 \mathrm{mg} \mathrm{L}^{-1}\left(5,21-5,88 \mathrm{mg} \mathrm{L}^{-1}\right)$
$31,81 \mathrm{mg} \mathrm{L}^{-1}\left(23,88-39,73 \mathrm{mg} \mathrm{L}^{-1}\right)$
$0,55 \mathrm{mg} \mathrm{L}^{-1}\left(0,37-0,72 \mathrm{mg} \mathrm{L}^{-1}\right)$
Hydra viridissima (Hydrozoa)
$43,59 \mathrm{mg} \mathrm{L}^{-1}\left(34,55-52,63 \mathrm{mg} \mathrm{L}^{-1}\right)$
$0,93 \mathrm{mg} \mathrm{L}^{-1}\left(0,70-1,16 \mathrm{mg} \mathrm{L}^{-1}\right)$
Dugesia tigrina (Turbellaria)
$17,9 \mathrm{mg} \mathrm{L}^{-1}\left(20,56-24,56 \mathrm{mg} \mathrm{L}^{-1}\right)$
$10,86 \mathrm{mg} \mathrm{L}^{-1}\left(12,01-13,17 \mathrm{mg} \mathrm{L}^{-1}\right)$

Os valores dos diferentes endpoints ecotoxicológicos $\left(\mathrm{CE}_{50}, \mathrm{CL}_{50}\right.$ e $\left.\mathrm{CI}_{50}\right)$ obtidos na literatura também apresentaram variabilidade (Tabela 1). A sensibilidade relativa de 
espécies aquáticas para os dois compostos estudados a partir de dados da literatura e do presente estudo, é apresentada nas curvas de SSD (Figuras 2 e 3). Notou-se que dentre as 12 espécies analisadas, a espécie mais sensível e a mais tolerante para a exposição do diclofenaco sódico foram: o peixe Danio rerio e o cladócero Daphnia magna, respectivamente (Figura 2), e para o propranolol foram as espécies de Rotifera Brachionus calyciflorus e a alga Lemna minor (Figura 3). Valores de HC5 (concentração perigosa para $5 \%$ das espécies analisadas) foram de $5,50 \mathrm{mg} \mathrm{L}^{-1}$ para o diclofenaco sódico (CI-95\%: 2,22-9,48 $\mathrm{mg} \mathrm{L}^{-1}$ ) e $0,22 \mathrm{mg} \mathrm{L}^{-1}$ para o propranolol (CI95\%: 0,04-0,58 $\mathrm{mg} \mathrm{L}^{-1}$ ), respectivamente.

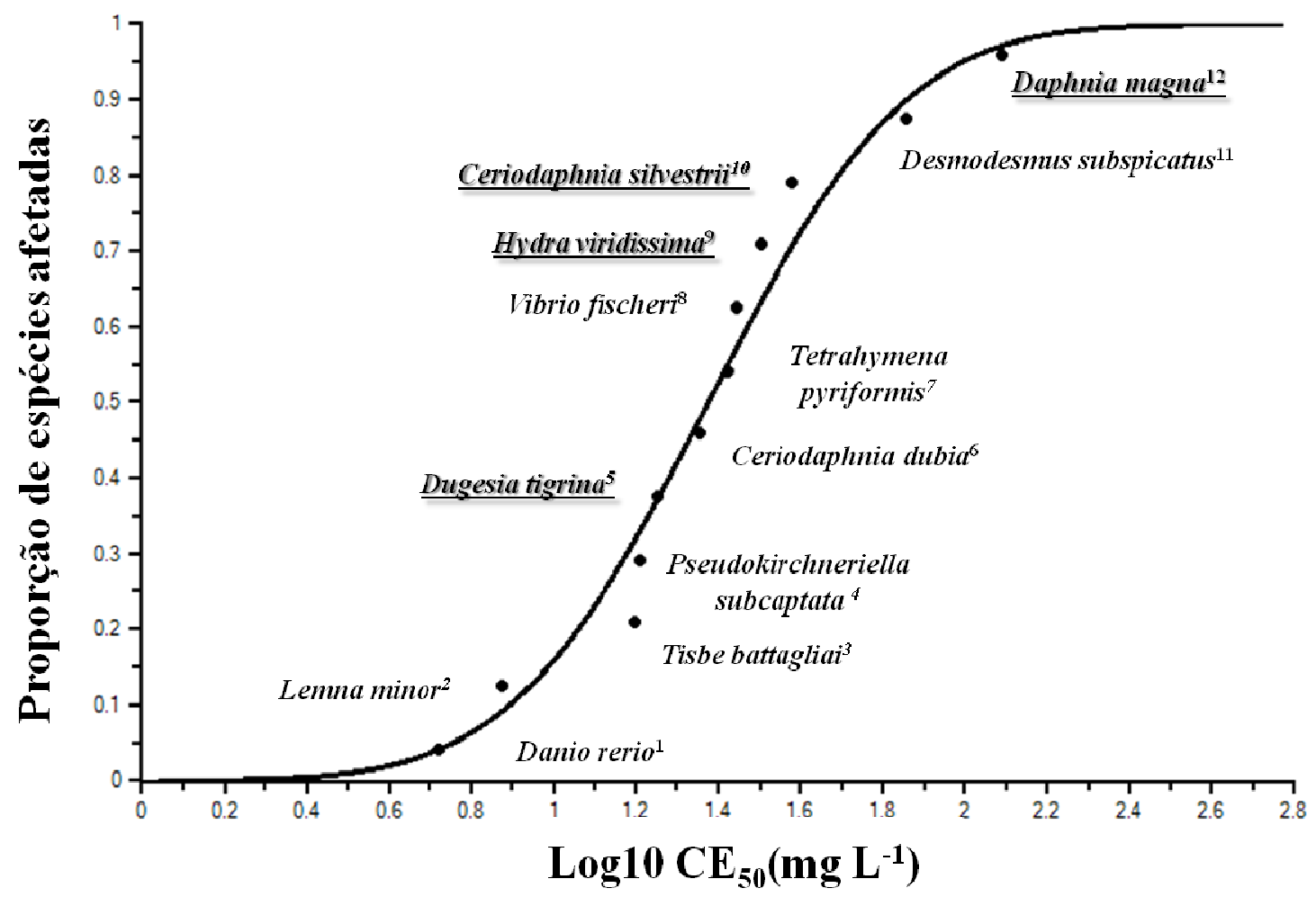

Figura 2. Distribuição das sensibilidades das espécies (SSD) de organismos de diferentes grupos taxonômicos, com base nos valores de $\mathrm{CE}_{50}$ e $\mathrm{CL}_{50}\left(\mathrm{mg} \mathrm{L}^{-1}\right)$ para o fármaco diclofenaco sódico. Fonte: (1) Danio rerio, van Brandhof \& Montforts (2010); (2) Lemna minor, Cleuvers (2003); (3) Tisbe battagliai, Schmidt et al. (2011); (4) Pseudokirchneriella subcapitata, Ferrari et al. (2004); (5) Dugesia tigrina, presente estudo; (6) Ceriodaphnia dubia, Ferrari et al. (2004); (7) Tetrahymena pyriformis, Láng \& Kohidai (2012); (8) Vibrio fischeri, Schmidt et al. (2011); (9) Hydra viridissima, presente estudo; (10) Ceriodaphnia silvestrii, presente estudo; (11) Desmodesmus subspicatus, Cleuvers (2004); (12) Daphnia magna, presente estudo. Os dados do presente estudo estão destacados em sublinhado e sombreado. 


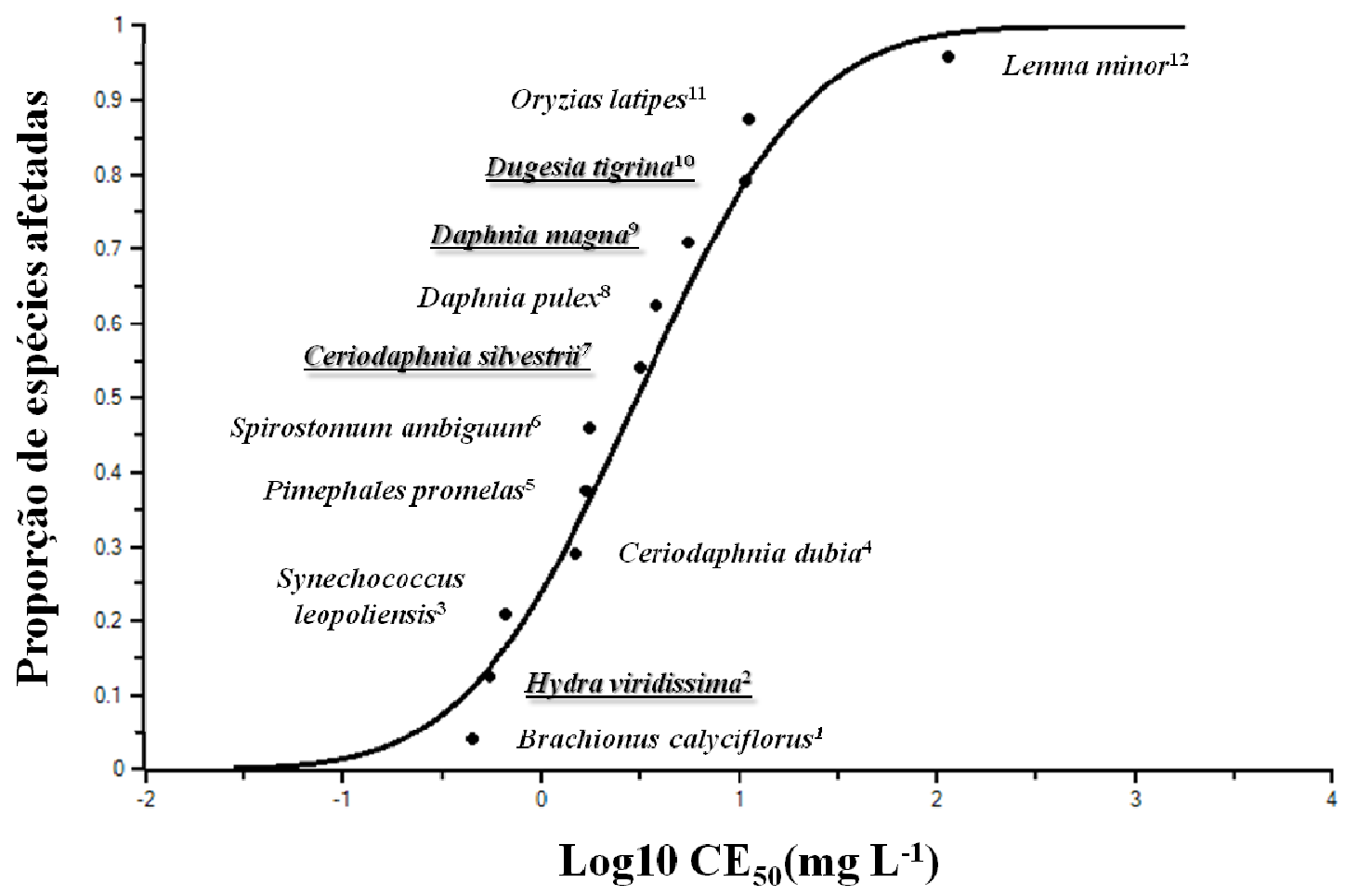

Figura 3. Distribuição das sensibilidades das espécies (SSD) de organismos de diferentes grupos taxonômicos, com base nos valores de $\mathrm{CE}_{50} \mathrm{e} \mathrm{CL}_{50}\left(\mathrm{mg} \mathrm{L}^{-1}\right)$ para o fármaco propranolol. Fonte: (1) Brachionus calyciflorus, Liu et al. (2009); (2) Hydra viridissima, presente estudo; (3) Synechococcus leopoliensis, Ferrari et al. (2004); (4) Ceriodaphnia dubia, Ferrari et al. (2004); (5) Pimephales promelas, Stanley et al. (2006); (6) Spirostomum ambiguum, Nałecz-Jawecki et al. (2008); (7) Ceriodaphnia silvestrii, presente estudo; (8) Daphnia pulex, Lilius et al. (1995); (9) Daphnia magna, presente estudo; (10) Dugesia tigrina, presente estudo; (11) Oryzias latipes, Kim et al. (2009a); (12) Lemna minor, Cleuvers (2003). Os dados do presente estudo estão destacados em sublinhado e sombreado.

\section{Discussão}

A Tabela 3 mostra o potencial tóxico dos fármacos diclofenaco sódico e propranolol para provocar efeitos tóxicos em todos os organismos testados. A partir de uma análise preliminar dos dados obtidos, é possível verificar que o diclofenaco de sódio foi mais tóxico para a espécie $D$. tigrina, que por sua vez, estes resultados foram contrários aos obtidos para o outro composto analisado. As duas espécies de crustáceos (C. silvestrii e D. magna) apresentaram valores intermediários a altos para ambas substâncias. Este conjunto de resultados são intrinsecamente relevantes porque estes organismos correspondem aos consumidores primários (crustáceos de água doce) que 
ocupam uma posição intermediária na cadeia alimentar e que ainda são conhecidos por sua sensibilidade a vários compostos tóxicos. Portanto, no nosso estudo as espécies de Cladocera apresentaram maior tolerância à exposição do composto diclofenaco sódico em relação a organismos mais complexos e que ocupam um nível trófico superior, como a espécie Hydra viridissima e Dugesia tigrina. Deste modo, nenhum efeito significativo sobre os consumidores primários pode ser atribuído ao diclofenaco sódico, uma vez que nenhum dos crustáceos apresentou baixos níveis deste composto farmacêutico. Entretanto, e apesar da ocorrência de efeitos agudos em todos os organismos-teste analisados, deve-se ressaltar que os níveis dos dois fármacos necessários para provocarem tais efeitos são várias ordens de magnitude superiores às concentrações já documentadas no compartimento aquático. Esta é uma consideração importante em termos ecológicos, uma vez que a exposição a estes compostos isoladamente provavelmente não resultará em efeitos agudos deletérios. Segundo Nunes et al. (2014), outros tipos de efeitos podem ocorrer em concentrações menores do que os níveis que induzem a letalidade ou retardo no crescimento, mas podem comprometer várias outras funções importantes nos organismos-teste. Este fato pode ser observado nos estudos de Rocco et al. (2010) e Schmidt et al. (2011) que verificaram que o fármaco diclofenaco sódico induziu danos no DNA do mexilhão marinho Mytilus spp e no peixe $D$. rerio, em concentrações a partir de ng $\mathrm{L}^{-1}$. Além disso, Saravanan et al. (2011) concluiu que em concentrações inferiores deste anti-inflamatório $\left(1,10\right.$ e $\left.100 \mu \mathrm{g} \mathrm{L}^{-1}\right)$ às que utilizadas no presente estudo, tiveram uma grande influência nos perfis hematológicos, bioquímicos e enzimológicos da espécie de peixe Cyprinus carpio. Outro estudo importante é o de Hugget et al. (2002), os quais demostraram que a exposição ao propranolol foi responsável por uma redução no número total de ovos produzidos e viáveis de Oryias latipes em concentrações que são reportadas no ambiente.

A Tabela 1 mostra os resultados obtidos da literatura sobre a toxicidade aguda dos fármacos diclofenaco sódico e propranolol para várias espécies aquáticas, incluindo bactérias, algas unicelulares, cnidários, platelmintos, crustáceos (água doce e salgada) e peixes. É importante enfatizar a multiplicidade dos diferentes valores de toxicidade reportados (Figuras 2 e 3); os valores variaram de 5,3 a 123,3 $\mathrm{mg} \mathrm{L}^{-1}$ para o diclofenaco sódico e 0,45 a $114,0 \mathrm{mg} \mathrm{L}^{-1}$ para o propranolol. Além disso, grandes variações podem ser observadas nos estudos que utilizam o mesmo organismo-teste, tais como aqueles que avaliaram a toxicidade do diclofenaco sódico e propranolol para D.magna (Tabela 
1). Apesar desta espécie ser um organismo-teste padronizado, os testes de toxicidade aguda (valores de $\mathrm{CE}_{50-48 \mathrm{~h}}$ ) resultaram em valores distintos, que variaram de 22,43$80,10 \mathrm{mg} \mathrm{L}^{-1}$ (diclofenaco sódico) e de 1,60-15,87 $\mathrm{mg} \mathrm{L}^{-1}$ (propranolol). Porém, comparando-se nossos resultados com o estudo de Massaro (2011) sobre a espécie $H$. viridissima em exposição ao diclofenaco sódico, os valores de $\mathrm{CE}_{50}(96 \mathrm{~h})(31,81-37,42$ $\left.\mathrm{mg} \mathrm{L}^{-1}\right)$ e $\mathrm{CL}_{50}$ (96h) $\left(43,59-49,30 \mathrm{mg} \mathrm{L}^{-1}\right)$ apresentaram pouca variação.

A toxicidade destes compostos também difere entre organismos com alguma similaridade filogenética (Tabela 1 e Figuras 2 e 3). Isso foi observado também comparando-se os valores de $\mathrm{CL}_{50}$ (96h) de diclofenaco sódico para os cnidários $H$. salmacidis (29,57 $\mathrm{mg} \mathrm{L}^{-1}$ ) no estudo de Massaro (2011) e H.viridissima (43,59 $\mathrm{mg} \mathrm{L}^{-1}$ ). Similarmente a estes resultados, o estudo de Li (2013) em experimentos com a planária D. japonica, evidenciou uma maior sensibilidade para este anti-antiflamatório ( $\mathrm{CL}_{50}$ (96h: 4,2 $\mathrm{mg} \mathrm{L}^{-1}$ ) em comparação com os nossos resultados para a espécie $D$. tigrina ( $\mathrm{CL}_{50}\left(96 \mathrm{~h}: 17,9 \mathrm{mg} \mathrm{L}^{-1}\right)$. Além disso, este autor igualmente observou uma diminuição nos valores de $\mathrm{CL}_{50}$ ao longo dos experimentos (24 a 96h), sendo que adultos de $D$. japonica também apresentaram uma maior sensibilidade ao diclofenaco sódico em relação à espécie $D$. magna.

Em nosso estudo, diferenças marcantes na exposição ao diclofenaco sódico (aproxidamente 3 vezes) foram observadas, comparando-se os valores de $\mathrm{CE}_{50}(48 \mathrm{~h})$ para a espécie nativa $C$. silvestrii $\left(37,91 \mathrm{mg} \mathrm{L}^{-1}\right)$ e a espécie exótica $D$. magna $(123,3$ $\mathrm{mg} \mathrm{L}^{-1}$ ), mostrando que a segunda espécie citada pode ser mais resistente à toxicidade do diclofenaco sódico. Entretanto, o estudo realizado por Haap et al. (2008) revelou que a espécie D. magna pode ser igualmente sensível ao diclofenaco sódico, quando comparada com $C$. silvestrii. Contudo, o cladócero $C$. silvestrii não é tão sensível quanto às outras nove espécies filogeneticamente distintas, principalmente em relação ao peixe Danio rerio e à macrófita Lemna minor (Figura 2). Não obstante essas comparações é possível verificar que as condições experimentais podem ter uma contribuição determinante para a variabilidade dos resultados.

Como todos os AINEs, o diclofenaco sódico atua por inibição reversível ou irreversível de uma ou ambas isoformas das enzimas ciclo-oxigenase (COX-1 e COX2), levando à inibição periférica da síntese das prostaglandinas, que são parcialmente envolvidas na gênese da dor e da inflamação (VANE \& BOTTING, 1998). Essa atividade pode interferir em funções fisiológicas importantes que antecedem a 
letalidade, como a reprodução, transporte de água, osmoregulação e defesa imunológica em organismos não-alvo (VANE et al., 1998; ROWLEY et al., 2005; FENT et al., 2006). A exposição ao diclofenaco sódico em espécies aquáticas especialmente em peixes pode induzir a toxicidade aguda e crônica, podendo afetar assim, a sobrevivência, natação, crescimento, comportamento alimentar, desenvolvimento embrionário e reprodução (NASSEF et al., 2010a, b; LEE et al., 2011). Segundo Cleuvers (2003), a questão do modo de ação dos fármacos, incluindo o diclofenaco sódico é de extrema importância na explicabilidade dos resultados, mas esta é somente conhecida para os organismos-alvo, ou seja, seres humanos e alguns mamíferos de laboratório. Segundo Lee et al. (2011), embora os efeitos tóxicos diretos do diclofenaco sódico sejam considerados insignificantes, preocupações sobre os efeitos negativos para a saúde dos organismos aquáticos por bioacumulação ainda permanecem. Além disso, no ambiente aquático, este composto farmacológico é conhecido pela sua rápida fototransformação e pode formar vários produtos de transformação (SVANFELT, 2013), sendo que também estes produtos, via transformação, podem representar riscos ecológicos para a biota aquática. Assim, estudos sobre os efeitos de exposição ao diclofenaco sódico em diferentes níveis das cadeias alimentares são necessários para uma melhor compreensão das conseqüências da exposição a este composto nos ecossistemas aquáticos.

Considerando-se os níveis de diclofenaco sódico necessários para causar efeitos agudos em espécies aquáticas, considera-se baixa a probabilidade de que esta substância possa comprometer a sobrevivência das espécies estudadas, sobretudo da espécie $D$. tigrina, a que apresentou maior sensibilidade a este composto. Apesar disso, não se deve desprezar os potenciais efeitos crônicos causados por este anti-inflamatório. O fármaco propranolol foi considerado mais tóxico às espécies estudadas em comparação com o diclofenaco sódico. Outros estudos como de Hugget et al. (2002) e Maszkowska et al. (2014) evidenciaram também que este composto farmacêutico apresentou maior toxicidade em relação a outros $\beta$ - bloqueadores (metoprolol e nadolol) para diferentes organismos-teste (bactérias, alga verde, macrófitas, crustáceos e peixes). Maszkowska et al. (2014) sugere que este fato está relacionado a características destas substâncias, como a sua hidrofobia, bem como aos seus modos de ação.

A espécie mais tolerante a este fármaco, D. tigrina, apresentou um valor de $\mathrm{CL}_{50}$ (96h) de 10,86 $\mathrm{mg} \mathrm{L}^{-1}$, na mesma ordem de grandeza comparada à planária $D$. 
japonica, (CL $\mathrm{C}_{50}$ (96h): 7,2 $\mathrm{mg} \mathrm{L}^{-1}$ ) ( $\left.\mathrm{Li}, 2013\right)$, sendo que também foi verificada uma diminuição nos valores $\mathrm{CL}_{50}$ ao longo dos experimentos (24 a 96h). Se as comparações são feitas com organismos-teste aquáticos filogeneticamente distintos, é possível verificar que a espécie de planária $D$. tigrina apresentou maior tolerância a este fármaco em relação às outras nove espécies distintas, principalmente em relação ao rotífero $B$. calyflorus e o cnidário H. viridissima (Figura 3). Alternativamente, espécies como os crustáceos D. pulex (LILIUS et al.,1995) e D. magna, o platelminto D. tigrina, o peixe O. latipes (KIM et al., 2009a) e a macrófita L. minor (CLEUVERS, 2003) são menos sensíveis do que $C$. silvestrii ao propranolol, com valores de $\mathrm{CE}_{50}$ superiores a 3,17 mg $\mathrm{L}^{-1}$ (Figura 3). Por sua vez, o cladócero C. silvestrii apresentou maior sensibilidade a este composto em comparação com as espécies $V$. fischeri (FERRARI et al., 2004) e $H$. azteca (HUGGET et al. (2002) (Tabela 1). No entanto, as diferentes causas da variabilidade na sensibilidade de espécies para um determinado poluente incluem características fisiológicas dos animais selecionados (estado de nutrição, sexo, estágio no ciclo de vida), as condições de cultivo (temperatura, alimentação, fotoperíodo e dureza da água) e dos experimentos, e sobretudo, propriedades das substâncias utilizadas nos ensaios (degradabilidade, solubilidade e pureza) e modos de ação nos organismos (COWGILL, 1987; RAND, 1995).

O $\beta$-bloqueador propranolol é considerado um potente agente da membrana de estabilização, uma característica ausente em outros compostos (ANDERSON et al., 1996; PEARCE et al., 1988). Cleuvers (2005) sugere que as diferenças nos valores de $\mathrm{CE}_{50} \mathrm{~s}$ dependem principalmente dos níveis de $\log \mathrm{K}_{\mathrm{ow}}$, causando narcose por rompimento da integridade da membrana. Tal partição de poluentes na membrana faz com que esta se expanda ou dilate, aumentando a fluidez, baixando a temperatura de transição de fase e a permabilidade dos íons da membrana. Por outro lado, ele enfatiza que substâncias tóxicas podem interagir com receptores específicos na região hidrofóbica da membrana de proteínas. Embora, não existam relatos que comprovem a existência de $\beta$ - receptores nos dafinideos e em algas; este fato não pode ser considerado sem importância. É de conhecimento que a partir de seres humanos, as reações adversas de drogas podem ser causadas por interações receptores-fármacos, receptores não identificados e por uma ampla diversidade de fenótipos de metabolização destas substâncias. Estas variáveis são ainda mal caracterizadas para as espécies da biota aquática (MASZKOWSKA et al., 2014). Para os mamíferos, incluindo os seres 
humanos, um $\beta$-bloqueador é um antagonista competitivo dos efeitos de catecolaminas (adrenalina e noradrenalina), a locais dos receptores $\beta$ adrenérgicos ( $\beta 1$ e /ou $\beta 2$ ). Estes compostos possuem diferentes afinidades para receptores $\beta 1$ e $\beta 2$ (MASZKOWSKA et al., 2014). Este fármaco, portanto, pode reduzir a permeabilidade da membrana de vários íons $\left(\mathrm{Na}+, \mathrm{K}+\mathrm{e} \mathrm{Ca}_{2}+\right)$. Assim, o efeito sobre a sobrevivência dos organismos pode em parte ser devido a efeitos adversos sobre a estabilização da membrana (DZIALOWSKI et al., 2006; CLAESSENS et al., 2013). Portanto, os mecanismos pelo qual os diferentes $\beta$-bloqueadores podem afetar os organismos aquáticos permanecem desconhecidos e devem ser examinados com maior profundidade.

\section{Conclusões}

Pode-se concluir que os fármacos diclofenaco sódico e propranolol ocasionaram toxicidade aguda a todas as espécies de invertebrados aquáticos testados e que as espécies $H$. viridissima e $D$. tigrina, apesar de não serem padronizados, se mostram excelentes organismos-teste na avaliação dos efeitos destes compostos farmacêuticos. A espécie $H$. viridissima pode ser considerada como bom indicador em estudos ecotoxicológicos e de monitoramento ambiental, por responder por meio de modificações morfológicas graduais a condições de crescente toxicidade, evidenciadas por concentrações subletais e letais para os fármacos estudados.

No entanto, e apesar da ocorrência de efeitos na sobrevivência das espécies estudadas sob níveis superiores aos documentados nos corpos d' água, deve-se ressaltar que efeitos a longo prazo podem ocorrer, resultando em potenciais riscos ecológicos à biota aquática. Portanto também, novos estudos são necessários para se entender os modos de ação específicos e uma melhor avaliação dos perigos ambientais destes compostos xenobióticos.

\section{Referências bibliográficas}

ANDERSON, R.; RAMAFI, G.; THERON, A. Membrane stabilizing, antioxidative interactions of propranolol and dexpropranolol with neutrophils. Biochemical Pharmacology, v.52, p.341-349, 1996. 
ASSOCIAÇÃO BRASILEIRA DE NORMAS TÉCNICAS (ABNT) 2004. NBR 12713. Ecotoxicologia aquática - Toxicidade aguda - Método de ensaio com Daphnia spp (Cladocera, Crustacea), 2004.

AGUINACO, A.; BELTRÁN, F.J.; GARCÍA-ARAYA, J.F.; OROPESA, A. Photocatalytic ozonation to remove the pharmaceutical diclofenac from water: influence of variables. Chemical Engineering Journal, v.189-190, p.275-282, 2012.

ALDER, A.C.; SCHAFFNER, C.; MAJEWSKY, M.; KLASMEIER, J.; FENNER, K. Fate of $\beta$-blocker human pharmaceuticals in surface water: comparison of measured and simulated concentrations in the glatt valley watershed, Switzerland. Water Research, v. 44, p. 936-948, 2010.

AMERICAN SOCIETY FOR TESTING AND MATERIALS (ASTM). Standard practice for conducting acute toxicity tests with fishes, macroinvertebrates and amphibians. Report E 729-80. American Society for Testing and Materials, Philadelphia, USA, 1980.

AMERICAN SOCIETY FOR TESTING AND MATERIALS (ASTM). Standard guide for conducting Daphnia magna life-cycle toxicity tests. Report E 1193-97. American Society for Testing and Materials, Philadelphia, USA, 1997.

BAIRD, D. J.; BARBER, I.; BRADLEY, M.C.; CALOW, P.; SOARES, A.M.VM. The Daphnia bioassay: a critique. Hydrobiologia, v.189, p.403-406, 1989.

BARBIERI, M.; LICHA, T.; NÖDLER, K.; CARRERAA, J.; AYORAA, C.; SANCHEZ-VILAC, $X$. Fate of $\beta$-blockers in aquifer material under nitrate reducing conditions: Batch experiments. Chemosphere, v.9, p.1272-1277, 2012.

BARNES, K.K.; KOPLIN, D.W.; FURLONG, E.T.; ZAUGG, S.D.; MEYER, M.T.; BARBER, L.B. A national reconnaissance of pharmaceuticals and other organic wastewater contaminants in the United States-I-Groundwater. The Science of the Total Environmental, v.402, p. 192-200, 2008. 
BENDZ, D.; PAXÉUS, T.R.; GINN, F.J.; LOGE F.J. Occurrence and fate of pharmaceutically active compounds in the environment, a case study: Höje River in Sweden. Journal of Hazard Materials, v.122, p. 195-204, 2005.

BENOTTI, M.J.; TRENHOLM, R.A.; VANDERFORD, B.J.; HOLADY, J.C.; STANFORD, B.D.; SNYDER, S.A. Pharmaceuticals and endocrine disrupting compounds in U.S. drinking water. Environmental Science \& Technology, v.43, p. 597-603, 2009.

BESSE, J.-P.; GARRIC, J. Human pharmaceuticals in surface waters. Implementation of a prioritization methodology and application to the French situation. Toxicology Letters, v.176, p.104-123, 2008.

BLAISE, C.; GAGNÉ, F.; EULLAFFROY, P.; FÉRAD, J-F. Ecotoxicity os selected pharmaceuticals of urban origin discharged to the Saint-Lawrence River (Québec, Canada): a review. Brazilian Journal of Aquatic Science and Technology, v. 10, p. 29-51, 2006.

CALlEJA, M.C.; PERSOONE, G.; GELADI, P. Comparative Acute Toxicity of the First 50 Multicentre Evaluation of In Vitro Cytotoxicity Chemicals to Aquatic NonVertebrates. Archives of Environmental Contamination and Toxicology, v.26, p. 69$78,1994$.

CASTRO, F.J.; SANTOS, D.R.A.; BUONGERMINO, C.R.P.; CORTEZ, F.S.; PEREIRA, C.D.S.; CHOERI, R.B.; CESAR, A. Ecotoxicological assessment of four pharmaceuticals compounds through acute toxicity tests. O mundo da Saúde, v.38, p.51-55, 2014.

CHAE, J-P.; PARK, M.S.; HWANG, Y-S.; MIN, B-H.; KIM，S-H.; LEE，H-S.; PARKA, M-J. Evaluation of developmental toxicity and teratogenicity of diclofenac using Xenopus embryos. Chemosphere, v. 120, p.52-58, 2015. 
CLAESSENS, M.; VANHAECKE, L.; WILLE, K.; JANSSEN, C.R. Emerging contaminants in Belgian marine waters: single toxicant and mixture risks of pharmaceuticals. Marine Pollutin Bulletin, v.71, p.41-50, 2013.

CLEMENTE, G. Estudo Comparativo de procedimentos experimentais e computacionais para o cálculo da lipofilia molecular. Saúde e Tecnologia, v.5, p. 29$34,2011$.

CLEUVERS, M. Aquatic ecotoxicity of pharmaceuticals including assessment of combination effects. Toxicology Letters, v. 3, p.185-194, 2003.

CLEUVERS, M. Mixture toxicity of the anti-inflammatory drugs diclofenac, ibuprofen, naproxen, and acetylsalicylic acid. Ecotoxicology \& Environmental Safety, v.59, p.309-315, 2004.

COWGILL, U.M. Critical analysis of factors affecting the sensitivity of zooplankton and the reproducibility of toxicity test results. Water Research, v. 21, p. 1453-1462, 1987.

DELORENZO, M.E.; FLEMING, J. Individual and Mixture Effects of Selected Pharmaceuticals and Personal Care Products on the Marine Phytoplankton Species Dunaliella tertiolecta. Archives of Environmental Contamination and Toxicology, v.54, p.203-210, 2008.

DZIALOWSKI, E.M.; TURNER, P.K.; BROOKS, B.W. Physiological and Reproductive Effects of Beta Adrenergic Receptor Antagonists in Daphnia magna. Archives of Environmental Contamination and Toxicology, v. 50, p.503-510, 2006.

ELRON-GROSS, I.; GLUCKSAM, Y.; MELIKHOV, D.; MARGALIT, R. Cyclooxygenase inhibition by diclofenac formulated in bioadhesive carriers. Biochimica Biophysica Acta, v.1778, p.931-936, 2008. 
EUROPEAN COMMISSION. Proposal for a Directive of the European Parliament and of the Council Amending Directives 2000/60/EC and 2008/105/EC as Regards Priority Substances in the Field of Water Policy. European Environment Agency, Brussels, p. 35, 2012a.

EUROPEAN COMMISSION. Report from the Commission to the European Parliament and the Council on the Outcome of the Review of Annex $X$ to Directive2000/60/EC of the European Parliament and of the Council on Priority Substances in the Field of Water Policy. European Environment Agency, Brussels, p. 6, 2012b.

FANG, T.-H.; NAN, F.-H.; CHIN, T.-S.; FENG, H.M. The occurrence and distribution of pharmaceutical compounds in the effluents of a major sewage treatment plant in Northern Taiwan and the receiving coastal waters. Marine Pollution Bulletin, v. 64, p. 1435-1444, 2012.

FENT, K.; WESTON, A.A.; CAMINADA, D. Ecotoxicology of human pharmaceuticals. Aquatic Toxicology, v.2, p.122-159, 2006.

FERRARI, B.; MONS, R.; VOLLAT, B.; FRAYSSE, B.; PAXEUS, N.; LO GIUDICE, R.; POLLIO, A.; GARRIC, J. Environmental risk assessment of six human pharmaceuticals: Are the current environmental risk assessment procedures sufficient for the protection of the aquatic environment? Environmental Toxicology and Chemistry, v.23, p.1344-1354, 2004.

FRAYSSE, B.; GARRIC J. Prediction and experimental validation of acute toxicity of $\beta$-blockers in Ceriodaphnia dubia. Environmental Toxicology and Chemistry, v.24, p.2470-2476, 2005.

FREITAS, E.C.; ROCHA, O. Acute and Chronic toxicity of chromium and cadmium to the tropical cladoceran Pseudosida ramosa and the implications for ecotoxicological studies. Environmental Toxicology, v. 29, p.176-186, 2011. 
GANIYAT, A. M. The Toxicological Evaluation of Sewage Effluents and Pharmaceuticals with the use of Zebrafish as a Model Organism. 2008. 58p. (Master of Science Programme in Veterinary Medicine for International Students) Faculty of Veterinary Medicine and Animal Science and Swedish University of Agricultural Sciences

GÓMEZ, M.J.; MARTÍNEZ, M.J.; LACORTE, S.; FERNÁNDEZ-ALBA, A.R.; AGUERA, A. Pilot survey monitoring pharmaceuticals and related compounds in a sewage treatment plant located on the Mediterranean coast. Chemosphere, v.66, p. 993$1002,2007$.

GOMES, R.M.V.A.G. Efeitos da tetraciclina em Gambusia holbrooki: enzimas antioxidantes e alterações histopatológicas. 2013. 75p. (Mestrado em Ciências Farmacêuticas). Universidade Fernando Pessoa, Faculdade de Ciências da Saúde, Porto, 2013.

HAAP, T.; TRIEBSKORN, R.; KÖHLER, H.R. Acute effects of diclofenac and DMSO to Daphnia magna: Immobilization and hsp70-induction. Chemosphere, v.73, p.353$359,2008$.

HAN, G. H.; HUR, H. G.; KIM, S. D. Ecotoxicological risk of pharmaceuticals from wastewater treatment plants in Korea: occurrence and toxicity to Daphnia magna. Environmental Toxicology and Chemistry, v. 25, p. 265-271, 2006.

HEBERER, T. Occurrence, fate, and removal of pharmaceutical residues in the aquatic environment: a review of recent research data. Toxicology Letters, v. 131, p.5-17, 2002.

HUGGETT, D.B.; BROOKS, B.W.; PETERSON, B.; FORAN, C.M.; SCHLENK, D. Toxicity of select beta adrenergic receptor-blocking pharmaceuticals ( $\beta$-Blockers) on aquatic organisms. Archives of Environmental Contamination and Toxicology, v. 43, p.229-235, 2002. 
INTERNATIONAL ORGANISATION FOR STANDARDIZATION (ISO). Water quality: determination of the inhibition of the mobility of Daphnia magna Straus (Cladocera, Crustacea) - Acute toxicity test. ISO International Standard 6341. International Organization for Standardization, Geneva, Switzerland, 1996.

KIM, J.W.; ISHIBASHI, H.; YAMAUCHI, R.; ICHIKAWA, N.; TAKAO, Y.; HIRANO, M.; KOGA, M.; ARIZONO, K. Acute toxicity of pharmaceutical and personal care products on freshwater crustacean (Thamnocephalus platyurus) and fish (Oryzias latipes). The Journal of Toxicological Sciences, v.34, p.227-232, 2009.

KÜSTER, A.; ALDER, A.C.; ESCHER, B.I.; DUIS, K.; FENNER, K.; GARRIC, J.; HUTCHINSON, T.H.; LAPEN, D.R.; PÉRY, A.; RÖMBKE, J.; SNAPE, J.; TERNES, T.; TOPP, E.; WEHRHAN, A.; KNACKER, T. Environmental risk assessment of human pharmaceuticals in the European Union: a case study with the b-blocker atenolol. Integrated Environmental Assessment and Management, v. 6, p.514-523, 2010.

LAMEIRA, V. Estudo dos efeitos ecotoxicológicos dos fármacos dipirona sódica e paracetamol para organismos aquáticos. 2012. 266 p. (Mestrado em Ciências na Área de Tecnologia Nuclear - Materiais). Instituto de Pesquisas Energéticas e Nucleares, Universidade de São Paulo, São Paulo, 2012.

LÁNG, J.; KOHIDAI, L. Effects of the aquatic contaminant human pharmaceuticals and their mixtures on the proliferation and migratory responses of the bioindicator freshwater ciliate Tetrahymena. Chemosphere, v. 89, p.592-601, 2012.

LEE, J.; JI, K.; KHO, Y.L.; KIM, P.; CHOI, K. Chronic exposure to diclofenac on two freshwater cladocerans and Japanese medaka. Ecotoxicology and Environmental Safety, v.74, p.1216-1225, 2011.

LI, M.H. Acute toxicity of 30 pharmaceutically active compounds to freshwater planarians, Dugesia japonica. Toxicological \& Environmental Chemistry, v.95, p. 1157-1170, 2013. 
LI, Z. H.; RANDAK, T. Residual pharmaceutically active compounds (PhAcs) in aquatic environment-status, toxicity and kinetics: a review. Veterinarni Medicina, v. 54, p.295-314, 2009.

LILIUS, H.; HASTBACKA, T.; ISOMAA, B. A comparison of the toxicity of 30 reference chemicals to Daphnia magna and Daphnia pulex. Environmental Toxicology and Chemistry, v. 12, p.2085-2088, 1995.

LIU, Q-T.; WILLIAMS, T.D.; CUMMING, R.I.; HOLM, G.; HETHERIDGE, M.J.; MURRAY-SMITH, R. Comparative Aquatic Toxicity of Propranolol and its Photodegraded Mixtures: Algae and Rotifer Screening. Environmental Toxicology and Chemistry, v.28, p. 2622-2631, 2009.

MACHADO, K. S.; CASALI, M.P.; OLIVEIRA, D.O.; ISIQUE, W.D.; LEITE, M.A.; MINILLO, A. Bioensaios de toxicidade aguda com fármacos: diclofenaco de sódio e paracetamol. Anais do VI Congresso de Meio Ambiente da AUGM. 8a Jornada Científica e Tecnológica da Universidade Federal de São Carlos, SP. v. 5, 2009.

MASSARO, F. C. Estudos Ecológicos e Ecotoxicológicos de Espécies Nativas de Hydra (Cnidaria: Hydrozoa). 2011. 502p. Tese (Doutorado em Ciências da Engenharia Ambiental) - Escola de Engenharia de São Carlos, Universidade de São Paulo, São Carlos, 2011.

MCEVOY, G.K. American Hospital Formulary Service - Drug Information 2003. Bethesda, MD: American Society of Health-System Pharmacists, Inc. 2003.

MASZKOWSKA， J.; STOLTE， S.; KUMIRSKA， J.; LUKASZEWICZ， P.; MIODUSZEWSKA, K.; PUCKOWSKI, A.; CABAN, M.; WAGIL, M.; STEPNOWSKI, P.; BIELIŃSKA, A.B. Beta-blockers in the environment: Part II. Ecotoxicity study. Science of the Total Environment, v. 493, p.1122-1126, 2014.

NASSEF, M.; KIM, S.G.; SEKI, M.; KANG, I.J.; SHIMASAKI, Y.; OSHIMA, Y.; HANO, T. In ovo nanoinjection of triclosan, diclofenac and carbamazepine affects 
embryonic development of medaka fish (Oryzias latipes). Chemosphere, v.79, p.966973, 2010a.

NASSEF, M., MATSUMOTO, S., SEKI, M., KHALIL, F., KANG, I.J., OSHIMA, Y., HONJO, T., SHI-MASAKI, Y. Acute effects of triclosan, diclofenac and carbamazepine on feeding performance of Japanese medaka fish (Oryzias latipes). Chemosphere, v. 80, p.1095-1100, 2010 b.

NAŁĘCZ-JAWECKI, G.; WÓJCIK, T.; SAWICKI, J. Evaluation of in vitro biotransformation of propranolol with HPLC, MS/MS, and two bioassays. Environmental Toxicology, v. 23, p.52-58, 2008.

NUNES, B. Fármacos no ambiente: implicações ecotoxicológicas. Captar, v. 2, p.9-20, 2010.

NUNES, B.; ANTUNES, S.C.; SANTOS, J.; MARTINS, L.; CASTRO, B.B. Toxic potential of paracetamol to freshwater organisms: a headache to environmental regulators? Ecotoxicology and Environmental Safety, v. 107, p.178- 1885, 2014.

OGGIER, D. M.; WEISBROD, C. J.; STOLLER, A. M.; ZENKER, A. K.; FENT, K. Effects of Diazepam on gene expression and link to physiological effects in different life stages in Zebrafish Danio rerio. Environmental Science \& Technology, v.44, p.7685-7691, 2010.

ORGANISATION FOR ECONOMIC CO-OPERATION AND DEVELOPMENT (OECD). Daphnia sp., acute immobilisation test. Revised proposal for updating guideline 202. OECD (Organisation for Economic Cooperation and Development), Paris, France, 2000.

ORGANISATION FOR ECONOMIC CO-OPERATION AND DEVELOPMENT (OECD). Guideline for Testing of Chemicals. Daphnia sp., Acute immobilization test. OECD 202. Paris, France: Organization for Economic Cooperation and Development, 2004. 
PAL, A.; GIN, KY-H.; LIN, A.Y.C.; REINHARD, M. Impacts of emerging organic contaminants on freshwater resources: Review of recent occurrences, sources, fate, and effects. Science of Total Environment, v. 408, p.6062- 6069, 2010.

PEARCE, P.; HAWKEY, C.; SYMONS, C.; OLSON, E. The importance of membrane stabilization in protecting the developing rat myocardium from the actions of triac. The American Journal of Cardiovascular Pathology, v.2, p.173-179, 1998.

QUINN, B.; SCHMIDT, W.; O'ROURKE, K.; HERNAN, R. Effects of the pharmaceuticals gemfibrozil and diclofenac on biomarker expression in the zebra mussel (Dreissena polymorpha) and their comparison with standardized toxicity tests. Chemosphere, v. 84, p.657-663, 2011.

RADJENOVIC, J.; PETROVIC, M.; BARCELO, D. Analysis of pharmaceuticals in wastewater and removal using a membrane bioreactor. Analytical and Bioanalytical Chemistry, v. 387, p.1365-1367, 2007.

RAMOS, R.C. Avaliação dos efeitos do agrotóxico Vertimec® 18 CE em ecossistemas de água doce por meio de estudos experimentais em laboratório e in situ. 2013.137p. Tese (Doutorado em Ciências da Engenharia Ambiental) - Escola de Engenharia de São Carlos, Universidade de São Paulo, São Carlos, 2013.

RAND, G.M. Fundamental Aquatic Toxicology: Effects, Environmental Fate, and Risk Assessment, 2a ed. Taylor \& Francis: USA, cap 31, 1995

RIBO, J. M. Interlaboratory comparison studies of the luminescent bacteria toxicity bioassay. Environmental Toxicology, v.12, p.283-294, 1997

ROBERTS, P.H.; THOMAS, K.V. The occurrence of selected pharmaceuticals in wastewater effluent and surface waters of the lower Tyne catchment. Science of the Total Environment, v. 356, p.143-153, 2006. 
ROCCO, L.; FRENZILLI, G.; FUSCO, D.; PELUSO, C.; STINGO, V. Evaluation of zebrafish DNA integrity after exposure to pharmacological agents present in aquatic environments. Ecotoxicology and Environmental Safety, v.73, p.1530-1536, 2010.

ROWLEY, A.F.; VOGAN, C.L.; TAYLOR, G.W.; CLARE, A.S. Prostaglandins in noninsectan invertebrates: recent insights and unsolved problems. The Journal of Experimental Biology, v.208, p.3-14, 2005.

SANTOS, L.H.M.L.M.; ARAUJO, N.A.; FACHINI, A.; PENA, A.; DELERUEMATOS, C.; MONTENEGRO, M.C.B.S.M. Ecotoxicological aspects related to the presence of pharmaceuticals in the aquatic environment. Review. Journal of Hazardous Materials, v.175, p.45-95, 2010.

SARAVANAN, M.; KARTHIKA, S.; MALARVIZHI, A.; RAMESH, M. Ecotoxicological impacts of clofibric acid and diclofenac in common carp (Cyprinus carpio) fingerlings: Hematological, biochemical, ionoregulatory and enzymological responses. Journal of Hazardous Materials, v.195, p.188- 194, 2011

SCHMIDT, W.; O'ROURKE, K.; HERNAN, R.; QUINN, B. Effects of the pharmaceuticals gemfibrozil and diclofenac on the marine mussel (Mytilus spp.) and their comparison with standardized toxicity tests. Marine Pollution Bulletin, v. 62, p.1389-1395, 2011.

SCHRAP, S.M.; RIJS, G.B.; BEEK, M.A.; MAASKANT, J.F.; STAEB, J.; STROOMBERG, G.; TIESNITSCH, J. Humane en veterinaire geneesmiddelen in Nederlands oppervlaktewater en afvalwater. RIZA report 86, 2003.

STANLEY, J.K.; RAMIREZ, A.J.; MOTTALEB, M.; CHAMBLISS, C.K.; BROOKS, B.W. Enantiospecific toxicity of the $\beta$-blocker propranolol to Daphnia magna and Pimephales promelas. Environmental Toxicology and Chemistry, v. 25, p.17801786, 2006. 
STEIN, J.R. Standard Methods for the Examination of Water and Wastewater. 19th edition. American public Health Association, Washington p 1-1100, 1973.

SVANFELT, J. Occurrence and photochemical fate of selected pharmaceutical active ingredients in the aquatic environment (PhD Thesis) Turku, Finland: Åbo Akademi University; 2013. Available at: http://www.doria.fi/bitstream/handle/10024/87829/svanfelt_jesper.pdfjesper.pdf?sequen ce $=2]$.

USEPA. Methods for measuring the acute toxicity of effluents and receiving waters to freshwater and marine organisms, $5^{\text {th }}$ ed., EPA-821-R-02-012. US Environmental Protection Agency, Washington, 2002.

VAN DEN BRANDHOF E.J.; MONTFORTS, M. Fish embryo toxicity of carbamazepine, diclofenac and metoprolol. Ecotoxicology and Environmental Safety, v.73, p.1862-1866, 2010.

VAN VLAARDINGEN, P.; TRAAS, T.P.; WINTERSEN, A.M.; ALDENBERG, T. ETX 2.0. A program 513 to calculate hazardous concentrations and fraction affected, based on normally distributed 514 toxicity data. RIVM Report No. 601501028/2004, Bilthoven, The Netherlands, 2004.

VANE, J.R.; BAKHLE, Y.S.; BOTTING, R.M. Cyclooxygenases 1 and 2. Annual Review of Pharmacology and Toxicology, v. 38, 97-120, 1998.

VANE, J.R.; BOTTING, R.M. Mechanism of action of anti-inflammatory drugs. International Journal of Tissue Reactions, v. 20, p.3-15, 1998.

VIENO, N.M.; TUHKANEN, T.; KRONBERG, L. Analysis of neutral and basic pharmaceuticals in sewage treatment plants and in recipient rivers using solid phase extraction and liquid chromatography-tandem mass spectrometry detection, Journal of Chromatography A, v.1134, p. 101-111, 2006. 
VULLIET, E.; CREN-OLIVÉ, C. Screening of pharmaceuticals and hormones at theregional scale, in surface and groundwaters intended to human consumption. Environmental Pollution, v.159, p.2929-2934, 2011.

YUAN, S.; JIANG, X.; XIA, X.; ZHANG, H.; ZHENG, S. Detection, occurrence and fate of 22 psychiatric pharmaceuticals in psychiatric hospital and municipal wastewater treatment plants in Beijing, China. Chemosphere, v.10, p.2520-2525, 2013.

YANG, L.; YU, L. E.; E RAY, M. B. Degradation of paracetamol in aqueous solutions by TiO2 photocatalysis. Water Research, v. 42, p.3480-3488, 2008.

WANG, Y.; LIU, H.; LIU, G.; XI, Y. Oxidation of diclofenac by aqueous chlorine dioxide: Identification of major disinfection byproducts and toxicity evaluation. Science of the Total Environment, v. 473-474, p. 437-445, 2014.

WILBY, OK. The Hydra regeneration assay. Proceedings of the Workshop organized by Association Française de Teratologie p.108-124, 1988.

WILDE, M.L.; MAHMOUD,W.M.M.; KÜMMERER, K.; MARTINS, A.F. Oxidationcoagulation of $\beta$-blockers by $\mathrm{K}_{2} \mathrm{FeVIO}_{4}$ in hospital wastewater: assessment of degradation products and biodegradability. Science of the Total Environment, v.452453, p.137-47, 2013.

ZHANG, Z.; HIBBERD, A.; ZHOU, J.L. Analysis of emerging contaminants in sewage effluent and river water: Comparison between spot and passive sampling. Analytica Chimica Acta, v. 607, p.37-44, 2008. 
CAPítulo 4

\author{
Efeitos ecotoxicológicos agudos e crônicos de quatro compostos farmacológicos \\ sobre a espécie Daphnia magna
}

\title{
Resumo
}

A ocorrência de compostos farmacêuticos no ambiente aquático tem recebido crescente atenção nos últimos anos, no que diz respeito a informações de persistência ambiental, atividade biológica e diferentes efeitos em relação a organismos não-alvo, mesmo em níveis extremamente baixos. Considerando a magnitude das concentrações (ng L ${ }^{-1}$ para $\mu \mathrm{g} \mathrm{L}^{-1}$ ) e os seus modos de ação, a avaliação de respostas fisiológicas da biota aquática exposta pode fornecer informações importantes sobre as potenciais consequências ecológicas da exposição a estes contaminantes. Assim, o presente estudo teve como objetivo avaliar os efeitos agudos e crônicos de quatro fármacos: paracetamol (analgésico), clorpromazina (antipsicótico), diclofenaco de sódio (anti-inflamatório) e propranolol (anti-hipertensivo), no cladócero Daphnia magna. Foram analisadas variáveis como imobilidade e subsequente história de vida (total de descendentes produzidos e taxa de crescimento da população). Os resultados das exposições agudas mostraram uma variabilidade considerável entre os fármacos, com o seguinte ranking de toxicidade: diclofenaco sódico $\left(\mathrm{EC}_{50}=123,3 \mathrm{mg} \mathrm{L}^{-1}\right)<$ propranolol $\left(\mathrm{EC}_{50}=5,531 \mathrm{mg}\right.$ $\left.\mathrm{L}^{-1}\right)<$ acetaminofeno $\left(\mathrm{EC}_{50}=2,831 \mathrm{mg} \mathrm{L}^{-1}\right)<$ clorpromazina $\left(\mathrm{EC}_{50}=1,805 \mathrm{mg} \mathrm{L}^{-1}\right)$. Os dados de toxicidade crônica mostraram efeitos reprodutivos adversos. Os compostos clorpromazina e propranolol causaram uma diminuição significativa na fecundidade, e a variável taxa de crescimento populacional sofreu uma redução significativa a partir das concentrações de $0,33 \mathrm{mg} \mathrm{L}^{-1}$ e $0,128 \mathrm{mg} \mathrm{L}^{-1}$, respectivamente. Este estudo demonstrou que os níveis de exposições agudas e crônicas em que o organismo-teste foi exposto estavam acima daqueles já relatados na natureza. No entanto, a extensiva produção, prescrição e liberação de compostos farmacêuticos irão continuar a crescer no futuro e, consequentemente, suas cargas para o meio ambiente podem resultar em potenciais riscos ecológicos a longo prazo para a biota aquática.

Palavras-chave: acetaminofeno, clorpromazina, diclofenaco de sódio, propranolol, biota aquática, cladóceros, efeitos agudos e crônicos. 


\begin{abstract}
The occurrence of pharmaceutical compounds in the aquatic environment has received increasing attention in recent years, as concerns have risen about their environmental persistence, biological activity and different effects toward non-target organisms, even at extremely low levels. Considering the magnitude of concentrations (ng $\mathrm{L}^{-1}$ to $\mu \mathrm{g} \mathrm{L}^{-1}$ ) and their often-specific modes of action, the assessment of physiological responses of exposed aquatic biota may provide significant information regarding the potential ecological consequences of exposure to these contaminants. Therefore, the present study intended to assess the acute and chronic effects of four pharmaceuticals: acetaminophen (analgesic), chlorpromazine (antipsychotic), diclofenac sodium (anti-inflammatory) and propranolol (antihypertensive) in the cladoceran species Daphnia magna. Variables such as immobility and subsequent life-history (total of offspring and rate of population increase) were analyzed. Results of acute exposures showed a considerable variability of toxicity among pharmaceuticals, with the following ranking of toxicity: diclofenac sodium $\left(\mathrm{CE}_{50=} 123.3 \mathrm{mg} \mathrm{L}^{-1}\right)<$ propranolol $\left(\mathrm{CE}_{50=} 5.531\right.$ $\left.\mathrm{mg} \mathrm{L}^{-1}\right)<$ acetaminophen $\left(\mathrm{CE}_{50=} 2.831 \mathrm{mg} \mathrm{L}^{-1}\right)<$ chlorpromazine $\left(\mathrm{CE}_{50=} 1.805 \mathrm{mg} \mathrm{L}^{-1}\right)$. The chronic toxicity data showed the exertion of reproductive adverse effects. The compounds chlorpromazine and propranolol caused a significant decrease in fecundity, and the rate of population increase parameter suffered a significant increase from 0.33 $\mathrm{mg} \mathrm{L}^{-1}$ and $0.128 \mathrm{mg} \mathrm{L}^{-1}$ onwards, respectively. This study demonstrated that the levels of exposure to which our test organism was acutely and chronically exposed were above those already reported in the wild. Nevertheless, the extensive production, prescription, and release of pharmaceuticals drugs will continue to grow in the future, and consequently their loadings to the environment can result in potential long-term ecological risks to aquatic biota.
\end{abstract}

Keywords: acetaminophen, chlorpromazine, diclofenac sodium, propranolol, aquatic biota, cladocerans, acute and chronic effects. 


\section{Introdução}

Fármacos tais como analgésicos, antibióticos, anti-epilépticos, anti-depressivos, $\beta$ bloqueadores, reguladores de lipídios do sangue e contraceptivos, são usados em grandes quantidades, que conduzem à sua ocorrência no ambiente (MASSARSKY et al., 2011). Estes xenobióticos são produzidos para cumprir um conjunto de prérequisitos, como modos de ação específicos e eficácia farmacológica, sendo lentamente metabolizados para agirem em períodos mais longos. No entanto, o metabolismo lento também pode implicar na persistência ambiental, quando essas substâncias atingem os distintos ecossistemas (BRANDÃO et al., 2013). Os fármacos podem assim exercer efeitos adversos sobre organismos não-alvo de diversas maneiras, potencialmente durante todo seu ciclo de vida em concentrações subletais. Esta modalidade de exposição crônica pode resultar na alteração irreversível de importantes processos fisiológicos em organismos individuais (MINGUEZ et al., 2014).

Apesar de sua importância ecotoxicológica em geral, pouco se sabe sobre as possíveis vias de receptores-alvo humanos/biomoléculas destes compostos em muitos vertebrados, e é ainda menor o conhecimento em invertebrados. Além disso, e para alguns produtos farmacêuticos, o modo específico de ação não é bem conhecido, e, muitas vezes, não só um, mas diferentes modos de ação podem estar presentes.

A avaliação ecotoxicológica de compostos farmacêuticos tem sido feita principalmente com base em experimentos de curta duração, realizados por meio de testes padronizados de acordo com as orientações existentes (por exemplo, OECD), utilizando organismos-teste a partir de diferentes níveis tróficos, como algas, organismos zooplanctônicos, outros invertebrados e peixes (KIM et al., 2009; LI, 2013). No entanto, dados de toxicidade crônica, ou sobre o potencial de bioacumulação de produtos farmacêuticos na biota aquática e em cadeias alimentares, são em grande parte desconhecidos. Considerando-se que a exposição a compostos pseudopersistentes (substâncias cuja degradação é igual à sua taxa de entrada para o ambiente), como os fármacos, é provável a ocorrência destes durante todo o ciclo de vida de organismos aquáticos, sendo de fundamental importância a determinação da sua toxicidade crônica, e os consequentes efeitos a longo prazo, tais como aqueles sobre o crescimento ou taxas de reprodução. 
O objetivo deste estudo foi avaliar os efeitos agudos e crônicos de quatro fármacos pertencentes a diferentes classes terapêuticas: paracetamol (analgésico, antitérmico), clorpromazina (antipsicóticos), diclofenaco sódico (anti-inflamatório) e propranolol (anti-hipertensivo), sobre a espécie de Cladocera Daphnia magna. Esta espécie é um modelo biológico de invertebrado que desempenha um papel importante na cadeia alimentar aquática, servindo como um intermediário entre os produtores primários e níveis tróficos superiores (FLAHERTY \& DODSON, 2005).

Acetaminofeno (APAP, N-acetil-p-aminofenol, paracetamol) é um medicamento de venda livre, comercializado na forma de cápsulas, drágeas ou comprimidos de 500 a $1.000 \mathrm{mg}$ cada e também em gotas ou solução, xarope e pastilhas. Este fármaco é utilizado para o alívio de febre e dores de cabeça, sendo frequentemente detectado no ambiente aquático (ANTUNES at al., 2013). Devido ao seu extensivo uso, este medicamento é classificado como composto de classe 2 - produtos farmacêuticos prioritários (VOOGT et al., 2009). Pelo fácil acesso e o desconhecimento da população sobre seus efeitos nocivos ao organismo têm aumentado muito o número de intoxicações por esse medicamento, sendo também comumente utilizado em casos de suicídios (SEBBEN et al. 2010; IBRAHIM et al., 2013).

O composto clorpromazina foi detectado em concentrações de 5-364 ng L $\mathrm{L}^{-1} \mathrm{em}$ estações de tratamento de águas residuárias (ETAR) a partir de influentes de hospitais psiquiátricos (YUAN et al., 2013), e abaixo de $1 \mathrm{ng} \mathrm{L}^{-1}$ em águas superficiais no Reino Unido (ROBERTS \& BERSUDER, 2006), e 0,9-2,6 ng L ${ }^{-1}$ no Rio Tejo, Espanha (FERNANDÉZ et al., 2010). Apesar da ocorrência ambiental, nenhuma classificação toxicológica para este fármaco foi relatada em bancos de dados farmacêuticos (VOOGT et al., 2009). Já o fármaco diclofenaco sódico foi classificado como um dos três medicamentos mais frequentemente detectados em ecossistemas aquáticos (SANTOS et al., 2010.), sendo classificado como de classe 1 - alta prioridade farmacêutica (VOOGT et al., 2009). A presença deste composto foi relatada em concentrações relativamente elevadas em efluentes de ETARs e águas superficiais de até $4,7 \mu \mathrm{g} \mathrm{L} \mathrm{L}^{-1}$ e $1,2 \mu \mathrm{g} \mathrm{L}^{-1}$, respectivamente, e até mesmo em amostras de água subterrâneas e de consumo em concentrações de até $380 \mathrm{ng} \mathrm{L}^{-1}$ e entre 1-7 $\mathrm{ng} \mathrm{L}^{-1}$, respectivamente (LÓPEZ-SERNA et al., 2013; VULLIET et al., 2011). O propranolol é um medicamento cuja presença ambiental requer atenção, uma vez que, se a relação PEC/PNEC for superior a 1, evidentemente, o limite adotado indica potenciais preocupações ambientais 
(ÅGERSTRAND \& RÜDEN, 2010). Dados sobre a fotodegradação de propranolol foi avaliado como tendo uma meia-vida de 16,8 dias (CLEUVERS, 2005). Esta substância foi detectada em efluente de ETAR (ZHOU et al., 2009), em concentrações de 16-388 $\mathrm{ng} \mathrm{L}^{-1}$ e em águas de superfície em níveis $<10 \mathrm{ng} \mathrm{L}^{-1}$ e abaixo de $37 \mathrm{ng} \mathrm{L}^{-1}$, respectivamente (KIM et al., 2009). Este fármaco também foi reportado em efluentes de hospitais, em concentrações que podem atingir 6,5 $\mu \mathrm{g} \mathrm{L}^{-1}$ (LIN \& TSAI, 2009).

\section{Material e Métodos}

\subsection{Organismo-teste e condições de cultivo}

Culturas monoclonais de Daphnia magna (clone A sensu BAIRD et al., 1989a) foram mantidas em laboratório por várias gerações em meio ASTM (ASTM, 1980; USEPA, 2002), complementadas com aditivo orgânico (suspensão extraída da alga Ascophyllum nodoso). As condições de manutenção das culturas de D. magna estão descritas com maiores detalhes no capítulo 3 desta tese.

\subsection{Fármacos}

Todos os medicamentos foram adquiridos da Sigma Aldrich, com pureza $\geq 99 \%$ : acetaminofeno (CAS: 32113-41-0), clorpromazina (CAS: 69-09-0), diclofenaco de sódio (CAS: 15307-79-6) e propranolol (CAS: 318-98-9).

\subsection{Testes de toxicidade aguda}

Bioensaios de ecotoxicidade aguda foram realizados para avaliar a toxicidade de quatro fármacos: acetaminofeno, clorpromazina, diclofenaco sódico e propranolol ao cladócero Daphnia magna. Os testes de toxicidade aguda foram realizados de acordo com protocolos-padrão (ASTM, 1997; ISO, 1996; OECD, 2000), sob as mesmas condições de laboratório descritas para a manutenção das culturas.

Os procedimentos experimentais para a realização dos testes de toxicidade aguda com D. magna estão descritas com maiores detalhes no capítulo 3 desta tese. As concentrações nominais finais utilizadas nos testes agudos foram: 1,2-9,0 $\mathrm{mg} \mathrm{L}^{-1}$ para o 
acetaminofeno; 0,50-3,14 $\mathrm{mg} \mathrm{L}^{-1}$ para a clorpromazina; 52,0-155,3 $\mathrm{mg} \mathrm{L}^{-1}$ para o diclofenaco de sódio e 4,0-11,9 $\mathrm{mg} \mathrm{L}^{-1}$ para o propranolol, respectivamente. Os organismos-teste não foram alimentados durante o experimento, e depois de 48 horas de exposição foram observados e registrados o número total de organismos imóveis/mortos, em cada réplica, por concentração analisada.

\subsection{Testes de toxicidade crônica}

Os ensaios de toxicidade crônica com D. magna foram realizados de acordo com protocolos-padrão (ASTM, 1997; ISO, 2000; OECD, 1998), por 21 dias sob os mesmos regimes de temperatura e fotoperíodos descritos para as condições de cultivo. Para a realização destes bioensaios semi-estáticos foram selecionados os neonatos aleatoriamente, $(\leq 24 \mathrm{~h}$ de idade) sendo 10 indivíduos atribuídos ao controle (ASTM) e a cada uma das réplicas para as diferentes concentrações testadas (ver Tabela 1 para maiores informações).

Os recipientes de ensaio consistiram em frascos de vidro contendo $50 \mathrm{~mL}$ de solução-teste. Os neonatos foram transferidos para os frascos com diluições recémpreparadas com os compostos estudados, a cada dois dias, e foram alimentados

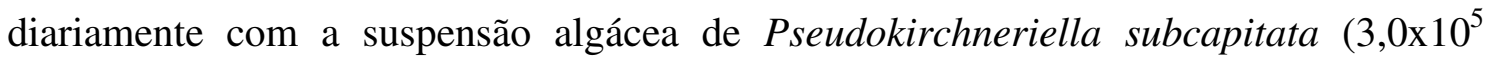
células $\left.\mathrm{mL}^{-1} \mathrm{dia}^{-1}\right)$. Ao longo dos 21 dias de duração do experimento, os organismos foram verificados diariamente para avaliação da sobrevivência e do estado reprodutivo, sendo que os indivíduos recém-nascidos eram contados e imediatamente descartados. Foram registrados os seguintes parâmetros de história de vida: mortalidade e total de descendentes. As estimativas de sobrevivência e fecundidade também foram utilizadas para calcular a taxa de crescimento populacional (r), a partir da equação (1) de EulerLotka:

$1=\sum 1 x m x e^{-r m x}$

em que $r$ é a taxa de aumento da população $\left(\right.$ dia $\left.^{-1}\right), x$ é a classe de idade em dias $(0, \ldots$ n), $l x$ é a probabilidade de sobrevivência na idade $x$, e $m x$ representa a fecundidade por fêmea em idade $x$. Os erros-padrão de $\mathrm{r}$ foram estimados utilizando-se a técnica de Jack 
-knife descrita por Meyer et al. (1986), permitindo assim os testes de hipóteses sobre este parâmetro demográfico.

\subsection{Análises estatísticas}

Os valores de $\mathrm{CE}_{50}$ e $\mathrm{CE}_{10}$ (apenas para os ensaios agudos) juntamente com os seus respectivos limites de confiança de $95 \%$ para o número de organismos imóveis e os testes crônicos (número total de descendentes) para cada fármaco correspondente foram determinadas por análise de regressão não-linear, ajustando-se uma equação logística aos dados utilizando-se a técnica dos quadrados mínimos. O Software Statistica 11.0 foi utilizado para esta finalidade. Uma análise de variância (ANOVA), seguida pelo teste de Dunnett (se aplicável), foi aplicada a cada endpoint dos testes crônicos para verificar diferenças estatísticas entre as diferentes concentrações e o controle $(\mathrm{p}<0,05)$.

\section{Resultados}

Na Tabela 1, estão representados os resultados obtidos nos testes de toxicidade aguda, indicando os valores calculados de $\mathrm{CE}_{50}$ (48h) e de $\mathrm{CE}_{10}$ (48h) e os seus respectivos intervalos de confiança (IC 95\%) para os quatro compostos farmacêuticos analisados (Tabelas 6, 21, 27 e 39, em apêndice A). É possível observar uma variabilidade considerável nos resultados entre todos os fármacos testados, com a seguinte classificação relativa de toxicidade: clorpromazina $\left(\mathrm{CE}_{50}=1,805 \mathrm{mg} \mathrm{L}^{-1}\right)>$ acetaminofeno $\left(\mathrm{CE}_{50}=2,831 \mathrm{mg} \mathrm{L} \mathrm{L}^{-1}\right)>$ propranolol $\left(\mathrm{CE}_{50}=5,531 \mathrm{mg} \mathrm{L}^{-1}\right)>$ diclofenaco sódico $\left(\mathrm{CE}_{50}=123,3 \mathrm{mg} \mathrm{L}^{-1}\right)$. Portanto, a espécie D. magna foi mais sensível ao fármaco clorpromazina quando comparada com os outros compostos estudados, com os menores valores de $\mathrm{CE}_{50}$ e $\mathrm{CE}_{10}$ de 1,805 e $1,069 \mathrm{mg} \mathrm{L}^{-1}$, respectivamente. Os valores de $\mathrm{CE}_{10}$ calculados foram considerados como pontos de partida para a escolha das concentrações nominais finais para serem usadas nos testes crônicos, a fim de evitar uma mortalidade considerável de organismos durante a exposição. 
Tabela 1. Valores de Concentração mediana $\left(\mathrm{CE}_{10}\right.$ e $\left.\mathrm{CE}_{50}, \mathrm{mg} \mathrm{L}^{-1}\right)$ dos compostos farmacêuticos: acetaminofeno, clorpromazina, diclofenaco sódico e propranolol em testes agudos e crônicos com Daphnia magna e seus respectivos intervalos de confiança de $95 \%$ $(\mathrm{IC} 95 \%) . \mathrm{nd}=$ não determinado

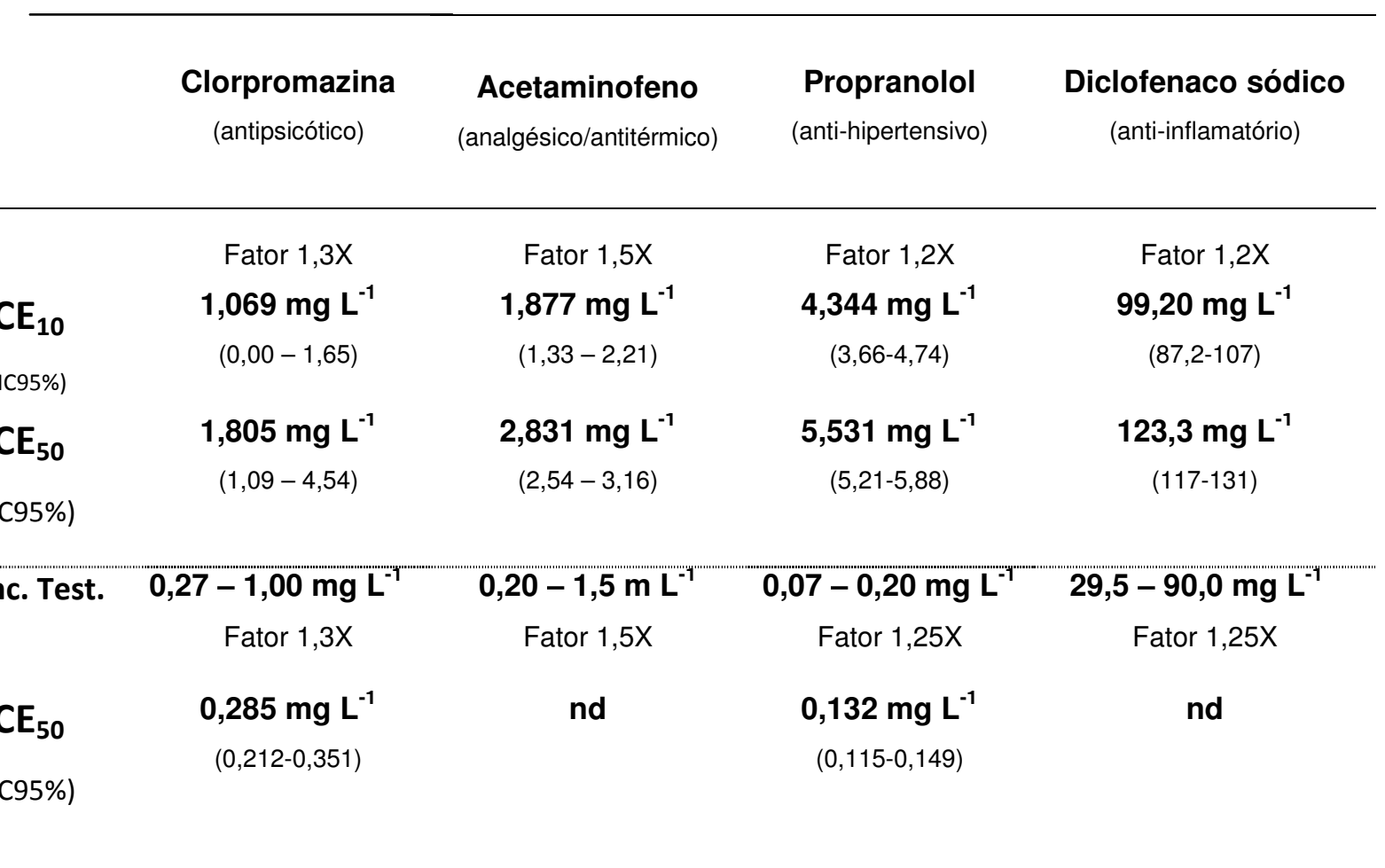

Os dados de toxicidade crônica mostraram a existência de efeitos reprodutivos adversos para os fármacos clorpromazina e propranolol (Figura 1). Estes dois medicamentos causaram uma redução significativa na produção de descendentes, quando comparados com o controle (ANOVA- total de neonatos produzidos: MS = 8626,$5 ; \mathrm{F}_{[4,43]}=15,71, \mathrm{p}<0,001$ e $\left.\mathrm{MS}=6784,8 \mathrm{~F}_{[3,33]}=70,33, \mathrm{p}<0,001\right)$, respectivamente. Os valores de $\mathrm{CE}_{50} \mathrm{~S}$ reprodutivos de $0,285 \mathrm{mg} \mathrm{L}^{-1}$ e $0,132 \mathrm{mg} \mathrm{L}^{-1}$ foram obtidos para a clorpromazina e o propranolol, respectivamente. Parâmetros de sobrevivência e fecundidade foram integrados para obtenção da taxa intrínseca de crescimento populacional (r), que mostraram uma diminuição significativa na população de D. magna para os compostos clorpromazina a partir das concentrações de $0,33 \mathrm{mg} \mathrm{L}^{-}$ ${ }^{1}$ e propranolol a partir de $0,128 \mathrm{mg} \mathrm{L}^{-1}$ em diante.

Diferentemente do que foi observado para a clorpromazina e o propranolol, não houve alterações na taxa de crescimento populacional para Daphnia magna exposta ao fármaco paracetamol, no entanto, na menor concentração testada $\left(0,2 \mathrm{mg} \mathrm{L}^{-1}\right)$ verificou- 
se um aumento significativo (one-way ANOVA, $\mathrm{MS}=0,118 ; \mathrm{F}_{[6,63]}=331,758 ; p<$ 0,001). Contudo, nenhum efeito significativo reprodutivo foi observado nas concentrações analisadas para o diclofenaco de sódio, considerando-se os parâmetros prole total (one-way ANOVA, MS $=1154,085 ; F_{[5,50]}=2,660 ; p=0,033$ ) e taxa de crescimento da população (one-way ANOVA, $\mathrm{MS}=0,00187 ; F_{[5,54]}=1,410 ; p=0,235$, respectivamente) (Figura 1). 

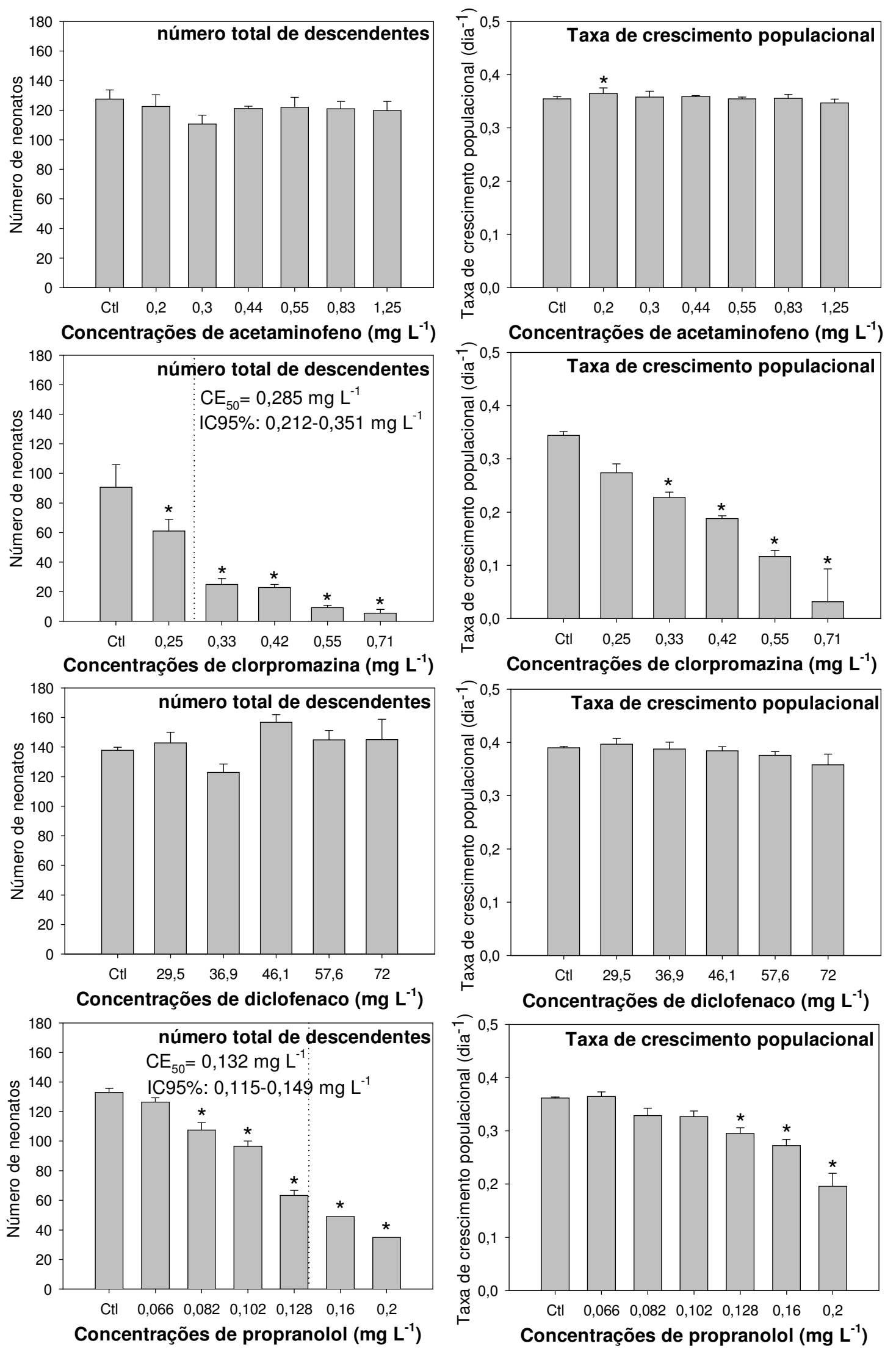

Figura 1. Parâmetros avaliados em relação às respostas da história de vida de Daphnia magna exposta por 21 dias aos compostos paracetamol, clorpromazina, diclofenaco sódico e propranolol (eixo-x, em $\mathrm{mg} \mathrm{L}^{-1}$ ). As barras de erro correspondem ao erro padrão e (*) 
representam as diferenças estatísticas (teste de Dunnett, $\mathrm{p} \leq 0,05$ ) entre as diferentes concentrações dos fármacos estudados, em relação ao controle.

\section{Discussão}

\section{Acetaminofeno}

O acetaminofeno é consensualmente considerado um composto tóxico em doses mais elevadas, o que nos vertebrados (nomeadamente mamíferos) pode causar hepatotoxicidade levando à insuficiência hepática e à morte (HADI, 2013). Em doses terapêuticas, o paracetamol é predominantemente eliminado nos vertebrados por conjugação (sulfatação e glucuronidação) (XU et al., 2008). Uma pequena quantidade é parcialmente metabolizada pelo sistema citocromo P-450, que conduz à formação de Nacetil-p-benzoquinonaimina (NAPQI). NAPQI é desintoxicado pela conjugação com glutationa (GSH) e excretado como a cisteína ou ácido conjugado mercaptopurina (KAVITHA et al., 2011). No entanto, em casos de doses excessivas desse composto, o NAPQI altamente reativo e electrofílico podem acumular e, exercer vários efeitos tóxicos, tais como modificações covalentes de grupos tiol em proteínas celulares (XU et al., 2008), eliminação da síntese de ATP, danos no DNA e no RNA, levando a lesões na membrana e necrose centrilobular de hepatócitos.

A toxicidade do paracetamol tem sido documentada em diferentes animais e seres humanos (XU et al., 2008; DAVE \& HERGER, 2012; Li, 2013). A comparação do valor de $\mathrm{CE}_{50}$ deste fármaco $\left(2,831 \mathrm{mg} \mathrm{L}^{-1}\right)$ para Daphnia magna, com valores previamente calculados para outras espécies pode resultar em grandes diferenças (NUNES et al., 2014). Apesar das diferenças intrínsecas observáveis entre as espécies, a importância dos valores de $\mathrm{CE}_{50}$ consiste na possibilidade de se estabelecerem comparações diretas em termos de estresse agudo, e sensibilidade para com um determinado composto. Assim, é possível concluir que D. magna foi mais sensível do que outros organismos-teste aquáticos, filogeneticamente distintos, tais como Scenedesmus subspicatus ( $\mathrm{CE}_{50}$ de $\left.134 \mathrm{mg} \mathrm{L}^{-1}\right)$, Lemna minor $\left(\mathrm{CE}_{50}\right.$ de 429,9 $\left.\mathrm{mg} \mathrm{L}^{-1}\right)$, Photobacterium phosphoreum (teste Microtox , $\mathrm{CE}_{50}$ de $331 \mathrm{mg} \mathrm{L}^{-1}$ ), Hydra vulgaris (> $10 \mathrm{mg} \mathrm{L}^{-1}$ ), e Dugesia japonica (150,8 mg L ${ }^{-1}$ ) (KUHN et al., 1989; LI, 2013; NUNES et al., 2014). Isso também foi verificado para espécies de crustáceos, como Moina macrocopa (KIM et al., 2012) e Hyalella azteca (GÓMEZ-OLIVÁN et al., 2012). 
$\mathrm{O}$ valor de $\mathrm{CE}_{50}$ (48h) obtido no nosso estudo é comparável ao $\mathrm{CE}_{50}$ (24h) relatado por Dave e Herger (2012) para Daphnia magna. No entanto, os valores calculados aqui são um pouco abaixo dos valores reportados na literatura, mostrando que fatores importantes, tais como condições de cultivo e experimentais (alimentação, temperatura, fotoperíodo e dureza da água) podem ter uma contribuição decisiva para a variabilidade dos resultados. Casos ilustrativos foram observados por Kuhn et al. (1989) e Kim et al. (2007), com valores de $\mathrm{CE}_{50}$ para D. magna de 9,2 e $11,85 \mathrm{mg} \mathrm{L}^{-1}$, respectivamente, significativamente superiores aos calculados para o presente estudo, mas na mesma ordem de grandeza. Estes resultados mostram que este cladócero pode ser uma espécie sensível para efeitos de acetaminofeno, sendo um importante organismo-teste em ensaios de ecotoxicidade para determinar o efeito das drogas farmacêuticas. No entanto, os riscos ecológicos agudos causados pelo paracetamol podem ser insignificantes, uma vez que as concentrações ambientais relatadas são geralmente várias ordens de grandeza menores do que as concentrações aqui analisadas. Alguns autores descreveram a presença de acetaminofeno em efluentes de ETARs em concentrações inferiores a $20 \mathrm{ng}$ $\mathrm{L}^{-1}$ (ROBERTS \& THOMAS, 2006) e a 4,3 $\mu \mathrm{g} \mathrm{L}^{-1}$ (GOMEZ et al., 2006), e em águas naturais nos EUA de até $10 \mu \mathrm{g} \mathrm{L}^{-1}$ (KOLPIN et al., 2002), e acima de $65 \mathrm{ng} \mathrm{L}^{-1}$ no rio Tyne, Reino Unido (ROBERTS \& THOMAS, 2006). Mesmo considerando que o paracetamol pode permanecer em corpos de água sem degradação por 15 dias (LIN \& TSAI, 2009), os efeitos adversos relatados neste estudo foram causados por níveis elevados de contaminação, que não são susceptíveis de serem alcançados em condições reais. Consequentemente, os dados relativos à toxicidade aguda deste composto são de baixa relevância ecológica, mas muito importantes em relação à proteção da vida selvagem, não apresentando riscos consideráveis para os organismos aquáticos.

Quanto aos dados de toxicidade crônica, o fármaco paracetamol nas concentrações testadas $\left(0,2-1,25 \mathrm{mg} \mathrm{L}^{-1}\right)$ não causou efeitos populacionais para a espécie estudada. No entanto, Nunes et al. (2014) observaram que, em concentrações a partir de $4,0 \mathrm{mg} \mathrm{L}^{-1} \mathrm{e}$ $17,8 \mathrm{mg} \mathrm{L}^{-1}$, este composto ocasionou redução significativa na taxa de crescimento populacional em Daphnia magna e Daphnia longispina, respectivamente. Espécies de crustáceos parecem ser particularmente sensíveis à exposição ao acetaminofeno, uma vez que este composto parece estar envolvido em perturbações do sistema endócrino, por interferência no processo de muda (RODRIGUEZ et al., 2007; FANJUL-MOLES \& GONSEBATT, 2012). 
A estrutura alquilfenólica do acetaminofeno pode ser responsável por este efeito, uma vez que este fármaco pertence a um grupo de compostos conhecidos por seus efeitos endócrinos em crustáceos (RODRÍGUEZ et al., 2007), que exibem atividade anti-ecdise esteroidais (LEBLANC, 2007). Entretanto, são necessários mais estudos sobre o potencial de perturbação endócrina do paracetamol e suas consequências ecológicas a longo prazo sobre a biota aquática, incluindo os crustáceos. Como mostrado por Kim et al. (2012), para concentrações superiores às utilizadas em nosso estudo $\left(0,64-51,50 \mathrm{mg} \mathrm{L}^{-1}\right)$, não foram relatados efeitos populacionais para a espécie $D$. magna. Contudo, e apesar da baixa possibilidade da ocorrência de diferentes efeitos nos níveis relatados, os impactos deste composto na sobrevivência e reprodução de organismos não-alvo, expostos através do ambiente, é uma possibilidade.

\section{Clorpromazina}

Clorpromazina (CPR) foi o primeiro antipsicótico moderno lançado em 1952 e aprovado pela Food and Drug Administration em 1954 (KANE \& CORRELL, 2010). No corpo humano, CPR é metabolizada para metabólitos de fase I e fase II, sendo alguns deles responsáveis pela atividade farmacológica. Apesar de ser geralmente seguro sob regimes terapêuticos, a toxicidade para diferentes organismos aquáticos tem sido relatada na literatura. Os valores de $\mathrm{CE}_{50}$ obtidos para a clorpromazina $(1,805 \mathrm{mg}$ $\mathrm{L}^{-1}$ ), com D. magna são ligeiramente superiores para outros organismos aquáticos, tais como a macrófita Lemna minor $\left(\mathrm{CE}_{50}(48 \mathrm{~h})\right.$ de $\left.0,92 \mathrm{mg} \mathrm{L}^{-1}\right)$, o protozoário Spirostomum ambiguum $\left(\mathrm{CL}_{50}(24 \mathrm{~h})\right.$ de $\left.0,5 \mathrm{mg} \mathrm{L}^{-1}\right)$ e o peixe Carassius auratus $\left(\mathrm{CE}_{50}(96 \mathrm{~h})\right.$ de 0,32 $\mathrm{mg} \mathrm{L}^{-1}$ ) (NAŁECZ-JAWECKI et al., 2008; LI et al., 2008). Outros estudos sobre a ecotoxicidade da clorpromazina são de difícil extrapolação e comparação com os nossos resultados, porque os endpoints analisados são muito diferentes (MUNRO et al., 1986; ARKHIPOVA et al., 2006; RIHEL et al., 2010; HUI- QIN et al., 2011). O estudo realizado por Arkhipova et al. (2006) com a espécie de molusco terrestre Helix lucorum mostrou que em concentrações subletais deste composto verifica-se um aumento significativo do tempo de fechamento da estrutura pneumostoma, bem como alterações no comportamento motor, com uma diminuição da taxa de locomoção. No entanto, estes efeitos foram observados apenas em níveis mais elevados deste fármaco em comparação com o presente estudo. O desenvolvimento da neurotoxicidade em embriões e larvas da 
espécie conhecida como peixe-zebra (Danio rerio) também foi afetado pela exposição à clorpromazina ( $\geq 5 \mathrm{mg} \mathrm{L}^{-1}$ ), como demonstrado por Hui-qin et al. (2011). Em adição a este parâmetro, Selderslaghs et al. (2013) mostraram que este antipsicótico pode afetar a atividade natatória de larvas e provocar a redução da atividade de embriões e larvas de peixe-zebra.

No entanto, em nosso estudo este composto farmacêutico provocou efeitos significativos em nível populacional para a espécie $D$. magna, com a redução dosedependentes do número total de descendentes produzidos e na taxa de crescimento da população (Figura 1). De acordo com Trautwein e Kummerer (2012) há uma quantidade limitada de dados sobre o destino e os efeitos ambientais da clorpromazina disponíveis na literatura. Contudo, e considerando a falta de estudos sobre seu modo de ação e efeitos populacionais em crustáceos, os nossos resultados são extremamente significativos, pois mostram o potencial desta substância em provocar consideráveis efeitos ecológicos. Apesar da baixa relevância ecológica em relação aos níveis de clorpromazina utilizados em nosso estudo, os potenciais riscos ecológicos a longo prazo para a biota aquática devem ser analisados, pois é difícil de se preverem os níveis deste composto na natureza.

\section{Diclofenaco sódico}

O diclofenaco de sódio é um fármaco anti-inflamatório não esteróide (AINE) que tem sido utilizado no tratamento de dor, inflamação e rigidez das articulações. Como todos os AINEs, este composto atua por inibição reversível ou irreversível de uma ou ambas as isoformas das enzimas ciclo-oxigenase (COX-1 e COX-2), envolvidos na síntese das diferentes prostaglandinas a partir do ácido araquidônico (VANE \& BOTTING, 1998). Apesar de não ser completamente conhecido o modo de ação do mesmo para a maioria dos organismos ecologicamente relevantes, este medicamento é considerado um dos compostos mais importantes que podem exercer efeitos tóxicos em organismos não-alvo pertencentes a diferentes níveis de organização biológica (CLEUVERS, 2003; FERRARI et al., 2003). Valores de $\mathrm{CE}_{50}$ determinados para $D$. magna em nosso estudo, mostram que, em termos comparativos, esta espécie pode ser menos sensível do que outros organismos tais como as espécies fitoplanctônicas Pseudokirchneriella subcapitata (QUINN et al., 2011) e a diatomácea Desmodesmus 
subspicatus (CLEUVERS, 2004), à espécie de macrófita Lemna minor (QUINN et al., 2011) e à bactéria Vibrio fischeri (ZHANG et al., 2008). Isso também foi observado para as espécies zooplanctônicas (Brachionus calyciflorus, Ceriodaphnia dubia e Thamnocephalus platyurus) e para o peixe Danio rerio (FERRARI et al., 2003). Contrariamente, o cladócero D. magna foi mais sensível à exposição ao diclofenaco de sódio em comparação ao crustáceo Moina macrocopa (LEE et al., 2011). A $\mathrm{CE}_{50}$ da exposição aguda aqui observada para D. magna, de $123,3 \mathrm{mg} \mathrm{L}^{-1}$, foi cerca de duas vezes superior à publicada por Cleuvers (2003), de $68 \mathrm{mg} \mathrm{L}^{-1}$.

Em relação aos dados de toxicidade crônica, não houve efeitos significativos sobre a reprodução para os indivíduos expostos ao diclofenaco sódico, considerando as variáveis: número total de descendentes e taxa de crescimento da população. No entanto, o estudo realizado por Sarma et al. (2013) mostrou que as taxas de crescimento populacional para o rotífero Plationus patulus e o cladócero Moina macrocopa foram negativamente afetadas pelo diclofenaco sódico nos níveis de 1,56 a $25 \mathrm{mg} \mathrm{L}^{-1}$. Como relatado por Lee et al. (2011), a exposição a este composto levou a uma redução significativa no número de filhotes por fêmea, no número de crias por ninhada e na taxa de crescimento populacional de D. magna, em concentrações menores do que as analisadas em nosso estudo $\left(0,93\right.$ a $\left.25 \mathrm{mg} \mathrm{L}^{-1}\right)$. De acordo com Cleuvers e Heinrichs (2008) e Lee et al. (2011), os valores de $\mathrm{CE}_{50}$ obtidos nos testes de toxicidade crônica para $D$. magna foram de 50,5 e $23,8 \mathrm{mg} \mathrm{L}^{-1}$, respectivamente, os quais são várias ordens de magnitude superiores às encontradas no ambiente aquático; por conseguinte, não é esperado impacto ambiental direto sobre a biota aquática em relação a este fármaco. Assim, são necessários mais estudos de efeitos adversos sobre espécies aquáticas nãoalvo, a fim de uma melhor compreensão sobre as consequências da exposição ao diclofenaco sódico em ecossistemas aquáticos.

\section{Propranolol}

Os $\beta$-bloqueadores, incluindo o propranolol, agem através da inibição competitiva dos receptores $\beta$-adrenérgicos, que estão envolvidos em muitas funções fisiológicas, incluindo a regulação da frequência cardíaca, nos níveis de oxigênio, na vasodilatação e na broncodilatação em mamíferos (FENT et al., 2006). O propranolol é um antagonista 
do receptor não seletivo $\beta$-adrenérgico que funciona como o 5-hidroxitriptamina (5HT), antagonista do receptor de serotonina em vertebrados (ALEXANDER \& WOOD, 1987). Como os invertebrados aquáticos podem ter receptores adrenérgicos que são distintos dos mamíferos, pode-se esperar diferentes impactos potenciais sobre estes organismos. Dados da literatura mostram que dentre os $\beta$-bloqueadores estudados, o propranolol é considerado o mais tóxico para os organismos aquáticos (FENT et al., 2006; KÜSTER et al., 2009). Os potenciais efeitos ecológicos adversos deste fármaco foram estudados nos organismos aquáticos, tais como as espécies de cladóceros Daphnia lumholtzi e Ceriodaphnia dubia (HUGGETT et al., 2002); a macrófita Lemna minor (CLEUVERS, 2003), o peixe Oryzias latipes (KIM et al., 2009) e o mexilhão Mytilus galloprovincialis (FRANZELLITTI et al., 2011). A CE 50 $_{50}$ calculada com base na resposta de $D$. magna à exposição aguda ao propranolol $\left(5,531 \mathrm{mg} \mathrm{L}^{-1}\right)$ está próxima aos valores já reportados na literatura para outras espécies, como o crustáceo Daphnia pulex (LILIUS et al., 1995), a espécie de diatomácea Desmodesmus subspicatus, e a plánaria Dugesia japonica (CLEUVERS, 2005; LI et al., 2013). Alternativamente, D. magna foi menos sensível do que outras espécies, tais como o protozoário Spirostomum ambiguum ( $\mathrm{CE}_{50}$ de $\left.1,77 \mathrm{mg} \mathrm{L}^{-1}\right)$, os crustáceos Ceriodaphnia dubia $\left(\mathrm{CE}_{50}\right.$ de $1,51 \mathrm{mg}$ $\left.\mathrm{L}^{-1}\right)$, Brachionus calyciflorus $\left(\mathrm{CE}_{50}\right.$ de $2,59 \mathrm{mg} \mathrm{L}^{-1}$ ), e larvas da espécie de peixe Danio rerio $\left(\mathrm{CE}_{50}\right.$ de 2,48 $\mathrm{mg} \mathrm{L}^{-1}$ ) (NAŁĘCZ-JAWECKI et al., 2008; FERRARI et al., 2004; CALLEJA et al., 1994; SUN et al., 2013). Os resultados aqui obtidos para o valor de $\mathrm{CE}_{50}$ é em ordem de grandeza menor do que os encontrados para a macrófita Lemna minor (CLEUVERS, 2005), a bactéria Vibrio fischeri (FERRARI et al., 2004), outros crustáceos (por exemplo, Hyalella azteca e Thamnocephalus platyurus; HUGGET et al., 2002; CALLEJA et al., 1994), e peixes (por exemplo Oryias latipes; KIM et al., 2009). Os valores de $\mathrm{CE}_{50}$ deste composto relatados na literatura para D. magna abrangem uma faixa de 1,6 a 15,9 $\mathrm{mg} \mathrm{L}^{-1}$ (CALLEJA et al., 1994; LILIUS et al., 1995; HUGGETT et al., 2002). Considerando-se os níveis de propranolol necessários para causar efeitos agudos em organismos aquáticos, não é provável que esta substância possa comprometer a sobrevivência de D. magna. Além disso, o mecanismo de ação deste fármaco e dos seus metabólitos em invertebrados não foi investigada até o momento. Assim, diferenças nos tipos de receptores poderiam estar mediando as respostas tóxicas diferenciais, mas não há dados publicados na literatura para organismos inferiores (FENT et al., 2006). 
No entanto, não se deve descartar o potencial dos efeitos crônicos causados pelo propranolol, resultando em efeitos deletérios a longo prazo. O nosso estudo mostrou que este fármaco causou uma diminuição significativa na fecundidade e na taxa de crescimento populacional de D. magna. Da mesma forma, Dzialowski et al. (2006) relataram reduções significativas em outros parâmetros fisiológicos, tais como nas taxas metabólicas e de batimento cardíaco, que acabaram resultando em reduções significativas na massa corporal seca, refletindo, assim, prejuízo no crescimento. Os estudos de Campbell et al. (2004) e Stanley et al. (2006) mostraram uma diminuição do ritmo cardíaco em D. magna exposta a diferentes concentrações de propranolol (29,6 $\mathrm{mg} \mathrm{L}^{-1}$ e 2,97 $\mathrm{mg} \mathrm{L}^{-1}$, respectivamente). Dzialowski et al. (2006) sugerem que, devido à redução da frequência cardíaca causada pelo bloqueio dos $\beta$-receptores do propranolol, uma consequência direta é a diminuição no metabolismo. Outros estudos, tais como o de Ericson et al. (2010) também demonstraram alterações no metabolismo dos organismos aquáticos causadas pelo propranolol. Este composto ocasionou uma redução do metabolismo em mexilhões azuis do Mar Báltico (Mytilus edulis trossulus) causando uma redução significativa no crescimento, na abundância e resistência dos segmentos de bisso. Também foram observados outros efeitos, como aumento das taxas de respiração e excreção nesta espécie de mexilhão em experimentos realizados por Oskarsson et al. (2014). Resultados semelhantes foram obtidos para outros organismos aquáticos, uma vez que a exposição ao propranolol afetou o metabolismo de Chironomus riparius, provocando uma diminuição no crescimento e na biomassa, como demonstrado por López-Doval et al. (2012). Os efeitos do propranolol sobre organismos aquáticos (especificamente, a espécie de mexilhão Mytilus galloprovincialis) estão relacionados à interferência na rota dependente de cAMP, o que pode explicar distúrbios nas funções metabólicas neuroendócrinas que são essenciais para este organismo (FRANZELLITTI et al., 2011). Segundo esses autores, as mudanças nos níveis de cAMP foram correlacionadas com mudanças nas atividades de PKA, as quais sofreram uma redução e um aumento nas glândulas digestivas e manto/gônadas de Mytilus galloprovincialis, respectivamente. Este estudo verificou que em baixas concentrações de $\beta$-bloqueadores reportados para o ambiente aquático, podem provocar diferentes impactos na fisiologia de moluscos. No entanto, e considerando que os $\beta$-bloqueadores podem causar diferentes impactos na reprodução, crescimento e nas taxas de batimento cardíaco/metabolismo em algumas espécies, juntamente com a falta de estudos que 
explicam estes mecanismos de toxicidade e modos de ação em crustáceos, só é possível sugerir a ocorrência de um percurso semelhante em D. magna, o que justificaria os resultados obtidos em relação à reprodução.

Organismos como Ceriodaphnia dubia e Hyalella azteca (HUGGETT et al., 2002), apresentaram respostas semelhantes após a exposição a longo prazo para o fármaco propranolol, com redução na reprodução, nas concentrações de 0,25 e $0,1 \mathrm{mg} \mathrm{L}^{-1}$, respectivamente. Este último estudo também relatou efeitos negativos causados por este composto em vertebrados (espécie de peixe Oryias latipes), como as reduções não significativas na produção de ovos, na taxa de crescimento, e nos níveis hormonais de esteróides sexuais. Entretanto, de acordo com os critérios propostos pelos autores, este tipo de relação dose-resposta bifásica já havia sido observado em receptores adrenérgicos, e a exposição a baixos níveis pode resultar em respostas opostas às registradas para concentrações mais elevadas, que são mediadas por meio da alteração dos níveis hormonais.

\section{Conclusões}

- Apesar das altas concentrações de paracetamol que foram selecionados para as exposições agudas e crônicas (consideravelmente mais elevadas do que os relatadas para os ecossistemas aquáticos), não foi possível observar efeitos sobre os parâmetros estudados na espécie D. magna.

- Os resultados obtidos para os fármacos clorpromazina e propranolol foram mais significativos, devido aos impactos nos parâmetros estudados (sobrevivência e reprodução) em D. magna. No entanto, deve-se ressaltar que os níveis de clorpromazina que causaram efeitos deletérios em nosso estudo foram da ordem de $\mathrm{mg} \mathrm{L}^{-1}$, enquanto que as concentrações detectadas na maioria dos ambientes aquáticos são de $n g \mathrm{~L}^{-1}$.

- A exposição ao composto propranolol produziu resultados semelhantes, uma vez que a alteração observada ocorreu apenas para altos níveis de exposição, que não são prováveis atingirem a biota aquática. Alguns estudos demonstraram o potencial desta substância em causar efeitos adversos, pelo menos para algumas espécies e para baixas concentrações de $\beta$-bloqueadores relatadas no compartimento aquático. 
- Os resultados obtidos para o diclofenaco sódico permitiram concluir que esta droga foi a mais inofensiva dentre as estudadas, uma vez que os níveis ambientais deste fármaco não representam uma potencial ameaça para a fauna aquática. Os níveis de exposição em que os organismos foram agudamente e cronicamente expostos, e que causaram efeitos significativos na espécie estudada são várias ordens de magnitude superiores aos reportados na natureza.

\section{Referências bibliográficas}

ÅGERSTRAND, M.; RUDÉN, C. Evaluation of the accuracy and consistency of the Swedish Environmental Classification and Information System for pharmaceuticals. Science of the Total Environment, v. 11, p. 2327-2339, 2010.

ALEXANDER, B.S.; WOOD, M.D. Stereoselective blockade of central [3H] 5hydroxytryptamine binding to multiple sites (5-HT1A, 5-HT1B, and 5-HT1C) by mianserin and propranolol. Journal of Pharmacy and Pharmacology, v.8, p. 664-666, 1987.

ANTUNES, S.C.; FREITAS, R.; FIGUEIRA, E.; GONÇALVES, F.; NUNES, B. Biochemical effects of acetaminophen in aquatic species: edible clams Venerupis decussate and Venerupis philippinarum. Environmental Science and Pollution Research, v.9, p.6658-6666, 2013.

ARKHIPOVA, S.S.; GAINUTDINOVA, T.S.H.; ISMAILOVA, A.I.; GAINUTDINOV, K.H.L. Comparative Studies of the Effects of Chlorpromazine and 5,6-Dihydroxytryptamine on Locomotion, Defensive Reactions in the Snail Helix lucorum, and Command Neuron Excitability in Long-Term Sensitization. Neuroscience and Behavioral Physiology, v. 7, p.759-766, 2006. 
AMERICAN SOCIETY FOR TESTING AND MATERIALS (ASTM). Standard practice for conducting acute toxicity tests with fishes, macroinvertebrates and amphibians. Report E 729-80. American Society for Testing and Materials, Philadelphia, USA, 1980.

AMERICAN SOCIETY FOR TESTING AND MATERIALS (ASTM). Standard guide for conducting Daphnia magna life-cycle toxicity tests. Report E 1193-97. American Society for Testing and Materials, Philadelphia, USA, 1997.

BAIRD, D. J.; BARBER, I.; BRADLEY, M.C.; CALOW, P.; SOARES, A.M.VM. The Daphnia bioassay: a critique. Hydrobiologia, v.189, p.403-406, 1989.

BRANDÃO, F.P.; RODRIGUES, S.; CASTRO, B.B.; GONÇALVES, F.; ANTUNES, S.C.; NUNES, B. Short-term effects of neuroactive pharmaceutical drugs on a fish species: Biochemical and behavioural effect. Aquatic Toxicology, v.144, p.145218$229,2013$.

CALLEJA, M.C.; PERSONNE, G.; GELADI, P. Comparative acute toxicity of the first 50 multicentre evaluation of in vitro cytotoxicity chemicals to aquatic non-vertebrates. Archives of Environmental Contamination and Toxicology, v.1, p.69-78, 1994.

CAMPBELL, A.K.; WANN, K.T.; MATTHEWS, S.B. Lactose causes heart arrhythmia in the water flea Daphnia pulex. Comparative Biochemistry and Physiology B, v.2, p.225-234, 2004.

CLEUVERS, M. Aquatic ecotoxicity of pharmaceuticals including assessment of combination effects. Toxicology Letters, v. 3, p.185-194, 2003.

CLEUVERS, M. Mixture toxicity of the anti-inflammatory drugs diclofenac, ibuprofen, naproxen, and acetylsalicylic acid. Ecotoxicology and Environmental Safety, v.3, p.309-315, 2004. 
CLEUVERS M. Initial risk assessment for three $\beta$-blockers found in the aquatic environment. Chemosphere, v.2, p.199-205, 2005.

CLEUVERS, M.; HEINRICHS, G. Chronic mixture toxicity of pharmaceuticals to Daphnia — the example of nonsteroidal anti-inflammatory drugs. In: Kummerer, K., ed. Pharmaceuticals in the Environment. Sources, Fate, Effects and Risk 3rd edition Springer-Verlag, p.277-284, 2008.

DAVE, G.; HERGER, G. Determination of detoxification to Daphnia magna of four pharmaceuticals and seven surfactants by activated sludge. Chemosphere, v.4, p.459 466, 2012.

DZIALOWSKI, E.M.; TURNER, P.K.; BROOKS, B.W. Physiological and Reproductive Effects of Beta Adrenergic Receptor Antagonists in Daphnia magna. Archives of Environmental Contamination and Toxicology, v.4, p.503-510, 2006.

ERICSON, H.; THORSÉN, G.; KUMBLAD, L. Physiological effects of diclofenac, ibuprofen and propranolol on Baltic Sea blue mussels. Aquatic Toxicology, v.2, p.223$231,2010$.

FANJUL-MOLES, GONSEBATT. Chapter 15 - Oxidative Stress and Antioxidant Systems in Crustacean Life Cycles In: Oxidative stress in aquatic ecosystems. Eds: Abele D, Vázquez-Medina JP, Zenteno-Savín T. Blackwell Publishing Ltd, p. 208-223, 2012.

FENT, K.; WESTON, A.A.; CAMINADA, D. Ecotoxicology of human pharmaceuticals. Aquatic Toxicology, v.2, p.122-159, 2006.

FERNÁNDEZ， C.; GONZÁLEZ-DONCEL， M.; PRO， J.; CARBONELL， G.; TARAZONA, J.V. Occurrence of pharmaceutically active compounds in surface waters of the Henares-Jarama-Tajo River system (Madrid, Spain) and a potential risk characterization. Science of the Total Environment, v.3, p.543-51, 2010. 
FERRARI, B.; PAXEUS, N.; GIUDICE, R.LO.; POLLIO, A.; GARRIC, J. Ecotoxicological impact of pharmaceuticals found in treated waste waters: study of carbamazepine, clofibric acid and diclofenac. Ecotoxicology and Environmental Safety, v.3, p.359-370, 2003.

FLAHERTY, C.M.; DODSON, S.I. Effects of pharmaceuticals on Daphnia survival, growth, and reproduction. Chemosphere, v. 2, p.200-207, 2005.

FRANZELLITTI, S.; BURATTI, S.; VALBONESI, P.; CAPUZZO, A.; FABBRI, E. The $\beta$-blocker propranolol affects cAMP-dependent signaling and induces the stress response in Mediterranean mussels, Mytilus galloprovincialis. Aquatic Toxicology, v. 2, p.299-308, 2011.

GOMEZ, M.J.; PETROVIC, M.; FERNANDEZ-ALBA, A.R.; BARCELO, D. Determination of pharmaceuticals of various therapeutic classes by solid-phase extraction and liquid chromatography-tandem mass spectrometry analysis in hospital effluent wastewaters. Journal of Chromatography A, v.1114, p.224-233, 2006.

GÓMEZ-OLIVÁN，L.M.; NERI-CRUZ，N.; GALAR-MARTÍNEZ，M.; VIEYRAREYES, P.; GARCÍA-MEDINA, S.; RAZO-ESTRADA, C.; DUBLÁN-GARCÍA, O.; CORRAL-AVITIA, A.Y. Assessing the Oxidative Stress Induced by Paracetamol Spiked in Artificial Sediment on Hyalella azteca. Water, Air \& Soil Pollution, v.8, p.5097-5104, 2012.

HADI, M.; DRAGOVIC, S.; VAN SWELM, R.; HERPERS, B.; VAN DE WATER, B.; FRANS, G.M.; COMMANDEUR, J.N.M.; GROOTHUIS, G.M.M. AMAP, the alleged non toxic isomer of acetaminophen, is toxic in rat and human liver. Archives of Toxicology, v. 1, p.155-165, 2013.

HUGGETT, D.B.; BROOKS, B.W.; PETERSON, B.; FORAN, C.M.; SCHLENK, D. Toxicity of select beta adrenergic receptor-blocking pharmaceuticals ( $\beta$-blockers) on aquatic organisms. Archives of Environmental Contamination and Toxicology, v.2, p.229-235, 2002. 
HUI-QIN, S.; LI-JUN, Z.; HUI, P.; JUN, H.; JIA-BIN, G.; JUN, Z.; SHUANG-QING, P. Developmental neurotoxicity effect of chlorpromazine on zebrafish embryo and larvae. Chinese Journal of Comparative Medicine. 2011. Available at: http://en.cnki.com.cn/Article en/ CJFDTOTAL-ZGDX2011Z1035.htm. Accessed on 02 March 2014.

IBRAHIM, T.; AGNIHOTRI, S.; AGNIHOTRI, A.K. Paracetamol Toxicity- An Overview. Emergency medicine, v.3, 2013. Available at: doi:10.4172/21657548.1000158. Acessed on 01 July 2014.

INTERNATIONAL ORGANISATION FOR STANDARDIZATION (ISO). Water quality: determination of the inhibition of the mobility of Daphnia magna Straus (Cladocera, Crustacea) - Acute toxicity test. ISO International Standard 6341. International Organization for Standardization, Geneva, Switzerland, 1996.

INTERNATIONAL ORGANISATION FOR STANDARDIZATION (ISO). Water quality: determination of long term toxicity of substances to Daphnia magna Straus (Cladocera, Crustacea). ISO International Standard 10706. International Organization for Standardization, Geneva, Switzerland, 2000.

KANE, J.M.; CORRELL, C.U. Past and present progress in the pharmacologic treatment of schizophrenia. Journal of Clinical Psychology, v.9, p.1115-1124, 2010.

KAVITHA, P.; RAMESH, R.; BUPESH, G.; STALIN, A.; SUBRAMANIAN, P. Hepatoprotective activity of Tribulus terrestris extract against acetaminophen-induced toxicity in a freshwater fish (Oreochromis mossambicus). In Vitro Cellular \& Developmental Biology- Animal, v.10, p.698-706, 2011.

KIM, Y.; CHOI, K.; JUNG, J.; PARK, S.; KIM, P.G.; PARK, J. Aquatic toxicity of acetaminophen, carbamazepine, cimetidine, diltiazem and six major sulfonamides, and their potential ecological risks in Korea. Environmental International, v.33, p. 275$370,2007$. 
KIM, J.W.; ISHIBASHI, H.; YAMAUCHI, R.; ICHIKAWA, N.; TAKAO, Y.; HIRANO, M.; KOGA, M.; ARIZONO, K. Acute toxicity of pharmaceutical and personal care products on freshwater crustacean (Thamnocephalus platyurus) and fish (Oryzias latipes). The Journal of Toxicological Sciences, v.2, p.227-232, 2009.

KIM, P.; PARK, Y.J.IK.; SEO, J.; LEE, S.; CHOI, K.; KHO, Y.; PARK, J.; CHOI, K.; Effect of chronic exposure to acetaminophen and lincomycin on Japanese medaka (Oryzias latipes) and freshwater cladocerans Daphnia magna and Moina macrocopa, and potential mechanisms of endocrine disruption. Chemosphere, v.1, p. 10-18, 2012.

KOLPIN, D.W.; FURLONG, E.T.; MEYER, M.T.; THURMAN, E.M.; ZAUGG, S.D.; BARBER, L.B.; BUXTON, H.T. Pharmaceuticals, hormones and other organic wastewater contaminants in US streams, 1999-2000: a national reconnaissance. Environmental Science \& Technology, v.36, p.1202-1211, 2002.

KÜHN, R.; PATTARD, M.; PERNAK, K.D.; WINTER, A. Results of the harmful effects of selected water pollutants (anilines, phenols, aliphatic compounds) to Daphnia magna. Water Research, v.4, p.495-499, 1989.

KÜSTER, A.; ALDER, A.C.; ESCHER, B.I.; DUIS, K.; FENNER, K.; GARRIC, J.; HUTCHINSON, T.H.; LAPEN, D.R.; PÉRY, A.; RÖMBKE, J.; SNAPE, J.; TERNES, T.; TOPP, E.; WEHRHAN, A.; KNACKER, T. Environmental risk assessment of human pharmaceuticals in the European Union: a case study with the $\beta$-blocker atenolol. Integrated Environmental Assessment Manage, v.6, p.514-523, 2009.

LEBLANC, G.A. Crustacean endocrine toxicology: a review. Ecotoxicology, v.1, p.6181, 2007.

LEE, J.; JI, K.; KHO, Y.L.; KIM, P.; CHOI, K. Chronic exposure to diclofenac on two freshwater cladocerans and Japanese medaka. Ecotoxicology and Environmental Safety. v.5, p. 1216-1225, 2011. 
LI, M.H. Acute toxicity of 30 pharmaceutically active compounds to freshwater planarians, Dugesia japonica. Toxicological \& Environmental Chemistry, v.7, p.1157-1170, 2013.

LI, T.; ZHOU, Q.; ZHANG, N.; LUO, Y. Toxic effects of chlorpromazine on Carassius auratus and its oxidative stress. Journal of Environmental Science and Health B, v.8, p.638-643, 2008.

LILIUS, H.; HASTBACKA, T.; ISOMAA, B. A comparison of the toxicity of 30 reference chemicals to Daphnia magna and Daphnia pulex. Environmental Toxicology and Chemistry, v. 12, p.2085-2088, 1995.

LIN, A.Y.C.; TSAI, Y.T. Occurrence of pharmaceuticals in Taiwan's surface waters: impact of waste streams from hospitals and pharmaceutical production facilities. Science of the Total Environment, v.12, p.3793-3802, 2009.

LÓPEZ-DOVAL, J.C.; KUKKONEN, J.V.K.; RODRIGO, P.; MUÑOZ, I. Effects of indomethacin and propranolol on Chironomus riparius and Physella (Costatella) acuta. Ecotoxicology and Environmental Safety, v.78, p.110-115, 2012.

LÓPEZ-SERNA, R.; JURADO, A.; VÁZQUES-SUNE， E.; CARRERA， J.; PETROVIC, M.; BARCELÓ, D. Occurrence of 95 pharmaceuticals and transformation products in urban ground waters underlying the metropolis of Barcelona, Spain. Environmental Pollution, v.174, p.305-15, 2013.

MASSARSKY, A.; TRUDEAU, V.L.; MOON, T.W. $\beta$-Blockers as endocrine disruptors: The potential effects of human $\beta$-blockers on aquatic organisms. Journal of Experimental Zoology A: Ecological Genetics and Physiology, v.5, p.251-265, 2011.

MEYER, J.S.; INGERSOLL, C.G.; MCDONALD, L.L.; BOYCE, M.S. Estimating uncertainty in population growth rates: Jack-Knife vs. Bootstrap techniques. Ecology, v.5, p.1156- 1166, 1986. 
MINGUEZ, L.; FARCY, E.; BALLANDONNE, C.; LEPAILLEUR, A.; SERPENTINI, A.; LEBEL, J.M.; BUREAU, R.; HALM-LEMEILLE, M.P. Acute toxicity of 8 antidepressants: What are their modes of action? Chemosphere, v.108, p.314-319, 2014.

MUNRO, A.D. The effects of apomorphine, d-amphetamine and chlorpromazine on the aggressiveness of isolated Aequidens pulcher (Teleostei, Cichlidae) Psychopharmacology, v.88, p.124-128, 1986.

NAŁECZ-JAWECKI, G.; HAJNAS, A.; SAWICKI, J. Photodegradation and phototoxicity of thioridazine and chlorpromazine evaluated with chemical analysis and aquatic organisms. Ecotoxicology, v.1, p.13-20, 2008.

NUNES, B.; ANTUNES, S.C.; SANTOS, J.; MARTINS, L.; CASTRO, B.B. Toxic potential of paracetamol to freshwater organisms: a headache to environmental regulators? Ecotoxicology and Environmental Safety, v. 107, p.178- 1885, 2014.

ORGANISATION FOR ECONOMIC CO-OPERATION AND DEVELOPMENT (OECD). Daphnia magna reproduction test. OECD (Organisation for Economic Cooperation and Development) Test guideline 211. Paris, France, 1998.

ORGANISATION FOR ECONOMIC CO-OPERATION AND DEVELOPMENT (OECD). Daphnia sp., acute immobilisation test. Revised proposal for updating guideline 202. OECD (Organisation for Economic Cooperation and Development), Paris, France, 2000.

OSKARSSON, H.; ERIKSSON WIKLUND, A.K.; THORSÉN, G.; DANIELSSON, G.; KUMBLAD, L. Community Interactions Modify the Effects of Pharmaceutical Exposure: A Microcosm Study on Responses to Propranolol in Baltic Sea Coastal Organisms. 2014. Plos one. Available at: http://www. doi:10.1371/journal.pone.00937740093774-g002. Accessed on 01 May 2014. 
QUINN, B.; SCHMIDT, W.; O'ROURKE, K.; HERNAN, R. Effects of the pharmaceuticals gemfibrozil and diclofenac on biomarker expression in the zebra mussel (Dreissena polymorpha) and their comparison with standardized toxicity tests. Chemosphere, v.5, p.657-663, 2011.

RIHEL, J.; PROBER, D.A.; ARVANITES, A.; LAM, K.; ZIMMERMAN, S.; JANG, S.; HAGGARTY, S.J.; KOKEL, D.; RUBIN, L.L.; PETERSON, R.T.; SCHIER, A.F. Zebrafish behavioral profiling links drugs to biological targets and rest/wake regulation. Science, v.5963, p.348-51, 2010.

ROBERTS, P.H.; BERSUDER, P. Analysis of OSPAR priority pharmaceuticals using high-performance liquid chromatography-electrospray ionisation tandem mass spectrometry. Journal of Chromatography A. , v.1-2, p.143-50, 2006.

ROBERTS, P.H.; THOMAS, K.V. The occurrence of selected pharmaceuticals in wastewater effluent and surface waters of the lower Tyne catchment. Science of the Total Environment, v.1-3, p.143-153, 2006.

RODRÍGUEZ, E.M.; MEDESANI, D.A.; FINGERMAN, M. Endocrine disruption in crustaceans due to pollutants: a review. Comparative Biochemistry and Physiology A, v.4, p. 661-671, 2007.

SANTOS, L.H.M.L.M.; ARAUJO, N.A.; FACHINI, A.; PENA, A.; DELERUEMATOS, C.; MONTENEGRO, M.C.B.S.M. Ecotoxicological aspects related to the presence of pharmaceuticals in the aquatic environment. Review. Journal of Hazardous Materials, v.175, p.45-95, 2010.

SARMA， S.S.S.; GONZÁLEZ-PÉREZ， B.K.; MORENO-GUTIÉRREZ， R.M.; NANDINI, S. Effect of paracetamol and diclofenac on population growth of Plationus patulus and Moina macrocopa. Journal of Environmental Biology, v.35, p.119-126, 2013. 
SEBBEN, V. C.; LUGOCH, R. W.; SCHLINKER, C. S.; ARBO, M. D.; VIANNA, R. L. Validação de metodologia analítica e estudo de estabilidade para quantificação sérica de paracetamol. Jornal Brasileiro de Patologia e Medicina Laboratorial. v.46, p.143148,2010

SELDERSLAGHS, I.W.T.; HOOYBERGHS, J.; BLUST, R.; WITTERS, H.E. Assessment of the developmental neurotoxicity of compounds by measuring locomotor activity in zebrafish embryos and larvae. Neurotoxicology and Teratology, v. 37, p.44-56, 2013.

STANLEY, J.K.; RAMIREZ, A.J.; MOTTALEB, M.; CHAMBLISS, C.K.; BROOKS, B.W. Enantiospecific toxicity of the $\beta$-blocker propranolol to Daphnia magna and Pimephales promelas. Environmental Toxicology and Chemistry, v.7, p.1780-1786, 2006.

SUN, L.; XIN, L.; PENG, Z.; JIN, R.; JIN, Y.; QIAN, H.; FU, Z. Toxicity and enantiospecific differences of two $\beta$-blockers, propranolol and metoprolol, in the embryos and larvae of zebrafish (Danio rerio). Environmental Toxicology. 2013. Available at: http://onlinelibrary.wiley.com/doi/10.1002/tox.21867/abstract?denied AccessCustomisedMessage $=\&$ userIsAuthenticated=false. Accessed on 30 March 2014.

TRAUTWEIN, C.; KÜMMERER K. Degradation of the tricyclic antipsychotic drug chlorpromazine under environmental conditions, identification of its main aquatic biotic and abiotic transformation products by $\mathrm{LC}-\mathrm{MS}^{\mathrm{n}}$ and their effects on environmental bacteria. Journal of Chromatography B, v.889-890, p.24-38, 2012.

TROTTIER, S.; BLAISE, C.; KUSUI, T.; JOHNSON, E. M. Acute toxicity assessment of aqueous samples using a microplate- based Hydra attenuata assay. Environmental Toxicology and Water Quality, v. 12, p.265-271, 1997.

USEPA. Methods for measuring the acute toxicity of effluents and receiving waters to freshwater and marine organisms, $5^{\text {th }}$ ed., EPA-821-R-02-012. US Environmental Protection Agency, Washington, 2002. 
VANE, J.R.; BOTTING, R.M. Mechanism of action of anti-inflammatory drugs. Scandinavian Journal of Rheumatology, v.25, p.9-21, 1998.

VOOGT, P.; JANEX-HABIBI, M.L.; SACHHER, F.; PUIJKER, L.; MONS, M. Development of a common priority list of pharmaceuticals relevant for the water cycle. Water Science and Technology, v.59, p.39-46, 2009.

VULLIET, E.; CREN-OLIVÉ, C.; GRENIER-LOUSTALOT, M-F. Occurrence of pharmaceuticals and hormones in drinking water treated from surface waters. Environmental Chemistry Letters, v. 9, p.103-14, 2011.

YUAN, S.; JIANG, X.; XIA, X.; ZHANG, H.; ZHENG, S. Detection, occurrence and fate of 22 psychiatric pharmaceuticals in psychiatric hospital and municipal wastewater treatment plants in Beijing, China. Chemosphere, v.10, p.2520-2525, 2013.

XU, J.J.; HENDRIKS, B.S.; ZHAO, J.; GRAAF, D. Multiple effects of acetaminophen and p38 inhibitors: Towards pathway toxicology. FEBS Letters, v.582, p. 1276-1282, 2008.

ZHANG, Y.; GEIBEN, S-U.; GAL, C. Carbamazepine and diclofenac: removal in wastewater treatment plants and occurrence in water bodies. Chemosphere, v.8, p. 1151-1161, 2008.

ZHOU, S.F. Polymorphism of human cytochrome P450 2D6 and its clinical significance. Clinical Pharmacokinetics, v.48, p.761-804, 2009. 


\section{Capítulo 5}

\section{Avaliação dos efeitos ecotoxicológicos de fármacos em Daphnia magna, utilizando diferentes biomarcadores enzimáticos}

\section{Resumo}

A ocorrência cada vez maior de resíduos de fármacos no meio aquático é motivo de preocupação, devido à ocorrência de fenômenos de toxicidade em espécies não-alvo, incluindo o estresse oxidativo. O presente estudo teve como objetivo avaliar o efeito agudo de quatro diferentes agentes terapêuticos extensivamente utilizados pela população humana: paracetamol (analgésico), clorpromazina (antipsicótico), diclofenaco sódico (anti-inflamatório) e propranolol (anti-hipertensivo), na espécie de Cladocera Daphnia magna. Considerando o envolvimento dos compostos mencionados na diminuição das atividades colinesterásicas e nas modificações nos sistemas redox celular, o propósito deste estudo foi analisar os seus efeitos sobre biomarcadores de regulação neuronal, como colinesterases solúveis (ChEs) e estresse e dano oxidativo, tais como catalase (CAT), glutationa-S-transferases (GSTs), glutationa peroxidase total e glutationa peroxidase selênio-dependente (GPx total; GPx-Se). A exposição ao fármaco acetaminofeno causou uma inibição significativa da atividade da acetilcolinesterase e GPx-Se em D. magna comparado ao controle. Entre os biomarcadores de estresse oxidativo, somente a atividade da catalase (CAT) foi alterada de forma significativa na concentração de $0,001 \mathrm{mg} \mathrm{L}^{-1}$ de clorpromazina, o que não foi consistente com os dados presentes na literatura. O composto diclofenaco sódico causou uma significativa inibição nas atividades de ChE, GPx-Se e GPx total. Já o fármaco propranolol foi responsável por uma redução significativa nas atividades das duas últimas enzimas mencionadas, e também por um ligeiro aumento na atividade de GSTs. Os resultados indicam que a exposição a todos os compostos testados induziu alterações do estado redox celular na espécie estudada. Além disso, o paracetamol e o diclofenaco sódico foram capazes de interferir no processo de neurotransmissão de D. magna, por meio da inibição da ChEs.

Palavras-chave: paracetamol, diclofenaco sódico, clorpromazina, propranolol, colinesterases, stresse oxidativo, fármacos. 


\begin{abstract}
The increasing occurrence of pharmaceutical drugs in the aquatic environment is cause of concern, due to the occurrence of toxic phenomena in non-target species, including oxidative stress. The present study aimed to assess the acute effect of four widely used therapeutic agents: acetaminophen (analgesic), chlorpromazine (antipsychotic), diclofenac (anti-inflammatory) and propranolol (antihypertensive), in the cladoceran species Daphnia magna. Considering the involvement of the mentioned compounds in the impairment of cholinesterasic activity and modifications in cellular redox systems, the purpose of this study was to analyze their effects on biomarkers of neuronal regulation, such as soluble cholinesterases (ChEs), and oxidative stress defense, such as catalase (CAT), glutathione-S-transferases (GSTs), and total and selenium-dependent glutathione-peroxidase (total GPx; Se-GPx) activity. Exposure to acetaminophen caused a significant inhibition of ChE and Se-GPx activities in $D$. magna relative to control. Among the biomarkers of oxidative stress, only the activity of CAT was significantly altered in the concentration of $0.001 \mathrm{mg} \mathrm{L}^{-1}$ of chlorpromazine, which was not consistent with the literature. Diclofenac caused a significant inhibition of ChE and Se-dependent GPx and total GPx activities. Propranolol was responsible for a significant decrease in the activity of the latter two enzymes, and also a slight increase of GSTs activity. The results indicate that the exposure to all the tested compounds induced alterations on the cellular redox status in the studied species. In addition, acetaminophen and diclofenac were shown to have the capability of interfering with $D$. magna neurotransmission, through the inhibition of ChEs.
\end{abstract}

Keywords: acetaminophen, chlorpromazine, sodium diclofenac, propranolol, cholinesterases, oxidative stress, pharmaceuticals. 


\section{Introdução}

Os fármacos são uma classe de contaminantes ambientais emergentes, cuja produção tem aumentado nas últimas décadas, e os gastos universais relacionados ao consumo destes compostos aumentou de 88 a 846 bilhões (USD) por ano de 1985 a 2010 (THAYER, 2011). Esses compostos possuem uma combinação de recursos exclusivos que as transformam em moléculas de interesse ambiental. As drogas são projetadas para serem biologicamente ativas através de um número variado de espécies, sendo metabolizadas lentamente; são altamente lipofílicas para maximizar sua absorção; a degradação dos fármacos é responsável pela liberação de novas moléculas; não caracterizadas em termos de sua farmacologia/toxicologia; fármacos são pseudopersistentes, porque a sua taxa de remoção é compensada pela entrada diária de novas moléculas para o ambiente; interações toxicológicas podem ocorrer com outros resíduos farmacêuticos no ambiente aquático (BRANDÃO et al., 2013). Essas características referidas, entre outras, fazem com que os fármacos sejam avaliados devido aos seus potenciais efeitos deletérios em organismos não-alvo, principalmente no ambiente aquático.

Dados de ecotoxicidade aguda têm sido reportados para um número considerável de fármacos, usando organismos-teste pertencentes a diferentes níveis tróficos (LI, 2013). No entanto, estas informações sozinhas não podem ser usadas para abordar especificamente a questão dos efeitos ambientais e, consequentemente, não podem ser imediatamente utilizadas nos processos de risco e de avaliação de risco (FENT et al., 2006). Na literatura científica, os dados disponíveis sobre os efeitos crônicos e ações de resíduos farmacêuticos nos ecossistemas aquáticos ainda são escassos (BOTTONI et al., 2010; LÓPEZ-SERNA et al., 2010). Além disso, considerando-se que efeitos de concentrações ambientais reportadas para muitos fármacos, raramente causam letalidade, a avaliação de risco de fármacos e outros poluentes a longo prazo nos ecossistemas aquáticos pode ser melhor avaliada se uma bateria de endpoints sub-letais é utilizada. Neste contexto, os biomarcadores são ferramentas úteis que têm sido utilizados como indicadores precoces de poluição ambiental, sendo que consequentes resultados são avaliados devido à sua capacidade de detectar diferentes efeitos em níveis muito baixos (COELHO et al., 2011). 
Os biomarcadores enzimáticos de diferentes vias metabólicas (por exemplo, neuronais, metabolismo energético e estresse oxidativo) podem ser utilizados para avaliar as respostas iniciais dos resíduos de compostos farmacêuticos (NUNES et al., 2006). Entre as enzimas neuronais, a atividade das colinesterases (ChE) é a mais utilizada como biomarcador para a poluição ambiental, devido ao seu papel fundamental na hidrólise do neurotransmissor acetilcolina nos sistemas periférico e nervoso (HOLTH et al., 2008). Em vertebrados, existem dois tipos de ChEs: acetilcolinesterase (AChE, EC 3.1.1.7) e butirilcolinesterase ou pseudocolinesterase (BChE, CE 3.1.1.8), que diferem na sua especificidade para o substrato (LETICIA \& GERARDO, 2008). A acetilcolinesterase (AChE), também conhecida como colinesterase verdadeira ou colinesterase específica, é importante na função do sistema nervoso. Estudos recentes também mostram que alguns fármacos aumentam a inibição da atividade da acetilcolinesterase (AChE) em organismos aquáticos (SOLE et al., 2010) mostrando a capacidade de resposta deste biomarcador para detectar a poluição ambiental por drogas.

O estresse oxidativo pode ser medido utilizando vários biomarcadores enzimáticos, como a catalase (CAT, uma enzima antioxidante que age contra as espécies reativas de oxigênio, ROS, convertendo peróxido de hidrogênio em água e oxigênio (LI et al., 2010). As isoenzimas da glutationa S-transferases (GSTs) são um grupo de enzimas que catalisam a conjugação da glutationa com xenobióticos, incluindo pesticidas organofosforados, e os aldeídos citotóxicos produzidos na peroxidação lipídica (BOOTH \& O'HALLORAN, 2001). A glutationa peroxidase (GPx) desempenha um papel protetor importante, agindo como depuradora para níveis elevados de peróxido de hidrogênio; durante este processo, a glutationa é oxidada e perde o seu potencial antioxidante protetor (NUNES et al., 2006). Alguns compostos farmacêuticos podem estimular a produção de ROS, provocando danos oxidativos para os organismos aquáticos, incluindo peixes e invertebrados como verificado em estudos com acetaminofeno (SOLÉ et al., 2010; GÓMEZ-OLIVÁN et al., 2012; ANTUNES et al., 2013; SUNG et al., 2014), clorpromazina (LI et al., 2008), diclofenaco sódico (OVIEDO-GÓMEZ et al, 2014; PAROLINI \& BINELLI, 2012; PAROLINI et al., 2013; NAVA-ÁLVAREZ et al., 2014) e propranolol (SOLÉ et al., 2010; FRANZILLITI et al., 2011). 
O acetaminofeno (APAP), também designado como paracetamol, é um analgésico e anti-inflamatório comum, amplamente utilizado para o alívio de dores de cabeça e febres e é frequentemente detectado no ambiente aquático (CHAOUCHI \& HAMDAOUI, 2014). A presença deste composto tem sido registrada em efluentes de tratamento de águas residuárias em quantidades consideráveis $\left(6 \mu \mathrm{g} \mathrm{L}^{-1}\right.$, TERNES, 1998), mas também em águas naturais (até $10 \mu \mathrm{g} \mathrm{L}^{-1}$, KOLPIN et al., 2002) e em rios (como o rio Danúbio, em níveis mais elevados que $78 \mu \mathrm{g} \mathrm{L}^{-1}$, conforme relatado por GRUJIĆ et al., 2009). Em doses elevadas, o paracetamol pode provocar efeitos tóxicos graves (DAVERNET al., 2006), associados ao estresse oxidativo e/ou pela produção de $\mathrm{N}$-acetil-p-benzoquinonaimina (NAPQI), um intermediário reativo responsável pela atividade oxidante. De acordo com Xu et al. (2008), NAPQI pode conduzir a efeitos tóxicos de natureza oxidante, bem como alterações covalentes de grupos tiol em proteínas celulares, danos no DNA e RNA, e a oxidação de lipídios da membrana, causando necrose e morte celular.

A clorpromazina é usada para controlar a emoção, agitação, agressividade e outros distúrbios psicomotores em pacientes esquizofrênicos, e às vezes é usado em outras condições psiquiátricas para o controle da ansiedade e tensão (BORGES et al., 2011). O efeito antipsicótico da clorpromazina pode estar relacionado com sua ação de bloqueio em adrenérgicos centrais e um pré-requisito para o efeito terapêutico desta substância é a sua capacidade de atravessar a barreira hemato-encefálica. Este composto tem sido detectado em baixas concentrações em efluentes de hospitais psiquiátricos (5-364 ng L ${ }^{-}$ ${ }^{1}$ ) (YUAN et al., 2013) e em menores níveis em águas de superfície (abaixo de $1 \mathrm{ng} \mathrm{L}^{-1}$ ) (ROBERTS \& BERSUDER, 2006).

O diclofenaco sódico é uma droga anti-inflamatória não esteróide (AINE) amplamente utilizada, que é indicada em condições que incluem inflamação, artrite e dores reumáticas, atuando como um inibidor da ciclo-oxigenase, e também têm-se demonstrado sua capacidade em induzir o estresse oxidativo (NAVA-ALVAREZ et al., 2014). Este composto é comumente detectado em corpos d'água, sendo um dos mais frequentemente relatados em águas superficiais na concentração de $1,03 \mu \mathrm{g} \mathrm{L^{-1 }}$ (HEBERER et al., 2002.); 2 ng L ${ }^{-1}$ em água potável (região do Mediterrâneo; RABIET et al., 2006) e 6,2 ng L ${ }^{-1}$ no Rio Elba (WEIGEL et al., 2002).

O propranolol é um bloqueador $\beta$-adrenérgico não-seletivo, usado principalmente no tratamento de angina, hipertensão e outras doenças relacionadas com o coração em 
seres humanos (FENT et al., 2006). Nos mamíferos, o sistema adrenérgico está envolvido em muitas funções fisiológicas, tais como a regulação do ritmo cardíaco, nos níveis de oxigênio, na vasodilatação e na broncodilatação (FENT et al., 2006a). No entanto, em invertebrados também tem sido relacionado com o controle da frequência cardíaca e com a força com que o músculo contrai o coração (TRAN et al., 2004). Investigações ecotoxicológicas foram realizadas com vários $\beta$-bloqueadores, principalmente propranolol (SOLE et al., 2010; FRANZELLITTI et al., 2011). A presença de resíduos de propranolol foi reportada em baixas concentrações em efluentes (16-388 ng L ${ }^{-1}$; ZHOU et al., 2009), e ainda em concentrações menores em águas de superfície (<10 $\mathrm{ng} \mathrm{L}^{-1}$ e abaixo de $37 \mathrm{ng} \mathrm{L}^{-1}$ ) (KIM et al., 2009).

Considerando o possível envolvimento dos compostos acima mencionados em atividades colinesterásicas e sistemas redox celular, juntamente com a falta de conhecimento sobre o impacto dessas drogas nos organismos aquáticos, o objetivo deste estudo foi avaliar os seus efeitos sobre biomarcadores de colinesterases solúveis (ChEs) e estresse oxidativo (catalase: CAT; glutationa-S-transferases: GSTs, glutationaperoxidase total e glutationa peroxidase selênio-dependente: GPx total e GPx-Se) na espécie de Cladocera Daphnia magna. Os fármacos estudados foram escolhidos devido ao grande consumo pela população mundial e pela frequência em que são reportados em estudos de monitoramento no ambiente aquático. Além disso, na literatura não existem muitos estudos com cladóceros após a exposição a estes fármacos, e a caracterização dos seus efeitos em nível de biomarcadores enzimáticos sobre estes consumidores primários em ambiente de água doce é fundamental para a avaliação dos seus potenciais impactos ecológicos.

A espécie Daphnia magna é amplamente utilizada como organismo-teste em Ecotoxicologia, devido à sua alta sensibilidade a uma ampla gama de poluentes, relevância ecológica, facilidade de manuseio e manutenção laboratorial, existência de protocolos padronizados, ciclo de vida curto e taxas de reprodução elevadas (MÜNZINGER \& MONICELLI, 1992; BONA et al., 2014). Esta espécie tem sido muito utilizada para avaliar diferentes compostos farmacêuticos e seus potenciais impactos ecotoxicológicos (HAN et al., 2006). 


\section{Material e Métodos}

\subsection{Organismo-teste e condições de cultivo}

As culturas monoclonais de Daphnia magna (Clonar A sensu Baird et al., 1989) foram mantidas em laboratório por várias gerações em meio ASTM (ASTM, 1980; USEPA, 2002), complementadas com aditivo orgânico obtido a partir do extrato da alga marinha, Ascophyllum nodosum, e vitaminas (de acordo com ELENDT \& BIAS, 1990). As condições de manutenção das culturas de D. magna estão descritas com maiores detalhes no capítulo 3 desta tese.

\subsection{Fármacos e concentrações-teste}

Os compostos farmacêuticos: acetaminofeno, clorpromazina, diclofenaco de sódio e propranolol com pureza $\geq 99 \%$, foram adquiridos da Sigma-Aldrich Chemical. As soluções-estoque foram preparadas por diluição em ASTM de cada fármaco imediatamente antes de cada experimento.

\subsection{Testes de toxicidade aguda}

Os bioensaios de toxicidade aguda seguiram protocolos padronizados (ASTM, 1997; ISO, 1996; OCDE, 2000), sob os mesmos regimes de fotoperíodo e temperatura descritos para os procedimentos de cultivo. Os organismos foram expostos por 48 horas em frascos de vidro de 1L, com volume final de $800 \mathrm{~mL}$ de cada solução- teste. Cada concentração testada foi composta por 3 réplicas, sendo que em cada uma foram adicionados 300 neonatos ( $\leq 24 \mathrm{~h}$ de idade nascidos entre a terceira e quinta ninhada). Durante o período de exposição, os animais não foram alimentados. Para todos os testes de toxicidade aguda, uma gama geométrica de três diferentes concentrações foram obtidas a partir das diluições dos quatro fármacos selecionados em água de cultivo.

As concentrações utilizadas foram todas sub-letais, sendo selecionadas de acordo com os valores de NOEC (do inglês, No Observed Effect Concentration) calculados em testes de toxicidade crônica destes compostos à espécie D. magna e também pelos níveis relatados em corpos d'água. As concentrações nominais finais testadas foram: 
0,00; 0,01; 0,1 e 1,0 mg L ${ }^{-1}$ de acetaminofeno; 0,00; 0,00001; 0,001 e 0,25 $\mathrm{mg} \mathrm{L}^{-1}$ de clorpromazina; 0,00; 0,0005; 0,5 e 7,2 $\mathrm{mg} \mathrm{L}^{-1}$ de diclofenaco de sódio e 0,00; 0,001; 0,01 e $1,0 \mathrm{mg} \mathrm{L}^{-1}$ para o propranolol, respectivamente. Após o período de exposição, os neonatos foram transferidos para tubos eppendorf, dependendo do número requerido para quantificar os diferentes biomarcadores, livres da solução-teste à qual foram previamente expostos e armazenados a $-80^{\circ} \mathrm{C}$, até serem homogeneizados para as determinações enzimáticas.

\subsection{Ensaios bioquímicos}

A atividade total das colinesterases $(\mathrm{ChE})$ foi determinada de acordo com o método de Ellman et al. (1961), adaptado para microplaca, como descrito e otimizado para $D$. magna em Guilhermino et al. (1996b). Este método baseia-se na degradação de acetiltiocolina (análogo estrutural de acetilcolina) pela atividade da presente acetilcolinesterase nas amostras, com formação de tiocolina.

As amostras para a determinação da atividade de $\mathrm{ChE}$ foram homogeneizadas em tampão fosfato $(0,1 \mathrm{M}$; pH 7,2) utilizando um homogeneizador de tecidos rotativo a $14.000 \mathrm{rpm}$, mantidos em gelo durante a homogeneização. Os homogeneizados foram posteriormente centrifugados a $6.000 \mathrm{rpm}$ durante $3 \mathrm{~min}$ a $4{ }^{\circ} \mathrm{C}$. As atividades enzimáticas foram medidas em um espectrofotômetro Thermo Scientific Multiskan EX (Ascent Software 2.6) a $412 \mathrm{~nm}$. As leituras foram feitas de 10 e 15 minutos após a adição da solução de reação. Os resultados foram expressos como nmoles de complexo formado por minuto, por miligrama de proteína.

A atividade da catalase (CAT) foi determinada por espectrofotometria, medindo-se a diminuição da absorbância a $240 \mathrm{~nm}\left(240 \varepsilon=0.00394 \pm 0,0002 \mathrm{mM}^{-1} \mathrm{~mm}^{-1}\right)$, tal como descrito por Aebi (1984), devido à decomposição do peróxido de hidrogênio $\left(\mathrm{H}_{2} \mathrm{O}_{2}\right)$ em água $\left(\mathrm{H}_{2} \mathrm{O}\right)$ e $\mathrm{O}_{2}$. As alterações na absorbância das amostras foram monitoradas espectrofotometricamente a $240 \mathrm{~nm}$ durante 30 segundos, e as atividades foram expressas como nmoles de $\mathrm{H}_{2} \mathrm{O}_{2}$ consumidos por minuto, por miligrama de proteína.

A atividade da glutationa-S-transferase (GSTs) também foi determinada por espectrofotometria, de acordo com Habig et al. (1974). As GSTs catalisam a conjugação do substrato 1-cloro-2,4-dinitrobenzeno (CDNB) com a glutationa (GSH), formando um 
tioéter cuja formação pode ser seguida pelo aumento da absorbância a um comprimento de onda de $340 \mathrm{~nm}\left(\varepsilon 340=0,96 \mathrm{mM}^{-1} \mathrm{~mm}^{-1}\right)$. Os resultados foram expressos como nmol de tioéter produzidas por minuto, por miligrama de proteína.

A atividade da glutationa peroxidase (GPx) foi determinada por espectrofotometria, de acordo com Flohe e Günzler (1984). As enzimas glutationa peroxidase participam na oxidação da glutationa reduzida $(\mathrm{GSH})$ e do peróxido de hidrogênio $\left(\mathrm{H}_{2} \mathrm{O}_{2}\right)$ em glutationa oxidada (GSSG) e $\mathrm{H}_{2} \mathrm{O}$. A oxidação mediada pela GPx de fosfato de nicotinamida adenina dinucleotídeo (NADPH) pode ser monitorada a $340 \mathrm{~nm}$. A determinação da atividade da GPx foi realizada com dois substratos: peróxido de hidrogênio (que corresponde a GPx- selênio dependente) e cumeno hidroperóxido (que corresponde a GPx total). As atividades enzimáticas foram expressas em nmol de NADPH oxidado por minuto por miligrama de proteína.

A determinação da concentração de proteína das amostras foi realizada de acordo com o método de espectrofotometria de Bradford (1976) (comprimento de onda de 595 $\mathrm{nm}$ ), adaptada para microplaca (96 poços) utilizando $\gamma$-globulina bovina como padrão, a fim de expressar as atividades enzimáticas em função da proteína.

\subsection{Análises estatísticas}

Os dados bioquímicos foram $\log (x+1)$ transformados antes da análise, para cumprir com as premissas normalidade e homocedasticidade. Os parâmetros bioquímicos foram analisados com ANOVA one-way, seguido pelo teste de Dunnett para discriminar diferenças significativas entre as concentrações analisadas e o controle. Todas as análises estatísticas foram realizadas utilizando-se o Software Sigmaplot (versão 11.0). O nível de significância adotado foi de 0,05 .

\section{Resultados}

\subsection{Respostas dos biomarcadores}

\section{Efeitos da exposição ao acetaminofeno}

Os nossos resultados mostraram que a exposição ao acetaminofeno causou uma significativa redução na atividade de ChE para as três concentrações mais elevadas 
testadas $(F=4,71 ; \mathrm{MS}=10,48 ; \mathrm{df}=3,0 ; p=0,035336$; Figura 1A). Isso também foi observado para a atividade de GPx selênio-dependente, para as mesmas concentrações $(F=5,71 ; \mathrm{MS}=77,71 ; \mathrm{df}=3,0 ; p=0,02183 ;$ Figura $1 \mathrm{~B})$.
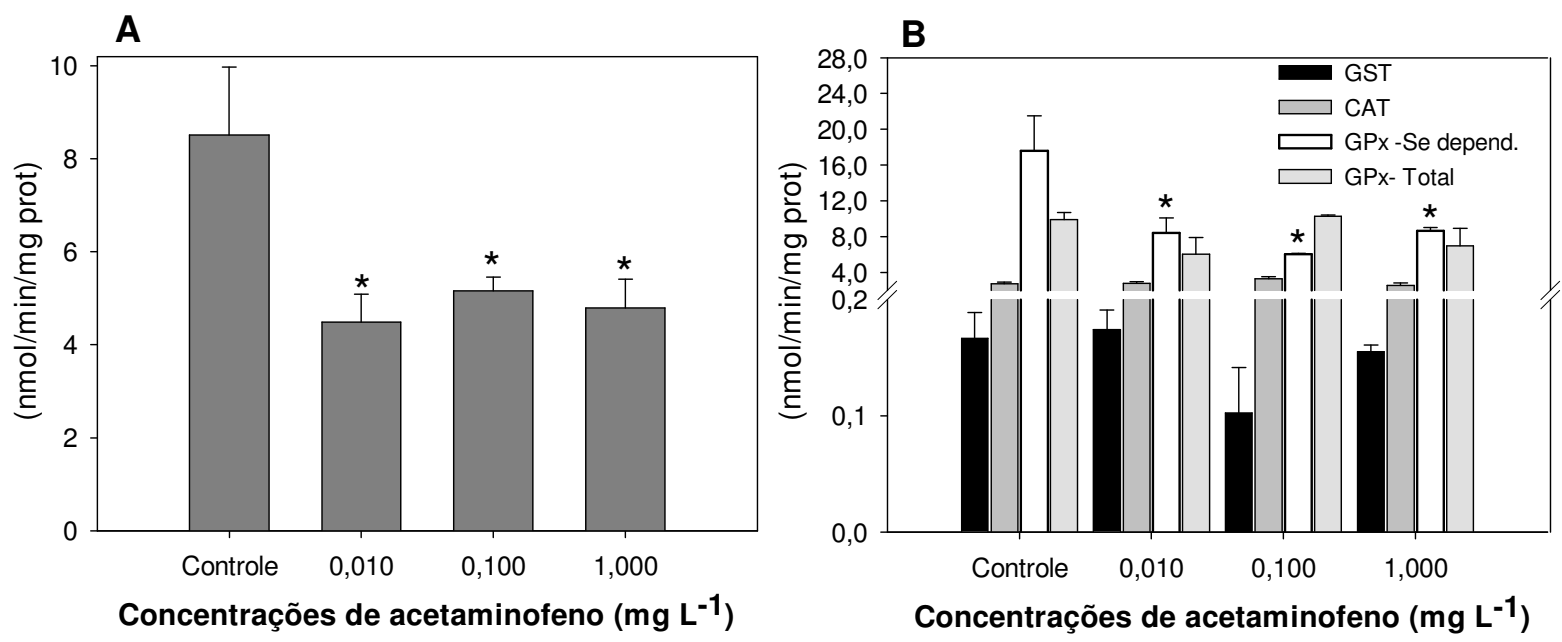

Figura 1. Efeitos do acetaminofeno nas atividades da $\mathrm{ChE}(\mathrm{A})$ e das enzimas de estresse oxidativo (GST, CAT, GPx-Se-dependente e GPx-total) (B), em Daphnia magna. Para cada parâmetro bioquímico, o valor médio e o desvio-padrão são mostrados. Os asteriscos no topo das barras representam diferenças estatisticamente significativas (Teste de Dunnett, $\mathrm{p} \leq 0,05$ ) entre as concentrações dos compostos farmacêuticos e o controle.

\section{Efeitos da exposição à clorpromazina}

Não houve efeito significativo sobre a atividade de ChE após a exposição de $D$. magna ao composto clorpromazina $(F=0,38 ; \mathrm{MS}=0,47 ; \mathrm{df}=3,0 ; p=0,76911$; Figura 2C). Entre os biomarcadores de estresse oxidativo, apenas a atividade da catalase (CAT) foi alterada de forma significativa na concentração de $0,001 \mathrm{mg} \mathrm{L}^{-1}(F=4,46$; $\mathrm{MS}=$ 0,$93 ; \mathrm{df}=3,0 ; p=0,040301$; Figura 2D). 

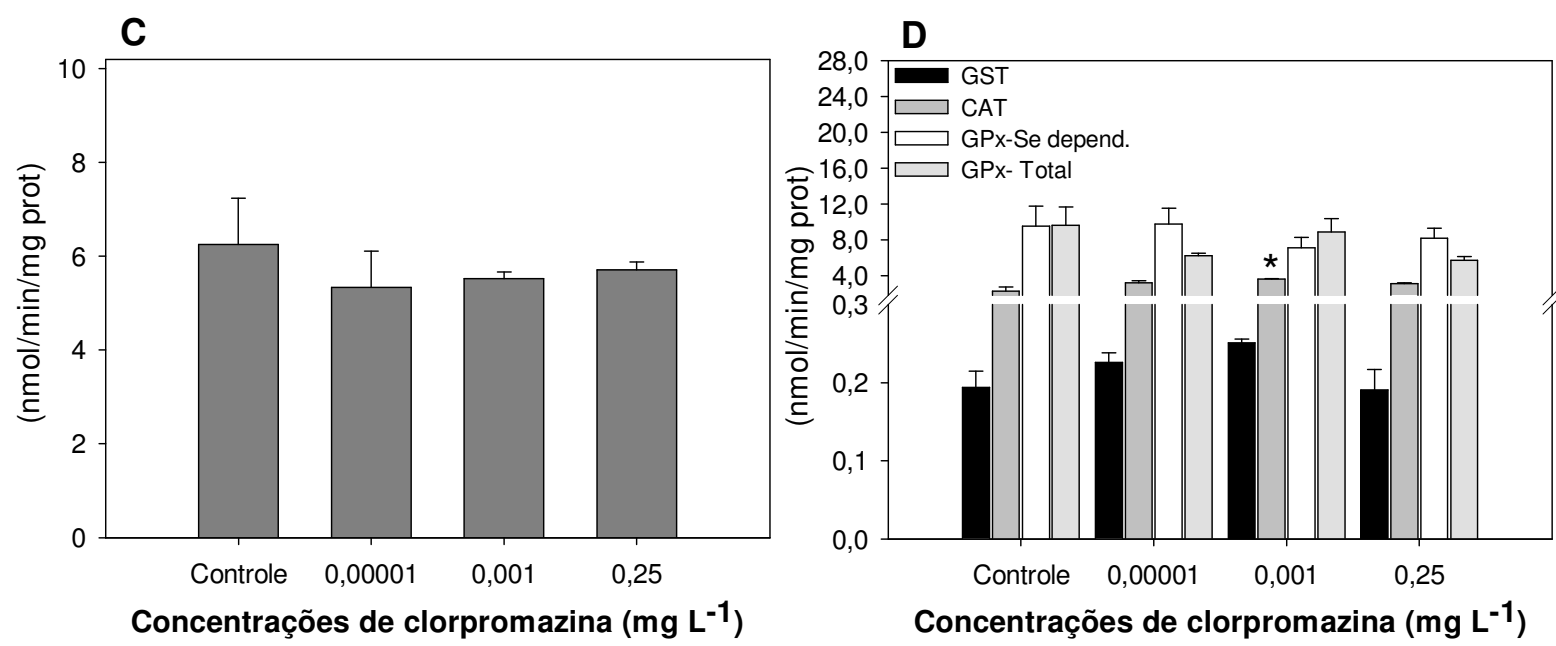

Figura 2. Efeitos da clorpromazina nas atividades da $\mathrm{ChE}(\mathrm{C})$ e das enzimas de estresse oxidativo (GST, CAT, GPx-Se-dependente e GPx-total) (D), em Daphnia magna. Para cada parâmetro bioquímico, a média e o desvio-padrão são mostrados. Os asteriscos no topo das barras representam diferenças estatisticamente significativas (Teste de Dunnett, $\mathrm{p} \leq 0,05$ ) entre as concentrações dos compostos farmacêuticos e o controle.

\section{Efeitos da exposição ao diclofenaco sódico}

A exposição ao diclofenaco sódico causou uma diminuição significativa da atividade da $\mathrm{ChE}$, mas somente para a primeira e última concentrações testadas $(F=$ 6,44; $\mathrm{MS}=4,40 ;$ df $=3,0 ; p=0,015832$; Figura 3E). A atividade da GPx- selênio dependente sofreu uma diminuição significativa no organismo-teste aqui exposto, para as concentrações de 0,0005 e $0,5 \mathrm{mg} \mathrm{L}^{-1}$, respectivamente $(F=5,45 ; \mathrm{MS}=53,86$; df $=$ 3,$0 ; p=0,02456$; Figura 3F). 


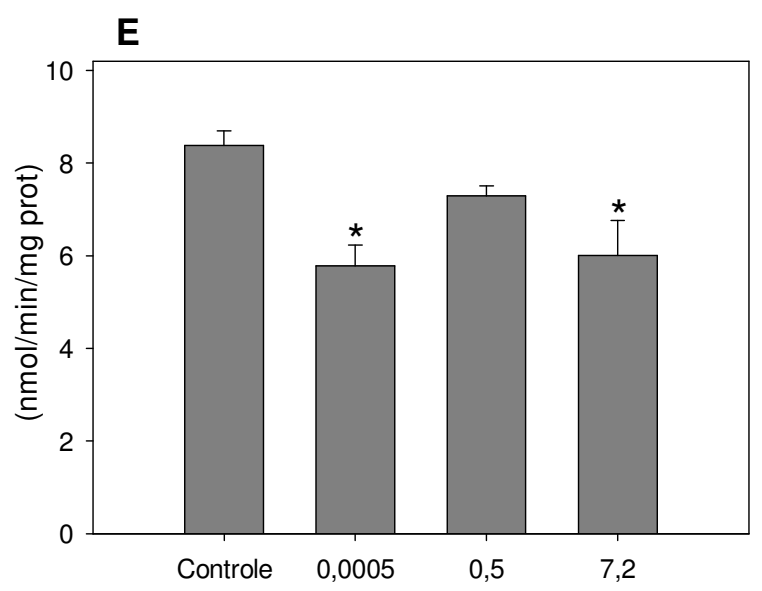

Concentrações de diclofenaco sódico $\left(\mathrm{mg} \mathrm{L}^{-1}\right)$

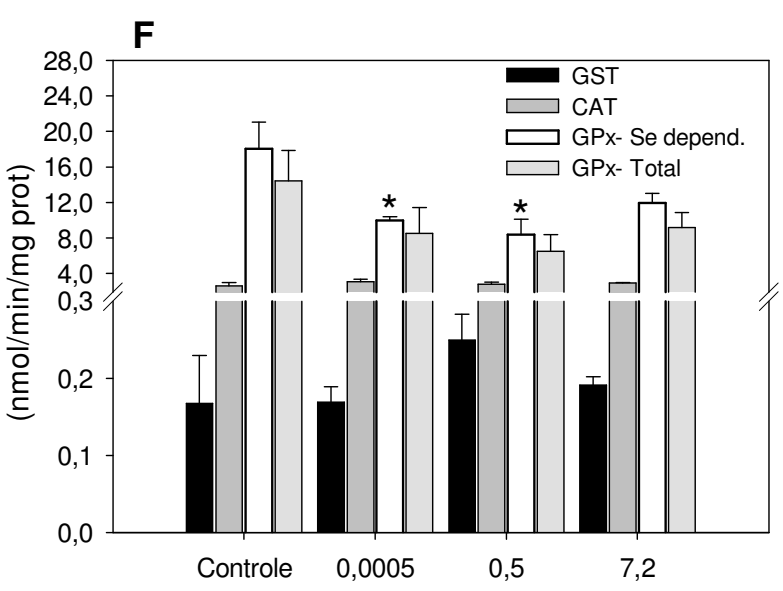

Concentrações de diclofenaco sódico $\left(\mathrm{mg} \mathrm{L}^{-1}\right)$

Figura 3. Efeitos do diclofenaco sódico nas atividades da $\mathrm{ChE}(\mathrm{E})$ e das enzimas de estresse oxidativo (GST, CAT, GPx-Se-dependente e GPx-total) (F), em Daphnia magna. Para cada parâmetro bioquímico, o valor médio e o desvio-padrão são mostrados. Os asteriscos no topo das barras representam diferenças estatisticamente significativas (Teste de Dunnett, $p \leq 0,05$ ) entre as concentrações dos compostos farmacêuticos e o controle.

\section{Efeitos da exposição ao propranolol}

A exposição ao propranolol não foi associado a qualquer mudança na atividade da ChE em D. magna ( $F=1,59 ; \mathrm{MS}=7,29 ; \mathrm{df}=3,0 ; p=0,266709$; Figura 4G). O metabolismo de GSH foi definitivamente afetado pela exposição ao fármaco propranolol, e os resultados obtidos para a atividade de GSTs mostraram um aumento evidente nos níveis desta enzima para as duas concentrações mais elevadas testadas (Figura 4H), $(F=10,37 ; \mathrm{MS}=0,01 ; \mathrm{df}=3,0 ; p=0,003941)$. Este fármaco induziu uma resposta significativa sobre a atividade inibidora da GPx total e GPx selênio-dependente $(F=2,68 ; \mathrm{MS}=41,40 ; \mathrm{df}=3,0 ; p=0,118119$ e $F=4,98 ; \mathrm{MS}=68,35 ; \mathrm{df}=3,0 ; p=$ 0,030907, respectivamente). Isto é particularmente evidente para as concentrações 0,01 e $0,1 \mathrm{mg} \mathrm{L}^{-1}$ (GPX-total) e apenas para a concentração mais elevada de propranolol (GPx- selênio-dependente) (Figura 4H). 

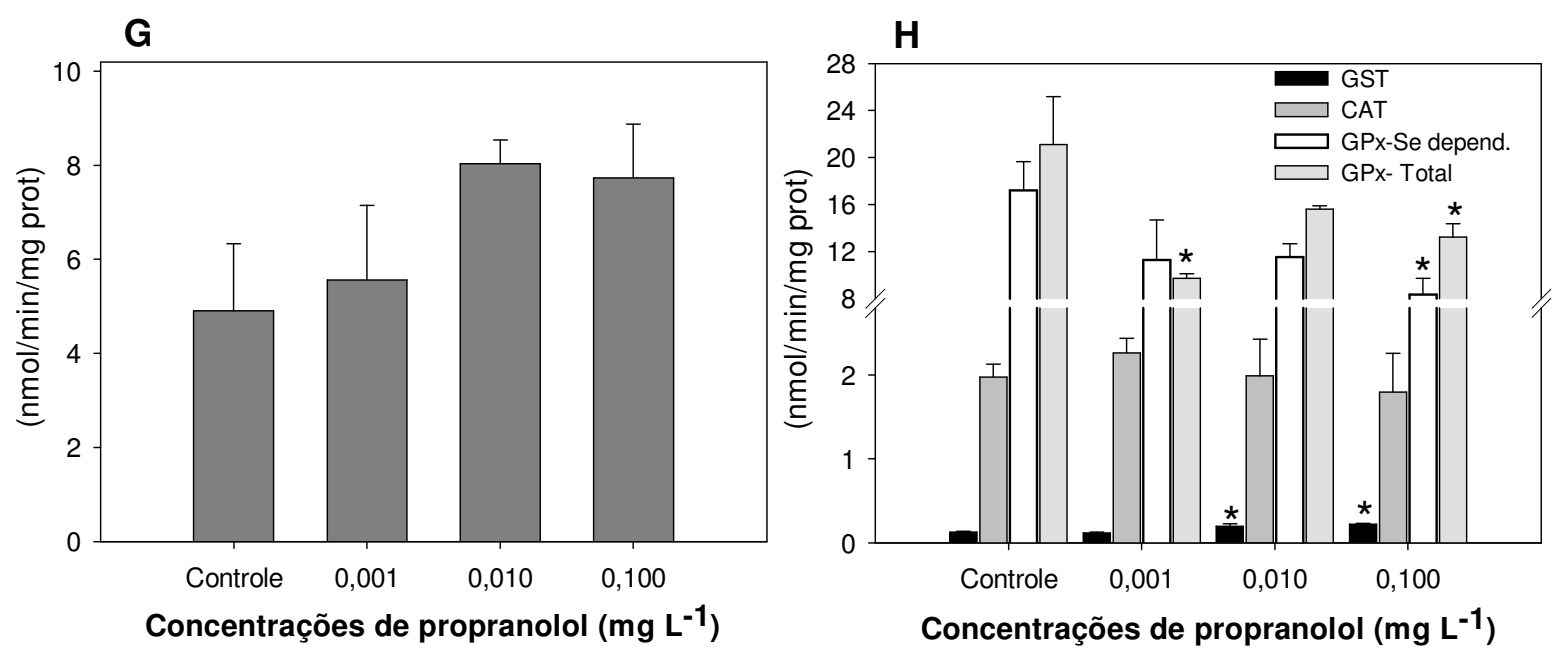

Figura 4. Efeitos do propranolol nas atividades da $\mathrm{ChE}(\mathrm{G})$ e das enzimas de estresse oxidativo (GST, CAT, GPx-Se-dependente e GPx-total) (H), em Daphnia magna. Para cada parâmetro bioquímico, o valor médio e o desvio-padrão são mostrados. Os asteriscos no topo das barras representam diferenças estatisticamente significativas (Teste de Dunnett, $\mathrm{p} \leq 0,05$ ) entre as concentrações dos compostos farmacêuticos e o controle.

\section{Discussão}

\section{Acetaminofeno}

A importância da neurotoxicidade em termos de consequências ecológicas é considerável, uma vez que a grande maioria dos organismos possui um sistema integrado de controle e regulação de outros tecidos/órgãos; até mesmo as formas de vida rudimentares apresentam algum tipo de integração nervosa, e qualquer perturbação neste nível pode comprometer ou prejudicar o funcionamento correto e estável de organismos, ameaçando a sobrevivência. Rotíferos e cladóceros não são exceções, uma vez que eles possuem um sistema neural primitivo e/ou mecanismo neurológico ágil, incluindo os receptores colinérgicos conservados, e a enzima AChE. Anteriormente, Pineda-Rosas et al. (2005) encontraram a acetilcolinesterase (AChE) em seis receptores de rotíferos de água doce, o que sugere que o sistema nervoso destes organismos seria capaz de utilizar a acetilcolina como neurotransmissor para posterior transdução de sinal. No entanto, informações de gene ou dados relevantes de proteína sobre a neurotoxicidade não foram ainda identificados em Rotifera, sublinhando o estado 
evolutivo incipiente destes organismos (RHEE et al., 2013). Estes resultados, em combinação com os nossos devem, portanto, ser úteis para se obter uma melhor compreensão do modo de ação do paracetamol no sistema nervoso destes crustáceos. A partir desses estudos, portanto, é possível determinar a relevância das enzimas colinesterásicas no processo de neurotransmissão da espécie de Cladocera D. magna. De acordo com Kwong (2002), a AChE é envolvida na hidrólise da acetilcolina em colina e acetato, e desempenha uma função fundamental na neurotransmissão nas sinapses colinérgicas. Assim, a inibição da atividade da AChE faz com que o neurotransmissor acetilcolina se acumule conduzindo à desordem do sistema nervoso. Os estudos mostram que em organismos aquáticos, a atividade da AChE é inibida por uma multiplicidade de contaminantes, que inclui pesticidas (especialmente inseticidas) metais pesados, detergentes, e alguns produtos farmacêuticos (SOLE et al., 2010; ROCHA et al., 2013). Os resultados aqui obtidos indicam que a inibição desta enzima causada pelo fármaco paracetamol ocorreu em $\mathrm{mg} \mathrm{L}^{-1}$, que é consideravelmente superior do que os níveis relatados para alguns organofosforados (incluindo malation, paration, clorpirifós e propoxur; PRINTES \& CALLAGHAN, 2004) para causar efeitos comparáveis. Esta tendência é comum, uma vez que os diferentes modos de ação esperados de produtos farmacêuticos são inevitavelmente distintos daqueles apresentados por um pesticida. Isso reflete inevitavelmente em níveis que podem exercer alterações significativas em biomarcadores específicos, como a atividade da colinesterase. Entretanto, e se consideram apenas os compostos farmacêuticos, os nossos resultados estão de acordo com dados publicados anteriormente. Na verdade, nossos resultados são semelhantes aos relatados por Solé et al. (2010) estudando a espécie de mexilhão marinho Mytilus galloprovincialis, que verificou a inibição da AChE (58\% comparativamente com o controle), com nível de significância nas brânquias, após a exposição aguda com acetaminofeno. Consequentemente, o efeito tóxico agudo de vários compostos farmacológicos está diretamente relacionado com a inibição da atividade da $\mathrm{AChE}$, o que sugere que algumas destas substâncias, incluindo o acetaminofeno, pode ter um potente efeito neurotóxico (RHEE et al., 2013). Da mesma forma, esses autores observaram que a atividade da AChE e seu nível de transcrição no rotífero Brachionus koreanus diminuíram significativamente após os experimentos (12 e 48 horas, e com concentrações comparáveis). Em relação aos perfis de transcrição em resposta à exposição ao paracetamol, a diminuição da atividade da 
AChE pode estar diretamente relacionada a um nível mais baixo do mRNA, como sugerido por Xing et al. (2010). Mas devido aos poucos estudos, os efeitos deste fármaco sobre os genes $\mathrm{AChE}$ requerem ser mais estudados, principalmente em crustáceos.

A ocorrência de estresse oxidativo na espécie D. magna pode ser inferida a partir dos resultados obtidos para ambas as formas de glutationa peroxidase (total e selênio dependente). Enzimas GPx pertencem à família da glutationa (GSH), cuja função é a remoção de espécies de radicais livres (tais como peróxido de hidrogênio e os radicais superóxido), e também está envolvida na proteção das membranas tióis proteicas (KAVITHA et al., 2011).

A redução na atividade da GPx em nosso estudo pode indicar que a sua capacidade antioxidante foi superada pela quantidade de produtos hidroperóxidos da peroxidação lipídica (MONTEIRO et al., 2006), ou como consequência da inativação direta da enzima causada por metabólitos reativos do paracetamol. Nossos dados estão de acordo com os resultados publicados por Gómez-Oliván (2012), em que a exposição ao paracetamol (72 h) induziu uma diminuição da atividade total da GPx em 32,2\% sobre a espécie de anfípodo Hyalella azteca. Estes autores sugerem que esta redução pode estar relacionada aos vários metabólitos do composto acetaminofeno, que são capazes de se ligar a moléculas proteicas inibindo a sua atividade. No entanto, a redução da atividade da GPx, após a exposição do paracetamol não é uma tendência genérica. Na verdade, os nossos resultados diferem dos dados publicados em outros estudos. A espécie de peixe Oncorhynchus mykiss quando exposta a este composto mostrou um aumento significativo em ambas as formas de glutationa peroxidase para as concentrações 5 ordens de grandeza acima $\left(0,05 ; 0,5\right.$ e $\left.5 \mathrm{mg} \mathrm{L}^{-1}\right)$ do que o presente estudo (RAMOS et al., 2014). Kavitha et al. (2011) em experimentos com o peixe Oreochromis mossambicus (tilápia), descreveu os aumentos notáveis nas atividades de GPx (e outras enzimas antioxidantes, incluindo a glutationa redutase e glutationa-S-transferases), após a exposição aguda ao paracetamol, em todos os tecidos analisados (brânquias, fígado , rim e músculo). Um aumento significativo na atividade da GPx foi igualmente observada em guelras, cérebro e fígado da espécie Cyprinus carpio, após exposição ao paracetamol (NAVA-ALVAREZ et al., 2014). Do mesmo modo, o aumento das atividades da GPx e de outras enzimas antioxidantes (catalase, superóxido dismutase, e glutationa-S-transferases) foi descrito por Parolini et al. (2010), após bioensaios agudos 
com acetaminofeno sobre a espécie de mexilhão zebra (Dreissena polymorpha). Nossos resultados mostraram que este composto farmacêutico não causou alterações na atividade da CAT em D. magna, com exceção da concentração de $0,1 \mathrm{mg} \mathrm{L}^{-1}$, que induziu um aumento da sua atividade. No entanto, o paracetamol causou uma inibição não significativa na atividade da GST, quando comparado com o controle. Parolini et al. (2010) sugere que o fármaco paracetamol é uma substância química muito polar (log Kow $=0,46$; LORPHENSRI et al., 2007) e pode ser facilmente conjugada à glutationa (GSH) por GST através das enzimas envolvidas na fase I da biotransformação. Esta via também é observada em mamíferos, onde níveis elevados de acetaminofeno são oxidados por enzimas do sistema citocromo P-450, conduzindo à formação de N-acetilp-benzoquinonaimina (NAPQI). O NAPQI é desintoxicado pela conjugação com a glutationa (GSH) e excretado como a cisteína ou ácido conjugado mercaptopurina (KAVITHA et al., 2011). No entanto, em casos de doses excessivas desse composto, o NAPQI interage fortemente com as proteínas e os ácidos nucleícos devido à sua natureza eletrófila resultando na formação de espécies reativas de oxigênio (ROS) (PAROLINI et al., 2010).

Além disso, Parolini e Binelli (2012) avaliaram os efeitos combinados de paracetamol em uma mistura com outros fármacos anti-inflamatórios não-esteróides (como o diclofenaco sódico e o ibuprofeno) sobre a espécie de bivalve de água doce Dreissena polymorpha; os resultados obtidos evidenciaram um aumento significativo nas atividades da GPx e GSTs após exposições agudas a esta mistura. De acordo com Aouacheri et al. (2009), pode-se observar que o incremento na atividade da GPx causada pelo paracetamol não é restrita à biota aquática; atividade da GPx no sangue de mamíferos também respondeu à administração oral deste fármaco.

A partir do conjunto global dos resultados, é possível propor a ocorrência de respostas baseadas no stresse oxidativo que ocorreram sob baixos níveis de exposição, e foram semelhantes aos dados já publicados para modelos distintos. Isso reforça a idéia de que a toxicidade do paracetamol é mediada, também em organismos aquáticos, por esta via específica. 


\section{Clorpromazina}

A exposição do composto farmacológico clorpromazina sobre o cladócero $D$. magna causou uma inibição não significativa na atividade da $\mathrm{ChE}$, quando comparada com o controle (Figura 1C). Resultados semelhantes foram obtidos por Seibt et al. (2009), que avaliaram os efeitos in vitro e in vivo de outros antipsicóticos (como a sulpirida, olanzapina e haloperidol) na atividade da AChE e o padrão de expressão no cérebro do peixe-zebra Danio rerio. Este estudo mostrou que a exposição in vitro de todas as substâncias foram capazes de promover uma redução na atividade da acetilcolinesterase; por outro lado, estudos in vivo demonstraram que apenas a olanzapina e a sulpirida não alteraram a atividade da enzima analisada. Um fator importante a considerar quando se interpreta a neurotoxicidade induzida pelos antipsicóticos é a sua farmacologia. Sem dúvida, os fármacos antipsicóticos que interagem com o arranjo lipídico na membrana neuronal são susceptíveis às alterações das propriedades biológicas da membrana (TESSIER et al., 2008), a qual é a base para a sua atividade farmacológica/terapêutica. Dado que a acetilcolina é ancorada à superfície externa da membrana plasmática dos neurônios por uma estrutura de glicosilfosfatidilinositol (GPI) presa de forma covalente, é possível propor que as mudanças no ambiente de dupla camada da membrana, causadas pela interação com os antipsicóticos podem ser capazes de estimular o efeito inibitório observado sobre a atividade da acetilcolinesterase para experimentos in vitro (SEIBT et al., 2009). No entanto, dados sobre experimentos in vivo não corroboram com esta tendência, uma vez que injeções por via intravenosa de clorpromazina $\left(10 \mathrm{mg} \mathrm{kg}^{-1}\right)$ em cães, causou um aumento significativo na atividade específica da $\mathrm{AChE}$ no fluido cerebrospinal da cisterna ventricular (CSF) (BAREGGI \& GIACOBINI, 1978).

Entre as enzimas de estresse oxidativo, apenas a atividade da catalase foi significativamente alterada em D. magna após exposição à clorpromazina. A enzima catalase tem sido considerada como uma das principais enzimas antioxidantes, e está principalmente envolvida na redução do peróxido de hidrogênio produzido a partir do metabolismo de ácidos graxos de cadeia longa nos peroxissomos (AFIYANTI \& CHEN, 2014). O aumento da atividade da catalase pode ocorrer como consequência do excesso de produção de peróxido de hidrogênio, que por sua vez resulta no aumento de ROS, e na perturbação do funcionamento regular dos sistemas de defesa antioxidantes. 
Os resultados aqui obtidos demonstram que a produção e a liberação do peróxido de hidrogênio foram claramente favorecidas após a exposição à clorpromazina. Através do aumento significativo na atividade da CAT, os organismos expostos foram, então, capazes de enfrentar as condições oxidativas desafiadoras criadas pelo metabolismo da clorpromazina. Entretanto, e ao contrário dos nossos resultados, Li et al. (2008) mostraram que a atividade da CAT no fígado da espécie Carassius auratus diminui gradualmente com o aumento das concentrações testadas de clorpromazina durante 21 dias de exposição. Contudo, esta tendência só foi relatada para níveis superiores aos adotados no presente estudo. Uma possível explicação para este fato é que a exposição a estas altas concentrações podem ter excedido o intervalo de tolerância para a catalase (ZHUANG \& YANG, 2005).

A clorpromazina é um composto farmacêutico usado extensivamente na psiquiatria, sendo administrada frequentemente durante longos períodos. Consequentemente, os efeitos toxicológicos de longo prazo (neurológicas e metabólicas) estão bem estabelecidos e descritos, pelo menos, para os mamíferos. Conforme mostrado por Roy et al. (1984), a administração intraperitoneal da clorpromazina provocou efeitos crônicos significativos sobre as enzimas antioxidantes SOD, GPx e GRed; peroxidação lipídica; e acumulação de lipofuscina no cérebro de ratos. A atividade da CAT nos animais tratados não foi alterada, indicando a ausência de efeitos; sendo possível, portanto sugerir que a peroxidação induzida pelo peróxido de hidrogênio não ocorreu. Por outro lado, a exposição à clorpromazina foi responsável por um aumento significativo nas atividades da SOD, GRed, e GPx no tronco cerebral de organismos expostos, de uma forma dependente das doses expostas. Estes resultados não estão de acordo com o estudo realizado por Abdalla e Bechara (1994), que constataram que a atividade total da GPx e da peroxidação lipídica de homogeneizados do cérebro e fígado de ratos não foram afetados pela administração aguda ou crônica deste agente terapêutico. A espécie D. magna quando exposta a este fármaco mostrou uma resposta de estresse oxidativo através da diminuição das atividades da GPX- total e GPx- selêniodependente. No entanto, esta diminuição não foi estatisticamente significativa. Além disso, os nossos resultados mostraram que a clorpromazina provocou um aumento não significativo na atividade da GSTs nos organismos expostos. Estes resultados estão de acordo com experimentos de Gopal et al. (2010), que mostraram que esta droga específica aumentou a atividade da GSTs no cérebro de ratos. 
Segundo Regoli et al. (2003), é muito difícil prever a capacidade de resposta antioxidante ao estresse químico, porque vários fatores que afetam a atividade das enzimas antioxidantes podem estar simultaneamente envolvidas. Os dados da literatura indicam que a clorpromazina in vitro inibe enzimas tais como citocromo-oxidase, enzimas envolvidas na fosforilação oxidativa, bem como da monoamina-oxidase, que é uma importante fonte enzimática na produção de peróxido de hidrogênio (AFIYANTI \& CHEN, 2014). Assim, o envolvimento da clorpromazina na via oxidativa não é apenas uma realidade já caracterizada, mas pode ser de fato uma possibilidade em cenários contaminados. Deve-se enfatizar também que a espécie D. magna foi exposta a concentrações de clorpromazina consideravelmente superiores às realmente reportadas no meio ambiente, e isso torna-se um fator que diminui a relevância ecológica dos nossos dados. Apesar da ausência de dados complexos sobre os efeitos neurológicos deste composto, o número de estudos sobre os efeitos potenciais da clorpromazina em organismos aquáticos, incluindo crustáceos, é ainda limitado, e as conclusões destes estudos são um pouco difíceis de interpretar. A maioria dos estudos encontrados na literatura sobre os efeitos da clorpromazina referem-se principalmente aos mamíferos, que foram expostos a este composto através de injeção ou alimentação, um fator que aumenta a dificuldade na extrapolação para as nossas condições experimentais.

\section{Diclofenaco sódico}

O fármaco diclofenaco de sódio induziu uma diminuição significativa na atividade colinesterásica em D. magna, que foi significativa apenas para a menor e maior concentrações testadas (Figura 1E). Os nossos resultados não estão de acordo com os resultados obtidos por outras espécies de moluscos, tais como o mexilhão Mytilus galloprovincialis, em que a atividade da AChE nas brânquias desta espécie aumentou gradualmente, atingindo níveis significativamente mais elevados depois da primeira semana, e em seguida diminuindo para controlar os níveis no final do experimento (15 dias). No entanto, a relação entre os efeitos anticolinesterásicos induzidos pelo diclofenaco pode ser mais complexa, podendo também estar relacionados com outras vias bioquímicas. A atividade da AChE foi diretamente relacionada com a atividade SOD na glândula digestiva e com os níveis de proteína vitelogenina em fêmeas expostas de M. galloprovincialis, indicando uma alteração na atividade estrogênica, ao invés de 
um colapso em função da neurotransmissão colinérgica (GONZALEZ-REY \& BEBIANNO, 2014). Este estudo confirmou que o diclofenaco sódico em concentrações muitas vezes observadas em águas de superfície, pode induzir respostas de biomarcadores em tecidos específicos. Além disso, dados comparáveis foram publicados por Solé et al. (2010); este estudo mostrou que a atividade da AChE foi inibida por outros anti-inflamatórios não-esteróides (AINE), como o acetaminofeno (23 e $403 \mu \mathrm{g} \mathrm{L}^{-1}$ ) nas brânquias de M. galloprovincialis. O fenômeno de indução da AChE pode ser parcialmente explicado devido ao seu envolvimento com a apoptose celular em várias células humanas e de mamíferos. A AChE é liberada após a ruptura da membrana celular (ZHANG et al., 2002), um fator que explica o seu aumento.

Apesar da biotransformação do composto diclofenaco sódico em organismos nãoalvo ser desconhecida até o momento (OVIEDO-GÓMEZ et al., 2010), vários estudos mostram que os AINEs podem causar estresse oxidativo em organismos de água doce (OVIEDO-GÓMEZ et al., 2010; SCHMIDT et al., 2013). Estudos realizados por Boelsterli (2003) relataram que, em mamíferos, o estresse oxidativo causado por este fármaco está ligado tanto com a bioativação do diclofenaco mediado pelo citocromo CYP formando imina p-quinona (derivada de metabólitos hidroxilados), que por sua vez está envolvido no ciclo de redução. Além disso, os AINEs inibem a síntese e a liberação de prostaglandinas que atuam como inibidores não seletivos da enzima ciclo-oxigenase, inibindo as isoenzimas ciclo-oxigenase-1 (COX1) e ciclo-oxigenase-2 (COX-2) (GAGNÉ et al., 2005). O metabólito eletrofílico para o diclofenaco sódico (intermediário da benzoquinonimina) induz a formação de ROS e prende-se aos grupos sulfidrilo em nível de citosol, bem como enzimas ou proteínas de membrana que contêm esses grupos (CHILO, 1999). A espécie D. magna exposta a diferentes concentrações de diclofenaco sódico mostrou uma resposta de estresse oxidativo, através da diminuição significativa da atividade da GPx selênio-dependente. Entretanto, contrariamente aos nossos dados, Gómez-Oliván et al. (2014) demonstraram que o diclofenaco de sódio foi responsável por danos no DNA e alterações nos biomarcadores bioquímicos, com um aumento significativo na atividade da GPx em D. magna. Resultados semelhantes também foram obtidos por Oviedo-Gómez et al. (2010) na espécie de crustáceo Hyalella azteca, seguindo um padrão dependente do tempo após a exposição aguda. Estes resultados podem ser explicados pela formação de 4'hidroxidiclofenaco e 5'-hidroxidiclofenaco, dois intermediários altamente reativos, cuja 
biotransformação a benzoquinonas pode resultar no aumento da formação de ROS (OVIEDO-GOMEZ et al., 2010). Contudo, este efeito não foi diretamente seguido para as atividades da GSTs e CAT (Figura 1F). Estes dois biomarcadores enzimáticos sofreram induções significativas nas suas atividades após a exposição a este antiinflamatório. As atividades de GST e CAT foram diretamente relacionadas às glândulas digestivas de $M$. galloprovincialis expostas a outro AINE (ibuprofeno) (GONZALEZREY \& BEBIANNO, 2012). Similarmente aos nossos dados, espécies de bivalves, como Dreissena polymorpha e Mytilus sp., uma vez expostas a uma concentração mais elevada de diclofenaco sódico $\left(1,0 \mu \mathrm{g} \mathrm{L}^{-1}\right)$, também apresentaram indução da GSTs, juntamente com um aumento na peroxidação lipídica (LPO) na massa visceral e na glândula digestiva (QUINN et al., 2011; SCHMIDT et al., 2011).

Os efeitos do composto farmacológico diclofenaco sódico em ambas as atividades da CAT (indução) e GPx (total e selênio dependente; inibição) em D. magna, é um tanto interessante. Segundo Parolini e Binelli (2012), apesar de ambas as enzimas serem responsáveis pela redução da toxicidade do mesmo radical de oxigênio $\left(\mathrm{H}_{2} \mathrm{O}_{2}\right)$, estas exibiram diferentes comportamentos que pode ser explicado por uma possível competição pelo mesmo substrato. Do mesmo modo, dados comparáveis foram publicados por Nava-Álvarez et al. (2014) que avaliaram danos peroxidativos no cérebro e no fígado do peixe de água doce Cyprinus carpio, exposto ao diclofenaco sódico ou a uma mistura dos compostos farmacêuticos diclofenaco e acetaminofeno. Por sua vez, Islas-Flores et al. (2013) não observaram nenhum efeito na atividade das enzimas antioxidantes no fígado do peixe Cyprinus carpio, exposto a este composto, provavelmente, devido à diferença nas concentrações empregadas. Apesar de estudos como o de Orhan et al. (1999), que demonstraram que o diclofenaco sódico exerce um efeito antioxidante potente, outros trabalhos destes autores mostraram que este composto não afetou as atividades das três enzimas: GSTs, GPx-Se e CAT em doses terapêuticas e nem em concentrações mais elevadas (ORHAN \& SAHIN, 2001).

Além disso, a variação das respostas antioxidantes entre os nossos resultados e os dados da literatura pode ser explicada pela variabilidade das diferentes atividades enzimáticas, que estão envolvidas em um amplo e complexo sistema que regula a homeostase para contrabalançar a superprodução de ROS (VALAVANIDIS et al., 2006). Além do mais, as diferenças entre os nossos resultados e os dados bibliográficos 
podem servir de base para os mecanismos de toxicidade espécie-específicos, mas podem resultar da tipologia dos estudos.

\section{Propranolol}

No presente trabalho, observou-se um aumento não significativo na atividade da ChE em D. magna exposta às concentrações selecionadas de propranolol (Figura 1G). Estudos como o de Solé et al. (2010), mostraram que respostas induzidas pela exposição subletal de propranolol na espécie de mexilhão marinho M. galloprovincialis, podem resultar em respostas significativas, incluindo a inibição da $\mathrm{AChE}$ e o estresse oxidativo em brânquias na maior concentração testada $\left(147 \mu \mathrm{g} \mathrm{L}^{-1}\right)$. No entanto, esta tendência não foi observada em nosso estudo, mostrando o impacto nulo dessa droga sobre a função nervosa colinérgica no cladócero D. magna.

O nosso estudo permitiu observar um aumento significativo e dependente da dose na atividade de GST causada pela exposição ao composto propranolol (Figura 1H). Os resultados obtidos podem ser explicados pelo papel central da glutationa reduzida (GSH) no metabolismo deste composto. Franzilliti et al. (2011) encontraram resultados semelhantes para GSTs $\left(0,3-30 \mathrm{ng} \mathrm{L}^{-1}\right)$ e CAT $\left(0,3-3 \mathrm{ng} \mathrm{L}^{-1}\right)$ na glândula digestiva do mexilhão M. galloprovincialis expostos ao propranolol. Na verdade, concluiu-se que os níveis de certas enzimas antioxidantes em peixes, incluindo a CAT, são aumentados em resposta à inflamação induzida pela toxicidade de ROS. No entanto, de acordo com elevados níveis de contaminação, as defesas antioxidantes são reduzidas (VALAVANIDIS et al., 2006). No presente estudo, o fármaco propranolol não causou qualquer alteração significativa na atividade da catalase em D. magna. Outros autores como Solé et al. (2010) relataram também a ausência de efeitos no mexilhão $M$. galloprovincialis em termos de atividade da CAT após a exposição a este $\beta$-bloqueador. Similarmente, a ausência geral de efeitos pró-oxidativos foram reportados por Davidovic'et al. (1999) em músculos de ratos aclimatados ao frio e expostos ao propranolol, em que ele inibiu a atividade desta enzima no tecido adiposo castanho. Este conjunto de resultados permite concluir que alterações baseadas em processos oxidativos causados pelo propranolol, não são inteiramente diretos, e podem variar de acordo com as espécies testadas, e ainda de tecido para tecido. Portanto, é possível verificar que não só a biota aquática é afetada pelo papel pró-oxidativo do propranolol, 
mas também os mamíferos são propensos aos esforços de modificações oxidativas por este composto.

Nossos resultados mostraram que uma diminuição significativa na atividade da GPx (GPx total e GPx-selênio-dependente) em D. magna não pode estar relacionada a um aumento dos níveis de peróxido de hidrogênio, que também foram evidenciados pelo aumento da atividade da CAT anteriormente relatados. Como anteriormente referido, estas duas enzimas desempenham papéis semelhantes, reduzindo os níveis de peróxido de hidrogênio. Contudo, Sun et al. (2013) observaram que os seus processos de transcrição exibiram resultados opostos quando expostos a $\beta$-bloqueadores, tais como propranolol e metoprolol em larvas de peixe-zebra (Danio rerio). É possível sugerir que mudanças no nível de transcrição frequentemente indicam modificações nos níveis de produtos gênicos e podem estar relacionadas com os processos fisiológicos. Mais estudos de longo prazo são claramente necessários para elucidar esse fato.

\section{Conclusões}

Nosso estudo evidenciou que os compostos paracetamol e diclofenaco de sódio têm o potencial de afetar a função normal da neurotransmissão de D. magna, por comprometer a atividade da colinesterase. Além disso, estes fármacos foram responsáveis por uma redução significativa na atividade da GPx selênio-dependente. No entanto, se considerarmos que os mecanismos de defesa antioxidante foram capazes de reagir com a concentração mais baixa testada de acetaminofeno e diclofenaco sódico, é possível concluir que a espécie D. magna é extremamente sensível a estes medicamentos, e, possivelmente, às condições pró-oxidativas, em geral.

Após a exposição aguda à clorpromazina, a extensão das atividades enzimática de inibição/indução de GPx e GSTs não foram suficientes para sustentar que um cenário de estresse oxidativo fosse observado. Além disso, após a exposição a esta droga, foi verificado um aumento significativo na atividade da CAT. Entretanto, deve-se enfatizar que os níveis de clorpromazina que causaram efeitos deletérios são da ordem de $\mathrm{mg} \mathrm{L}^{-1}$, enquanto que as concentrações detectadas na maioria dos ambientes aquáticos são em ng $\mathrm{L}^{-1}$. Apesar disso, os dados são ecologicamente relevantes, pois mesmo que as concentrações isoladamente registradas nos sistemas aquáticos naturais não representem 
riscos à biota aquática, as misturas e os efeitos sinergísticos precisam ser avaliados caso a caso.

A exposição aguda ao propranolol provocou uma redução significativa na atividade da GPx (GPx total e GPx-selênio-dependente). Do mesmo modo, observou-se um aumento significativo na atividade da GSTs com o estabelecimento de uma relação dose-resposta. Estes resultados obtidos referem-se a concentrações da ordem de $\mathrm{mg} \mathrm{L}^{-1}$, que são muito mais elevadas do que os níveis ambientais já documentados. A partir dos dados aqui obtidos, pode-se revelar os possíveis efeitos adversos em termos de estresse oxidativo que o propranolol causou em D. magna, mas não se pode inferir completamente o risco real para este organismo e, consequentemente, para a biocenose aquática.

Assim, este estudo deve servir de base para novas pesquisas, a fim de elucidar os efeitos dos compostos aqui estudados sobre as enzimas antioxidantes, de peroxidação lipídica e neurotransmissão, ou possíveis intervenções em nível de stresse oxidativo na biota aquática.

\section{Referências bibliográficas}

ABDALLA, D.S.; BECHARA, E.J. The effect of chlorpromazine and $\mathrm{Li}_{2} \mathrm{CO}_{3}$ on the superoxide dismutase and glutathione peroxidase activities of rat brain, liver and erythrocytes. Biochemistry and Molecular Biology International. v.34, p.1085-90, 1994.

AFIYANTI, M.; CHEN, H-J. Catalase activity is modulated by calcium and calmodulin in detached mature leaves of sweet potato. Journal of Plant Physiology, v.171, p.3547, 2014.

ANTUNES, S.C.; FREITAS, R.; FIGUEIRA, E.; GONÇALVES, F.; NUNES, B. Biochemical effects of acetaminophen in aquatic species: edible clams Venerupis decussata and Venerupis philippinarum. Environmental Science and Pollution Research, v.20, p.6658-6666, 2013. 
AMERICAN SOCIETY FOR TESTING AND MATERIALS (ASTM) 1980. Standard practice for conducting acute toxicity tests with fishes, macroinvertebrates and amphibians. Report E 729-80. American Society for Testing and Materials, Philadelphia, USA.

AMERICAN SOCIETY FOR TESTING AND MATERIALS (ASTM). Standard guide for conducting Daphnia magna life-cycle toxicity tests. Report E 1193-97. American Society for Testing and Materials, Philadelphia, USA, 1997.

AOUACHERI, W.; SAKA, S.; DJAFER, R.; LEFRANC, G. Protective effect of diclofenac towards the oxidative stress induced by paracetamol toxicity in rats. Annales de Biologie Clinique, v.67, p.619-627, 2009.

BAIRD, D.J.; BARBER, I.; BRADLEY, M.C.; CALOW, P.; SOARES, A.M.V.M. The Daphnia bioassay: a critique. Hydrobiologia, v. 188, p.403-406, 1989.

BAREGGI, S.R.; GIACOBINI, E. Acetylcholinesterase activity in ventricular and cisternal CSF of dogs: effect of chlorpromazine. Journal of Neuroscience Research, v. 3, p.335-339, 1978.

BONA, M.D.; LEVA, V.D.; LIGUOROA, M. DE. 2014. The sensitivity of Daphnia magna and Daphnia curvirostris to 10 veterinary antibacterials and to some of their binary mixtures. Chemosphere. 2014. http://DOI: 10.1016/j.chemosphere.2014.02.003

BOELSTERLI, U. Diclofenac-induced liver injury: a paradigm of idiosyncratic drug toxicity. Toxicology and Applied Pharmacology, v.192, p.307-322, 2003.

BOOTH, L.H.; O' HALLORAN, K. A comparison of biomarker responses in the earthworm Aporrectodea caliginosa to the organophosphorous insecticides diazinon and chlorpyrifos. Environmental Toxicology and Chemistry, v.20, p.2494-2502, 2001. 
BORGES, N.C.; REZENDE, V.M.; SANTANA, J.M.; MOREIRA, R.P.; MOREIRA, R.F.; MORENO, P.; BORGES, D.C.; DONATO, J.L.; MORENO, R. A. Chlorpromazine quantification in human plasma by UPLC-electrospray ionization tandem mass spectrometry. Application to a comparative pharmacokinetic study. Journal of Chromatography B, v. 879, p.3728- 3734, 2011.

BOTTONI, P.; CAROLI, S.; CARACCIOLO, A.B. Pharmaceuticals as priority water contaminants. Toxicology \& Environmental Chemistry, v.92, p.549-565, 2010.

BRADFORD, M. A rapid and sensitive method for the quantification of microgram quantities of protein utilizing the principle of protein dye binding. Analytical Biochemistry, v.72, p. 248-254, 1976.

BRANDÃO, FP.; RODRIGUES, S.; CASTRO, B.B.; GONÇALVES, F.; ANTUNES, S.C.; NUNES, B. Short-term effects of neuroactive pharmaceutical drugs on a fish species: Biochemical and behavioural effect. Aquatic Toxicology, v.144, p. 218- 229, 2013.

CHAOUCHI, S.; HAMDAOU, O. Acetaminophen extraction by emulsion liquid membrane using Aliquat 336 as extractant. Separation and Purification Technology, v.129, p.32- 40, 2014.

CHILO, N.H. El citocromo P450 y su rol en la hepatotoxicidad inducida por drogas. Enfermedades del aparato respiratório, v. 2, p.34-37, 1999.

COELHO, S.; OLIVEIRA, R.; PEREIRA, S.; MUSSO, C.; DOMINGUES, I.; BHUJEL, R.C.; SOARES, A.M.V.M.; NOGUEIRA, A.J. Assessing lethal and sublethal effects of trichlorfon on different trophic levels. Aquatic Toxicology, v. 103, p.191-198, 2011.

DAVIDOVIC', V.; DJOKIC', N.; PETROVIC', N.; DURASLEVIC', S.; CVIJIC, G. Activity of antioxidant enzymes in rat skeletal muscle and brown fat: effect of cold and propranolol. Journal of Thermal Biology, v.24, p.385-389, 1999. 
DAVERN，T.J.; JAMES， L.P.; HINSON，J.A.; POLSON，J.; LARSON，A.M.; FONTANA, R.J.; LALANI, E.; MUNOZ, S.; SHAKIL, A.O.; LEE, W.M. Measurement of serum acetaminophen-protein adducts in patients with acute liver failure. Gastroenterology, v.130, p.687-694, 2006.

ELENDT, B.P.; BIAS, W.R. Trace nutrient deficiency in Daphnia magna cultured in standard medium for toxicity testing. Effects of the optimisation of culture conditions on life history parameters of Daphnia magna. Water Research, v.24, p. 1157-1167, 1990.

ELLMAN, G.L.; COURTNEY, K.D.; ANDRES, V.; FEATHERSTONE, R.M. A new and rapid colorimetric determination of acetylcholinesterase activity. Biochemical Pharmacology, v.7, p.88-95, 1961.

FENT, K.; WESTON, A. A.; CAMINADA, D. Ecotoxicology of human pharmaceuticals. Aquatic Toxicology, v.76, p.122-159, 2006.

FLOHÉ, L.; GÜNZLER, W.A. Assays of glutathione peroxidase. Methods in Enzymology, v.105, p.114-121, 1984.

FRANZELLITTI, S.; BURATTI, S.; VALBONESI, P.; CAPUZZO, A.; FABBRI, E. The $\beta$-blocker propranolol affects cAMP-dependent signaling and induces the stress response in Mediterranean mussels, Mytilus galloprovincialis. Aquatic Toxicology, v.101, p.299-308, 2011.

GAGNÉ, F.; BLAISE, C.; ANDRÉ, C. Occurrence of pharmaceutical products in a municipal effluent and toxicity to rainbow trout (Oncorhynchus mykiss) hepatocytes. Ecotoxicology and Environmental Safety, v.64, p.329- 336, 2005.

GÓMEZ-OLIVÁN, L.M.; NERI-CRUZ, N.; GALAR-MARTÍNEZ, M.; VIEYRAREYES, P.; GARCÍA-MEDINA, S.; RAZO-ESTRADA, C.; DUBLÁN-GARCÍA, O.; CORRAL-AVITIA, A.Y. Assessing the Oxidative Stress Induced by Paracetamol 
Spiked in Artificial Sediment on Hyalella azteca. Water, Air, \& Soil Pollution, v.223, p. 5097-5104, 2012.

GÓMEZ-OLIVÁN, L.M.; GALAR-MARTÍNEZ， M.; GARCÍA-MEDINA， S.; VALDÉZ- ALANÍS, A.; ISLAS-FLORES, H.; NERI-CRUZ, N. Genotoxic response and oxidative stress induced by diclofenac, ibuprofen and naproxen in Daphnia magna. Drug and Chemical Toxicology. 2014. http://doi:10.3109/01480545.2013.870191.

GONZALEZ-REY, M.; BEBIANO, M.J. Effects of non-steroidal anti-inflammatory drug (NSAID) diclofenac exposure in mussel Mytilus galloprovincialis. Aquatic Toxicology, v.148, p.221-230, 2014.

GOPAL, V.P.; SRIRAM, A.V.; SHARMA, D.; SINGH, R. Glutathione-S-transferase in the ageing rat brain cerebrum and the effect of chlorpromazine. Gerontology, v.46, p.7$11,2000$.

GRUJÍC, S.; VASILJEVÍC, T.; LAUSEVIÍC, M. Determination of multiple pharmaceutical classes in surface and ground waters by liquid chromatography-ion traptandem mass spectrometry. Journal of Chromatography A, v.1216, p.4989-5000, 2009.

GUILHERMINO, L.; LOPES, M.C.; CARVALHO, A.P.; SOARES, A.M.V.M. Acetylcholinesterase activity in juveniles of Daphnia magna Straus. Bulletin of Environmental Contamination and Toxicology, v.57, p.979-985, 1996 b.

HABIG, W. H.; PABST, M. J.; JAKOBY, W. B. Glutathione- S-transferases-the first enzymatic step in mercapturic acid formation. The Journal of Biological Chemistry, v.249, p.7130-7139, 1974.

HAN, G. H.; HUR, H. G.; KIM, S. D. Ecotoxicological risk of pharmaceuticals from wastewater treatment plants in Korea: occurrence and toxicity to Daphnia magna. Environmental Toxicology and Chemistry, v. 25, p. 265-271, 2006. 
HEBERER, T.; REDDERSEN, K.; MECHLINSKI, A. From municipal sewage to drinking water: fate and removal of pharmaceutical residues in the aquatic environment in urban areas. Water Science \& Technology, v.46, p.81-88, 2002.

HOLTH, T.F.; NOURIZADEH-LILLABADI, R.; BLAESBJERG, M.; GRUNG, M.; HOLBECH, H.; PETERSEN, G.I.; ALESTRÖM, P.; HYLlAND, K. A. Differential gene expression and biomarkers in zebrafish (Danio rerio) following exposure to produced water components. Aquatic Toxicology, v. 90, p.277-91, 2008.

ISLAS-FLORES, H.; GÓMEZ-OLIVÁN, L.M.; GALAR-MARTÍNEZ, M.; COLÍNCRUZ, A.; NERI-CRUZ, N.; GARCÍA-MEDINA, S. Diclofenac-induced oxidative stress in brain, liver, gill and blood of common carp (Cyprinus carpio). Ecotoxicology and Environmental Safety, v.92, p.32-38, 2013.

INTERNATIONAL ORGANISATION FOR STANDARDIZATION (ISO). Water quality: determination of the inhibition of the mobility of Daphnia magna Straus (Cladocera, Crustacea) - Acute toxicity test. ISO International Standard 6341. International Organization for Standardization, Geneva, Switzerland, 1996.

INTERNATIONAL ORGANISATION FOR STANDARDIZATION (ISO). Water quality: determination of long term toxicity of substances to Daphnia magna Straus (Cladocera, Crustacea). ISO International Standard 10706. International Organization for Standardization, Geneva, Switzerland, 2000.

KAVITHA, P.; RAMESH, R.; BUPESH, G.; STALIN, A.; SUBRAMANIAN, P. Hepatoprotective activity of Tribulus terrestris extract against acetaminophen-induced toxicity in a freshwater fish (Oreochromis mossambicus). In Vitro Cellular \& Developmental Biology- Animal, v.47, p.698-706, 2011.

KIM, J.W.; ISHIBASHI, H.; YAMAUCHI, R.; ICHIKAWA, N.; TAKAO, Y.; HIRANO, M.; KOGA, M.; ARIZONO, K. Acute toxicity of pharmaceutical and personal care products on freshwater crustacean (Thamnocephalus platyurus) and fish (Oryzias latipes). The Journal of Toxicological Sciences, v.2, p.227-232, 2009. 
KOLPIN, D.W.; FURLONG, E.T.; MEYER, M.T.; THURMAN, E.M.; ZAUGG, S.D.; BARBER, L.B.; BUXTON, H.T. Pharmaceuticals, hormones and other organic wastewater contaminants in US streams, 1999-2000: a national reconnaissance. Environmental Science \& Technology, v.36, p.1202-1211, 2002.

KWONG, T.C. Organophosphate pesticides: biochemistry and clinical toxicology. Therapeutic Drug Monitoring, v.24, p.144-149, 2002.

LETICIA, A.G.; GERARDO, G.B. Determination of esterase activity and characterization of cholinesterases in the reef fish Haemulon plumier. Ecotoxicology and Environmental Safety, v.71, p.787-797, 2008.

LI, T.; ZHOU, O.; ZHANG, N.; LUO, Y. Toxic effects of chlorpromazine on Carassius auratus and its oxidative stress. Journal Environmental Science and Health Part B, v. 43, p.638-643, 2008.

LI, Z.-H.; ZLABEK, V.; VELISEK, J.; GRABIC, R.; MACHOVA, J.; RANDAK, T. Physiological condition status and muscle-based biomarkers in rainbow trout (Oncorhynchus mykiss), after long-term exposure to carbamazepine. Journal of Applied Toxicology, v.30, p.197-203, 2010.

LÓPEZ-SERNA, R.; PÉREZ, S.; GINEBREDA, A.; PETROVIĆ, M.; BARCELÓ, D. Fully automated determination of 74 pharmaceuticals in environmental and waste waters by online solid phase extraction-liquid chromatography-electrospray-tandem mass spectrometry. Talanta, v.83, p.410-424, 2010.

LORPHENSRI, O.; SABATINI, D.A.; KIBBEY, T.C.G.; OSATHAPHAN, K.; SAIWAN, C. Sorption and transport of acetaminophen, 17a-ethynylestradiol, nalidixic acid with low organic content aquifer sand. Water Research, v.41, p.2180-2188, 2007.

MONTEIRO, D.A.; DE ALMEIDA, J.A.; RANTIN, F.T.; KALININ, A.L. Oxidative stress biomarkers in the freshwater characid fish, Brycon cephalus, exposed to 
organophosphorus insecticide Folisuper 600 (methyl parathion). Comparative Biochemistry and Physiology C, v.143, p.141-149, 2006.

MÜNZINGER, A.; MONICELLI, F. Heavy metal co-tolerance in a chromium tolerant strain of Daphnia magna. Aquatic Toxicology. v.23, p.203-216, 1992.

NAVA-ÁLVAREZ, R.; RAZO-ESTRADA, A.C.; GARCÍA-MEDINA, S.; GÓMEZOLIVAN, L.M.; GALAR-MARTÍNEZ, M. Oxidative Stress Induced by Mixture of Diclofenac and Acetaminophen on Common Carp (Cyprinus carpio). Water, Air, \& Soil Pollution, v.225, p.1873, 2014.

NUNES, B.; CARVALHO, F.; GUILHERMINO, L. Effects of widely used pharmaceuticals and a detergent on oxidative stress biomarkers of the crustacean Artemia parthenogenetica. Chemosphere, v.62, p.581-594, 2006.

ORGANISATION FOR ECONOMIC CO-OPERATION AND DEVELOPMENT (OECD). Daphnia sp., acute immobilisation test. Revised proposal for updating guideline 202. OECD (Organisation for Economic Cooperation and Development), Paris, France, 2000.

ORHAN, H.; MAROL, S.; HEPSEN, I.F.; SAHIN, G. Effects of some probable antioxidants on selenite-induced cataract formation and oxidative stress-related parameters in rats. Toxicology, v.139, p.219-232, 1999.

ORHAN, H.; SAHIN, G. In vitro effects of NSAIDS and paracetamol on oxidative stress-related parameters of human erythrocytes. Experimental and Toxicology Pathology, v.53, p.133-140, 2001.

OVIEDO-GÓMEZ，D. G. C.; GALAR-MARTÍNEZ, M.; GARCÍA-MEDINA, S.; RAZO-ESTRADA， C.; GOMÉZ-OLIVÁN， L. M. Diclofenac-enriched artificial sediment induces oxidative stress in Hyalella azteca. Environmental Toxicology and Pharmacology, v.29, p.39-43, 2010. 
PAROLINI, M.; BINELLI, A.; COGNI, D.; PROVINI, A. Multi-biomarker approach for the evaluation of thecyto-genotoxicity of paracetamol on the zebra mussel (Dreissena polymorpha). Chemosphere, v.79, p.489-498, 2010.

PAROLINI, M.; BINELLI, A. Sub-lethal effects induced by a mixture of three nonsteroidal anti-inflammatory drugs (NSAIDs) on the freshwater bivalve Dreissena polymorpha. Ecotoxicology, v. 221, p.379-392, 2012.

PAROLINI, M.; PEDRIALI, A.; BINELLI, A. Application of a biomarker response index for ranking the toxicity of five pharmaceutical and personal care products (PPCPs) to the bivalve Dreissena polymorpha. Archives of Environmental Contamination and Toxicology, v.64, p.439-447, 2013.

PINEDA-ROSAS, A.; SANTOS-MEDRANO, G.E.; ZAVALA-REYNOSO, M.F.; RICO-MARTÍNEZ, R. Identification of acetylcholinesterase receptors in Rotifera. Hydrobiologia, v.546, p.249-253, 2005.

PRINTES, L.B.; CALLAGHAN, A. A comparative study on the relationship between acetylcholinesterase activity and acute toxicity in Daphnia magna exposed to anticholinesterase insecticides. Environmental Toxicology and Chemistry, v.23, p.1241-1247, 2004.

QUINN, B.; SCHMIDT, W.; O'ROURKE, K.; HERNAN, R. Effects of the pharmaceuticals gemfibrozil and diclofenac on biomarker expression in the zebra mussel (Dreissena polymorpha) and their comparison with standardized toxicity tests. Chemosphere, v.84, p.657-663, 2011.

RABIET, M.; TOGOLA, A.; BRISSAUD, F.; SEIDEL, J.L.; BUDZINSKI, H.; POULICHET, E.F. Consequences of treated water recycling as regards pharmaceuticals and drugs in surface and ground waters of a medium-sized Mediterranean catchment. Environmental Science \& Technology, v.40, p.5282-5288, 2006. 
RAMOS, A.S.; CORREIA, A.T.; ANTUNES, S.C.; GONÇALVES, F.; NUNES, B. Effect of acetaminophen exposure in Oncorhynchus mykiss gills and liver: Detoxification mechanisms, oxidative defence system and peroxidative damage. Environmental Toxicology and Pharmacology, v.37, p.1221-1228, 2014.

REGOLI, F.; WINSTON, G.W.; GORBI, S.; FRENZILLI, G.; NIGRO, M.; CORSI, I.; FOCARDI, S. Integrating enzymatic responses to organic chemical exposure with total oxyradical absorbing capacity and DNA damage in the European eel Anguilla anguilla. Environmental Toxicology and Chemistry, v.22, p.2120-2129, 2003.

RHEE, J-S.; KIM, B-M.; JEONG, C-B.; PARK, H.; LEUNG, K.M.Y.; LEE, Y-M.; LEE, J-S. Effect of pharmaceuticals exposure on acetylcholinesterase (AchE) activity and on the expression of AchE gene in the monogonont rotifer, Brachionus koreanus. Comparative Biochemistry and Physiology C, v.158, p.216-224, 2013.

ROBERTS, P.H.; BERSUDER, P. Analysis of OSPAR priority pharmaceuticals using high-performance liquid chromatography-electrospray ionisation tandem mass spectrometry. Journal of Chromatography A, v.1134, p.143-50, 2006.

ROCHA, R.; GONÇALVES, F.; MARQUES, C.; NUNES, B. Environmental effects of anticholinesterasic therapeutic drugs on a crustacean species, Daphnia magna Environmental Science and Pollution Research, v. 21, p.4418-29, 2013.

ROY, D.; PATHAK, D.N.; SINGH, R. Effects of chlorpromazine on the activities of antioxidant enzymes and lipid peroxidation in the various regions of aging rat brain. Journal of Neurochemistry, v.42, p.628-33, 1984.

SCHMIDT, W.; O'ROURKE, K.; HERNAN, R.; QUINN, B. Effects of the pharmaceuticals gemfibrozil and diclofenac on the marine mussel (Mytilus sp.) and their comparison with standardized toxicity tests. Marine Pollution Bulletin, v.62, p.13891395, 2011. 
SCHMIDT, W.; RAINVILLE, L.-C.; MCENEFF, G.; SHEEHAN, D.; QUINN, B. A proteomice valuation of the effects of the pharmaceuticals diclofenac and gemfibrozilon on marine mussels (Mytilus spp.): evidence for chronic sublethal effects on stressresponse proteins. Drug Testing and Analysis, v.6, p.210-219, 2013.

SEIBT, K.J.; OLIVEIRA, R.L.; RICO, E.P.; DIAS, R.D.; BOGO, M.R.; BONAN, C.D. Typical and atypical antipsychotics alter acetylcholinesterase activity and ache expression in zebrafish (Danio rerio) brain. Comparative Biochemistry and Physiology C, v.150, p.10-15, 2009.

SOLÉ, M.; SHAW, J.P.; FRICKERS, P.E.; READMAN, J.W.; HUTCHINSON, T.H. Effects on feeding rate and biomarker responses of marine mussels experimentally exposed to propranolol and acetaminophen. Analytical and Bioanalytical Chemistry, v.396, p.649-656, 2010.

SUN, L.; XIN, L.; PENG, Z.; JIN, R.; JIN, Y.; QIAN, H.; FU, Z. Toxicity and enantiospecific differences of two $\beta$-blockers, propranolol and metoprolol, in the embryos and larvae of zebrafish (Danio rerio). Environmental Toxicology. 2013. http://doi: 10.1002/tox.21867.

SUNG, H-H.; CHIUB, Y-W.; WANGC, S-Y.; CHEND, C-M.; HUANG, DA-JI. Acute toxicity of mixture of acetaminophen and ibuprofen to Green Neon Shrimp, Neocaridina denticulate. Environmental Toxicolology and Pharmacology, v.38, p.813, 2014.

TERNES, T.A. Occurrence of drugs in German sewage treatment plants and rivers. Water Research, v.32, p.3245-3260, 1998.

TESSIER, C.; NUSS, P.; STANEVA, G.; WOLF, C. Modification of membrane heterogeneity by antipsychotic drugs: an X-ray diffraction comparative study. Journal of Colloid and Interface Science, v.320, p.469-475, 2008. 
THAYER, A.M. Emerging strategies. Chemical Engineer News, v. 89, p.15-20, 2011. TRAN, C.D.; OLIVEIRA, O.; GRISHKO, V.I. Determination of enantiomeric compositions of pharmaceutical products by near-infrared spectrometry. Analytical Biochemistry, v.325, p.206-214, 2004.

UNITED STATES ENVIRONMENTAL PROTECTION AGENCY (USEPA). Methods for measuring the acute toxicity of effluents and receiving waters to freshwater and marine organisms, $5^{\text {th }}$ ed., EPA-821-R-02-012. US Environmental Protection Agency, Washington, 2002.

VALAVANIDIS, A.; VLAHOGIANNI, T.; DASSENAKIS, M.; SCOULLOS, M. Molecular biomarkers of oxidative stress in aquatic organisms in relation to toxic environmental pollutants. Ecotoxicology and Environmental Safety, v.64, p.178-189, 2006.

YUAN, S.; JIANG, X.; XIA, X.; ZHANG, H.; ZHENG, S. Detection, occurrence and fate of 22 psychiatric pharmaceuticals in psychiatric hospital and municipal wastewater treatment plants in Beijing, China. Chemosphere, v.90, p.2520-2525, 2013.

XING, H.; HAN, Y.; LI, SH.U.; WNAG, J.; WANG, J.; WNAG, X.; XU, S. Alterations in mRNA expression of acetylcholinesterase in brain and muscle of common carp exposed to atrazine and chlorpyrifos. Ecotoxicology and Environmental Safety, v.73, p.1666-1670, 2010.

XU, J.J.; HENDRIKS, B.S.; ZHAO, J.; GRAAF, D. Multiple effects of acetaminophen and p38 inhibitors: Towards pathway toxicology. FEBS Letters, v.582, p.1276-1282, 2008 .

WEIGEL, S.; KUHLMANN, J.; HUHNERFUSS, H. Drugs and personal care products as ubiquitous pollutants: occurrence and distribution of clofibric acid, caffeine and DEET in the North Sea. Science of Total Environment, v.295, p.131-141, 2002. 
ZHANG, X.J.; YANG, L.; ZHAO, Q.; CAEN, J.P.; HE, H.Y.; GUO, L.H.; ALEMANY, M.; ZHANG, L.Y.; SHI, Y.F. Induction of acetylcholinesterase expression during apoptosis in various cell types. Cell Death and Differentiation, v.9, p.790-800, 2002.

ZHOU, S.F. Polymorphism of human cytochrome P450 2D6 and its clinical significance. Clinical Pharmacokinetics, v.48, p.761-804, 2009.

ZHUANG, H.S.; YANG, G. Study on the acute and subacute toxicities of bisphenol A on the carp. Environmental Chemistry, v.24, p.682- 684, 2005. 


\section{CONCLUSÕES GERAIS}

Com este estudo, as seguintes conclusões gerais puderam ser obtidas:

- A ocorrência de resíduos de fármacos no Reservatório de Guarapiranga reflete o resultado de toda a contaminação encontrada nas estações amostradas, devido às altas cargas poluidoras, decorrentes de problemas relacionados às atividades antrópicas;

- Os nossos resultados sugerem que o dafinideo Ceriodaphnia silvestrii é uma espécie alternativa para ser utilizada como organismo-teste em ensaios de ecotoxicidade realizados nas regiões tropicais, especialmente para determinar os efeitos das drogas farmacêuticas;

- Os testes com as espécies Hydra viridissima e Dugesia tigrina apresentaram resultados ecotoxicológicos relevantes que demonstram a sensibilidade destas espécies e sua potencialidade de serem integradas como organismos-teste para estudos de ecotoxicidade com compostos farmacológicos;

- O fármaco propranolol foi o mais tóxico dentre os estudados nas exposições agudas e crônicas, sendo que a espécies Hydra viridissima e Ceriodaphnia silvestrii foram as mais sensíveis a este composto nos bioensaios agudos e crônicos, respectivamente;

- Os testes de toxicidade crônica revelaram alterações na dinâmica populacional das espécies Ceriodaphnia silvestrii e Daphnia magna para os fármacos paracetamol, cloropromazina e propranolol nas concentrações testadas; 
- Os fármacos analisados provocaram diferentes alterações nas atividades enzimáticas que indicam neurotoxicidade e estresse oxidativo após exposição aguda para a espécie Daphnia magna;

- Os diferentes biomarcadores enzimáticos constituiram importantes ferramentas na avaliação dos efeitos tóxicos dos fármacos analisados sobre a espécie Daphnia magna;

- Alterações no ciclo de vida e na dinâmica populacional das espécies estudadas podem estar relacionadas com alterações nas atividades das enzimas de neurotransmissão e estresse oxidativo causada pela exposição aos compostos farmacológicos e seus metabólitos;

- Com base nas informações obtidas em nosso estudo, envolvendo a quantificação de concentrações ambientais de fármacos e as concentrações que ocasionam efeitos letais e sub-letais, podemos concluir que as concentrações de cada fármaco no ambiente não são suficientes para causar isoladamente efeitos deletérios à biota aquática; 


\section{CONSIDERAÇÕES FINAIS}

Atualmente os compostos farmacêuticos fazem parte da vida cotidiana da população mundial, sendo utilizados para diversas finalidades, tais como: fornecer elementos carentes ao organismo, como vitaminas, sais minerais e hormônios; prevenção de várias doenças ou infecções; correção de uma função desregulada e desintoxicação do organismo. Os avanços na medicina, e por conseguinte da indústria farmacêutica, não seguem a mesma velocidade que os estudos dos potenciais impactos ecológicos na natureza, uma vez que, apesar de novas substâncias sendo continuamente lançadas no mercado, uma quantidade mínima destas é analisada quanto aos seus modos de ação e efeitos ecotoxicológicos sobre a biota aquática.

A avaliação dos efeitos ecotoxicológicos sobre os componentes biológicos, por meio de biomonitoramento e testes de toxicidade, representa uma forma efetiva para predizer ou detectar impactos diversos, pois enquanto as análises químicas identificam e quantificam alguns dos poluentes presentes, os bioensaios avaliam o efeito global destes sobre os sistemas bióticos medindo a capacidade que os compostos químicos têm de interferir nas vias bioquímicas celulares, causando-lhes efeitos adversos. Além disso, estes estudos são considerados essenciais para o desenvolvimento de Leis e Diretrizes que visam a proteção dos organismos, além de estabeler limites para o descarte de efluentes que contenham estas substâncias.

Observou-se neste estudo a ocorrência de resíduos de fármacos no ambiente aquático e o potencial ecotoxicológico destas substâncias sobre os diferentes organismos-teste estudados. Os diferentes efeitos seja na toxicidade aguda ou crônica, que causaram alterações no ciclo de vida e na dinâmica populacional das espécies estudadas foram ocasionados por níveis de exposição de várias ordens de magnitude superiores aos reportados no compartimento aquático. Contudo, deve-se considerar que esses compostos farmacêuticos juntamente com outras classes de poluentes, não são facilmente eliminados nos processos de tratamento convencionais de água, e mesmo em níveis mínimos, podem estar presentes diariamente na água consumida pela população e também resultarem em riscos ecológicos a longo prazo para a biota aquática. Os dados de ecotoxicidade crônica são escassos na literatura em relação aos agudos, por isso há 
necessidade de se desenvolver mais estudos nessa área para se compreender melhor qual o grau do impacto dos fármacos.

Apesar de avaliarmos os efeitos dos compostos em estudo individualmente, e os dados obtidos não representarem perigo as espécies estudadas, é importante determinar o risco que cada fármaco representa. Em uma dada concentração um composto pode não ser tóxico a uma espécie, mas pode ser tóxico a outra; Além disso, é conhecido que quando estas substâncias são inseridas nos ecossistemas aquáticos, podem sofrer transformações ou interagir com as outras substâncias apresentando sua ecotoxicidade potencializada por sinergismos. Por isso recomenda-se que os diferentes efeitos de fármacos também sejam avaliados por misturas tóxicas.

Mediante os resultados obtidos com as espécies nativas, além das que não estão incluídas em protocos ecotoxicológicos (como o crustáceo Ceriodaphnia silvestrii, Hydra viridissima e Dugesia tigrina), são imprescindíveis maiores estudos utilizando estes organismos-teste em ensaios de ecotoxidade para aquisição de informações ecologicamente relevantes sobre a toxicidade dos fármacos nos ambientes aquáticos tropicais. Bioensaios analisando endpoints diferentes, como a capacidade de regeneração nas espécies $H$. viridissima e $D$. tigrina também são relevantes na avaliação destas substâncias tóxicas.

Os fármacos paracetamol, diclofenaco sódico e propranolol são muito consumidos pela população pelo seu menor preço e fácil aquisição, tendo como consequência a frequente ocorrência destas substâncias nos ecossistemas aquáticos. Entretanto, estudos relacionados sobre a presença da clorpromazina no ambiente aquático e seus possíveis impactos, considerando avaliações sobre parâmetros individuais e sub-individuais são escassos em comparação com os outros três compostos.

Há necessidade de se identificarem os resíduos de fármacos nos compartimentos ambientais (águas e solos), desenvolvendo e validando métodos cada vez mais precisos para detecção, e buscando compreender também os mecanismos de interação das drogas e/ou misturas delas próprias entre si e com os organismos, populações e comunidades nos ecossistemas, a fim de se reduzirem os possíveis impactos na saúde humana e na biota aquática.

Estes fatos reforçam a utilização de estudos ecotoxicológicos com os componentes biológicos, bem como a conscientização e divulgação massiva dos problemas associados aos fármacos e ao meio ambiente. Além disso, há a necessidade também de 
melhoria e adequação das plantas de tratamento de efluentes, assim como, o desenvolvimento de novas tecnologias apropriadas para a remoção, de forma mais eficiente, destes compostos farmacêuticos. 


\section{Apêndice A}

\section{Resultados analíticos e ecotoxicológicos}


1. Curvas analíticas dos compostos farmacêuticos estudados (referentes ao Capítulo 1).

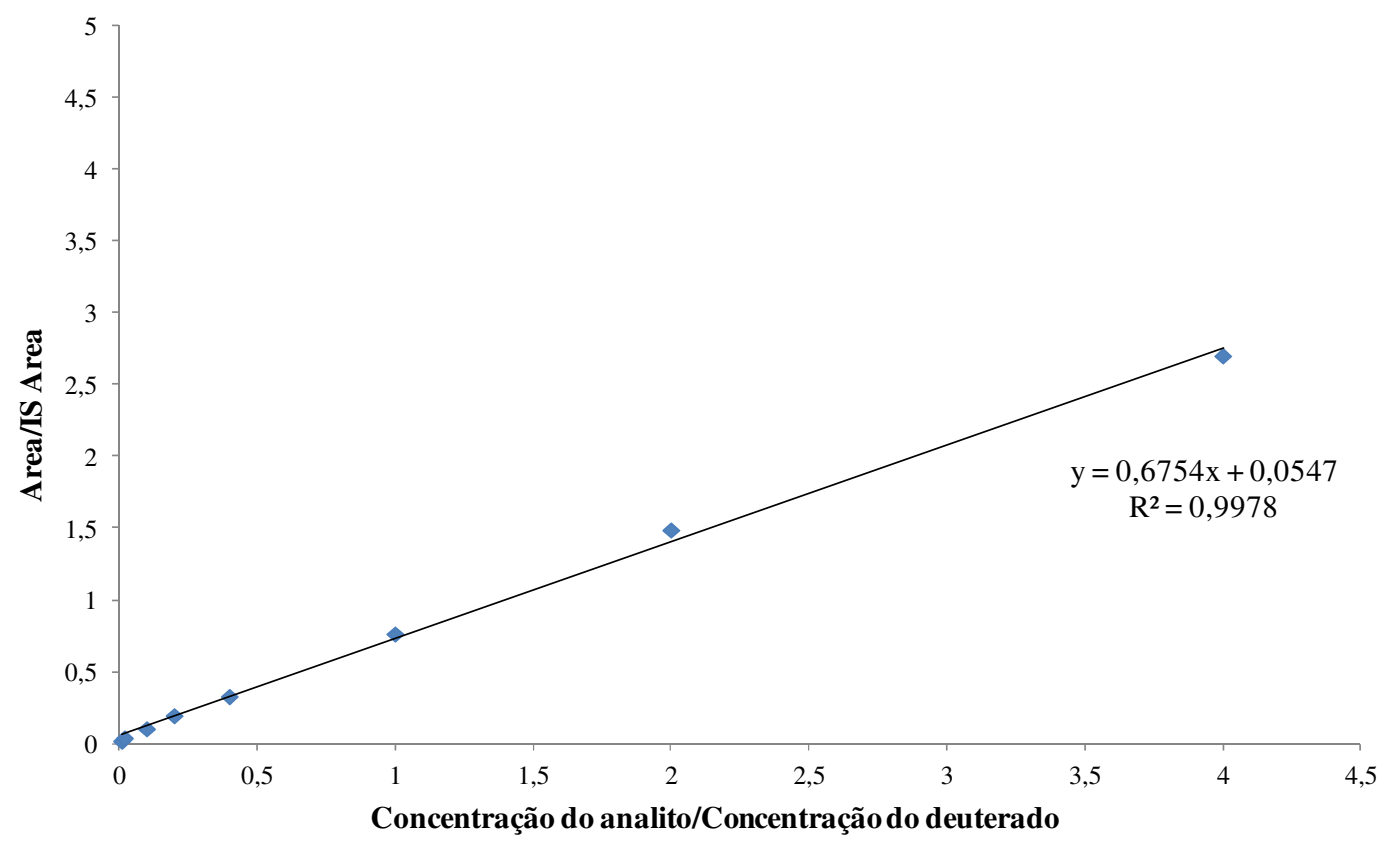

Figura 1. Curva de calibração para análise do fármaco diclofenaco sódico.

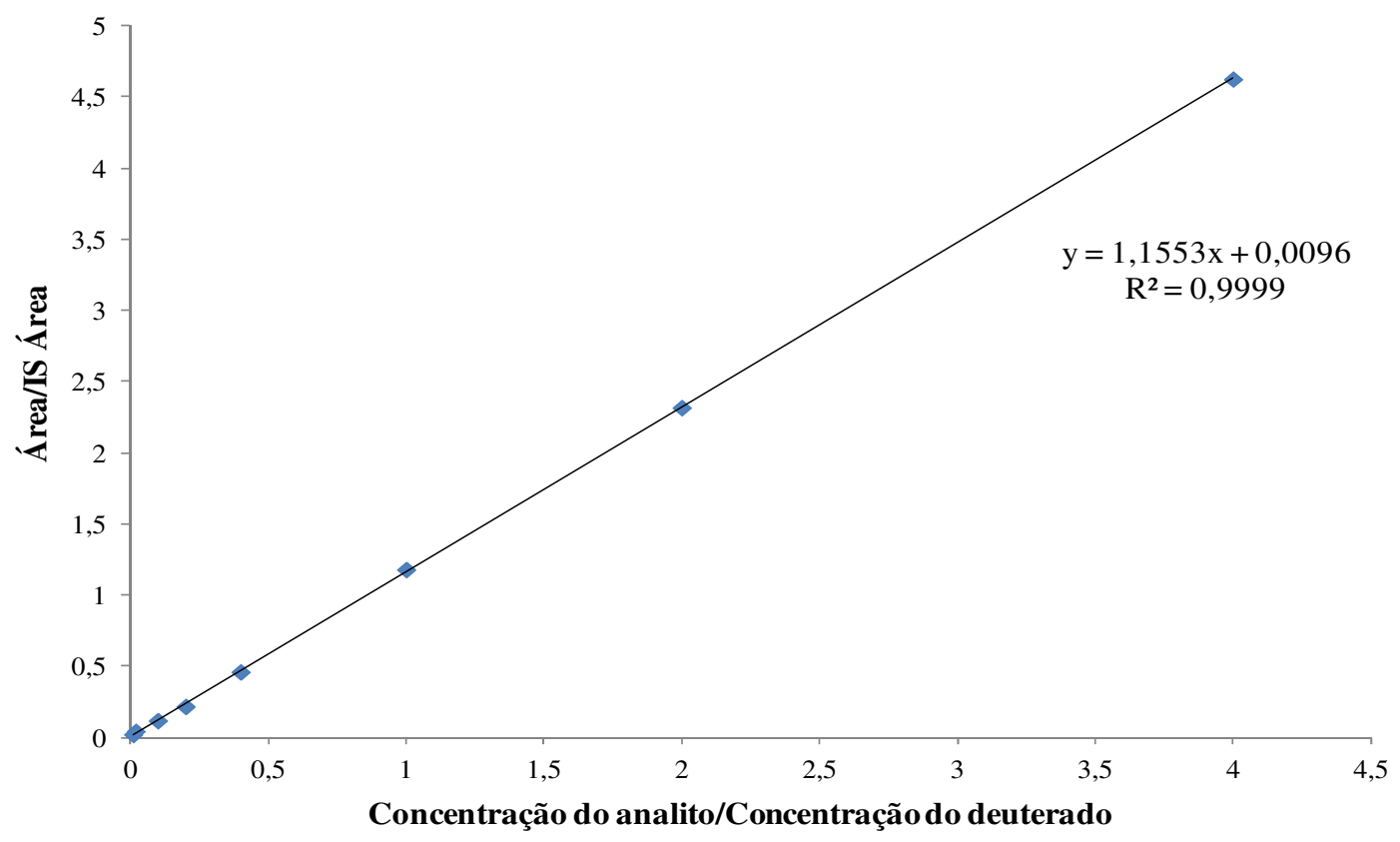

Figura 2. Curva de calibração para o fármaco paracetamol. 


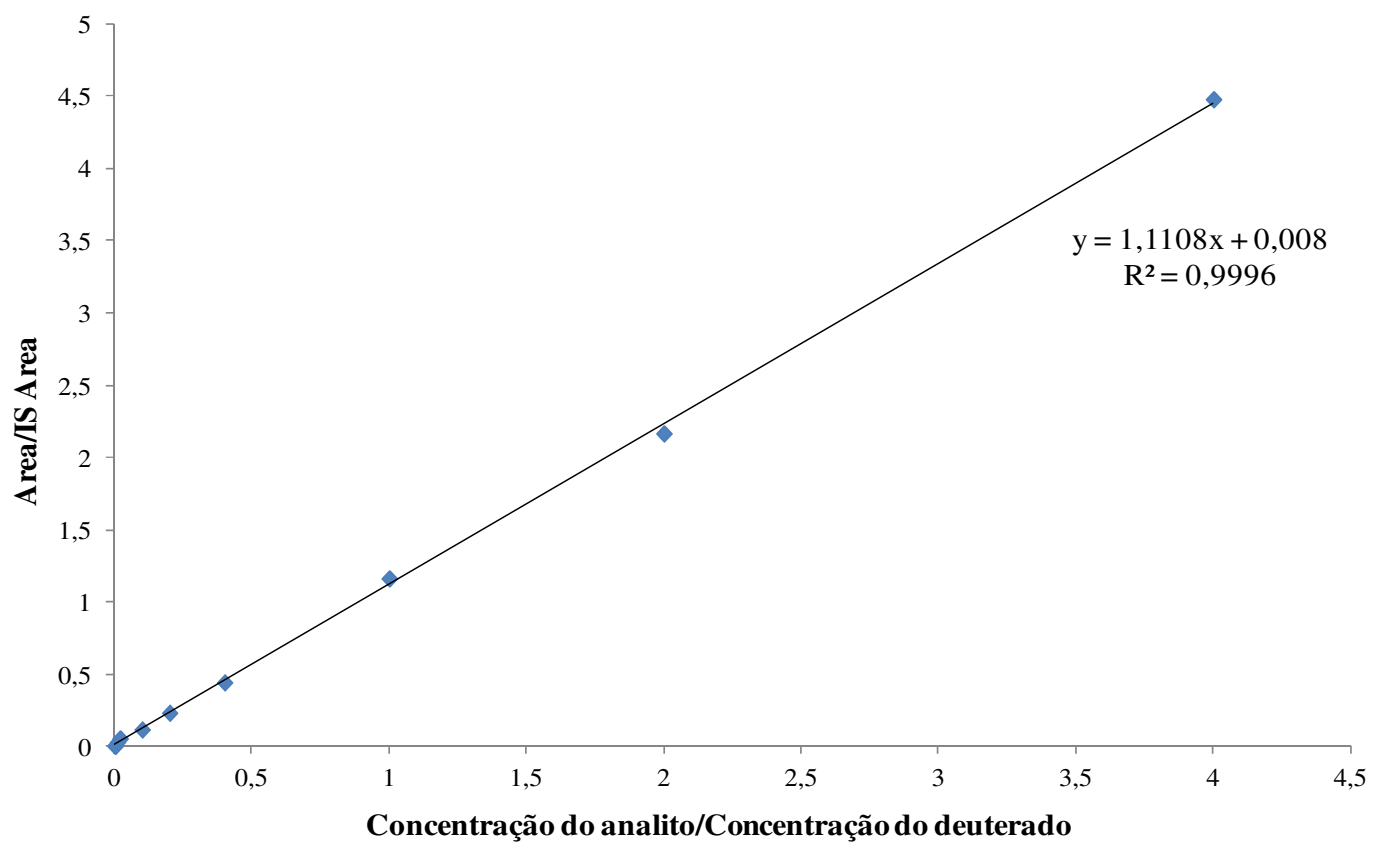

Figura 3. Curva de calibração para o fármaco propranolol. 
2. Resultados dos testes de sensibilidade com as espécies estudadas (referentes aos Capítulos 2 e 3).

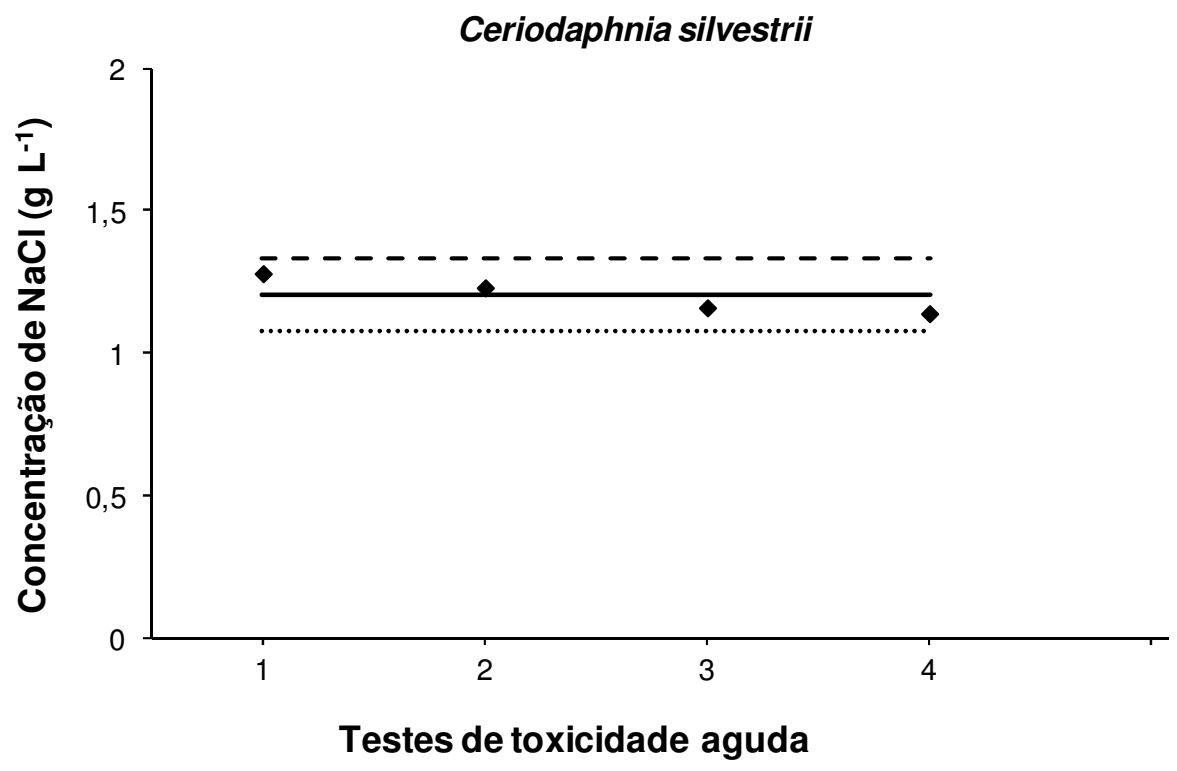

- CE50-48h …..... Limite Inferior - - - Limite Superior — Média

Figura 4. Faixa de sensibilidade de Ceriodaphnia silvestrii ao cloreto de sódio expressa em $\mathrm{CE}_{50^{-}} 48 \mathrm{~h}\left(\mathrm{~g} \mathrm{~L}^{-1}\right)$.

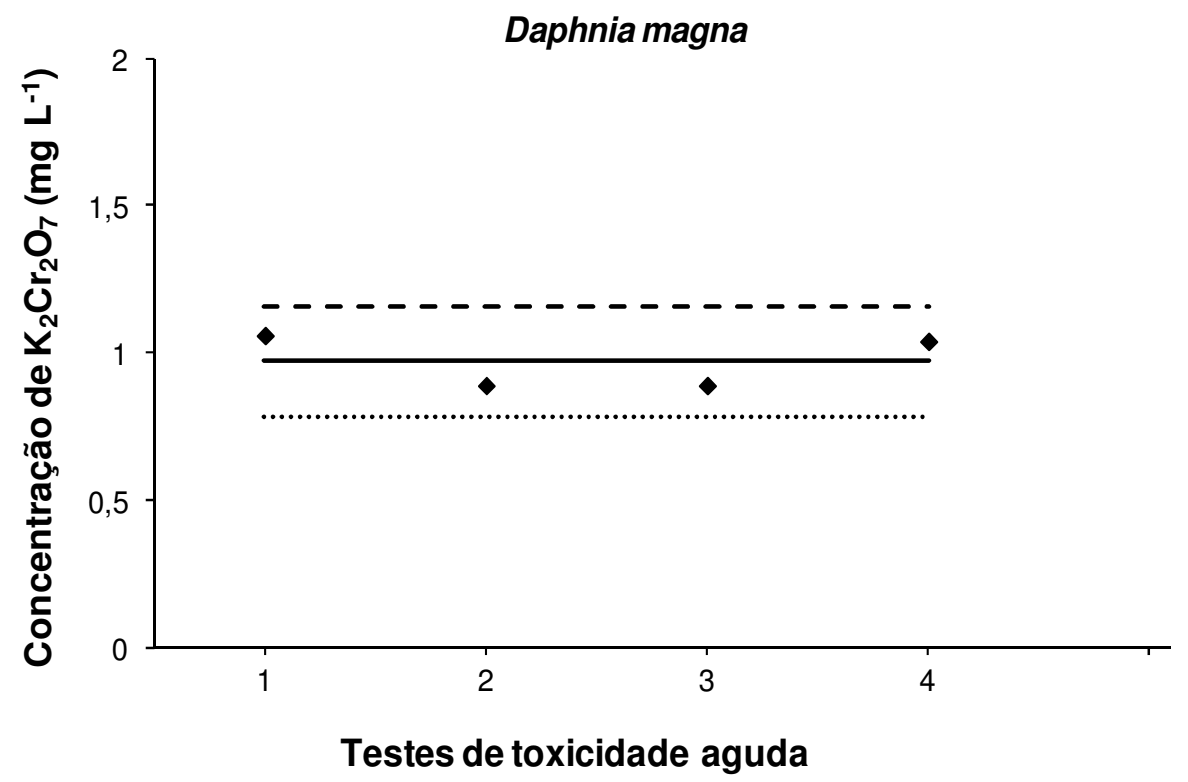

- CE50-48h ……. Limite Inferior - - - Limite Superior — Média

Figura 5. Faixa de sensibilidade de Daphnia magna ao dicromato de potássio expressa em $\mathrm{CE}_{50^{-}} 48 \mathrm{~h}\left(\mathrm{mg} \mathrm{L}^{-1}\right)$. 


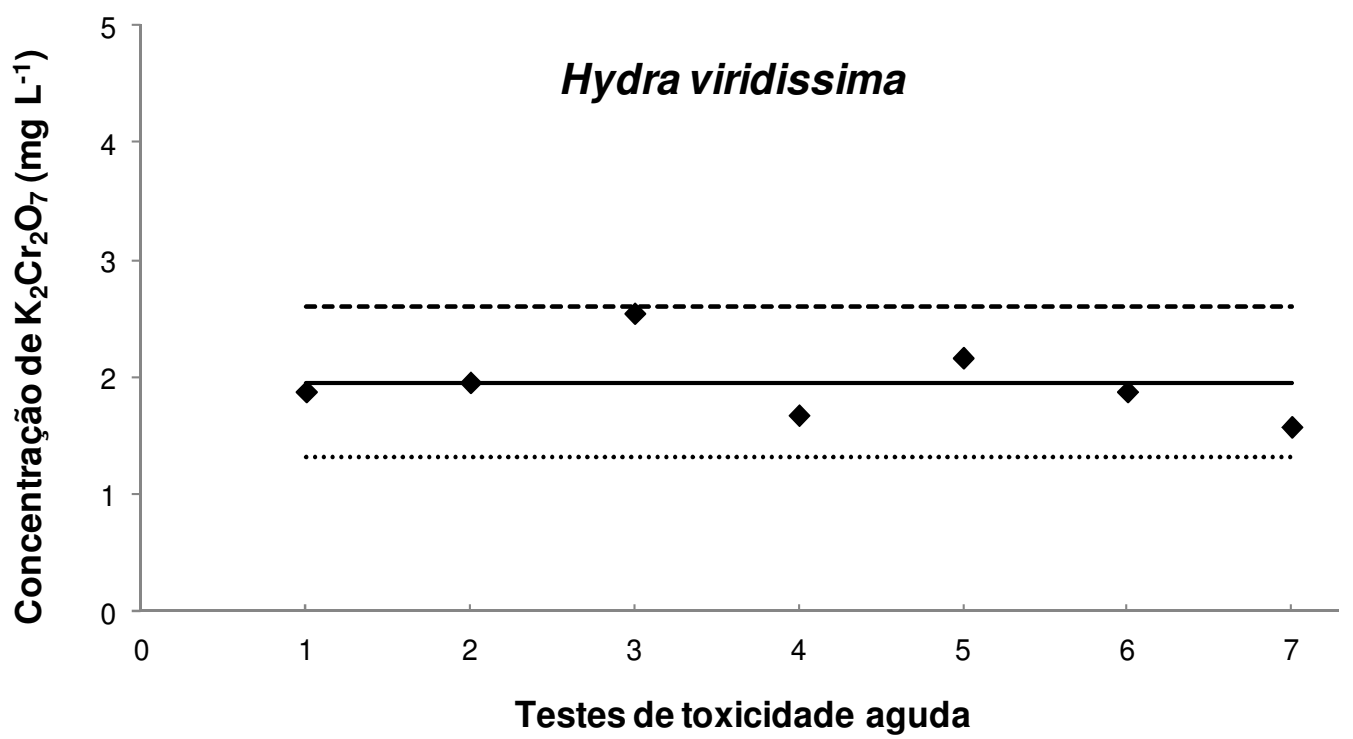

- EC50-96h …..... Limite inferior ----- Limite superior — Média

Figura 6. Faixa de sensibilidade de Hydra viridissima ao dicromato de potássio expressa em $\mathrm{CE}_{50}-96 \mathrm{~h}\left(\mathrm{mg} \mathrm{L}^{-1}\right)$.

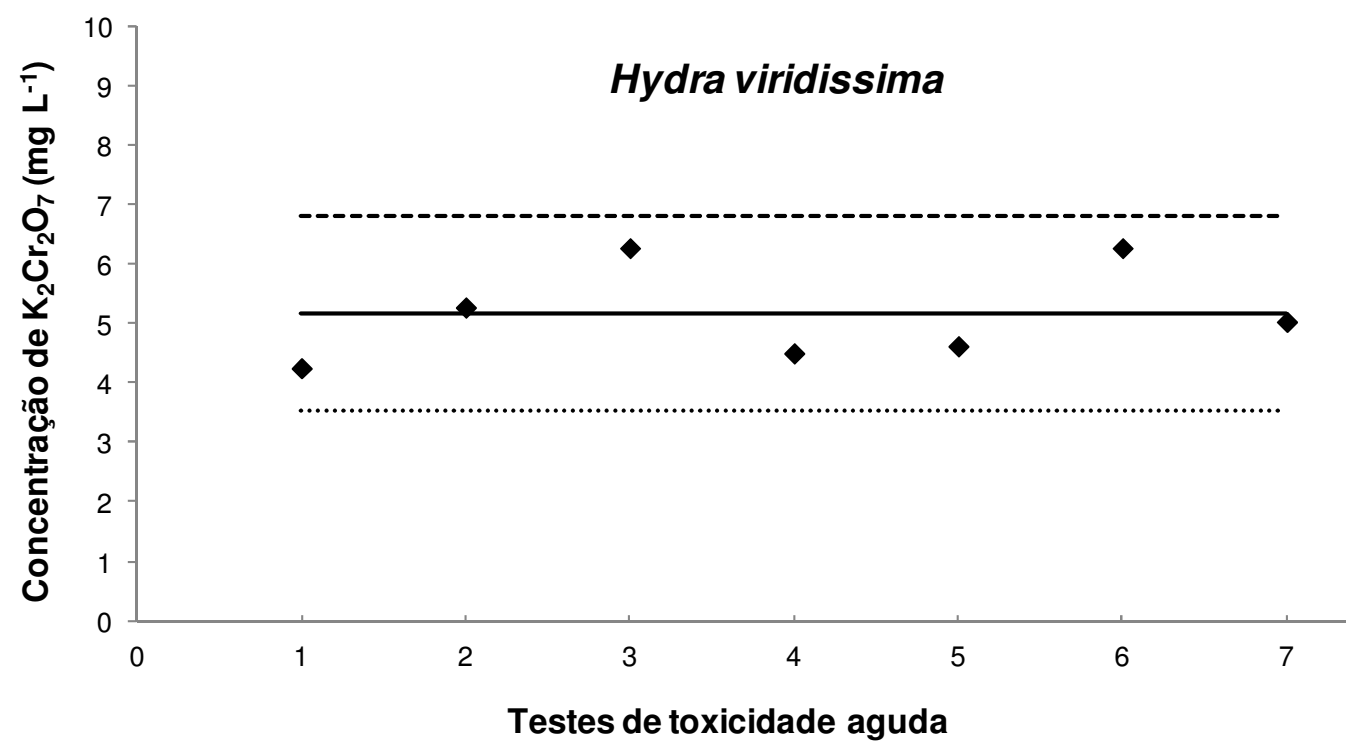

- EC50-96h ….... Limiteinferior --.-.. Limite superior — Média

Figura 7. Faixa de sensibilidade de Hydra viridissima ao dicromato de potássio expressa em $\mathrm{CL}_{50^{-}} 96 \mathrm{~h}\left(\mathrm{mg} \mathrm{L}^{-1}\right)$. 
3. Resultados dos testes de toxicidade aguda com as espécies $H$. viridissima e $D$. tigrina, mostrando os valores de $\mathrm{CE}_{50}$ e $\mathbf{C L}_{50}$ de diclofenaco sódico e propranolol ao longo de 96 horas (referentes ao Capítulo 3).

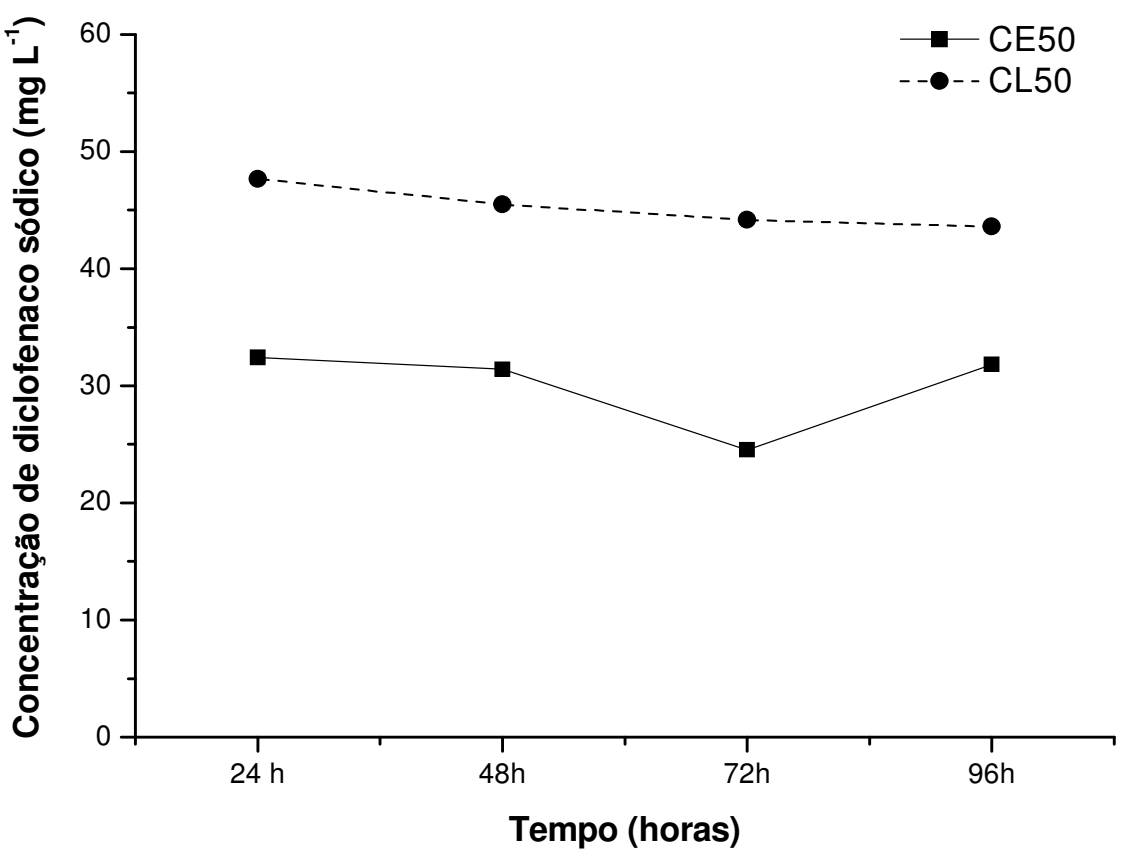

Figura 8. Valores médios da Concentração Efetiva Mediana $\left(\mathrm{CE}_{50}, \mathrm{mg} \mathrm{L}^{-1}\right)$ e da Concentração Letal Mediana $\left(\mathrm{CL}_{50}, \mathrm{mg} \mathrm{L}^{-1}\right)$ de diclofenaco sódico, ao longo de 96 horas, em testes de toxicidade aguda com Hydra viridissima.

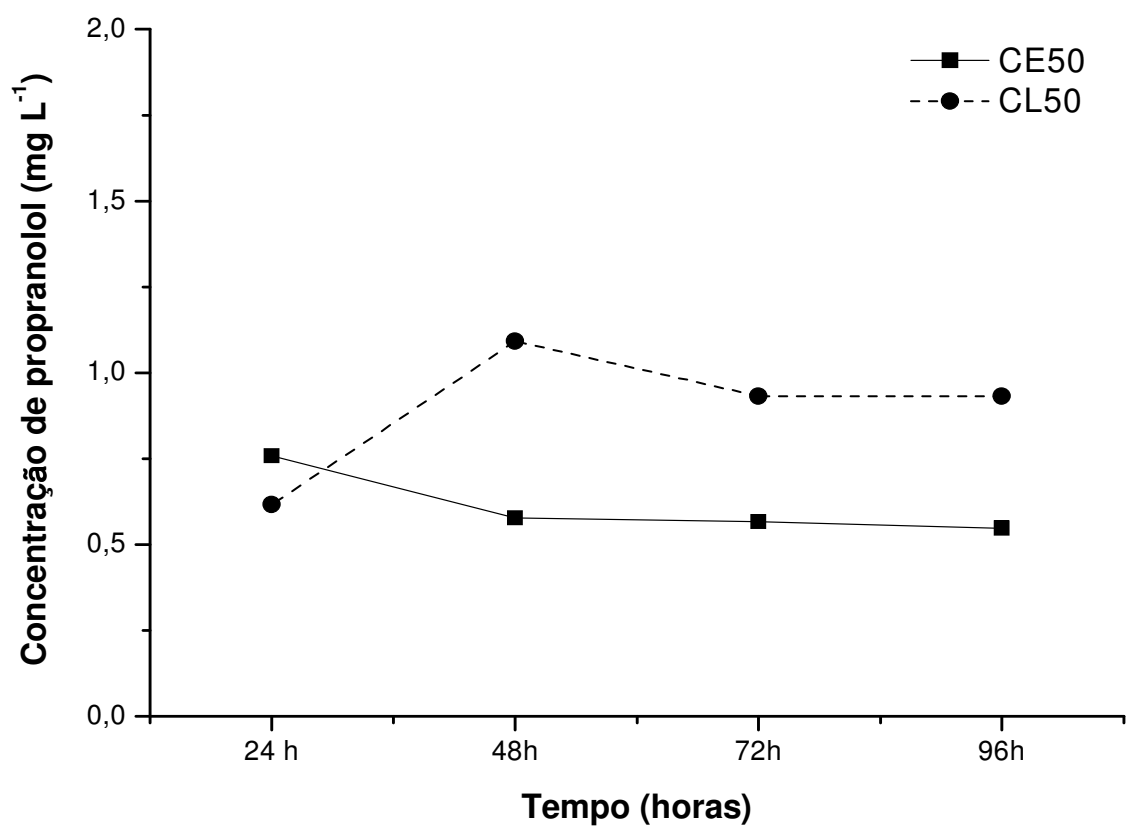

Figura 9. Valores médios da Concentração Efetiva Mediana $\left(\mathrm{CE}_{50}, \mathrm{mg} \mathrm{L}^{-1}\right)$ e da Concentração Letal Mediana $\left(\mathrm{CL}_{50}, \mathrm{mg} \mathrm{L}^{-1}\right)$ de propranolol, ao longo de 96 horas, em testes de toxicidade aguda com Hydra viridissima. 


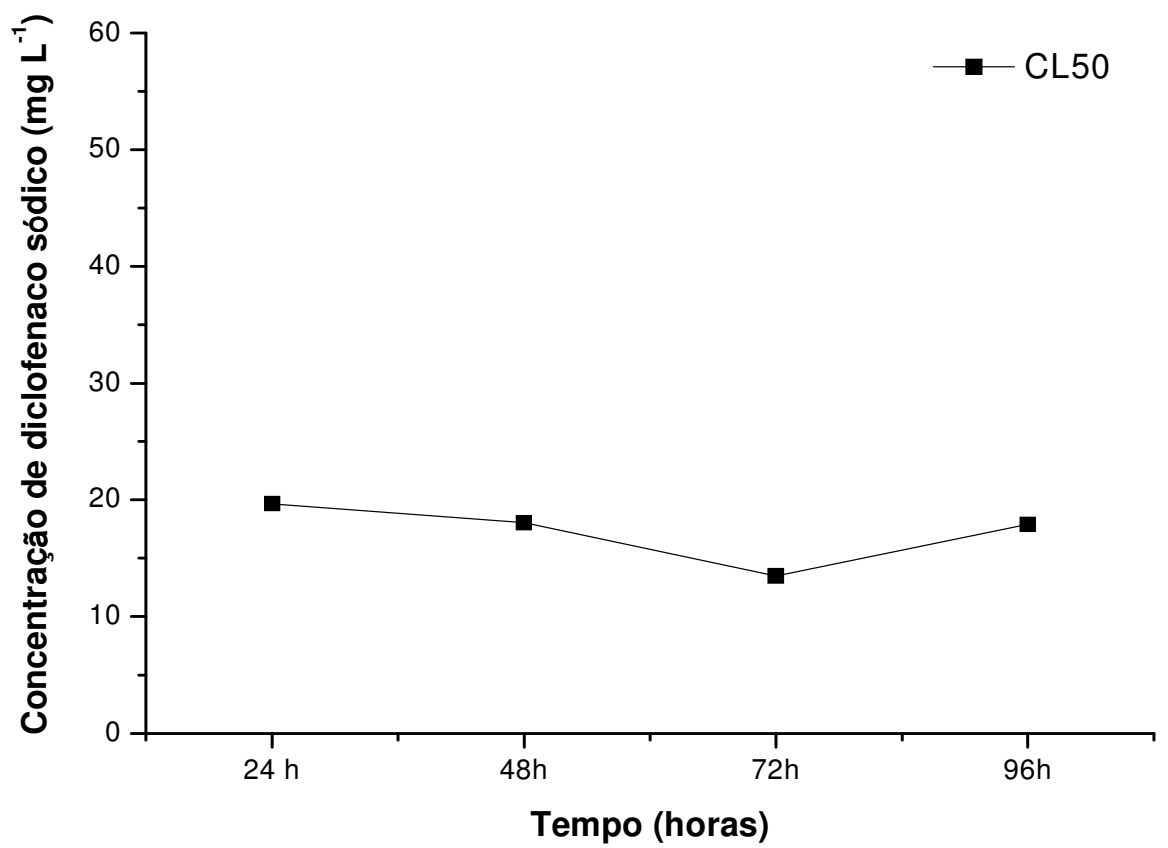

Figura 10. Valores da Concentração Letal Mediana $\left(\mathrm{CL}_{50}, \mathrm{mg} \mathrm{L}^{-1}\right)$ de diclofenaco sódico, ao longo de 96 horas, em testes de toxicidade aguda com Dugesia tigrina.

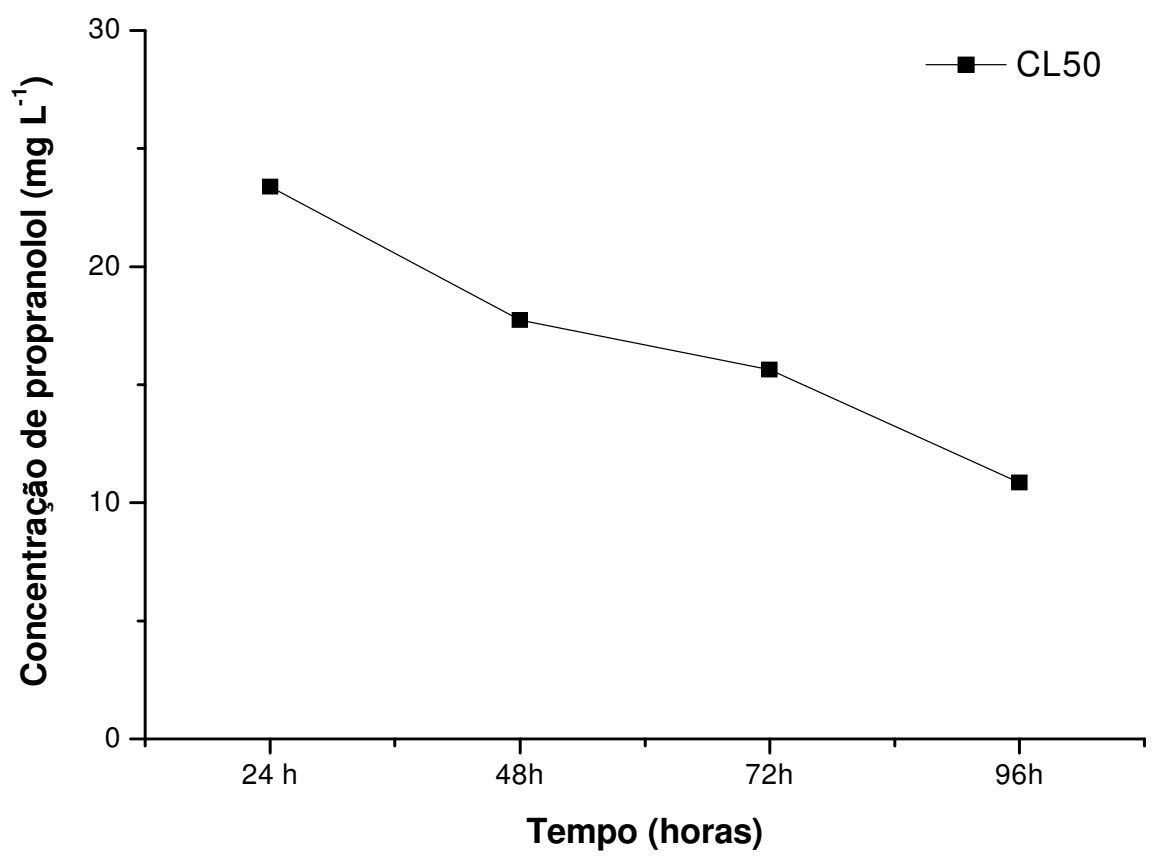

Figura 11. Valores da Concentração Letal Mediana $\left(\mathrm{CL}_{50}, \mathrm{mg} \mathrm{L}^{-1}\right)$ de propranolol, ao longo de 96 horas, em testes de toxicidade aguda com Dugesia tigrina. 


\section{Registro dos resultados dos testes de toxicidade aguda com o fármaco diclofenaco sódico (Capítulos 2, 3 e 4).}

\section{Ceriodaphnia silvestrii}

Tabela 1. Resultados do primeiro teste de toxicidade aguda $(\mathrm{n}=5)$ com Ceriodaphnia silvestrii exposta ao diclofenaco sódico.

\begin{tabular}{|c|c|c|c|c|c|c|c|c|c|c|c|}
\hline \multirow{2}{*}{$\begin{array}{l}\text { Solução- } \\
\text { teste } \\
\left(\mathrm{mg} \mathrm{L}^{-1}\right)\end{array}$} & \multicolumn{2}{|c|}{$\mathrm{pH}$} & \multicolumn{2}{|c|}{$\begin{array}{l}\text { Condutividade } \\
\qquad\left(\mu \mathrm{S} \mathrm{cm}^{-1}\right)\end{array}$} & \multirow{2}{*}{$\begin{array}{c}\text { Dureza } \\
\left(\mathrm{mg} \mathrm{L}^{-1}\right. \\
\left.\mathrm{CaCO}_{3}\right) \\
\mathrm{i}\end{array}$} & \multicolumn{2}{|c|}{$\begin{array}{c}\text { Temperatura } \\
\left({ }^{\circ} \mathrm{C}\right)\end{array}$} & \multicolumn{2}{|c|}{$\begin{array}{c}\mathrm{N}^{\circ} \mathrm{de} \\
\text { organismos } \\
\text { móveis }\end{array}$} & \multicolumn{2}{|c|}{ Imobilidade } \\
\hline & $\mathrm{i}$ & $f$ & $\mathrm{i}$ & $\mathrm{F}$ & & $\mathrm{i}$ & $\mathrm{f}$ & $\mathrm{i}$ & $\mathrm{f}$ & Total & $\%$ \\
\hline Controle & 7,32 & 7,89 & 155,0 & 157,8 & 40 & 23,8 & 24,2 & 20 & 19 & 1 & 5 \\
\hline 3,12 & 7,28 & 7,84 & 146,8 & 167,4 & 44 & 23,7 & 24,2 & 20 & 20 & 0 & 0 \\
\hline 6,25 & 7,33 & 7,86 & 145,7 & 164,9 & 40 & 23,7 & 24,1 & 20 & 18 & 2 & 10 \\
\hline 12,5 & 7,32 & 7,89 & 146,0 & 156,5 & 42 & 23,7 & 24,4 & 20 & 20 & 0 & 0 \\
\hline 25 & 7,30 & 7,87 & 142,0 & 153,0 & 42 & 23,7 & 24,5 & 20 & 15 & 5 & 25 \\
\hline 50 & 7,29 & 7,89 & 140,9 & 162,7 & 46 & 23,7 & 24,4 & 20 & 0 & 20 & 100 \\
\hline 100 & 7,31 & 7,92 & 134,7 & 149,5 & 46 & 23,8 & 24,4 & 20 & 0 & 20 & 100 \\
\hline wi & & & $\mathrm{g} \mathrm{L}^{-1}$ & Inter & $\mathrm{A} C \mathrm{C}$ & & & & & & \\
\hline
\end{tabular}


Tabela 2. Resultados do segundo teste de toxicidade aguda $(\mathrm{n}=5)$ com Ceriodaphnia silvestrii exposta ao diclofenaco sódico.

\begin{tabular}{|c|c|c|c|c|c|c|c|c|c|c|c|}
\hline \multirow{2}{*}{$\begin{array}{l}\text { Solução- } \\
\text { teste } \\
\left(\mathrm{mg} \mathrm{L}^{-1}\right)\end{array}$} & \multicolumn{2}{|c|}{$\mathrm{pH}$} & \multicolumn{2}{|c|}{$\begin{array}{l}\text { Condutividade } \\
\qquad\left(\mu \mathrm{S} \mathrm{cm}^{-1}\right)\end{array}$} & \multirow{2}{*}{$\begin{array}{c}\text { Dureza } \\
\left(\mathrm{mg} \mathrm{L}^{-1}\right. \\
\left.\mathrm{CaCO}_{3}\right) \\
\mathrm{i}\end{array}$} & \multicolumn{2}{|c|}{$\begin{array}{c}\text { Temperatura } \\
\left({ }^{\circ} \mathrm{C}\right)\end{array}$} & \multicolumn{2}{|c|}{$\begin{array}{c}\mathrm{N}^{\circ} \mathrm{de} \\
\text { organismos } \\
\text { móveis }\end{array}$} & \multicolumn{2}{|c|}{ Imobilidade } \\
\hline & $\mathrm{i}$ & $\mathrm{f}$ & $\mathrm{i}$ & $\mathrm{F}$ & & $\mathrm{i}$ & $\mathrm{f}$ & $\mathrm{i}$ & $\mathrm{f}$ & Total & $\%$ \\
\hline Controle & 7,04 & 7,46 & 139,6 & 158,8 & 40 & 26,0 & 27,5 & 20 & 19 & 1 & 5 \\
\hline 3,12 & 7,05 & 7,44 & 144,6 & 160,4 & 46 & 26,2 & 27,8 & 20 & 19 & 1 & 5 \\
\hline 6,25 & 7,08 & 7,48 & 141,3 & 164,8 & 46 & 26,2 & 27,0 & 20 & 20 & 0 & 0 \\
\hline 12,5 & 7,08 & 7,49 & 136,6 & 156,0 & 42 & 26,3 & 27,6 & 20 & 18 & 2 & 10 \\
\hline 25 & 7,12 & 7,56 & 133,4 & 153,0 & 40 & 26,4 & 27,4 & 20 & 20 & 0 & 0 \\
\hline 50 & 7,11 & 7,51 & 134,5 & 152,8 & 42 & 26,4 & 27,0 & 20 & 16 & 4 & 20 \\
\hline 100 & 7,20 & 7,59 & 122,3 & 150,2 & 46 & 26,5 & 27,1 & 20 & 0 & 20 & 100 \\
\hline
\end{tabular}

Tabela 3. Resultados do terceiro teste de toxicidade aguda $(n=5)$ com Ceriodaphnia silvestrii exposta ao diclofenaco sódico.

\begin{tabular}{|c|c|c|c|c|c|c|c|c|c|c|c|}
\hline \multirow{2}{*}{$\begin{array}{l}\text { Solução- } \\
\text { teste } \\
\left(\mathrm{mg} \mathrm{L}^{-1}\right)\end{array}$} & \multicolumn{2}{|c|}{$\mathrm{pH}$} & \multicolumn{2}{|c|}{$\begin{array}{l}\text { Condutividade } \\
\left(\mu \mathrm{S} \mathrm{cm}^{-1}\right)\end{array}$} & \multirow{2}{*}{$\begin{array}{l}\text { Dureza } \\
\left(\mathrm{mg} \mathrm{L}^{-1}\right. \\
\left.\mathrm{CaCO}_{3}\right) \\
\mathrm{i}\end{array}$} & \multicolumn{2}{|c|}{$\begin{array}{c}\text { Temperatura } \\
\left({ }^{\circ} \mathrm{C}\right)\end{array}$} & \multicolumn{2}{|c|}{$\begin{array}{c}\mathrm{N}^{\circ} \mathrm{de} \\
\text { organismos } \\
\text { móveis }\end{array}$} & \multicolumn{2}{|c|}{ Imobilidade } \\
\hline & $\mathrm{i}$ & $\mathrm{f}$ & $\mathrm{i}$ & $\mathrm{F}$ & & $\mathrm{i}$ & f & $\mathrm{i}$ & $f$ & Total & $\%$ \\
\hline Controle & 7,27 & 7,80 & 135,9 & 142,0 & 44 & 24,4 & 27,8 & 20 & 18 & 2 & 10 \\
\hline 3,12 & 7,15 & 8,13 & 132,7 & 159,1 & 40 & 24,3 & 27,4 & 20 & 19 & 1 & 5 \\
\hline 6,25 & 7,08 & 7,99 & 131,3 & 144,6 & 42 & 24,5 & 27,1 & 20 & 19 & 1 & 5 \\
\hline 12,5 & 7,12 & 7,82 & 134,8 & 151,6 & 42 & 24,4 & 27,0 & 20 & 16 & 4 & 20 \\
\hline 25 & 7,25 & 7,66 & 135,4 & 149,0 & 44 & 24,4 & 27,4 & 20 & 12 & 8 & 40 \\
\hline 50 & 7,20 & 7,70 & 135,2 & 142,6 & 42 & 24,5 & 27,2 & 20 & 11 & 9 & 45 \\
\hline 100 & 7,15 & 7,56 & 130,0 & 137,2 & 42 & 24,5 & 27,9 & 20 & 0 & 20 & 100 \\
\hline
\end{tabular}

$\operatorname{Resultado~CE}_{50}(48 \mathrm{~h})=37,61 \mathrm{mg} \mathrm{L}^{-1} \quad$ Intervalo de Confiança $(95 \%)=\left(29,62-47,76 \mathrm{mg} \mathrm{L}^{-1}\right)$ 
Tabela 4. Resultados do quarto teste de toxicidade aguda ( $\mathrm{n}=5$ ) com Ceriodaphnia silvestrii exposta ao diclofenaco sódico.

\begin{tabular}{|c|c|c|c|c|c|c|c|c|c|c|c|}
\hline \multirow{2}{*}{$\begin{array}{l}\text { Solução- } \\
\text { teste } \\
\left(\mathrm{mg} \mathrm{L}^{-1}\right)\end{array}$} & \multicolumn{2}{|c|}{$\mathrm{pH}$} & \multicolumn{2}{|c|}{$\begin{array}{l}\text { Condutividade } \\
\left(\mu \mathrm{S} \mathrm{cm}^{-1}\right)\end{array}$} & \multirow{2}{*}{$\begin{array}{l}\text { Dureza } \\
\left(\mathrm{mg} \mathrm{L}^{-1}\right. \\
\left.\mathrm{CaCO}_{3}\right) \\
\frac{\mathrm{i}}{}\end{array}$} & \multicolumn{2}{|c|}{$\begin{array}{c}\text { Temperatura } \\
\left({ }^{\circ} \mathrm{C}\right)\end{array}$} & \multicolumn{2}{|c|}{$\begin{array}{c}\mathrm{N}^{\circ} \mathrm{de} \\
\text { organismos } \\
\text { móveis }\end{array}$} & \multicolumn{2}{|c|}{ Imobilidade } \\
\hline & $\mathrm{i}$ & $\mathrm{f}$ & $\mathrm{i}$ & $\mathrm{f}$ & & $\mathrm{i}$ & $\mathrm{f}$ & $\mathrm{i}$ & $\mathrm{f}$ & Total & $\%$ \\
\hline Controle & 7,55 & 7,87 & 143,9 & 186,7 & 40 & 23,1 & 24,6 & 20 & 19 & 1 & 5 \\
\hline 3,12 & 7,51 & 7,80 & 145,0 & 162,7 & 40 & 23,0 & 24,9 & 20 & 19 & 1 & 5 \\
\hline 6,25 & 7,62 & 7,76 & 144,3 & 161,8 & 44 & 23,6 & 24,8 & 20 & 18 & 2 & 10 \\
\hline 12,5 & 7,52 & 7,82 & 145,7 & 163,4 & 42 & 23,0 & 24,7 & 20 & 13 & 7 & 35 \\
\hline 25 & 7,46 & 7,84 & 145,1 & 161,7 & 46 & 23,4 & 24,8 & 20 & 11 & 9 & 45 \\
\hline 50 & 7,51 & 7,90 & 144,2 & 161,8 & 44 & 23,5 & 25,1 & 20 & 3 & 17 & 85 \\
\hline 100 & 7,44 & 7,85 & 142,9 & 158,6 & 48 & 23,0 & 25,0 & 20 & 0 & 20 & 100 \\
\hline
\end{tabular}

Resultado $\mathrm{CE}_{50}(48 \mathrm{~h})=22,82 \mathrm{mg} \mathrm{L}^{-1} \quad$ Intervalo de Confiança $(95 \%)=\left(17,80-29,26 \mathrm{mg} \mathrm{L}^{-1}\right)$

Tabela 5. Resultados do quinto teste de toxicidade aguda ( $\mathrm{n}=5$ ) com Ceriodaphnia silvestrii exposta ao diclofenaco sódico.

\begin{tabular}{|c|c|c|c|c|c|c|c|c|c|c|c|}
\hline \multirow{2}{*}{$\begin{array}{l}\text { Solução- } \\
\text { teste } \\
\left(\mathrm{mg} \mathrm{L}^{-1}\right)\end{array}$} & \multicolumn{2}{|c|}{$\mathrm{pH}$} & \multicolumn{2}{|c|}{$\begin{array}{l}\text { Condutividade } \\
\qquad\left(\mu \mathrm{S} \mathrm{cm}^{-1}\right)\end{array}$} & \multirow{2}{*}{$\begin{array}{c}\text { Dureza } \\
\left(\mathrm{mg} \mathrm{L}^{-1}\right. \\
\left.\mathrm{CaCO}_{3}\right) \\
\mathrm{i}\end{array}$} & \multicolumn{2}{|c|}{$\begin{array}{c}\text { Temperatura } \\
\left({ }^{\circ} \mathrm{C}\right)\end{array}$} & \multicolumn{2}{|c|}{$\begin{array}{l}\mathrm{N}^{\circ} \mathrm{de} \\
\text { organismos } \\
\text { móveis }\end{array}$} & \multicolumn{2}{|c|}{ Imobilidade } \\
\hline & $\mathrm{i}$ & $\mathrm{f}$ & $\mathrm{i}$ & $\mathrm{f}$ & & $\mathrm{i}$ & $f$ & $\mathrm{i}$ & $\mathrm{f}$ & Total & $\%$ \\
\hline Controle & 7,31 & 7,75 & 160,4 & 152,0 & 44 & 22,5 & 24,6 & 20 & 20 & 0 & 0 \\
\hline 3,12 & 7,20 & 7,64 & 152,1 & 153,0 & 42 & 22,5 & 24,7 & 20 & 20 & 0 & 0 \\
\hline 6,25 & 7,13 & 7,61 & 150,3 & 159,9 & 40 & 22,4 & 25,3 & 20 & 19 & 1 & 5 \\
\hline 12,5 & 7,10 & 7,68 & 149,9 & 152,2 & 42 & 22,4 & 25,1 & 20 & 19 & 1 & 5 \\
\hline 25 & 7,08 & 7,67 & 150,1 & 154,8 & 44 & 22,5 & 25,0 & 20 & 19 & 1 & 5 \\
\hline 50 & 7,04 & 7,63 & 147,1 & 160,6 & 42 & 22,6 & 25,2 & 20 & 12 & 8 & 40 \\
\hline 100 & 7,02 & 7,60 & 138,7 & 144,3 & 40 & 22,6 & 25,1 & 20 & 0 & 20 & 100 \\
\hline 16 & & & $\mathrm{~g} \mathrm{~L}^{-1}$ & Inter & $\mathrm{CO}_{0}$ & 0 & & & & & \\
\hline
\end{tabular}




\section{$\underline{\text { Daphnia magna }}$}

Tabela 6. Resultados do teste de toxicidade aguda com Daphnia magna exposta ao diclofenaco sódico.

\begin{tabular}{|c|c|c|c|c|c|c|c|c|c|c|c|}
\hline \multirow{2}{*}{$\begin{array}{l}\text { Solução- } \\
\text { teste } \\
\left(\mathrm{mg} \mathrm{L}^{-1}\right)\end{array}$} & \multicolumn{2}{|c|}{$\mathrm{pH}$} & \multicolumn{2}{|c|}{$\begin{array}{l}\text { Condutividade } \\
\qquad\left(\mu \mathrm{S} \mathrm{cm}^{-1}\right)\end{array}$} & \multirow{2}{*}{$\begin{array}{l}\text { Dureza } \\
\left(\mathrm{mg} \mathrm{L}^{-1}\right. \\
\left.\mathrm{CaCO}_{3}\right) \\
\frac{\mathrm{i}}{}\end{array}$} & \multicolumn{2}{|c|}{$\begin{array}{c}\text { Temperatura } \\
\left({ }^{\circ} \mathrm{C}\right)\end{array}$} & \multicolumn{2}{|c|}{$\begin{array}{c}\mathrm{N}^{\circ} \mathrm{de} \\
\text { organismos } \\
\text { móveis }\end{array}$} & \multicolumn{2}{|c|}{ Imobilidade } \\
\hline & $\mathrm{i}$ & $\mathrm{f}$ & $\mathrm{i}$ & $\mathrm{F}$ & & $\mathrm{i}$ & $\mathrm{f}$ & $\mathrm{i}$ & $f$ & Total & $\%$ \\
\hline Controle & - & - & - & - & - & - & - & 20 & 20 & 0 & 0 \\
\hline 52,0 & - & - & - & - & - & - & - & 20 & 20 & 0 & 0 \\
\hline 62,4 & - & - & - & - & - & - & - & 20 & 20 & 0 & 0 \\
\hline 74,9 & - & - & - & - & - & - & - & 20 & 20 & 0 & 0 \\
\hline 89,9 & - & - & - & - & - & - & - & 20 & 18 & 2 & 10 \\
\hline 107,8 & - & - & - & - & - & - & - & 20 & 17 & 3 & 15 \\
\hline 129,4 & - & - & - & - & - & - & - & 20 & 9 & 11 & 55 \\
\hline 155,3 & - & - & - & - & - & - & - & 20 & 0 & 20 & 100 \\
\hline
\end{tabular}

- : não foram medidas os parâmetros físico e químicos das soluções-teste. 


\section{$\underline{\text { Dugesia tigrina }}$}

Tabela 7. Resultados do teste de toxicidade aguda com Dugesia tigrina exposta ao diclofenaco sódico.

\begin{tabular}{|c|c|c|c|c|c|c|c|c|c|c|c|}
\hline \multirow{2}{*}{$\begin{array}{l}\text { Solução- } \\
\text { teste } \\
\left(\mathrm{mg} \mathrm{L}^{-1}\right)\end{array}$} & \multicolumn{2}{|c|}{$\mathrm{pH}$} & \multicolumn{2}{|c|}{$\begin{array}{l}\text { Condutividade } \\
\qquad\left(\mu \mathrm{S} \mathrm{cm}^{-1}\right)\end{array}$} & \multirow{2}{*}{$\begin{array}{c}\text { Dureza } \\
\left(\mathrm{mg} \mathrm{L}^{-1}\right. \\
\left.\mathrm{CaCO}_{3}\right) \\
\mathrm{i}\end{array}$} & \multicolumn{2}{|c|}{$\begin{array}{c}\text { Temperatura } \\
\left({ }^{\circ} \mathrm{C}\right)\end{array}$} & \multicolumn{2}{|c|}{$\begin{array}{c}\mathrm{N}^{\circ} \mathrm{de} \\
\text { organismos } \\
\text { vivos }\end{array}$} & \multicolumn{2}{|c|}{ Mortalidade } \\
\hline & $\mathrm{i}$ & $\mathrm{f}$ & $\mathrm{i}$ & $\mathrm{F}$ & & $\mathrm{i}$ & $\mathrm{f}$ & $\mathrm{i}$ & $\mathrm{f}$ & Total & $\%$ \\
\hline Controle & 7,48 & 8,19 & 141,9 & 161,1 & 46 & 22,5 & 24,8 & 24 & 0 & 0 & 0 \\
\hline 1,0 & 7,40 & 8,05 & 144,7 & 140,5 & 46 & 22,1 & 24,5 & 24 & 0 & 0 & 0 \\
\hline 2,0 & 7,52 & 8,03 & 144,0 & 143,5 & 44 & 22,1 & 24,8 & 24 & 0 & 0 & 0 \\
\hline 4,0 & 7,52 & 7,90 & 137,4 & 146,8 & 42 & 22,3 & 24,1 & 24 & 0 & 0 & 0 \\
\hline 8,0 & 7,53 & 7,97 & 137,9 & 146,7 & 40 & 22,4 & 24,7 & 24 & 23 & 1 & 5 \\
\hline 16,0 & 7,52 & 8,02 & 140,7 & 147,6 & 42 & 22,4 & 24,8 & 24 & 21 & 3 & 13 \\
\hline 32,0 & 7,55 & 8,05 & 137,8 & 137,1 & 44 & 22,5 & 24,7 & 24 & 0 & 24 & 100 \\
\hline & & & $\mathrm{g} \mathrm{L}^{-1}$ & Inter & $\mathrm{Co}$ & & & & & $-1)$ & \\
\hline
\end{tabular}

Logo abaixo, são apresentados os registros dos testes de toxicidade aguda com o diclofenaco sódico utilizando a espécie Hydra viridissima, como organismo-teste. Os scores aplicados para cada individuo exposto correspondem aos números $*()$, sendo que nas tabelas a seguir, quando não há especificações, $\mathrm{N}(10)$, ou seja, hidra normal com score 10; $\mathrm{B}(8)$, hidra com bulbos nos tentáculos com score 8 e $\mathrm{D}(0)$, hidra com corpo desintegrado com score 0 . 
Tabela 8. Modificações morfológicas em Hydra viridissima exposta a diferentes concentrações de diclofenaco sódico (mg $\mathrm{L}^{-1}$ ), em teste definitivo de toxicidade aguda (teste $1, \mathrm{n}=8$ ), com leituras a cada 24 horas, e valores de $\mathrm{pH}$, condutividade, temperatura e dureza monitorados mo início e final dos teste. $\mathrm{N}=$ hidra normal; $\mathrm{B}=$ hidra com bulbos nos tentáculos; $\mathrm{C}=$ hidra com tentáculos encurtados; $\mathrm{T}=$ hidra em estado de tulipa; $\mathrm{D}=$ hidra desintegrada, sendo que os números dentro dos *() referem-se aos scores aplicados.

\begin{tabular}{|c|c|c|c|c|c|c|c|c|c|c|c|c|c|c|}
\hline \multirow{2}{*}{$\begin{array}{l}\text { Concentração } \\
\left(\mathrm{mg} \mathrm{L}^{-1}\right)\end{array}$} & \multirow{2}{*}{ Leitura } & \multicolumn{4}{|c|}{ Réplicas } & \multirow{2}{*}{ Total } & \multicolumn{2}{|c|}{$\mathrm{pH}$} & \multicolumn{2}{|c|}{ cond. } & \multicolumn{2}{|c|}{ Temp. } & \multicolumn{2}{|c|}{ Dureza } \\
\hline & & 1 & 2 & 3 & 4 & & Oh & $96 \mathrm{~h}$ & Oh & $96 \mathrm{~h}$ & Oh & $96 \mathrm{~h}$ & Oh & $96 h^{*}$ \\
\hline \multirow{4}{*}{ Controle } & $24 \mathrm{~h}$ & $4 \mathrm{~N}$ & $4 \mathrm{~N}$ & $4 \mathrm{~N}$ & $4 \mathrm{~N}$ & $16 \mathrm{~N}$ & \multirow{4}{*}{7,25} & \multirow{4}{*}{8,07} & \multirow{4}{*}{149,9} & \multirow{4}{*}{160,5} & \multirow{4}{*}{21,40} & \multirow{4}{*}{28,2} & \multirow{4}{*}{44} & \multirow{4}{*}{-} \\
\hline & $48 \mathrm{~h}$ & $4 \mathrm{~N}$ & $4 \mathrm{~N}$ & $4 \mathrm{~N}$ & $4 \mathrm{~N}$ & $16 \mathrm{~N}$ & & & & & & & & \\
\hline & $72 \mathrm{~h}$ & $4 \mathrm{~N}$ & $4 \mathrm{~N}$ & $4 \mathrm{~N}$ & $4 \mathrm{~N}$ & $16 \mathrm{~N}$ & & & & & & & & \\
\hline & $96 \mathrm{~h}$ & $4 \mathrm{~N}$ & $4 \mathrm{~N}$ & $4 \mathrm{~N}$ & $4 \mathrm{~N}$ & $16 \mathrm{~N}$ & & & & & & & & \\
\hline \multirow{4}{*}{10,0} & $24 \mathrm{~h}$ & $4 \mathrm{~N}$ & $4 \mathrm{~N}$ & $4 \mathrm{~N}$ & $4 \mathrm{~N}$ & $16 \mathrm{~N}$ & \multirow{4}{*}{7,35} & \multirow{4}{*}{8,0} & \multirow{4}{*}{142,0} & \multirow{4}{*}{145,0} & \multirow{4}{*}{21,80} & \multirow{4}{*}{28,0} & \multirow{4}{*}{42} & \multirow{4}{*}{-} \\
\hline & $48 \mathrm{~h}$ & $4 \mathrm{~N}$ & $4 \mathrm{~N}$ & $4 \mathrm{~N}$ & $4 \mathrm{~N}$ & $16 \mathrm{~N}$ & & & & & & & & \\
\hline & $72 \mathrm{~h}$ & $4 \mathrm{~N}$ & $4 \mathrm{~N}$ & $4 \mathrm{~N}$ & $4 \mathrm{~N}$ & $16 \mathrm{~N}$ & & & & & & & & \\
\hline & $96 \mathrm{~h}$ & $4 \mathrm{~N}$ & $4 \mathrm{~N}$ & $4 \mathrm{~N}$ & $4 \mathrm{~N}$ & $16 \mathrm{~N}$ & & & & & & & & \\
\hline \multirow{4}{*}{20,0} & $24 \mathrm{~h}$ & $4 \mathrm{~N}$ & $4 \mathrm{~N}$ & $4 \mathrm{~N}$ & $4 \mathrm{~N}$ & $16 \mathrm{~N}$ & & & & & & & & \\
\hline & $48 \mathrm{~h}$ & $4 \mathrm{~N}$ & $4 \mathrm{~N}$ & $4 \mathrm{~N}$ & $4 \mathrm{~N}$ & $16 \mathrm{~N}$ & 736 & 803 & 1400 & 1452 & 2190 & 280 & 40 & - \\
\hline & $72 \mathrm{~h}$ & $4 \mathrm{~N}$ & $4 \mathrm{~N}$ & $4 N$ & $4 \mathrm{~N}$ & $16 \mathrm{~N}$ & 1,30 & 8,03 & 140,0 & 145,2 & 21,90 & 28,0 & 40 & \\
\hline & $96 \mathrm{~h}$ & $4 \mathrm{~N}$ & $4 \mathrm{~N}$ & $4 \mathrm{~N}$ & $4 \mathrm{~N}$ & $16 \mathrm{~N}$ & & & & & & & & \\
\hline & $24 \mathrm{~h}$ & $2 \mathrm{~N}, 1 \mathrm{~B}, 1 \mathrm{C}(7)$ & $3 \mathrm{~N}, 1 \mathrm{~B}$ & $3 N, 1 C(7)$ & $4 \mathrm{~N}$ & $12 \mathrm{~N}, 2 \mathrm{~B}, 2 \mathrm{C}$ & & & & & & & & \\
\hline 300 & $48 \mathrm{~h}$ & $2 \mathrm{~N}, 2 \mathrm{C}(7)$ & $2 \mathrm{~N}, 2 \mathrm{~B}$ & $3 N, 1 C(7)$ & $4 \mathrm{~N}$ & $11 \mathrm{~N}, 2 \mathrm{~B}, 3 \mathrm{C}$ & & & & & & & & - \\
\hline 30,0 & $72 \mathrm{~h}$ & $2 \mathrm{~N}, 2 \mathrm{C}(7)$ & $2 \mathrm{~N}, 2 \mathrm{~B}$ & $3 \mathrm{~N}, 1 \mathrm{~B}$ & $4 \mathrm{~N}$ & $11 \mathrm{~N}, 3 \mathrm{~B}, 2 \mathrm{C}$ & 7,37 & 8,03 & 139,4 & 134,9 & 21,80 & 28,0 & 48 & - \\
\hline & $96 \mathrm{~h}$ & $1 \mathrm{~N}, 1 \mathrm{~B}, 2 \mathrm{C}(7)$ & $2 \mathrm{~N}, 1 \mathrm{~B}, 1 \mathrm{C}(7)$ & $4 \mathrm{~N}$ & $4 \mathrm{~N}$ & $11 \mathrm{~N}, 2 \mathrm{~B}, 3 \mathrm{C}$ & & & & & & & & \\
\hline & $24 \mathrm{~h}$ & $1 \mathrm{~N}, 2 \mathrm{~B}, 1 \mathrm{C}(7)$ & $1 \mathrm{~B}, 3 \mathrm{C}(7)$ & $1 \mathrm{~N}, 1 \mathrm{~B}, 1 \mathrm{C}(7), 1 \mathrm{D}$ & $1 \mathrm{~B}, 2 \mathrm{C}(7), 1 \mathrm{D}$ & $4 \mathrm{~N}, 4 \mathrm{~B}, 7 \mathrm{C}, 1 \mathrm{D}$ & & & & & & & & \\
\hline 400 & $48 \mathrm{~h}$ & $1 \mathrm{~N}, 1 \mathrm{~B}, 2 \mathrm{C}(7)$ & $1 \mathrm{~N}, 1 \mathrm{C}(7), 2 \mathrm{D}$ & $1 \mathrm{~N}, 2 \mathrm{C}(7), 1 \mathrm{D}$ & $3 \mathrm{C}(7), 1 \mathrm{D}$ & $3 \mathrm{~N}, 1 \mathrm{~B}, 8 \mathrm{C}, 4 \mathrm{D}$ & 740 & 804 & 1358 & 1396 & 2180 & 280 & 40 & - \\
\hline 40,0 & $72 \mathrm{~h}$ & $1 \mathrm{~N}, 1 \mathrm{~B}, 2 \mathrm{C}(7)$ & $2 \mathrm{~B}, 2 \mathrm{D}$ & $3 \mathrm{C}(7), 1 \mathrm{D}$ & $3 \mathrm{C}(2(6), 1(7)), 1 \mathrm{D}$ & $2 \mathrm{~N}, 6 \mathrm{C}, 4 \mathrm{~T}, 4 \mathrm{D}$ & 7,40 & 8,04 & 735,8 & 139,6 & 21,80 & 28,0 & 40 & - \\
\hline & $96 \mathrm{~h}$ & 2B, 2C (7) & $1 \mathrm{C}(7), 3 \mathrm{D}$ & $3 \mathrm{C}(7), 1 \mathrm{D}$ & $3 \mathrm{C},(7), 1 \mathrm{D}$ & $2 \mathrm{~B}, 9 \mathrm{C}, 5 \mathrm{D}$ & & & & & & & & \\
\hline & $24 \mathrm{~h}$ & $1 \mathrm{C}(7), 2 \mathrm{~T}(1), 1 \mathrm{D}$ & $1 \mathrm{~T}(1), 3 \mathrm{D}$ & $2 \mathrm{~T}(1), 2 \mathrm{D}$ & $2 \mathrm{C}(6), 2 \mathrm{D}$ & $4 C, 4 T, 8 D$ & & & & & & & & \\
\hline 500 & $48 \mathrm{~h}$ & $1 \mathrm{C}(7), 3 \mathrm{D}$ & 4D & 4D & $2 \mathrm{C}(7), 2 \mathrm{D}$ & $3 C, 13 D$ & 742 & 804 & 1381 & 1400 & 2180 & 279 & 42 & 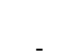 \\
\hline 50,0 & $72 \mathrm{~h}$ & $1 \mathrm{C}(7), 3 \mathrm{D}$ & $4 \mathrm{D}$ & $4 \mathrm{D}$ & $2 \mathrm{C}(7), 2 \mathrm{D}$ & $3 C, 13 D$ & 1,42 & 8,04 & 130,1 & 140,0 & 21,80 & 27,9 & 42 & - \\
\hline & $96 \mathrm{~h}$ & $1 \mathrm{C}(7), 3 \mathrm{D}$ & $4 \mathrm{D}$ & $4 \mathrm{D}$ & $2 \mathrm{C}(7), 2 \mathrm{D}$ & $3 C, 13 D$ & & & & & & & & \\
\hline & $24 \mathrm{~h}$ & $1 \mathrm{~T}(1), 3 \mathrm{D}$ & $1 \mathrm{~T}, 3 \mathrm{D}$ & 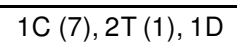 & $2 \mathrm{~T}(1), 2 \mathrm{D}$ & $1 \mathrm{C}, 6 \mathrm{~T}, 9 \mathrm{D}$ & & & & & & & & \\
\hline 600 & $48 \mathrm{~h}$ & 4D & $4 \mathrm{D}$ & $1 \mathrm{C}(7), 3 \mathrm{D}$ & $4 \mathrm{D}$ & $1 \mathrm{C}, 15 \mathrm{D}$ & & & & & & & & \\
\hline 60,0 & $72 \mathrm{~h}$ & $4 \mathrm{D}$ & $4 \mathrm{D}$ & $1 \mathrm{C}(7), 3 \mathrm{D}$ & $4 \mathrm{D}$ & $1 C, 15 D$ & 7,45 & 8,06 & 135,0 & 161,5 & 21,90 & 27,9 & 40 & - \\
\hline & $96 \mathrm{~h}$ & $4 \mathrm{D}$ & $4 \mathrm{D}$ & $1 \mathrm{~T}(2), 3 \mathrm{D}$ & $4 \mathrm{D}$ & $1 \mathrm{~T}, 15 \mathrm{D}$ & & & & & & & & \\
\hline
\end{tabular}


Tabela 9. Modificações morfológicas em Hydra viridissima exposta a diferentes concentrações de diclofenaco sódico ( $\mathrm{mg} \mathrm{L}^{-1}$ ), em teste definitivo de toxicidade aguda (teste $2, \mathrm{n}=8$ ), com leituras a cada 24 horas, e valores de $\mathrm{pH}$, condutividade, temperatura e dureza monitorados mo início e final dos teste. $\mathrm{N}=$ hidra normal; $\mathrm{B}=$ hidra com bulbos nos tentáculos; $\mathrm{C}=$ hidra com tentáculos encurtados; $\mathrm{T}=$ hidra em estado de tulipa; $\mathrm{D}=\mathrm{hidra}$ desintegrada, sendo que os números dentro dos *() referem-se aos scores aplicados.

\begin{tabular}{|c|c|c|c|c|c|c|c|c|c|c|c|c|c|c|}
\hline \multirow{2}{*}{$\begin{array}{c}\text { Concentração } \\
\left(\mathrm{mg} \mathrm{L}^{-1}\right)\end{array}$} & \multirow{2}{*}{ Leitura } & \multicolumn{4}{|c|}{ Réplicas } & \multirow{2}{*}{ Total } & \multicolumn{2}{|c|}{$\mathrm{pH}$} & \multicolumn{2}{|c|}{ cond. } & \multicolumn{2}{|c|}{ Temp. } & \multicolumn{2}{|c|}{ Dureza } \\
\hline & & 1 & 2 & 3 & 4 & & Oh & $96 \mathrm{~h}$ & Oh & $96 \mathrm{~h}$ & Oh & $96 \mathrm{~h}$ & Oh & $96 \mathrm{~h}^{\star}$ \\
\hline \multirow{4}{*}{ Controle } & $24 \mathrm{~h}$ & $4 \mathrm{~N}$ & $4 \mathrm{~N}$ & $4 \mathrm{~N}$ & $4 \mathrm{~N}$ & $16 \mathrm{~N}$ & \multirow{4}{*}{7,29} & \multirow{4}{*}{8,25} & \multirow{4}{*}{135,8} & \multirow{4}{*}{160,0} & \multirow{4}{*}{25,00} & \multirow{4}{*}{28,20} & \multirow{4}{*}{40} & \multirow{4}{*}{-} \\
\hline & $48 \mathrm{~h}$ & $4 \mathrm{~N}$ & $4 \mathrm{~N}$ & $4 \mathrm{~N}$ & $4 \mathrm{~N}$ & $16 \mathrm{~N}$ & & & & & & & & \\
\hline & $72 \mathrm{~h}$ & $4 \mathrm{~N}$ & $4 \mathrm{~N}$ & $4 \mathrm{~N}$ & $4 \mathrm{~N}$ & $16 \mathrm{~N}$ & & & & & & & & \\
\hline & $96 \mathrm{~h}$ & $4 \mathrm{~N}$ & $4 \mathrm{~N}$ & $4 \mathrm{~N}$ & $4 \mathrm{~N}$ & $16 \mathrm{~N}$ & & & & & & & & \\
\hline \multirow{4}{*}{10,0} & $24 \mathrm{~h}$ & $4 \mathrm{~N}$ & $4 \mathrm{~N}$ & $4 \mathrm{~N}$ & $4 \mathrm{~N}$ & $16 \mathrm{~N}$ & \multirow{4}{*}{7,36} & \multirow{4}{*}{8,21} & \multirow{4}{*}{133,1} & \multirow{4}{*}{141,0} & \multirow{4}{*}{24,50} & \multirow{4}{*}{28,00} & \multirow{4}{*}{40} & \multirow{4}{*}{-} \\
\hline & $48 \mathrm{~h}$ & $4 N$ & $4 \mathrm{~N}$ & $4 N$ & $4 \mathrm{~N}$ & $16 \mathrm{~N}$ & & & & & & & & \\
\hline & $72 \mathrm{~h}$ & $4 \mathrm{~N}(1(9))$ & $4 \mathrm{~N}$ & $4 \mathrm{~N}$ & $4 \mathrm{~N}$ & $16 \mathrm{~N}$ & & & & & & & & \\
\hline & $96 \mathrm{~h}$ & $4 \mathrm{~N}$ & $4 \mathrm{~N}$ & $4 \mathrm{~N}$ & $4 \mathrm{~N}$ & $16 \mathrm{~N}$ & & & & & & & & \\
\hline \multirow{4}{*}{20,0} & $24 \mathrm{~h}$ & $4 \mathrm{~N}$ & $4 \mathrm{~N}$ & $4 \mathrm{~N}$ & $4 \mathrm{~N}$ & $16 \mathrm{~N}$ & & & & & & & & \\
\hline & $48 \mathrm{~h}$ & $4 N$ & $4 \mathrm{~N}$ & $4 \mathrm{~N}$ & $4 \mathrm{~N}$ & $16 \mathrm{~N}$ & 736 & 025 & 1211 & 1410 & 2150 & 0 & 10 & \\
\hline & $72 \mathrm{~h}$ & $4 \mathrm{~N}$ & $4 \mathrm{~N}$ & $4 \mathrm{~N}$ & $4 \mathrm{~N}$ & $16 \mathrm{~N}$ & 年, & $0,<0$ & 101,1 & 141, & 24,00 & 20,00 & 40 & \\
\hline & $96 \mathrm{~h}$ & $4 \mathrm{~N}$ & $4 \mathrm{~N}$ & $4 \mathrm{~N}$ & $4 \mathrm{~N}$ & $16 \mathrm{~N}$ & & & & & & & & \\
\hline & $24 \mathrm{~h}$ & $1 \mathrm{~N}, 1 \mathrm{~B}, 2 \mathrm{C}(7)$ & $1 \mathrm{~N}, 3 \mathrm{~B}$ & $3 \mathrm{~N}, 1 \mathrm{C}(7)$ & $4 \mathrm{~N}$ & $9 \mathrm{~N}, 4 \mathrm{~B}, 3 \mathrm{C}$ & & & & & & & & \\
\hline 300 & $48 \mathrm{~h}$ & $3 \mathrm{~N}, 1 \mathrm{~B}$ & $2 \mathrm{~N}, 2 \mathrm{~B}$ & $3 \mathrm{~N}, 1 \mathrm{C}(7)$ & $3 \mathrm{~N}, 1 \mathrm{~B}$ & $11 \mathrm{~N}, 4 \mathrm{~B}, 1 \mathrm{C}$ & 740 & 812 & 1395 & 1329 & 2480 & 2800 & 40 & - \\
\hline & $72 \mathrm{~h}$ & $3 \mathrm{~N}, 1 \mathrm{~B}$ & $3 \mathrm{~N}, 1 \mathrm{~B}$ & $3 \mathrm{~N}, 1 \mathrm{~B}$ & $4 N$ & $14 \mathrm{~N}, 3 \mathrm{~B}$ & & & & & & & & \\
\hline & $96 \mathrm{~h}$ & $4 \mathrm{~N}$ & $3 \mathrm{~N}, 1 \mathrm{~B}$ & $4 \mathrm{~N}$ & $3 \mathrm{~N}, 1 \mathrm{~B}$ & $14 \mathrm{~N}, 2 \mathrm{~B}$ & & & & & & & & \\
\hline & $24 \mathrm{~h}$ & $4 \mathrm{C}(2(7), 2(6))$ & $2 \mathrm{C}(7), 1 \mathrm{~T}(1), 1 \mathrm{D}$ & $3 \mathrm{C}(7), 1 \mathrm{D}$ & $2 \mathrm{~B}, 2 \mathrm{C}(7)$ & $2 \mathrm{~B}, 11 \mathrm{C}, 1 \mathrm{~T}, 2 \mathrm{D}$ & & & & & & & & \\
\hline 400 & $48 \mathrm{~h}$ & $1 \mathrm{C}(7), 3 \mathrm{D}$ & $2 \mathrm{C}(7), 2 \mathrm{D}$ & $3 \mathrm{C}(7), 1 \mathrm{D}$ & $2 \mathrm{~B}, 2 \mathrm{C}(7)$ & $2 \mathrm{~B}, 8 \mathrm{C}, 6 \mathrm{D}$ & 744 & 8.25 & 1319 & 134.3 & 2460 & 2800 & 40 & - \\
\hline & $72 \mathrm{~h}$ & $1 \mathrm{C}(7), 3 \mathrm{D}$ & $2 \mathrm{C}(7), 2 \mathrm{D}$ & $3 \mathrm{C}(7), 1 \mathrm{D}$ & $2 \mathrm{~B}, 2 \mathrm{C}(7)$ & $2 \mathrm{~B}, 8 \mathrm{C}, 6 \mathrm{D}$ & & & & & & & & \\
\hline & $96 \mathrm{~h}$ & $1 \mathrm{C}(7), 3 \mathrm{D}$ & $2 \mathrm{C}(7), 2 \mathrm{D}$ & $1 \mathrm{~B}, 2 \mathrm{C}(7), 1 \mathrm{D}$ & $3 \mathrm{~B}, 1 \mathrm{C}(7)$ & $4 \mathrm{~B}, 6 \mathrm{C}, 6 \mathrm{D}$ & & & & & & & & \\
\hline & $24 \mathrm{~h}$ & $1 \mathrm{~T}(1), 3 \mathrm{D}$ & $3 \mathrm{~T}(1), 1 \mathrm{D}$ & $1 \mathrm{~B}, 1 \mathrm{~T}(1), 2 \mathrm{D}$ & $1 \mathrm{~T}(1), 3 \mathrm{D}$ & $1 \mathrm{~B}, 6 \mathrm{~T}, 9 \mathrm{D}$ & & & & & & & & \\
\hline 500 & $48 \mathrm{~h}$ & 4D & 4D & 4D & 4D & $16 \mathrm{D}$ & 749 & 804 & 1329 & 1296 & 2450 & 2790 & 40 & - \\
\hline & $72 \mathrm{~h}$ & $4 \mathrm{D}$ & $4 \mathrm{D}$ & $4 \mathrm{D}$ & $4 \mathrm{D}$ & $16 \mathrm{D}$ & J & & & $1<0,0$ & & & & \\
\hline & $96 \mathrm{~h}$ & $4 \mathrm{D}$ & $4 \mathrm{D}$ & 4D & $4 \mathrm{D}$ & $16 \mathrm{D}$ & & & & & & & & \\
\hline & $24 \mathrm{~h}$ & $1 \mathrm{~T}(1), 3 \mathrm{D}$ & $2 \mathrm{~T}(1), 2 \mathrm{D}$ & $4 \mathrm{D}$ & $4 \mathrm{D}$ & $3 \mathrm{~T}, 13 \mathrm{D}$ & & & & & & & & \\
\hline 600 & $48 \mathrm{~h}$ & $4 \mathrm{D}$ & 4D & $4 \mathrm{D}$ & $4 \mathrm{D}$ & $16 \mathrm{D}$ & 751 & 821 & $130-5$ & 1210 & 0400 & 2700 & 10 & \\
\hline 60,0 & $72 \mathrm{~h}$ & $4 \mathrm{D}$ & $4 \mathrm{D}$ & $4 \mathrm{D}$ & $4 \mathrm{D}$ & $16 \mathrm{D}$ & (1,5I & 8,34 & 130,5 & 134,9 & 24,60 & 27,90 & 40 & - \\
\hline & $96 \mathrm{~h}$ & $4 \mathrm{D}$ & $4 \mathrm{D}$ & $4 \mathrm{D}$ & $4 \mathrm{D}$ & $16 \mathrm{D}$ & & & & & & & & \\
\hline
\end{tabular}


Tabela 10. Modificações morfológicas em Hydra viridissima exposta a diferentes concentrações de diclofenaco sódico ( $\mathrm{mg} \mathrm{L}^{-1}$ ), em teste definitivo de toxicidade aguda (teste $3, \mathrm{n}=8$ ), com leituras a cada 24 horas, e valores de $\mathrm{pH}$, condutividade, temperatura e dureza monitorados mo início e final dos teste. $\mathrm{N}=$ hidra normal; $\mathrm{B}=$ hidra com bulbos nos tentáculos; $\mathrm{C}=$ hidra com tentáculos encurtados; $\mathrm{T}=$ hidra em estado de tulipa; $\mathrm{D}=$ hidra desintegrada, sendo que os números dentro dos *() referem-se aos scores aplicados.

\begin{tabular}{|c|c|c|c|c|c|c|c|c|c|c|c|c|c|c|}
\hline \multirow{2}{*}{$\begin{array}{c}\text { Concentração } \\
\left(\mathrm{mg} \mathrm{L}^{-1}\right)\end{array}$} & \multirow{2}{*}{ Leitura } & \multicolumn{4}{|c|}{ Réplicas } & \multirow{2}{*}{ Total } & \multicolumn{2}{|c|}{$\mathrm{pH}$} & \multicolumn{2}{|c|}{ cond. } & \multicolumn{2}{|c|}{ Temp. } & \multicolumn{2}{|c|}{ Dureza } \\
\hline & & 1 & 2 & 3 & 4 & & Oh & $96 \mathrm{~h}$ & Oh & $96 \mathrm{~h}$ & $\mathrm{Oh}$ & $96 \mathrm{~h}$ & Oh & $96 h^{*}$ \\
\hline \multirow{4}{*}{ Controle } & $24 \mathrm{~h}$ & $4 \mathrm{~N}$ & $4 \mathrm{~N}$ & $4 \mathrm{~N}$ & $4 \mathrm{~N}$ & $16 \mathrm{~N}$ & \multirow{4}{*}{7,38} & \multirow{4}{*}{8,28} & \multirow{4}{*}{158,7} & \multirow{4}{*}{167,0} & \multirow{4}{*}{24,40} & \multirow{4}{*}{26,40} & \multirow{4}{*}{48} & \multirow{4}{*}{-} \\
\hline & $48 \mathrm{~h}$ & $4 \mathrm{~N}$ & $4 \mathrm{~N}$ & $4 \mathrm{~N}$ & $4 \mathrm{~N}$ & $16 \mathrm{~N}$ & & & & & & & & \\
\hline & $72 \mathrm{~h}$ & $4 \mathrm{~N}$ & $4 \mathrm{~N}$ & $4 \mathrm{~N}$ & $4 \mathrm{~N}$ & $16 \mathrm{~N}$ & & & & & & & & \\
\hline & $96 \mathrm{~h}$ & $4 \mathrm{~N}$ & $4 N$ & $4 \mathrm{~N}$ & $4 \mathrm{~N}$ & $16 \mathrm{~N}$ & & & & & & & & \\
\hline \multirow{4}{*}{10,0} & $24 \mathrm{~h}$ & $4 \mathrm{~N}$ & $4 \mathrm{~N}$ & $4 \mathrm{~N}$ & $4 \mathrm{~N}$ & $16 \mathrm{~N}$ & \multirow{4}{*}{7,41} & \multirow{4}{*}{8,14} & \multirow{4}{*}{146,6} & \multirow{4}{*}{147,5} & \multirow{4}{*}{24,50} & \multirow{4}{*}{26,40} & \multirow{4}{*}{46} & \multirow{4}{*}{-} \\
\hline & $48 \mathrm{~h}$ & $4 N$ & $4 \mathrm{~N}$ & $4 \mathrm{~N}$ & $4 \mathrm{~N}$ & $16 \mathrm{~N}$ & & & & & & & & \\
\hline & $72 \mathrm{~h}$ & $4 \mathrm{~N}$ & $4 \mathrm{~N}$ & $4 \mathrm{~N}$ & $4 \mathrm{~N}$ & $16 \mathrm{~N}$ & & & & & & & & \\
\hline & $96 \mathrm{~h}$ & $4 \mathrm{~N}$ & $4 \mathrm{~N}$ & $4 \mathrm{~N}$ & $4 \mathrm{~N}$ & $16 \mathrm{~N}$ & & & & & & & & \\
\hline \multirow{4}{*}{20,0} & $24 \mathrm{~h}$ & $4 \mathrm{~N}$ & $4 \mathrm{~N}$ & $4 \mathrm{~N}$ & $4 \mathrm{~N}$ & $16 \mathrm{~N}$ & & & & & & & & \\
\hline & $48 \mathrm{~h}$ & $4 \mathrm{~N}$ & $4 \mathrm{~N}$ & $4 \mathrm{~N}$ & $4 \mathrm{~N}$ & $16 \mathrm{~N}$ & 7.41 & 8,16 & 147.5 & 143.7 & 24,50 & 26.30 & 40 & - \\
\hline & $72 \mathrm{~h}$ & $4 \mathrm{~N}$ & $4 \mathrm{~N}$ & $4 \mathrm{~N}$ & $4 \mathrm{~N}$ & $16 \mathrm{~N}$ & & & S147 & $143, r$ & 24,50 & 20,30 & 40 & - \\
\hline & $96 \mathrm{~h}$ & $3 \mathrm{~N}, 1 \mathrm{~B}$ & $4 \mathrm{~N}$ & $4 \mathrm{~N}$ & $4 \mathrm{~N}$ & $16 \mathrm{~N}$ & & & & & & & & \\
\hline & $24 \mathrm{~h}$ & $2 \mathrm{~N}, 2 \mathrm{~B}$ & $1 \mathrm{~N}, 3 \mathrm{~B}$ & $2 \mathrm{~N}, 1 \mathrm{~B}, 1 \mathrm{C}(7)$ & $3 \mathrm{~B}, 1 \mathrm{C}(7)$ & $9 \mathrm{~N}, 4 \mathrm{~B}, 3 \mathrm{C}$ & & & & & & & & \\
\hline 30,0 & $48 \mathrm{~h}$ & $2 \mathrm{~N}, 2 \mathrm{~B}$ & $2 \mathrm{~N}, 2 \mathrm{~B}$ & $2 \mathrm{~N}, 1 \mathrm{~B}, 1 \mathrm{C}(7)$ & $4 \mathrm{~B}$ & $11 \mathrm{~N}, 4 \mathrm{~B}, 1 \mathrm{C}$ & 7.42 & 8,10 & 140.0 & 147.2 & 24.50 & 26,20 & 48 & - \\
\hline & $72 \mathrm{~h}$ & $4 \mathrm{~N}$ & $3 \mathrm{~N}, 1 \mathrm{~B}$ & $2 \mathrm{~N}, 2 \mathrm{~B}$ & 4B & $14 \mathrm{~N}, 3 \mathrm{~B}$ & & & & & & & & \\
\hline & $96 \mathrm{~h}$ & $3 \mathrm{~N}, 1 \mathrm{~B}$ & $3 \mathrm{~N}, 1 \mathrm{~B}$ & $3 \mathrm{~N}, 1 \mathrm{~B}$ & $2 \mathrm{~N}, 1 \mathrm{~B}, 1 \mathrm{C}(6)$ & $14 \mathrm{~N}, 2 \mathrm{~B}$ & & & & & & & & \\
\hline & $24 \mathrm{~h}$ & $2 \mathrm{C}(7), 2 \mathrm{D}$ & $4 C(7)$ & 2C (7), 1T, 1D & $3 \mathrm{C}(7), 1 \mathrm{~T}(1)$ & $2 \mathrm{~B}, 11 \mathrm{C}, 1 \mathrm{~T}, 2 \mathrm{D}$ & & & & & & & & \\
\hline 400 & $48 \mathrm{~h}$ & $2 \mathrm{C}(7), 2 \mathrm{D}$ & $2 \mathrm{C}(7), 2 \mathrm{D}$ & $2 \mathrm{C}(7), 2 \mathrm{D}$ & $3 \mathrm{C}(7), 1 \mathrm{D}$ & 2B, 8C, 6D & 742 & 816 & 1446 & 1458 & 245 & 2640 & 42 & \\
\hline 40,0 & $72 \mathrm{~h}$ & 1B, 3D & $2 \mathrm{C}(7), 2 \mathrm{D}$ & $2 \mathrm{C}(7), 2 \mathrm{D}$ & $3 \mathrm{C}(7), 1 \mathrm{D}$ & $2 \mathrm{~B}, 8 \mathrm{C}, 6 \mathrm{D}$ & 1,42 & 8,10 & 144,6 & 140,8 & 24,00 & 20,40 & 42 & - \\
\hline & $96 \mathrm{~h}$ & 1B, 3D & $1 \mathrm{~B}, 1 \mathrm{C}(6), 2 \mathrm{D}$ & $2 \mathrm{C}(1(7), 1(6)), 2 \mathrm{D}$ & $3 \mathrm{C}(2(6), 1(7))$ & 4B, 6C, 6D & & & & & & & & \\
\hline & $24 \mathrm{~h}$ & $1 \mathrm{~T}(1), 3 \mathrm{D}$ & $1 \mathrm{C}(7), 3 \mathrm{D}$ & $4 \mathrm{D}$ & $1 \mathrm{C}(7), 3 \mathrm{D}$ & $1 \mathrm{~B}, 6 \mathrm{~T}, 9 \mathrm{D}$ & & & & & & & & \\
\hline 500 & $48 \mathrm{~h}$ & 4D & $1 \mathrm{~T}(2), 3 \mathrm{D}$ & $4 \mathrm{D}$ & $1 \mathrm{C}(7), 3 \mathrm{D}$ & $16 \mathrm{D}$ & 744 & 811 & 1435 & 1435 & 2460 & 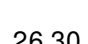 & 46 & \\
\hline 0,0 & $72 \mathrm{~h}$ & $4 \mathrm{D}$ & $1 \mathrm{~T}(2), 3 \mathrm{D}$ & $4 \mathrm{D}$ & $1 \mathrm{C}(7), 3 \mathrm{D}$ & $16 \mathrm{D}$ & 1,44 & ו ו, & 140,0 & 140,0 & 24,00 & $<0,00$ & 40 & 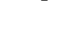 \\
\hline & $96 \mathrm{~h}$ & $4 \mathrm{D}$ & $1 \mathrm{~T}(2), 3 \mathrm{D}$ & $4 \mathrm{D}$ & $1 \mathrm{C}(7), 3 \mathrm{D}$ & $16 \mathrm{D}$ & & & & & & & & \\
\hline & $24 \mathrm{~h}$ & $4 \mathrm{D}$ & $1 \mathrm{~T}(1), 3 \mathrm{D}$ & $4 \mathrm{D}$ & $4 \mathrm{D}$ & $3 \mathrm{~T}, 13 \mathrm{D}$ & & & & & & & & \\
\hline 60,0 & $48 \mathrm{~h}$ & $4 \mathrm{D}$ & $4 \mathrm{D}$ & $4 \mathrm{D}$ & $4 \mathrm{D}$ & $16 \mathrm{D}$ & 7,50 & 8,08 & 141,1 & 147.9 & 24,50 & 26.00 & 44 & - \\
\hline 60,0 & $72 \mathrm{~h}$ & $4 \mathrm{D}$ & $4 \mathrm{D}$ & $4 \mathrm{D}$ & $4 \mathrm{D}$ & $16 \mathrm{D}$ & 7,50 & 8,08 & 141,1 & $14 /, 9$ & 24,50 & 26,00 & 44 & - \\
\hline & $96 \mathrm{~h}$ & 4D & $4 \mathrm{D}$ & 4D & 4D & $16 \mathrm{D}$ & & & & & & & & \\
\hline
\end{tabular}


Tabela 11. Modificações morfológicas em Hydra viridissima exposta a diferentes concentrações de diclofenaco sódico ( $\mathrm{mg} \mathrm{L}^{-1}$ ), em teste definitivo de toxicidade aguda (teste $4, \mathrm{n}=8$ ), com leituras a cada 24 horas, e valores de $\mathrm{pH}$, condutividade, temperatura e dureza monitorados mo início e final dos teste. $\mathrm{N}=$ hidra normal; $\mathrm{B}=$ hidra com bulbos nos tentáculos; $\mathrm{C}=$ hidra com tentáculos encurtados; $\mathrm{T}=$ hidra em estado de tulipa; $\mathrm{D}=$ hidra desintegrada, sendo que os números dentro dos *() referem-se aos scores aplicados.

\begin{tabular}{|c|c|c|c|c|c|c|c|c|c|c|c|c|c|c|}
\hline \multirow{2}{*}{$\begin{array}{l}\text { Concentração } \\
\left(\mathrm{mg} \mathrm{L}^{-1}\right)\end{array}$} & \multirow{2}{*}{ Leitura } & \multicolumn{4}{|c|}{ Réplicas } & \multirow{2}{*}{ Total } & \multicolumn{2}{|c|}{$\mathrm{pH}$} & \multicolumn{2}{|c|}{ cond. } & \multicolumn{2}{|c|}{ Temp. } & \multicolumn{2}{|c|}{ Dureza } \\
\hline & & 1 & 2 & 3 & 4 & & Oh & $96 \mathrm{~h}$ & Oh & $96 \mathrm{~h}$ & Oh & $96 \mathrm{~h}$ & Oh & $96 h^{*}$ \\
\hline \multirow{4}{*}{ Controle } & $24 \mathrm{~h}$ & $4 \mathrm{~N}$ & $4 \mathrm{~N}$ & $4 \mathrm{~N}$ & $4 \mathrm{~N}$ & $16 \mathrm{~N}$ & \multirow{4}{*}{7,08} & \multirow{4}{*}{8,05} & \multirow{4}{*}{148,0} & \multirow{4}{*}{180,4} & \multirow{4}{*}{24,10} & \multirow{4}{*}{25,6} & \multirow{4}{*}{48} & \multirow{4}{*}{-} \\
\hline & $48 \mathrm{~h}$ & $4 \mathrm{~N}$ & $4 \mathrm{~N}$ & $4 \mathrm{~N}$ & $4 \mathrm{~N}$ & $16 \mathrm{~N}$ & & & & & & & & \\
\hline & $72 \mathrm{~h}$ & $4 \mathrm{~N}$ & $4 \mathrm{~N}$ & $4 \mathrm{~N}$ & $4 \mathrm{~N}$ & $16 \mathrm{~N}$ & & & & & & & & \\
\hline & $96 \mathrm{~h}$ & $4 \mathrm{~N}$ & $4 \mathrm{~N}$ & $4 \mathrm{~N}$ & $4 \mathrm{~N}$ & $16 \mathrm{~N}$ & & & & & & & & \\
\hline \multirow{4}{*}{10,0} & $24 \mathrm{~h}$ & $4 \mathrm{~N}$ & $4 \mathrm{~N}$ & $4 \mathrm{~N}$ & $4 \mathrm{~N}$ & $16 \mathrm{~N}$ & \multirow{4}{*}{7,24} & \multirow{4}{*}{8,08} & \multirow{4}{*}{143,9} & \multirow{4}{*}{159,5} & \multirow{4}{*}{24,10} & \multirow{4}{*}{25,1} & \multirow{4}{*}{46} & \multirow{4}{*}{-} \\
\hline & $48 \mathrm{~h}$ & $4 \mathrm{~N}$ & $4 \mathrm{~N}$ & $4 \mathrm{~N}$ & $4 \mathrm{~N}$ & $16 \mathrm{~N}$ & & & & & & & & \\
\hline & $72 \mathrm{~h}$ & $4 \mathrm{~N}$ & $4 \mathrm{~N}$ & $4 \mathrm{~N}$ & $4 \mathrm{~N}$ & $16 \mathrm{~N}$ & & & & & & & & \\
\hline & $96 \mathrm{~h}$ & $4 \mathrm{~N}$ & $4 \mathrm{~N}$ & $4 \mathrm{~N}$ & $4 \mathrm{~N}$ & $16 \mathrm{~N}$ & & & & & & & & \\
\hline \multirow{4}{*}{20,0} & $24 \mathrm{~h}$ & $4 \mathrm{~N}$ & $4 \mathrm{~N}$ & $4 \mathrm{~N}$ & $4 \mathrm{~N}$ & $16 \mathrm{~N}$ & & & & & & & & \\
\hline & $48 \mathrm{~h}$ & $3 \mathrm{~N}, 1 \mathrm{~B}$ & $2 \mathrm{~N}, 2 \mathrm{C}(7)$ & $4 \mathrm{~N}$ & $3 \mathrm{~N}, 1 \mathrm{C}(7)$ & $12 \mathrm{~N}, 1 \mathrm{~B}, 3 \mathrm{C}$ & 726 & 811 & 1448 & 1570 & 2410 & 252 & 40 & 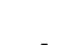 \\
\hline & $72 \mathrm{~h}$ & $4 N$ & $4 \mathrm{~N}$ & $4 \mathrm{~N}$ & $4 \mathrm{~N}$ & $16 \mathrm{~N}$ & r, & 0,11 & 144,0 & 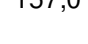 & 24,10 & 20,2 & 40 & \\
\hline & $96 \mathrm{~h}$ & $4 \mathrm{~N}$ & $4 \mathrm{~N}$ & $4 \mathrm{~N}$ & $4 N$ & $16 \mathrm{~N}$ & & & & & & & & \\
\hline & $24 \mathrm{~h}$ & $2 \mathrm{~N}, 1 \mathrm{~B}, 1 \mathrm{C}(7)$ & $2 \mathrm{~N}, 2 \mathrm{C}(7)$ & $3 \mathrm{~N}, 1 \mathrm{~B}$ & $3 \mathrm{~B}, 1 \mathrm{C}(7)$ & $7 \mathrm{~N}, 5 \mathrm{~B}, 4 \mathrm{C}$ & & & & & & & & \\
\hline 300 & $48 \mathrm{~h}$ & $3 \mathrm{~N}, 1 \mathrm{~B}$ & $2 \mathrm{~N}, 2 \mathrm{C}(7)$ & $4 \mathrm{~N}$ & $3 \mathrm{~B}, 1 \mathrm{C}(7)$ & $9 \mathrm{~N}, 4 \mathrm{~B}, 3 \mathrm{C}$ & 732 & 815 & 1415 & 1565 & 2410 & 253 & 48 & 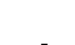 \\
\hline 30,0 & $72 \mathrm{~h}$ & $2 \mathrm{~N}, 2 \mathrm{C}(7)$ & $2 \mathrm{~N}, 2 \mathrm{C}(7)$ & $4 \mathrm{~N}$ & $3 \mathrm{~B}, 1 \mathrm{C}(7)$ & $8 \mathrm{~N}, 3 \mathrm{~B}, 5 \mathrm{C}$ & 㑲, & 0,10 & of & & 24,10 & $<0,0$ & 40 & \\
\hline & $96 \mathrm{~h}$ & $2 \mathrm{~N}, 2 \mathrm{C}(7)$ & $2 \mathrm{~N}, 2 \mathrm{C}(7)$ & $4 \mathrm{~N}$ & $3 \mathrm{~B}, 1 \mathrm{C}(7)$ & $8 \mathrm{~N}, 3 \mathrm{~B}, 5 \mathrm{C}$ & & & & & & & & \\
\hline & $24 \mathrm{~h}$ & $4 \mathrm{C}(7)$ & $2 \mathrm{~B}, 2 \mathrm{C}(7)$ & $4 \mathrm{C}(7)$ & $4 \mathrm{C}(7)$ & $2 \mathrm{~B}, 14 \mathrm{C}$ & & & & & & & & \\
\hline 40,0 & $48 \mathrm{~h}$ & $3 \mathrm{C}(7), 1 \mathrm{D}$ & $1 \mathrm{~N}, 1 \mathrm{C}(7), 2 \mathrm{D}$ & $3 \mathrm{C}(1(6), 2(7)), 1 \mathrm{D}$ & $4 C(7)$ & $1 \mathrm{~N}, 11 \mathrm{C}, 4 \mathrm{D}$ & 7.35 & 8.15 & 139.5 & 148.7 & 24.10 & 25,5 & 42 & - \\
\hline & $72 \mathrm{~h}$ & $3 \mathrm{C}(7), 1 \mathrm{D}$ & $1 \mathrm{~N}, 1 \mathrm{~T}(2), 2 \mathrm{D}$ & $3 \mathrm{~T}(2), 1 \mathrm{D}$ & 4C (7) & $1 \mathrm{~N}, 7 \mathrm{C}, 4 \mathrm{~T}, 2 \mathrm{D}$ & & & & & & & & \\
\hline & $96 \mathrm{~h}$ & $3 \mathrm{C}(7), 1 \mathrm{D}$ & $1 \mathrm{~N}, 1 \mathrm{~T}(2), 2 \mathrm{D}$ & 3T (2(3),1(2)),1D & 4C (7) & $1 \mathrm{~N}, 7 \mathrm{C}, 4 \mathrm{~T}, 4 \mathrm{D}$ & & & & & & & & \\
\hline & $24 \mathrm{~h}$ & $3 \mathrm{~T}(1(1), 2(4)), 1 \mathrm{D}$ & $1 \mathrm{C}(7), 1 \mathrm{~T}(4), 2 \mathrm{D}$ & $1 \mathrm{C}(7), 3 \mathrm{D}$ & $1 \mathrm{C}(7), 2 \mathrm{~T}(1), 1 \mathrm{D}$ & $3 \mathrm{C}, 6 \mathrm{~T}, 7 \mathrm{D}$ & & & & & & & & \\
\hline 500 & $48 \mathrm{~h}$ & $4 \mathrm{D}$ & $4 \mathrm{D}$ & $1 \mathrm{C}(7), 3 \mathrm{D}$ & $2 \mathrm{~T}(1), 2 \mathrm{D}$ & $1 \mathrm{C}, 2 \mathrm{~T}, 13 \mathrm{D}$ & 736 & 817 & $140 ?$ & 1560 & 2410 & 255 & 46 & - \\
\hline & $72 \mathrm{~h}$ & $4 \mathrm{D}$ & $4 \mathrm{D}$ & $1 \mathrm{~T}(2), 3 \mathrm{D}$ & $2 \mathrm{~T}(1), 2 \mathrm{D}$ & $3 \mathrm{~T}, 13 \mathrm{D}$ & & & & & & & & \\
\hline & $96 \mathrm{~h}$ & $4 \mathrm{D}$ & $4 \mathrm{D}$ & $4 \mathrm{D}$ & $2 \mathrm{~T}(1), 2 \mathrm{D}$ & $2 \mathrm{~T}, 14 \mathrm{D}$ & & & & & & & & \\
\hline & $24 \mathrm{~h}$ & $2 \mathrm{C}(7), 2 \mathrm{D}$ & $2 \mathrm{~T}(1), 2 \mathrm{D}$ & $3 \mathrm{~T}(2), 1 \mathrm{D}$ & $2 \mathrm{C}(1(6), 1(7)), 1 \mathrm{~T}(2), 1 \mathrm{D}$ & $4 \mathrm{C}, 6 \mathrm{~T}, 6 \mathrm{D}$ & & & & & & & & \\
\hline 60 & $48 \mathrm{~h}$ & $1 \mathrm{C}(6), 1 \mathrm{~T}(2), 2 \mathrm{D}$ & $3 \mathrm{~T}(1), 1 \mathrm{D}$ & $4 \mathrm{~T}(1)$ & $4 \mathrm{D}$ & $1 \mathrm{C}, 8 \mathrm{~T}, 7 \mathrm{D}$ & 705 & 810 & 1200 & 152 & 241 & 251 & 14 & \\
\hline 00,0 & $72 \mathrm{~h}$ & $1 \mathrm{C}(6), 1 \mathrm{~T}(2), 2 \mathrm{D}$ & $3 \mathrm{~T}(1), 1 \mathrm{D}$ & $4 \mathrm{~T}(1)$ & $4 \mathrm{D}$ & 1C, 8T,7D & 1,25 & 8,19 & 139,9 & 153,4 & 24,10 & 25,4 & 44 & - \\
\hline & $96 \mathrm{~h}$ & $1 \mathrm{C}(6), 1 \mathrm{~T}(2), 2 \mathrm{D}$ & $3 \mathrm{~T}(1), 1 \mathrm{D}$ & $4 \mathrm{~T}(1)$ & 4D & 1C, 8T,7D & & & & & & & & \\
\hline
\end{tabular}


Tabela 12. Modificações morfológicas em Hydra viridissima exposta a diferentes concentrações de diclofenaco sódico ( $\mathrm{mg} \mathrm{L}^{-1}$ ), em teste definitivo de toxicidade aguda (teste $5, \mathrm{n}=8$ ), com leituras a cada 24 horas, e valores de $\mathrm{pH}$, condutividade, temperatura e dureza monitorados mo início e final dos teste. $\mathrm{N}=$ hidra normal; $\mathrm{B}=$ hidra com bulbos nos tentáculos; $\mathrm{C}=$ hidra com tentáculos encurtados; $\mathrm{T}=$ hidra em estado de tulipa; $\mathrm{D}=$ hidra desintegrada, sendo que os números dentro dos $*()$ referem-se aos scores aplicados.

\begin{tabular}{|c|c|c|c|c|c|c|c|c|c|c|c|c|c|c|}
\hline \multirow{2}{*}{$\begin{array}{l}\text { Concentração } \\
\left(\mathrm{mg} \mathrm{L}^{-1}\right)\end{array}$} & \multirow{2}{*}{ Leitura } & \multicolumn{4}{|c|}{ Réplicas } & \multirow{2}{*}{ Total } & \multicolumn{2}{|c|}{ pH } & \multicolumn{2}{|c|}{ cond. } & \multicolumn{2}{|c|}{ Temp. } & \multicolumn{2}{|c|}{ Dureza } \\
\hline & & 1 & 2 & 3 & 4 & & Oh & $96 \mathrm{~h}$ & $\mathrm{Oh}$ & $96 \mathrm{~h}$ & Oh & $96 \mathrm{~h}$ & $\mathrm{Oh}$ & $96 h^{*}$ \\
\hline \multirow{4}{*}{ Controle } & $24 \mathrm{~h}$ & $4 \mathrm{~N}$ & $4 \mathrm{~N}$ & $4 \mathrm{~N}$ & $4 \mathrm{~N}$ & $16 \mathrm{~N}$ & \multirow{4}{*}{7,23} & \multirow{4}{*}{8,15} & \multirow{4}{*}{160,2} & \multirow{4}{*}{149,0} & \multirow{4}{*}{22,50} & \multirow{4}{*}{24,9} & \multirow{4}{*}{40} & \multirow{4}{*}{ - } \\
\hline & $48 \mathrm{~h}$ & $4 \mathrm{~N}$ & $4 \mathrm{~N}$ & $4 \mathrm{~N}$ & $4 \mathrm{~N}$ & $16 \mathrm{~N}$ & & & & & & & & \\
\hline & $72 \mathrm{~h}$ & $4 \mathrm{~N}$ & $4 \mathrm{~N}$ & $4 \mathrm{~N}$ & $4 \mathrm{~N}$ & $16 \mathrm{~N}$ & & & & & & & & \\
\hline & $96 \mathrm{~h}$ & $4 \mathrm{~N}$ & $4 \mathrm{~N}$ & $4 \mathrm{~N}$ & $4 \mathrm{~N}$ & $16 \mathrm{~N}$ & & & & & & & & \\
\hline \multirow{4}{*}{10,0} & $24 \mathrm{~h}$ & $4 \mathrm{~N}$ & $4 \mathrm{~N}$ & $4 \mathrm{~N}$ & $4 \mathrm{~N}$ & $16 \mathrm{~N}$ & \multirow{4}{*}{7,36} & \multirow{4}{*}{8,1} & \multirow{4}{*}{149,5} & \multirow{4}{*}{148,2} & \multirow{4}{*}{22,60} & \multirow{4}{*}{24,8} & \multirow{4}{*}{42} & \multirow{4}{*}{ - } \\
\hline & $48 \mathrm{~h}$ & $4 \mathrm{~N}$ & $4 \mathrm{~N}$ & $4 \mathrm{~N}$ & $4 \mathrm{~N}$ & $16 \mathrm{~N}$ & & & & & & & & \\
\hline & $72 \mathrm{~h}$ & $4 \mathrm{~N}$ & $4 \mathrm{~N}$ & $4 \mathrm{~N}$ & $4 \mathrm{~N}$ & $16 \mathrm{~N}$ & & & & & & & & \\
\hline & $96 \mathrm{~h}$ & $4 \mathrm{~N}$ & $4 \mathrm{~N}$ & $4 \mathrm{~N}$ & $4 \mathrm{~N}$ & $16 \mathrm{~N}$ & & & & & & & & \\
\hline \multirow{4}{*}{20,0} & $24 \mathrm{~h}$ & $4 \mathrm{~N}$ & $4 \mathrm{~N}$ & $4 \mathrm{~N}$ & $4 \mathrm{~N}$ & $16 \mathrm{~N}$ & & & & & & & & \\
\hline & $48 \mathrm{~h}$ & $4 \mathrm{~N}$ & $4 \mathrm{~N}$ & $4 \mathrm{~N}$ & $4 \mathrm{~N}$ & $16 \mathrm{~N}$ & 7.38 & 8,12 & 146.1 & 151,0 & 22,60 & 24,9 & 44 & - \\
\hline & $72 \mathrm{~h}$ & $4 \mathrm{~N}$ & $4 \mathrm{~N}$ & $4 \mathrm{~N}$ & $4 \mathrm{~N}$ & $16 \mathrm{~N}$ & & & & & & & & \\
\hline & $96 \mathrm{~h}$ & $4 \mathrm{~N}$ & $4 \mathrm{~N}$ & $4 \mathrm{~N}$ & $4 \mathrm{~N}$ & $16 \mathrm{~N}$ & & & & & & & & \\
\hline & $24 \mathrm{~h}$ & $4 \mathrm{~N}$ & $2 \mathrm{~N}, 2 \mathrm{~B}$ & $4 \mathrm{~N}$ & $2 \mathrm{~N}, 2 \mathrm{C}(7)$ & $12 \mathrm{~N}, 2 \mathrm{~B}, 2 \mathrm{C}$ & & & & & & & & \\
\hline 30.0 & $48 \mathrm{~h}$ & $4 \mathrm{~N}$ & $3 N, 1 C(7)$ & $4 \mathrm{~N}$ & $2 \mathrm{~N}, 2 \mathrm{C}(7)$ & $13 N, 3 C$ & 7.35 & 8.11 & 1399 & 1477 & 22.60 & 24.8 & 48 & - \\
\hline 年, & $72 \mathrm{~h}$ & $2 \mathrm{~N}, 2 \mathrm{~B}$ & $2 \mathrm{~N}, 2 \mathrm{C}(7)$ & $4 \mathrm{~N}$ & $2 \mathrm{~N}, 2 \mathrm{C}(7)$ & $10 \mathrm{~N}, 2 \mathrm{~B}, 2 \mathrm{C}$ & , & , & 年 & 年, & 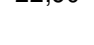 & 2,0 & ( & \\
\hline & $96 \mathrm{~h}$ & $2 \mathrm{~N}, 2 \mathrm{~B}$ & $2 \mathrm{~N}, 2 \mathrm{C}(7)$ & $3 \mathrm{~N}, 1 \mathrm{~B}$ & $2 \mathrm{~N}, 2 \mathrm{C}(7)$ & $9 \mathrm{~N}, 3 \mathrm{~B}, 4 \mathrm{C}$ & & & & & & & & \\
\hline & $24 \mathrm{~h}$ & $2 \mathrm{~N}, 2 \mathrm{~B}$ & $3 \mathrm{~N}, 1 \mathrm{C}(7)$ & $4 \mathrm{~N}$ & $2 \mathrm{~N}, 2 \mathrm{C}(6)$ & $11 \mathrm{~N}, 2 \mathrm{~B}, 3 \mathrm{C}$ & & & & & & & & \\
\hline 40,0 & $48 \mathrm{~h}$ & $1 \mathrm{~B}, 3 \mathrm{C}(7)$ & $1 \mathrm{~N}, 1 \mathrm{~B}, 2 \mathrm{C}(7)$ & $3 \mathrm{~N}, 1 \mathrm{~B}$ & $1 \mathrm{~N}, 3 \mathrm{C}(7)$ & $5 \mathrm{~N}, 3 \mathrm{~B}, 8 \mathrm{C}$ & 7,39 & 8,15 & 140,7 & 146,5 & 22,60 & 24,8 & 44 & - \\
\hline & $72 \mathrm{~h}$ & $1 \mathrm{~B}, 3 \mathrm{C}(7)$ & $1 \mathrm{~B}, 3 \mathrm{C}(7)$ & $4 \mathrm{~N}$ & $1 \mathrm{~N}, 3 \mathrm{C}(7)$ & $5 \mathrm{~N}, 2 \mathrm{~B}, 9 \mathrm{C}$ & & & & & & & & \\
\hline & $96 \mathrm{~h}$ & $1 \mathrm{~B}, 3 \mathrm{C}(7)$ & $1 \mathrm{~B}, 3 \mathrm{C}(7)$ & $1 \mathrm{~N}, 3 \mathrm{~B}$ & $1 \mathrm{~N}, 3 \mathrm{C}(7)$ & $2 \mathrm{~N}, 5 \mathrm{~B}, 9 \mathrm{C}$ & & & & & & & & \\
\hline & $24 \mathrm{~h}$ & $4 C(7)$ & $3 \mathrm{C}(7), 1 \mathrm{D}$ & $2 \mathrm{~B}, 2 \mathrm{C}(7)$ & $4 \mathrm{C}(7)$ & $2 \mathrm{~B}, 13 \mathrm{C}, 1 \mathrm{D}$ & & & & & & & & \\
\hline 50,0 & $48 \mathrm{~h}$ & $4 \mathrm{C}(7)$ & $3 \mathrm{C}(7), 1 \mathrm{D}$ & $2 \mathrm{~B}, 2 \mathrm{C}(7)$ & $4 \mathrm{C}(7)$ & 2B, 13C, 1D & 7,40 & 8,19 & 141,7 & 151,4 & 22,60 & 24,8 & 44 & - \\
\hline 50,0 & $72 \mathrm{~h}$ & $2 \mathrm{C}(7), 2 \mathrm{~T}(1(2), 1(3))$ & $3 C(7), 1 D$ & $2 \mathrm{~B}, 2 \mathrm{C}(7)$ & $4 C(7)$ & $2 \mathrm{~B}, 11 \mathrm{C}, 2 \mathrm{~T}, 1 \mathrm{D}$ & & & & & & & & \\
\hline & $96 \mathrm{~h}$ & $2 \mathrm{C}(7), 2 \mathrm{~T}(1(2), 1(3))$ & $3 C(7), 1 D$ & $1 \mathrm{~B}, 3 \mathrm{C}(7)$ & $4 \mathrm{C}(2(6), 2(7))$ & $1 \mathrm{~B}, 12 \mathrm{C}, 2 \mathrm{~T}, 1 \mathrm{D}$ & & & & & & & & \\
\hline & $24 \mathrm{~h}$ & $3 \mathrm{C}(7), 1 \mathrm{~T}(1)$ & $2 \mathrm{C}(7), 2 \mathrm{~T}(1)$ & $2 \mathrm{~T}(2), 2 \mathrm{D}$ & $1 \mathrm{C}(7), 3 \mathrm{~T}(1)$ & $6 \mathrm{C}, 8 \mathrm{~T}, 2 \mathrm{D}$ & & & & & & & & \\
\hline 60,0 & $48 \mathrm{~h}$ & $2 \mathrm{~T}(2), 2 \mathrm{D}$ & 2C(7), 2D & $1 \mathrm{~T}(2), 3 \mathrm{D}$ & $4 \mathrm{~T}(3(1), 1(2))$ & $2 \mathrm{C}, 7 \mathrm{~T}, 7 \mathrm{D}$ & 7.45 & 8.21 & 133,20 & 152.4 & 22.60 & 24.8 & 44 & - \\
\hline 00,0 & $72 \mathrm{~h}$ & $2 \mathrm{~T}(2), 2 \mathrm{D}$ & $1 \mathrm{C}(7), 1 \mathrm{~T}(3), 2 \mathrm{D}$ & $1 \mathrm{~T}(2), 3 \mathrm{D}$ & $4 \mathrm{~T}(3(1), 1(2))$ & 1C, 8T,7D & (,,45 & $0, \angle 1$ & 103,20 & $10<, 4$ & $<<, 00$ & 24,0 & 44 & - \\
\hline & $96 \mathrm{~h}$ & $2 \mathrm{~T}(2), 2 \mathrm{D}$ & $1 \mathrm{C}(7), 1 \mathrm{~T}(3), 2 \mathrm{D}$ & $1 \mathrm{~T}(2), 3 \mathrm{D}$ & $1 \mathrm{~T}(2), 3 \mathrm{D}$ & $1 \mathrm{C}, 5 \mathrm{~T}, 10 \mathrm{D}$ & & & & & & & & \\
\hline
\end{tabular}


Tabela 13. Modificações morfológicas em Hydra viridissima exposta a diferentes concentrações de diclofenaco sódico ( $\mathrm{mg} \mathrm{L}^{-1}$ ), em teste definitivo de toxicidade aguda (teste $6, \mathrm{n}=8$ ), com leituras a cada 24 horas, e valores de $\mathrm{pH}$, condutividade, temperatura e dureza monitorados mo início e final dos teste. $\mathrm{N}=$ hidra normal; $\mathrm{B}=$ hidra com bulbos nos tentáculos; $\mathrm{C}=$ hidra com tentáculos encurtados; $\mathrm{T}=$ hidra em estado de tulipa; $\mathrm{D}=\mathrm{hidra}$ desintegrada, sendo que os números dentro dos *() referem-se aos scores aplicados.

\begin{tabular}{|c|c|c|c|c|c|c|c|c|c|c|c|c|c|c|}
\hline \multirow{2}{*}{$\begin{array}{c}\text { Concentração } \\
\left(\mathrm{mg} \mathrm{L}^{-1}\right)\end{array}$} & \multirow{2}{*}{ Leitura } & \multicolumn{4}{|c|}{ Réplicas } & \multirow{2}{*}{ Total } & \multicolumn{2}{|c|}{$\mathrm{pH}$} & \multicolumn{2}{|c|}{ cond. } & \multicolumn{2}{|c|}{ Temp. } & \multicolumn{2}{|c|}{ Dureza } \\
\hline & & 1 & 2 & 3 & 4 & & Oh & $96 \mathrm{~h}$ & Oh & $96 \mathrm{~h}$ & $\mathrm{Oh}$ & $96 \mathrm{~h}$ & Oh & $96 h^{*}$ \\
\hline \multirow{4}{*}{ Controle } & $24 \mathrm{~h}$ & $4 \mathrm{~N}$ & $4 \mathrm{~N}$ & $4 \mathrm{~N}$ & $4 \mathrm{~N}$ & $16 \mathrm{~N}$ & \multirow{4}{*}{7,34} & \multirow{4}{*}{7,82} & \multirow{4}{*}{130,8} & \multirow{4}{*}{141,7} & \multirow{4}{*}{24,30} & \multirow{4}{*}{25,3} & \multirow{4}{*}{44} & \multirow{4}{*}{ - } \\
\hline & $48 \mathrm{~h}$ & $4 \mathrm{~N}$ & $4 \mathrm{~N}$ & $4 \mathrm{~N}$ & $4 \mathrm{~N}$ & $16 \mathrm{~N}$ & & & & & & & & \\
\hline & $72 \mathrm{~h}$ & $4 \mathrm{~N}$ & $4 \mathrm{~N}$ & $4 \mathrm{~N}$ & $4 \mathrm{~N}$ & $16 \mathrm{~N}$ & & & & & & & & \\
\hline & $96 \mathrm{~h}$ & $4 \mathrm{~N}$ & $4 \mathrm{~N}$ & $4 \mathrm{~N}$ & $4 \mathrm{~N}$ & $16 \mathrm{~N}$ & & & & & & & & \\
\hline \multirow{4}{*}{10,0} & $24 \mathrm{~h}$ & $4 \mathrm{~N}$ & $4 \mathrm{~N}$ & $4 \mathrm{~N}$ & $4 \mathrm{~N}$ & $16 \mathrm{~N}$ & \multirow{4}{*}{7,42} & \multirow{4}{*}{7,85} & \multirow{4}{*}{134,3} & \multirow{4}{*}{134,8} & \multirow{4}{*}{24,30} & \multirow{4}{*}{25,6} & \multirow{4}{*}{40} & \multirow{4}{*}{-} \\
\hline & $48 \mathrm{~h}$ & $4 \mathrm{~N}$ & $4 \mathrm{~N}$ & $4 \mathrm{~N}$ & $4 \mathrm{~N}$ & $16 \mathrm{~N}$ & & & & & & & & \\
\hline & $72 \mathrm{~h}$ & $4 \mathrm{~N}$ & $4 \mathrm{~N}$ & $4 \mathrm{~N}$ & $4 \mathrm{~N}$ & $16 \mathrm{~N}$ & & & & & & & & \\
\hline & $96 \mathrm{~h}$ & $4 \mathrm{~N}$ & $4 \mathrm{~N}$ & $4 \mathrm{~N}$ & $4 \mathrm{~N}$ & $16 \mathrm{~N}$ & & & & & & & & \\
\hline \multirow{4}{*}{20,0} & $24 \mathrm{~h}$ & $4 \mathrm{~N}$ & $4 \mathrm{~N}$ & $4 \mathrm{~N}$ & $4 \mathrm{~N}$ & $16 \mathrm{~N}$ & & & & & & & & \\
\hline & $48 \mathrm{~h}$ & $4 \mathrm{~N}$ & $4 \mathrm{~N}$ & $4 \mathrm{~N}$ & $4 \mathrm{~N}$ & $16 \mathrm{~N}$ & 743 & 785 & 1293 & 1387 & 2430 & 26 & 42 & - \\
\hline & $72 \mathrm{~h}$ & $4 \mathrm{~N}$ & $4 \mathrm{~N}$ & $3 \mathrm{~N}, 1 \mathrm{~B}$ & $4 \mathrm{~N}$ & $16 \mathrm{~N}$ & , & 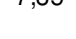 & $1<0,0$ & 100,1 & 27,00 & 20 & the & \\
\hline & $96 \mathrm{~h}$ & $3 \mathrm{~N}, 1 \mathrm{~B}$ & $4 \mathrm{~N}$ & $3 \mathrm{~N}, 1 \mathrm{~B}$ & $4 \mathrm{~N}$ & $16 \mathrm{~N}$ & & & & & & & & \\
\hline & $24 \mathrm{~h}$ & $1 \mathrm{~B}, 3 \mathrm{C}(7)$ & $1 \mathrm{~N}, 3 \mathrm{~B}$ & $2 \mathrm{~N}, 2 \mathrm{C}(7)$ & $4 \mathrm{C}(7)$ & $3 \mathrm{~N}, 4 \mathrm{~B}, 9 \mathrm{C}$ & & & & & & & & \\
\hline 30.0 & $48 \mathrm{~h}$ & $1 \mathrm{~B}, 3 \mathrm{C}(7)$ & $1 \mathrm{~N}, 3 \mathrm{C}(7)$ & $2 \mathrm{~N}, 2 \mathrm{C}(7)$ & $4 C(7)$ & $3 \mathrm{~N}, 1 \mathrm{~B}, 12 \mathrm{C}$ & 7.48 & 786 & 126.0 & 1309 & 24,30 & 25.3 & 44 & - \\
\hline & $72 \mathrm{~h}$ & $1 \mathrm{~B}, 3 \mathrm{C}(7)$ & $1 \mathrm{~N}, 3 \mathrm{C}(7)$ & $2 \mathrm{~N}, 2 \mathrm{C}(7)$ & $4 \mathrm{C}(7)$ & $3 \mathrm{~N}, 1 \mathrm{~B}, 12 \mathrm{C}$ & & & & & & & & \\
\hline & $96 \mathrm{~h}$ & $2 \mathrm{~B}, 2 \mathrm{C}(7)$ & $1 \mathrm{~N}, 3 \mathrm{C}(7)$ & $2 \mathrm{~N}, 2 \mathrm{C}(7)$ & $4 \mathrm{C}(2(6), 2(7))$ & $3 \mathrm{~N}, 2 \mathrm{~B}, 11 \mathrm{C}$ & & & & & & & & \\
\hline & $24 \mathrm{~h}$ & $4 \mathrm{C}(7)$ & $4 \mathrm{C}(7)$ & $1 \mathrm{~B}, 2 \mathrm{C}(7), 1 \mathrm{~T}(1)$ & $2 \mathrm{~N}, 2 \mathrm{C}(6)$ & $2 \mathrm{~N}, 1 \mathrm{~B}, 12 \mathrm{C}, 1 \mathrm{~T}$ & & & & & & & & \\
\hline 400 & $48 \mathrm{~h}$ & $3 \mathrm{C}(7), 1 \mathrm{~T}(2)$ & $3 \mathrm{C}(7), 1 \mathrm{D}$ & $2 \mathrm{C}(7), 2 \mathrm{D}$ & $3 \mathrm{C}(7), 1 \mathrm{D}$ & $11 \mathrm{C}, 1 \mathrm{~T}, 4 \mathrm{D}$ & 748 & 788 & 1300 & 1328 & 2440 & 254 & 46 & - \\
\hline 40,0 & $72 \mathrm{~h}$ & $2 \mathrm{C}(1(6), 1(7)), 1 \mathrm{~T}(2), 1 \mathrm{D}$ & $1 \mathrm{~B}, 3 \mathrm{C}(7)$ & $2 \mathrm{C}(7), 2 \mathrm{D}$ & $3 \mathrm{C}(7), 1 \mathrm{D}$ & $1 \mathrm{~B}, 1 \mathrm{OC}, 1 \mathrm{~T}, 4 \mathrm{D}$ & , & 正, & 100,0 & $10<, 0$ & 24,40 & 20,4 & 40 & \\
\hline & $96 \mathrm{~h}$ & 1C (7), $2 \mathrm{~T}(2), 1 \mathrm{D}$ & $1 \mathrm{~B}, 3 \mathrm{C}(7)$ & $2 \mathrm{C}(7), 2 \mathrm{D}$ & $3 \mathrm{C}(7), 1 \mathrm{D}$ & $1 \mathrm{~B}, 9 \mathrm{C}, 2 \mathrm{~T}, 4 \mathrm{D}$ & & & & & & & & \\
\hline & $24 \mathrm{~h}$ & $1 \mathrm{~T}(1), 3 \mathrm{D}$ & $1 \mathrm{~B}, 2 \mathrm{C}(1(6), 1(7)), 1 \mathrm{D}$ & $1 \mathrm{C}(7), 3 \mathrm{D}$ & $2 \mathrm{C}(7), 2 \mathrm{D}$ & $1 \mathrm{~B}, 5 \mathrm{C}, 1 \mathrm{~T}, 9 \mathrm{D}$ & & & & & & & & \\
\hline 500 & $48 \mathrm{~h}$ & $4 \mathrm{D}$ & $1 \mathrm{C}(6), 3 \mathrm{D}$ & $1 \mathrm{~T}(2), 3 \mathrm{D}$ & $1 \mathrm{C}(7), 1 \mathrm{~T}(5), 2 \mathrm{D}$ & 2C, 2T, 12D & 749 & 788 & 1270 & 1291 & 2440 & 258 & 46 & - \\
\hline 0,0 & $72 \mathrm{~h}$ & $4 \mathrm{D}$ & 4D & $1 \mathrm{~T}(4), 3 \mathrm{D}$ & $1 \mathrm{C}(7), 1 \mathrm{~T}(3), 2 \mathrm{D}$ & $1 \mathrm{C}, 2 \mathrm{~T}, 13 \mathrm{D}$ & (1,49 & 1,,00 & I & $1<0,1$ & $2 \pi,+0$ & 2,0 & 70 & \\
\hline & $96 \mathrm{~h}$ & $4 \mathrm{D}$ & $4 \mathrm{D}$ & $1 \mathrm{~T}(4), 3 \mathrm{D}$ & $1 \mathrm{C}(7), 1 \mathrm{~T}(4), 2 \mathrm{D}$ & $1 \mathrm{C}, 2 \mathrm{~T}, 13 \mathrm{D}$ & & & & & & & & \\
\hline & $24 \mathrm{~h}$ & $1 \mathrm{~T}(1), 3 \mathrm{D}$ & $2 \mathrm{~T}(1), 2 \mathrm{D}$ & $1 \mathrm{~T}(1), 3 \mathrm{D}$ & $4 \mathrm{D}$ & $4 \mathrm{~T}, 12 \mathrm{D}$ & & & & & & & & \\
\hline 600 & $48 \mathrm{~h}$ & $4 \mathrm{D}$ & $4 \mathrm{D}$ & $4 \mathrm{D}$ & $4 \mathrm{D}$ & $16 \mathrm{D}$ & 751 & 788 & 1280 & 1380 & 24,40 & 259 & 46 & - \\
\hline 00,0 & $72 \mathrm{~h}$ & $4 \mathrm{D}$ & $4 \mathrm{D}$ & $4 \mathrm{D}$ & $4 \mathrm{D}$ & $16 \mathrm{D}$ & (1,01 & 1,80 & & & 24,40 & $<0,5$ & U & \\
\hline & $96 \mathrm{~h}$ & 4D & 4D & 4D & 4D & $16 \mathrm{D}$ & & & & & & & & \\
\hline
\end{tabular}


Tabela 14. Modificações morfológicas em Hydra viridissima exposta a diferentes concentrações de diclofenaco sódico (mg $\mathrm{L}^{-1}$ ), em teste definitivo de toxicidade aguda (teste $7, \mathrm{n}=8$ ), com leituras a cada 24 horas, e valores de $\mathrm{pH}$, condutividade, temperatura e dureza monitorados mo início e final dos teste. $\mathrm{N}=$ hidra normal; $\mathrm{B}=$ hidra com bulbos nos tentáculos; $\mathrm{C}=$ hidra com tentáculos encurtados; $\mathrm{T}=$ hidra em estado de tulipa; $\mathrm{D}=\mathrm{hidra}$ desintegrada, sendo que os números dentro dos $*()$ referem-se aos scores aplicados.

\begin{tabular}{|c|c|c|c|c|c|c|c|c|c|c|c|c|c|c|}
\hline \multirow{2}{*}{$\begin{array}{c}\text { Concentração } \\
\left(\mathrm{mg} \mathrm{L}^{-1}\right)\end{array}$} & \multirow{2}{*}{ Leitura } & \multicolumn{4}{|c|}{ Réplicas } & \multirow{2}{*}{ Total } & \multicolumn{2}{|c|}{ pH } & \multicolumn{2}{|c|}{ cond. } & \multicolumn{2}{|c|}{ Temp. } & \multicolumn{2}{|c|}{ Dureza } \\
\hline & & 1 & 2 & 3 & 4 & & Oh & $96 \mathrm{~h}$ & Oh & $96 \mathrm{~h}$ & Oh & $96 \mathrm{~h}$ & Oh & $96 \mathrm{~h}^{*}$ \\
\hline \multirow{4}{*}{ Controle } & $24 \mathrm{~h}$ & $5 \mathrm{~N}$ & $5 \mathrm{~N}$ & $5 \mathrm{~N}$ & $5 \mathrm{~N}$ & $20 \mathrm{~N}$ & \multirow{4}{*}{7,15} & \multirow{4}{*}{8,14} & \multirow{4}{*}{183,0} & \multirow{4}{*}{156,7} & \multirow{4}{*}{24,60} & \multirow{4}{*}{27,3} & \multirow{4}{*}{44} & \\
\hline & $48 \mathrm{~h}$ & $5 \mathrm{~N}$ & $5 \mathrm{~N}$ & $5 \mathrm{~N}$ & $5 \mathrm{~N}$ & $20 \mathrm{~N}$ & & & & & & & & \multirow{3}{*}{-} \\
\hline & $72 \mathrm{~h}$ & $5 \mathrm{~N}$ & $5 \mathrm{~N}$ & $5 \mathrm{~N}$ & $5 \mathrm{~N}$ & $20 \mathrm{~N}$ & & & & & & & & \\
\hline & $96 \mathrm{~h}$ & $5 \mathrm{~N}$ & $5 \mathrm{~N}$ & $5 \mathrm{~N}$ & $5 \mathrm{~N}$ & $20 \mathrm{~N}$ & & & & & & & & \\
\hline \multirow{4}{*}{10,0} & $24 \mathrm{~h}$ & $5 \mathrm{~N}$ & $5 \mathrm{~N}$ & $5 \mathrm{~N}$ & $5 \mathrm{~N}$ & $20 \mathrm{~N}$ & \multirow{4}{*}{7,22} & \multirow{4}{*}{8,23} & \multirow{4}{*}{144,1} & \multirow{4}{*}{144,3} & \multirow{4}{*}{24,60} & \multirow{4}{*}{27,7} & \multirow{4}{*}{40} & \\
\hline & $48 \mathrm{~h}$ & $5 \mathrm{~N}$ & $5 \mathrm{~N}$ & $5 \mathrm{~N}$ & $5 \mathrm{~N}$ & $20 \mathrm{~N}$ & & & & & & & & - \\
\hline & $72 \mathrm{~h}$ & $5 \mathrm{~N}$ & $5 \mathrm{~N}$ & $5 \mathrm{~N}$ & $5 \mathrm{~N}$ & $20 \mathrm{~N}$ & & & & & & & & \\
\hline & $96 \mathrm{~h}$ & $5 \mathrm{~N}$ & $5 \mathrm{~N}$ & $5 \mathrm{~N}$ & $5 \mathrm{~N}$ & $20 \mathrm{~N}$ & & & & & & & & \\
\hline \multirow{4}{*}{20,0} & $24 \mathrm{~h}$ & $5 \mathrm{~N}$ & $5 \mathrm{~N}$ & $5 \mathrm{~N}$ & $5 \mathrm{~N}$ & $20 \mathrm{~N}$ & \multirow{4}{*}{7,23} & & & & & & & \\
\hline & $48 \mathrm{~h}$ & $5 \mathrm{~N}$ & $5 \mathrm{~N}$ & $5 \mathrm{~N}$ & $5 \mathrm{~N}$ & $20 \mathrm{~N}$ & & 822 & 1259 & 1332 & 2460 & 271 & 40 & \\
\hline & $72 \mathrm{~h}$ & $5 \mathrm{~N}$ & $5 \mathrm{~N}$ & $5 \mathrm{~N}$ & $5 \mathrm{~N}$ & $20 \mathrm{~N}$ & & - & 然 & (1) & 2,00 & 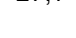 & & \\
\hline & $96 \mathrm{~h}$ & $5 \mathrm{~N}$ & $5 \mathrm{~N}$ & $5 \mathrm{~N}$ & $5 \mathrm{~N}$ & $20 \mathrm{~N}$ & & & & & & & & \\
\hline & $24 \mathrm{~h}$ & $5 \mathrm{~N}$ & $5 \mathrm{~N}$ & $1 \mathrm{~N}, 4 \mathrm{~B}$ & $5 \mathrm{~N}$ & $19 \mathrm{~N}, 1 \mathrm{~B}$ & & & & & & & & \\
\hline 30,0 & $48 \mathrm{~h}$ & $5 \mathrm{~N}$ & $5 \mathrm{~N}$ & $5 \mathrm{~N}$ & $5 \mathrm{~N}$ & $20 \mathrm{~N}$ & 7,24 & 8,24 & 124,8 & 133,4 & 24,50 & 27,9 & 42 & \\
\hline & $72 \mathrm{~h}$ & $5 \mathrm{~N}$ & $5 \mathrm{~N}$ & $5 \mathrm{~N}$ & $5 \mathrm{~N}$ & $20 \mathrm{~N}$ & & & & & & & & \\
\hline & $96 \mathrm{~h}$ & $5 \mathrm{~N}$ & $5 \mathrm{~N}$ & $5 \mathrm{~N}$ & $5 \mathrm{~N}$ & $20 \mathrm{~N}$ & & & & & & & & \\
\hline & $24 \mathrm{~h}$ & $3 \mathrm{~N}, 1 \mathrm{~B}, 1 \mathrm{C}(7)$ & $2 \mathrm{~N}, 3 \mathrm{C}(7)$ & $1 \mathrm{~N}, 1 \mathrm{~B}, 3 \mathrm{C}(7)$ & $4 \mathrm{~N}, 1 \mathrm{~B}$ & $10 \mathrm{~N}, 3 \mathrm{~B}, 7 \mathrm{C}$ & & & & & & & & \\
\hline 400 & $48 \mathrm{~h}$ & $4 \mathrm{~B}, 1 \mathrm{C}(7)$ & $1 \mathrm{~N}, 1 \mathrm{~B}, 3 \mathrm{C}(7)$ & $1 \mathrm{~N}, 2 \mathrm{~B}, 2 \mathrm{C}(7)$ & $4 \mathrm{~N}, 1 \mathrm{~B}$ & $6 \mathrm{~N}, 8 \mathrm{~B}, 6 \mathrm{C}$ & 725 & 83 & 1209 & 1304 & 24.50 & 276 & 44 & - \\
\hline 0,0 & $72 \mathrm{~h}$ & $5 B$ & $1 \mathrm{~N}, 1 \mathrm{~B}, 3 \mathrm{C}(7)$ & $1 \mathrm{~N}, 1 \mathrm{~B}, 3 \mathrm{C}(7)$ & $4 \mathrm{~N}, 1 \mathrm{C}(7)$ & $6 \mathrm{~N}, 7 \mathrm{~B}, 7 \mathrm{C}$ & (, & 0,0 & 100 & & & & & \\
\hline & $96 \mathrm{~h}$ & $5 \mathrm{~B}$ & $2 \mathrm{~B}, 3 \mathrm{C}(7)$ & $1 \mathrm{~N}, 1 \mathrm{~B}, 3 \mathrm{C}(7)$ & $4 \mathrm{~N}, 1 \mathrm{C}(7)$ & $5 \mathrm{~N}, 8 \mathrm{~B}, 7 \mathrm{C}$ & & & & & & & & \\
\hline & $24 \mathrm{~h}$ & $2 \mathrm{C}(1(6), 1(7)), 3 \mathrm{D}$ & $4 C(7), 1 D$ & $2 \mathrm{C}(7), 1 \mathrm{~T}(1), 2 \mathrm{D}$ & $1 \mathrm{C}(7), 4 \mathrm{D}$ & $9 \mathrm{C}, 1 \mathrm{~T}, 10 \mathrm{D}$ & & & & & & & & \\
\hline 50,0 & $48 \mathrm{~h}$ & 1C(7), $4 \mathrm{D}$ & $4 C(7), 1 D$ & 2C(7), 3D & $1 \mathrm{C}(7), 4 \mathrm{D}$ & 8C,12D & 7,28 & 8,32 & 122.9 & 141.4 & 24.40 & 27.5 & 46 & \\
\hline & $72 \mathrm{~h}$ & $1 \mathrm{C}(7), 4 \mathrm{D}$ & $3 \mathrm{C}(7), 1 \mathrm{~T}(3), 1 \mathrm{D}$ & $1 \mathrm{C}(7), 1 \mathrm{~T}(3), 3 \mathrm{D}$ & $1 \mathrm{C}(7), 4 \mathrm{D}$ & $6 \mathrm{C}, 2 \mathrm{~T}, 12 \mathrm{D}$ & & & & & & & & \\
\hline & $96 \mathrm{~h}$ & 1C(7), $4 \mathrm{D}$ & $3 \mathrm{C}(7), 1 \mathrm{~T}(3), 1 \mathrm{D}$ & $2 \mathrm{~T}(3), 3 \mathrm{D}$ & $1 \mathrm{C}(7), 4 \mathrm{D}$ & $5 \mathrm{C}, 3 \mathrm{~T}, 12 \mathrm{D}$ & & & & & & & & \\
\hline & $24 \mathrm{~h}$ & $1 \mathrm{C}(7), 4 \mathrm{D}$ & $3 C(7), 2 D$ & $1 \mathrm{C}(7), 4 \mathrm{D}$ & $4 \mathrm{C}(7), 1 \mathrm{D}$ & $9 \mathrm{C}, 11 \mathrm{D}$ & & & & & & & & \\
\hline 600 & $48 \mathrm{~h}$ & $1 \mathrm{~T}(3), 4 \mathrm{D}$ & $2 \mathrm{C}(7), 3 \mathrm{D}$ & $1 \mathrm{C}(7), 4 \mathrm{D}$ & $2 \mathrm{C}(1(6), 1(7)), 1 \mathrm{~T}(2), 2 \mathrm{D}$ & $5 \mathrm{C}, 2 \mathrm{~T}, 13 \mathrm{D}$ & 730 & 833 & 1255 & 1334 & 244 & 277 & 44 & - \\
\hline 00,0 & $72 \mathrm{~h}$ & $1 \mathrm{~T}(2), 4 \mathrm{D}$ & $1 \mathrm{C}(7), 1 \mathrm{~T}(2), 3 \mathrm{D}$ & $1 \mathrm{C}(7), 4 \mathrm{D}$ & $2 \mathrm{C}(1(6), 1(7)), 1 \mathrm{~T}(2), 2 \mathrm{D}$ & 4C, 3T,13D & 促 & 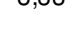 & $1<0, \sigma$ & 10,4 & 24,70 & $2 r, r$ & 47 & \\
\hline & $96 \mathrm{~h}$ & $1 \mathrm{~T}(2), 4 \mathrm{D}$ & $1 \mathrm{C}(7), 1 \mathrm{~T}(2), 3 \mathrm{D}$ & $1 \mathrm{C}(6), 4 \mathrm{D}$ & $2 \mathrm{C}(1(6), 1(7)), 1 \mathrm{~T}(2), 2 \mathrm{D}$ & 4C, 3T, 13D & & & & & & & & \\
\hline
\end{tabular}


Tabela 15. Modificações morfológicas em Hydra viridissima exposta a diferentes concentrações de diclofenaco sódico (mg $\mathrm{L}^{-1}$ ), em teste definitivo de toxicidade aguda (teste $8, \mathrm{n}=8$ ), com leituras a cada 24 horas, e valores de $\mathrm{pH}$, condutividade, temperatura e dureza monitorados mo início e final dos teste. $\mathrm{N}=$ hidra normal; $\mathrm{B}=$ hidra com bulbos nos tentáculos; $\mathrm{C}=$ hidra com tentáculos encurtados; $\mathrm{T}=$ hidra em estado de tulipa; $\mathrm{D}=$ hidra desintegrada, sendo que os números dentro dos *() referem-se aos scores aplicados.

\begin{tabular}{|c|c|c|c|c|c|c|c|c|c|c|c|c|c|c|}
\hline \multirow{2}{*}{$\begin{array}{c}\text { Concentração } \\
\left(\mathrm{mg} \mathrm{L}^{-1}\right)\end{array}$} & \multirow{2}{*}{ Leitura } & \multicolumn{4}{|c|}{ Réplicas } & \multirow{2}{*}{ Total } & \multicolumn{2}{|c|}{ pH } & \multicolumn{2}{|c|}{ cond. } & \multicolumn{2}{|c|}{ Temp. } & \multicolumn{2}{|c|}{ Dureza } \\
\hline & & 1 & 2 & 3 & 4 & & $\mathrm{Oh}$ & $96 \mathrm{~h}$ & Oh & $96 \mathrm{~h}$ & $\mathrm{Oh}$ & $96 \mathrm{~h}$ & $\mathrm{Oh}$ & $96 h^{\star}$ \\
\hline \multirow{4}{*}{ Controle } & $24 \mathrm{~h}$ & $4 \mathrm{~N}$ & $4 \mathrm{~N}$ & $4 \mathrm{~N}$ & $4 \mathrm{~N}$ & $16 \mathrm{~N}$ & \multirow{4}{*}{7,01} & \multirow{4}{*}{8,1} & \multirow{4}{*}{150,2} & \multirow{4}{*}{160,7} & \multirow{4}{*}{23,80} & \multirow{4}{*}{26,3} & \multirow{4}{*}{40} & \multirow{4}{*}{ - } \\
\hline & $48 \mathrm{~h}$ & $4 \mathrm{~N}$ & $4 \mathrm{~N}$ & $4 \mathrm{~N}$ & $4 \mathrm{~N}$ & $16 \mathrm{~N}$ & & & & & & & & \\
\hline & $72 \mathrm{~h}$ & $4 \mathrm{~N}$ & $4 \mathrm{~N}$ & $4 \mathrm{~N}$ & $4 \mathrm{~N}$ & $16 \mathrm{~N}$ & & & & & & & & \\
\hline & $96 \mathrm{~h}$ & $4 \mathrm{~N}$ & $4 \mathrm{~N}$ & $4 \mathrm{~N}$ & $4 \mathrm{~N}$ & $16 \mathrm{~N}$ & & & & & & & & \\
\hline \multirow{4}{*}{10,0} & $24 \mathrm{~h}$ & $4 \mathrm{~N}$ & $4 \mathrm{~N}$ & $4 \mathrm{~N}$ & $4 \mathrm{~N}$ & $16 \mathrm{~N}$ & \multirow{4}{*}{7,02} & \multirow{4}{*}{8,2} & \multirow{4}{*}{154,6} & \multirow{4}{*}{160,0} & \multirow{4}{*}{23,80} & \multirow{4}{*}{26,7} & \multirow{4}{*}{44} & \multirow{4}{*}{ - } \\
\hline & $48 \mathrm{~h}$ & $4 \mathrm{~N}$ & $4 \mathrm{~N}$ & $4 \mathrm{~N}$ & $4 \mathrm{~N}$ & $16 \mathrm{~N}$ & & & & & & & & \\
\hline & $72 \mathrm{~h}$ & $4 \mathrm{~N}$ & $4 \mathrm{~N}$ & $4 \mathrm{~N}$ & $4 \mathrm{~N}$ & $16 \mathrm{~N}$ & & & & & & & & \\
\hline & $96 \mathrm{~h}$ & $4 \mathrm{~N}$ & $4 \mathrm{~N}$ & $4 \mathrm{~N}$ & $4 \mathrm{~N}$ & $16 \mathrm{~N}$ & & & & & & & & \\
\hline \multirow{4}{*}{20,0} & $24 \mathrm{~h}$ & $4 \mathrm{~N}$ & $4 \mathrm{~N}$ & $4 \mathrm{~N}$ & $4 \mathrm{~N}$ & $16 \mathrm{~N}$ & & & & & & & & \\
\hline & $48 \mathrm{~h}$ & $4 \mathrm{~N}$ & $4 \mathrm{~N}$ & $4 \mathrm{~N}$ & $4 \mathrm{~N}$ & $16 \mathrm{~N}$ & 704 & 82 & 1451 & 1532 & 2388 & 251 & 40 & - \\
\hline & $72 \mathrm{~h}$ & $4 \mathrm{~N}$ & $4 \mathrm{~N}$ & $4 \mathrm{~N}$ & $4 \mathrm{~N}$ & $16 \mathrm{~N}$ & 7,07 & 0,2 & 170,1 & (1) & $0,0,0$ & 20,1 & 70 & \\
\hline & $96 \mathrm{~h}$ & $4 \mathrm{~N}$ & $4 \mathrm{~N}$ & $4 \mathrm{~N}$ & $4 \mathrm{~N}$ & $16 \mathrm{~N}$ & & & & & & & & \\
\hline & $24 \mathrm{~h}$ & $3 \mathrm{~N}, 1 \mathrm{~B}$ & $3 \mathrm{~N}, 1 \mathrm{~B}$ & $4 \mathrm{~N}$ & $4 \mathrm{~N}$ & $16 \mathrm{~N}$ & & & & & & & & \\
\hline 30,0 & $48 \mathrm{~h}$ & $3 N, 1 C(7)$ & $3 \mathrm{~N}, 1 \mathrm{C}(7)$ & $3 \mathrm{~N}, 1 \mathrm{~B}$ & $4 \mathrm{~N}$ & $16 \mathrm{~N}$ & 7,04 & 8,24 & 142,3 & 153,4 & 23,70 & 25,9 & 48 & - \\
\hline & $72 \mathrm{~h}$ & $3 \mathrm{~N}, 1 \mathrm{C}(7)$ & $3 N, 1 C(7)$ & $1 \mathrm{~N}, 1 \mathrm{~B}, 2 \mathrm{C}(7)$ & 4C (7) & $16 \mathrm{~N}$ & & & & & & & & \\
\hline & $96 \mathrm{~h}$ & $3 \mathrm{~N}, 1 \mathrm{C}(7)$ & $3 \mathrm{~N}, 1 \mathrm{C}(7)$ & $4 \mathrm{~N}$ & $4 \mathrm{~N}$ & $16 \mathrm{~N}$ & & & & & & & & \\
\hline & $24 \mathrm{~h}$ & $1 \mathrm{~N}, 3 \mathrm{C}(7)$ & 4C (7) & $2 \mathrm{~N}, 2 \mathrm{C}(7)$ & $1 \mathrm{~B}, 3 \mathrm{C}(7)$ & $3 \mathrm{~N}, 1 \mathrm{~B}, 12 \mathrm{C}$ & & & & & & & & \\
\hline 400 & $48 \mathrm{~h}$ & $1 \mathrm{~N}, 3 \mathrm{C}(7)$ & 4C (7) & $1 \mathrm{~N}, 1 \mathrm{~B}, 2 \mathrm{C}(7)$ & $1 \mathrm{~B}, 3 \mathrm{C}(7)$ & $2 \mathrm{~N}, 2 \mathrm{~B}, 12 \mathrm{C}$ & 7.04 & 8,34 & 144,1 & 146,4 & 23,70 & 25,6 & 48 & - \\
\hline 40,0 & $72 \mathrm{~h}$ & $2 \mathrm{~N}, 2 \mathrm{~B}$ & $1 \mathrm{~B}, 3 \mathrm{C}(7)$ & $1 \mathrm{~N}, 1 \mathrm{~B}, 2 \mathrm{C}(7)$ & 2B, 2C(7) & $3 \mathrm{~N}, 6 \mathrm{~B}, 7 \mathrm{C}$ & & 0,04 & 144,1 & 140,4 & $<, i v$ & $2<, 0$ & 40 & 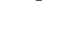 \\
\hline & $96 \mathrm{~h}$ & $2 \mathrm{~N}, 2 \mathrm{~B}$ & $1 \mathrm{~B}, 3 \mathrm{C}(7)$ & $2 \mathrm{~N}, 2 \mathrm{C}(7)$ & $2 \mathrm{~N}, 1 \mathrm{~B}, 1 \mathrm{C}(7)$ & $6 \mathrm{~N}, 4 \mathrm{~B}, 6 \mathrm{C}$ & & & & & & & & \\
\hline & $24 \mathrm{~h}$ & $2 \mathrm{~B}, 1 \mathrm{C}(7), 1 \mathrm{D}$ & $1 \mathrm{C}(7), 2 \mathrm{~T}(1), 1 \mathrm{D}$ & 1B, 3C (2(7), 1(6)) & $1 \mathrm{C}(6), 3 \mathrm{~T}(1)$ & $3 \mathrm{~B}, 6 \mathrm{C}, 5 \mathrm{~T}, 2 \mathrm{D}$ & & & & & & & & \\
\hline 50.0 & $48 \mathrm{~h}$ & 2C(7), 2D & $4 \mathrm{D}$ & $2 \mathrm{C}(7), 2 \mathrm{D}$ & 4D & 4C,12D & 705 & 8.32 & 140.5 & 15 & 2370 & 25.5 & 40 & - \\
\hline & $72 \mathrm{~h}$ & $2 \mathrm{C}(7), 2 \mathrm{D}$ & $4 \mathrm{D}$ & $2 \mathrm{C}(7), 2 \mathrm{D}$ & $4 \mathrm{D}$ & $4 C, 12 D$ & & & & & & & & \\
\hline & $96 \mathrm{~h}$ & $2 \mathrm{C}(7), 2 \mathrm{D}$ & $4 \mathrm{D}$ & $2 \mathrm{C}(7), 2 \mathrm{D}$ & 4D & $4 \mathrm{C}, 12 \mathrm{D}$ & & & & & & & & \\
\hline & $24 \mathrm{~h}$ & 4D & $1 \mathrm{C}(6), 3 \mathrm{~T}(2(1), 1(2))$ & 4D & $2 \mathrm{~T}(1), 2 \mathrm{D}$ & $1 \mathrm{C}, 5 \mathrm{~T}, 10 \mathrm{D}$ & & & & & & & & \\
\hline 60 & $48 \mathrm{~h}$ & $4 \mathrm{D}$ & $1 \mathrm{C}(7), 3 \mathrm{D}$ & $4 \mathrm{D}$ & 4D & $1 C, 15 D$ & 706 & 84 & 1446 & 1524 & 2390 & 257 & 44 & \\
\hline 00,0 & $72 \mathrm{~h}$ & $4 \mathrm{D}$ & $1 \mathrm{C}(7), 3 \mathrm{D}$ & $4 \mathrm{D}$ & $4 \mathrm{D}$ & $1 \mathrm{C}, 15 \mathrm{D}$ & 促, & 0,4 & 144,0 & $10<, 4$ & 20,00 & $2<, r$ & 44 & 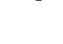 \\
\hline & $96 \mathrm{~h}$ & $4 \mathrm{D}$ & $1 C(7), 3 D$ & $4 \mathrm{D}$ & $4 \mathrm{D}$ & $1 \mathrm{C}, 15 \mathrm{D}$ & & & & & & & & \\
\hline
\end{tabular}




\section{Registro dos resultados dos testes de toxicidade aguda com o fármaco paracetamol (Capítulos 2 e 4).}

\section{Ceriodaphnia silvestrii}

Tabela 16. Resultados do primeiro teste de toxicidade aguda $(\mathrm{n}=5)$ com Ceriodaphnia silvestrii exposta ao paracetamol.

\begin{tabular}{|c|c|c|c|c|c|c|c|c|c|c|c|}
\hline \multirow{2}{*}{$\begin{array}{l}\text { Solução- } \\
\text { teste } \\
\left(\mathrm{mg} \mathrm{L}^{-1}\right)\end{array}$} & \multicolumn{2}{|c|}{$\mathrm{pH}$} & \multicolumn{2}{|c|}{$\begin{array}{l}\text { Condutividade } \\
\left(\mu \mathrm{S} \mathrm{cm}^{-1}\right)\end{array}$} & \multirow{2}{*}{$\begin{array}{l}\text { Dureza } \\
\left(\mathrm{mg} \mathrm{L}^{-1}\right. \\
\left.\mathrm{CaCO}_{3}\right) \\
\frac{\mathrm{i}}{}\end{array}$} & \multicolumn{2}{|c|}{$\begin{array}{c}\text { Temperatura } \\
\left({ }^{\circ} \mathrm{C}\right)\end{array}$} & \multicolumn{2}{|c|}{$\begin{array}{c}\mathrm{N}^{\circ} \mathrm{de} \\
\text { organismos } \\
\text { móveis }\end{array}$} & \multicolumn{2}{|c|}{ Imobilidade } \\
\hline & $\mathrm{i}$ & $\mathrm{f}$ & $\mathrm{i}$ & $\mathrm{F}$ & & $\mathrm{i}$ & $\mathrm{f}$ & $\mathrm{i}$ & $\mathrm{f}$ & Total & $\%$ \\
\hline Controle & 7,18 & 7,87 & 166,2 & 170,8 & 46 & 23,8 & 24,6 & 20 & 19 & 1 & 5 \\
\hline 3,12 & 7,29 & 7,89 & 158,8 & 166,9 & 44 & 23,7 & 24,9 & 20 & 20 & 0 & 0 \\
\hline 6,25 & 7,43 & 8,0 & 155,9 & 165,7 & 42 & 23,7 & 24,1 & 20 & 20 & 0 & 0 \\
\hline 12,5 & 7,39 & 8,05 & 156,9 & 165,6 & 40 & 23,7 & 24,5 & 20 & 18 & 2 & 10 \\
\hline 25 & 7,35 & 8,02 & 154,1 & 166,5 & 42 & 23,7 & 24,8 & 20 & 15 & 5 & 25 \\
\hline 50 & 7,34 & 8,01 & 143,9 & 163,6 & 48 & 23,7 & 24,4 & 20 & 0 & 20 & 100 \\
\hline 100 & 7,32 & 8,05 & 132,9 & 160,7 & 48 & 23,8 & 24,0 & 20 & 0 & 20 & 100 \\
\hline
\end{tabular}

Resultado $\mathrm{CE}_{50}(48 \mathrm{~h})=28,28 \mathrm{mg} \mathrm{L}^{-1} \quad$ Intervalo de Confiança $(95 \%)=\left(24,16-33,11 \mathrm{mg} \mathrm{L}^{-1}\right)$ 
Tabela 17. Resultados do segundo teste de toxicidade aguda $(n=5)$ com Ceriodaphnia silvestrii exposta ao paracetamol.

\begin{tabular}{|c|c|c|c|c|c|c|c|c|c|c|c|}
\hline \multirow{2}{*}{$\begin{array}{l}\text { Solução- } \\
\text { teste } \\
\left(\mathrm{mg} \mathrm{L}^{-1}\right)\end{array}$} & \multicolumn{2}{|c|}{$\mathrm{pH}$} & \multicolumn{2}{|c|}{$\begin{array}{l}\text { Condutividade } \\
\left(\mu \mathrm{S} \mathrm{cm}^{-1}\right)\end{array}$} & \multirow{2}{*}{$\begin{array}{c}\text { Dureza } \\
\left(\mathrm{mg} \mathrm{L}^{-1}\right. \\
\left.\mathrm{CaCO}_{3}\right) \\
\mathrm{i}\end{array}$} & \multicolumn{2}{|c|}{$\begin{array}{c}\text { Temperatura } \\
\left({ }^{\circ} \mathrm{C}\right)\end{array}$} & \multicolumn{2}{|c|}{$\begin{array}{c}\mathrm{N}^{\circ} \mathrm{de} \\
\text { organismos } \\
\text { móveis }\end{array}$} & \multicolumn{2}{|c|}{ Imobilidade } \\
\hline & $\mathrm{i}$ & $\mathrm{f}$ & $\mathrm{i}$ & $\mathrm{F}$ & & $\mathrm{i}$ & $\mathrm{f}$ & $\mathrm{i}$ & $\mathrm{f}$ & Total & $\%$ \\
\hline Controle & 7,42 & 8,05 & 154,0 & 158,8 & 48 & 25,3 & 26,6 & 20 & 20 & 0 & 0 \\
\hline 3,12 & 7,43 & 8,03 & 161,0 & 163,9 & 40 & 25,4 & 26,8 & 20 & 20 & 0 & 0 \\
\hline 6,25 & 7,48 & 8,05 & 149,6 & 148,7 & 40 & 25,3 & 26,1 & 20 & 20 & 0 & 0 \\
\hline 12,5 & 7,44 & 8,01 & 148,7 & 143,6 & 42 & 25,4 & 26,3 & 20 & 20 & 0 & 0 \\
\hline 25 & 7,45 & 8,05 & 144,2 & 149,5 & 44 & 25,3 & 26,3 & 20 & 19 & 1 & 5 \\
\hline 50 & 7,48 & 8,04 & 137,4 & 150,6 & 48 & 25,3 & 26,4 & 20 & 6 & 14 & 70 \\
\hline 100 & 7,40 & 8,05 & 124,6 & 144,7 & 48 & 25,4 & 26,2 & 20 & 0 & 20 & 100 \\
\hline
\end{tabular}

Resultado $\mathrm{CE}_{50}(48 \mathrm{~h})=42,04 \mathrm{mg} \mathrm{L}^{-1} \quad$ Intervalo de Confiança $(95 \%)=\left(35,93-49,21 \mathrm{mg} \mathrm{L}^{-1}\right)$

Tabela 18. Resultados do terceiro teste de toxicidade aguda $(n=5)$ com Ceriodaphnia silvestrii exposta ao paracetamol.

\begin{tabular}{|c|c|c|c|c|c|c|c|c|c|c|c|}
\hline \multirow{2}{*}{$\begin{array}{l}\text { Solução- } \\
\text { teste } \\
\left(\mathrm{mg} \mathrm{L}^{-1}\right)\end{array}$} & \multicolumn{2}{|c|}{$\mathrm{pH}$} & \multicolumn{2}{|c|}{$\begin{array}{l}\text { Condutividade } \\
\qquad\left(\mu \mathrm{S} \mathrm{cm}^{-1}\right)\end{array}$} & \multirow{2}{*}{$\begin{array}{c}\text { Dureza } \\
\left(\mathrm{mg} \mathrm{L}^{-1}\right. \\
\left.\mathrm{CaCO}_{3}\right) \\
\mathrm{i}\end{array}$} & \multicolumn{2}{|c|}{$\begin{array}{c}\text { Temperatura } \\
\left({ }^{\circ} \mathrm{C}\right)\end{array}$} & \multicolumn{2}{|c|}{$\begin{array}{c}\mathrm{N}^{\circ} \mathrm{de} \\
\text { organismos } \\
\text { móveis }\end{array}$} & \multicolumn{2}{|c|}{ Imobilidade } \\
\hline & $\mathrm{i}$ & $\mathrm{f}$ & $\mathrm{i}$ & $\mathrm{F}$ & & $\mathrm{i}$ & $\mathrm{f}$ & $\mathrm{i}$ & f & Total & $\%$ \\
\hline Controle & 7,16 & 7,80 & 135,1 & 144,5 & 42 & 20,2 & 22,4 & 20 & 20 & 0 & 0 \\
\hline 3,12 & 7,22 & 7,84 & 135,4 & 143,3 & 44 & 20,4 & 22,1 & 20 & 18 & 2 & 10 \\
\hline 6,25 & 7,22 & 7,86 & 133,5 & 144,7 & 40 & 20,1 & 22,5 & 20 & 18 & 2 & 10 \\
\hline 12,5 & 7,23 & 7,89 & 130,6 & 142,2 & 48 & 20,3 & 22,2 & 20 & 19 & 1 & 5 \\
\hline 25 & 7,21 & 7,86 & 128,1 & 140,5 & 44 & 20,6 & 22,7 & 20 & 15 & 5 & 25 \\
\hline 50 & 7,25 & 7,82 & 119,9 & 130,1 & 44 & 20,3 & 22,5 & 20 & 1 & 19 & 95 \\
\hline 100 & 7,21 & 7,83 & 120,1 & 128,7 & 44 & 20,5 & 22,9 & 20 & 0 & 20 & 100 \\
\hline & & 20 & $n g$ & Inte & $C$ & & & & & & \\
\hline
\end{tabular}


Tabela 19. Resultados do quarto teste de toxicidade aguda $(n=5)$ com Ceriodaphnia silvestrii exposta ao paracetamol.

\begin{tabular}{|c|c|c|c|c|c|c|c|c|c|c|c|}
\hline \multirow{2}{*}{$\begin{array}{l}\text { Solução- } \\
\text { teste } \\
\left(\mathrm{mg} \mathrm{L}^{-1}\right)\end{array}$} & \multicolumn{2}{|c|}{$\mathrm{pH}$} & \multicolumn{2}{|c|}{$\begin{array}{l}\text { Condutividade } \\
\qquad\left(\mu \mathrm{S} \mathrm{cm}^{-1}\right)\end{array}$} & \multirow{2}{*}{$\begin{array}{c}\text { Dureza } \\
\left(\mathrm{mg} \mathrm{L}^{-1}\right. \\
\left.\mathrm{CaCO}_{3}\right) \\
\mathrm{i}\end{array}$} & \multicolumn{2}{|c|}{$\begin{array}{c}\text { Temperatura } \\
\left({ }^{\circ} \mathrm{C}\right)\end{array}$} & \multicolumn{2}{|c|}{$\begin{array}{c}\mathrm{N}^{\circ} \mathrm{de} \\
\text { organismos } \\
\text { móveis }\end{array}$} & \multicolumn{2}{|c|}{ Imobilidade } \\
\hline & $\mathrm{i}$ & $f$ & $\mathrm{i}$ & $\mathrm{F}$ & & $\mathrm{i}$ & $f$ & $\mathrm{i}$ & $f$ & Total & $\%$ \\
\hline Controle & 7,21 & 7,82 & 136,1 & 148,0 & 40 & 20,1 & 22,3 & 20 & 20 & 0 & 0 \\
\hline 3,12 & 7,23 & 7,85 & 135,0 & 144,3 & 44 & 20,2 & 22,1 & 20 & 20 & 0 & 0 \\
\hline 6,25 & 7,23 & 7,89 & 125,7 & 143,1 & 44 & 20,4 & 22,7 & 20 & 17 & 3 & 15 \\
\hline 12,5 & 7,23 & 7,85 & 132,9 & 141,2 & 46 & 20,3 & 22,8 & 20 & 19 & 1 & 5 \\
\hline 25 & 7,23 & 7,86 & 126,2 & 140,0 & 48 & 20,2 & 22,9 & 20 & 14 & 6 & 30 \\
\hline 50 & 7,26 & 7,80 & 122,3 & 139,5 & 48 & 20,3 & 22,8 & 20 & 4 & 16 & 80 \\
\hline 100 & 7,20 & 7,81 & 121,9 & 137,2 & 40 & 20,8 & 22,3 & 20 & 0 & 20 & 100 \\
\hline
\end{tabular}

Resultado $\mathrm{CE}_{50}(48 \mathrm{~h})=28,72 \mathrm{mg} \mathrm{L}^{-1} \quad$ Intervalo de Confiança $(95 \%)=\left(22,82-36,14 \mathrm{mg} \mathrm{L}^{-1}\right)$

Tabela 20. Resultados do quinto teste de toxicidade aguda $(\mathrm{n}=5)$ com Ceriodaphnia silvestrii exposta ao paracetamol.

\begin{tabular}{|c|c|c|c|c|c|c|c|c|c|c|c|}
\hline \multirow{2}{*}{$\begin{array}{l}\text { Solução- } \\
\text { teste } \\
\left(\mathrm{mg} \mathrm{L}^{-1}\right)\end{array}$} & \multicolumn{2}{|c|}{$\mathrm{pH}$} & \multicolumn{2}{|c|}{$\begin{array}{l}\text { Condutividade } \\
\left(\mu \mathrm{S} \mathrm{cm}^{-1}\right)\end{array}$} & \multirow{2}{*}{$\begin{array}{c}\text { Dureza } \\
\left(\mathrm{mg} \mathrm{L}^{-1}\right. \\
\left.\mathrm{CaCO}_{3}\right) \\
\mathrm{i}\end{array}$} & \multicolumn{2}{|c|}{$\begin{array}{c}\text { Temperatura } \\
\left({ }^{\circ} \mathrm{C}\right)\end{array}$} & \multicolumn{2}{|c|}{$\begin{array}{c}\mathrm{N}^{\circ} \mathrm{de} \\
\text { organismos } \\
\text { móveis }\end{array}$} & \multicolumn{2}{|c|}{ Imobilidade } \\
\hline & $\mathrm{i}$ & $\mathrm{f}$ & $\mathrm{i}$ & $\mathrm{F}$ & & $\mathrm{i}$ & $\mathrm{f}$ & $\mathrm{i}$ & $\mathrm{f}$ & Total & $\%$ \\
\hline Controle & 7,32 & 7,89 & 169,1 & 182,0 & 44 & 22,1 & 23,4 & 20 & 20 & 0 & 0 \\
\hline 3,12 & 7,28 & 7,87 & 134,5 & 144,5 & 44 & 22,2 & 23,1 & 20 & 19 & 1 & 5 \\
\hline 6,25 & 7,36 & 7,93 & 139,9 & 146,7 & 44 & 22,2 & 23,2 & 20 & 19 & 1 & 5 \\
\hline 12,5 & 7,30 & 7,90 & 142,2 & 148,2 & 46 & 22,3 & 23,8 & 20 & 20 & 0 & 0 \\
\hline 25 & 7,32 & 7,95 & 135,4 & 145,5 & 42 & 22,3 & 23,5 & 20 & 20 & 0 & 0 \\
\hline 50 & 7,34 & 7,92 & 129,1 & 143,9 & 40 & 22,4 & 23,0 & 20 & 5 & 15 & 75 \\
\hline 100 & 7,24 & 7,89 & 126,3 & 142,2 & 40 & 22,4 & 23,3 & 20 & 3 & 17 & 85 \\
\hline ultas & & & $\sigma \mathrm{I}$ & Inte & $\mathrm{de} C$ & & $\%)=$ & & & $\left.\mathrm{C}^{-1}\right)$ & \\
\hline
\end{tabular}




\section{Daphnia magna}

Tabela 21. Resultados do teste de toxicidade aguda com Daphnia magna exposta ao paracetamol.

\begin{tabular}{|c|c|c|c|c|c|c|c|c|c|c|c|}
\hline \multirow{2}{*}{$\begin{array}{c}\text { Solução- } \\
\text { teste } \\
\left(\mathrm{mg} \mathrm{L}^{-1}\right)\end{array}$} & \multicolumn{2}{|c|}{$\mathrm{pH}$} & \multicolumn{2}{|c|}{$\begin{array}{l}\text { Condutividade } \\
\qquad\left(\mu \mathrm{S} \mathrm{cm}^{-1}\right)\end{array}$} & \multirow{2}{*}{$\begin{array}{c}\text { Dureza } \\
\left(\mathrm{mg} \mathrm{L}^{-1}\right. \\
\left.\mathrm{CaCO}_{3}\right) \\
\mathrm{i}\end{array}$} & \multicolumn{2}{|c|}{$\begin{array}{c}\text { Temperatura } \\
\left({ }^{\circ} \mathrm{C}\right)\end{array}$} & \multicolumn{2}{|c|}{$\begin{array}{l}\mathrm{N}^{\circ} \mathrm{de} \\
\text { organismos } \\
\text { móveis }\end{array}$} & \multicolumn{2}{|c|}{ Imobilidade } \\
\hline & i & f & $\mathrm{i}$ & $\mathrm{F}$ & & $\mathrm{i}$ & $\mathrm{f}$ & $\mathrm{i}$ & $\mathrm{f}$ & Total & $\%$ \\
\hline Controle & - & - & - & - & - & - & - & 20 & 20 & 0 & 0 \\
\hline 1,2 & - & - & - & - & - & - & - & 20 & 20 & 0 & 0 \\
\hline 1,8 & - & - & - & - & - & - & - & 20 & 19 & 1 & 5 \\
\hline 2,7 & - & - & - & - & - & - & - & 20 & 9 & 11 & 55 \\
\hline 4,0 & - & - & - & - & - & - & - & 20 & 2 & 18 & 90 \\
\hline 6,0 & - & - & - & - & - & - & - & 20 & 0 & 20 & 100 \\
\hline 9,0 & - & - & - & - & - & - & - & 20 & 0 & 20 & 100 \\
\hline esultad & & & & & e Con & 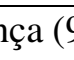 & & - & $\operatorname{lg~L}$ & & \\
\hline
\end{tabular}

- : não foram medidas os parâmetros físico e químicos das soluções-teste. 


\section{Registro dos resultados dos testes de toxicidade aguda com o fármaco propranolol (Capítulos 2, 3 e 4).}

\section{Ceriodaphnia silvestrii}

Tabela 22. Resultados do primeiro teste de toxicidade aguda $(\mathrm{n}=5)$ com Ceriodaphnia silvestrii exposta ao propranolol.

\begin{tabular}{|c|c|c|c|c|c|c|c|c|c|c|c|}
\hline \multirow{2}{*}{$\begin{array}{l}\text { Solução- } \\
\text { teste } \\
\left(\mathrm{mg} \mathrm{L}^{-1}\right)\end{array}$} & \multicolumn{2}{|c|}{$\mathrm{pH}$} & \multicolumn{2}{|c|}{$\begin{array}{l}\text { Condutividade } \\
\qquad\left(\mu \mathrm{S} \mathrm{cm}^{-1}\right)\end{array}$} & \multirow{2}{*}{$\begin{array}{l}\text { Dureza } \\
\left(\mathrm{mg} \mathrm{L}^{-1}\right. \\
\left.\mathrm{CaCO}_{3}\right) \\
\frac{\mathrm{i}}{}\end{array}$} & \multicolumn{2}{|c|}{$\begin{array}{c}\text { Temperatura } \\
\left({ }^{\circ} \mathrm{C}\right)\end{array}$} & \multicolumn{2}{|c|}{$\begin{array}{c}\mathrm{N}^{\circ} \text { de } \\
\text { organismos } \\
\text { móveis }\end{array}$} & \multicolumn{2}{|c|}{ Imobilidade } \\
\hline & $\mathrm{i}$ & $\mathrm{f}$ & $\mathrm{i}$ & $\mathrm{F}$ & & $\mathrm{i}$ & f & $\mathrm{i}$ & $f$ & Total & $\%$ \\
\hline Controle & 7,27 & 8,05 & 144,3 & 149,7 & 44 & 21,2 & 23,0 & 20 & 19 & 1 & 5 \\
\hline 0,62 & 7,30 & 7,95 & 144,6 & 158,3 & 44 & 21,2 & 23,0 & 20 & 19 & 1 & 5 \\
\hline 1,25 & 7,30 & 7,94 & 145,4 & 159,8 & 42 & 21,2 & 23,0 & 20 & 18 & 2 & 10 \\
\hline 2,5 & 7,31 & 7,96 & 141,6 & 146,0 & 42 & 21,2 & 23,2 & 20 & 17 & 3 & 15 \\
\hline 5,0 & 7,32 & 7,98 & 146,0 & 160,3 & 40 & 21,3 & 23,4 & 20 & 0 & 20 & 100 \\
\hline 10 & 7,35 & 8,01 & 147,0 & 157,7 & 40 & 21,3 & 23,0 & 20 & 0 & 20 & 100 \\
\hline
\end{tabular}


Tabela 23. Resultados do segundo teste de toxicidade aguda $(n=5)$ com Ceriodaphnia silvestrii exposta ao propranolol.

\begin{tabular}{|c|c|c|c|c|c|c|c|c|c|c|c|}
\hline \multirow{2}{*}{$\begin{array}{l}\text { Solução- } \\
\text { teste } \\
\left(\mathrm{mg} \mathrm{L}^{-1}\right)\end{array}$} & \multicolumn{2}{|c|}{$\mathrm{pH}$} & \multicolumn{2}{|c|}{$\begin{array}{l}\text { Condutividade } \\
\qquad\left(\mu \mathrm{S} \mathrm{cm}^{-1}\right)\end{array}$} & \multirow{2}{*}{$\begin{array}{c}\text { Dureza } \\
\left(\mathrm{mg} \mathrm{L}^{-1}\right. \\
\left.\mathrm{CaCO}_{3}\right) \\
\mathrm{i}\end{array}$} & \multicolumn{2}{|c|}{$\begin{array}{c}\text { Temperatura } \\
\left({ }^{\circ} \mathrm{C}\right)\end{array}$} & \multicolumn{2}{|c|}{$\begin{array}{c}\mathrm{N}^{\circ} \mathrm{de} \\
\text { organismos } \\
\text { móveis }\end{array}$} & \multicolumn{2}{|c|}{ Imobilidade } \\
\hline & $\mathrm{i}$ & $\mathrm{f}$ & $\mathrm{i}$ & $\mathrm{F}$ & & $\mathrm{i}$ & $\mathrm{f}$ & $\mathrm{i}$ & $\mathrm{f}$ & Total & $\%$ \\
\hline Controle & 7,19 & 7,80 & 159,9 & 157,3 & 48 & 23,7 & 23,4 & 20 & 20 & 0 & 0 \\
\hline 0,62 & 7,30 & 7,79 & 155,0 & 157,4 & 44 & 23,7 & 23,6 & 20 & 17 & 3 & 15 \\
\hline 1,25 & 7,33 & 7,87 & 156,4 & 160,7 & 44 & 23,6 & 23,6 & 20 & 14 & 6 & 30 \\
\hline 2,5 & 7,35 & 7,92 & 153,0 & 157,9 & 42 & 23,6 & 23,8 & 20 & 12 & 8 & 40 \\
\hline 5,0 & 7,40 & 7,91 & 153,5 & 163,1 & 40 & 23,5 & 23,6 & 20 & 6 & 14 & 70 \\
\hline 10,0 & 7,49 & 7,92 & 156,2 & 161,4 & 40 & 23,3 & 23,8 & 20 & 0 & 20 & 100 \\
\hline
\end{tabular}

Resultado $\mathrm{CE}_{50}(48 \mathrm{~h})=2,66 \mathrm{mg} \mathrm{L}^{-1} \quad$ Intervalo de Confiança $(95 \%)=\left(1,86-3,79 \mathrm{mg} \mathrm{L}^{-1}\right)$

Tabela 24. Resultados do terceiro teste de toxicidade aguda $(n=5)$ com Ceriodaphnia silvestrii exposta ao propranolol.

\begin{tabular}{|c|c|c|c|c|c|c|c|c|c|c|c|}
\hline \multirow{2}{*}{$\begin{array}{l}\text { Solução- } \\
\text { teste } \\
\left(\mathrm{mg} \mathrm{L}^{-1}\right)\end{array}$} & \multicolumn{2}{|c|}{$\mathrm{pH}$} & \multicolumn{2}{|c|}{$\begin{array}{l}\text { Condutividade } \\
\qquad\left(\mu \mathrm{S} \mathrm{cm}^{-1}\right)\end{array}$} & \multirow{2}{*}{$\begin{array}{c}\text { Dureza } \\
\left(\mathrm{mg} \mathrm{L}^{-1}\right. \\
\left.\mathrm{CaCO}_{3}\right) \\
\mathrm{i}\end{array}$} & \multicolumn{2}{|c|}{$\begin{array}{c}\text { Temperatura } \\
\left({ }^{\circ} \mathrm{C}\right)\end{array}$} & \multicolumn{2}{|c|}{$\begin{array}{c}\mathrm{N}^{\circ} \mathrm{de} \\
\text { organismos } \\
\text { móveis }\end{array}$} & \multicolumn{2}{|c|}{ Imobilidade } \\
\hline & $\mathrm{i}$ & $\mathrm{f}$ & $\mathrm{i}$ & $\mathrm{F}$ & & $\mathrm{i}$ & $\mathrm{f}$ & $\mathrm{i}$ & $\mathrm{f}$ & Total & $\%$ \\
\hline Controle & 7,19 & 7,81 & 159,9 & 170,3 & 48 & 23,7 & 23,9 & 20 & 18 & 2 & 10 \\
\hline 0,62 & 7,30 & 7,80 & 155,0 & 147,4 & 44 & 23,7 & 23,7 & 20 & 18 & 2 & 10 \\
\hline 1,25 & 7,33 & 7,86 & 156,4 & 165,2 & 44 & 23,6 & 23,9 & 20 & 18 & 2 & 10 \\
\hline 2,5 & 7,35 & 7,89 & 153,0 & 159,0 & 42 & 23,6 & 23,9 & 20 & 11 & 9 & 45 \\
\hline 5,0 & 7,40 & 7,89 & 153,5 & 160,3 & 40 & 23,5 & 23,8 & 20 & 1 & 19 & 95 \\
\hline 10 & 7,49 & 7,89 & 156,2 & 159,3 & 40 & 23,3 & 23,7 & 20 & 0 & 20 & 100 \\
\hline
\end{tabular}

Resultado $\mathrm{CE}_{50}(48 \mathrm{~h})=2,81 \mathrm{mg} \mathrm{L}^{-1} \quad$ Intervalo de Confiança $(95 \%)=\left(2,37-3,32 \mathrm{mg} \mathrm{L}^{-1}\right)$ 
Tabela 25. Resultados do quarto teste de toxicidade aguda $(\mathrm{n}=5)$ com Ceriodaphnia silvestrii exposta ao propranolol.

\begin{tabular}{|c|c|c|c|c|c|c|c|c|c|c|c|}
\hline \multirow{2}{*}{$\begin{array}{l}\text { Solução- } \\
\text { teste } \\
\left(\mathrm{mg} \mathrm{L}^{-1}\right)\end{array}$} & \multicolumn{2}{|c|}{$\mathrm{pH}$} & \multicolumn{2}{|c|}{$\begin{array}{l}\text { Condutividade } \\
\left(\mu \mathrm{S} \mathrm{cm}^{-1}\right)\end{array}$} & \multirow{2}{*}{$\begin{array}{l}\text { Dureza } \\
\left(\mathrm{mg} \mathrm{L}^{-1}\right. \\
\left.\mathrm{CaCO}_{3}\right) \\
\mathrm{i}\end{array}$} & \multicolumn{2}{|c|}{$\begin{array}{c}\text { Temperatura } \\
\left({ }^{\circ} \mathrm{C}\right)\end{array}$} & \multicolumn{2}{|c|}{$\begin{array}{c}\mathrm{N}^{\circ} \mathrm{de} \\
\text { organismos } \\
\text { móveis }\end{array}$} & \multicolumn{2}{|c|}{ Imobilidade } \\
\hline & $\mathrm{i}$ & f & $\mathrm{i}$ & $\mathrm{F}$ & & i & $\mathrm{f}$ & $\mathrm{i}$ & f & Total & $\%$ \\
\hline Controle & 7,49 & 7,57 & 156,0 & 155,7 & 48 & 27,1 & 25,4 & 20 & 20 & 0 & 0 \\
\hline 0,62 & 7,53 & 7,64 & 155,5 & 154,3 & 48 & 27,2 & 25,3 & 20 & 20 & 0 & 0 \\
\hline 1,25 & 7,50 & 7,63 & 155,3 & 157,7 & 48 & 27,2 & 25,4 & 20 & 19 & 1 & 5 \\
\hline 2,5 & 7,53 & 7,60 & 155,8 & 155,4 & 48 & 27,2 & 25,4 & 20 & 15 & 5 & 25 \\
\hline 5,0 & 7,55 & 7,60 & 156,1 & 154,2 & 48 & 27,1 & 25,4 & 20 & 2 & 18 & 90 \\
\hline 10,0 & 7,50 & 7,55 & 155,7 & 156,9 & 48 & 27,1 & 25,5 & 20 & 20 & 20 & 100 \\
\hline
\end{tabular}

Resultado $\mathrm{CE}_{50}(48 \mathrm{~h})=3,08 \mathrm{mg} \mathrm{L}^{-1} \quad$ Intervalo de Confiança $(95 \%)=\left(2,58-3,67 \mathrm{mg} \mathrm{L}^{-1}\right)$

Tabela 26. Resultados do quinto teste de toxicidade aguda $(\mathrm{n}=5)$ com Ceriodaphnia silvestrii exposta ao propranolol.

\begin{tabular}{|c|c|c|c|c|c|c|c|c|c|c|c|}
\hline \multirow{2}{*}{$\begin{array}{c}\text { Solução- } \\
\text { teste } \\
\left(\mathrm{mg} \mathrm{L}^{-1}\right)\end{array}$} & \multicolumn{2}{|c|}{$\mathrm{pH}$} & \multicolumn{2}{|c|}{$\begin{array}{l}\text { Condutividade } \\
\left(\mu \mathrm{S} \mathrm{cm}^{-1}\right)\end{array}$} & \multirow{2}{*}{$\begin{array}{l}\text { Dureza } \\
\left(\mathrm{mg} \mathrm{L}^{-1}\right. \\
\left.\mathrm{CaCO}_{3}\right) \\
\frac{\mathrm{i}}{}\end{array}$} & \multicolumn{2}{|c|}{$\begin{array}{c}\text { Temperatura } \\
\left({ }^{\circ} \mathrm{C}\right)\end{array}$} & \multicolumn{2}{|c|}{$\begin{array}{c}\mathrm{N}^{\circ} \mathrm{de} \\
\text { organismos } \\
\text { móveis }\end{array}$} & \multicolumn{2}{|c|}{ Imobilidade } \\
\hline & $\mathrm{i}$ & $\mathrm{f}$ & $\mathrm{i}$ & $\mathrm{F}$ & & $\mathrm{i}$ & $\mathrm{f}$ & $\mathrm{i}$ & $\mathrm{f}$ & Total & $\%$ \\
\hline Controle & 7,28 & 7,44 & 153,3 & 162,0 & 40 & 26,1 & 26,5 & 20 & 20 & 0 & 0 \\
\hline 0,62 & 7,22 & 7,46 & 154,7 & 163,5 & 44 & 26,1 & 26,6 & 20 & 18 & 2 & 10 \\
\hline 1,25 & 7,18 & 7,35 & 153,4 & 166,7 & 48 & 26,3 & 26,5 & 20 & 17 & 3 & 15 \\
\hline 2,5 & 7,14 & 7,31 & 158,1 & 162,2 & 46 & 26,4 & 26,5 & 20 & 11 & 9 & 45 \\
\hline 5,0 & 7,14 & 7,33 & 158,0 & 162,8 & 40 & 26,3 & 26,6 & 20 & 6 & 14 & 70 \\
\hline 10,0 & 7,14 & 7,35 & 160,4 & 166,5 & 40 & 26,2 & 26,5 & 20 & 20 & 20 & 100 \\
\hline oultodo & & & $\mathrm{L}^{-1}$ & 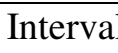 & 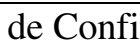 & & )$=($ & & & & \\
\hline
\end{tabular}




\section{Daphnia magna}

Tabela 27. Resultados do teste de toxicidade aguda com Daphnia magna exposta ao propranolol.

\begin{tabular}{|c|c|c|c|c|c|c|c|c|c|c|c|}
\hline \multirow{2}{*}{$\begin{array}{l}\text { Solução- } \\
\text { teste } \\
\left(\mathrm{mg} \mathrm{L}^{-1}\right)\end{array}$} & \multicolumn{2}{|c|}{$\mathrm{pH}$} & \multicolumn{2}{|c|}{$\begin{array}{l}\text { Condutividade } \\
\qquad\left(\mu \mathrm{S} \mathrm{cm}^{-1}\right)\end{array}$} & \multirow{2}{*}{$\begin{array}{l}\text { Dureza } \\
\left(\mathrm{mg} \mathrm{L}^{-1}\right. \\
\left.\mathrm{CaCO}_{3}\right) \\
\frac{\mathrm{i}}{}\end{array}$} & \multicolumn{2}{|c|}{$\begin{array}{c}\text { Temperatura } \\
\left({ }^{\circ} \mathrm{C}\right)\end{array}$} & \multicolumn{2}{|c|}{$\begin{array}{c}\mathrm{N}^{\circ} \mathrm{de} \\
\text { organismos } \\
\text { móveis }\end{array}$} & \multicolumn{2}{|c|}{ Imobilidade } \\
\hline & $\mathrm{i}$ & $\mathrm{f}$ & $\mathrm{i}$ & $\mathrm{F}$ & & $\mathrm{i}$ & $\mathrm{f}$ & $\mathrm{i}$ & $f$ & Total & $\%$ \\
\hline Controle & - & - & - & - & - & - & - & 20 & 20 & 0 & 0 \\
\hline 4,0 & - & - & - & - & - & - & - & 20 & 19 & 1 & 5 \\
\hline 4,8 & - & - & - & - & - & - & - & 20 & 15 & 5 & 25 \\
\hline 5,8 & - & - & - & - & - & - & - & 20 & 9 & 11 & 55 \\
\hline 6,9 & - & - & - & - & - & - & - & 20 & 1 & 19 & 95 \\
\hline 8,3 & - & - & - & - & - & - & - & 20 & 20 & 20 & 100 \\
\hline 10,0 & - & - & - & - & - & - & - & 20 & 20 & 20 & 100 \\
\hline 11,9 & - & - & - & - & - & - & - & 20 & 20 & 20 & 100 \\
\hline
\end{tabular}

Resultado $\mathrm{CE}_{50}(48 \mathrm{~h})=5,531 \mathrm{mg} \mathrm{L}^{-1} \quad$ Intervalo de Confiança $(95 \%)=\left(5,21-5,88 \mathrm{mg} \mathrm{L}^{-1}\right)$

- : não foram medidas os parâmetros físico e químicos das soluções-teste. 


\section{$\underline{\text { Dugesia tigrina }}$}

Tabela 28. Resultados do teste de toxicidade aguda com Dugesia tigrina exposta ao propranolol.

\begin{tabular}{|c|c|c|c|c|c|c|c|c|c|c|c|}
\hline \multirow{2}{*}{$\begin{array}{l}\text { Solução- } \\
\text { teste } \\
\left(\mathrm{mg} \mathrm{L}^{-1}\right)\end{array}$} & \multicolumn{2}{|c|}{$\mathrm{pH}$} & \multicolumn{2}{|c|}{$\begin{array}{l}\text { Condutividade } \\
\qquad\left(\mu \mathrm{S} \mathrm{cm}^{-1}\right)\end{array}$} & \multirow{2}{*}{$\begin{array}{c}\text { Dureza } \\
\left(\mathrm{mg} \mathrm{L}^{-1}\right. \\
\left.\mathrm{CaCO}_{3}\right) \\
\mathrm{i}\end{array}$} & \multicolumn{2}{|c|}{$\begin{array}{c}\text { Temperatura } \\
\left({ }^{\circ} \mathrm{C}\right)\end{array}$} & \multicolumn{2}{|c|}{$\begin{array}{c}\mathrm{N}^{\circ} \text { de } \\
\text { organismos } \\
\text { vivos }\end{array}$} & \multicolumn{2}{|c|}{ Mortalidade } \\
\hline & $\mathrm{i}$ & $f$ & $\mathrm{i}$ & $\mathrm{F}$ & & $\mathrm{i}$ & $f$ & $\mathrm{i}$ & $f$ & Total & $\%$ \\
\hline Controle & 7,36 & 7,56 & 155,1 & 162,0 & 40 & 20,7 & 22,2 & 24 & 0 & 0 & 0 \\
\hline 0,5 & 7,40 & 7,63 & 147,8 & 164,0 & 44 & 20,5 & 22,6 & 24 & 0 & 0 & 0 \\
\hline 4,5 & 7,41 & 7,69 & 153,2 & 169,2 & 42 & 20,4 & 22,5 & 24 & 0 & 0 & 0 \\
\hline 8,5 & 7,40 & 7,6 & 151,4 & 160,3 & 40 & 20,6 & 22,7 & 24 & 19 & 5 & 20,83 \\
\hline 12,5 & 7,42 & 7,67 & 152,9 & 164,2 & 46 & 20,6 & 22,1 & 24 & 11 & 13 & 54,16 \\
\hline 16,5 & 7,41 & 7,68 & 142,7 & 161,4 & 42 & 20,6 & 22,3 & 24 & 3 & 21 & 87,5 \\
\hline 20,5 & 7,45 & 7,67 & 144,1 & 162,6 & 42 & 20,6 & 22,4 & 24 & 0 & 24 & 100 \\
\hline 24,5 & 7,45 & 7,69 & 139,6 & 162,2 & 44 & 20,5 & 22,5 & 24 & 0 & 24 & 100 \\
\hline
\end{tabular}

Logo abaixo, são apresentados os registros dos testes de toxicidade aguda com o propranolol utilizando a espécie Hydra viridissima, como organismo-teste. Os scores aplicados para cada individuo exposto correspondem aos números *(), sendo que nas tabelas a seguir, quando não há especificações, N(10), ou seja, hidra normal com score 10; $\mathrm{B}(8)$, hidra com bulbos nos tentáculos com score 8 e $\mathrm{D}(0)$, hidra com corpo desintegrado com score 0 . 
Tabela 29. Modificações morfológicas em Hydra viridissima exposta a diferentes concentrações de propranolol (mg $\mathrm{L}^{-1}$ ), em teste definitivo de toxicidade aguda (teste $1, \mathrm{n}=10$ ), com leituras a cada 24 horas, e valores de $\mathrm{pH}$, condutividade, temperatura e dureza monitorados mo início e final dos teste. $\mathrm{N}=$ hidra normal; $\mathrm{B}=$ hidra com bulbos nos tentáculos; $\mathrm{C}=$ hidra com tentáculos encurtados; $\mathrm{T}=$ hidra em estado de tulipa; $\mathrm{D}=$ hidra desintegrada, sendo que os números dentro dos *() referem-se aos scores aplicados.

\begin{tabular}{|c|c|c|c|c|c|c|c|c|c|c|c|c|c|c|}
\hline \multirow{2}{*}{$\begin{array}{l}\text { Concentração } \\
\left(\mathrm{mg} \mathrm{L}^{-1}\right)\end{array}$} & \multirow{2}{*}{ Leitura } & \multicolumn{4}{|c|}{ Réplicas } & \multirow{2}{*}{ Total } & \multicolumn{2}{|c|}{$\mathrm{pH}$} & \multicolumn{2}{|c|}{ cond. } & \multicolumn{2}{|c|}{ Temp. } & \multicolumn{2}{|c|}{ Dureza } \\
\hline & & 1 & 2 & 3 & 4 & & $\mathrm{Oh}$ & $96 \mathrm{~h}$ & Oh & $96 \mathrm{~h}$ & $\mathrm{Oh}$ & $96 \mathrm{~h}$ & $\mathrm{Oh}$ & $96 h^{*}$ \\
\hline \multirow{4}{*}{ Controle } & $24 \mathrm{~h}$ & $3 \mathrm{~N}, 1 \mathrm{~B}$ & $4 \mathrm{~N}$ & $4 \mathrm{~N}$ & $4 \mathrm{~N}$ & $15 \mathrm{~N}, 1 \mathrm{~B}$ & \multirow{4}{*}{7,32} & \multirow{4}{*}{8,10} & \multirow{4}{*}{150,6} & \multirow{4}{*}{180,5} & \multirow{4}{*}{21,50} & \multirow{4}{*}{28,60} & \multirow{4}{*}{44} & \multirow{4}{*}{-} \\
\hline & $48 \mathrm{~h}$ & $4 \mathrm{~N}$ & $4 N$ & $4 \mathrm{~N}$ & $4 \mathrm{~N}$ & $16 \mathrm{~N}$ & & & & & & & & \\
\hline & $72 \mathrm{~h}$ & $4 N$ & $2 \mathrm{~N}, 2 \mathrm{~B}$ & $4 N$ & $4 \mathrm{~N}$ & $14 \mathrm{~N}, 2 \mathrm{~B}$ & & & & & & & & \\
\hline & $96 \mathrm{~h}$ & $4 N$ & $4 \mathrm{~N}$ & $4 \mathrm{~N}$ & $4 \mathrm{~N}$ & $16 \mathrm{~N}$ & & & & & & & & \\
\hline \multirow{4}{*}{0,50} & $24 \mathrm{~h}$ & $4 \mathrm{~N}$ & $4 \mathrm{~N}$ & $4 \mathrm{~N}$ & $4 \mathrm{~N}$ & $16 \mathrm{~N}$ & \multirow{4}{*}{7,44} & \multirow{4}{*}{8,01} & \multirow{4}{*}{140,8} & \multirow{4}{*}{151,8} & \multirow{4}{*}{21,80} & \multirow{4}{*}{28,20} & \multirow{4}{*}{40} & \multirow{4}{*}{-} \\
\hline & $48 \mathrm{~h}$ & $4 \mathrm{~N}$ & $3 \mathrm{~N}, 1 \mathrm{~B}$ & $4 \mathrm{~N}$ & $4 \mathrm{~N}$ & $15 \mathrm{~N}, 1 \mathrm{~B}$ & & & & & & & & \\
\hline & $72 \mathrm{~h}$ & $4 N$ & $4 \mathrm{~N}$ & $4 \mathrm{~N}$ & $4 \mathrm{~N}$ & $16 \mathrm{~N}$ & & & & & & & & \\
\hline & $96 \mathrm{~h}$ & $4 N$ & $4 N$ & $4 \mathrm{~N}$ & $4 \mathrm{~N}$ & $16 \mathrm{~N}$ & & & & & & & & \\
\hline \multirow{4}{*}{0,75} & $24 \mathrm{~h}$ & $4 \mathrm{~N}$ & $4 \mathrm{~N}$ & $4 \mathrm{~N}$ & $4 \mathrm{~N}$ & $16 \mathrm{~N}$ & \multirow{4}{*}{7,44} & \multirow{4}{*}{8,00} & & & & & & \\
\hline & $48 \mathrm{~h}$ & $3 \mathrm{~B}, 1 \mathrm{C}(6)$ & $3 \mathrm{~B}, 1 \mathrm{C}(7)$ & $2 \mathrm{~N}, 2 \mathrm{~B}$ & $4 \mathrm{~B}$ & $6 \mathrm{~N}, 8 \mathrm{~B}, 2 \mathrm{C}$ & & & 1000 & 151 & 0100 & ק00 & 10 & \\
\hline & $72 \mathrm{~h}$ & $3 \mathrm{~N}, 1 \mathrm{C}(7)$ & $3 \mathrm{~N}, 1 \mathrm{~B}$ & $4 \mathrm{~N}$ & $42 \mathrm{~N}, 1 \mathrm{C}(7), 1 \mathrm{~T}(2)$ & $12 \mathrm{~N}, 1 \mathrm{~B}, 2 \mathrm{C}, 1 \mathrm{D}$ & & & 138,8 & 151,4 & 21,90 & 28,00 & 48 & - \\
\hline & $96 \mathrm{~h}$ & $2 \mathrm{~N}, 2 \mathrm{D}$ & 4B & $4 \mathrm{~B}$ & $3 \mathrm{~N}, 1 \mathrm{C}(6)$ & $5 \mathrm{~N}, 8 \mathrm{~B}, 1 \mathrm{C}, 2 \mathrm{D}$ & & & & & & & & \\
\hline & $24 \mathrm{~h}$ & $2 \mathrm{~N}, 2 \mathrm{~B}$ & $4 \mathrm{~B}$ & $2 \mathrm{~N}, 2 \mathrm{~B}$ & $2 \mathrm{~N}, 2 \mathrm{~B}$ & $12 \mathrm{~N}, 2 \mathrm{~B}, 2 \mathrm{C}$ & & & & & & & & \\
\hline 100 & $48 \mathrm{~h}$ & $2 \mathrm{~N}, 1$ (2) & $2 \mathrm{~N}, 2 \mathrm{~B}$ & $1 \mathrm{~N}, 2 \mathrm{~B}, 1 \mathrm{C}(7)$ & $2 \mathrm{~N}, 2 \mathrm{~B}$ & $11 \mathrm{~N}, 2 \mathrm{~B}, 3 \mathrm{C}$ & 710 & 801 & 1000 & 450 & 0170 & 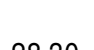 & 10 & \\
\hline 1,00 & $72 \mathrm{~h}$ & $1 \mathrm{~N}, 1 \mathrm{C}(5), 1 \mathrm{~T}(2), 1 \mathrm{D}$ & $3 \mathrm{~B}, 1 \mathrm{C}(6)$ & $2 \mathrm{C}(7), 1(2), 1 \mathrm{D}$ & $2 \mathrm{C}(6), 2 \mathrm{D}$ & $11 \mathrm{~N}, 3 \mathrm{~B}, 2 \mathrm{C}$ & 7,42 & 8,01 & 139,0 & 152,4 & $21, / 0$ & 28,30 & 48 & - \\
\hline & $96 \mathrm{~h}$ & $1 \mathrm{C}, 1 \mathrm{~T}(2), 1 \mathrm{D}$ & $2 \mathrm{C}(7)$ & $4 \mathrm{~N}$ & $4 \mathrm{~N}$ & $11 \mathrm{~N}, 2 \mathrm{~B}, 3 \mathrm{C}$ & & & & & & & & \\
\hline & $24 \mathrm{~h}$ & $1 \mathrm{~N}, 3 \mathrm{~B}$ & $4 \mathrm{~N}$ & $1 \mathrm{~N}, 3 \mathrm{C}(6)$ & $2 \mathrm{~N}, 1 \mathrm{~B}$ e $1 \mathrm{C}$ & $8 \mathrm{~N}, 4 \mathrm{~B}, 4 \mathrm{C}$ & & & & & & & & \\
\hline 125 & $48 \mathrm{~h}$ & $1 \mathrm{~B}, 21 \mathrm{C}(7)$ & $1 \mathrm{~B}, 2 \mathrm{C}(6), 1 \mathrm{~T}(2)$ & $4 \mathrm{D}$ & $12 \mathrm{C}(7), 1 \mathrm{D}$ & $3 \mathrm{~N}, 1 \mathrm{~B}, 8 \mathrm{C}, 4 \mathrm{D}$ & 742 & 801 & 1331 & 1391 & 2180 & 2860 & 42 & _- \\
\hline & $72 \mathrm{~h}$ & $2 \mathrm{~N}(1), 2 \mathrm{D}$ & $1 \mathrm{~B}, 1 \mathrm{C}(7), 1 \mathrm{D}$ & $4 \mathrm{D}$ & $1 \mathrm{~B}, 1 \mathrm{C}(7), 2 \mathrm{D}$ & $3 \mathrm{~N}, 2 \mathrm{~B}, 2 \mathrm{C}, 9 \mathrm{D}$ & $1,4<$ & & & & & & & \\
\hline & $96 \mathrm{~h}$ & $1 \mathrm{~T}(3), 3 \mathrm{D}$ & 2B, $2 \mathrm{D}$ & $4 \mathrm{D}$ & $2 \mathrm{C}(7), 2 \mathrm{D}$ & $2 \mathrm{~B}, 2 \mathrm{C}, 1 \mathrm{~T}, 11 \mathrm{D}$ & & & & & & & & \\
\hline & $24 \mathrm{~h}$ & $2 \mathrm{~B}, 2 \mathrm{C}(6)$ & $1 \mathrm{~B}, 2 \mathrm{C}(7), 1 \mathrm{D}$ & $1 \mathrm{~B}, 1 \mathrm{C}(6), 2 \mathrm{~T}(1)$ & $1 \mathrm{~B}, 1 \mathrm{C}(6), 2 \mathrm{D}$ & $5 \mathrm{~B}, 6 \mathrm{C}, 2 \mathrm{~T}, 3 \mathrm{D}$ & & & & & & & & \\
\hline 150 & $48 \mathrm{~h}$ & $2 \mathrm{~T}(1), 2 \mathrm{D}$ & $4 \mathrm{D}$ & $4 \mathrm{D}$ & $4 \mathrm{D}$ & $2 \mathrm{~T}, 14 \mathrm{D}$ & 746 & 800 & 1364 & 1448 & 2160 & 2870 & 42 & - \\
\hline 促, & $72 \mathrm{~h}$ & $4 \mathrm{D}$ & $4 \mathrm{D}$ & 4D & $4 \mathrm{D}$ & $16 \mathrm{D}$ & 1,70 & 0,00 & 100,4 & 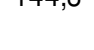 & & $20, \pi 0$ & $4 c$ & \\
\hline & $96 \mathrm{~h}$ & $4 \mathrm{D}$ & $4 \mathrm{D}$ & $4 \mathrm{D}$ & $4 \mathrm{D}$ & $16 \mathrm{D}$ & & & & & & & & \\
\hline
\end{tabular}


Tabela 30. Modificações morfológicas em Hydra viridissima exposta a diferentes concentrações de propranolol (mg $\mathrm{L}^{-1}$ ), em teste definitivo de toxicidade aguda (teste $2, \mathrm{n}=10$ ), com leituras a cada 24 horas, e valores de $\mathrm{pH}$, condutividade, temperatura e dureza monitorados mo início e final dos teste. $\mathrm{N}=$ hidra normal; $\mathrm{B}=$ hidra com bulbos nos tentáculos; $\mathrm{C}=$ hidra com tentáculos encurtados; $\mathrm{T}=$ hidra em estado de tulipa; $\mathrm{D}=$ hidra desintegrada, sendo que os números dentro dos *() referem-se aos scores aplicados.

\begin{tabular}{|c|c|c|c|c|c|c|c|c|c|c|c|c|c|c|}
\hline \multirow{2}{*}{$\begin{array}{c}\text { Concentração } \\
\left(\mathrm{mg} \mathrm{L}^{-1}\right)\end{array}$} & \multirow{2}{*}{ Leitura } & \multicolumn{4}{|c|}{ Réplicas } & \multirow{2}{*}{ Total } & \multicolumn{2}{|c|}{$\mathrm{pH}$} & \multicolumn{2}{|c|}{ cond. } & \multicolumn{2}{|c|}{ Temp. } & \multicolumn{2}{|c|}{ Dureza } \\
\hline & & 1 & 2 & 3 & 4 & & Oh & $96 \mathrm{~h}$ & Oh & $96 \mathrm{~h}$ & Oh & $96 \mathrm{~h}$ & Oh & $96 \mathrm{~h}^{*}$ \\
\hline \multirow{4}{*}{ Controle } & $24 \mathrm{~h}$ & $4 \mathrm{~N}$ & $4 \mathrm{~N}$ & $4 \mathrm{~N}$ & $4 \mathrm{~N}$ & $16 \mathrm{~N}$ & \multirow{4}{*}{7,46} & \multirow{4}{*}{7,98} & \multirow{4}{*}{143,4} & \multirow{4}{*}{139,1} & \multirow{4}{*}{22,80} & \multirow{4}{*}{23,10} & \multirow{4}{*}{48} & \multirow{4}{*}{-} \\
\hline & $48 \mathrm{~h}$ & $4 \mathrm{~N}$ & $4 \mathrm{~N}$ & $4 \mathrm{~N}$ & $4 \mathrm{~N}$ & $16 \mathrm{~N}$ & & & & & & & & \\
\hline & $72 \mathrm{~h}$ & $4 \mathrm{~N}$ & $4 \mathrm{~N}$ & $4 \mathrm{~N}$ & $4 \mathrm{~N}$ & $16 \mathrm{~N}$ & & & & & & & & \\
\hline & $96 \mathrm{~h}$ & $4 \mathrm{~N}$ & $4 \mathrm{~N}$ & $4 \mathrm{~N}$ & $4 \mathrm{~N}$ & $16 \mathrm{~N}$ & & & & & & & & \\
\hline \multirow{4}{*}{0,50} & $24 \mathrm{~h}$ & $4 \mathrm{~N}$ & $4 \mathrm{~N}$ & $4 \mathrm{~N}$ & $4 \mathrm{~N}$ & $16 \mathrm{~N}$ & \multirow{4}{*}{7,49} & \multirow{4}{*}{7,99} & \multirow{4}{*}{137,1} & \multirow{4}{*}{142,1} & \multirow{4}{*}{22,40} & \multirow{4}{*}{23,10} & \multirow{4}{*}{42} & \multirow{4}{*}{ - } \\
\hline & $48 \mathrm{~h}$ & $4 \mathrm{~B}$ & $3 \mathrm{~N}, 1 \mathrm{~B}$ & $4 \mathrm{~N}$ & $4 \mathrm{~N}$ & $11 \mathrm{~N}, 5 \mathrm{~B}$ & & & & & & & & \\
\hline & $72 \mathrm{~h}$ & $1 \mathrm{~N}, 3 \mathrm{~B}$ & $4 N$ & $4 N$ & $4 \mathrm{~N}$ & $13 N, 3 B$ & & & & & & & & \\
\hline & $96 \mathrm{~h}$ & $2 \mathrm{~N}, 2 \mathrm{~B}$ & $4 \mathrm{~N}$ & $3 \mathrm{~N}, 1 \mathrm{~B}$ & $4 \mathrm{~N}$ & $13 \mathrm{~N}, 3 \mathrm{~B}$ & & & & & & & & \\
\hline \multirow{4}{*}{0,75} & $24 \mathrm{~h}$ & $2 \mathrm{~N}, 2 \mathrm{~B}$ & $1 \mathrm{~N}, 3 \mathrm{~B}$ & $2 \mathrm{~N}, 2 \mathrm{~B}$ & $4 \mathrm{~B}$ & $5 \mathrm{~N}, 11 \mathrm{~B}$ & \multirow{4}{*}{7,48} & \multirow{4}{*}{7,95} & & & & & & \\
\hline & $48 \mathrm{~h}$ & 4B & $2 \mathrm{~B}, 1 \mathrm{C}(7), 1 \mathrm{D}$ & $1 \mathrm{~N}, 2 \mathrm{~B}, 1 \mathrm{D}$ & $4 \mathrm{~B}$ & $1 \mathrm{~N}, 12 \mathrm{~B}, 1 \mathrm{C}, 2 \mathrm{D}$ & & & 1309 & 1425 & 2240 & 2320 & 46 & - \\
\hline & $72 \mathrm{~h}$ & $2 \mathrm{~N}, 1 \mathrm{~B}, 1 \mathrm{C}(7)$ & $1 \mathrm{~B}, 1 \mathrm{~T}(2), 2 \mathrm{D}$ & $1 \mathrm{~N}, 1 \mathrm{~B}, 1 \mathrm{C}(7), 1 \mathrm{D}$ & 4B & $3 \mathrm{~N}, 7 \mathrm{~B}, 2 \mathrm{C}, 1 \mathrm{~T}, 3 \mathrm{D}$ & & & & $14<, 0$ & $2<, 40$ & $<0,<0$ & 40 & 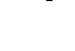 \\
\hline & $96 \mathrm{~h}$ & $3 \mathrm{~N}(2(9), 1(10)), 1 \mathrm{C}(7$ & $1 \mathrm{C}(7), 1 \mathrm{~T}(2), 2 \mathrm{D}$ & $1 \mathrm{~N}, 1 \mathrm{C}(7), 2 \mathrm{D}$ & $3 \mathrm{~B}, 1 \mathrm{C}(6)$ & $4 \mathrm{~N}, 3 \mathrm{~B}, 4 \mathrm{C}, 1 \mathrm{~T}, 4 \mathrm{D}$ & & & & & & & & \\
\hline & $24 \mathrm{~h}$ & $2 \mathrm{~B}, 2 \mathrm{C}(7)$ & $3 \mathrm{~B}, 1 \mathrm{C}(6)$ & $4 \mathrm{~B}$ & $1 \mathrm{~N}, 3 \mathrm{~B}$ & $1 \mathrm{~N}, 12 \mathrm{~B}, 3 \mathrm{C}$ & & & & & & & & \\
\hline 1.00 & $48 \mathrm{~h}$ & $2 \mathrm{C}(6), 2 \mathrm{D}$ & 1B, 3D & $2 \mathrm{~B}, 1 \mathrm{C}(6), 1 \mathrm{~T}(1)$ & $1 \mathrm{~B}, 2 \mathrm{C}(6), 1 \mathrm{D}$ & $4 \mathrm{~B}, 5 \mathrm{C}, 1 \mathrm{~T}, 6 \mathrm{D}$ & 747 & 797 & 1318 & 1413 & 2230 & 2310 & 40 & \\
\hline & $72 \mathrm{~h}$ & $1 \mathrm{C}(7), 1 \mathrm{~T}(1), 2 \mathrm{D}$ & $1 \mathrm{~N}, 3 \mathrm{D}$ & $1 \mathrm{~N}(9), 1 \mathrm{C}(7), 2 \mathrm{D}$ & $1 \mathrm{~N}(9), 1 \mathrm{C}(6), 2 \mathrm{D}$ & $3 \mathrm{~N}, 3 \mathrm{C}, 1 \mathrm{~T}, 9 \mathrm{D}$ & 1,41 & וכ, & 作 & 141,0 & $2<, 00$ & 20,10 & 40 & 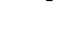 \\
\hline & $96 \mathrm{~h}$ & $1 \mathrm{C}(7), 1 \mathrm{~T}(1), 2 \mathrm{D}$ & $1 \mathrm{~B}, 3 \mathrm{D}$ & 1B, 1C(7), 2D & 2B, 2D & 4B, 2C, 1T, 9D & & & & & & & & \\
\hline & $24 \mathrm{~h}$ & $4 \mathrm{~N}$ & $2 \mathrm{~N}, 2 \mathrm{~B}$ & $2 \mathrm{~N}, 2 \mathrm{~B}$ & $4 \mathrm{~B}$ & $8 \mathrm{~N}, 8 \mathrm{~B}$ & & & & & & & & \\
\hline 125 & $48 \mathrm{~h}$ & $3 \mathrm{~B}, 1 \mathrm{~T}(1)$ & 4B & $1 \mathrm{~N}, 3 \mathrm{~B}$ & $3 \mathrm{~B}, 1 \mathrm{C}(7)$ & $1 \mathrm{~N}, 13 \mathrm{~B}, 1 \mathrm{C}, 1 \mathrm{~T}$ & 749 & 797 & 1341 & 1389 & 2230 & 23.30 & 42 & - \\
\hline $1, L$ & $72 \mathrm{~h}$ & 1B, 3C(2(6),1(7)) & $2 \mathrm{~B}, 2 \mathrm{C}(7)$ & 4B & $1 \mathrm{~N}, 3 \mathrm{~B}$ & $1 \mathrm{~N}, 10 \mathrm{~B}, 5 \mathrm{C}$ & $1,4+3$ & וכ, ו & 104,1 & 100,0 & $2<, 00$ & $<0,00$ & $4 c$ & \\
\hline & $96 \mathrm{~h}$ & $2 \mathrm{~N}, 1 \mathrm{~B}, 1 \mathrm{C}(6)$ & $1 \mathrm{~N}, 1 \mathrm{~B}, 1 \mathrm{C}(6), 1 \mathrm{~T}(2)$ & 3B, 1C(7) & $4 \mathrm{~B}$ & $3 \mathrm{~N}, 9 \mathrm{~B}, 3 \mathrm{C}, 1 \mathrm{~T}$ & & & & & & & & \\
\hline & $24 \mathrm{~h}$ & $2 \mathrm{~B}, 2 \mathrm{C}(7)$ & $1 \mathrm{~B}, 1 \mathrm{C}(7), 1 \mathrm{~T}(1), 1 \mathrm{D}$ & $2 \mathrm{~B}, 2 \mathrm{D}$ & $1 \mathrm{~B}, 3 \mathrm{D}$ & $6 \mathrm{~B}, 3 \mathrm{C}, 1 \mathrm{~T}, 6 \mathrm{D}$ & & & & & & & & \\
\hline 150 & $48 \mathrm{~h}$ & 4D & $4 \mathrm{D}$ & 4D & 4D & $16 \mathrm{D}$ & 751 & 799 & 1329 & 1304 & 2260 & 23.30 & 40 & - \\
\hline 1,00 & $72 \mathrm{~h}$ & $4 \mathrm{D}$ & $4 \mathrm{D}$ & $4 \mathrm{D}$ & $4 \mathrm{D}$ & $16 \mathrm{D}$ & 1, I I & 1,99 & 10<,9 & 100,4 & $2<, 00$ & 20,00 & 40 & - \\
\hline & $96 \mathrm{~h}$ & $4 \mathrm{D}$ & $4 \mathrm{D}$ & $4 \mathrm{D}$ & $4 \mathrm{D}$ & $16 \mathrm{D}$ & & & & & & & & \\
\hline
\end{tabular}


Tabela 31. Modificações morfológicas em Hydra viridissima exposta a diferentes concentrações de propranolol (mg $\mathrm{L}^{-1}$ ), em teste definitivo de toxicidade aguda (teste $3, \mathrm{n}=10$ ), com leituras a cada 24 horas, e valores de $\mathrm{pH}$, condutividade, temperatura e dureza monitorados mo início e final dos teste. $\mathrm{N}=$ hidra normal; $\mathrm{B}=$ hidra com bulbos nos tentáculos; $\mathrm{C}=$ hidra com tentáculos encurtados; $\mathrm{T}=$ hidra em estado de tulipa; $\mathrm{D}=$ hidra desintegrada, sendo que os números dentro dos *() referem-se aos scores aplicados.

\begin{tabular}{|c|c|c|c|c|c|c|c|c|c|c|c|c|c|c|}
\hline \multirow{2}{*}{$\begin{array}{c}\text { Concentração } \\
\left(\mathrm{mg} \mathrm{L}^{-1}\right)\end{array}$} & \multirow{2}{*}{ Leitura } & \multicolumn{4}{|c|}{ Réplicas } & \multirow{2}{*}{ Total } & \multicolumn{2}{|c|}{$\mathrm{pH}$} & \multicolumn{2}{|c|}{ cond. } & \multicolumn{2}{|c|}{ Temp. } & \multicolumn{2}{|c|}{ Dureza } \\
\hline & & 1 & 2 & 3 & 4 & & Oh & $96 \mathrm{~h}$ & Oh & $96 \mathrm{~h}$ & Oh & $96 \mathrm{~h}$ & Oh & $96 \mathrm{~h}^{*}$ \\
\hline \multirow{4}{*}{ Controle } & $24 \mathrm{~h}$ & $4 \mathrm{~N}$ & $4 \mathrm{~N}$ & $4 \mathrm{~N}$ & $4 \mathrm{~N}$ & $16 \mathrm{~N}$ & \multirow{4}{*}{7,49} & \multirow{4}{*}{7,98} & \multirow{4}{*}{132,6} & \multirow{4}{*}{144,6} & \multirow{4}{*}{23,00} & \multirow{4}{*}{24,60} & \multirow{4}{*}{46} & \multirow{4}{*}{-} \\
\hline & $48 \mathrm{~h}$ & $4 \mathrm{~N}$ & $4 \mathrm{~N}$ & $4 \mathrm{~N}$ & $4 \mathrm{~N}$ & $16 \mathrm{~N}$ & & & & & & & & \\
\hline & $72 \mathrm{~h}$ & $4 \mathrm{~N}$ & $4 \mathrm{~N}$ & $4 \mathrm{~N}$ & $4 \mathrm{~N}$ & $16 \mathrm{~N}$ & & & & & & & & \\
\hline & $96 \mathrm{~h}$ & $4 \mathrm{~N}$ & $4 \mathrm{~N}$ & $4 \mathrm{~N}$ & $4 \mathrm{~N}$ & $16 \mathrm{~N}$ & & & & & & & & \\
\hline \multirow{4}{*}{0,50} & $24 \mathrm{~h}$ & $3 \mathrm{~N}, 1 \mathrm{~B}$ & $4 \mathrm{~N}$ & $3 \mathrm{~N}, 1 \mathrm{~B}$ & $3 \mathrm{~N}, 1 \mathrm{~B}$ & $13 \mathrm{~N}, 3 \mathrm{~B}$ & \multirow{4}{*}{7,50} & \multirow{4}{*}{7,99} & \multirow{4}{*}{133,0} & \multirow{4}{*}{139,3} & \multirow{4}{*}{23,10} & \multirow{4}{*}{24,60} & \multirow{4}{*}{44} & \multirow{4}{*}{-} \\
\hline & $48 \mathrm{~h}$ & $4 \mathrm{~B}$ & $4 \mathrm{~N}$ & $3 \mathrm{~N}, 1 \mathrm{~B}$ & $4 \mathrm{~N}$ & $11 \mathrm{~N}, 5 \mathrm{~B}$ & & & & & & & & \\
\hline & $72 \mathrm{~h}$ & $3 \mathrm{~N}, 1 \mathrm{~B}$ & $4 \mathrm{~N}$ & $4 \mathrm{~N}$ & $4 \mathrm{~N}$ & $15 \mathrm{~N}, 1 \mathrm{~B}$ & & & & & & & & \\
\hline & $96 \mathrm{~h}$ & $2 \mathrm{~N}, 1 \mathrm{~B}, 1 \mathrm{C}(6)$ & $4 \mathrm{~N}$ & $4 \mathrm{~N}$ & $4 \mathrm{~N}$ & $14 \mathrm{~N}, 1 \mathrm{~B}, 1 \mathrm{C}$ & & & & & & & & \\
\hline \multirow{4}{*}{0,75} & $24 \mathrm{~h}$ & $2 \mathrm{~N}, 2 \mathrm{~B}$ & $2 \mathrm{~N}, 2 \mathrm{~B}$ & $1 \mathrm{~N}, 2 \mathrm{~B}, 1 \mathrm{C}(6)$ & $2 \mathrm{~N}, 1 \mathrm{~B}, 1 \mathrm{C}(6)$ & $7 \mathrm{~N}, 7 \mathrm{~B}, 2 \mathrm{C}$ & \multirow{4}{*}{7,49} & \multirow{4}{*}{7,98} & & & & & & \\
\hline & $48 \mathrm{~h}$ & $1 \mathrm{~N}, 3 \mathrm{~B}$ & $1 \mathrm{~N}, 3 \mathrm{~B}$ & $1 \mathrm{~N}, 2 \mathrm{~B}, 1 \mathrm{C}(6)$ & $2 \mathrm{~N}, 1 \mathrm{~B}, 1 \mathrm{C}(7)$ & $5 \mathrm{~N}, 9 \mathrm{~B}, 2 \mathrm{C}$ & & & 1348 & 1401 & 2300 & 2400 & 42 & - \\
\hline & $72 \mathrm{~h}$ & $3 \mathrm{~B}, 1 \mathrm{C}(7)$ & $2 \mathrm{~N}, 2 \mathrm{~B}$ & $4 \mathrm{~N}$ & $1 \mathrm{~N}, 3 \mathrm{~B}$ & $7 \mathrm{~N}, 8 \mathrm{~B}, 1 \mathrm{C}$ & & & 104,0 & 140,1 & $<0,00$ & 24,00 & $4 c$ & 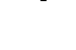 \\
\hline & $96 \mathrm{~h}$ & $1 \mathrm{~N}, 2 \mathrm{~B}, 1 \mathrm{C}(7)$ & $1 \mathrm{~N}, 3 \mathrm{~B}$ & $3 \mathrm{~N}, 1 \mathrm{~B}$ & $4 \mathrm{C}(3(7), 1(6))$ & $5 \mathrm{~N}, 6 \mathrm{~B}, 5 \mathrm{C}$ & & & & & & & & \\
\hline & $24 \mathrm{~h}$ & $1 \mathrm{~N}, 2 \mathrm{~B}, 1 \mathrm{C}(6)$ & $1 \mathrm{~N}, 3 \mathrm{C}(2(6), 1(7))$ & $2 \mathrm{~N}, 1 \mathrm{~B}, 1 \mathrm{D}$ & $3 \mathrm{~B}, 1 \mathrm{C}(6)$ & $4 \mathrm{~N}, 6 \mathrm{~B}, 5 \mathrm{C}, 1 \mathrm{D}$ & & & & & & & & \\
\hline 100 & $48 \mathrm{~h}$ & $2 \mathrm{~N}(9), 1 \mathrm{C}(6), 1 \mathrm{D}$ & $2 \mathrm{C}(1(6), 1(7)), 1 \mathrm{D}$ & $1 \mathrm{~N}(9), 1 \mathrm{C}(7), 2 \mathrm{D}$ & $3 \mathrm{C}(2(6), 1(7)), 1 \mathrm{D}$ & $3 \mathrm{~N}, 7 \mathrm{C}, 5 \mathrm{D}, 1 \mathrm{D}$ & 751 & 802 & 1352 & 1432 & 2290 & 2460 & 44 & - \\
\hline 1,00 & $72 \mathrm{~h}$ & 2N,1C(7), 1D & $1 \mathrm{C}(7), 2 \mathrm{~T}(1(2), 1(3)), 1 \mathrm{D}$ & 1B, 1T(2), 2D & $1 \mathrm{~B}, 2 \mathrm{C}(1(6), 1(7)), 1 \mathrm{D}$ & $2 \mathrm{~N}, 2 \mathrm{~B}, 4 \mathrm{C}, 3 \mathrm{~T}, 5 \mathrm{D}$ & ודונ, & , VL & 100,2 & (2) & $2,, 0$ & $2 T, 00$ & Th & \\
\hline & $96 \mathrm{~h}$ & $3 \mathrm{~N}, 1 \mathrm{~B}$ & $3 \mathrm{~N}, 1 \mathrm{~B}$ & $3 \mathrm{~N}, 1 \mathrm{~B}$ & $2 \mathrm{~N}, 1 \mathrm{~B}, 1 \mathrm{C}(6)$ & $11 \mathrm{~N}, 4 \mathrm{~B}, 1 \mathrm{C}$ & & & & & & & & \\
\hline & $24 \mathrm{~h}$ & $1 \mathrm{C}(6), 3 \mathrm{D}$ & $1 \mathrm{~N}, 1 \mathrm{~B}, 1 \mathrm{~T}(1), 1 \mathrm{D}$ & $1 \mathrm{C}(7), 3 \mathrm{D}$ & $4 \mathrm{C}(6)$ & $1 \mathrm{~N}, 1 \mathrm{~B}, 6 \mathrm{C}, 1 \mathrm{~T}, 7 \mathrm{D}$ & & & & & & & & \\
\hline 125 & $48 \mathrm{~h}$ & $4 \mathrm{D}$ & $4 \mathrm{D}$ & $1 \mathrm{~T}(1), 3 \mathrm{D}$ & $4 \mathrm{D}$ & $1 \mathrm{~T}, 15 \mathrm{D}$ & 750 & 802 & 1358 & 1424 & 2300 & 2470 & 44 & - \\
\hline 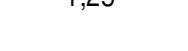 & $72 \mathrm{~h}$ & $4 \mathrm{D}$ & $4 \mathrm{D}$ & $1 \mathrm{~T}(1), 3 \mathrm{D}$ & $4 \mathrm{D}$ & $1 \mathrm{~T}, 15 \mathrm{D}$ & סט, & $0, v c$ & 100,0 & 146,4 & 20,00 & 24,10 & 44 & \\
\hline & $96 \mathrm{~h}$ & $4 \mathrm{D}$ & $4 \mathrm{D}$ & $1 \mathrm{~T}(1), 3 \mathrm{D}$ & $4 \mathrm{D}$ & $1 \mathrm{~T}, 15 \mathrm{D}$ & & & & & & & & \\
\hline & $24 \mathrm{~h}$ & $3 \mathrm{C}(6), 1 \mathrm{D}$ & $1 \mathrm{~B}, 1 \mathrm{C}(7), 2 \mathrm{D}$ & $3 \mathrm{C}(2(6), 1(7)), 1 \mathrm{D}$ & $1 \mathrm{~B}, 1 \mathrm{C}(7), 2 \mathrm{D}$ & $2 \mathrm{~B}, 8 \mathrm{C}, 6 \mathrm{D}$ & & & & & & & & \\
\hline 1.50 & $48 \mathrm{~h}$ & $4 \mathrm{D}$ & $4 \mathrm{D}$ & $4 \mathrm{D}$ & $4 \mathrm{D}$ & $16 \mathrm{D}$ & 7,51 & 8.04 & 138.5 & 144.8 & 23.00 & 24,70 & 44 & - \\
\hline & $72 \mathrm{~h}$ & 4D & $4 \mathrm{D}$ & $4 \mathrm{D}$ & 4D & $16 \mathrm{D}$ & & & & & & & & \\
\hline & $96 \mathrm{~h}$ & $4 \mathrm{D}$ & $4 \mathrm{D}$ & $4 \mathrm{D}$ & $4 \mathrm{D}$ & $16 \mathrm{D}$ & & & & & & & & \\
\hline
\end{tabular}


Tabela 32. Modificações morfológicas em Hydra viridissima exposta a diferentes concentrações de propranolol (mg $\mathrm{L}^{-1}$ ), em teste definitivo de toxicidade aguda (teste $4, \mathrm{n}=10$ ), com leituras a cada 24 horas, e valores de $\mathrm{pH}$, condutividade, temperatura e dureza monitorados mo início e final dos teste. $\mathrm{N}=$ hidra normal; $\mathrm{B}=$ hidra com bulbos nos tentáculos; $\mathrm{C}=$ hidra com tentáculos encurtados; $\mathrm{T}=$ hidra em estado de tulipa; $\mathrm{D}=$ hidra desintegrada, sendo que os números dentro dos *() referem-se aos scores aplicados.

\begin{tabular}{|c|c|c|c|c|c|c|c|c|c|c|c|c|c|c|}
\hline \multirow{2}{*}{$\begin{array}{c}\text { Concentração } \\
\left(\mathrm{mg} \mathrm{L}^{-1}\right)\end{array}$} & \multirow{2}{*}{ Leitura } & \multicolumn{4}{|c|}{ Réplicas } & \multirow{2}{*}{ Total } & \multicolumn{2}{|c|}{$\mathrm{pH}$} & \multicolumn{2}{|c|}{ cond. } & \multicolumn{2}{|c|}{ Temp. } & \multicolumn{2}{|c|}{ Dureza } \\
\hline & & 1 & 2 & 3 & 4 & & Oh & $96 \mathrm{~h}$ & Oh & $96 \mathrm{~h}$ & $\mathrm{Oh}$ & $96 \mathrm{~h}$ & Oh & $96 h^{*}$ \\
\hline \multirow{4}{*}{ Controle } & $24 \mathrm{~h}$ & $4 \mathrm{~N}$ & $4 \mathrm{~N}$ & $4 \mathrm{~N}$ & $4 \mathrm{~N}$ & $16 \mathrm{~N}$ & \multirow{4}{*}{7,27} & \multirow{4}{*}{7,99} & \multirow{4}{*}{136,9} & \multirow{4}{*}{143,3} & \multirow{4}{*}{22,00} & \multirow{4}{*}{22,90} & \multirow{4}{*}{46} & \multirow{4}{*}{-} \\
\hline & $48 \mathrm{~h}$ & $4 \mathrm{~N}$ & $4 \mathrm{~N}$ & $4 \mathrm{~N}$ & $4 \mathrm{~N}$ & $16 \mathrm{~N}$ & & & & & & & & \\
\hline & $72 \mathrm{~h}$ & $4 \mathrm{~N}$ & $4 \mathrm{~N}$ & $4 \mathrm{~N}$ & $4 \mathrm{~N}$ & $16 \mathrm{~N}$ & & & & & & & & \\
\hline & $96 \mathrm{~h}$ & $4 \mathrm{~N}$ & $4 \mathrm{~N}$ & $4 \mathrm{~N}$ & $4 \mathrm{~N}$ & $16 \mathrm{~N}$ & & & & & & & & \\
\hline \multirow{4}{*}{0,50} & $24 \mathrm{~h}$ & $3 \mathrm{~N}, 1 \mathrm{~B}$ & $3 \mathrm{~N}, 1 \mathrm{~B}$ & $4 \mathrm{~N}$ & $4 \mathrm{~N}$ & $14 \mathrm{~N}, 2 \mathrm{~B}$ & \multirow{4}{*}{7,35} & \multirow{4}{*}{7,98} & \multirow{4}{*}{136,3} & \multirow{4}{*}{140,9} & \multirow{4}{*}{22,20} & \multirow{4}{*}{23,30} & \multirow{4}{*}{40} & \multirow{4}{*}{-} \\
\hline & $48 \mathrm{~h}$ & $4 \mathrm{~N}$ & $3 \mathrm{~N}, 1 \mathrm{D}$ & $4 \mathrm{~N}$ & $4 \mathrm{~N}$ & $15 \mathrm{~N}, 1 \mathrm{D}$ & & & & & & & & \\
\hline & $72 \mathrm{~h}$ & $2 \mathrm{~N}, 2 \mathrm{~B}$ & $3 \mathrm{~N}, 1 \mathrm{D}$ & $4 \mathrm{~N}$ & $4 \mathrm{~N}$ & $13 \mathrm{~N}, 2 \mathrm{~B}, 1 \mathrm{D}$ & & & & & & & & \\
\hline & $96 \mathrm{~h}$ & $2 \mathrm{~N}, 2 \mathrm{~B}$ & $3 \mathrm{~N}, 1 \mathrm{D}$ & $4 \mathrm{~N}$ & $2 \mathrm{~N}, 2 \mathrm{~B}$ & $11 \mathrm{~N}, 4 \mathrm{~B}, 1 \mathrm{D}$ & & & & & & & & \\
\hline \multirow{4}{*}{0,75} & $24 \mathrm{~h}$ & $1 \mathrm{~N}, 1 \mathrm{~B}, 2 \mathrm{C}(7)$ & $1 \mathrm{~N}, 3 \mathrm{~B}$ & $3 \mathrm{~N}, 1 \mathrm{C}(7)$ & $3 \mathrm{~B}, 1 \mathrm{C}(7)$ & $5 \mathrm{~N}, 7 \mathrm{~B}, 4 \mathrm{C}$ & \multirow{4}{*}{7,35} & \multirow{4}{*}{8,03} & & & & & & \\
\hline & $48 \mathrm{~h}$ & $1 \mathrm{~N}, 1 \mathrm{~B}, 1 \mathrm{C}(6), 1 \mathrm{~T}(1)$ & $2 \mathrm{~N}, 2 \mathrm{~B}$ & $1 \mathrm{~N}, 3 \mathrm{C}(6)$ & $1 \mathrm{~N}, 2 \mathrm{~B}, 1 \mathrm{C}(7)$ & $5 \mathrm{~N}, 5 \mathrm{~B}, 5 \mathrm{C}, 1 \mathrm{~T}$ & & & 1356 & 1413 & 2230 & 2340 & 44 & - \\
\hline & $72 \mathrm{~h}$ & $2 \mathrm{~N}, 1 \mathrm{~B}, 1 \mathrm{~T}(1)$ & $1 \mathrm{~N}, 2 \mathrm{~B}, 1 \mathrm{C}(6)$ & $1 \mathrm{~B}, 2 \mathrm{C}(6), 1 \mathrm{D}$ & $1 \mathrm{~N}, 2 \mathrm{~B}, 1 \mathrm{C}(7)$ & $4 \mathrm{~N}, 6 \mathrm{~B}, 4 \mathrm{C}, 1 \mathrm{~T}, 1 \mathrm{D}$ & & & 10,0 & 141,0 & $2<, 00$ & 20,40 & 44 & \\
\hline & $96 \mathrm{~h}$ & $2 \mathrm{~N}, 1 \mathrm{~B}, 1 \mathrm{D}$ & $1 \mathrm{~N}, 2 \mathrm{~B}, 1 \mathrm{C}(7)$ & $2 \mathrm{~B}, 1 \mathrm{C}(6), 1 \mathrm{D}$ & $2 \mathrm{~B}, 2 \mathrm{C}(6)$ & $3 \mathrm{~N}, 7 \mathrm{~B}, 4 \mathrm{C}, 2 \mathrm{D}$ & & & & & & & & \\
\hline & $24 \mathrm{~h}$ & $3 \mathrm{~B}, 1 \mathrm{C}(7)$ & $1 \mathrm{~N}, 1 \mathrm{~B}, 2 \mathrm{C}(1(6), 1(7))$ & $1 \mathrm{~B}, 3 \mathrm{C}(2(6), 1(7))$ & $4 \mathrm{C}(7)$ & $1 \mathrm{~N}, 5 \mathrm{~B}, 10 \mathrm{C}$ & & & & & & & & \\
\hline 1.00 & $48 \mathrm{~h}$ & $1 \mathrm{~B}, 1 \mathrm{C}(7), 2 \mathrm{D}$ & $3 \mathrm{~N}, 1 \mathrm{C}(6)$ & $2 \mathrm{C}(1(7), 1(6)), 2 \mathrm{D}$ & $1 \mathrm{C}(7), 1 \mathrm{~T}(2), 2 \mathrm{D}$ & $3 \mathrm{~N}, 1 \mathrm{~B}, 5 \mathrm{C}, 1 \mathrm{~T}, 6 \mathrm{D}$ & 736 & 8.04 & 1350 & 1396 & 2240 & 2270 & 42 & - \\
\hline & $72 \mathrm{~h}$ & $1 \mathrm{~B}, 1 \mathrm{C}(7), 2 \mathrm{D}$ & $2 \mathrm{~N}, 1 \mathrm{~B}, 1 \mathrm{~T}(1)$ & 2C(6), 2D & $1 \mathrm{C}(6), 1 \mathrm{~T}(1), 2 \mathrm{D}$ & $2 \mathrm{~N}, 2 \mathrm{~B}, 4 \mathrm{C}, 2 \mathrm{~T}, 6 \mathrm{D}$ & 促 & 0,04 & ofus & 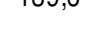 & $2 c,+u$ & $2 \alpha, 10$ & $4 c$ & \\
\hline & $96 \mathrm{~h}$ & $1 \mathrm{~B}, 1 \mathrm{C}(6), 2 \mathrm{D}$ & $2 \mathrm{~B}, 1 \mathrm{C}(7), 1 \mathrm{D}$ & $1 \mathrm{~B}, 1 \mathrm{C}(7), 2 \mathrm{D}$ & $1 \mathrm{~B}, 1 \mathrm{~T}(2), 2 \mathrm{D}$ & 5B, 3C, 1T, 7D & & & & & & & & \\
\hline & $24 \mathrm{~h}$ & $2 \mathrm{C}(6), 2 \mathrm{D}$ & $2 C(7), 2 D$ & $1 \mathrm{C}(6), 3 \mathrm{D}$ & $3 \mathrm{C}(6), 1 \mathrm{D}$ & $8 \mathrm{C}, 8 \mathrm{D}$ & & & & & & & & \\
\hline 125 & $48 \mathrm{~h}$ & $1 \mathrm{C}(7), 1 \mathrm{~T}(2), 2 \mathrm{D}$ & $4 \mathrm{D}$ & $4 \mathrm{D}$ & $4 \mathrm{D}$ & $1 \mathrm{C}, 1 \mathrm{~T}, 14 \mathrm{D}$ & 737 & 8.01 & 1355 & 1448 & 2230 & 2290 & 42 & - \\
\hline $1,0 v$ & $72 \mathrm{~h}$ & $1 \mathrm{C}(7), 1 \mathrm{~T}(2), 2 \mathrm{D}$ & $4 \mathrm{D}$ & $4 \mathrm{D}$ & $4 \mathrm{D}$ & $1 \mathrm{C}, 1 \mathrm{~T}, 14 \mathrm{D}$ & זוט, & (1) & ט, & 144,0 & $c<, 00$ & $2<, 00$ & 46 & \\
\hline & $96 \mathrm{~h}$ & 1B,1T(2), 2D & $4 \mathrm{D}$ & $4 \mathrm{D}$ & $4 \mathrm{D}$ & 1B, 1T, 14D & & & & & & & & \\
\hline & $24 \mathrm{~h}$ & $3 \mathrm{~T}(1), 1 \mathrm{D}$ & $2 \mathrm{C}(6), 2 \mathrm{D}$ & $2 \mathrm{C}(6), 2 \mathrm{D}$ & $1 \mathrm{C}(6), 3 \mathrm{D}$ & $5 \mathrm{C}, 3 \mathrm{~T}, 8 \mathrm{D}$ & & & & & & & & \\
\hline 150 & $48 \mathrm{~h}$ & 4D & $4 \mathrm{D}$ & 4D & $4 \mathrm{D}$ & $16 \mathrm{D}$ & 737 & 801 & 1346 & 1450 & 20 & 234 & 40 & - \\
\hline , & $72 \mathrm{~h}$ & $4 \mathrm{D}$ & $4 \mathrm{D}$ & $4 \mathrm{D}$ & $4 \mathrm{D}$ & $16 \mathrm{D}$ & ו וס, & o, & 104,0 & 140,0 & $2<, 00$ & $<0,40$ & 40 & \\
\hline & $96 \mathrm{~h}$ & $4 \mathrm{D}$ & $4 \mathrm{D}$ & $4 \mathrm{D}$ & $4 \mathrm{D}$ & $16 \mathrm{D}$ & & & & & & & & \\
\hline
\end{tabular}


Tabela 33. Modificações morfológicas em Hydra viridissima exposta a diferentes concentrações de propranolol (mg $\mathrm{L}^{-1}$ ), em teste definitivo de toxicidade aguda (teste $5, \mathrm{n}=10$ ), com leituras a cada 24 horas, e valores de $\mathrm{pH}$, condutividade, temperatura e dureza monitorados mo início e final dos teste. $\mathrm{N}=$ hidra normal; $\mathrm{B}=$ hidra com bulbos nos tentáculos; $\mathrm{C}=$ hidra com tentáculos encurtados; $\mathrm{T}=$ hidra em estado de tulipa; $\mathrm{D}=$ hidra desintegrada, sendo que os números dentro dos *() referem-se aos scores aplicados.

\begin{tabular}{|c|c|c|c|c|c|c|c|c|c|c|c|c|c|c|}
\hline \multirow{2}{*}{$\begin{array}{l}\text { Concentração } \\
\qquad\left(\mathrm{mg} \mathrm{L}^{-1}\right)\end{array}$} & \multirow{2}{*}{ Leitura } & \multicolumn{4}{|c|}{ Réplicas } & \multirow{2}{*}{ Total } & \multicolumn{2}{|c|}{ pH } & \multicolumn{2}{|c|}{ cond. } & \multicolumn{2}{|c|}{ Temp. } & \multicolumn{2}{|c|}{ Dureza } \\
\hline & & 1 & 2 & 3 & 4 & & $\mathrm{Oh}$ & $96 \mathrm{~h}$ & $\mathrm{Oh}$ & $96 \mathrm{~h}$ & $\mathrm{Oh}$ & $96 \mathrm{~h}$ & $\mathrm{Oh}$ & $96 h^{*}$ \\
\hline \multirow{4}{*}{ Controle } & $24 \mathrm{~h}$ & $4 \mathrm{~N}$ & $4 \mathrm{~N}$ & $4 \mathrm{~N}$ & $4 \mathrm{~N}$ & $16 \mathrm{~N}$ & \multirow{4}{*}{7,48} & \multirow{4}{*}{7,98} & \multirow{4}{*}{135,3} & \multirow{4}{*}{141,6} & \multirow{4}{*}{23,70} & \multirow{4}{*}{24,30} & \multirow{4}{*}{40} & \multirow{4}{*}{ - } \\
\hline & $48 \mathrm{~h}$ & $4 \mathrm{~N}$ & $4 \mathrm{~N}$ & $4 \mathrm{~N}$ & $4 \mathrm{~N}$ & $16 \mathrm{~N}$ & & & & & & & & \\
\hline & $72 \mathrm{~h}$ & $4 \mathrm{~N}$ & $4 \mathrm{~N}$ & $4 \mathrm{~N}$ & $4 \mathrm{~N}$ & $16 \mathrm{~N}$ & & & & & & & & \\
\hline & $96 \mathrm{~h}$ & $4 \mathrm{~N}$ & $4 \mathrm{~N}$ & $4 \mathrm{~N}$ & $4 \mathrm{~N}$ & $16 \mathrm{~N}$ & & & & & & & & \\
\hline \multirow{4}{*}{0,50} & $24 \mathrm{~h}$ & $3 \mathrm{~N}, 1 \mathrm{~B}$ & $3 \mathrm{~N}, 1 \mathrm{~B}$ & $2 \mathrm{~N}, 2 \mathrm{~B}$ & $1 \mathrm{~N}, 3 \mathrm{~B}$ & $8 \mathrm{~N}, 7 \mathrm{~B}$ & \multirow{4}{*}{7,45} & \multirow{4}{*}{8,01} & \multirow{4}{*}{136,1} & \multirow{4}{*}{140,5} & \multirow{4}{*}{23,70} & \multirow{4}{*}{24,20} & \multirow{4}{*}{42} & \multirow{4}{*}{-} \\
\hline & $48 \mathrm{~h}$ & $2 \mathrm{~N}, 2 \mathrm{~B}$ & $2 \mathrm{~N}, 2 \mathrm{~B}$ & $1 \mathrm{~N}, 3 \mathrm{~B}$ & $1 \mathrm{~N}, 2 \mathrm{~B}, 1 \mathrm{C}(7)$ & $6 \mathrm{~N}, 9 \mathrm{~B}, 1 \mathrm{C}$ & & & & & & & & \\
\hline & $72 \mathrm{~h}$ & $1 \mathrm{~N}, 3 \mathrm{~B}$ & $3 \mathrm{~N}, 1 \mathrm{~B}$ & $2 \mathrm{~N}, 2 \mathrm{~B}$ & $2 \mathrm{~N}, 2 \mathrm{~B}$ & $8 \mathrm{~N}, 8 \mathrm{~B}$ & & & & & & & & \\
\hline & $96 \mathrm{~h}$ & $3 \mathrm{~N}, 1 \mathrm{C}(7)$ & $2 \mathrm{~N}, 2 \mathrm{~B}$ & $1 \mathrm{~N}, 2 \mathrm{~B}, 1 \mathrm{C}(7)$ & $3 \mathrm{~B}, 1 \mathrm{D}$ & $6 \mathrm{~N}, 7 \mathrm{~B}, 2 \mathrm{C}, 1 \mathrm{D}$ & & & & & & & & \\
\hline \multirow{4}{*}{0,75} & $24 \mathrm{~h}$ & $1 \mathrm{~N}, 3 \mathrm{~B}$ & $2 \mathrm{~N}, 2 \mathrm{~B}$ & $2 \mathrm{~N}, 1 \mathrm{~B}, 1 \mathrm{C}(7)$ & $2 \mathrm{~N}, 2 \mathrm{~B}$ & $7 \mathrm{~N}, 8 \mathrm{~B}, 1 \mathrm{C}$ & \multirow{4}{*}{7,45} & \multirow{4}{*}{8,02} & & & & & & \\
\hline & $48 \mathrm{~h}$ & $1 \mathrm{~B}, 3 \mathrm{C}(7)$ & $1 \mathrm{~N}, 3 \mathrm{~B}$ & $1 \mathrm{~N}, 2 \mathrm{~B}, 1 \mathrm{C}(6)$ & $2 \mathrm{~B}, 1 \mathrm{C}(6), 1 \mathrm{D}$ & $2 \mathrm{~N}, 8 \mathrm{~B}, 5 \mathrm{C}, 1 \mathrm{D}$ & & & 1384 & 1440 & 2370 & 2410 & 46 & - \\
\hline & $72 \mathrm{~h}$ & $3 \mathrm{C}(6), 1 \mathrm{~T}(1)$ & $1 \mathrm{~B}, 3 \mathrm{C}(7)$ & $1 \mathrm{~B}, 1 \mathrm{C}(6), 1 \mathrm{~T}(3), 1 \mathrm{D}$ & $2 \mathrm{~B}, 1 \mathrm{C}(6), 1 \mathrm{D}$ & $4 \mathrm{~B}, 8 \mathrm{C}, 2 \mathrm{~T}, 2 \mathrm{D}$ & & & 150,4 & 144,0 & $\angle 3,10$ & 24,10 & 40 & - \\
\hline & $96 \mathrm{~h}$ & $2 \mathrm{C}(7), 1 \mathrm{~T}(1), 1 \mathrm{D}$ & $1 \mathrm{~B}, 2 \mathrm{C}(7), 1 \mathrm{~T}(3)$ & 1B,1T(1), 2D & $1 \mathrm{~B}, 2 \mathrm{C}(1(7), 1(6)), 1 \mathrm{D}$ & 3B, 6C, 3T, 4D & & & & & & & & \\
\hline & $24 \mathrm{~h}$ & $1 \mathrm{~N}, 2 \mathrm{~B}, 1 \mathrm{C}(6)$ & $1 \mathrm{~B}, 3 \mathrm{C}(7)$ & $1 \mathrm{~N}, 2 \mathrm{C}(6), 1 \mathrm{~T}(2)$ & $3 \mathrm{~B}, 1 \mathrm{C}(7)$ & $2 \mathrm{~N}, 6 \mathrm{~B}, 7 \mathrm{C}, 1 \mathrm{~T}$ & & & & & & & & \\
\hline 100 & $48 \mathrm{~h}$ & $3 \mathrm{C}(6), 1 \mathrm{D}(1)$ & $3 \mathrm{C}(6), 1 \mathrm{~T}(2)$ & $2 \mathrm{C}(6), 1 \mathrm{~T}(1), 1 \mathrm{D}$ & $3 \mathrm{C}(6), 1 \mathrm{D}$ & $11 \mathrm{C}, 2 \mathrm{~T}, 3 \mathrm{D}$ & 746 & 805 & 1389 & 1440 & 2380 & 24.20 & 44 & - \\
\hline 1,00 & $72 \mathrm{~h}$ & $1 \mathrm{~B}, 1 \mathrm{C}(6), 1 \mathrm{~T}(1), 1 \mathrm{D}$ & $2 \mathrm{~T}(1), 2 \mathrm{D}$ & $1 \mathrm{~T}(5), 3 \mathrm{D}$ & $1 \mathrm{C}(6), 2 \mathrm{~T}(1), 1 \mathrm{D}$ & $1 \mathrm{~B}, 2 \mathrm{C}, 6 \mathrm{~T}, 7 \mathrm{D}$ & 佂 & 0,00 & 然, & 年, & 0,00 & 2,20 & . & \\
\hline & $96 \mathrm{~h}$ & 1B, 2C(1(6), 1(7)),1D & $2 \mathrm{~T}(1(1), 1(4)), 2 \mathrm{D}$ & $1 \mathrm{~T}(4), 3 \mathrm{D}$ & $2 \mathrm{C}(7), 2 \mathrm{D}$ & 1B, 4C, 3T, 8D & & & & & & & & \\
\hline & $24 \mathrm{~h}$ & $3 \mathrm{C}(7), 1 \mathrm{~T}(1)$ & $4 \mathrm{C}(2(6), 2(7))$ & $1 \mathrm{~B}, 2 \mathrm{C}(7), 1 \mathrm{D}$ & $2 \mathrm{C}(6), 1 \mathrm{~T}(1), 1 \mathrm{D}$ & $1 \mathrm{~B}, 11 \mathrm{C}, 2 \mathrm{~T}, 2 \mathrm{D}$ & & & & & & & & \\
\hline 125 & $48 \mathrm{~h}$ & $4 \mathrm{D}$ & $4 \mathrm{D}$ & $1 \mathrm{C}(7), 3 \mathrm{D}$ & $4 \mathrm{D}$ & $1 \mathrm{C}, 15 \mathrm{D}$ & 752 & 8.06 & 1397 & 1459 & 2380 & 2420 & 40 & - \\
\hline $1,<v$ & $72 \mathrm{~h}$ & $4 \mathrm{D}$ & $4 \mathrm{D}$ & $1 \mathrm{C}(7), 3 \mathrm{D}$ & $4 \mathrm{D}$ & $1 \mathrm{C}, 15 \mathrm{D}$ & 促, & 0,00 & IVs, & of & $<, 00$ & $<4,<v$ & 40 & \\
\hline & $96 \mathrm{~h}$ & 4D & 4D & $4 \mathrm{D}$ & $4 \mathrm{D}$ & $16 \mathrm{D}$ & & & & & & & & \\
\hline & $24 \mathrm{~h}$ & $2 \mathrm{C}(7), 2 \mathrm{~T}(1)$ & $1 \mathrm{C}(7), 1 \mathrm{~T}(2), 2 \mathrm{D}$ & $2 \mathrm{C}(7), 1 \mathrm{~T}(2), 1 \mathrm{D}$ & $1 T(1), 3 D$ & $5 \mathrm{C}, 5 \mathrm{~T}, 6 \mathrm{D}$ & & & & & & & & \\
\hline 150 & $48 \mathrm{~h}$ & $4 \mathrm{D}$ & $4 \mathrm{D}$ & $1 \mathrm{~T}(1), 3 \mathrm{D}$ & $4 \mathrm{D}$ & $1 \mathrm{~T}, 15 \mathrm{D}$ & 752 & 806 & 1380 & 1452 & 2390 & 24.40 & 40 & - \\
\hline , & $72 \mathrm{~h}$ & $4 \mathrm{D}$ & $4 \mathrm{D}$ & $4 \mathrm{D}$ & $4 \mathrm{D}$ & $16 \mathrm{D}$ & (O) & $0, \infty$ & 0 & 10, & 0,00 & 2,10 & 然 & \\
\hline & $96 h$ & $4 \mathrm{D}$ & $4 \mathrm{D}$ & $4 \mathrm{D}$ & 4D & $14 \mathrm{D}$ & & & & & & & & \\
\hline
\end{tabular}


Tabela 34. Modificações morfológicas em Hydra viridissima exposta a diferentes concentrações de propranolol (mg $\mathrm{L}^{-1}$ ), em teste definitivo de toxicidade aguda (teste $6, \mathrm{n}=10$ ), com leituras a cada 24 horas, e valores de $\mathrm{pH}$, condutividade, temperatura e dureza monitorados mo início e final dos teste. $\mathrm{N}=$ hidra normal; $\mathrm{B}=$ hidra com bulbos nos tentáculos; $\mathrm{C}=$ hidra com tentáculos encurtados; $\mathrm{T}=$ hidra em estado de tulipa; $\mathrm{D}=$ hidra desintegrada, sendo que os números dentro dos *() referem-se aos scores aplicados.

\begin{tabular}{|c|c|c|c|c|c|c|c|c|c|c|c|c|c|c|}
\hline \multirow{2}{*}{$\begin{array}{l}\text { Concentração } \\
\qquad\left(\mathrm{mg} \mathrm{L}^{-1}\right)\end{array}$} & \multirow{2}{*}{ Leitura } & \multicolumn{4}{|c|}{ Réplicas } & \multirow{2}{*}{ Total } & \multicolumn{2}{|c|}{ pH } & \multicolumn{2}{|c|}{ cond. } & \multicolumn{2}{|c|}{ Temp. } & \multicolumn{2}{|c|}{ Dureza } \\
\hline & & 1 & 2 & 3 & 4 & & Oh & $96 \mathrm{~h}$ & $\mathrm{Oh}$ & $96 \mathrm{~h}$ & $\mathrm{Oh}$ & $96 \mathrm{~h}$ & $\mathrm{Oh}$ & $96 h^{*}$ \\
\hline \multirow{4}{*}{ Controle } & $24 \mathrm{~h}$ & $4 \mathrm{~N}$ & $4 \mathrm{~N}$ & $4 \mathrm{~N}$ & $4 \mathrm{~N}$ & $16 \mathrm{~N}$ & \multirow{4}{*}{7,25} & \multirow{4}{*}{8,20} & \multirow{4}{*}{155,9} & \multirow{4}{*}{145,5} & \multirow{4}{*}{24,90} & \multirow{4}{*}{23,30} & \multirow{4}{*}{40} & \multirow{4}{*}{ - } \\
\hline & $48 \mathrm{~h}$ & $4 \mathrm{~N}$ & $4 \mathrm{~N}$ & $4 \mathrm{~N}$ & $4 \mathrm{~N}$ & $16 \mathrm{~N}$ & & & & & & & & \\
\hline & $72 \mathrm{~h}$ & $4 \mathrm{~N}$ & $4 \mathrm{~N}$ & $4 \mathrm{~N}$ & $4 \mathrm{~N}$ & $16 \mathrm{~N}$ & & & & & & & & \\
\hline & $96 \mathrm{~h}$ & $4 \mathrm{~N}$ & $4 \mathrm{~N}$ & $4 \mathrm{~N}$ & $4 \mathrm{~N}$ & $16 \mathrm{~N}$ & & & & & & & & \\
\hline \multirow{4}{*}{0,50} & $24 \mathrm{~h}$ & $4 \mathrm{~N}$ & $4 \mathrm{~N}$ & $4 \mathrm{~N}$ & $4 \mathrm{~N}$ & $16 \mathrm{~N}$ & \multirow{4}{*}{7,28} & \multirow{4}{*}{8,15} & \multirow{4}{*}{143,8} & \multirow{4}{*}{139,0} & \multirow{4}{*}{24,70} & \multirow{4}{*}{23,30} & \multirow{4}{*}{40} & \multirow{4}{*}{-} \\
\hline & $48 \mathrm{~h}$ & $2 \mathrm{~N}, 2 \mathrm{~B}$ & $4 \mathrm{~N}$ & $4 \mathrm{~N}$ & $3 \mathrm{~N}, 1 \mathrm{~B}$ & $13 \mathrm{~N}, 3 \mathrm{~B}$ & & & & & & & & \\
\hline & $72 \mathrm{~h}$ & $4 \mathrm{~N}$ & $4 \mathrm{~N}$ & $4 \mathrm{~N}$ & $3 \mathrm{~N}, 1 \mathrm{~B}$ & $15 \mathrm{~N}, 1 \mathrm{~B}$ & & & & & & & & \\
\hline & $96 \mathrm{~h}$ & $3 \mathrm{~N}, 1 \mathrm{~B}$ & $4 \mathrm{~N}$ & $4 \mathrm{~N}$ & $3 \mathrm{~N}, 1 \mathrm{C}(7)$ & $14 \mathrm{~N}, 1 \mathrm{~B}, 1 \mathrm{C}$ & & & & & & & & \\
\hline \multirow{4}{*}{0,75} & $24 \mathrm{~h}$ & $4 \mathrm{~N}$ & $2 \mathrm{~N}, 2 \mathrm{~B}$ & $4 \mathrm{~N}$ & $4 \mathrm{~N}$ & $14 \mathrm{~N}, 2 \mathrm{~B}$ & \multirow{4}{*}{7,33} & \multirow{4}{*}{8,05} & & & & & & \\
\hline & $48 \mathrm{~h}$ & $2 \mathrm{~N}, 2 \mathrm{~B}$ & $4 \mathrm{~N}$ & $3 \mathrm{~N}, 1 \mathrm{~B}$ & $2 \mathrm{~N}, 2 \mathrm{~B}$ & $11 \mathrm{~N}, 5 \mathrm{~B}$ & & & 1409 & 1426 & 2470 & 2340 & 40 & - \\
\hline & $72 \mathrm{~h}$ & $2 \mathrm{~N}, 2 \mathrm{~B}$ & $2 \mathrm{~N}, 2 \mathrm{~B}$ & $3 \mathrm{~B}, 1 \mathrm{C}(6)$ & $3 \mathrm{~B}, 1 \mathrm{C}(7)$ & $4 \mathrm{~N}, 10 \mathrm{~B}, 2 \mathrm{C}$ & & & 0 & 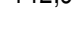 & $2,1,0$ & , 10 & 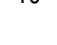 & \\
\hline & $96 \mathrm{~h}$ & $3 \mathrm{~N}, 1 \mathrm{~B}$ & $2 \mathrm{~N}, 2 \mathrm{~B}$ & $1 \mathrm{~N}, 3 \mathrm{~B}$ & 2B, 2C(7) & $6 \mathrm{~N}, 8 \mathrm{~B}, 2 \mathrm{C}$ & & & & & & & & \\
\hline & $24 \mathrm{~h}$ & $1 \mathrm{~N}, 3 \mathrm{~B}$ & $2 \mathrm{~N}, 2 \mathrm{~B}$ & $3 \mathrm{~N}, 1 \mathrm{~B}$ & $1 \mathrm{~N}, 3 \mathrm{~B}$ & $7 \mathrm{~N}, 9 \mathrm{~B}$ & & & & & & & & \\
\hline 1.00 & $48 \mathrm{~h}$ & $2 \mathrm{~N}, 1 \mathrm{~B}, 1 \mathrm{C}(7)$ & $4 \mathrm{~B}$ & $3 \mathrm{~B}, 1 \mathrm{C}(7)$ & $1 \mathrm{~B}, 3 \mathrm{C}(7)$ & $2 \mathrm{~N}, 9 \mathrm{~B}, 5 \mathrm{C}$ & 7.37 & 8.02 & 139.4 & 1449 & 2480 & 23.40 & 42 & - \\
\hline , & $72 \mathrm{~h}$ & $2 \mathrm{~B}, 2 \mathrm{C}(6)$ & $2 \mathrm{~B}, 2 \mathrm{C}(7)$ & $2 \mathrm{C}(7), 1 \mathrm{~T}(2), 1 \mathrm{D}$ & $1 \mathrm{~B}, 3 \mathrm{C}(1(6), 2(7))$ & $5 \mathrm{~B}, 9 \mathrm{C}, 1 \mathrm{~T}, 1 \mathrm{D}$ & t & $0,0 L$ & 100,7 & ט, דרדו & $-7,00$ & $2 v, 70$ & $T L$ & \\
\hline & $96 \mathrm{~h}$ & $4 \mathrm{C}(1(6), 3(7))$ & $2 \mathrm{~B}, 2 \mathrm{C}(7)$ & $2 \mathrm{C}(7), 1 \mathrm{~T}(2), 1 \mathrm{D}$ & $4 \mathrm{C}(2(7), 2(6))$ & 2B, 12C, 1T,1D & & & & & & & & \\
\hline & $24 \mathrm{~h}$ & $1 \mathrm{~N}, 3 \mathrm{~B}$ & $1 \mathrm{~N}, 3 \mathrm{~B}$ & $1 \mathrm{~N}, 3 \mathrm{~B}$ & $2 \mathrm{~B}, 2 \mathrm{C}(7)$ & $3 \mathrm{~N}, 11 \mathrm{~B}, 2 \mathrm{C}$ & & & & & & & & \\
\hline 1.25 & $48 \mathrm{~h}$ & $1 \mathrm{~B}, 3 \mathrm{C}(7)$ & $4 \mathrm{C}(1(6), 3(7))$ & $4 \mathrm{C}(7)$ & $1 \mathrm{C}(7), 2 \mathrm{~T}(2), 1 \mathrm{D}$ & $1 \mathrm{~B}, 12 \mathrm{C}, 2 \mathrm{~T}, 1 \mathrm{D}$ & 7.44 & 8.09 & 138.9 & 1492 & 2470 & 23.30 & 42 & - \\
\hline & $72 h$ & $4 \mathrm{C}(7)$ & $2 \mathrm{C}(7), 1 \mathrm{~T}(2), 1 \mathrm{D}$ & $4 \mathrm{~T}(2)$ & $1 \mathrm{~T}(4), 3 \mathrm{D}$ & $6 \mathrm{C}, 6 \mathrm{~T}, 4 \mathrm{D}$ & T, & & & & & & & \\
\hline & $96 \mathrm{~h}$ & $4 C(7)$ & $3 \mathrm{~T}(2), 1 \mathrm{D}$ & 1T(4), 3D & $1 \mathrm{~T}(2), 3 \mathrm{D}$ & 4C, 5T, 7D & & & & & & & & \\
\hline & $24 \mathrm{~h}$ & $4 \mathrm{~B}$ & $3 \mathrm{~B}, 1 \mathrm{C}(7)$ & 4B & 2B, 2C(7) & 13B, 3C & & & & & & & & \\
\hline 150 & $48 \mathrm{~h}$ & $2 \mathrm{C}(7), 2 \mathrm{~T}(2)$ & $2 \mathrm{C}(7), 1 \mathrm{~T}(2), 1 \mathrm{D}$ & $3 \mathrm{C}(7), 1 \mathrm{D}$ & $1 \mathrm{C}(7), 2 \mathrm{~T}(2), 1 \mathrm{D}$ & $8 \mathrm{C}, 5 \mathrm{~T}, 3 \mathrm{D}$ & 745 & 810 & 1417 & 1451 & 2160 & 2332 & 12 & \\
\hline 促 & $72 \mathrm{~h}$ & 1T(5), 3D & $1 \mathrm{C}(7), 1 \mathrm{~T}(5), 2 \mathrm{D}$ & $2 \mathrm{~T}(1), 2 \mathrm{D}$ & $3 \mathrm{~T}(1), 1 \mathrm{D}$ & $1 \mathrm{C}, 7 \mathrm{~T}, 8 \mathrm{D}$ & $7,4 \mathrm{~J}$ & 0,10 & $141, r$ & 140,1 & 24,00 & 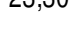 & $4 c$ & \\
\hline & $96 \mathrm{~h}$ & $1 \mathrm{~T}(3), 3 \mathrm{D}$ & $1 \mathrm{C}(7), 1 \mathrm{~T}(3), 2 \mathrm{D}$ & 4D & $2 \mathrm{~T}(1(2), 1(3)), 2 \mathrm{D}$ & $1 \mathrm{C}, 4 \mathrm{~T}, 11 \mathrm{D}$ & & & & & & & & \\
\hline
\end{tabular}


Tabela 35. Modificações morfológicas em Hydra viridissima exposta a diferentes concentrações de propranolol (mg $\mathrm{L}^{-1}$ ), em teste definitivo de toxicidade aguda (teste $7, \mathrm{n}=10$ ), com leituras a cada 24 horas, e valores de $\mathrm{pH}$, condutividade, temperatura e dureza monitorados mo início e final dos teste. $\mathrm{N}=$ hidra normal; $\mathrm{B}=$ hidra com bulbos nos tentáculos; $\mathrm{C}=$ hidra com tentáculos encurtados; $\mathrm{T}=$ hidra em estado de tulipa; $\mathrm{D}=$ hidra desintegrada, sendo que os números dentro dos *() referem-se aos scores aplicados.

\begin{tabular}{|c|c|c|c|c|c|c|c|c|c|c|c|c|c|c|}
\hline \multirow{2}{*}{$\begin{array}{l}\text { Concentração } \\
\qquad\left(\mathrm{mg} \mathrm{L}^{-1}\right)\end{array}$} & \multirow{2}{*}{ Leitura } & \multicolumn{4}{|c|}{ Réplicas } & \multirow{2}{*}{ Total } & \multicolumn{2}{|c|}{$\mathrm{pH}$} & \multicolumn{2}{|c|}{ cond. } & \multicolumn{2}{|c|}{ Temp. } & \multicolumn{2}{|c|}{ Dureza } \\
\hline & & 1 & 2 & 3 & 4 & & $\mathrm{Oh}$ & $96 \mathrm{~h}$ & $\mathrm{Oh}$ & $96 \mathrm{~h}$ & $\mathrm{Oh}$ & $96 \mathrm{~h}$ & $\mathrm{Oh}$ & $96 h^{*}$ \\
\hline \multirow{4}{*}{ Controle } & $24 \mathrm{~h}$ & $4 \mathrm{~N}$ & $4 \mathrm{~N}$ & $4 \mathrm{~N}$ & $4 \mathrm{~N}$ & $20 \mathrm{~N}$ & \multirow{4}{*}{7,38} & \multirow{4}{*}{8,03} & \multirow{4}{*}{136,3} & \multirow{4}{*}{143,6} & \multirow{4}{*}{22,00} & \multirow{4}{*}{24,2} & \multirow{4}{*}{40} & \multirow{4}{*}{-} \\
\hline & $48 \mathrm{~h}$ & $4 \mathrm{~N}$ & $4 \mathrm{~N}$ & $4 \mathrm{~N}$ & $4 \mathrm{~N}$ & $20 \mathrm{~N}$ & & & & & & & & \\
\hline & $72 \mathrm{~h}$ & $4 \mathrm{~N}$ & $4 \mathrm{~N}$ & $4 \mathrm{~N}$ & $4 \mathrm{~N}$ & $20 \mathrm{~N}$ & & & & & & & & \\
\hline & $96 \mathrm{~h}$ & $4 \mathrm{~N}$ & $4 \mathrm{~N}$ & $4 \mathrm{~N}$ & $4 \mathrm{~N}$ & $20 \mathrm{~N}$ & & & & & & & & \\
\hline \multirow{4}{*}{0,50} & $24 \mathrm{~h}$ & $3 \mathrm{~N}, 1 \mathrm{~B}$ & $3 \mathrm{~N}, 1 \mathrm{~B}$ & $1 \mathrm{~N}, 3 \mathrm{~B}$ & $3 \mathrm{~N}, 1 \mathrm{~B}$ & $20 \mathrm{~N}$ & \multirow{4}{*}{7,38} & \multirow{4}{*}{8,04} & \multirow{4}{*}{137,2} & \multirow{4}{*}{146,4} & \multirow{4}{*}{22,00} & \multirow{4}{*}{24} & \multirow{4}{*}{40} & \multirow{4}{*}{ - } \\
\hline & $48 \mathrm{~h}$ & $1 \mathrm{~N}, 3 \mathrm{~B}$ & $3 \mathrm{~B}, 1 \mathrm{C}(6)$ & $1 \mathrm{~N}, 3 \mathrm{~B}$ & $2 \mathrm{~N}, 2 \mathrm{~B}$ & $20 \mathrm{~N}$ & & & & & & & & \\
\hline & $72 \mathrm{~h}$ & $4 \mathrm{~B}$ & $3 \mathrm{~B}, 1 \mathrm{D}$ & $1 \mathrm{~N}, 3 \mathrm{~B}$ & $2 \mathrm{~N}, 1 \mathrm{~B}, 1 \mathrm{C}(6)$ & $20 \mathrm{~N}$ & & & & & & & & \\
\hline & $96 \mathrm{~h}$ & $2 \mathrm{~B}, 2 \mathrm{C}(7)$ & $1 \mathrm{~B}, 2 \mathrm{C}(7), 1 \mathrm{D}$ & $2 \mathrm{~N}, 2 \mathrm{~B}$ & $2 \mathrm{~N}, 1 \mathrm{~B}, 1 \mathrm{C}(6)$ & $20 \mathrm{~N}$ & & & & & & & & \\
\hline \multirow{4}{*}{0,75} & $24 \mathrm{~h}$ & $1 \mathrm{~N}, 2 \mathrm{~B}, 1 \mathrm{C}(7)$ & $2 \mathrm{~B}, 2 \mathrm{C}(6)$ & $3 \mathrm{~B}, 1 \mathrm{C}(7)$ & $3 \mathrm{~B}, 1 \mathrm{C}(7)$ & $20 \mathrm{~N}$ & \multirow{4}{*}{7,39} & \multirow{4}{*}{8,08} & & & & & & \\
\hline & $48 \mathrm{~h}$ & $4 C(6)$ & $3 \mathrm{C}(7), 1 \mathrm{D}$ & $1 \mathrm{~B}, 2 \mathrm{C}(6), 1 \mathrm{~T}(2)$ & $3 \mathrm{~B}, 1 \mathrm{~T}(2)$ & $20 \mathrm{~N}$ & & & 1346 & 1499 & 22,00 & 24.1 & 40 & - \\
\hline & $72 \mathrm{~h}$ & $4 \mathrm{C}(3(6), 1(7))$ & $1 \mathrm{~B}, 1 \mathrm{C}(7), 2 \mathrm{D}$ & $3 \mathrm{C}(7), 1 \mathrm{D}$ & $1 \mathrm{~B}, 3 \mathrm{C}(6)$ & $20 \mathrm{~N}$ & & & 104,0 & 145,5 & $<<, 00$ & 24,1 & 40 & 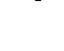 \\
\hline & $96 \mathrm{~h}$ & $4 \mathrm{C}(6)$ & $1 \mathrm{~B}, 1 \mathrm{C}(7), 2 \mathrm{D}$ & $1 \mathrm{C}(7), 2 \mathrm{~T}(3), 1 \mathrm{D}$ & $1 \mathrm{~B}, 3 \mathrm{C}(6)$ & $20 \mathrm{~N}$ & & & & & & & & \\
\hline & $24 \mathrm{~h}$ & $4 \mathrm{C}(3(6), 1(7))$ & $1 \mathrm{~B}, 3 \mathrm{C}(6)$ & $3 \mathrm{~B}, 1 \mathrm{C}(7)$ & $2 \mathrm{~B}, 2 \mathrm{C}(6)$ & $19 \mathrm{~N}, 1 \mathrm{~B}$ & & & & & & & & \\
\hline 1.00 & $48 \mathrm{~h}$ & 1T(2), 3D & $2 \mathrm{C}(1(6), 1(7), 2 \mathrm{D}$ & $1 C(6), 3 D$ & $3 \mathrm{~T}(2(2), 1(5)), 1 \mathrm{D}$ & $20 \mathrm{~N}$ & 7.42 & 8.11 & 134.4 & 144,3 & 21.90 & 24.1 & 44 & - \\
\hline & $72 \mathrm{~h}$ & $1 C(7), 3 D$ & $2 \mathrm{~T}(2), 2 \mathrm{D}$ & $1 C(6), 3 D$ & $3 \mathrm{~T}(2(2), 1(5)), 1 \mathrm{D}$ & $20 \mathrm{~N}$ & & & & & & & & \\
\hline & $96 \mathrm{~h}$ & $1 \mathrm{C}(7), 3 \mathrm{D}$ & $2 \mathrm{~T}(2), 2 \mathrm{D}$ & $1 \mathrm{~T}(1), 3 \mathrm{D}$ & $3 \mathrm{~T}(1(2), 1(3) 1(5)), 1 \mathrm{D}$ & $20 \mathrm{~N}$ & & & & & & & & \\
\hline & $24 \mathrm{~h}$ & $1 \mathrm{C}(7), 3 \mathrm{D}$ & $2 \mathrm{C}(6), 2 \mathrm{D}$ & $1 \mathrm{~T}(5), 3 \mathrm{D}$ & $2 \mathrm{C}(6), 2 \mathrm{D}$ & $10 \mathrm{~N}, 3 \mathrm{~B}, 7 \mathrm{C}$ & & & & & & & & \\
\hline 1.25 & $48 \mathrm{~h}$ & $1 T(1), 3 \mathrm{D}$ & $1 C(6), 3 D$ & $4 \mathrm{D}$ & $4 \mathrm{D}$ & $6 \mathrm{~N}, 8 \mathrm{~B}, 6 \mathrm{C}$ & 7.41 & 8.1 & 137.9 & 144.9 & 22,00 & 24.2 & 44 & - \\
\hline 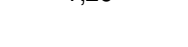 & $72 \mathrm{~h}$ & $4 \mathrm{D}$ & $1 \mathrm{~T}(1), 3 \mathrm{D}$ & $4 \mathrm{D}$ & $4 \mathrm{D}$ & $6 \mathrm{~N}, 7 \mathrm{~B}, 7 \mathrm{C}$ & I & $0, i$ & ט, & 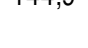 & 2,00 & {$[T, L$} & TT & \\
\hline & $96 \mathrm{~h}$ & $4 \mathrm{D}$ & 1T(1), 3D & $4 \mathrm{D}$ & $4 \mathrm{D}$ & $4 \mathrm{~N}, 8 \mathrm{~B}, 7 \mathrm{C}$ & & & & & & & & \\
\hline & $24 \mathrm{~h}$ & $3 \mathrm{C}(6), 1 \mathrm{D}$ & $4 \mathrm{D}$ & $2 \mathrm{~T}(2), 2 \mathrm{D}$ & $1 C(6), 3 D$ & $9 \mathrm{C}, 1 \mathrm{~T}, 10 \mathrm{D}$ & & & & & & & & \\
\hline 1.50 & $48 \mathrm{~h}$ & $1 \mathrm{~T}(4), 3 \mathrm{D}$ & $4 \mathrm{D}$ & $4 \mathrm{D}$ & $4 \mathrm{D}$ & $8 \mathrm{C}, 12 \mathrm{D}$ & 7.40 & 81 & 1387 & 1383 & 22,00 & 24.3 & 42 & - \\
\hline 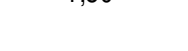 & $72 \mathrm{~h}$ & $1 \mathrm{~T}(1), 3 \mathrm{D}$ & $4 \mathrm{D}$ & $4 \mathrm{D}$ & $4 \mathrm{D}$ & $6 \mathrm{C}, 2 \mathrm{~T}, 12 \mathrm{D}$ & , & 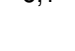 & & & 2,00 & 2,0 & . & \\
\hline & $96 \mathrm{~h}$ & $1 \mathrm{~T}(1), 3 \mathrm{D}$ & $4 \mathrm{D}$ & 4D & $4 \mathrm{D}$ & 4C, 3T, 12D & & & & & & & & \\
\hline
\end{tabular}


Tabela 36. Modificações morfológicas em Hydra viridissima exposta a diferentes concentrações de propranolol (mg $\mathrm{L}^{-1}$ ), em teste definitivo de toxicidade aguda (teste $8, \mathrm{n}=10$ ), com leituras a cada 24 horas, e valores de $\mathrm{pH}$, condutividade, temperatura e dureza monitorados mo início e final dos teste. $\mathrm{N}=$ hidra normal; $\mathrm{B}=$ hidra com bulbos nos tentáculos; $\mathrm{C}=$ hidra com tentáculos encurtados; $\mathrm{T}=$ hidra em estado de tulipa; $\mathrm{D}=$ hidra desintegrada, sendo que os números dentro dos *() referem-se aos scores aplicados.

\begin{tabular}{|c|c|c|c|c|c|c|c|c|c|c|c|c|c|c|}
\hline \multirow{2}{*}{$\begin{array}{c}\text { Concentração } \\
\left(\mathrm{mg} \mathrm{L}^{-1}\right)\end{array}$} & \multirow{2}{*}{ Leitura } & \multicolumn{4}{|c|}{ Réplicas } & \multirow{2}{*}{ Total } & \multicolumn{2}{|c|}{$\mathrm{pH}$} & \multicolumn{2}{|c|}{ cond. } & \multicolumn{2}{|c|}{ Temp. } & \multicolumn{2}{|c|}{ Dureza } \\
\hline & & 1 & 2 & 3 & 4 & & $\mathrm{Oh}$ & $96 \mathrm{~h}$ & $\mathrm{Oh}$ & $96 \mathrm{~h}$ & $\mathrm{Oh}$ & $96 \mathrm{~h}$ & $\mathrm{Oh}$ & $96 h^{*}$ \\
\hline \multirow{4}{*}{ Controle } & $24 \mathrm{~h}$ & $4 \mathrm{~N}$ & $4 \mathrm{~N}$ & $4 \mathrm{~N}$ & $4 \mathrm{~N}$ & $16 \mathrm{~N}$ & \multirow{4}{*}{7,27} & \multirow{4}{*}{8,00} & \multirow{4}{*}{135,4} & \multirow{4}{*}{146,3} & \multirow{4}{*}{23,10} & \multirow{4}{*}{26,20} & \multirow{4}{*}{48} & \multirow{4}{*}{-} \\
\hline & $48 \mathrm{~h}$ & $4 \mathrm{~N}$ & $4 \mathrm{~N}$ & $4 \mathrm{~N}$ & $4 \mathrm{~N}$ & $16 \mathrm{~N}$ & & & & & & & & \\
\hline & $72 \mathrm{~h}$ & $4 \mathrm{~N}$ & $3 \mathrm{~N}, 1 \mathrm{~B}$ & $4 \mathrm{~N}$ & $4 \mathrm{~N}$ & $15 \mathrm{~N}, 1 \mathrm{~B}$ & & & & & & & & \\
\hline & $96 \mathrm{~h}$ & $4 \mathrm{~N}$ & $4 \mathrm{~N}$ & $4 \mathrm{~N}$ & $4 \mathrm{~N}$ & $16 \mathrm{~N}$ & & & & & & & & \\
\hline \multirow{4}{*}{0,50} & $24 \mathrm{~h}$ & $4 \mathrm{~N}$ & $3 \mathrm{~N}, 1 \mathrm{~B}$ & $4 \mathrm{~N}$ & $4 \mathrm{~N}$ & $15 \mathrm{~N}, 1 \mathrm{~B}$ & \multirow{4}{*}{7,35} & \multirow{4}{*}{8,01} & \multirow{4}{*}{134,7} & \multirow{4}{*}{136,9} & \multirow{4}{*}{22,90} & \multirow{4}{*}{26,10} & \multirow{4}{*}{44} & \multirow{4}{*}{ - } \\
\hline & $48 \mathrm{~h}$ & $4 \mathrm{~N}$ & $3 \mathrm{~N}, 1 \mathrm{~B}$ & $2 \mathrm{~N}, 2 \mathrm{~B}$ & $4 \mathrm{~N}$ & $13 \mathrm{~N}, 3 \mathrm{~B}$ & & & & & & & & \\
\hline & $72 \mathrm{~h}$ & $1 \mathrm{~N}, 3 \mathrm{~B}$ & $3 \mathrm{~N}, 1 \mathrm{~B}$ & $1 \mathrm{~N}, 3 \mathrm{~B}$ & $4 \mathrm{~N}$ & $9 \mathrm{~N}, 7 \mathrm{~B}$ & & & & & & & & \\
\hline & $96 \mathrm{~h}$ & $2 \mathrm{~N}, 2 \mathrm{~B}$ & $3 \mathrm{~N}, 1 \mathrm{~B}$ & $1 \mathrm{~N}, 3 \mathrm{C}(2(7), 1(6))$ & $4 \mathrm{~N}$ & $10 \mathrm{~N}, 3 \mathrm{~B}, 3 \mathrm{C}$ & & & & & & & & \\
\hline \multirow{4}{*}{0,75} & $24 \mathrm{~h}$ & $3 \mathrm{~N}, 1 \mathrm{~B}$ & $4 \mathrm{~N}$ & $3 \mathrm{~N}, 1 \mathrm{~B}$ & $1 \mathrm{~N}, 3 \mathrm{~B}$ & $11 \mathrm{~N}, 5 \mathrm{~B}$ & \multirow{4}{*}{7,36} & \multirow{4}{*}{8,00} & & & & & & \\
\hline & $48 \mathrm{~h}$ & $4 \mathrm{~N}$ & $1 \mathrm{~N}, 3 \mathrm{~B}$ & $1 \mathrm{~N}, 3 \mathrm{~B}$ & $1 \mathrm{~N}, 2 \mathrm{~B}, 1 \mathrm{C}(7)$ & $7 \mathrm{~N}, 8 \mathrm{~B}, 1 \mathrm{C}$ & & & 1368 & 1415 & 2350 & 2600 & 48 & - \\
\hline & $72 \mathrm{~h}$ & $3 \mathrm{~B}, 1 \mathrm{C}(7)$ & $3 \mathrm{~B}, 1 \mathrm{C}(7)$ & $4 \mathrm{~B}$ & $1 \mathrm{~N}, 2 \mathrm{~B}, 1 \mathrm{C}(7)$ & $1 \mathrm{~N}, 12 \mathrm{~B}, 3 \mathrm{C}$ & & & 100,0 & 141,0 & $<0,00$ & $<, 00$ & 40 & 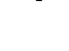 \\
\hline & $96 \mathrm{~h}$ & $3 \mathrm{~B}, 1 \mathrm{C}(7)$ & $3 \mathrm{~B}, 1 \mathrm{C}(6)$ & $3 \mathrm{~B}, 1 \mathrm{C}(7)$ & $3 \mathrm{~B}, 1 \mathrm{C}(7)$ & $12 B, 4 C$ & & & & & & & & \\
\hline & $24 \mathrm{~h}$ & $4 \mathrm{~B}$ & $1 \mathrm{~N}, 3 \mathrm{~B}$ & $3 \mathrm{~B}, 1 \mathrm{C}(7)$ & $3 \mathrm{~B}, 1 \mathrm{D}$ & $1 \mathrm{~N}, 13 \mathrm{~B}, 1 \mathrm{C}, 1 \mathrm{D}$ & & & & & & & & \\
\hline 100 & $48 \mathrm{~h}$ & $1 \mathrm{~B}, 2 \mathrm{C}(6), 1 \mathrm{~T}(2)$ & $1 \mathrm{C}(7), 2 \mathrm{~T}(1), 1 \mathrm{D}$ & $1 \mathrm{~B}, 1 \mathrm{C}(7), 2 \mathrm{D}$ & $2 \mathrm{~T}(1(1), 1(3)), 2 \mathrm{D}$ & $2 \mathrm{~B}, 4 \mathrm{C}, 5 \mathrm{~T}, 5 \mathrm{D}$ & 737 & 800 & 1377 & 1384 & 2360 & 2600 & 42 & - \\
\hline & $72 \mathrm{~h}$ & $1 \mathrm{C}(7), 3 \mathrm{~T}(1(1), 2(2))$ & $1 \mathrm{C}(7), 2 \mathrm{~T}(1), 1 \mathrm{D}$ & $1 \mathrm{~B}, 1 \mathrm{C}(7), 2 \mathrm{D}$ & $2 \mathrm{~T}(1(1), 1(3)), 2 \mathrm{D}$ & $1 \mathrm{~B}, 3 \mathrm{C}, 7 \mathrm{~T}, 5 \mathrm{D}$ & Th, & 0,00 & I & 100,4 & $<0,00$ & $<, \infty$ & $4 c$ & \\
\hline & $96 \mathrm{~h}$ & $1 \mathrm{C}(7), 1 \mathrm{~T}(2), 2 \mathrm{D}$ & $1 \mathrm{C}(7), 2 \mathrm{~T}(1), 1 \mathrm{D}$ & $2 \mathrm{~N}, 2 \mathrm{D}$ & $2 \mathrm{~T}(1(1), 1(3)), 2 \mathrm{D}$ & 2N, 2C, 5T, 7D & & & & & & & & \\
\hline & $24 \mathrm{~h}$ & $1 \mathrm{~N}, 1 \mathrm{~T}(1), 2 \mathrm{D}$ & $3 C(7), 1 \mathrm{D}$ & $2 \mathrm{~B}, 2 \mathrm{C}(7)$ & $2 \mathrm{~B}, 1 \mathrm{C}(6), 1 \mathrm{~T}(1)$ & $1 \mathrm{~N}, 4 \mathrm{~B}, 6 \mathrm{C}, 2 \mathrm{~T}, 3 \mathrm{D}$ & & & & & & & & \\
\hline 125 & $48 \mathrm{~h}$ & $4 \mathrm{D}$ & $1 \mathrm{~N}, 3 \mathrm{D}$ & $1 \mathrm{C}(7), 3 \mathrm{D}$ & $2 \mathrm{C}(7), 2 \mathrm{D}$ & $1 \mathrm{~N}, 3 \mathrm{C}, 12 \mathrm{D}$ & 741 & 799 & 1380 & 1437 & 2360 & 2600 & 44 & - \\
\hline , & $72 \mathrm{~h}$ & $4 \mathrm{D}$ & $1 \mathrm{~N}, 3 \mathrm{D}$ & $1 C(6), 3 D$ & $1 \mathrm{~B}, 1 \mathrm{C}(6), 2 \mathrm{D}$ & $1 \mathrm{~N}, 1 \mathrm{~B}, 2 \mathrm{C}, 12 \mathrm{D}$ & $1,4 \mathrm{I}$ & J & 100,0 & $140, r$ & $<0,00$ & $<, \infty$ & 44 & \\
\hline & $96 \mathrm{~h}$ & $4 \mathrm{D}$ & $1 \mathrm{~N}, 3 \mathrm{D}$ & $1 \mathrm{C}(7), 3 \mathrm{D}$ & 1B, 1C(7), 2D & $1 \mathrm{~N}, 1 \mathrm{~B}, 2 \mathrm{C}, 12 \mathrm{D}$ & & & & & & & & \\
\hline & $24 \mathrm{~h}$ & $1 \mathrm{~B}, 3 \mathrm{C}(7)$ & $1 \mathrm{~B}, 3 \mathrm{C}(7)$ & $1 \mathrm{~N}, 1 \mathrm{~B}, 2 \mathrm{C}(7)$ & $2 \mathrm{~B}, 2 \mathrm{C}(7)$ & $1 \mathrm{~N}, 5 \mathrm{~B}, 10 \mathrm{C}$ & & & & & & & & \\
\hline 150 & $48 \mathrm{~h}$ & $1 \mathrm{C}(6), 3 \mathrm{D}$ & $1 \mathrm{~T}(2), 3 \mathrm{D}$ & $1 \mathrm{C}(7), 1 \mathrm{~T}(2), 2 \mathrm{D}$ & $2 \mathrm{C}(7), 1 \mathrm{~T}, 1 \mathrm{D}$ & 4C, 3T, 9D & 745 & 801 & $138 ?$ & 1447 & 2340 & 2600 & 42 & - \\
\hline 1,00 & $72 \mathrm{~h}$ & 4D & $1 \mathrm{~T}(2), 3 \mathrm{D}$ & $1 \mathrm{C}(6), 1 \mathrm{~T}, 2 \mathrm{D}$ & $2 \mathrm{C}(6), 1 \mathrm{~T}(1), 1 \mathrm{D}$ & 3C, 3T, 10D & $, 4,4 \mathrm{~J}$ & 0,01 & $100, c$ & $144, l$ & $<0,40$ & $<, 00$ & $4 c$ & \\
\hline & $96 \mathrm{~h}$ & $4 \mathrm{D}$ & $4 \mathrm{D}$ & $1 \mathrm{C}(7), 1 \mathrm{~T}(2), 2 \mathrm{D}$ & $1 \mathrm{~N}, 1 \mathrm{C}(7), 1 \mathrm{~T}(1), 1 \mathrm{D}$ & $1 \mathrm{~N}, 2 \mathrm{C}, 2 \mathrm{~T}, 11 \mathrm{D}$ & & & & & & & & \\
\hline
\end{tabular}


Tabela 37. Modificações morfológicas em Hydra viridissima exposta a diferentes concentrações de propranolol (mg $\mathrm{L}^{-1}$ ), em teste definitivo de toxicidade aguda (teste $9, \mathrm{n}=10$ ), com leituras a cada 24 horas, e valores de $\mathrm{pH}$, condutividade, temperatura e dureza monitorados mo início e final dos teste. $\mathrm{N}=$ hidra normal; $\mathrm{B}=$ hidra com bulbos nos tentáculos; $\mathrm{C}=$ hidra com tentáculos encurtados; $\mathrm{T}=$ hidra em estado de tulipa; $\mathrm{D}=$ hidra desintegrada, sendo que os números dentro dos *() referem-se aos scores aplicados.

\begin{tabular}{|c|c|c|c|c|c|c|c|c|c|c|c|c|c|c|}
\hline \multirow{2}{*}{$\begin{array}{l}\text { Concentração } \\
\left(\mathrm{mg} \mathrm{L}^{-1}\right)\end{array}$} & \multirow{2}{*}{ Leitura } & \multicolumn{4}{|c|}{ Réplicas } & \multirow{2}{*}{ Total } & \multicolumn{2}{|c|}{$\mathrm{pH}$} & \multicolumn{2}{|c|}{ cond. } & \multicolumn{2}{|c|}{ Temp. } & \multicolumn{2}{|c|}{ Dureza } \\
\hline & & 1 & 2 & 3 & 4 & & Oh & $96 \mathrm{~h}$ & Oh & $96 \mathrm{~h}$ & Oh & $96 \mathrm{~h}$ & $\mathrm{Oh}$ & $96 h^{*}$ \\
\hline \multirow{4}{*}{ Controle } & $24 \mathrm{~h}$ & $4 \mathrm{~N}$ & $4 \mathrm{~N}$ & $4 \mathrm{~N}$ & $4 \mathrm{~N}$ & $16 \mathrm{~N}$ & \multirow{4}{*}{7,33} & \multirow{4}{*}{8,06} & \multirow{4}{*}{142,5} & \multirow{4}{*}{135,9} & \multirow{4}{*}{22,40} & \multirow{4}{*}{26,40} & \multirow{4}{*}{40} & \\
\hline & $48 \mathrm{~h}$ & $4 \mathrm{~N}$ & $4 \mathrm{~N}$ & $4 \mathrm{~N}$ & $4 \mathrm{~N}$ & $16 \mathrm{~N}$ & & & & & & & & \\
\hline & $72 \mathrm{~h}$ & $4 \mathrm{~N}$ & $4 \mathrm{~N}$ & $4 \mathrm{~N}$ & $4 \mathrm{~N}$ & $16 \mathrm{~N}$ & & & & & & & & \\
\hline & $96 \mathrm{~h}$ & $4 \mathrm{~N}$ & $4 \mathrm{~N}$ & $4 \mathrm{~N}$ & $4 \mathrm{~N}$ & $16 \mathrm{~N}$ & & & & & & & & \\
\hline \multirow{4}{*}{0,50} & $24 \mathrm{~h}$ & $4 \mathrm{~N}$ & $4 \mathrm{~N}$ & $4 \mathrm{~N}$ & $4 \mathrm{~N}$ & $16 \mathrm{~N}$ & \multirow{4}{*}{7,38} & \multirow{4}{*}{8,04} & \multirow{4}{*}{135,0} & \multirow{4}{*}{140,7} & \multirow{4}{*}{22,40} & \multirow{4}{*}{26,60} & \multirow{4}{*}{44} & \\
\hline & $48 \mathrm{~h}$ & $4 \mathrm{~N}$ & $4 \mathrm{~N}$ & $4 \mathrm{~N}$ & $2 \mathrm{~N}, 2 \mathrm{~B}$ & $14 \mathrm{~N}, 2 \mathrm{~B}$ & & & & & & & & \\
\hline & $72 \mathrm{~h}$ & $4 \mathrm{~N}$ & $2 \mathrm{~N}, 2 \mathrm{~B}$ & $1 \mathrm{~N}, 3 \mathrm{~B}$ & $2 \mathrm{~N}, 1 \mathrm{~B}, 1 \mathrm{C}(7)$ & $9 \mathrm{~N}, 6 \mathrm{~B}, 1 \mathrm{C}$ & & & & & & & & \\
\hline & $96 \mathrm{~h}$ & $4 \mathrm{~N}$ & $3 \mathrm{~N}, 1 \mathrm{~B}$ & $3 \mathrm{~N}, 1 \mathrm{~B}$ & $2 \mathrm{~N}, 1 \mathrm{~B}, 1 \mathrm{C}(7)$ & $12 \mathrm{~N}, 3 \mathrm{~B}, 1 \mathrm{C}$ & & & & & & & & \\
\hline \multirow{4}{*}{0,75} & $24 \mathrm{~h}$ & $4 \mathrm{~N}$ & $4 \mathrm{~N}$ & $3 \mathrm{~N}, 1 \mathrm{~B}$ & $4 \mathrm{~N}$ & $15 \mathrm{~N}, 1 \mathrm{~B}$ & \multirow{4}{*}{7,43} & \multirow{4}{*}{8,06} & \multirow{4}{*}{136,9} & \multirow{4}{*}{139,7} & & & & \\
\hline & $48 \mathrm{~h}$ & $4 \mathrm{~B}$ & $4 \mathrm{~B}$ & $3 \mathrm{~B}, 1 \mathrm{C}(7)$ & $1 \mathrm{~N}, 3 \mathrm{~B}$ & $1 \mathrm{~N}, 14 \mathrm{~B}, 1 \mathrm{C}$ & & & & & & 2650 & 18 & \\
\hline & $72 \mathrm{~h}$ & $2 \mathrm{~N}, 2 \mathrm{C}(7)$ & $1 \mathrm{~N}, 2 \mathrm{~B}, 1 \mathrm{C}(7)$ & $4 C(7)$ & $1 \mathrm{~N}, 3 \mathrm{~B}$ & $4 N, 5 B, 7 C$ & & & & & 22,40 & 26,50 & 48 & \\
\hline & $96 \mathrm{~h}$ & $1 \mathrm{~N}, 2 \mathrm{~B}, 1 \mathrm{C}(7)$ & $3 \mathrm{~B}, 1 \mathrm{C}(7)$ & $1 \mathrm{~B}, 2 \mathrm{C}(7), 1 \mathrm{~T}(2)$ & $3 \mathrm{~B}, 1 \mathrm{C}(7)$ & $1 \mathrm{~N}, 9 \mathrm{~B}, 5 \mathrm{C}, 1 \mathrm{~T}$ & & & & & & & & \\
\hline & $24 \mathrm{~h}$ & $4 \mathrm{~B}$ & $1 \mathrm{~N}, 3 \mathrm{~B}$ & $1 \mathrm{~N}, 3 \mathrm{~B}$ & $1 \mathrm{~N}, 3 \mathrm{~B}$ & $3 \mathrm{~N}, 13 \mathrm{~B}$ & & & & & & & & \\
\hline & $48 \mathrm{~h}$ & $4 \mathrm{C}(7)$ & $1 \mathrm{C}(6), 2 \mathrm{~T}(2), 1 \mathrm{D}$ & $4 \mathrm{C}(6)$ & $4 \mathrm{C}(7)$ & $13 \mathrm{C}, 2 \mathrm{~T}, 1 \mathrm{D}$ & & & & & & & & \\
\hline 1,00 & $72 \mathrm{~h}$ & $1 \mathrm{C}(7), 3 \mathrm{~T}(2(2), 1(3))$ & $1 \mathrm{~T}(2), 3 \mathrm{D}$ & $3 \mathrm{~T}(1(2), 2(3)), 1 \mathrm{D}$ & $2 \mathrm{C}(7), 1 \mathrm{~T}(2), 1 \mathrm{D}$ & $3 \mathrm{C}, 8 \mathrm{~T}, 5 \mathrm{D}$ & 7,46 & 8,09 & 134,8 & 134,8 & 22,30 & 26,60 & 46 & \\
\hline & $96 \mathrm{~h}$ & $4 \mathrm{~T}(3(3), 1(2))$ & $1 \mathrm{~T}(1), 3 \mathrm{D}$ & $3 \mathrm{~T}(1(2), 2(3)), 1 \mathrm{D}$ & $1 \mathrm{C}(7), 2 \mathrm{~T}(2), 1 \mathrm{D}$ & $1 \mathrm{C}, 10 \mathrm{~T}, 5 \mathrm{D}$ & & & & & & & & \\
\hline & $24 \mathrm{~h}$ & $3 \mathrm{~B}, 1 \mathrm{C}(7)$ & $2 \mathrm{~B}, 2 \mathrm{C}(7)$ & $3 \mathrm{~B}, 1 \mathrm{C}(7)$ & $1 \mathrm{~N}, 2 \mathrm{~B}, 1 \mathrm{C}(7)$ & $1 \mathrm{~N}, 10 \mathrm{~B}, 5 \mathrm{C}$ & & & & & & & & \\
\hline 125 & $48 \mathrm{~h}$ & $2 \mathrm{~T}(2), 2 \mathrm{D}$ & $1 \mathrm{C}(7), 2 \mathrm{~T}(1), 1 \mathrm{D}$ & $4 \mathrm{C}(6)$ & $4 \mathrm{C}(7)$ & $9 \mathrm{C}, 4 \mathrm{~T}, 3 \mathrm{D}$ & 751 & 810 & 1357 & 1425 & 2230 & 2660 & 42 & \\
\hline $1, \angle 0$ & $72 \mathrm{~h}$ & $1 \mathrm{~T}(2), 3 \mathrm{D}$ & 1T(2), 3D & $2 \mathrm{~T}(1(1), 1(2)), 2 \mathrm{D}$ & $3 T(3), 1 D$ & 7T, 9D & 7,01 & 8,10 & 130,1 & $14<, 0$ & $\angle 2,3 \mathrm{U}$ & $\angle 0,00$ & 42 & \\
\hline & $96 \mathrm{~h}$ & $1 \mathrm{~T}(2), 3 \mathrm{D}$ & $1 \mathrm{~T}(2), 3 \mathrm{D}$ & $2 \mathrm{~T}(3), 2 \mathrm{D}$ & $3 \mathrm{~T}(3), 1 \mathrm{D}$ & $7 \mathrm{~T}, 9 \mathrm{D}$ & & & & & & & & \\
\hline & $24 \mathrm{~h}$ & $4 \mathrm{~B}$ & $3 \mathrm{~B}, 1 \mathrm{C}(7)$ & $4 \mathrm{~B}$ & $2 \mathrm{~B}, 1 \mathrm{C}(7), 1 \mathrm{~T}(1)$ & $13 \mathrm{~B}, 2 \mathrm{C}, 1 \mathrm{~T}$ & & & & & & & & \\
\hline & $48 \mathrm{~h}$ & $1 \mathrm{~T}(1), 3 \mathrm{D}$ & $1 \mathrm{C}(7), 1 \mathrm{~T}(1), 2 \mathrm{D}$ & $4 \mathrm{D}$ & 1T(2), 3D & $1 \mathrm{C}, 3 \mathrm{~T}, 12 \mathrm{D}$ & & & & & & & & \\
\hline 1,50 & $72 \mathrm{~h}$ & $4 \mathrm{D}$ & $1 \mathrm{C}(7), 1 \mathrm{~T}(2), 2 \mathrm{D}$ & $4 \mathrm{D}$ & $1 T(1), 3 D$ & $1 \mathrm{C}, 2 \mathrm{~T}, 13 \mathrm{D}$ & 7,55 & 8,15 & 739,6 & 138,1 & 22,40 & 26,80 & 42 & \\
\hline & $96 \mathrm{~h}$ & $4 \mathrm{D}$ & $1 \mathrm{C}(7), 1 \mathrm{~T}(1), 2 \mathrm{D}$ & $4 \mathrm{D}$ & $4 \mathrm{D}$ & $1 \mathrm{C}, 1 \mathrm{~T}, 14 \mathrm{D}$ & & & & & & & & \\
\hline
\end{tabular}


Tabela 38. Modificações morfológicas em Hydra viridissima exposta a diferentes concentrações de propranolol (mg $\mathrm{L}^{-1}$ ), em teste definitivo de toxicidade aguda (teste 10, $\mathrm{n}=10$ ), com leituras a cada 24 horas, e valores de $\mathrm{pH}$, condutividade, temperatura e dureza monitorados mo início e final dos teste. $\mathrm{N}=$ hidra normal; $\mathrm{B}=$ hidra com bulbos nos tentáculos; $\mathrm{C}=$ hidra com tentáculos encurtados; $\mathrm{T}=$ hidra em estado de tulipa; $\mathrm{D}=$ hidra desintegrada, sendo que os números dentro dos *() referem-se aos scores aplicados.

\begin{tabular}{|c|c|c|c|c|c|c|c|c|c|c|c|c|c|c|}
\hline \multirow{2}{*}{$\begin{array}{l}\text { Concentração } \\
\left(\mathrm{mg} \mathrm{L}^{-1}\right)\end{array}$} & \multirow{2}{*}{ Leitura } & \multicolumn{4}{|c|}{ Réplicas } & \multirow{2}{*}{ Total } & \multicolumn{2}{|c|}{$\mathrm{pH}$} & \multicolumn{2}{|c|}{ cond. } & \multicolumn{2}{|c|}{ Temp. } & \multicolumn{2}{|c|}{ Dureza } \\
\hline & & 1 & 2 & 3 & 4 & & $\mathrm{Oh}$ & $96 \mathrm{~h}$ & $\mathrm{Oh}$ & $96 \mathrm{~h}$ & Oh & $96 \mathrm{~h}$ & $\mathrm{Oh}$ & $96 h^{*}$ \\
\hline \multirow{4}{*}{ Controle } & $24 \mathrm{~h}$ & $4 \mathrm{~N}$ & $4 \mathrm{~N}$ & $4 \mathrm{~N}$ & $4 \mathrm{~N}$ & $16 \mathrm{~N}$ & \multirow{4}{*}{7,37} & \multirow{4}{*}{7,81} & \multirow{4}{*}{146,9} & \multirow{4}{*}{166,4} & \multirow{4}{*}{27,50} & \multirow{4}{*}{24,30} & \multirow{4}{*}{46} & \multirow{4}{*}{-} \\
\hline & $48 \mathrm{~h}$ & $4 \mathrm{~N}$ & $4 \mathrm{~N}$ & $4 \mathrm{~N}$ & $4 \mathrm{~N}$ & $16 \mathrm{~N}$ & & & & & & & & \\
\hline & $72 \mathrm{~h}$ & $4 \mathrm{~N}$ & $4 \mathrm{~N}$ & $4 \mathrm{~N}$ & $4 \mathrm{~N}$ & $16 \mathrm{~N}$ & & & & & & & & \\
\hline & $96 \mathrm{~h}$ & $4 \mathrm{~N}$ & $4 \mathrm{~N}$ & $4 \mathrm{~N}$ & $4 \mathrm{~N}$ & $16 \mathrm{~N}$ & & & & & & & & \\
\hline \multirow{4}{*}{0,50} & $24 \mathrm{~h}$ & $4 \mathrm{~N}$ & $4 \mathrm{~N}$ & $2 \mathrm{~N}, 2 \mathrm{~B}$ & $2 \mathrm{~N}, 2 \mathrm{~B}$ & $14 \mathrm{~N}, 2 \mathrm{~B}$ & \multirow{4}{*}{7,38} & \multirow{4}{*}{7,82} & \multirow{4}{*}{140,9} & \multirow{4}{*}{144,2} & \multirow{4}{*}{27,50} & \multirow{4}{*}{24,30} & \multirow{4}{*}{44} & \multirow{4}{*}{-} \\
\hline & $48 \mathrm{~h}$ & $4 \mathrm{~N}$ & $2 \mathrm{~N}, 2 \mathrm{~B}$ & $1 \mathrm{~N}, 3 \mathrm{~B}$ & $1 \mathrm{~N}, 3 \mathrm{~B}$ & $8 \mathrm{~N}, 8 \mathrm{~B}$ & & & & & & & & \\
\hline & $72 \mathrm{~h}$ & $3 \mathrm{~N}, 1 \mathrm{~B}$ & $2 \mathrm{~N}, 2 \mathrm{~B}$ & $1 \mathrm{~N}, 3 \mathrm{~B}$ & $2 \mathrm{~N}, 2 \mathrm{~B}$ & $8 \mathrm{~N}, 8 \mathrm{~B}$ & & & & & & & & \\
\hline & $96 \mathrm{~h}$ & $2 \mathrm{~N}, 2 \mathrm{~B}$ & $2 \mathrm{~N}, 2 \mathrm{~B}$ & $1 \mathrm{~N}, 3 \mathrm{~B}$ & $3 \mathrm{~N}, 1 \mathrm{C}(6)$ & $8 \mathrm{~N}, 7 \mathrm{~B}, 1 \mathrm{C}$ & & & & & & & & \\
\hline \multirow{4}{*}{0,75} & $24 \mathrm{~h}$ & $1 \mathrm{~N}, 3 \mathrm{~B}$ & $2 \mathrm{~N}, 2 \mathrm{~B}$ & $3 \mathrm{~N}, 1 \mathrm{~B}$ & $1 \mathrm{~N}, 3 \mathrm{~B}$ & $7 \mathrm{~N}, 9 \mathrm{~B}$ & \multirow{4}{*}{7,39} & \multirow{4}{*}{7,86} & & & & & & \\
\hline & $48 \mathrm{~h}$ & $2 \mathrm{~B}, 2 \mathrm{C}(7)$ & $2 \mathrm{~B}, 2 \mathrm{C}(6)$ & $1 \mathrm{~N}, 3 \mathrm{~B}$ & $1 \mathrm{~N}, 2 \mathrm{~B}, 1 \mathrm{C}(7)$ & $2 \mathrm{~N}, 9 \mathrm{~B}, 5 \mathrm{C}$ & & & 1375 & 1387 & 2740 & 2420 & 42 & - \\
\hline & $72 \mathrm{~h}$ & $2 \mathrm{C}(7), 2 \mathrm{D}$ & $4 C(7)$ & $2 \mathrm{~N}, 1 \mathrm{~B}, 1 \mathrm{C}(6)$ & $2 \mathrm{~B}, 1 \mathrm{C}(7), 1 \mathrm{D}$ & $2 \mathrm{~N}, 3 \mathrm{~B}, 8 \mathrm{C}, 3 \mathrm{D}$ & & & ט, ודו & $100, r$ & $26,+0$ & $24,<v$ & $4 c$ & \\
\hline & $96 \mathrm{~h}$ & $2 \mathrm{C}(7), 2 \mathrm{D}$ & $4 \mathrm{C}(7)$ & $1 \mathrm{~N}, 3 \mathrm{~B}$ & $2 \mathrm{~B}, 1 \mathrm{C}(7), 1 \mathrm{D}$ & $1 \mathrm{~N}, 5 \mathrm{~B}, 7 \mathrm{C}, 3 \mathrm{D}$ & & & & & & & & \\
\hline & $24 \mathrm{~h}$ & $4 \mathrm{C}(7)$ & $1 \mathrm{~B}, 1 \mathrm{C}(7), 1 \mathrm{~T}(1), 1 \mathrm{D}$ & $1 \mathrm{~N}, 2 \mathrm{C}(7), 1 \mathrm{~T}(3)$ & $3 \mathrm{~B}, 1 \mathrm{C}(7)$ & $1 \mathrm{~N}, 4 \mathrm{~B}, 8 \mathrm{C}, 2 \mathrm{~T}, 1 \mathrm{D}$ & & & & & & & & \\
\hline 100 & $48 \mathrm{~h}$ & $4 \mathrm{D}$ & $1 \mathrm{~T}(1), 3 \mathrm{D}$ & $4 \mathrm{D}$ & $1 \mathrm{C}(7), 1 \mathrm{~T}(3), 2 \mathrm{D}$ & 1C, 2T, 13D & 752 & 788 & 1378 & 1416 & 2740 & 2460 & 46 & \\
\hline 1,00 & $72 \mathrm{~h}$ & $4 \mathrm{D}$ & 4D & $4 \mathrm{D}$ & $1 \mathrm{C}(7), 3 \mathrm{D}$ & $1 C, 15 D$ & , & 1,,00 & 作 & 141,0 & $2 T, 40$ & 24,00 & 40 & - \\
\hline & $96 \mathrm{~h}$ & $4 \mathrm{D}$ & $4 \mathrm{D}$ & $4 \mathrm{D}$ & $1 C(7), 3 \mathrm{D}$ & $1 \mathrm{C}, 15 \mathrm{D}$ & & & & & & & & \\
\hline & $24 \mathrm{~h}$ & $4 \mathrm{D}$ & $4 \mathrm{D}$ & $1 \mathrm{C}(7), 3 \mathrm{D}$ & $2 \mathrm{~T}(1(1), 1(2)), 2 \mathrm{D}$ & $1 \mathrm{C}, 2 \mathrm{~T}, 13 \mathrm{D}$ & & & & & & & & \\
\hline 125 & $48 \mathrm{~h}$ & $4 \mathrm{D}$ & $4 \mathrm{D}$ & $4 \mathrm{D}$ & $4 \mathrm{D}$ & 16D & 758 & 788 & 1380 & 1310 & 2740 & 2460 & 44 & - \\
\hline , & $72 \mathrm{~h}$ & $4 \mathrm{D}$ & $4 \mathrm{D}$ & $4 \mathrm{D}$ & $4 \mathrm{D}$ & $16 \mathrm{D}$ & 标 & (1,00 & (100,0 & ofu, & $2 \pi,+0$ & 4,00 & 47 & \\
\hline & $96 \mathrm{~h}$ & $4 \mathrm{D}$ & $4 \mathrm{D}$ & $4 \mathrm{D}$ & $4 \mathrm{D}$ & $16 \mathrm{D}$ & & & & & & & & \\
\hline & $24 \mathrm{~h}$ & $1 \mathrm{~T}(2), 3 \mathrm{D}$ & $2 \mathrm{C}(7), 2 \mathrm{~T}(1)$ & $1 \mathrm{~T}(1), 3 \mathrm{D}$ & $1 \mathrm{~B}, 1 \mathrm{C}(6), 2 \mathrm{~T}(1)$ & $1 \mathrm{~B}, 3 \mathrm{C}, 6 \mathrm{~T}, 6 \mathrm{D}$ & & & & & & & & \\
\hline 150 & $48 \mathrm{~h}$ & $1 \mathrm{~T}(2), 3 \mathrm{D}$ & $4 \mathrm{D}$ & $4 \mathrm{D}$ & 1C(7), 3D & 1C, 1T, 14D & 750 & 791 & 1363 & 1361 & 2740 & 2460 & 42 & - \\
\hline 1,00 & $72 \mathrm{~h}$ & 4D & $4 \mathrm{D}$ & $4 \mathrm{D}$ & $1 C(7), 3 \mathrm{D}$ & $1 \mathrm{C}, 15 \mathrm{D}$ & (I, & 开 & 100,0 & 100,1 & $2 \pi, 40$ & 24,00 & $4 c$ & 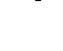 \\
\hline & $96 \mathrm{~h}$ & $4 \mathrm{D}$ & 4D & $4 \mathrm{D}$ & $1 C(7), 3 D$ & $1 \mathrm{C}, 15 \mathrm{D}$ & & & & & & & & \\
\hline
\end{tabular}


7. Registro dos resultados dos testes de toxicidade aguda com o fármaco clorpromazina (Capítulo 4).

\section{Daphnia magna}

Tabela 39. Resultados do teste de toxicidade aguda com Daphnia magna exposta ao clorpromazina.

\begin{tabular}{|c|c|c|c|c|c|c|c|c|c|c|c|}
\hline \multirow{2}{*}{$\begin{array}{c}\text { Solução- } \\
\text { teste } \\
\left(\mathrm{mg} \mathrm{L}^{-1}\right)\end{array}$} & \multicolumn{2}{|c|}{$\mathrm{pH}$} & \multicolumn{2}{|c|}{$\begin{array}{l}\text { Condutividade } \\
\qquad\left(\mu \mathrm{S} \mathrm{cm}^{-1}\right)\end{array}$} & \multirow{2}{*}{$\begin{array}{l}\text { Dureza } \\
\left(\mathrm{mg} \mathrm{L}^{-1}\right. \\
\left.\mathrm{CaCO}_{3}\right) \\
\frac{\mathrm{i}}{}\end{array}$} & \multicolumn{2}{|c|}{$\begin{array}{c}\text { Temperatura } \\
\qquad\left({ }^{\circ} \mathrm{C}\right)\end{array}$} & \multicolumn{2}{|c|}{$\begin{array}{c}\mathrm{N}^{\circ} \mathrm{de} \\
\text { organismos } \\
\text { móveis }\end{array}$} & \multicolumn{2}{|c|}{ Imobilidade } \\
\hline & $\mathrm{i}$ & f & $\mathrm{i}$ & $\mathrm{F}$ & & $\mathrm{i}$ & $\mathrm{f}$ & $\mathrm{i}$ & $f$ & Total & $\%$ \\
\hline Controle & - & - & - & - & - & - & - & 20 & 19 & 1 & 5 \\
\hline 0,5 & - & - & - & - & - & - & - & 20 & 20 & 0 & 0 \\
\hline 0,65 & - & - & - & - & - & - & - & 20 & 20 & 0 & 0 \\
\hline 0,85 & - & - & - & - & - & - & - & 20 & 20 & 0 & 0 \\
\hline 1,10 & - & - & - & - & - & - & - & 20 & 18 & 2 & 10 \\
\hline 1,43 & - & - & - & - & - & - & - & 20 & 15 & 5 & 25 \\
\hline 1,86 & - & - & - & - & - & - & - & 20 & 10 & 10 & 50 \\
\hline 2,41 & - & - & - & - & - & - & - & 20 & 2 & 18 & 90 \\
\hline 3,14 & - & - & - & - & - & - & - & 20 & 0 & 20 & 100 \\
\hline & & & & & de $\mathrm{Co}$ & & & & & & \\
\hline
\end{tabular}

- : não foram medidas os parâmetros físico e químicos das soluções-teste. 


\section{Apêndice B}

\section{Dados de precipitação pluviométrica}




\section{Dados pluviométricos mensais registrados no Reservatório de Guarapiranga} (referentes ao Capítulo 1).

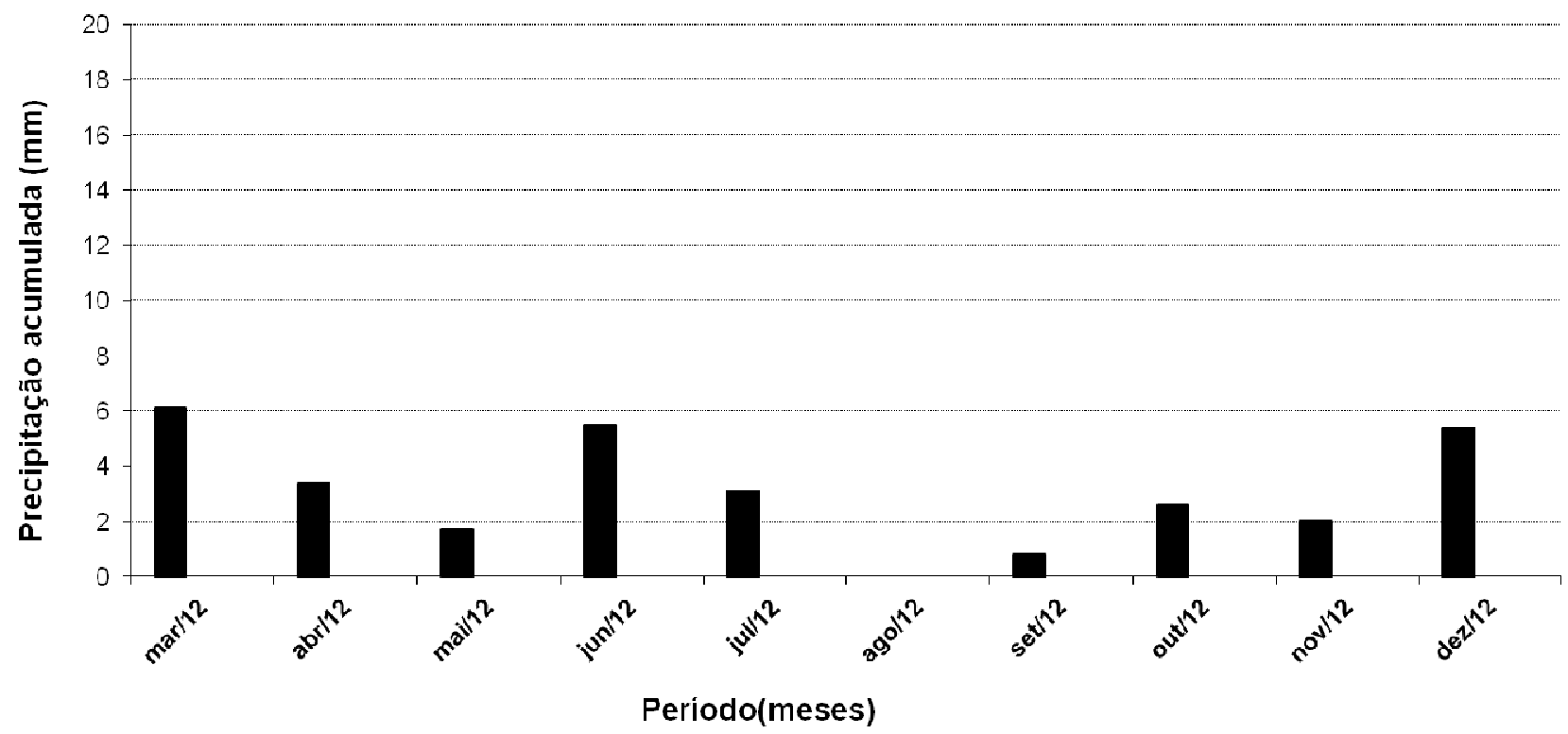

Figura 1. Variação dos valores mensais de precipitação pluviométrica registrados no Reservatório de Guarapiranga, segundo o banco de dados da SABESP (Companhia de Saneamento básico do Estado de São Paulo) durante o período de março a dezembro de 2012. 
Apêndice C

\author{
Fotos
}




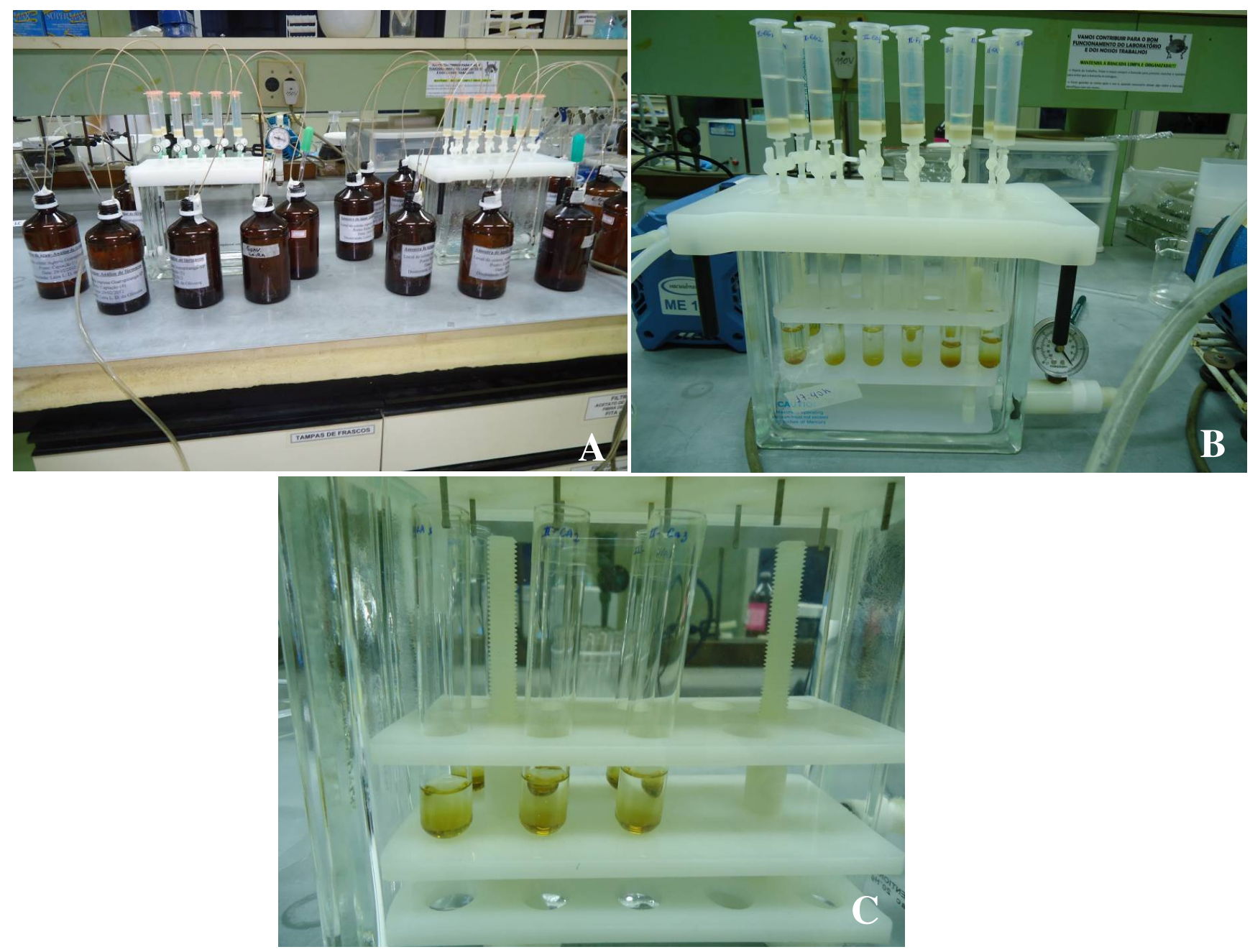

Figura 1. Sequência de fotos mostrando os processos de SPE (Extração de Fase sólida) em laboratório; A) ilustra o processo de extração das amostras de água; B) eluição dos cartuchos de extração; C) extratos obtidos da SPE (Fotos: Laira L. Damasceno de Oliveira). 

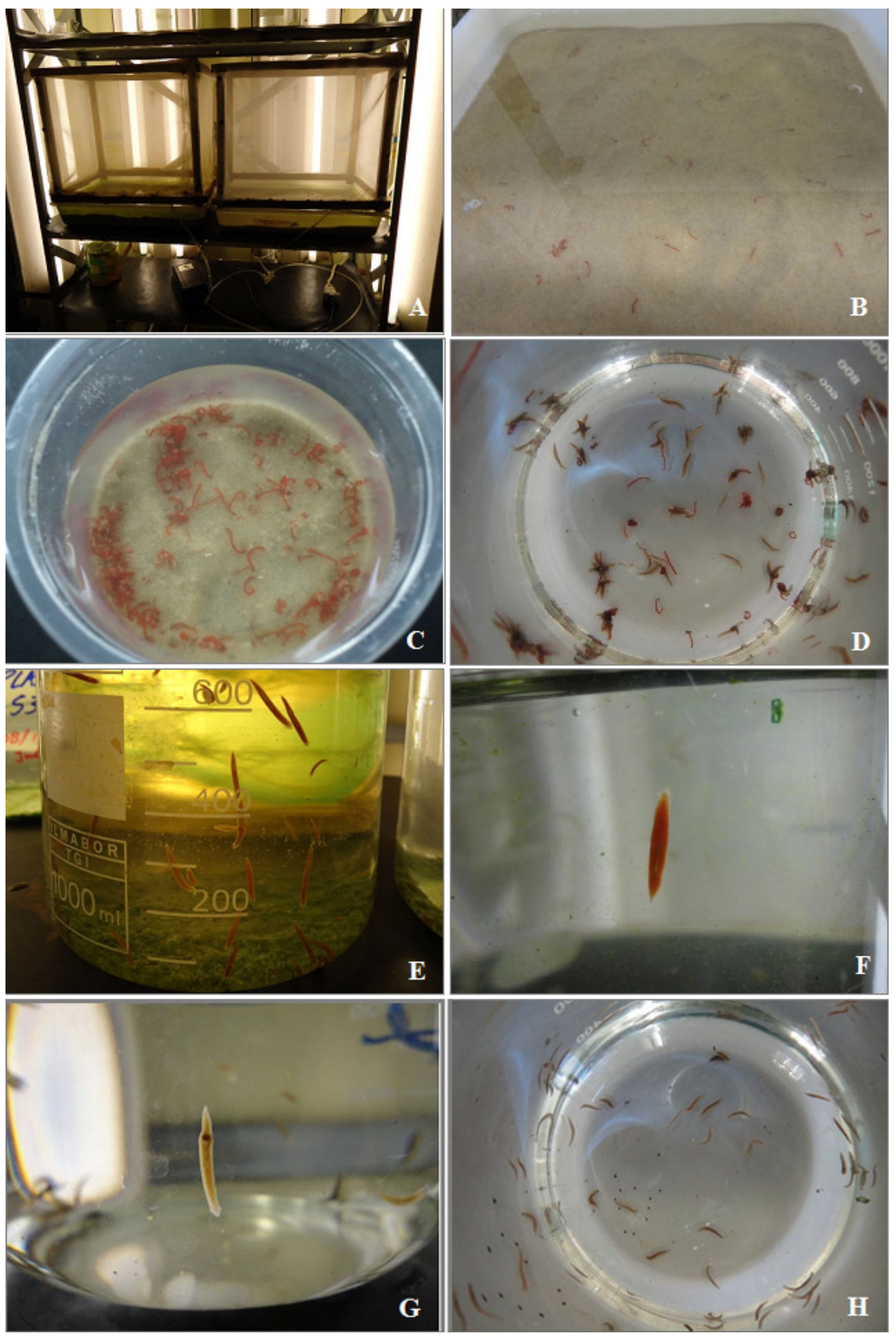

Figura 2. Sequência de fotos evidenciando o cultivo e manutenção de Dugesia tigrina; A e B) ilustram o cultivo de Chironomus sancticaroli; B, C e D) larvas de Chironomus sancticaroli utilizadas como alimento para os indivíduos de D. tigrina; E e F) organismos de D. tigrina após serem alimentados; $\mathbf{G}$ e H) momento da postura e fixação dos casulos no béquer (Fotos: Laira L. Damasceno de Oliveira e Raphael C. Ramos). 